Editora Poisson

\title{
Gestão da Produção em Foco Volume 21
}

\author{
1a Edição
}

Belo Horizonte

Poisson

2018 
Editor Chefe: Dr. Darly Fernando Andrade

\section{Conselho Editorial}

Dr. Antônio Artur de Souza - Universidade Federal de Minas Gerais

Dra. Cacilda Nacur Lorentz - Universidade do Estado de Minas Gerais

Dr. José Eduardo Ferreira Lopes - Universidade Federal de Uberlândia

Dr. Otaviano Francisco Neves - Pontifícia Universidade Católica de Minas Gerais

Dr. Luiz Cláudio de Lima - Universidade FUMEC

Dr. Nelson Ferreira Filho - Faculdades Kennedy

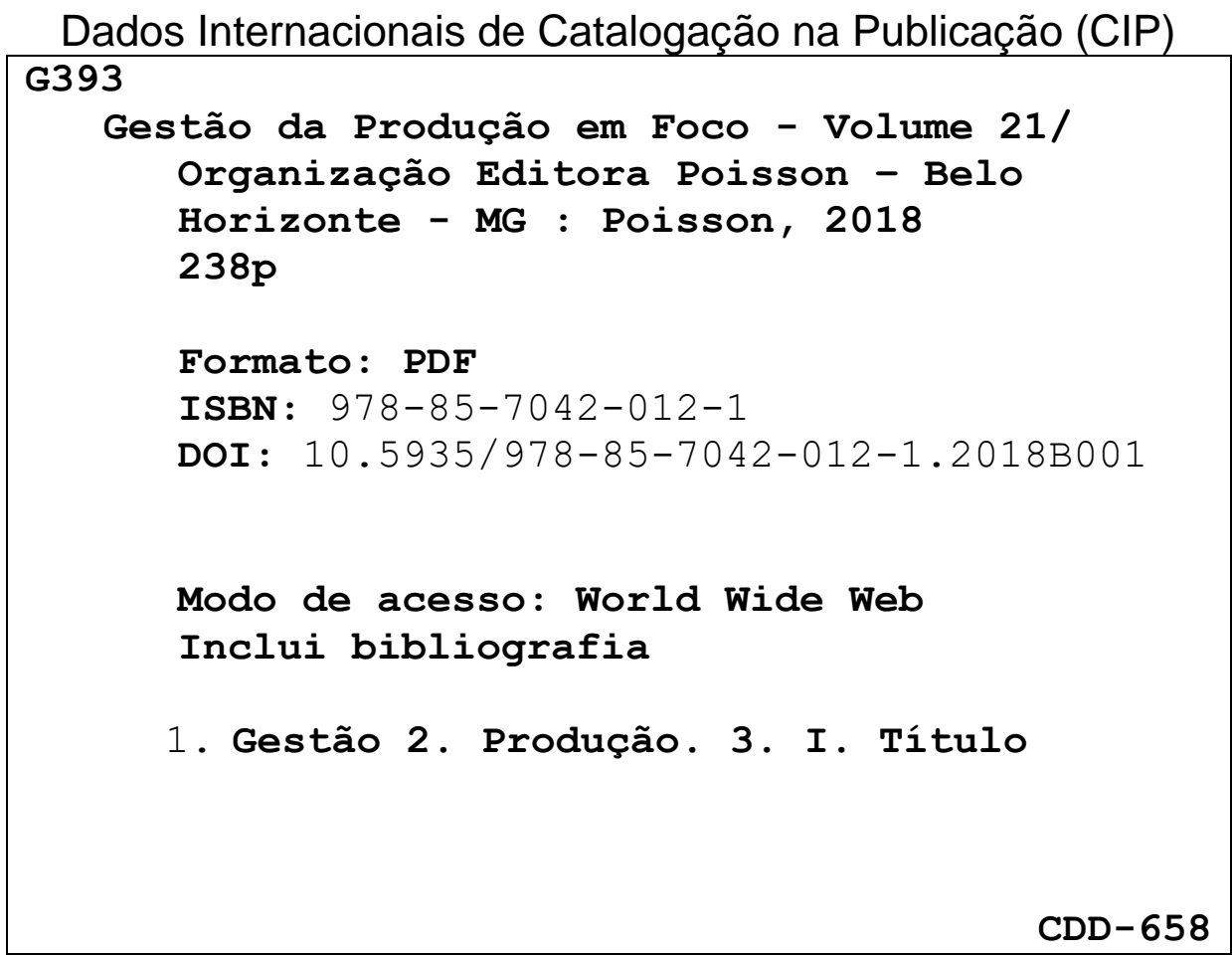

O conteúdo dos artigos e seus dados em sua forma, correção e confiabilidade são de responsabilidade exclusiva dos seus respectivos autores.

www.poisson.com.br

contato@poisson.com.br 


\section{Sumárīio}

Capítulo 1: Metodologia Delphi integrada ao mapeamento de processos como ferramenta de auxílio na tomada de decisão estratégica.

Kamila Matos Andrade Silva, João Thiago de Guimarães Anchieta e Araújo Campos, Jonathas do Nascimento Pereira, Carla Monique Rocha dos Santos

Capítulo 2: Seleção de modelo de avaliação de nível de maturidade em gestão de projetos para uma empresa de mineração.

Andressa de Paula Cruz, Fernanda de Oliveira Galdiano, Sandra Miranda Neves, Tarcísio Gonçalves de Brito

Capítulo 3: O uso AHP (Processo de Análise Hierárquica) na tomada de uma decisão para escolha do método de avaliação.

Benedito Manoel de Almeida, Suelen Cristian de Freitas Morais

Capítulo 4: Projeto de um laboratório de cerveja artesanal.

Simone Ferigolo Venturini, Charles Rech

Capítulo 5: Estudo da influência da melhoria contínua no tempo de setup e tempo de reparo do lead time: Uma simulação em ambiente Flowshop com um recurso restritivo de capacidade.

Miguel Bergamasso Moura, Marcel Heimar Ribeiro Utiyama

Capítulo 6: Aplicação da cronanálise para melhoria do processo produtivo numa fábrica de eletroeletrônicos.

Larissa Nayara Oliveira dos Santos, Nathalia Stephane Santos Nascimento, Hicaro Ferreira Matos Cardial, Alexandre dos Santos Santana, Glaucia Regina de Oliveira Almeida

Capítulo 7: Logística reversa de caneta piloto: diagnóstico em uma instituição de ensino superior no sul da Bahia. Jacqueline Silva de Jesus, Aline Santana dos Santos, Celso Carlino Maria Fornari Junior

Capítulo 8: Implantação de uma ferramenta para determinar a eficiência global dos equipamentos (OEE) em uma usina de biodiesel.

Thiago Roncada Guedes, Mabio Teodoro Borges 


\section{Sumárīo}

Capítulo 9: Aplicação dos conceitos de takt time e tempo de ciclo para o cálculo da eficiência nos processos de um pronto atendimento hospitalar

Maria Suzanna Maia Costa, Carlos Henrique de Oliveira, Emerson Jose de Paiva, Sandra Miranda Neves, Marcio Dimas Ramos

Capítulo 10: Virtualização de documentos e método eletrônico de arquivamento: avaliação dos resultados da gestão da tecnologia em MPES

Roberto Carlos Santos Pedroga, Cristopher Santos Pedroga

Capítulo 11: O processo de implantação do terminal portuário de novo remanso e as perspectivas de transformações econômicas locais.........

Marcos Antônio de Souza Queiroz, Rute Holanda Lopes, Renata de Oliveira Teixeira, Pollyanna Menezes de Sousa, Yara Almeida da Rocha, Alessandra Ferreira Reis

Capítulo 12: Análise do nível de pressão sonora em uma biblioteca de uma instituição de ensino superior.

Rodrigo Costa Silva, Matheus das Neves Almeida, Aianna Rios Magalhães Véras e Silva, Bárbara Cristina Costa Bacelar de Carvalho, Hélio Cavalcanti Albuquerque Neto

Capítulo 13: Análise ergonômica do trabalho: Utilização dos métodos Owas e Rula em uma empresa de confecções na cidade de Mossoró-

$\mathrm{RN}$.

Paulo Ricardo Fernandes de Lima, Cryslaine Cinthia Carvalho Nascimento, Sonagno de Paiva Oliveira, Manoel Isac Maia Junior, Thuana Maria de Melo Gonzaga, João Victor Nunes Lopes

Capítulo 14: O trabalho em um centro de equoterapia sob a compreensão da ergonomia da atividade.

Maria de Lourdes Santiago Luz, Marcelo Dondelli Boaretto, Jullia Maria Zullim Rodrigues

Capítulo 15: Análise Ergonômica do Trabalho: Um estudo de caso em um setor de produção de um frigorífico

Thiago Dan Said, Cristiano Manhães de Oliveira, Tiago Andrade Muniz Terra, Ailton Silva Ferreira 


\section{Sumário}

Capítulo 16: Análise dos fatores de risco de acidente no trabalho: um estudo de caso em uma movelaria do município de Itacoatiara-

Amazonas.

Adriano da Mata Gama, Ariane Batista Maquine, Camila Martins de Oliveira, João Marcos de Oliveira

Capítulo 17: Gestão da radioproteção hospitalar: Um estudo sobre a proteção radiológica em radiodiagnósticos médicos

Claudio Covas Fernandes

Capítulo 18: Estudo de caso: Identificação e avaliação dos riscos ocupacionais em uma marmoraria na cidade de Marabá - PA.

Andressa dos Santos Araújo, Eduardo Zimmer Zen, Giovanna Brito de Araújo, Maria Luiza Oliveira Ferreira

Capítulo 19: Análise de distúrbios musculares: Um estudo de caso na área de estética.

Gabriela de Souza Raymundo, Ivana Salvagni Rotta

Capítulo 20: Segurança do trabalho: perfil das empresas de pequeno porte da construção civil em Angicos/RN

Thalis Paulino Ginani, Marcos Antonio Araujo da Costa, Adriana Georgia Borges Soares, Allan Araujo Veloso , Fabricia Nascimento de Oliveira

Capítulo 21: A percepção dos agentes de risco em frigoríficos do extremo oeste do Paraná

Grasielly Bruna Vincenzi Rockenbach, Evandro Andre Konopatzki

Capítulo 22: Levantamento do risco físico ruído: um estudo de caso numa marcenaria na cidade de Campina Grande.

Luan Emerson Soares de Lima, Antonio Carlos de Queiroz Santos, Suelyn Fabiana Aciole Morais de Queiroz, Vanessa Nobrega da Silva

Autores: 


\section{CAPÍTULO 1}

\section{METODOLOGIA DELPHI INTEGRADA AO MAPEAMENTO DE PROCESSOS COMO FERRAMENTA DE AUXÍLIO NA TOMADA DE DECISÃO ESTRATÉGICA}

\section{Kamila Matos Andrade Silva}

João Thiago de Guimarães Anchieta e Araújo Campos

Jonathas do Nascimento Pereira

Carla Monique Rocha dos Santos

Resumo: A alta competitividade do mercado exige que as empresas estejam constantemente em inovação, e torna-se imprescindível que elas compreendam a realidade organizacional para poderem arquitetar o aperfeiçoamento do processo e sua permanência no mercado. Para facilitar a análise organizacional é fundamental mapear o processo, visando identificar as fraquezas do processo e os pontos de possíveis melhorias. Este estudo foi realizado em uma fábrica de biscoitos da região sudoeste da Bahia, e teve como objetivo integrar a técnica Delphi ao mapeamento de processos, visando a coleta sistêmica da opinião de especialistas dentro da organização, de forma que os resultados obtidos auxiliassem a empresa no processo de melhor entendimento e visualização do próprio processo, identificando gargalos e pontos para melhorias. Após a aplicação da técnica, foi possível identificar os pontos críticos do processo, e apontou-se que a técnica é eficiente quando aplicada em um ambiente industrial com poucas informações. 


\section{INTRODUÇÃO}

A alta competitividade do mercado exige constante inovação, um dos fatores primordiais que as empresas devem buscar para conseguir se sobressair no mercado e obter um diferencial competitivo. As inovações de produto ou de processo são conceituadas como inovações tecnológicas, e podem estar associadas a novos mercados, modelos de negócio, processos e métodos organizacionais. Segundo Neto (2006) a classe das pequenas e médias empresas é a que se mostra mais despreparada para as imposições que o ambiente mercadológico exige, associando o despreparo gerencial e a falta de recursos como os principais fatores que conduzem ao insucesso empresarial.

Desta forma, torna-se imprescindível que as empresas visem compreender a realidade organizacional para que o aperfeiçoamento dos processos e a permanência no mercado sejam possíveis. Segundo Migliato e Escrivão Filho (2004) um modelo que evidencie os diversos aspectos que compõem e envolvem uma organização, fundamentado nas teorias administrativas, possibilitaria a identificação de um conjunto de características gerais relacionadas tanto aos componentes internos da organização quanto ao ambiente no qual ela está inserida.

Segundo Hunt (1996) para facilitar a análise da eficácia e a localização de deficiências de uma organização, é fundamental mapear o processo para verificar como funcionam todos os componentes do sistema. De acordo com Salgado (2005) para se gerenciar um processo é necessário, primeiramente, visualizá-lo. Isso é possível pelo emprego de técnicas de análise do processo que, permitem detectar falhas e oportunidades de melhoria, destacando as tarefas críticas e eliminando tarefas que não agregam valor ou que são duplicadas, tentando levar a organização para um patamar diferente do atual e igual aquele em que a alta direção deseja.

Dentre as inúmeras técnicas que visam à estruturação de uma pesquisa eficiente, destaca-se a técnica Delphi que, segundo Corrêa e Corrêa (2012) trata-se de um modelo qualitativo de previsão, que visa a aplicação de questionários a um grupo de especialistas sobre uma problemática específica. $\mathrm{Na}$ presente pesquisa a problemática é definir, através do Delphi, o fluxo correto do processo, num ambiente industrial de pouca informação, de forma que as respostas alcancem um nível desejado de convergência, como o intuito de que esses dados mais subjetivos possam ter mais capacidade de explicar o futuro. Segundo Rojo (2006) a metodologia Delphi foi desenvolvida com objetivo de auxiliar o aumento da probabilidade de acerto dos estudos voltados à previsão de cenários e eventos futuros, também estimar os parâmetros desconhecidos a serem pesquisados. Através desse desenvolvimento metodológico, o método é entendido como uma técnica sistemática para coleta de opinião, válida cientificamente. (DALKEY, 1969). A metodologia Delphi, segundo Giovinazzo e Wright (2000) possui inúmeras vantagens, dentre elas, destaca-se o fato da consulta ser realizada com pessoas especialistas, trazendo uma análise do problema, no que se refere ao nível de informação, pelo olhar do membro melhor informado, ocasionando em um volume muito maior de informações, por ser uma técnica em que não há interação entre os participantes, facilita a liberdade de expressão e limita as inibições, além disso, tem fácil aplicação.

As ferramentas e técnicas utilizadas nessa metodologia irão auxiliar a elaboração de um mapa de processo em uma empresa de pequeno porte, de forma que possibilite a visualização de todos os componentes que fazem parte da organização e agregam valor ao produto final, e também com o intuito de identificação dos pontos críticos do processo, bem como, servir de fundamento para possíveis melhorias e otimizações no ambiente interno. Dentro dessa perspectiva, a técnica Delphi será utilizada, com o objetivo de coleta sistêmica da opinião de pessoas específicas dentro da organização sobre o fluxo do processo a ser estudado, integrada ao mapeamento de processos, de forma que os resultados obtidos auxiliem a empresa no processo de melhor entendimento e visualização do próprio processo, identificando gargalos e pontos para melhorias.

\section{FUNDAMENTAÇÃO TEÓRICA}

\subsection{MÉTODO DELPHI}

O método Delphi consiste em uma pesquisa realizada com um grupo de especialistas de forma estruturada e organizada através de um direcionamento feito por um mediador. Começou a ser disseminada no começo dos 
anos 60, com base nos trabalhos desenvolvidos por Olaf Helmer e Norman Dalker, pesquisadores da Rand Corporation (ESTES e KUESPERT, 1976).

A técnica é recomendada tanto quando há ausência de dados históricos, quanto há deficiência destes, ou seja, quando não possuem um grau de confiabilidade aceitável para projetar decisões futuras. Consiste na aplicação sucessiva de questionários a um grupo de especialistas em busca de um consenso a respeito da problemática em questão, no intervalo entre as rodadas de questões é realizado um estudo estatístico de todas as respostas, de forma que esse resultado seja exposto aos participantes na rodada subsequente. Dessa maneira os participantes podem reavaliar suas respostas à luz da opinião dos demais especialistas. Baseia-se na ideia que o julgamento coletivo, ao ser bem organizado, é melhor do que a opinião de um só indivíduo (GIOVINAZZO e WRIGHT, 2000).

Para que a pesquisa seja caracterizada como método Delphi, fazem-se necessárias algumas características, sendo elas: anonimato, consulta dos especialistas para cada rodada de dados, troca das informações entre as rodadas (feedback controlado), possibilidade de revisão das respostas individuais em função da representação estatística e a busca do consenso (MUNARETTO, 2013).

Segundo MUNARETTO (2013), a pesquisa Delphi segue os passos a seguir:

Figura 1 - Etapas método Delphi

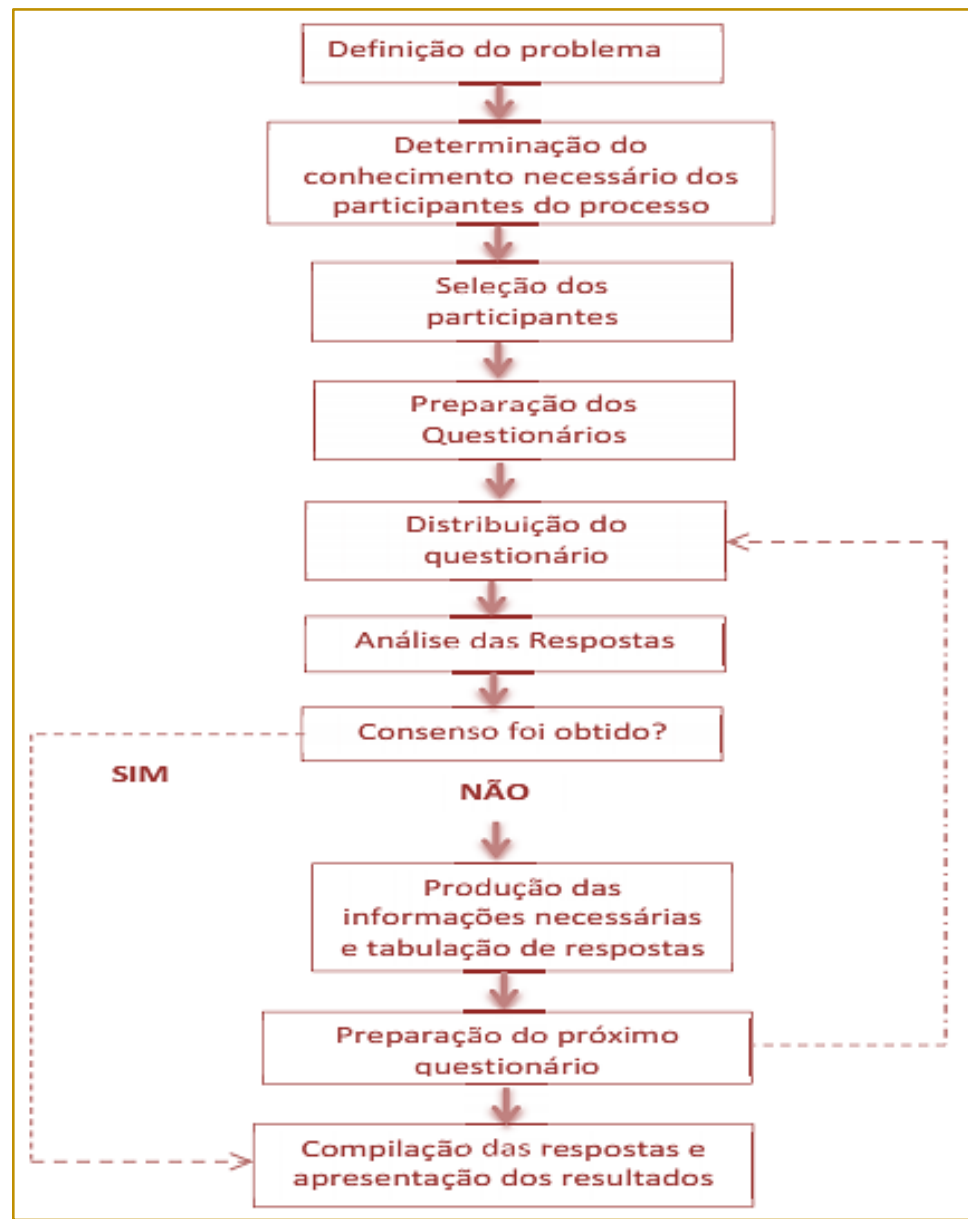

Fonte: MUNARETTO, 2013. 


\section{METODOLOGIA}

O presente trabalho foi realizado segundo as etapas abaixo:

No primeiro contato com a empresa, foi realizada visita técnica, com apresentação da metodologia de estudo proposta, uma vez que, o mapeamento de processos com utilização da técnica Delphi, possui continuidade com a aplicação de outras ferramentas de engenharia, e por isso outras visitas serão realizadas, visando fazer futuramente a simulação e adequação de cenários a uma nova estratégia organizacional, que será abordada em artigos subsequentes. Ainda durante a visita técnica, foram identificados os especialistas ideais para realização da pesquisa.

Após primeiro contato com a empresa foi realizada a elaboração do questionário, que, segundo Giovinazzo e Wright (2000) deve seguir algumas recomendações, com o objetivo de otimizar o tempo em que os especialistas utilizarão para transmitir as informações necessárias, sendo elas: evitar elementos compostos, evitar colocações ambíguas, tornar o questionário fácil de ser respondido, se atentar a quantidade de questões e permitir complementações dos especialistas. Como método de mensuração foi utilizada a escala de Likert, que segundo Costa e Silva Júnior (2014) é hoje um dos modelos de mensuração mais utilizado e mais discutido por pesquisadores, e tem a finalidade de mensuração de atitudes, opiniões e avaliações. A figura abaixo apresenta o modelo de questionário que será utilizado nessa pesquisa:

Figura 2 - Questionário

\begin{tabular}{|c|c|c|c|c|c|}
\hline \multicolumn{6}{|c|}{ DIFICULDADES PARA ENTREGA AO CUIENTE } \\
\hline \multicolumn{6}{|l|}{ Vendas } \\
\hline \multirow{4}{*}{$\begin{array}{l}\text { Cancelamento de vendas } \\
\text { Demora na Confirm ação de venda } \\
\text { Informações incom pletas (cliente) } \\
\text { Demora de fornecer informação }\end{array}$} & 1 & 2 & 3 & 4 & 5 \\
\hline & 1 & 2 & 3 & 4 & 5 \\
\hline & 1 & 2 & 3 & 4 & 5 \\
\hline & 1 & 2 & 3 & 4 & 5 \\
\hline \multicolumn{6}{|l|}{ Suprimentos } \\
\hline \multirow{3}{*}{$\begin{array}{l}\text { Avarias de produto em estoque } \\
\text { Atraso na entrega de solicitações } \\
\text { Falta de material/Matéria prima }\end{array}$} & 1 & 2 & 3 & 4 & 5 \\
\hline & 1 & 2 & 3 & 4 & 5 \\
\hline & 1 & 2 & 3 & 4 & 5 \\
\hline \multicolumn{6}{|l|}{ Manutenção } \\
\hline \multirow{3}{*}{$\begin{array}{l}\text { Quebras de máquinas } \\
\text { Tempo de preparação de máquina. } \\
\text { Troca de ferramentas }\end{array}$} & 1 & 2 & 3 & 4 & 5 \\
\hline & 1 & 2 & 3 & 4 & 5 \\
\hline & 1 & 2 & 3 & 4 & 5 \\
\hline \multicolumn{6}{|l|}{ Plan eja mento e Controle da Produçăo } \\
\hline \multirow{2}{*}{$\begin{array}{l}\text { Quantidade solicitada maior que a capacidade de produção } \\
\text { Falta de funcionários para atender a quantidade solicłzada }\end{array}$} & 1 & 2 & 3 & 4 & 5 \\
\hline & 1 & 2 & 3 & 4 & 5 \\
\hline \multicolumn{6}{|l|}{ Qualidade } \\
\hline \multirow{3}{*}{$\begin{array}{l}\text { Inspe ção da qualidade interrom pe a produção } \\
\text { Retrabalho ou descarte de produtos defe ituosos } \\
\text { Produto devolvido pelo cliente }\end{array}$} & 1 & 2 & 3 & 4 & 5 \\
\hline & 1 & 2 & 3 & 4 & 5 \\
\hline & 1 & 2 & 3 & 4 & 5 \\
\hline \multicolumn{6}{|l|}{ Manuseio de materiais e distribuiçăo } \\
\hline \multirow{2}{*}{$\begin{array}{l}\text { Transporte atrasado (Produto finalizado aguardando transporte } \\
\text { Tempo para arm azenamento (Produto não chega em estoque em } \\
\text { tempo hábil) }\end{array}$} & 1 & 2 & 3 & 4 & 5 \\
\hline & 1 & 2 & 3 & 4 & 5 \\
\hline \multicolumn{6}{|l|}{ Financeiro } \\
\hline Atraso na liberação do faturamento & 1 & 2 & 3 & 4 & 5 \\
\hline \multicolumn{6}{|l|}{ Considerações: } \\
\hline
\end{tabular}

Fonte: Própria Pesquisa

A primeira rodada consolidou-se através da distribuição dos questionários que foi feita pessoalmente durante visitas à empresa, em que solicita-se aos participantes uma descrição e esboço do processo, bem como uma relação entre os vários setores da empresa e as dificuldades para entrega do produto ao cliente, com a utilização da escala Linket.

Após isso, para o desenvolvimento da segunda rodada, de posse das respostas dadas pelos participantes na primeira rodada, formula-se novo questionário com ordenamento de proposições, relativas com 
as partes do processo citadas pelos participantes e, após análise estatística (desvio padrão) das respostas relacionadas às dificuldades de entrega do produto ao cliente, reformulou-se as questões com maiores divergências.

Para a etapa seguinte, buscou-se a resolução das divergências relacionadas ao mapeamento do processo. Solicita-se aos participantes que dentre os fatores relacionados com as dificuldades de entrega do produto ao cliente destacados nas rodadas anteriores, que se ordenasse de acordo com o grau de importância, sendo 05 (cinco) para o mais importante, 04 (quatro) para importante, 03 (três) para média importância, 02 (dois) para pouco importante e 01 (um) para o menos importante.

\section{RESULTADOS E DISCUSSÕES}

Este estudo foi resultado de pesquisa realizada em uma fábrica de biscoitos da região do sudoeste do estado da Bahia. Foram realizadas várias visitas na empresaalvo, onde se obteve dados suficientes para o referido trabalho. A pesquisa foi desenvolvida entre os meses de fevereiro a abril de 2017. A aplicação dos questionários foi feita junto a seis participantes estratégicos da organização, para a obtenção de dados referentes ao funcionamento do processo, bem como, identificação dos seus pontos críticos.

Durante realização da primeira rodada de questões, os participantes destacaram como parte do processo: chegada da matériaprima, estoque, planejamento da produção, venda, produção, manuseio de materiais, distribuição e entrega. Com as respostas adquiridas nessa fase possibilitou o desenvolvimento da segunda rodada de questionários. As dificuldades relacionadas à entrega do produto ao cliente foram associadas aos setores: vendas, suprimentos, manutenção, planejamento e controle da produção, qualidade, manuseio de materiais, distribuição e financeiro.

Quadro 1 - Resultado da primeira rodada da pesquisa

\begin{tabular}{|c|c|c|c|c|c|c|}
\hline Especialistas & A & B & C & D & E & F \\
\hline Matéria-prima & 1 & - & - & - & 1 & 1 \\
\hline Estoque & - & - & - & - & - & 2 \\
\hline Venda & 5 & 1 & 1 & 4 & 5 & - \\
\hline Planejamento da Produção & 2 & 2 & - & 1 & 2 & 3 \\
\hline Produção & 3 & 3 & 2 & 2 & 3 & 4 \\
\hline Manuseio de Materiais & 4 & 4 & 3 & 3 & 4 & 5 \\
\hline Distribuição & - & 5 & - & 5 & - & 6 \\
\hline Entrega & - & - & 4 & - & - & 7 \\
\hline
\end{tabular}

Fonte: A própria pesquisa

Com a primeira rodada, notou-se que há diferença quanto a descrição das partes do processo pelos especialistas, e também houve divergência quanto ao grau de relação entre os setores da empresa e as dificuldades de entrega do produto ao cliente.
$\mathrm{Na}$ segunda rodada de questões, os participantes ordenaram as etapas do processo de acordo com quadro abaixo:

Quadro 2 - Resultado da segunda rodada da pesquisa

\begin{tabular}{|c|c|c|c|c|c|c|}
\hline Especialistas & A & B & C & D & E \\
\hline Matéria-prima & 1 & 1 & 1 & 1 & 2 & 1 \\
\hline Estoque & 2 & 2 & 2 & 2 & 4 & 2 \\
\hline Venda & 3 & 3 & 3 & 3 & 5 & 6 \\
\hline Planejamento da Produção & 4 & 4 & 4 & 4 & 1 & 3 \\
\hline Produção & 5 & 5 & 5 & 5 & 3 & 4 \\
\hline Manuseio de Materiais & 6 & 6 & 6 & 6 & 6 & 5 \\
\hline Distribuição & 7 & 7 & 7 & 7 & 7 & 7 \\
\hline Entrega & 8 & 8 & 8 & 8 & 8 & 8 \\
\hline
\end{tabular}

Fonte: A própria pesquisa 
Observa-se que, com o ordenamento de proposições, as divergências relacionadas à descrição do processo foram minimizadas. Os principais fatores que, dentro da organização, dificultam que a entrega do produto ao cliente seja feita de maneira eficiente, de acordo com os participantes são: fluxo de informações deficiente entre os setores da empresa, falta de matéria-prima, transporte, capacidade solicitada maior que a capacidade produtiva e falta de treinamento para os funcionários.

A partir dos dados obtidos na rodada anterior, e adequação dos questionários para realização da última rodada, obteve-se os seguintes resultados:

Quadro 3 - Resultado da terceira rodada de pesquisa

\begin{tabular}{|l|l|l|l|l|l|l|}
\multicolumn{1}{c}{ Especialistas } & A & B & C & D & E \\
\hline Matéria-prima & 1 & 1 & 1 & 1 & 1 & 1 \\
\hline Estoque & 2 & 2 & 2 & 2 & 2 & 2 \\
\hline Venda & 3 & 3 & 3 & 3 & 3 & 3 \\
\hline Planejamento da Produção & 4 & 4 & 4 & 4 & 4 & 4 \\
\hline Produção & 5 & 5 & 5 & 5 & 5 & 5 \\
\hline Manuseio de Materiais & 6 & 6 & 6 & 6 & 6 & 6 \\
\hline Distribuição & 7 & 7 & 7 & 7 & 7 & 7 \\
\hline Entrega & 8 & 8 & 8 & 8 & 8 & 8 \\
\hline
\end{tabular}

Fonte: A própria pesquisa

Conforme quadro acima, os resultados do mapeamento convergiram, e o consenso em relação ao funcionamento do processo foi alcançado, foi possível a confecção do fluxograma de processo, que conforme imagens abaixo se difere do fluxograma fornecido pela empresa.

Figura 3 - Fluxograma do Processo

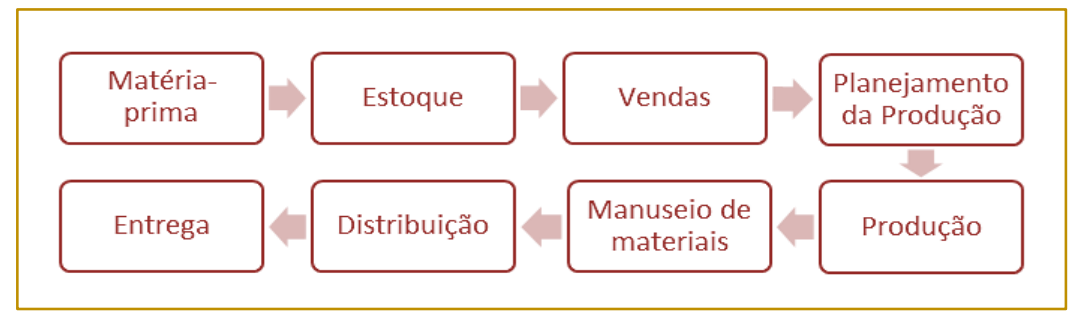

Fonte: Elaborado pelos autores como resultado da pesquisa

Figura 4 - Fluxograma fornecido pela empresa

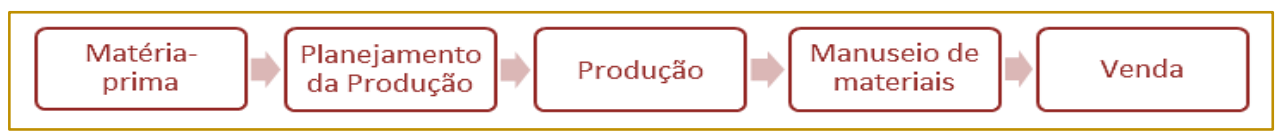

Fonte: Elaborado pela empresa

Os fatores que obtiveram maior destaque nas rodadas iniciais como fatores que dificultam a entrega dos produtos aos clientes, foram ordenados pelos participantes de acordo com sua importância. 
Quadro 4 - Ordem de prioridades dentre os fatores destacados

\begin{tabular}{|l|c|c|c|c|c|c|c|}
\multicolumn{1}{|c}{ Especialistas } & A & B & C & D & E & F & MÉDIA \\
\hline Fluxo de Informações deficiente & 3 & 3 & 1 & 5 & 4 & 5 & 3,50 \\
\hline Falta de matéria-prima & 2 & 5 & 5 & 3 & 5 & 1 & 3,50 \\
\hline $\begin{array}{l}\text { Transporte } \\
\text { Capacidade solicitada maior que a } \\
\text { capacidade produtiva }\end{array}$ & 5 & 4 & 3 & 4 & 2 & 4 & 3,67 \\
\hline $\begin{array}{l}\text { Falta de treinamento com os } \\
\text { funcionários }\end{array}$ & 1 & 1 & 3 & 1 & 1 & 3 & 1,67 \\
\hline
\end{tabular}

Fonte: A própria pesquisa

Pode-se relacionar os fatores mais dificultam a entrega eficiente dos produtos aos clientes com o mapeamento de processo realizado durante a pesquisa, considerando como foco a ordem estabelecida como prioridade pelos participantes na última rodada. Como foco de possíveis melhorias destaca-se o setor de transporte, que no mapeamento se relaciona com os setores de distribuição e entrega, falta de matéria-prima que está relacionada diretamente ao setor de matéria-prima e fluxo de informações deficientes que entende-se que esteja relacionado a todos os setores da empresa.

\section{CONSIDERAÇÕES}

Este estudo apresentou a proposta de uma discussão acerca da possibilidade de construir o mapeamento de processos com a utilização da técnica Delphi, possibilitando que a empresa estudada compreenda a realidade do funcionamento do seu processo,

\section{REFERÊNCIAS}

[1]. Corrêa, H. L.; Corrêa, C. A. Administração de Produção e Operações: Manufatura e serviços Uma abordagem estratégica. 3ำ edição. São Paulo, editora altas, 2012. Cap.8.

[2]. Costa, F. J.; Silva Júnior, S. D. Mensuração e Escalas de Verificação: uma análise comparativa das Escalas de Likert e Phrase Completion. PMKT - Revista Brasileira de Pesquisas de Marketing, Opinião e Mídia. 2014.

[3]. Dalkey, N. C. The Delphi method. An experimental study of group opinion. Santa Monica: Rand Corporation, 1969.

[4]. Estes, Gerald M e Kuespert, Don. Delphi in industrial forecasting. Chemical and Engineering News, EUA, p. 40-47, agosto 1976.

[5]. Giovinazzo, Renata A.; Wright, J. T. C. Delphi: uma ferramenta de apoio ao planejamento sobre a luz do consenso obtido na aplicação da técnica, com o intuito de comparar os resultados com a visão previamente estabelecida pela gestão, e assim identificar gargalos de processo, implementar melhorias, colher bons resultados e se tornar mais competitiva no mercado.

A pesquisa mostrou que existem alguns fatores que tem maior relevância e que tem impacto direto na entrega do produto, e que devem ser considerados para delinear novas estratégias empresariais. Diante disso, acredita-se que esse modelo proposto, pode ser utilizado em cenários organizacionais os quais objetivam realizar o mapeamento de processo, sendo que suas principais vantagens são flexibilidade na aplicação dos questionários, realização da pesquisa sem que o foco seja perdido, vantagem por ser focada em um grupo de especialistas, onde o fluxo e a qualidade das informações são maiores.

prospectivo. Caderno de Pesquisas em Administração, p. 54-65, 2000.

[6]. Hunt, V. Daniel. Process mapping: how to reengeneer your business processes. New York: John Wiley \& Sons, Inc., 1996.

[7]. Migliato, Antonio Luiz Tonissi; Escrivão Filho, Edmundo. A pequena empresa e suas especificidades: uma proposta de classificação Fundamentada em um modelo de concepção organizacional. Anais do VII Seminários em Administração-SemeAd, São Paulo, SP, Brasil, 2004.

[8]. Munaretto, Lorimar Francisco; Corrêa, Hamilton Luiz; DA Cunha, Júlio Araújo Carneiro. Um estudo sobre as características do método Delphi e de grupo focal, como técnicas na obtenção de dados em pesquisas exploratórias. Revista de Administração da UFSM, v. 6, n. 1, p. 924, 2013. 
[9]. Neto, Alfredo I; Junior, I. C. Classificação das principais dificuldades enfrentadas pelas pequenas e médias empresas (PMEs). 2006.

[10]. Rojo, C. A. Planejamento Estratégico: modelo de simulação de cenários - uma aplicação em instituição de ensino. Cascavel: Assoeste, 2006.

[11]. Salgado, Eduardo Gomes. Mapeamento dos processos em serviços: estudo de caso em duas pequenas empresas da área de saúde. 2005. 


\section{GAPÍTULO 2}

\section{SELEÇÃO DE MODELO DE AVALIAÇÃO DE NÍVEL DE MATURIDADE EM GESTÃO DE PROJETOS PARA UMA EMPRESA DE MINERAÇÃO}

\section{Andressa de Paula Cruz}

Fernanda de Oliveira Galdiano

Sandra Miranda Neves;

Tarcísio Gonçalves de Brito

Resumo: A maturidade em gestão de projetos proporciona um direcionamento para que empresas consigam atingir a excelência. As empresas de mineração têm apresentado uma queda de investimentos e também na produção mineral, o que ressalta a importância de buscar melhorias no setor por meio de um gerenciamento de projetos mais eficaz. Dessa forma, este artigo tem como objetivo selecionar um modelo de avaliação de nível de maturidade mais adequado para aplicação a uma empresa mineradora. O método de pesquisa adotado foi o estudo de caso. Como resultado, identificou-se que o modelo de maturidade proposto por Kerzner, denominado Project Management Maturity Model (PMMM), é o mais adequado para aplicação à empresa, devido, principalmente, às questões que permitem analisar os projetos voltados para a área de mineração. Além disso, o modelo considera a influência da cultura organizacional para identificar a mudança de nível de maturidade.

Palavras-Chave: Nível de maturidade; Gestão de projetos; Empresas de mineração. 


\section{INTRODUÇÃO}

O Instituto Brasileiro de Mineração (IBRAM) é uma entidade que representa as instituições brasileiras que atuam na indústria de mineração. $O$ instituto busca contribuir para o desenvolvimento de pesquisas, melhores práticas de saúde e segurança na mineração e na qualidade de vida da sociedade. Em uma pesquisa realizada em fevereiro de 2016 foi apontada uma queda na produção mineral brasileira de US\$ 14 bilhões do ano de 2014 para 2015, apresentando ainda uma estimativa de uma produção de US\$30 bilhões, valor ainda considerado baixo (IBRAM, 2016).

O investimento no setor mineral também apresentou uma queda, segundo pesquisa realizada em março de 2015 pelo IBRAM. A Figura 1 contempla a apuração do investimento no setor para um período de cinco anos. Pode-se observar que, no período de 2007 até o ano de 2012 as estimativas eram de um grande aumento no investimento. Contudo, a estimativa realizada em 2013 e 2014 apontam um decréscimo significativo dos valores a serem aplicados no setor.

Figura 1 - Apuração de investimentos no setor mineral

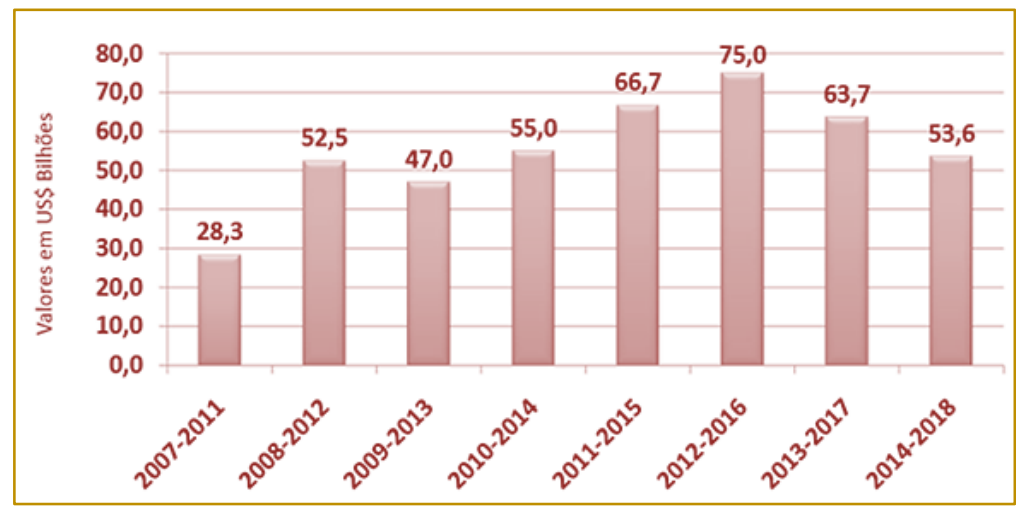

Fonte: IBRAM (2015)

Devido à importância de se compreender o cenário das empresas, com $\mathrm{o}$ intuito de melhorar a sua situação frente ao mercado, as mesmas devem ser capazes de definir seus pontos fortes e pontos fracos, assegurando um gerenciamento de projetos eficaz. Um gerenciamento de projetos eficaz proporciona para as empresas oportunidades de melhorias nas áreas críticas, sendo essencial para alcançar os principais objetivos (SPALEK, 2015).

Para que as organizações sejam capazes de medir seu desempenho e avaliar práticas com relação à normas e benchmark, o conceito de maturidade em gestão de projetos destaca-se como uma importante ferramenta de avaliação que irá contribuir para a melhoria dos processos e maior competitividade (MARZOUK; ATTIA; EL-BENDARY, 2012).

A maturidade em gerenciamento de projetos fornece um caminho para que a excelência seja atingida, sendo capaz de prover informações relacionadas à insuficiência evidenciada pelo nível de maturidade encontrado e de propor soluções para melhorar esse nível, tendo assim um impacto direto no desempenho da organização (MATEEN, 2015; KLUTH et al., 2014). Entretanto, há uma grande diversidade de modelos de níveis de maturidade, que devem ser analisados pelas organizações para que se escolha o mais adequado (GOLÇALVES; GASPAR; CARDOSO, 2016).

Dessa forma, esta pesquisa pretende responder às seguintes questões: Quais os principais modelos de avaliação de nível de maturidade existentes? Quais as vantagens e desvantagens apresentadas em cada modelo? Qual modelo melhor se adequa à avaliação do nível de maturidade em gestão de projetos de uma empresa de mineração?

Assim, estabeleceu-se como objetivo geral selecionar o modelo de avaliação de nível de maturidade mais adequado para aplicação a uma empresa de mineração.

O artigo está estruturado da seguinte forma: a Seção 1 apresenta a introdução, envolvendo as justificativas para a realização da pesquisa, a questão de pesquisa e o objetivo. A Seção 2 abrange o referencial teórico sobre gestão de projetos e maturidade em gestão 
de projetos. Na Seção 3 são apresentados os procedimentos metodológicos. A Seção 4 contempla os dados coletados e a análise dos mesmos. E, finalmente, a Seção 5 apresenta a conclusão da pesquisa, sugestões para pesquisas futuras e as limitações.

\section{GESTÃO DE PROJETOS}

Segundo Julio e Piscopo (2013), nos últimos anos houve um crescimento do número de artigos abordando temas relacionados a questões estratégicas e empreendedoras nas organizações, incluindo principalmente a gestão de projetos, por colaborar, em grande parte, para que a empresa atinja excelentes resultados no mercado. Confirmando tal afirmação, a Figura 2 mostra o resultado de uma busca realizada na base de dados Web of Science sobre o número de artigos referentes ao tema gestão de projetos entre os anos de 2007 e 2015.

Figura 2 - Evolução da quantidade de artigos referentes ao tema gestão de projetos

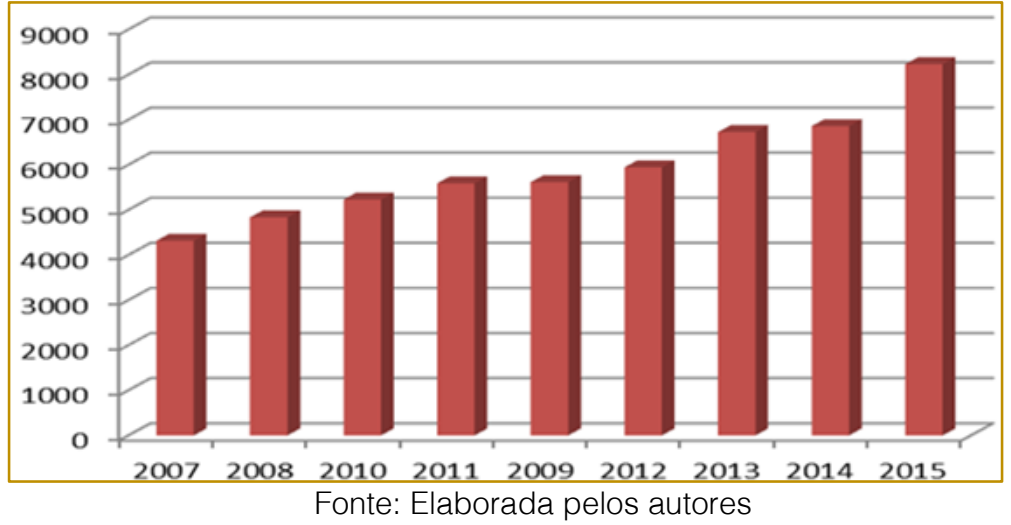

O gerenciamento de projetos é definido pelo Project Management Institute (PMI, 2013) como a aplicação do conhecimento, habilidades, ferramentas e técnicas referentes aos projetos para que assim seja possível executá-lo. Para a realização do gerenciamento de projetos faz-se necessário a aplicação de alguns processos, agrupados em 5 grupos: Iniciação, planejamento, execução, monitoramento e controle e encerramento. Para Pinto, Vasconcelos e Lezana (2014), é importante que se compreenda os conceitos de projeto, para assim evitar possíveis falhas no gerenciamento. Os autores ainda ressaltam que o sucesso de um projeto depende de boas práticas da gerência, além da cooperação entre os envolvidos, o trabalho em equipe, a confiança e comunicação eficiente.

\subsection{MATURIDADE EM GERENCIAMENTO DE PROJETOS}

A maturidade em gerenciamento de projetos tem como objetivo ajudar a organização a conseguir atingir os resultados desejados (MIKLOSIK, 2015). Compreende-se que uma organização com um alto nível de maturidade é capaz de realizar atividades de modo sistêmico, fazendo uso de ferramentas e técnicas para promover um projeto em que a metodologia envolvida possa ser discutida para evidenciar erros e realizar recomendações (JULIO; PISCOPO, 2013). De acordo com Oliveira (2014), a quantificação numérica da maturidade em gestão de projetos é possível por meio de modelos de maturidade, os quais são capazes de realizar a identificação do nível em que o projeto se encontra e a sua capacidade de evoluir. A ideia de melhoria contínua presente nos modelos de maturidade tiveram inspiração na gestão da qualidade total (Total Quality Management - TQM), aplicando os conhecimentos nos processos e, com isso, melhorando as saídas dos projetos (MIKLOSIK, 2015).

Existem diferentes modelos de maturidade e a empresa é responsável por escolher aquele que irá guiar a organização a melhor definir seus processos e melhorar seu desempenho (KERRIGAN, 2013). O Quadro 1 apresenta uma análise sobre o tema considerando pesquisas realizadas nos últimos quatro anos. 
Quadro 1 - Análise de artigos sobre maturidade em gestão de projetos

\begin{tabular}{|c|c|c|c|c|c|}
\hline Revista & Ano & Autor & $\begin{array}{l}\text { Área de } \\
\text { aplicação }\end{array}$ & Objetivo do artigo & $\begin{array}{l}\text { Modelo } \\
\text { utilizado }\end{array}$ \\
\hline $\begin{array}{l}\text { Production and } \\
\text { Operations } \\
\text { Management }\end{array}$ & 2016 & $\begin{array}{l}\text { MISHRA, A; } \\
\text { DAS, S; } \\
\text { MURRAY, J. }\end{array}$ & Tecnologia & $\begin{array}{l}\text { Propor um modelo para } \\
\text { redução de gastos que } \\
\text { melhore a gestão dos projetos } \\
\text { de tecnologia do governo } \\
\text { federal dos EUA. }\end{array}$ & CMMI \\
\hline $\begin{array}{l}\text { Information } \\
\text { Systems } \\
\text { Frontiers }\end{array}$ & 2016 & $\begin{array}{l}\text { DIJKMAN, } \\
\text { R.; } \\
\text { LAMMERS, } \\
\text { SV.; JONG, } \\
\text { A. }\end{array}$ & Organizacional & $\begin{array}{l}\text { Análise da relação da } \\
\text { maturidade nos processos } \\
\text { gerenciais com o } \\
\text { desempenho dos mesmos. }\end{array}$ & BPMM \\
\hline $\begin{array}{l}\text { Information } \\
\text { Resources } \\
\text { Management } \\
\text { Journal }\end{array}$ & 2016 & $\begin{array}{l}\text { KABIR, M.; } \\
\text { RUSU, L. }\end{array}$ & $\begin{array}{l}\text { Tecnologia da } \\
\text { informação }\end{array}$ & $\begin{array}{l}\text { Utilizar o modelo CMM para } \\
\text { melhorar o desenvolvimento de } \\
\text { projetos de TI em uma grande } \\
\text { empresa. }\end{array}$ & CMM \\
\hline $\begin{array}{l}\text { International } \\
\text { Journal of } \\
\text { Advanced } \\
\text { Computer } \\
\text { Science and } \\
\text { Applications }\end{array}$ & 2016 & $\begin{array}{l}\text { FARID, A.; } \\
\text { ABD } \\
\text { ELGHANY, A.; } \\
\text { HELMY, Y. }\end{array}$ & $\begin{array}{l}\text { Engenharia da } \\
\text { computação }\end{array}$ & $\begin{array}{l}\text { Analisar a satisfação e } \\
\text { utilização dos diferentes } \\
\text { modelos de maturidade das } \\
\text { diferentes versões do modelo } \\
\text { CMMI. }\end{array}$ & CMMI e Scrum \\
\hline $\begin{array}{l}\text { International } \\
\text { Journal of Project } \\
\text { Management }\end{array}$ & 2015 & $\begin{array}{l}\text { GOLINI, R.; } \\
\text { KALCHSCHMI } \\
\text { DT, M.; } \\
\text { LANDONI, P. }\end{array}$ & $\begin{array}{l}\text { Organizações não } \\
\text { governamentais }\end{array}$ & $\begin{array}{l}\text { Desenvolver uma metodologia } \\
\text { de análise de gerenciamento } \\
\text { de projetos que apresente } \\
\text { melhores resultados de } \\
\text { desempenho. }\end{array}$ & $\begin{array}{l}\text { Desenvol-vido } \\
\text { pelos autores }\end{array}$ \\
\hline $\begin{array}{l}\text { The International } \\
\text { Journal of } \\
\text { Advanced } \\
\text { Manufacturing } \\
\text { Technology }\end{array}$ & 2014 & $\begin{array}{l}\text { VEZZETTI, F.; } \\
\text { VIOLANTE, M.; } \\
\text { MARCOLIN, F. }\end{array}$ & Organizacional & $\begin{array}{l}\text { Realizar um benchmarking do } \\
\text { modelo PLM. }\end{array}$ & PLM \\
\hline Production & 2014 & $\begin{array}{l}\text { GUEDES, R. et } \\
\text { al. }\end{array}$ & $\begin{array}{l}\text { Tecnologia da } \\
\text { informação e } \\
\text { Sistema de } \\
\text { informação }\end{array}$ & $\begin{array}{l}\text { Verificar o nível de maturidade } \\
\text { em empresas de tecnologia de } \\
\text { informação e sistemas de } \\
\text { informação. }\end{array}$ & OPM3 \\
\hline $\begin{array}{l}\text { International } \\
\text { Journal of } \\
\text { Managing Project } \\
\text { in Business } \\
\end{array}$ & 2014 & $\begin{array}{l}\text { BROOKES, N.; } \\
\text { DEY, M.; } \\
\text { CLARK, R. }\end{array}$ & Organizacional & $\begin{array}{l}\text { Explorar o impacto do modelo } \\
\text { PMMM no desempenho de } \\
\text { projetos. }\end{array}$ & PMMM \\
\hline $\begin{array}{l}\text { Journal of } \\
\text { Business and } \\
\text { Projects }\end{array}$ & 2014 & OLIVEIRA, J. & Engenharia & $\begin{array}{l}\text { Avaliar o nível de maturidade } \\
\text { em gestão de projetos no setor } \\
\text { de Engenharia de Projetos de } \\
\text { um estaleiro. }\end{array}$ & MMGP \\
\hline $\begin{array}{l}\text { Digital } \\
\text { Investigation: The } \\
\text { International } \\
\text { Journal of Digital } \\
\text { Forensics \& } \\
\text { Incident } \\
\text { Response } \\
\end{array}$ & 2013 & KERRIGAN, M. & Organizacional & $\begin{array}{l}\text { Desenvolver um modelo que } \\
\text { seja capaz de analisar a } \\
\text { capacidade de investigação } \\
\text { digital da organização. }\end{array}$ & DI-CMM \\
\hline
\end{tabular}

Fonte: Elaborado pelos autores

A busca por artigos sobre maturidade em gestão de projetos proporcionou a identificação dos modelos de maturidade mais utilizados, como o CMM, CMMI, OPM3, PMMM e MMGP, assim como a área de aplicação. Por meio de uma pesquisa na base de dados Web of Science, foi possível identificar que entre os anos de 2010 e 2017 as áreas relacionadas à tecnologia da informação e organizacional foram bastante citadas e utilizadas com finalidades diferentes, como mostrado na Figura 3. 
Figura 3 - Áreas de aplicação dos modelos de maturidade

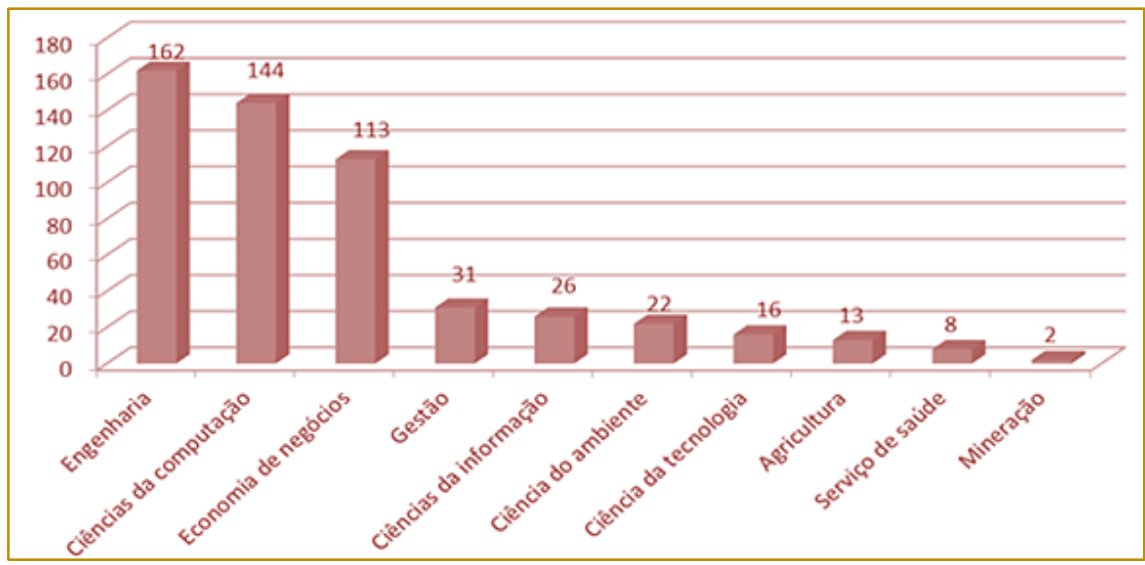

Fonte: Elaborada pelos autores

Contudo, a Figura 3 demonstra que a área da mineração ainda é pouco explorada, justificando estudos nessa área.

\section{PROCEDIMENTOS METODOLÓGICOS}

O objeto de estudo desta pesquisa é uma mineradora brasileira com mais de sessenta mil empregados, entre próprios e terceirizados. Presente em treze estados brasileiros e em cinco continentes, a empresa se destaca como produtora de minério de ferro, pelotas e níquel. A mineradora apresenta seis diretorias, sendo elas: Ferrosos e estratégia, Fertilizantes e carvão, Finanças e relações com investidores, Logística e pesquisa mineral, Metais básicos e $\mathrm{RH}$, saúde, segurança, sustentabilidade e energia. A unidade a ser analisada pertence à diretoria de Ferrosos e estratégia. A empresa foi selecionada como objeto de estudo por apresentar grande relevância no mercado internacional, o que proporciona um campo de pesquisa propício e abrangente.

De acordo com Prodanov e Freitas (2013) a pesquisa científica pode ser classificada de acordo com o objetivo de estudo, o procedimento técnico, a abordagem e a natureza. O Quadro 2 contempla, dessa forma, a classificação da presente pesquisa.

Quadro 2 - Classificação da pesquisa científica

\begin{tabular}{|c|c|c|}
\hline Critérios & Classificações & Descrição \\
\hline $\begin{array}{l}\text { Objetivo do } \\
\text { estudo }\end{array}$ & $\begin{array}{l}\text { Pesquisa } \\
\text { exploratória }\end{array}$ & $\begin{array}{l}\text { Tem como objetivo proporcionar maior familiaridade com o problema em } \\
\text { questão, visando torná-lo mais explícito ou construindo hipóteses sobre } \\
\text { ele. }\end{array}$ \\
\hline $\begin{array}{l}\text { Procedimentos } \\
\text { técnicos }\end{array}$ & $\begin{array}{l}\text { Estudo de } \\
\text { caso }\end{array}$ & $\begin{array}{l}\text { Consiste em estudar fenômenos atuais inseridos em algum contexto da } \\
\text { vida real. }\end{array}$ \\
\hline Abordagem & Qualitativa & $\begin{array}{l}\text { A coleta de dados, interpretação de fenômenos e atribuição de } \\
\text { significados são informações retiradas a partir do ambiente de estudo. }\end{array}$ \\
\hline Natureza & Aplicada & $\begin{array}{l}\text { Tem como finalidade produzir conhecimento para aplicação prática, } \\
\text { procurando solução de problemas específicos. }\end{array}$ \\
\hline
\end{tabular}

Fonte: Adaptado de Prodanov e Freitas (2013)

O fluxo metodológico da pesquisa, tendo como base o método de estudo de caso proposto por Miguel (2007), é constituído por cinco etapas: Definir uma estrutura conceitualteórica, Planejar o caso, coletar os dados, analisar os dados e gerar relatórios.

\section{RESULTADOS E DISCUSSÕES}

Considerando a primeira etapa da pesquisa (definir uma estrutura conceitual-teórica), foram identificados os principais modelos de avaliação de nível de maturidade e apresentadas as vantagens e desvantagens de cada um, conforme preconizado na literatura (Quadro 3). 
Quadro 3 - Resumo dos modelos de maturidade

\begin{tabular}{|c|c|c|c|}
\hline Modelo & Descrição & Vantagens & Desvantagens \\
\hline $\begin{array}{l}\text { Capability } \\
\text { Maturity } \\
\text { Model (CMM) }\end{array}$ & $\begin{array}{l}\text { Tem como foco os } \\
\text { conceitos da área de } \\
\text { tecnologia da } \\
\text { informação (TI). O } \\
\text { modelo apresentava } \\
\text { cinco níveis. } \\
\text { Desenvolvido pelo } \\
\text { Software Engineering } \\
\text { Institute (SEI) de } 1987 \\
\text { até 1997(JULIO; } \\
\text { PISCOPO, 2013; TAHRI; } \\
\text { DRISSI-KAITOUNI, } \\
\text { 2015). }\end{array}$ & $\begin{array}{l}\text { Método simplificado; } \\
\text { Propõe a melhoria contínua dos } \\
\text { processos de desenvolvimento } \\
\text { de software; } \\
\text { Auxilia a identificar os erros } \\
\text { comuns na gestão de projetos, } \\
\text { desde a implementação; } \\
\text { Viabiliza uma ferramenta de } \\
\text { avaliação de desempenho } \\
\text { objetiva, confiável e consistente } \\
\text { (CROWSTON; QUIN, 2011; } \\
\text { BARBAS, 2012). }\end{array}$ & $\begin{array}{l}\text { Destinado a projetos de } \\
\text { software; } \\
\text { Não apresenta integralmente } \\
\text { as questões relacionadas ao } \\
\text { sucesso do projeto; } \\
\text { Apresenta apenas o } \\
\text { treinamento necessário, ou } \\
\text { seja, não aborda as questões } \\
\text { sobre a seleção, contratação } \\
\text { e retenção de pessoas dentro } \\
\text { da organização (BARBAS, } \\
\text { 2012). }\end{array}$ \\
\hline $\begin{array}{l}\text { Capability } \\
\text { Maturity } \\
\text { Model } \\
\text { Integration } \\
\text { (CMMI) }\end{array}$ & $\begin{array}{l}\text { O modelo contempla } \\
\text { conceitos de } \\
\text { desenvolvimento de } \\
\text { produto, engenharia de } \\
\text { sistemas, além de ter } \\
\text { uma estrutura que } \\
\text { permite a geração de } \\
\text { múltiplos modelos. A } \\
\text { última versão do modelo } \\
\text { foi lançada em } \\
\text { 2010(WENDLER, 2012; } \\
\text { TAHRI; DRISSI- } \\
\text { KAITOUNI, 2015). }\end{array}$ & $\begin{array}{l}\text { Modelo mais completo que o } \\
\text { CMM. } \\
\text { Apresenta duas } \\
\text { representações para } \\
\text { proporcionar melhorias na } \\
\text { organização: faseada ou } \\
\text { corporativa; } \\
\text { Pode ser utilizado } \\
\text { independentemente da área de } \\
\text { atuação da organização } \\
\text { (BARBAS, 2012). }\end{array}$ & $\begin{array}{l}\text { Mais complexo que o CMM } \\
\text { (BARBAS, 2012). }\end{array}$ \\
\hline $\begin{array}{l}\text { Project } \\
\text { Management } \\
\text { Maturity } \\
\text { Model } \\
\text { (PMMM) }\end{array}$ & $\begin{array}{l}\text { Modelo desenvolvido } \\
\text { por Kerzner que tem } \\
\text { como foco o } \\
\text { gerenciamento de } \\
\text { mudanças por meio de } \\
\text { aplicações práticas de } \\
\text { gestão de projetos. } \\
\text { Assim, o PMMM realiza } \\
\text { a integração dos } \\
\text { processos na } \\
\text { organização com base } \\
\text { na análise dos cinco } \\
\text { níveis pelo qual é } \\
\text { composto (OLIVEIRA, } \\
\text { 2014; JULIO; PISCOPO, } \\
\text { 2013). }\end{array}$ & $\begin{array}{l}\text { Utiliza o método benchmarking } \\
\text { nos níveis de maturidade; } \\
\text { Aborda tanto as constituições } \\
\text { internas e externas à } \\
\text { organização, quanto as forças } \\
\text { e fraquezas da mesma; } \\
\text { Pode ser utilizado } \\
\text { independentemente da área de } \\
\text { atuação da organização; } \\
\text { Integra os processos da } \\
\text { organização; } \\
\text { Aplica uma metodologia e } \\
\text { questionários estruturados } \\
\text { (BARBAS, 2012). }\end{array}$ & $\begin{array}{l}\text { Possui uma utilização } \\
\text { complexa, além de possuir } \\
\text { um questionário extenso; } \\
\text { Tem como foco principal } \\
\text { apenas o diagnóstico, não } \\
\text { apresentando um plano de } \\
\text { ação para elevar o nível de } \\
\text { maturidade em gestão de } \\
\text { projetos na organização; } \\
\text { Não possui o devido foco nas } \\
\text { melhorias das equipes de } \\
\text { projetos (BARBAS, 2012). }\end{array}$ \\
\hline $\begin{array}{l}\text { Organizational } \\
\text { Project } \\
\text { Management } \\
\text { Maturity } \\
\text { Model (OPM3) }\end{array}$ & $\begin{array}{l}\text { Modelo desenvolvido } \\
\text { pelo PMI o qual realiza } \\
\text { uma avaliação de como } \\
\text { realizar melhorias nas } \\
\text { organizações para } \\
\text { melhor compreensão da } \\
\text { gestão de projetos. O } \\
\text { modelo tem como foco } \\
\text { principal a divisão em } \\
\text { estágios e tem como } \\
\text { base três elementos: } \\
\text { conhecimento, } \\
\text { avaliação e } \\
\text { desenvolvimento } \\
\text { (OLIVEIRA, 2014; } \\
\text { SOUZA; GOMES, 2015; } \\
\text { THIELMANN, 2014). }\end{array}$ & $\begin{array}{l}\text { Dispõe de checklists para se } \\
\text { obter as informações; } \\
\text { Analisa a maturidade nas áreas } \\
\text { de projetos, programas e } \\
\text { portfólios; } \\
\text { Contribui para que a } \\
\text { organização estabeleça uma } \\
\text { estratégia alinhada ao negócio } \\
\text { organizacional; } \\
\text { Pode ser utilizado } \\
\text { independentemente da área de } \\
\text { atuação da organização } \\
\text { (BARBAS, 2012). }\end{array}$ & $\begin{array}{l}\text { Utilização complexa; } \\
\text { Falta de rigor estatístico; } \\
\text { Não possui o devido foco nas } \\
\text { melhorias das equipes de } \\
\text { projetos (BARBAS, 2012). }\end{array}$ \\
\hline
\end{tabular}


Quadro 3 - Resumo dos modelos de maturidade (continuação)

\begin{tabular}{|c|c|c|c|}
\hline Modelo & Descrição & Vantagens & Desvantagens \\
\hline $\begin{array}{l}\text { Modelo de } \\
\text { Maturidade em } \\
\text { Gerenciamento } \\
\text { de Projetos } \\
\text { (MMGP) }\end{array}$ & $\begin{array}{l}\text { Foi desenvolvido por } \\
\text { Darci Prado. O modelo } \\
\text { identifica estágio de } \\
\text { maturidade em que } \\
\text { um setor da } \\
\text { organização } \\
\text { encontra. Para isso, } \\
\text { utiliza-se re } \\
\text { questionário cujas } \\
\text { questões abrangem os } \\
\text { cinco níveis } \\
\text { (OLIVEIRA, 2014). }\end{array}$ & $\begin{array}{l}\text { Possui uma aplicação simples, } \\
\text { devido ao fato do formulário } \\
\text { apresentar poucas questões; } \\
\text { O método evidencia dois } \\
\text { componentes para avaliação do } \\
\text { nível de maturidade nas } \\
\text { organizações: componente } \\
\text { setorial e corporativa; } \\
\text { Grande aderência do método } \\
\text { por parte das organizações } \\
\text { brasileiras; } \\
\text { Pode ser aplicado a diversas } \\
\text { organizações pois o modelo } \\
\text { possui uma subdivisão em } \\
\text { setorial e corporativo (BARBAS, } \\
\text { 2012; SILVA, 2011). }\end{array}$ & $\begin{array}{l}\text { Devido à simplicidade do } \\
\text { método são necessárias } \\
\text { informações adicionais para a } \\
\text { complementação do método e } \\
\text { uma melhor avaliação } \\
\text { (BARBAS, 2012). }\end{array}$ \\
\hline
\end{tabular}

Fonte: Elaborado pelos autores

Para definir qual questionário de nível de maturidade em gestão de projetos melhor se adapta à realidade da mineradora, foi elaborada uma matriz de priorização utilizando os critérios contemplados por Silva e Santos (2014), sendo eles: facilidade de utilização, adaptabilidade, custo de aplicação, alinhamento com o planejamento estratégico da empresa e disponibilidade do material. Optou-se pela utilização desses critérios pois Silva e Santos (2014) ressaltam, em sua pesquisa, que cada modelo possui peculiaridades com relação ao tipo de questão, formulação das mesmas e conceitos ressaltados. Ademais, faz-se necessário relacionar esses fatores com os aspectos internos da organização a ser estudada. Dessa forma, para cada critério foram atribuídas pontuações de acordo com a escala proposta por Kotoleto (2008), onde a pontuação varia de 0 a 3, sendo 0 inexistente, 1 baixo, 2 médio e 3 alto.

A pontuação foi estabelecida por três especialistas em gestão de projetos da empresa (Quadro 4). A responsabilidade dos especialistas consistia em alinhar o modelo com os métodos de gestão de projetos da empresa.

Quadro 4 - Especialistas responsáveis pela priorização dos modelos de nível de maturidade

\begin{tabular}{|c|c|c|}
\hline Colaborador & \multicolumn{2}{|c|}{ Cargo } \\
1 & $\begin{array}{c}\text { Engenheiro } \\
\text { Mecânico } \\
\text { Sênior }\end{array}$ & $\begin{array}{r}\text { Trabalha há seis anos com gestão de contratos de fornecimento de } \\
\text { estruturas metálicas e caldeiraria. }\end{array}$ \\
\hline 2 & $\begin{array}{c}\text { Engenheiro } \\
\text { Eletricista } \\
\text { Máster }\end{array}$ & $\begin{array}{r}\text { Trabalha há quatro anos com fiscalização de montagem, com foco } \\
\text { em produção, segurança e qualidade da montagem. }\end{array}$ \\
\hline 3 & $\begin{array}{c}\text { Engenheiro } \\
\text { Mecânico } \\
\text { Sênior }\end{array}$ & $\begin{array}{c}\text { Trabalha há 10 anos com Gestão de Contratos em implantação de } \\
\text { projetos nas áreas de Mineração, Siderurgia e Bens de Capital. }\end{array}$ \\
\hline
\end{tabular}

Fonte: Elaborado pelos autores

No Quadro 5 podem ser visualizados os resultados da priorização dos modelos de maturidade. Os modelos CMM e CMMI tiveram nota zero em todos os critérios pois foram considerados como questionários mais voltados para a área tecnológica. 
Quadro 5 - Priorização dos modelos de maturidade

\begin{tabular}{|l|c|c|c|c|c|}
\multicolumn{1}{|c}{ Critérios } & \multicolumn{7}{c}{ CMM } & CMMI & PMMM & OPM3 & MMGP \\
\hline Facilidade de utilização & 0 & 0 & 2 & 2 & 2 \\
\hline Adaptabilidade & 0 & 0 & 2 & 1 & 1 \\
\hline $\begin{array}{l}\text { Alinhamento com o planejamento } \\
\text { estratégico da empresa }\end{array}$ & 0 & 0 & 3 & 1 & 2 \\
\hline Disponibilidade do material & 0 & 0 & 3 & 3 & 3 \\
\hline TOTAL & 0 & 0 & 10 & 6 & 8 \\
\hline
\end{tabular}

Fonte: Elaborado pelos autores.

Analisando o critério adaptabilidade, o modelo PMMM foi considerado como o que mais se enquadra à realidade da empresa. $\mathrm{O}$ terceiro critério analisado (alinhamento com o planejamento estratégico da empresa) teve sua maior nota no modelo PMMM, sendo considerado o modelo que abrange, de forma mais adequada, o perfil estratégico da empresa.

Os questionários PMMM, OPM3 e MMGP tiveram as mesmas notas para o último critério (disponibilidade do material) uma vez que foi considerada a facilidade de acesso ao questionário referente ao modelo e a disponibilização dos questionários via e-mail. Sendo assim, o modelo selecionado pelos especialistas para utilização na empresa é o PMMM, com um total de 10 pontos na priorização. Nesse modelo, Kerzner (2009) ressalta que a identificação dos níveis de maturidade contribui para que as empresas possam perceber 0 que precisa ser modificado com o intuito de aumentar a eficácia e eficiência da empresa. O autor afirma ainda que os níveis de maturidade apresentam níveis de dificuldade diferentes, relacionando essas dificuldades com 0 impacto na cultura organizacional.

Segundo os especialistas, os setores relacionados a projetos de uma empresa de mineração possuem particularidades com relação à cultura e ao modo de gerenciar projetos. É possível que que a empresa apresente pontos maiores em determinado nível de maturidade e menores em outros (BROOKES; DAY; CLARK, 2014).

\section{CONCLUSÃO}

O presente artigo teve como objetivo selecionar o modelo de avaliação de nível de maturidade mais adequado para aplicação a uma empresa mineradora. Diante disso, com a realização das análises dos principais modelos e com o resultado obtido na priorização realizada pelos especialistas, pode-se concluir que o objetivo definido foi alcançado. Outra importante contribuição da pesquisa foi identificar as vantagens $e$ desvantagens de cada modelo, permitindo aos especialistas priorizá-los por meio de informações mais consolidadas.

Cada modelo apresentou particularidades com relação aos critérios observados devido ao conteúdo das questões e influências organizacionais. O modelo de maturidade PMMM foi selecionado pelos especialistas devido a abrangência do conteúdo das questões, podendo ser aplicado na avaliação da gestão dos projetos nas diferentes áreas dentro da empresa mineração. Contudo, como limitações, ressalta-se que esse modelo apresenta a desvantagem de ter um questionário para cada nível podendo causar dificuldades na obtenção de respostas ao aplicá-lo.

Esta pesquisa seguirá para uma fase futura onde pretende-se relacionar o nível de maturidade em gestão de projetos da empresa mineradora com os fatores críticos de sucesso em gestão de projetos, o objetivo será avaliar se há uma relação entre esses dois fatores.

\section{AGRADECIMENTOS}

Os autores gostariam de expressar sua gratidão à CNPq, Capes, FAPEMIG, DPPG/UNIFEl e ao Grupo de Estudos em Qualidade e Produtividade - GEQProd, pelo seu apoio na realização deste trabalho. Também, aos especialistas da empresa analisada. 


\section{REFERÊNCIAS}

[1] Barbas, C. Estudo e comparação de Modelos de Maturidade no contexto da Gestão de Projetos. Dissertação de Mestrado, Universidade de Trás-os-Montes e Alto Douro, Vila Real, 2012.

[2] Brookes, N.; DEY, M.; Clark, R. The use of maturity models in improving project management performance: An empirical investigation. International Journal of Managing Projects in Business, v. 7, n. 2, p. 231-246, 2014.

[3] Crowston, K.; Quin, J. A Capability Maturity Model for Scientific Data Management: Evidence from the Literature. Proceedings of the Association for Information Science and Technology, v. 48, n. 1, p. 1-9, 2011.

[4] Dijkman, R.; Lammers, SV.; Jong, A. Properties that influence business process management maturity and its effect on organizational performance. Information Systems Frontiers, v. 18, n. 4, p. 717-734, 2016

[5] Farid, A.; ABD Elghany, A.; Helmy, Y. Implementing Project Management Category Process Areas of CMMI Version 1.3 Using Scrum Practices, and Assets. International Journal of Advanced Computer Science and Applications, v. 7, n. 2, p. 243-252, 2016

[6] Golini, R.; Kalchschmidt, M.; Landoni, P. Adoption of project management practices: The impact on international development projects of non-governmental organizations. International Journal of Project Management, v. 33, n. 3, p. 650663, 2015.

[7] Gonçalves, A.; Gaspar, M.; Cardoso, M. Governança de Tecnologia da Informação: Uma análise do nível de maturidade em empresas atuantes no Brasil. Revista Gestão e Produção, v. 7, n. 1, p. 56-69, 2016.

[8] Guedes, R.; Gonçalves, M.; Laurindo, F.; Maximiano, A. Maturidade de gestão de projetos de sistemas de informação: um estudo exploratório quantitativo no Brasil. Production, v. 24, n. 2, p. 364-378, 2014.

[9] Ibram - Instituto Brasileiro de Mineração. Produção Mineral Brasileira 2015. Disponível em: <http://www.ibram.org.br/sites/1300/1382/0000600 9.pdf>. Acesso em: 19 set. 2016.

[10] Ibram - Instituto Brasileiro de Mineração. Investimentos no setor mineral em bilhões de US\$. Disponível em: http://www.ibram.org.br/sites/1300/1382/00005476. pdf>. Acesso em: 24 set. 2016.

[11] JULIO, L.; PISCOPO, M. Maturidade em Gestão de Projetos e Empreendedorismo Estratégico em Empresas do Setor Financeiro. Revista Gestão \& Tecnologia, v. 13, n. 3, p. 178208, 2013

[12] Kabir, M.; Rusu, L. IT Project Development using Capability Maturity Model. Information resources management journal, v.29, n.4, pp.35-48, 2016.

[13] Kerrigan, M. A capability maturity model for digital investigations. Digital Investigation: The International Journal of Digital Forensics \& Incident Response, v. 10, n. 1, p. 19-33, 2013.

[14] Kerzner, H. Project Management: A systems approach to planning, scheduling, and controlling. 10. ed. New York: John Wiley \& Sons, Inc, 2009.

[15] Kotoleto, J. Nível de Maturidade em Gerenciamento de Projetos: levantamento das indústrias do Estado do Paraná. Dissertação de Mestrado, Universidade Tecnológica Federal do Paraná, Ponta Grossa, 2008.

[16] Kluth, A.; Jager, J.; Schatz, A.; Bauernhansl, T. Evaluation of Complexity Management Systems - Systematical and MaturityBased Approach. Procedia CIRP, v. 17, n. 1, p. 224-229, 2014

[17] Marzouk, M.; Attia, T.; EL-Bendary, N. Construction Based Model for Assessing Maturity Level of Enterprises. Journal of Construction Engineering and Project Management, v.2, n.1, p. 14-19, 2012.

[18] Mateen, M. Measuring Project Management Maturity - A framework for better and

[19] efficient Projects delivery. Master's Thesis, Chalmers University of Technology, Sweden, 2015.

[20] MIGUEL, P.. Estudo de caso na engenharia de produção: estruturação e recomendações para sua condução. Revista Produção, v. 17, n. 1, p. 216-229, 2007.

[21] Miklosik, A. Improving project management performance through capability maturity measurement. Procedia-Economics and Finance, v. 30, n. 1, p. 522-530, 2015

[22] Mishra, A; DAS, S; Murray, J. Risk, Process Maturity, and Project Performance: AnEmpirical Analysis of US Federal Government Technology Projects. Production dnd Operations Management, v. 25, n. 2, p. 210-232, 2016.

[23] Oliveira, J. Avaliação do nível de maturidade em gerenciamento de projetos no setor de engenharia de projetos de um estaleiro de grande porte no nordeste brasileiro. Revista Gestão e Projetos, v.5, n. 3, p. 1-13, 2014.

[24] Pinto, E.; Vasconcelos, A.; Lezana, A. Abordagens do Pmbok e Cmmi sobre o sucesso dos projetos de softwares. Revista Gestão e Projetos, v. 5, n. 1, p. 55-70, 2014.

[25] PMI. Um guia do conhecimento em gerenciamento de projetos - Guia PMBOK. 5. ed. Pennsylvania: Project Management Institute (PMI), 2013.

[26] Prodanov, C. C., Freitas, E. C. Metodologia do Trabalho Científico: Métodos e Técnicas da 
Pesquisa e do Trabalho Acadêmico. 2. ed. Novo Hamburgo: Ed. Feevale, 2013. 276 p.

[27] Silva, R.; Santos, E. Análise comparativa de modelos de maturidade em gerenciamento de projetos: uma contribuição ao estudo da maturidade organizacional em setores de engenharia. In: III Simpósio Internacional de Gestão de Projetos, 2014.

[28] Souza, T.; Gomes, C. Assessment of Maturity in Project Management: A Bibliometric Study of Main Models. Procedia-Computer Science, v. 55, n. 1, p. 92-101, 2015.

[29] SPALEK, S. Establishing a conceptual model for assessing project management maturity in industrial companies. International Journal of Industrial Engineering: Theory, Applications and Practice, v.22, n. 2, p. 242-254, 2015.
[30] Tahri, H.; Drissi-Kaitouni. New design for calculating Project Management Maturity (PMM). Procedia-Social and Behavioral Sciences, v. 181, n. 1, p. 171-177, 2015.

[31] Thielmann, R. Avaliação de maturidade em gestão de projetos: estudo de caso de um projeto automotivo. GEPROS - Gestão da Produção, Operações e Sistemas, v. 34, n.2, p. 35-49, 2014

[32] Vezzetti, F.; Violante, M.; Marcolin, F. A benchmarking framework for product lifecycle management (PLM) maturity models. The International Journal of Advanced Manufacturing Technology, v. 71, n. 5, p. 899-918, 2014.

[33] Wendler, R. The maturity of maturity model research: A systematic mapping study. Information and Software Tecnology, v. 54, n.12, p. 1317-1339, 2012. 


\section{GAPÍTULO 3}

\section{O USO AHP (PROCESSO DE ANÁLISE HIERÁRQUICA) NA TOMADA DE UMA DECISÃO PARA ESCOLHA DO MÉTODO DE AVALIAÇÃO}

\section{Benedito Manoel de Almeida}

Suelen Cristian de Freitas Morais

Resumo: $O$ artigo traz como objeto de estudo, a escolha e adequação de uma sistemática de avaliação, coerente com o método de ensino aprendizagem de Engenharia. Metodologia Ativa de ensino aprendizagem, método AHP (Processo de Análise Hierárquica) e ferramenta Servqual são as bases da fundamentação teórica. O estudo de caso delimitado no curso de Engenharia de Produção de uma "IES" (Instituição de Ensino Superior), com o objetivo de conhecer uma sistemática de avaliação e o grau de satisfação dos alunos avaliados. Pretende-se com este trabalho fornecer uma contribuição aos profissionais da educação que queiram usar de metodologia ativa e avaliar de forma funcional conhecendo o grau de satisfação de seus alunos.

Palavras-chave: Processo de Análise Hierárquica; Metodologia Ativa; SERVQUAL. 


\section{INTRODUÇÃO}

É notório que a educação nos dias atuais, apresenta-se inserida em um cenário composto por grandes desafios. Educadores são levados a refletirem suas práticas pedagógicas (LOPEZ,2014).

A conquista de melhores níveis de qualidade em qualquer estágio e área de ensino, vem desafiando educadores a encontrarem alternativas para suas propostas pedagógicas (FRANCISCHETTI, 2014).

Um novo perfil social de aluno vem se caracterizando, aluno esse fortemente sustentado por um sistema de informações que o coloca de maneira instantânea em contato com o conhecimento humano generalizado. São tecnologias aplicadas a plataformas virtuais, bases de pesquisa e outros, que permitem que as informações fluam com grande rapidez e eficiência, levando alguns alunos a desenvolverem hábitos de se dedicarem a múltiplas atividades simultaneamente, porém, em um curto espaço de tempo. Surge assim uma nova categoria cognitiva, chamada por alguns autores de geração Milenium. Com a geração Milenium as informações são transmitidas e usadas de maneira quase imediata, passando a fazer parte do seu ambiente escolar (TAPSCOTT, 2010).

A geração Milenium causa preocupação no corpo docente, especialmente sobre seu papel nesta nova realidade (HANGREANES, 2015).

Com o uso de métodos de ensino como a aprendizagem ativa, pretende-se potencializar a aprendizagem significativa, diminuindo assim, a grande diferença ente o ideal e o real no mundo acadêmico, em especial no ensino de Engenharia.

A aprendizagem ativa é útil para aumentar nos alunos a sua responsabilidade, promovendo a sua participação, facilitando a compreensão e o uso dos conceitos, desenvolvendo competências transversais, tais como iniciativa e colaboração (ESTEVES AYRES, 2014).

Buscou-se com o uso da metodologia ativa, aprender fazendo, com satisfação e criatividade. São vários os métodos ativos apresentados hoje nas literaturas, que podem ser usados no ensino de Engenharia. A metodologia ativa usada nesse estudo de caso foi o Team Based Learning (TBL).
O TBL é um método de ensino de aprendizagem, que usa de um problema para prática real ou simulada para iniciar, motivar e focar a construção de conhecimento, além de promover habilidades de solução de problemas (LIMA, 2015).

O método TBL em questão conta com etapas que se complementam: leitura prévia das aulas, prática de laboratórios, aulas expositivas dialogadas, formação sistemática pedagógica a ser utilizada, dentre outros. A disciplina usada como objeto de estudo foi à química geral, do curso básico de engenharia de produção de uma Instituição de Ensino Superior (IES). Com o uso da metodologia ativa, fez-se necessário avaliar o conhecimento de maneira ativa, já que a avaliação é por sua natureza um ato funcional (planejado/usado/avaliado). Esse método busca avaliar de maneira inovadora, permitindo quantificar o teor cognitivo, traduzindo na eficiência de resolver problemas e fazendo bom uso dos conceitos trabalhados.

Medir os resultados é importante para uma IES, pois, quando a mensuração acontece, as informações são mais precisas e a tomada de decisão é feita com mais confiabilidade (LUCKESI, 2011).

O estudo de caso tem como objetivo, conhecer um método de avaliação que seja ativo e coerente com a metodologia ativa utilizada, podendo contribuir com a satisfação do aluno avaliado. A necessidade de avaliação da aprendizagem pode ser um indicador da coerência com os pressupostos epistemológicos que norteiam um currículo que utiliza de métodos ativos.

Falar de avaliação na metodologia ativa é pensar em uma estrutura metodológica diferenciada, que ressalta e prioriza a avaliação diagnosticada, formativa, processuais e somativa, perpassando todas as fases de desenvolvimento metodológico (LUCKESI, 2011).

Para responder à questão de pesquisa: "Como escolher a sistemática de avaliação que seja pertinente ao método usado e satisfatório ao aluno avaliado? ", usou-se o método Processo de Análise Hierárquica (AHP) para selecionar a forma de avaliação. $O$ método AHP de decisão multicriteriado foi escolhido em função de sua flexibilidade quando aplicado a problemas de tomada de decisão. 
O AHP transforma as comparações, na maioria das vezes empíricas, em número que são processados e comparados (SAATY, 2015).

As expectativas e percepções (satisfação do aluno) foi medida utilizando a ferramenta SERVQUAL, responsável por avaliar a satisfação do cliente, em função da diferença entre a expectativa e o desempenho obtido (OLIVEIRA, 2015).

Espera-se com este artigo, contribuir especialmente com professores que queiram fazer uso da metodologia ativa em suas disciplinas e precisam escolher a forma de avaliação mais pertinente e satisfatória.

\section{FUNDAMENTAÇÃO TEÓRICA}

\subsection{MÉTODO AHP}

O método AHP propõe uma decomposição hierárquica de critérios definidos e com relevância

conforme mostra a Figura 1.

Figura 1 - Modelagem

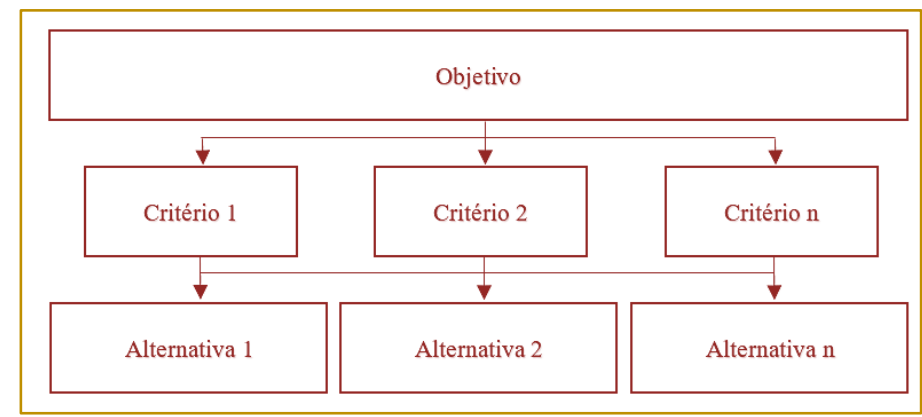

Fonte: adaptado de Fogliatto e Albin (2003)

Sequência para uso do AHP:

Identificar as alternativas e atributos significativos da decisão;

Identificar o significado entre os atributos;

Para cada atributo e para cada par de alternativas, os tomadores de decisão indicam suas preferências.

A comparação entre os atributos e as alternativas são registradas em matriz na forma de frações, entre $\frac{1}{9}$ e 9 . Cada matriz é avaliada pelo seu autovalor para verificar a coerência dos julgamentos e calculam-se valores globais de preferência para cada alternativa. Essa comparação pode utilizar dados concretos das alternativas ou julgamento humano como forma de informação subjacente (SAATY, 2008).

Os elementos fundamentais do método AHP são:

Atributos: as alternativas são comparadas em relação a um conjunto de critério;

Correlação primária: para cada critério, duas alternativas são comparadas binariamente, isto é, uma alternativa é preferencial ou indiferente ao outro;

Escala Fundamental: a cada elemento associa-se um valor de prioridade numa escalada numérica, a escala SAATY $(1,2,3,4,5,6,7,8,9)$ conforme Tabela 1.

Tabela 1 - Valores

\begin{tabular}{|c|l|l|}
\hline \multicolumn{1}{|c|}{ Valores } & \multicolumn{1}{c|}{ Explinição } & Contribuição idêntica \\
\hline 1 & Igual importância & Julgamento levemente superior \\
\hline 3 & Fraca importância & Julgamento fortemente superior \\
\hline 5 & Forte importância & Dominância reconhecida \\
\hline 7 & Muito Forte importância & Domínio comprovado \\
\hline 9 & Importância absoluta & Dúvidas \\
\hline $2,4,6,8$ & Valores intermediários & \multicolumn{2}{|c|}{ Fonte: Saaty (2017) } \\
\hline \multicolumn{2}{|c|}{}
\end{tabular}




\subsection{FERRAMENTA SERVQUAL}

A ferramenta SERVQUAL pode ser aplicada independe do tipo de serviço, onde constitui uma série de experiências dos respondentes, avaliando assim, a satisfação entre expectativa e o desempenho obtido em função das suas diferenças (OLIVEIRA, 2015).

As expectativas, as percepções e o gap devem ser avaliados em uma escala Likert de $\begin{array}{llllll}1 & \text { a } & 7 & \text { conforme a Tabela } 2 .\end{array}$

Tabela 2 - Padrão da Escala Likert para SERVQUAL

\begin{tabular}{|c|c|c|c|c|c|c|}
\hline 7 & 6 & 5 & 4 & 3 & 2 \\
Excelente & Muito bom & Bom & Satisfatório & $\begin{array}{c}\text { Pouco } \\
\text { satisfatório }\end{array}$ & Fraco & Medíocre \\
\hline
\end{tabular}

Os valores atribuídos em escala numérica são comparados para chegar a um parâmetro (gap) para cada uma das questões, ou seja, a pontuação final é gerada pela diferença entre elas.

Parâmetro $=$ Percepção - Expectativa

Um resultado com valor numérico menor que zero, indica que as percepções estão abaixo das expectativas, indicando os itens a serem trabalhados.

\section{METODOLOGIA}

Desenvolveu-se o Questionário 1 contendo critérios para julgamento do tipo de avaliação a ser aplicado, dentro do sistema de metodologia ativa de ensino.

Aplicou-se o Questionário 1 para uma amostra de 148 alunos, cursando a matéria de química geral de uma IES, do primeiro ano do curso de engenharia de produção.

Para o resultado de caso, a escolha da forma de avaliação, foi feita, usando o método AHP, sendo definida uma hierarquia, conforme a Figura 2.

Figura 2 - Definição hierárquica

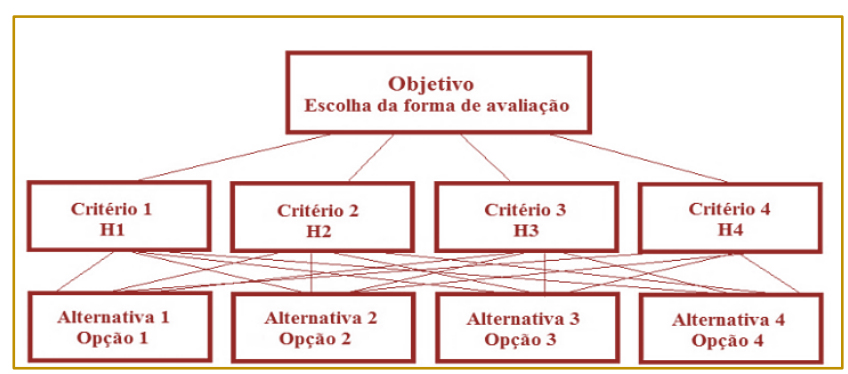

Fonte: Adaptado de Saaty $(1990,1991)$

Onde para cada critério foi abordado um parâmetro baseado na metodologia ativa, sendo eles:

H1: aprofundamento de assuntos trabalhados; H2: habilidades (fazer, resolver, aplicar);

H3: construção do conhecimento individual/coletivo;

H4: uso do raciocínio.

E para cada opção foi proposta um tipo de avaliação, sendo elas:

Opção 01: Relatório;

Opção 02: Avaliação ativa por pares, por projetos, em grupo;

Opção 03: Avaliação tradicional;
Opção 04: Avaliação combinada.

A Tabela 3 apresenta o Questionário 1, onde o aluno deverá atribuir um conceito de 1, 3, 5, 7 ou 9, obedecendo os seguintes itens:

1: Igual importância (Contribuição idêntica);

3: Fraca importância (Contribuição levemente superior);

5: Forte importância (Julgamento fortemente superior);

7: Muito forte importância (Julgamento fortemente superior);

9: Importância absoluta (Domínio comprovado). 
Tabela 3 - Questionário 1

\begin{tabular}{|c|c|c|}
\hline \multicolumn{3}{|c|}{ H1: Aprofundamento nos assuntos tratados } \\
\hline \multirow{4}{*}{ Opção 1} & Opção 1 & Relatório \\
\hline & Opção2 & Avaliação ativa por pares, por projetos, em grupo \\
\hline & Opção3 & Avaliação tradicional \\
\hline & Opção4 & Avaliação combinada \\
\hline \multirow{3}{*}{ Opção 2} & Opção2 & Avaliação ativa por pares, por projetos, em grupo \\
\hline & Opção3 & Avaliação tradicional \\
\hline & Opção4 & Avaliação combinada \\
\hline \multirow{2}{*}{ Opção 3} & Opção3 & Avaliação tradicional \\
\hline & Opção4 & Avaliação combinada \\
\hline Opção 4 & Opção4 & Avaliação combinada \\
\hline \multicolumn{3}{|c|}{ H2: habilidades (fazer, resolver, aplicar) } \\
\hline \multirow{4}{*}{ Opção 1} & Opção 1 & Relatório \\
\hline & Opção2 & Avaliação ativa por pares, por projetos, em grupo \\
\hline & Opção3 & Avaliação tradicional \\
\hline & Opção4 & Avaliação combinada \\
\hline \multirow{3}{*}{ Opção 2} & Opção2 & Avaliação ativa por pares, por projetos, em grupo \\
\hline & Opção3 & Avaliação tradicional \\
\hline & Opção4 & Avaliação combinada \\
\hline \multirow{2}{*}{ Opção 3} & Opção3 & Avaliação tradicional \\
\hline & Opção4 & Avaliação combinada \\
\hline Opção 4 & Opção4 & Avaliação combinada \\
\hline \multicolumn{3}{|c|}{ H3: construção do conhecimento individual/coletivo } \\
\hline \multirow{4}{*}{ Opção 1} & Opção 1 & Relatório \\
\hline & Opção2 & Avaliação ativa por pares, por projetos, em grupo \\
\hline & Opção3 & Avaliação tradicional \\
\hline & Opção4 & Avaliação combinada \\
\hline \multirow{3}{*}{ Opção 2} & Opção2 & Avaliação ativa por pares, por projetos, em grupo \\
\hline & Opção3 & Avaliação tradicional \\
\hline & Opção4 & Avaliação combinada \\
\hline \multirow{2}{*}{ Opção 3} & Opção3 & Avaliação tradicional \\
\hline & Opção4 & Avaliação combinada \\
\hline Opção 4 & Opção4 & Avaliação combinada \\
\hline \multicolumn{3}{|c|}{ H4: uso do raciocínio } \\
\hline \multirow{4}{*}{ Opção 1} & Opção 1 & Relatório \\
\hline & Opção2 & Avaliação ativa por pares, por projetos, em grupo \\
\hline & Opção3 & Avaliação tradicional \\
\hline & Opção4 & Avaliação combinada \\
\hline \multirow{3}{*}{ Opção 2} & Opção2 & Avaliação ativa por pares, por projetos, em grupo \\
\hline & Opção3 & Avaliação tradicional \\
\hline & Opção4 & Avaliação combinada \\
\hline \multirow{2}{*}{ Opção 3} & Opção3 & Avaliação tradicional \\
\hline & Opção4 & Avaliação combinada \\
\hline Opção 4 & Opção4 & Avaliação combinada \\
\hline
\end{tabular}

Com os dados resultantes do questionário 1, $\quad$ apresentada na Tabela 4. compõe-se a matriz de decisão

Tabela 4 - Matriz da decisão

\begin{tabular}{|l|c|c|c|c|c|}
\hline & $H 1$ & $H 2$ & $H 4$ & Total \\
\hline Opção 1 & 0,11 & 0,25 & 0,22 & 0,55 & 0,34 \\
\hline Opção 2 & 0,55 & 0,55 & 0,04 & 0,04 & 0,35 \\
\hline Opção 3 & 0,30 & 0,10 & 0,15 & 0,15 & 0,17 \\
\hline Opção 4 & 0,04 & 0,10 & 0,16 & 0,26 & 0,15 \\
\hline Somatório & 0,14 & 0,46 & 0,05 & 0,35 & \\
\hline
\end{tabular}

Por meio da matriz de decisão identificou-se que a "opção 02: Avaliação ativa por pares, por projetos, em grupo", foi a escolhida pelos alunos.
A fim de mapear os parâmetros: expectativas e percepções, o questionário 2 foi elaborado tendo como base a ferramenta SERVQUAL, 
gerando o gap entre elas, que é diferença dos parâmetros.

Após escolhido o método de avaliação, o Questionário 2, apresentado na Tabela 4, foi aplicado aos mesmos alunos que contribuíram com os dados para a escolha do método de avaliação. As aplicações ocorreram antes e depois da aplicação do questionário 1, gerando assim as expectativas, percepções e gap.

Tabela 5 - Questionário 2

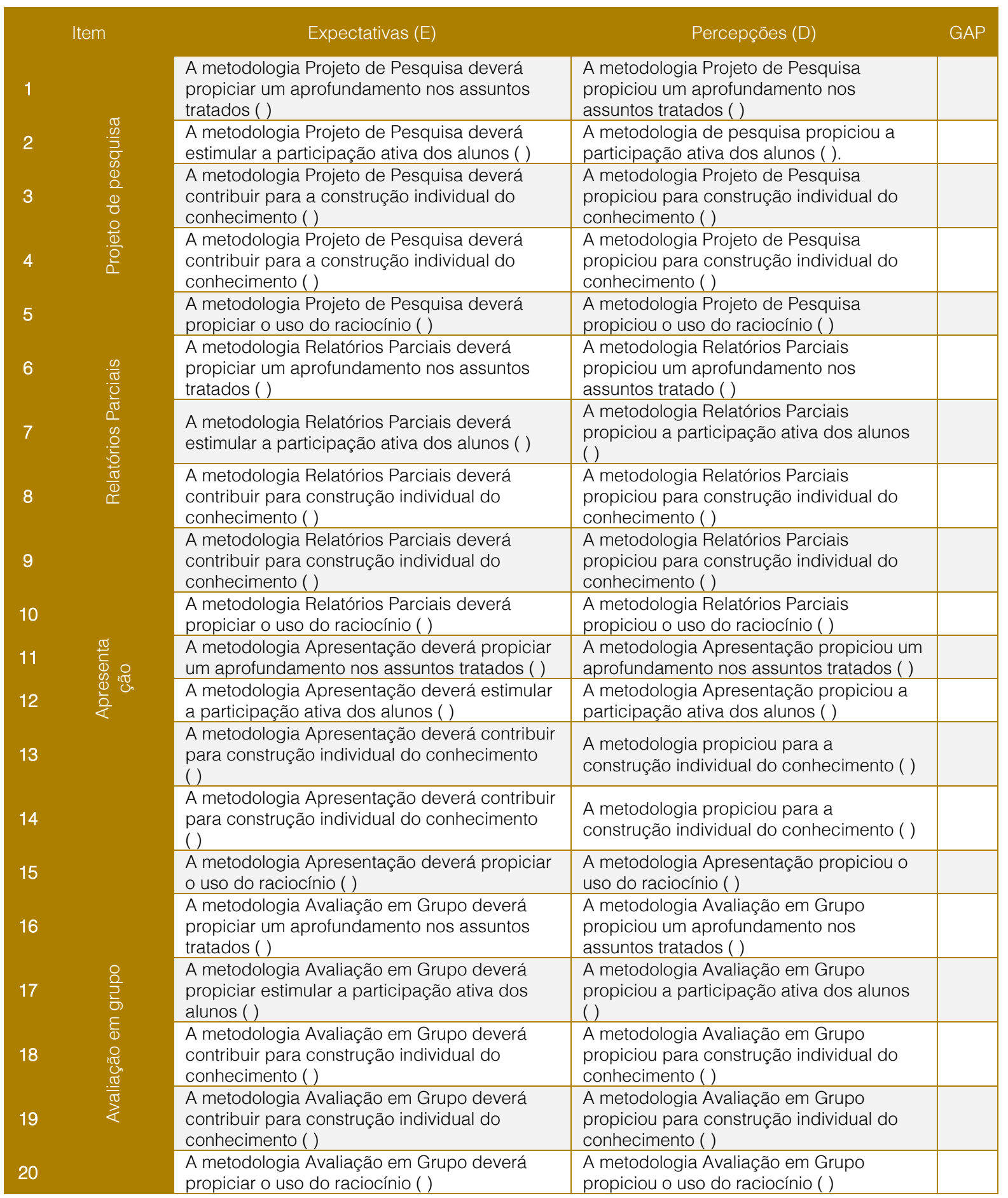

Fonte: elaborada pelos autores (2017) 
Para validação da confiabilidade interna do questionário, aplicou-se a análise alfa de Cronbach, cujo resultado, calculado a partir da Equação 1, mensura a relação interna de qualidade. Segundo Almeida et al (2010) o alfa com valor acima de 0,7 é considerado aceitável.

$$
\alpha=\frac{K}{K-1} *\left(1-\frac{\sum S_{i}^{2}}{S_{t}^{2}}\right)
$$

Onde:

$\mathrm{K}=$ número de itens da escala

$S_{i}^{2}=$ somatório da variância dos itens

$S_{t}^{2}=$ variância total da escala

A Figura 3 compila os cálculos realizados para o resultado do Alfa de Cronbach.

Figura 3 - Análise de Alfa de Cronbach

\begin{tabular}{|c|c|c|c|c|c|c|c|c|c|c|c|c|c|c|c|c|c|c|c|c|}
\hline Questões & 1 & 2 & 3 & 4 & 5 & 6 & 7 & 8 & 9 & 10 & 11 & 12 & 13 & 14 & 15 & 16 & 17 & 18 & 19 & 20 \\
\hline Média $(\bar{x})$ & 6,3 & 6,2 & 6,1 & 6,1 & 6,2 & 6,1 & 6,1 & 6,3 & 6,0 & 6,0 & 6,4 & 6,3 & 5,9 & 6,0 & 5,9 & 6,2 & 5,8 & 6,4 & 6,3 & 6,1 \\
\hline $\begin{array}{l}\text { Desvio } \\
\text { Padrão } \\
\text { (S) }\end{array}$ & 0,8 & 1,0 & 1,1 & 1,1 & 1,1 & 1,1 & 1,1 & 1,0 & 1,0 & 1,1 & 0,9 & 0,9 & 1,1 & 1,1 & 1,2 & 1,0 & 1,2 & 0,9 & 0,9 & 1,0 \\
\hline $\begin{array}{l}\text { Variância } \\
\text { (var) }\end{array}$ & 0,7 & 0,9 & 1,2 & 1,2 & 1,2 & 1,2 & 1,3 & 1,0 & 1,1 & 1,2 & 0,8 & 0,8 & 1,2 & 1,2 & 1,5 & 1,0 & 1,5 & 0,8 & 0.9 & 1,0 \\
\hline & \multicolumn{6}{|c|}{$\sum \operatorname{var} x$} & \multicolumn{2}{|c|}{21,8} & & & & & & & & & & & & \\
\hline & \multicolumn{6}{|c|}{$\operatorname{var} \sum x$} & \multicolumn{2}{|c|}{149,2} & & & & & & & & & & & & \\
\hline & \multicolumn{6}{|c|}{ Alfa de Cronbach } & \multicolumn{2}{|c|}{0,899} & & & & & & & & & & & & \\
\hline
\end{tabular}

Fonte: elaborada pelos autores (2017)

\section{RESULTADOS E DISCUSSÃO}

As respostas do questionário 2 gerou os

resultados apresentados na Tabela 6.

Tabela 6 - Resultados gerados do questionário 2

\begin{tabular}{|c|c|c|c|}
\hline & Expectativa & Percepções & Gap \\
\hline $\mathrm{H} 1$ & $85,0 \%$ & $82,8 \%$ & $-4,28 \%$ \\
\hline $\mathrm{H} 2$ & $85,7 \%$ & $81,0 \%$ & $-5,90 \%$ \\
\hline $\mathrm{H} 3$ & $84,3 \%$ & $81,4 \%$ & $-2,77 \%$ \\
\hline $\mathrm{H} 4$ & $89,8 \%$ & $81,0 \%$ & $-2,30 \%$ \\
\hline
\end{tabular}

Fonte: elaborada pelos autores (2017)

Para as discussões dos itens analisados foi utilizada a técnica de análise de conteúdo (VERGARA, 2005).

A tabela 6 mostra que todas as expectativas e todas as percepções obtiveram valores numéricos acima de $80 \%$ (Bom), valorizando as expectativas e as percepções. O gap $<0$ indica tendência de melhoria a ser atingida. 


\section{CONCLUSÃO}

A questão de pesquisa pôde ser respondida de forma satisfatória, onde o método AHP possibilitou a tomada de decisão quanto a escolha do método de avaliação, definindo a "opção 02 - Avaliação ativa por pares, por projetos, em grupo" a ser aplicado em turmas que fizerem o uso de metodologia ativa.

A ferramenta SERVQUAL nos forneceu uma comprovação do acerto na escolha do

\section{REFERÊNCIAS}

[1] Almeida, D; Santos, M; Costa, A. Aplicação do coeficiente Alfa de Cronbach nos resultados de um questionário para avaliação de desempenho da saúde pública. XXX ENEGEP Maturidade e desafios da Engenharia de Produção: competitividade das empresas, condições de trabalho, meio ambiente. São Carlos - SP, 2010.

[2] Fogliatto, Flavio S. (2003) "Proposta metodológica para coleta e análise de dados sensoriais no desenvolvimento de produtos e em estudos de confiabilidade". 4 CBGDP, Gramado, RS, Brasil, 6 ao 8 de Outubro de 2003.

[3] Francischetti, leda et al. Active Learning Methodologies: An Experience for Faculty Training at Medical Education. Creative Education, v. 5, n. 21, p. 1882,2014

[4] Hämäläinen, Raija et al. Education and working life: VET adults' problem-solving skills in technology-rich environments. Computers \& Education, v. 88, p. 38-47, 2015.

[5] Lima, Valeria Vernaschi et al. Ativadores de processos de mudança: uma proposta orientada à transformação das práticas educacionais e da formação de profissionais de saúde. Ciência \& Saúde Coletiva, v. 20, n. 1, p. 279-288, 2015.

[6] Luckesi, C. C. Avaliação da aprendizagem escolar: estudos e proposições. 22 ed. São Paulo: Cortez, 2011

O Lopez, Susana Tor et al. Service-learning as Training for Social Entrepreneurship: An Experience in the University. Procedia-Social and Behavioral Sciences, v. 139, p. 504-511, 2014. método de avaliação quantificado na relação expectativa $x$ percepção com parâmetros acima de $80 \%$.

Esses resultados podem orientar especificamente professores que queiram fazer uso da metodologia ativa em suas disciplinas ou outros trabalhos voltados a qualidade no ensino de uma forma geral.

[7] Oliveira, Otávio J. Curso básico de gestão da qualidade. São Paulo: Cengage Learning, 2014.

[8] Oliveira, Otávio J.; Ferreira, Euriane C. Adaptação e aplicação da escala SERVQUAL na educação superior. GEPROS. Gestão da Produção, Operações e Sistemas - Ano 3, no 3, Jul-Set/2008, p. $133-146$

[9] Saaty, T.L. (2008) 'Decision making with the analytic hierarchy process', Int. J. Services Sciences, Vol. 1, No. 1, pp.83-98.

[10] Saaty, T.L. How to make a decision: The analytic hierarchy process. European Journal of Operational Research, Amsterdam, v.48, p.9-26, 1990.

[11] Saaty, T.L. Método de análise hierárquica. São Paulo: Makron Books, 1991, 367p.

[12] Saaty, T.L., D. Ergu. When is a decisionmaking method trustworthy? Criteria for evaluating multi-criteria decision-making methods. International Journal of Information Technology \& Decision Making, 14 (2015), pp. 1-17

[13] Stevens, Shawn Y.; SHIN, Namsoo; PEEKBROWN, Deborah. Learning progressions as a guide for developing meaningful science learning: A new framework for old ideas. Educación Química, v. 24, n. 4, p. 381-390, 2013.

[14] Tapscott, Don. A hora da geração digital: como os jovens que cresceram usando a internet estão mudando tudo, das empresas aos governos. Rio de Janeiro: Agir Negócios, 2010.

[15] Vergara, S. C. (2005). Método de pesquisa em administração. São Paulo: Editora Atlas, 2005. 


\section{GAPÍTULO 4}

\section{PROJETO DE UM LABORATÓRIO ARTESANAL}

Simone Ferigolo Venturini

Charles Rech

Resumo: O planejamento do arranjo físico das instalações industriais ou de serviços visa a melhor disposição dos recursos de transformação utilizados, buscando eliminar perdas por movimentações; fluxo dos materiais, de informações, de equipamentos e das pessoas. O resultado de um bom layout é o arranjo mais efetivo com segurança para os operadores, minimização de distâncias, acesso as operações do equipamento, boas condições de gerenciamento e supervisão e otimização do uso do espaço físico. Com o aumento do consumo e da produção de cervejas artesanais, há o aumento de instalações de micro cervejarias, algumas delas totalmente artesanais e outras utilizando equipamentos mais sofisticados, ambas com a necessidade de serem projetadas com o máximo de segurança. De qualquer forma, há a necessidade de estudos que busquem o melhor arranjo a ser aplicado tornando o processo mais eficiente, seguro e com a possibilidade de adequações de acordo com a evolução da produção. O objetivo deste trabalho é projetar um laboratório de cerveja, que proporcione a melhor utilização do espaço físico disponível e a otimização na instalação dos equipamentos para micro cervejarias. Nesse sentido, a proposta é utilizar um layout que proporcione o rearranjo de forma rápida e segura, atendendo suas necessidades de produção e de melhorias futuras. A estrutura da bancada para os equipamentos e a disposição dos mesmos foi projetada oferecendo essa mobilidade de forma segura e prática, favorecendo as atividades de manuseio de insumos para a produção da cerveja e a acessibilidade para a realização das atividades de manutenção e limpeza.

Palavras-chave: micro cervejaria, layout, arranjo físico 


\section{INTRODUÇÃO}

O mercado de cervejas artesanais está em crescimento e é impulsionado pela tendência de valorização da sensorialidade e retomada do padrão criado pela Lei da Pureza da Cerveja Alemã, de 1516, que instituiu que a cerveja deveria ser fabricada apenas com água, malte de cevada e lúpulo. A partir deste princípio, diversas micro cervejarias estão se instalando para produzir cervejas especiais baseadas neste conceito. A legislação brasileira (BRASIL, 2009), declara cerveja como sendo a bebida obtida pela fermentação alcoólica do mosto cervejeiro oriundo do malte de cevada e água potável, por ação da levedura, com adição de lúpulo. Pode ainda, receber o acréscimo de adjuntos e especiarias.

A mesma lei define mosto cervejeiro como sendo a solução, em água potável, de carboidratos, proteínas, glicídios e sais minerais, resultantes da degradação enzimática dos componentes da matériaprima que compõem o mosto. Assim, surge a necessidade de criar um arranjo físico das instalações de micro cervejarias, para melhorar a disposição dos equipamentos e insumos, a segurança e conforto das pessoas envolvidas e facilitar o gerenciamento, controle e comunicação do processo, em função disso não estar previsto na lei da Pureza da Cerveja Alemã, de 1516.

O presente projeto tem como objetivo geral projetar um laboratório de cerveja artesanal que proporcione a melhor utilização do espaço físico disponível e a otimização na instalação dos equipamentos para micro cervejarias. Através da aplicação da proposta, pretende-se: (a) elaborar o projeto do laboratório, (b) estabelecer o arranjo físico, (c) quantificar e orçar equipamentos e mão de obra para a construção do laboratório.

\section{FUNDAMENTAÇÃO TEÓRICA}

O arranjo físico de uma operação ou processo é como seus recursos transformadores são posicionados uns em relação aos outros e como as várias tarefas da operação serão alocadas a esses recursos transformadores (SLACK et al., 2009). O arranjo é a primeira impressão que observamos quando entramos em um ambiente. Desta forma, o arranjo físico ideal de uma planta industrial pode mudar para satisfazer objetivos distintos, procurando integrar o fluxo dos recursos de transformação e dos recursos transformados ao longo da operação.

Os benefícios associados a um bom arranjo físico que se destacam são: fornecer suficiente capacidade de produção; reduzir custo do manuseio de matérias primas; adequar-se as restrições do lugar e do prédio; permitir elevada utilização e produtividade da mão de obra, das máquinas e do espaço; atingir os objetivos com menos investimento de capital; promover movimentação de matéria-prima e de mão de obra com maior eficiência (MARTINS e LAUGENI, 2005). Dentre os objetivos gerais relevantes a todas as operações, o uso adequado do espaço deve possibilitar a melhor utilização do local utilizado.

O fluxo de insumos e informações tem de ser canalizado e sinalizado de forma clara e evidente para os executores. Preocupa-se de forma especial à segurança dos envolvidos, visto a utilização de água a altas temperaturas durante vários estágios do processo. A estrutura precisa proporcionar acessibilidade para limpeza e manutenção. As etapas de fabricação de cerveja são: a moagem do malte, a mostura, a filtração, a lavagem, a fervura, o resfriamento, a fermentação, a maturação, o armazenamento, a pasteurização (na cerveja industrial) e o envase (KUNZE, 2004). Na Figura 1 são mostrados os passos do processo baseado em informações da literatura (PALMER, 2006).

A moagem do malte é o primeiro passo e um dos mais importantes, pois o malte deve ser moído de forma que suas cascas, que servirão de elemento filtrante durante o processo de clarificação permaneçam parcialmente inteiras e o amido existente no grão fique exposto e não triturado. A mostura é o processo no qual o malte moído é inserido em água, na proporção de 2,5 litros de água por quilograma de malte, à temperatura de 68 o C, ocasionando a atuação das enzimas nele presentes, convertendo o amido do malte em açucares fermentáveis e não fermentáveis. Essa operação dura em torno de 90 minutos. 
Figura 1 - Fluxograma de fabricação de cerveja

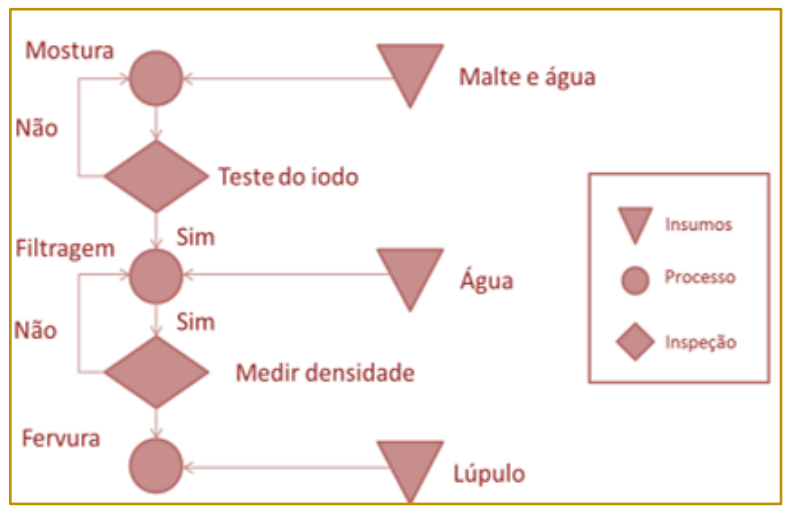

Fonte: Autores (2017)

A verificação do rendimento da extração do malte, isto é, da conversão do amido em açucares durante a mostura é feita através do teste do iodo. A eficiência de extração do malte é a porcentagem do peso do malte que é convertido em açucares. Esse número varia de $50 \%$ a $80 \%$ por peso. A tintura de iodo escurece em contato com o amido. Misturamse algumas gotas do mosto com tintura de iodo e obtendo-se uma coloração clara é a evidência de que a mostura está concluída, pois o amido está totalmente convertido em açúcares menores e não reage em contato com o iodo. Após a mostura, separa-se o mosto dos grãos, porém eles continuam com boa concentração de açúcares.

Para aproveitar esses açúcares fazemos uma lavagem dos grãos com água quente, à temperatura de $75^{\circ} \mathrm{C}$, o que possibilita um maior aproveitamento dos grãos com relação à extração do açúcar. O líquido produto dessa filtragem dos grãos é adicionado ao mosto previamente separado. Nesse instante é realizada a medição da densidade do mosto, valor este necessário para o cálculo do teor alcoólico da cerveja. A fervura visa concentrar, esterilizar, inativar enzimas e aromatizar. Durante a fervura, que dura cerca de uma hora, adicionamos o lúpulo, de acordo com a receita. O lúpulo tem a função de conceder amargor, sabor e aroma a cerveja.

Além de ter a propriedade de conservála. Após a fervura há o processo de resfriamento do mosto, que serve para evitar contaminação da cerveja, uma vez que o rápido resfriamento provoca a coagulação de algumas proteínas que acabam decantando e assim ficam mais facilmente separadas do mosto que será passado ao fermentador. Esse processo tem ser realizado no menor tempo possível. Os métodos mais comuns de resfriamento são o chiller de imersão, que é uma serpentina geralmente de cobre ou alumínio, e o chiller de placas, que é um trocador de calor com o princípio de contra-fluxo. A fermentação do mosto é realizada pela levedura, que consome o açúcar e produz gás carbônico e álcool. Após o resfriamento o mosto é transferido pra um fermentador e a levedura é dissolvida nele.

A fermentação ocorre em temperatura controlada, de acordo com a receita utilizada. Antes do envase, é realizada a carbonatação através do priming, que é a adição de água com açúcar na cerveja de forma que a levedura produza gás no líquido já dentro da garrafa. Outra possibilidade de carbonatação é a forçada, o que é a simples aplicação de gás carbônico na cerveja. Isso exige equipamentos mais específicos, como barris e cilindros de gás. O período de maturação serve para que subprodutos da fermentação sejam consumidos pela levedura, o que melhora o paladar da cerveja. Ela demora de uma semana a meses.

Nesse contexto, o laboratório servirá de estrutura para alunos das diversas áreas de conhecimento interagirem com os processos, aplicando seus conhecimentos e buscando soluções e melhorias. Para a área de processos de gestão podem ser realizados estudos logísticos, procedimentos, apontamentos de tempos padrão e melhorias no próprio layout. A área de processos mecânicos poderá melhorar a eficiência energética do processo em relação ao consumo de energia e trocas térmicas. Cabe a área ambiental racionalizar a utilização dos insumos, tratar os subprodutos da elaboração da cerveja artesanal e avaliar os impactos ambientais. Busca-se a automação do 
processo por meio do controle e instrumentação nas diversas etapas e ainda elencar alternativas para a utilização do malte, após a mostura.

\section{METODOLOGIA}

A ação inicial foi a realização de levantamento bibliográfico do assunto em artigos, normas e literatura profissional relacionada ao tema. $\mathrm{Na}$ sequência, foram realizadas visitas e levantamento de dados junto ao LabBeer do Laboratório de Ensaios Térmicos e Aerodinâmicos - LETA da Universidade Federal do Rio Grande do Sul - UFRGS e empresas fornecedoras de equipamentos e insumos para cervejarias. O estudo de campo junto a UFRGS possibilitou a aprendizagem sobre o processo de elaboração da cerveja artesanal e os melhores materiais e equipamentos para a estruturação do laboratório. Verificou-se a integração entre os cursos de graduação nos estudos referentes a montagem do laboratório e nos diversos trabalhos de conclusão de curso em andamento. A revisão bibliográfica sobre arranjo físico (SLACK et al., 2009) e sobre o processo de fabricação de cerveja artesanal (KUNZE, 2004; PALMER, 2006) norteou as especificações e posicionamento dos recursos. O dimensionamento da bancada e equipamentos baseou-se na literatura pesquisada, no estudo de campo em outras instituições de ensino e em lojas especializadas. Com base na literatura (KUNZE, 2004; PALMER, 2006) e dados de campo definiu-se que o laboratório tem a capacidade de produzir 50 I por batelada, visto esse ser o valor usual utilizado por cervejarias artesanais.

Enfim, foi determinado o espaço mínimo que o laboratório necessita. A partir disso foi elaborado cronograma para o projeto, definindo prazos para cada atividade.

A metodologia de trabalho está representada na figura 2.

Figura 2 - Fluxograma de ações

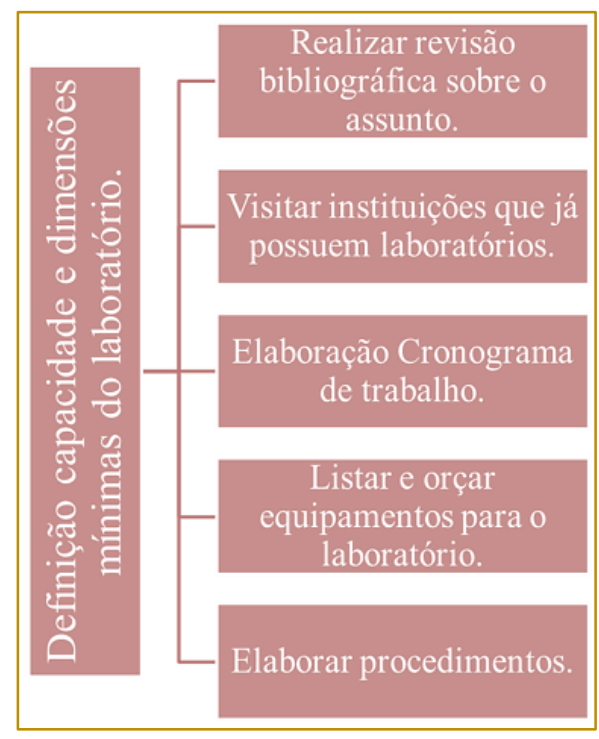

Fonte: Autores (2017).

\section{RESULTADOS}

A partir das premissas elencadas, definiu-se as dimensões mínimas para a montagem do laboratório e iniciou-se o detalhamento dos equipamentos, acessórios e materiais necessários a concepção do laboratório de cervejas artesanais. O cronograma de atividades construído está representado na Figura 3. 
Figura 3 - Cronograma

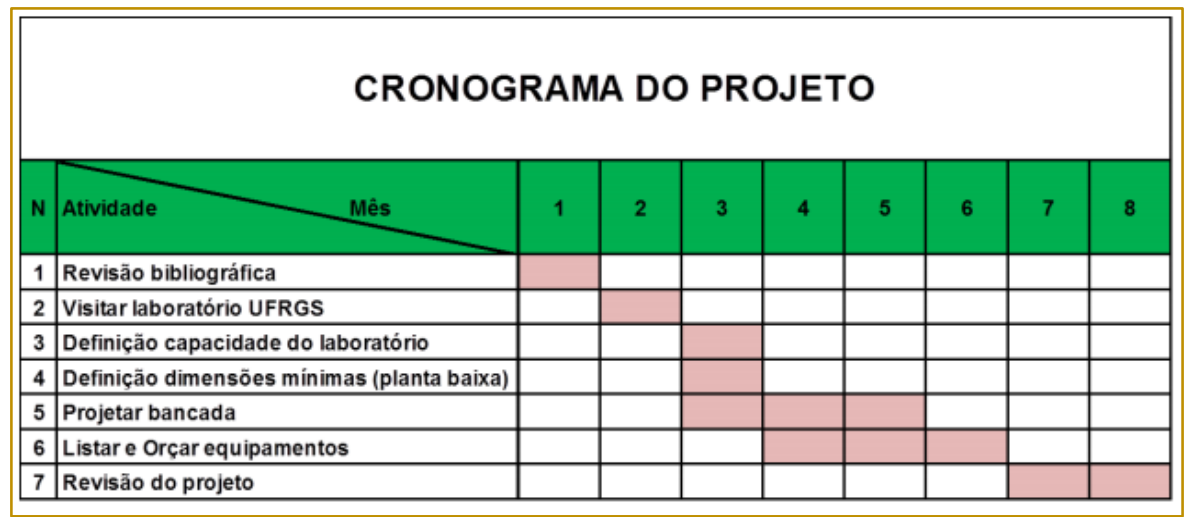

Fonte: Autores (2017).

O desenho da planta baixa, com as dimensões mínimas, está representado na Figura 4 e foi realizado utilizando o programa AutoCAD 2005. As dimensões são: ao mínimo 4,0 m por 6,0 m totalizando uma área de $24 \mathrm{~m}$ de área total, proporcionando espaço suficiente para a realização das tarefas e acessibilidade das pessoas.

Figura 4 - Planta baixa.

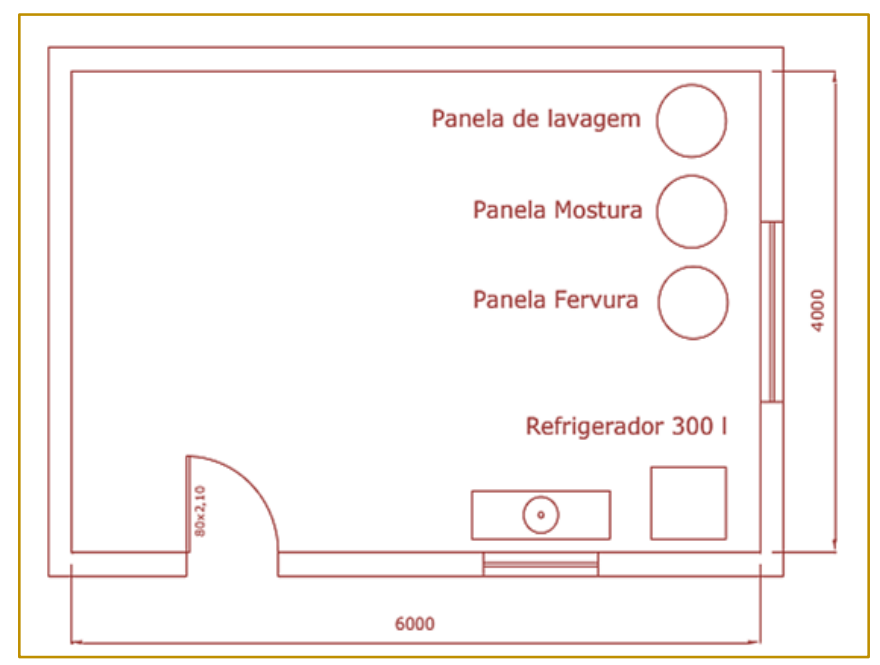

Fonte: Autores (2017).

A bancada foi projetada em tubo quadrado nas dimensões $20 \times 20 \times 1,5 \mathrm{~mm}$, em forma de degraus a fim de utilizar a energia potencial para as trasfegas entre um tanque e outro de acordo com a Figura 5. Essa especificação baseou-se no trabalho de Calegari (2013). 
Figura 5 - Projeto da bancada.

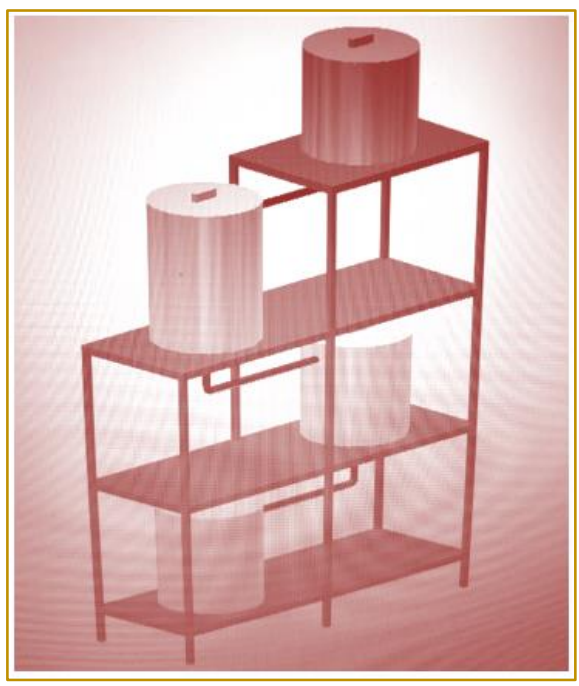

Fonte: Autores (2017).

As alturas foram definidas para que 0 manuseio dos insumos e equipamentos ocorra de forma segura e ergonomicamente adequada. Essa estrutura proporciona melhorias futuras, como a inserção de um termoacumulador para a refrigeração da água de resfriamento do mosto. Foi definida a utilização de resistências elétricas para todas as fases do processo, por permitirem a futura instrumentação e controle mais eficiente do processo, especialmente no momento da mostura. As resistências elétricas são do tipo imersão e alimentadas por uma tensão de 220 V. Projetadas três panelas em aço inox 304 , com capacidade de 60 litros, sendo a primeira para água de lavagem, a segunda para o processo de mostura do malte e a terceira para a fervura do mosto juntamente ao lúpulo.

A panela de lavagem terá uma resistência elétrica de $9000 \mathrm{~W}$, um termômetro analógico para leitura da temperatura, uma válvula esfera de 3/4" e um visor de nível. Para a panela de mostura foi projetado um fundo falso, em inox, que servirá como base para o malte e como elemento filtrante do mosto e uma válvula esfera de 3/4". A válvula fica localizada na lateral da panela, abaixo do fundo falso, para a trasfega do mosto para a panela de fervura.

A panela de mostura terá duas resistências elétricas de $6000 \mathrm{~W}$ permitindo um melhor controle da temperatura no momento da mostura. Na panela de fervura serão utilizadas duas resistências elétricas de 6000 W e uma válvula esfera de 3/4 " instalada na lateral da panela para realizar a trasfega do mosto fervido para o fermentador. O fermentador é um recipiente de plástico alimentício, acompanhado de torneira plástica e tampa com válvula airlock. Para o resfriamento do mosto, após a fervura, será utilizado um trocador de calor do tipo serpentina em alumínio.

A interligação entre panelas será feita através de mangueiras de silicone atóxica $3 / 4$ ". Os acessórios previstos para o processo são: pá cervejeira $450 \mathrm{~mm}$, balança digital $10 \mathrm{~kg}$, refratômetro, termômetro digital tipo espeto, peneira em inox, jarra capacidade 2 litros, borrifador manual $500 \mathrm{ml}$, arrolador manual e tampas metálicas. Os produtos necessários para a limpeza e testes são o sanitizante e tintura de iodo $2 \%$. As especificações e o orçamento contemplam os equipamentos, acessórios, produtos e materiais para a execução da bancada. Também foi elencada a mão de obra necessária para a confecção da bancada e montagem de equipamentos. Foi realizado pesquisa de preços em lojas especializadas no período de setembro a outubro de 2016.

O Anexo 1 traz descrição, quantidade, custo unitário e custo total desses itens. 4. Considerações finais Durante a evolução dos estudos para a elaboração do projeto, mostrase muito importante a escolha do arranjo físico das micro cervejarias, pois este possibilita a segurança dos envolvidos e minimiza o esforço físico no manuseio dos equipamentos e insumos utilizados no processo, isso facilita a manutenção da estrutura, preparação e limpeza dos instrumentos e equipamentos afins. Cabe ressaltar que a estrutura proposta 
aceita melhorias futuras em seu arranjo físico e contribuições para seu controle e automação. O que poderá agregar possíveis alterações referentes a segurança e

\section{REFERÊNCIAS}

[1] Brasil. Decreto n. 6871, de 04 de junho de 2009. Regulamenta a Lei no 8.918, de 14 de julho de 1994, que dispõe sobre a padronização, a classificação, o registro, a inspeção, a produção e a fiscalização de bebidas. Disponível em: Acesso em: 29 nov. 2016.

[2] Calegari, R. Structure for Experiments on a Microbrewery: Concepcion, Dimensions and Construction. 2013. 21 folhas. Monografia (Trabalho de Conclusão do Curso em Engenharia Mecânica) - Departamento de Engenharia Mecânica, Universidade Federal do Rio Grande do Sul, Porto Alegre, 2013.

[3] Kunze, W., "Technology of Malting and Brewing”, Edição 9, Berlim, Alemanha, 2007. Lei de ergonomia das pessoas. Isso pode e deve ser tratado em novos trabalhos de conclusão de curso.

Pureza da Cerveja. Disponível em: < http://www.brejas.com.br/reinheitsgebot.shtml> Acesso em: 28 abr. 2017.

[4] Martins, Petrônio G.; Laugeni, Fernando P., Administração da produção. 2. ed. São Paulo: Saraiva, 2005.

[5] Palmer, J.J., "How to Brew", Brewers Publications, 3를 ed., 2006.

[6] Slack, Nigel; Chambers, S.; Johnston, Robert, Administração da produção. São Paulo: Atlas, 2009. http://www.ufrgs.br/labbeer, acessado em 10/06/2016. http://loja.weconsultoria.com.br, acessado em 20/06/2016. 
ANEXO 1

Anexo 1 - Descrição, quantidade, custo unitário e custo total

\begin{tabular}{|c|c|c|c|}
\hline Item & $\begin{array}{c}\text { Quantidade } \\
\text { (Pc) }\end{array}$ & Custo Unitário (R\$) & $\begin{array}{c}\text { Custo Total } \\
\text { (R\$) }\end{array}$ \\
\hline Panela água de lavagem & 1 & $1.300,00$ & $1.300,00$ \\
\hline Panela mostura & 1 & $1.300,00$ & $1.300,00$ \\
\hline Fundo fals o & 1 & 280,00 & 280,00 \\
\hline Panela fervura & 1 & $1.300,00$ & $1.300,00$ \\
\hline Resistência elétrica $9000 \mathrm{~W}$ & 1 & 200,00 & 200,00 \\
\hline Resistência elétrica $6000 \mathrm{~W}$ & 4 & 110,00 & 440,00 \\
\hline Válvula esfera 3/4" & 3 & 90,00 & 270,00 \\
\hline Balde fermentador & 1 & 105,00 & 105,00 \\
\hline Chiller & 1 & 250,00 & 250,00 \\
\hline Mangueira em silicone atóxica 3/4" (metro) & 20 & 37,00 & 740,00 \\
\hline Refrige rador 300 litros & 1 & 900,00 & 900,00 \\
\hline Termôme tro cervejeiro & 1 & 32,00 & 32,00 \\
\hline Refratômetro & 1 & 180,00 & 180,00 \\
\hline Balança digital $10 \mathrm{Kg}$ & 1 & 40,00 & 40,00 \\
\hline Pá cerve jeira $450 \mathrm{~mm}$ & 1 & 16,00 & 16,00 \\
\hline Peneira inox & 1 & 25,00 & 25,00 \\
\hline Borrifador manual $500 \mathrm{ml}$ & 1 & 20,00 & 20,00 \\
\hline Jarra em plástico alimentício 21 & 1 & 20,00 & 20,00 \\
\hline Tampas metálicas & 100 & 12,00 & $1.200,00$ \\
\hline Arrolhador de bancada manual & 1 & 53,00 & 53,00 \\
\hline Sanitizante $100 \mathrm{ml}$ & 1 & 55,00 & 55,00 \\
\hline Tintura de iodo $50 \mathrm{ml}$ & 1 & 12,00 & 12,00 \\
\hline Tubo quadrado $25 \times 25 \times 2 \mathrm{~mm}$ (metos) & 36 & 14,00 & 504,00 \\
\hline Mão de Obra (horas) & 240 & 14,00 & $3.360,00$ \\
\hline \multicolumn{3}{|l|}{ Valor total: } & $12.602,00$ \\
\hline
\end{tabular}




\section{CAPÍTULO 5}

\section{ESTUDO DA INFLUENNCIA DA MELHORIA CONTINNUA NO TEMPO DE SETUP E TEMPO DE REPARO DO LEAD TIME: UMA SIMULACÃO EM AMBIENTE FLOWSHOP COM UM RECURSO RESTRITIVO DE CAPACIDADE}

\section{Miguel Bergamasso Moura,}

Marcel Heimar Ribeiro Utiyama

Resumo: O presente artigo científico se dispôs a fundamentar conceitualmente a importância do lead time produtivo como critério competitivo entre as empresas no mercado, demonstrando como a responsividade de um sistema de produção pode ser otimizada quando diagnosticado os tempos desperdiçados e aplicado programas de melhoria contínua. Foram destacados três aspectos cruciais que influenciam o desempenho do lead time produtivo, sendo eles: (1) atividades de preparação (setup), (2) atividades de manutenção (reparo) e (3) determinação do Recurso Restritivo de Capacidade (RRC) do sistema. O método de simulação foi utilizado com o intuito de demonstrar quantitativamente a influência de atividades de preparação e manutenção sobre o lead time produtivo, por meio do modelo híbrido System Dynamics-Factory Physics junto ao software Vensim, e da aplicação de três estratégias de melhoria contínua: $30 \%$ de redução focada na variável Tempo de Setup (TS); 30\% de redução focada na variável Tempo de Reparo (TR); $15 \%$ de redução conjunta nas variáveis TS e TR, simultaneamente. Os resultados para três cenários de sistema de produção distintos verificaram que para todos as três estratégias aplicadas, a influência da redução nos tempos das atividades de preparação e manutenção é positiva ao lead time produtivo, o reduzindo significativamente. A estratégia que representa a opção mais vantajosa para aplicação de programa de melhoria dependerá dos parâmetros e características do cenário de manufatura em questão. Para os cenários simulados, foi verificado que quando a disponibilidade de um RRC for inferior a 95\%, a estratégia de melhoria que emprega a redução focada em TS é a mais indicada; quando a disponibilidade de um RRC for superior a 95\%, a estratégia de melhoria que emprega a redução focada em TR é a mais indicada; e quando a disponibilidade de um RRC for aproximadamente 95\%, a estratégia de melhoria que emprega a redução conjunta em TS e TR é a mais indicada.

Palavras Chave: Lead time, Melhoria Contínua, System Dynamics-Factory Physics; Teoria das Restrições; Setup; Manutenção. 


\section{INTRODUÇÃO}

A atual disputa no mercado pela preferência dos consumidores tem acirrado a competitividade entre as empresas. Diante dessa situação, os profissionais que administram os setores de produção buscam encontrar meios que estabeleçam a melhoria contínua nos processos de produção para manterem suas organizações com bom desempenho frente à concorrência. Neste contexto, os principais critérios competitivos considerados pelos clientes são: custos, qualidade, tempo de entrega, confiabilidade e flexibilidade (SLACK, 2002). A competitividade empresarial se passa pela alta performance em pelo menos um desses critérios.

Nos últimos tempos, o mercado consumidor deseja cada vez mais uma pronta entrega das aquisições, muito em causa da variedade de opções e alternativas que o comprador encontra nos mais diversificados segmentos de produtos existentes. Dentro deste contexto surgiu a Time Based Competition (TBC) (STALK, 1988), a qual busca aumentar a velocidade para ganhar vantagem competitiva. Empresas que usavam o TBC entregavam seus produtos ou serviços mais rapidamente que seus concorrentes. Shingo (1996, p.54) explica que "a quantidade de tempo que um cliente está disposto a esperar pela entrega (o intervalo admissível de compra) deve ser a preocupação essencial da gerência da produção". Ainda, o mesmo autor expõe que o intervalo admissível de compra ideal é a entrega imediata, sendo que o cliente reconhece e tolera um certo tempo para a programação da produção.

Ao longo do tempo, conforme a entrega imediata se tornava uma prioridade mercadológica, o gerenciamento da produção e as estratégias de operações se voltaram para o desenvolvimento de métodos que reduzam o lead time de produção. Atualmente, o estudo nesta área se mostra relevante por se relacionar com o tempo de entrega, um critério competitivo em evidência no mercado. Existem diversas abordagens gerenciais que apresentam ferramentas cuja implantação no sistema produtivo proporciona a redução do lead time, entre eles o Lean Manufacturing (Liker, 2005) e o Quick Response Manufacturing (Suri, 1998). Esta pesquisa relaciona algumas dessas ferramentas com os principais fatores apresentados por um sistema de produção que causam o mau aproveitamento do tempo nas atividades de manufatura.

\subsection{OBJETIVO E MÉTODO DE PESQUISA}

O objetivo da pesquisa se passa pela investigação de como as atividades de manutenção e preparação, bem como as variáveis de chão de fábrica Tempo de Setup (TS) e Tempo de Reparo (TR), se relacionam e interferem quantitativamente no lead time de produção. Especificamente, empregando o método de pesquisa modelagem/simulação e o Modelo Híbrido Systems Dynamics-Factory Physics (Godinho Filho e Uzsoy, 2008), foi utilizado para simular as atividades dos sistemas de produção, assim como a implantação de programas de melhoria contínua nas variáveis investigadas nesse estudo. A modelagem permite que seja simulado um sistema de produção em operação, visualizando as reações decorrentes das alterações nos parâmetros e variáveis de entrada e representando o efeito associado à aplicação de programas de melhoria. Para executar a simulação, o software Vensim fornecido pela Ventana Systems, Inc. foi utilizado.

O estudo retrata a importância dos programas de melhorias contínua nas gestões de produção que têm por objetivo reduzir os desperdícios de tempos em atividades do chão de fábrica.

\section{REFERENCIAL TEÓRICO}

\subsection{LEAD TIME}

A redução do tempo que o cliente aguarda para receber a aquisição é fundamental para se alcançar uma alta responsividade nos processos. No ambiente de gestão da produção, este tempo é denominado lead time. O termo lead time, na tradução literal do inglês significa "tempo de espera" e refere-se ao tempo decorrente entre a liberação de uma ordem e o material correspondente estar pronto e disponível para uso (FERNANDES; GODINHO FILHO, 2010). A ordem pode representar a manufatura de um item ou a execução de um serviço. Ou seja, o termo lead time pode ser utilizado tanto para empresas de manufatura quanto as prestadoras de serviços. Tubino (1999) explica que para reduzir o lead time de produção deve haver a eliminação de 
desperdícios de tempos em quatro grupos de atividades distintas: (1) esperas, (2) processamento, (3) inspeção e (4) transporte. O grupo 2, atividades de processamento, é o único que executa processos que agregam valor ao produto, entretanto, de acordo com os setes grandes desperdícios do STP, também pode haver perdas nestas etapas. $O$ grupo 1 - tempos de esperas - ocorre devido às atividades de programação da produção, de espera na fila e de espera no lote. Para Corrêa e Gianesi (2007), as atividades em que os materiais esperam em filas para serem processados representam os elementos mais importantes a serem atacados quando se implementa a filosofia JIT. Isto posto, os tempos de espera em fila são gerados por três fatores: desbalanceamento entre carga e produção, esperas para setup e espera por problemas decorridos de falhas no sistema produtivo (TUBINO, 1999).

\subsubsection{FATOR: DESBALANCEAMENTO ENTRE CARGA E PRODUÇÃO}

Como solução para o desbalanceamento entre carga e produção, o aprimoramento pode ser realizado com a orientação da produção de acordo com a capacidade produtiva do RRC. Desta forma, todo o fluxo produtivo fluirá suavemente pelo sistema de produção sem a geração de filas ou estoques de materiais em processo. A implantação de programas de melhorias que apliquem os conceitos defendidos pela Teoria das Restrições (Theory of Constraints - TOC) podem solucionar os problemas gerados por este fator.

De acordo com Cox III e Spencer (2002), a TOC é uma filosofia administrativa embasada no sistema de gerenciamento das restrições que busca a melhoria contínua ao considerar que o desempenho produtivo depende da efetividade de todo o sistema. Pode-se entender que a TOC é uma grande síntese conceitual quanto à administração da produção, desenvolvida a partir dos princípios e técnicas provenientes do software de gestão da produção OPT (Optimized Production Technology) e da abordagem administrativa advinda do best-seller "A Meta", de Elyiahu M. Goldratt. Cox III e Spencer (2002), tal como Fernandes e Godinho Filho (2010), apresentam as cinco etapas da sistemática que caracteriza a aplicação da TOC: (1) identificar a restrição do sistema; (2) decidir como explorar a restrição do sistema; (3) subornar tudo o mais à restrição do sistema; (4) elevar a restrição do sistema; (5) se na etapa 4 a restrição é quebrada, volte à etapa 1 .

\subsubsection{FATOR: ESPERAS PARA SETUP}

Em relação às esperas para setup, este fator pode ser solucionado com a implantação de programas de melhoria que reduzam ou elimine os tempos gastos com atividades de preparação, como o método elaborado pelo engenheiro japonês Shigeo Shingo, Troca Rápida de Ferramentas (TRF ou SMED Single Minute Exchange of Die).

A TRF busca detalhar e categorizar as atividades de setup em interno e externo. O setup interno é aquele que só pode ser realizado quando a máquina não está operando, ou seja, quando ela se encontra desligada. Por outro lado, o setup externo se refere às atividades de preparação que podem ser realizadas enquanto a máquina estiver em pleno funcionamento, não interferindo em seu processamento. Assim, é viabilizada as posteriores análises e aplicação de técnicas que objetivam a redução dos tempos de espera, através de quatro estágios (SHINGO, 2000): Estágio inicial, onde as condições de setup interno e externo não se distinguem; Estágio 1, separar os setups internos dos externos; Estágio 2, converter os setups internos em externos; Estágio 3, racionalizar todos os aspetos da operação de setup.

\subsubsection{FATOR: ESPERAS POR PROBLEMAS DECORRIDOS DE FALHAS NO SISTEMA PRODUTIVO}

As esperas por problemas decorridos de falhas podem ser solucionadas com a implantação de programas de melhoria que reduzam ou elimine os tempos gastos com atividades de manutenção e reparo, como o método de Manutenção Produtiva Total (MPT ou TPM - Total Productive Maintenance), desenvolvido no Japão por volta dos anos 70 e 80 através do aperfeiçoamento das técnicas de manutenção preventiva e o estabelecimento da cultura de qualidade total que impõe a falha/defeito zero (KARDEC; RIBEIRO, 2002).

A implementação da MPT se baseia na aplicação prática de quatro atividades que será tratada como fundamentais (FOGLIATTO; 
RIBEIRO, 2009): (1) capacitação técnica dos profissionais envolvidos no sistema de produção para identificação e resolução rápida do problema; (2) melhoria nos equipamentos, de acordo com resultados obtidos por indicadores de desempenho de disponibilidade, performance e qualidade; (3) prática da manutenção autônoma, onde 0 profissional que mantém maior contato com dado equipamento desenvolva competências para detectar anomalias e intervir de forma preventiva às falhas; (4) prática da manutenção planejada, considerando fatores como prioridade competitiva da empresa, existência de recurso restritivo de capacidade no sistema de produção, preferência pela execução de manutenção preditiva, mantimento de estoque de peças para reposição, entre outros.

\subsection{MODELO HÍBRIDO: SYSTEM DYNAMICS- FACTORY PHYSICS}

O modelo híbrido System Dynamics-Factory Physics é composto por estações de trabalho sequenciais, sendo que cada uma representa as funções de apenas uma máquina. A Figura 1 apresenta o esquema de ordenamento para as estações de trabalho no modelo:

Figura 1. llustração esquemática do modelo utilizado neste trabalho.

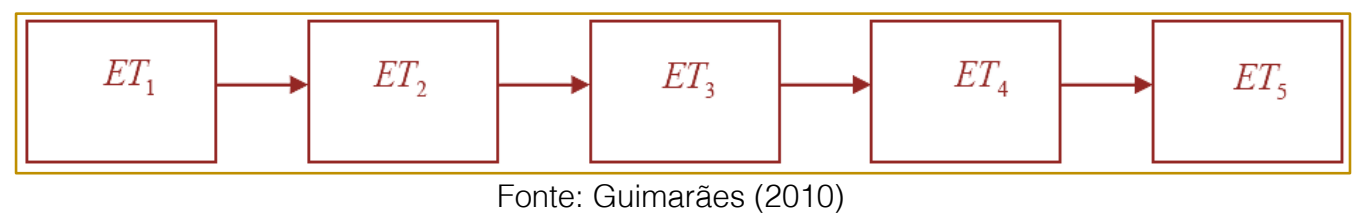

O modelo representa as relações existentes entre diversas variáveis que se encontram no contexto de um sistema de produção por meio de equações que encaminham ao resultado final do Lead time Total, possibilitando que seja estudado os efeitos da implantação de melhorias ou de variações no desempenho de seis variáveis de chão de fábrica, a saber: (1) Tempo médio de setup; (2) Tempo médio de reparo; (3) Tempo médio entre falhas; (4) Taxa média de defeitos; (5) Variabilidade do tempo entre chegadas; (6) Variabilidade do tempo de processamento efetivo global.

Tal modelagem foi desenvolvida pelos professores Dr. Moacir Godinho Filho e Dr. Reha Uzsoy (2008) com a combinação das teorias System Dynamics (FORRESTER, 1961) e Factory Physics (HOPP; SPEARMAN, 2008), posteriormente sendo utilizada no desenvolvimento de pesquisas científicas pelos próprios autores, dentre outros pesquisadores na área do gerenciamento do chão de fábrica, como, Godinho Filho, Guimarães e Oprime (2013), Godinho Filho e
Barco (2015) e Godinho Filho e Utiyama (2015, 2016).

\section{SIMULAÇÃO}

Cada cenário simulado dispõe de um Recurso Restritivo de Capacidade (RRC) dentre as cinco estações de trabalho no fluxo de produção flowshop e da aplicação de estratégias de melhoria contínua neste recurso. Para tanto, o processo simulatório é realizado a partir da definição dos parâmetros de entrada, da qualificação do cenário e da determinação dos efeitos provenientes das estratégias de melhoria contínua que serão testadas. O teste de cada cenário verifica os resultados quantitativos obtidos para a variável dependente Lead time Total em cada uma das cinco localizações possíveis do RRC na linha de produção.

\subsection{PARÂMETROS DE ENTRADA}

Neste estudo, foram utilizados os parâmetros descritos na Figura 2: 
Figura 2. Parâmetros de entrada estabelecidos para a simulação.

\begin{tabular}{|c|c|}
\hline VARLÁVIS E PARÂMETROS DE ENTRADA & $\begin{array}{c}\text { VALORES } \\
\text { ATRIBUIDOS }\end{array}$ \\
\hline Demanda Média & 11.520 peças/ano \\
\hline Tempo Anual Trabalhado & 1.920 horas/ano \\
\hline Tamanho do Lote & 200 peças \\
\hline Tempo Natural de Processamento (TP) & 6,8 minutos \\
\hline Tempo Natural de Processamento no RRC & 8 minutos \\
\hline Tempo Médio de Setup (TS) & 90 minutos \\
\hline Tempo Médio de Reparo (TR) & 120 minutos \\
\hline Tempo Médio entre Fallas (TF) & De acordo com o cenário \\
\hline Taxa Média de Defeitos (TD) & $10 \%$ \\
\hline Coeficiente de Variação do Tempo de Setup & 0,8 (moderado) \\
\hline Coeficiente de Variação do Tempo de Reparo & 0,8 (moderado) \\
\hline Coeficiente de Variação do Tempo Natural de Processamento & 1,5 (alto) \\
\hline Coeficiente de Variação de Chegadas & 1,5 (alto) \\
\hline Nivel de Utilização dos Recursos & $82,44 \%$ \\
\hline Nivel de Utilização do RRC & $96,11 \%$ \\
\hline
\end{tabular}

Fonte: (AUTOR, 2017)

Os parâmetros de entrada definiram o Tempo Natural de Processamento (TP) no RRC 15\% superior ao TP dos demais recursos, com os valores de 8 minutos e 6,8 minutos, respectivamente. Esta definição proporcionou um nível de utilização para o RRC de 96,11\% e para os demais recursos de $82,44 \%$. Os coeficientes de variação do Tempo de Setup e do Tempo de Reparo apresentam grau moderado de variabilidade, de acordo com Hopp e Spearman (2008). O Tempo Médio Entre Falhas (TF) atribuído foi de 4.800 minutos, proporcionando uma média de 24 atividades de manutenção por ano em cada estação de trabalho. A Demanda Média anual estabelecida é de 11.520 peças, produzidas em lotes de 200 unidades, sendo assim, é estipulado uma média de 58 lotes a serem produzidos no ano, o que configura uma média de 58 atividades de preparação a serem executadas em cada estação de trabalho.

\subsection{CENÁRIOS}

Os cenários são representações de sistemas de produção que diferem entre si em pelo menos um aspecto. Para esta simulação, três cenários foram elaborados com os parâmetros de entradas estabelecidos na seção anterior. A diferenciação entre eles ocorre na variável de chão de fábrica Tempo médio entre falhas (TF), como mostra Figura 3:

Figura 3. Cenários para a simulação.

\begin{tabular}{|l|l|l|}
\hline CENÁRIO 1 & Tempo médio entre falhas (TF) & 4.800 minutos \\
\hline CENÁRIO 2 & Tempo médio entre falhas (TF) & 1.800 minutos \\
\hline CENÁRIO 3 & Tempo médio entre falhas (TF) & 2.200 minutos \\
\hline
\end{tabular}
Fonte: (AUTOR, 2017)

A quantidade de minutos atribuída à variável TF para cada cenário interfere na quantidade média de atividades de manutenção a serem executadas anualmente. Isto posto, o Cenário 1 apresenta uma média de 24 atividades de manutenção por ano, o Cenário 2 apresenta uma média de 64 atividades de manutenção por ano e o Cenário 3 apresenta uma média de 37 atividades de manutenção por ano, o que no presente trabalho resulta em uma disponibilidade de máquina de aproximadamente $95 \%$. 


\subsection{ESTRATÉGIAS DE MELHORIA} CONTÍNUA

Diante aos parâmetros de entrada e aos cenários explicados, as simulações foram executadas para cada cenário e os resultados quantitativos do Lead time Total para cada localização do RRC foram registrados. Neste ponto, definimos a Estratégia 0 a ser testada, na qual o desempenho do sistema não está sob influência de um programa de melhoria contínua. As estratégias 1, 2 e 3 a serem testadas ocorrem da mesma maneira, porém na modelagem de simulação se configura as variáveis "Objetivo com relação à melhoria no tempo de reparo" e "Objetivo com relação à melhoria no tempo de setup" para representar a influência que programas de melhoria contínua efetuariam no sistema de produção. A Figura 4 apresenta detalhadamente a influência exercida por cada estratégia no sistema de produção.

Figura 4. Estratégias de melhoria contínua testadas.

\begin{tabular}{|l|l|}
\hline ESTRATEGIA 0 & Sistema de produção sem implantação de programa de melhoria contínua; \\
\hline ESTRATÉGIA 1 & $\begin{array}{l}\text { Sistema de produção com implantação de programa de melhoria contínua, } \\
\text { gerando uma redução focada no Tempo de Setup (TS) de 30\%; }\end{array}$ \\
\hline ESTRATÉGIA 2 & $\begin{array}{l}\text { Sistema de produção com implantação de programa de melhoria contínua, } \\
\text { gerando uma redução focada no Tempo de Reparo (TR) de 30\%; }\end{array}$ \\
\hline ESTRATÉGIA 3 & $\begin{array}{l}\text { Sistema de produção com implantação de programa de melhoria continua, } \\
\text { gerando uma redução conjunta de 15\% no Tempo de Setup (TS) e 15\% no } \\
\text { Tempo de Reparo (TR), simultaneamente. }\end{array}$ \\
\hline
\end{tabular}

Fonte: (AUTOR, 2017).

A estratégia 0 representa testes para os três cenários quando não houver a implantação de programas de melhoria contínua. As estratégias 1, 2 e 3 representam testes para os três cenários quando houver esforços investidos em programas de melhoria contínua que reduzam tempos nas respectivas atividades de preparação, de manutenção e de preparação e manutenção simultaneamente.

\subsection{RESULTADOS DA SIMULAÇÃO}

Com posse das informações determinadas para os parâmetros de entrada, cenários e estratégias de melhoria contínua, os testes simulatórios são executados para cada uma das cinco localizações do RRC na linha de produção. A partir dos resultados obtidos para a variável Lead time Total, é verificada a estratégia mais efetiva dentre as três estratégias testadas para cada cenário.

A Figura 5 apresenta os resultados obtidos a partir da simulação, demonstrando quantitativamente os tempos da variável Lead time Total em minutos.

A estratégia que proporciona os menores tempos para a variável Lead time Total é entendida como a mais efetiva. A visualização da estratégia mais efetiva para cada um dos cenários possibilita analisar qual atividade do chão de fábrica que desperdiça tempos no processo de fabricação deve ser priorizada na busca pela redução do lead time de produção. 
Figura 5. Resultados de Lead time Total obtidos pela simulação.

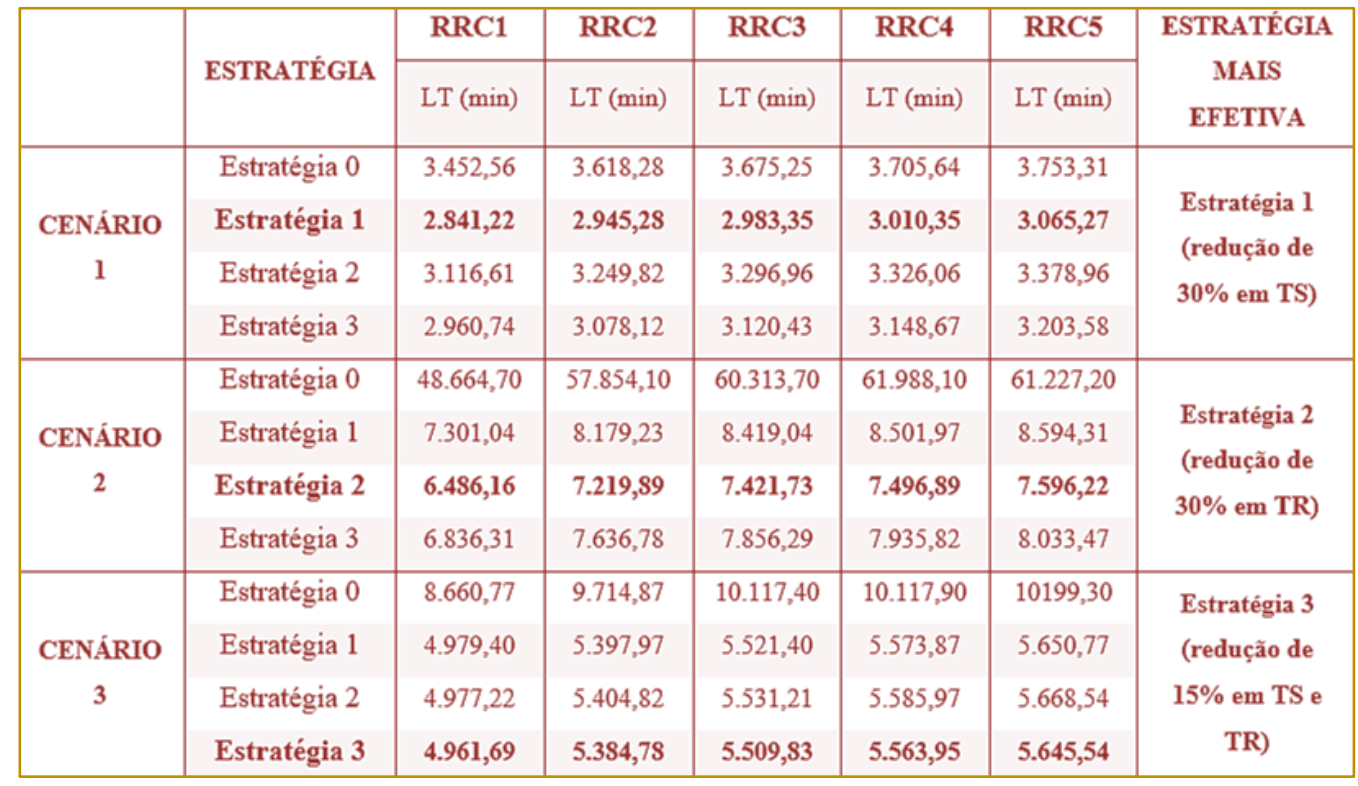

Fonte: (AUTOR, 2017)

\subsection{ANÁLISE DOS RESULTADOS}

Diante aos dados apresentados pela Figura 5, inicialmente observa-se um grande salto diferencial entre os resultados das estratégias 1,2 e 3 e os resultados da estratégia 0, para os três cenários. Esta diferença percebida comprova a grande contribuição que programas de melhorias contínua exercem na busca pela redução do lead time de produção.

O Cenário 1 teve como menores Lead time Total os proporcionados pela Estratégia 1. Já - Cenário 2, a Estratégia 2 proporcionou os menores Lead time Total. No Cenário 3, a estratégia mais efetiva foi a Estratégia 3, que impôs a redução conjunta de 15\% em TS e TR, entretanto, analisando o percentual de diferença entre as estratégias 1,2 e 3 testadas, os resultados são inferiores a 1\%, ou seja, é possível afirmar que os resultados se equivalem na prática, se considerarmos a variabilidade dos sistemas produtivos. Sendo assim, pode-se concluir que para o Cenário 3 , as aplicações das estratégias 1, 2 e 3 culminam em resultados equivalentes na redução do lead time de produção.

\section{CONCLUSÕES}

De acordo com as análises dos resultados, observa-se que cada cenário testado apresentou uma estratégia de melhoria contínua diferente como mais efetiva. Outra observação pertinente é que o diferencial entre os cenários é o valor atribuído à variável de chão de fábrica TF (tempo médio entre falhas) e, portanto, entende-se que esta variável pode ser tratada como um parâmetro que define em qual programa de melhoria é mais efetivo para a redução do lead time de produção. Considerando que a variável TF determina a quantidade de operações de manutenção em cada estação de trabalho por ano, a tomada de decisão por qual programa de melhoria contínua deve ser escolhido de modo a reduzir o lead time de produção se dá em função deste fator.

Para o Cenário 1 que apresenta 24 operações de manutenção em cada estação de trabalho por ano, a redução focada de $30 \%$ em TS foi a opção mais efetiva. No Cenário 2 que apresenta 64 operações de manutenção em cada estação de trabalho por ano, a redução focada de $30 \%$ em TR foi a opção mais efetiva, e no Cenário 3 que apresentou 37 operações de manutenção as três estratégias apresentaram efetividade equivalente, com leve proeminência à redução conjunta de $15 \%$ em TS e TR.

Portanto, conclui-se que:

Para as situações nas quais a quantidade de operações de manutenção em cada estação de trabalho por ano for inferior a 37 (ou seja, uma disponibilidade de máquina superior a $95 \%)$, o programa de melhoria contínua mais viável a ser implantado é o que proporcione uma redução focada nos tempos de setup (atividades de preparação), pois na simulação 
foi o que obteve maior redução do Lead time Total;

Para as situações nas quais a quantidade de operações de manutenção em cada estação de trabalho por ano for superior a 37 (ou seja, uma disponibilidade de máquina superior a 95\%), o programa de melhoria contínua mais viável a ser implantado é o que proporcione uma redução focada nos tempos de reparo (atividades de manutenção), pois na simulação foi o que obteve maior redução do Lead time Total;

Para as situações nas quais a quantidade de operações de manutenção em cada estação de trabalho for exatamente 37 (ou seja, uma disponibilidade de máquina de 95\%), o programa de melhoria contínua mais viável a ser implantado será o que proporcionar uma redução conjunta nos tempos de reparo e setup (atividades de preparação e manutenção simultaneamente), pois na simulação, apesar da equivalência com os resultados dos demais testes, foi o que obteve maior redução do Lead time Total.

Observa-se que 37 operações de manutenção por ano ou 95\% de disponibilidade de máquina é o fator determinante para a tomada de decisão por apresentar resultados equivalentes nos testes

\section{REFERÊNCIAS}

[1] Corrêa, H. L; Gianesi, I. G. Just in time, MRP e OPT: um enfoque estratégico. 2. ed. São Paulo: Atlas, 2007.

[2] Cox III, James F.; Spencer, Michael S. Manual da teoria das restrições. Fernanda Kohmann Dietrich (Trad.). Porto Alegre: Bookman, 2002.

[3] Fernandes; F. C.; Godinho Filho, M. Planejamento e controle da produção: dos fundamentos ao essencial. 1. ed. São Paulo: Atlas, 2010.

[4] Fogliatto, F. S.; Ribeiro, J. L. D. Confiabilidade e manutenção industrial. Rio de Janeiro: Elsevier, 2009.

[5] Forrester, J. W. Industrial Dynamics. Portland: Productivity Press, 1961. 464p.

[6] Godinho Filho, M.; Barco, C.F. A framework for choosing among different lean-based improvement programs. International Journal of Advanced Manufacturing Technology, v.81, p. 183197, 2015.

[7] Godinho Filho, M.; Guimaraes, A. A.; Oprime, P.C. Guiding improvement programs towards lead time reduction in a single-machine e, sendo assim, representar o ponto de equilíbrio entre as estratégias testadas.

A partir da constatação da quantidade média de operações de manutenção realizadas por ano nas estações de trabalho, é possível optar pelo programa de melhoria contínua mais interessante na busca pela redução dos tempos desperdiçados.

É importante ressaltar que o presente estudo adotou a suposição de que os investimentos necessários para implantar cada uma das estratégias aqui abordadas são equivalentes. Por esses motivos, as conclusões elencadas a partir das simulações realizadas são determinadas única e exclusivamente para seus respectivos cenários verificados e considerando essa suposição de investimento equivalente. Entretanto, os resultados fornecem recomendações práticas para os gerentes de produção decidirem a melhor estratégia de realização de melhorias.

Pesquisas futuras podem ser realizadas de forma a estender o presente estudo, alternando os desempenhos das variáveis de chão de fábrica ou determinando cenários com novos parâmetros de entrada para simular algumas outras variedades de sistemas de produção existentes.

environment. International Journal of Advanced Manufacturing Technology, v.66, p. 1987- 1998, 2013.

[8] Godinho Filho, M.; Utiyama, M. H. R. Comparing different strategies for the allocation of improvement programmes in a flow shop environment. International Journal of Advanced Manufacturing Technology, v.77, p. 1365- 1385, 2015.

[9] Godinho Filho, M; Utiyama, M. H. R. Comparing the effect of different strategies of continuous improvement programmes on repair time to reduce lead time. The International Journal of Advanced Manufacturing Technology, v. 87, n. 1-4, p. 315-327, 2016.

[10] Godinho Filho, M.; Uzsoy, R. Combining System Dynamics And Factory Physics Approach To Study The Effect Of Continuous Improvement On Lot Size - Cycle Time Relationships. In: Production and Operation Management Society (POMS), 19, 2008, La Jolla, Proceedings... California, 2008.

[11] Guimaraes, A. A. Utilização de um método híbrido System-Dynamics - Factory Physics para a investigação do efeito de ações de melhoria contínua na redução do Lead Time. Dissertação (Mestrado em engenharia de produção) - 
Departamento de Engenharia de Produção, Universidade Federal de São Carlos, 2010.

[12] Hopp, W. J.; Spearman, M.L. Factory Physics: Foundations of Manufacturing Management. Nova lorque: McGraw Hill Higher Education, 2008, 720p.

[13] Kardec, A.; Ribeiro, H. Gestão estratégica e manutenção autônoma. Rio de Janeiro: ABRAMAN, 2002.

[14] Liker, J. K. O modelo Toyota: 14 princípios de gestão do maior fabricante do mundo. Lene Belon Ribeiro (Trad.). Porto Alegre: Bookman, 2005.

[15] Shingo, Shigeo. Sistemas de produção com estoque zero: o Sistema Shingo para melhorias contínuas. Lia Weber Mendes (Trad.). Porto Alegre: Artes Médicas, 1996.

[16] Shingo, Shigeo. Sistema de troca rápida de ferramenta: uma revolução nos sistemas produtivos. Eduardo Schaan e Cristina Schumacher (Trad.). Porto Alegre: Bookman, 2000.

[17] Stalk JR., G. Time - the next source of competitive advantage. Harvard Business Review, p 41-51, 1988.

[18] Suri, R. Quick Response Manufacturing: A companywide approach to reducing lead times. Portland: Productivity Press, 1998.

[19] Tubino, D. F. Sistemas de Produção: A produtividade no chão de fábrica. Porto Alegre: Bookman, 1999. 


\section{CAPÍTULO 6}

\section{APLICAÇÃO DA CRONANÁLISE PARA MELHORIA DO PROCESSO ELETROELETRÔNICOS}

\section{Larissa Nayara Oliveira dos Santos}

Nathalia Stephane Santos Nascimento

Hicaro Ferreira Matos Cardial

Alexandre dos Santos Santana

Glaucia Regina de Oliveira Almeida

Resumo: O presente artigo teve como objetivo a aplicação da técnica de cronoanálise no processo de fabricação de Nobreak de uma indústria de eletroeletrônicos localizada no Estado de Sergipe. Foi cronometrado os movimentos dos trabalhadores da linha de produção sendo a atividade fragmentada em tarefas específicas. O cálculo dos tempos através do tempo real (tempo cronometrado) calculou-se o tempo normal, que é acrescido do fator eficiência. O tempo padrão é calculado incluindo o fator fadiga sobre o tempo normal. A partir do tempo padrão realizado em cada posto de trabalho é possível identificar a ociosidade desses postos, depois de identificar foi feita uma avaliação de quais fatores influenciaram nesse problema, podendo assim ser feita alteração na ordem de realização das atividades ou simplesmente eliminá-las. Após análise dos dados obtidos no estudo, concluiu-se que as atividades dos postos 01 a 03 apresentavam ociosidade, o que diminuía a eficiência da mão de obra. Com o balanceamento de linha foi possível deixar as operações desses postos balanceadas, reduzir uma mão de obra, e aumentar a eficiência de $81 \%$ para $87 \%$.

Palavras-chave: Estudos de tempos e movimentos, cronoanálise, produção

* Artigo apresentado no XXXVII Encontro Nacional de Engenharia de Produção 


\section{INTRODUÇÃO}

Atualmente, diante do avanço tecnológico e do aumento da competitividade, muitas empresas objetivam adquirir métodos e técnicas que melhorem seu desempenho produtivo. Passaram a adotar métodos como Estudo de Tempos e Movimentos, ou simplesmente Estudo de Métodos, para aplicar nas linhas de produção a fim de aperfeiçoar seus processos, eliminando desperdícios de tempo, esforços e diminuir custos, assim como estar ciente da sua real capacidade.

Os sistemas de produção, com o passar dos anos, foram aprimorados por meio de investigações científicas que levaram ao aperfeiçoamento da eficiência nos processos. Taylor foi um dos precursores dessas investigações, o responsável por estudar e aplicar as primeiras soluções de melhorias dos processos. O Sistema Taylor de produção estabeleceu fortes contribuições na racionalização do trabalho, eliminação de custos por causa de desperdício de tempo e esforços desnecessários, entre outros fatores, e hoje o que parece ser simples, na época foi inédito. Os resultados desejados empregando esses métodos utilizam de ferramentas como: cronometragens, cartões de instruções, roteiros e especificações, supervisão, seleção e treinamento.

A Cronoanálise é um dos estudos de métodos que objetiva verificar o tempo de realização de tarefas de determinada operação e a partir desse histórico realizar análises para identificar os tempos ociosos, capacidade real de produção, e, dentre outros, gerar um escopo para estudo de balanceamento de linha. O mesmo auxilia na distribuição equilibrada das atividades, objetivando resolver duas problemáticas: definir o tempo de ciclo e o número de postos de trabalhos necessários. De forma generalizada, esses estudos visam aumentar a produtividade e eficiência por meio da diminuição de movimentos desnecessários, otimização de materiais e esforços sem que gere custos e/ou que diminuam os custos existentes.

O Nobreak é um dispositivo que estabiliza a voltagem de energia, oferecendo segurança ao equipamento que a ele está conectado, evitando um possível dano ao aparelho. Em caso de queda de energia é possível manter o equipamento em uso por algum tempo, a depender da autonomia de cada bateria, pois varia de aparelho para aparelho, dependendo da potência do nobreak.

Diante destas informações o objetivo deste trabalho foi analisar o processo produtivo de uma linha de desmontagem de nobreak, numa empresa de eletroeletrônicos, aplicando - Estudo de Métodos, através do balanceamento de linha da produção foi possível propor melhorias na otimização da mão de obra aumentando a eficiência do processo distribuindo de maneira equilibrada as operações e tarefas.

\section{REFERENCIAL TEÓRICO}

\subsection{DIVISÃO DO TRABALHO E ADMINISTRAÇÃO CIENTÍFICA}

Segundo SLACK et al., 2010 a ideia da divisão do trabalho em dividir o total de tarefas em pequenas partes e cada uma sendo desempenhada por uma só pessoa apresenta vantagens agregadas como proporcionar aprendizado mais rápido, automação mais fácil nas tarefas simplificadas e trabalho não produtivo reduzido. Todavia, há também as desvantagens como a monotonia, dano físico, baixa flexibilidade e robustez.

Taylor descobriu seu interesse em usar as investigações e experimentações científicas para melhorar as operações de manufatura onde suas investigações levaram a melhorias na eficiência dos trabalhadores resultando em grandes economias com custos de mão-deobra. O grande marco da administração científica ocorreu na Ford Motor Company no início do século XX. Henry Ford projetou o Ford Modelo $T$ para ser construído em linhas de montagem que incorporavam os elementos principais da administração científica. Era necessária produção em massa e eficiência, ao mesmo tempo em que se concentravam nos detalhes das operações (GAITHER \& FRAZIER, 2001).

De acordo SLACK et al., 2010 junto com o movimento da administração cientifica, sugiram dois campos de estudo: um para a determinação dos métodos e atividades que devem ser incluídas nos trabalhos, e outro para medição do tempo que deveria tomar a execução de trabalhos, respectivamente. 0 autor ainda cita seis passos do estudo de métodos:

a) Selecionar o trabalho a ser estudado; 
b) Registrar todos os fatos relevantes do método presente;

c) Examinar esses fatos criteriosamente e na sequência;

d) Desenvolver o método de mais prático, econômico e efetivo;

e) Manter o método através da checagem periódica dele em uso.

\subsection{ESTUDO DE TEMPOS E MOVIMENTOS}

Segundo MAYNARD (1970), o estudo de tempos refere-se à análise de uma dada operação determinando seus elementos de trabalho, a sequência e os tempos necessários para realizá-los. GAITHER \& FRAZIER (2001) completam dizendo que no estudo do tempo, os analistas cronometram a operação que é executada pelos trabalhadores e se apropriam dessa técnica de medida do trabalho com o objetivo de registrar o tempo e ritmo da realização de determinada tarefa definindo o intervalo de tempo que essa tarefa leva para ser completada.

Esse estudo se torna importante e de grande utilidade nas indústrias, pois permite um planejamento eficiente para utilizar a melhor forma os recursos disponíveis, fornece dados que possibilitam balanceamento de estruturas de produção, comparação dos roteiros de fabricação e análise de planejamento de capacidade, possibilita ainda, análises referentes a custos de produção e planejamento de capacidade e avaliação de desempenho (MARTINS \& LAUGENI, 2005).

Existem ainda propósitos do estudo de tempos, são eles (MAYNARD, 1970):

a) Analisar as operações e condições de trabalho para verificar as possibilidades de melhoria dos métodos existentes;

b) Incrementar a eficiência do trabalho através de mudanças necessárias dos movimentos;

c) Estabelecer e padronizar condições pertinentes à operação eficiente;

d) Estabelecer padrões de trabalho consistentes e equitativos;

e) Fornecer dados confiáveis para a compilação de gráficos e fórmulas;

f) Fornecer um registro constante das condições reais de trabalho referentes ao tempo padrão.

\subsection{CRONOANÁLISE}

GAITHER \& FRAZIER (2001) dizem que Taylor entra com uma abordagem sistemática para melhorar a eficiência do trabalhador e MOREIRA (2013) enfatiza que Gilbreth parte do estudo dos movimentos do corpo humano durante uma operação. Significa dizer que é a junção da divisão do trabalho e real capacidade do operador, além dos aspectos ligados a fadiga e a movimentos desnecessários ao longo da operação que revelam o objetivo principal e quando pode ser indicada a cronoanálise. Quando as empresas buscam melhorar a produtividade e entender todos os fatores que influenciam em uma avaliação minuciosa do processo produtivo, a cronoanálise é indicada, pois seu objetivo principal é identificar os desperdícios de tempo, bem como os pontos de ineficiência de determinada operação.

Uma operação pode ser dividida em partes, chamado por MARTINS \& LAUGENI (2005) de elementos de uma operação. Esses elementos serão cronometrados para que ao final se tenha os dados necessários para estudo. GAITHER \& FRAZIER (2001, p.9), afirmam que as "cronometragens eram usadas para definir com precisão a produção padrão por trabalhador em cada tarefa. O produto esperado em cada tarefa era usado para planejar e programar o trabalho e para comparar diferentes métodos de executar as tarefas".

MARTINS \& LAUGENI (2005) afirmam que as cronometragens, determinam-se o tempo médio do ciclo de trabalho. O estudo deve ainda avaliar o fator de ritmo ou velocidade da operação, tempo normal, tolerâncias para fadiga e para necessidades pessoais após isso se determina o tempo padrão da operação.

O número de medidas que devem ser tomadas, ou seja, o número de ciclos a cronometrar, MOREIRA (2013) afirma que é fácil perceber que o número de medidas dependerá de três fatores:

1) A variabilidade dos tempos;

2) A precisão desejada;

3) O nível de confiança sobre a medida tomada.

E ressalta, ainda, que esse número de medidas pode ser determinado de duas formas diferentes: 
a) Pela via prática ou do bom senso: o analista vai fazendo medidas dos ciclos, conforme eles acontecem, e para quando sente confiança nos resultados obtidos;

b) Pela via estatística, que permite a determinação matemática do número de ciclos a cronometrar.

O analista, ao mesmo tempo em que cronometra o tempo real do operador, também registra a sua eficiência. Isso possibilita a melhoria dos processos e aumento da produtividade, o que torna importante acrescentar certo percentual de tempo perdido devido à fadiga e às demoras inevitáveis, ou seja, que não dependem da vontade do operador. O analista deve familiarizar-se com a operação e tudo que a cerca: o local onde ela é desenvolvida, os equipamentos que são utilizados $e$ as condições gerais em que o trabalho é realizado (iluminação, ruído, poeira, posição do operador etc.) (MOREIRA, 2013).

Para se chegar ao tempo padrão, há dois tipos de tempos antes determinados, são eles: o tempo real (TR) e o tempo normal (TN), conforme Equação 1. O tempo real decorre quando é feita uma operação, obtido por cronometragem direta. $O$ tempo normal refere-se ao tempo preciso para a operação ser completa operando com velocidade normal (eficiência), durante um dia de trabalho sem fadiga indevida. Vale ressaltar que se costuma acrescentar ao tempo normal certo percentual de tempo perdido por fatores que não dependem da vontade do colaborador.

\section{$T N=T R \times E(1)$}

Para o cálculo do tempo padrão inclui-se o fator fadiga, onde, para Maynard (1970):

\begin{abstract}
A fadiga é reconhecida como um fator de permissão e de influência sobre operações industriais. Uma vez que este é um item extremamente para se medir ou para se chegar a um acordo, é mais aconselhável justificar os
\end{abstract}

possiveis efeitos de fadiga estabelecendo padrões que possam ser razoavelmente mantidos pelo trabalhador durante todo o período de trabalho.

Assim para o tempo padrão, poderá ser expresso como (MOREIRA, 2013):
Sendo:

$\mathrm{T}$ = Tolerância em porcentagem permitida para operação.

Em um mercado cada vez mais competitivo as empresas buscam estabelecer melhorias que possibilitem alcançar posições competitivas dentro do mercado em que está inserido. Através da melhoria contínua dos seus diversos processos e gestão, e com essas estratégias que pode se alcançar o patamar estabelecido. O balanceamento de linha de montagem, conforme afirmam SOUZA \& PIRES (1999, apud DINIZ \& CALIFE,
2015), é feito pelas empresas de manufatura com o objetivo de alcançar um equilíbrio entre a capacidade dos seus recursos e a demanda do mercado. Essa é uma forma de a empresa melhorar seus processos e atender ao mercado de maneira adequada, com chances de redução de custos.

DAVIS (2001, apud DEMBOGURSKI et al., 2008) define as etapas do balanceamento de linha de produção da seguinte forma:

a) Especificar a relação sequencial entre as tarefas, utilizando um diagrama de precedência; 
b) Determinar o tempo de ciclo necessário;

c) Determinar o número mínimo teórico de estações de trabalho;

d) Selecionar uma regra básica na qual as tarefas têm de ser alocadas às estações de trabalho e uma regra secundária para desempatar;

e) Delegar tarefas, uma de cada vez, à primeira estação, até que a soma dos tempos seja igual ao tempo de ciclo. Repetir o processo nas estações seguintes;

f) Avaliar a eficiência da linha.

\section{ESTUDO DE CASO}

Para delimitação da base teórica realizou-se uma pesquisa bibliográfica para justificar as aplicações dos cálculos e teorias presentes no estudo de caso e pesquisa de campo na obtenção dos dados da área estudada;

$\mathrm{Na}$ elaboração deste trabalho foram executadas as seguintes operações:

a) Cronometragem dos movimentos dos trabalhadores da linha de produção: a atividade de cada operador é fragmentada em tarefas mais específicas, com auxílio do cronômetro é computado o tempo de cada tarefa desde o movimento inicial até seu movimento final, até atingir a quantidade de tempos necessários para validar o estudo;

b) Cálculo dos tempos: através do tempo real (tempo cronometrado) calcula-se o tempo normal, que é acrescido do fator eficiência, o qual MOREIRA (2013) sugere ser registrado durante a cronometragem, isso possibilita obter um resultado mais preciso. O tempo padrão é calculado incluindo o fator fadiga sobre o tempo normal;

c) Balanceamento dos tempos obtidos: a partir do tempo padrão realizado em cada posto de trabalho é possível identificar a ociosidade desses postos, depois de identificar é feita uma avaliação de quais fatores influenciam nesse problema, podendo assim ser feita alteração na ordem de realização das atividades ou simplesmente eliminá-las, desde que não implique na modificação do funcionamento do produto acabado; delimita-se o tempo de ciclo e o número de postos necessários para realizar as tarefas dentro desse tempo; por fim, de acordo com DAVIS (2001, apud DEMBOGURSKI et al., 2008) delega-se tarefas, uma de cada vez, a cada posto, até que a soma dos tempos seja aproximado ao tempo de ciclo, para que seja possível a avaliação a eficiência da linha.

O estudo de caso foi feito mediante análise de uma linha de produção de nobreak, o produto escolhido para esse estudo, dentre tantos outros, foi o Nobreak X, por apresentar um volume de produção bastante representativo para empresa. Para montagem deste produto, atualmente, são necessárias 09 estações de trabalho com 10 operadores. O processo está dividido na seguinte sequência:

a) Soldagem da placa no painel;

b) Inserção de fiação;

c) Testes;

d) Embalagem.

Os cálculos são executados com base nos seguintes dados:

a) Carga Horária: 8,08 h/dia

b) Dias de trabalho semanal: 5 dias

c) Eficiência: Entre 90\% a 110\%

d) Fator de tolerância (estipulado pela empresa): $15 \%$

e) Unidade de medida: segundos (s)

\subsection{BALANCEAMENTO ANTERIOR}

O processo atual da linha é configurado conforme Tabela 1 e na Tabela 2 é apresentada a eficiência do processo. 
Tabela 6 - Descrição do processo anterior ao balanceamento

\begin{tabular}{|c|c|c|c|c|c|c|c|c|}
\hline Posto & Descrição operação & $\operatorname{Tr}$ & $\begin{array}{l}E-90 \% \text { a } \\
110 \%\end{array}$ & $\mathrm{Ft}$ & Tn & Tp & $\begin{array}{l}\text { Mod } \\
\text { por } \\
\text { posto }\end{array}$ & $\begin{array}{l}\text { Tempo de } \\
\text { operação }\end{array}$ \\
\hline \multirow{10}{*}{1} & $\begin{array}{l}\text { Pegar Painel Traseiro e } \\
\text { Encaixar no Mocaf }\end{array}$ & 5,74 & 1 & 1,15 & 5,74 & 6,6 & \multirow{10}{*}{2} & \multirow{10}{*}{30,56} \\
\hline & $\begin{array}{l}\text { Pegar Placa e Quebrar } \\
\text { a Borda }\end{array}$ & 8,49 & 1 & 1,15 & 8,49 & 9,76 & & \\
\hline & $\begin{array}{l}\text { Encaixar Placa no } \\
\text { Mocaf }\end{array}$ & 3,43 & 1 & 1,15 & 3,43 & 3,95 & & \\
\hline & $\begin{array}{l}\text { Parafusar Placa no } \\
\text { Painel }\end{array}$ & 5,24 & 1 & 1,15 & 5,24 & 6,03 & & \\
\hline & $\begin{array}{l}\text { Soldar } 3 \text { Barras de } \\
\text { Saída do Painel na } \\
\text { Placa }\end{array}$ & 12,57 & 1 & 1,15 & 12,57 & 14,45 & & \\
\hline & $\begin{array}{l}\text { Encaixar Conector do } \\
\text { Cooler na Placa (CN2) }\end{array}$ & 3,29 & 1 & 1,15 & 3,29 & 3,79 & & \\
\hline & $\begin{array}{l}\text { Encaixar Fiação Verde } \\
\text { na Placa (GND) }\end{array}$ & 3,53 & 1 & 1,15 & 3,53 & 4,06 & & \\
\hline & $\begin{array}{l}\text { Encaixar Conector de } 2 \\
\text { Vias do Porta-Fusível } \\
\text { na Placa (CN4) }\end{array}$ & 3,56 & 1 & 1,15 & 3,56 & 4,1 & & \\
\hline & $\begin{array}{l}\text { Encaixar } 1 \text { Fiação } \\
\text { PR/BAT na Placa }\end{array}$ & 4,75 & 1 & 1,15 & 4,75 & 5,47 & & \\
\hline & $\begin{array}{l}\text { Colocar Kit Placa/ } \\
\text { Painel na Esteira }\end{array}$ & 2,54 & 1 & 1,15 & 2,54 & 2,92 & & \\
\hline \multirow{4}{*}{2} & $\begin{array}{l}\text { Pegar Gabinete na } \\
\text { Caixa, Posicionar } \\
\text { Gabinete LD na Esteira }\end{array}$ & 5,82 & 1 & 1,15 & 5,82 & 6,69 & \multirow{4}{*}{1} & \multirow{4}{*}{31,57} \\
\hline & $\begin{array}{l}\text { Pegar Trafo, } \\
\text { Desenrolar Fiação, } \\
\text { Colocar no Gabinete }\end{array}$ & 12,45 & 1 & 1,15 & 12,45 & 14,32 & & \\
\hline & $\begin{array}{l}\text { Encaixar } 1 \text { Fiação } \\
\text { VM/BAT na Placa }\end{array}$ & 4,94 & 1 & 1,15 & 4,94 & 5,68 & & \\
\hline & $\begin{array}{l}\text { Encaixar Fiação BR/TR } \\
\text { na Placa }\end{array}$ & 4,24 & 1 & 1,15 & 4,24 & 4,88 & & \\
\hline \multirow{5}{*}{3} & $\begin{array}{l}\text { Encaixar Fiação AZ/TR } \\
\text { na Placa }\end{array}$ & 3,44 & 1 & 1,15 & 3,44 & 3,95 & \multirow{5}{*}{1} & \multirow{5}{*}{27,8} \\
\hline & $\begin{array}{l}\text { Pegar Bateria e } \\
\text { Colocar na Esteira }\end{array}$ & 3,64 & 1 & 1,15 & 3,64 & 4,19 & & \\
\hline & $\begin{array}{l}\text { Encaixar Conector de } 6 \\
\text { vias na Placa (CN1) }\end{array}$ & 3,57 & 1 & 1,15 & 3,57 & 4,1 & & \\
\hline & $\begin{array}{l}\text { Encaixar Conector de } 2 \\
\text { vias na Placa (CN3) }\end{array}$ & 3,3 & 1 & 1,15 & 3,3 & 3,8 & & \\
\hline & $\begin{array}{l}\text { Encaixar Kit Placa/ } \\
\text { Painel no Gabinete LD }\end{array}$ & 10,22 & 1 & 1,15 & 10,22 & 11,75 & & \\
\hline \multirow{3}{*}{4} & $\begin{array}{l}\text { Conectar Fiação para } \\
\text { Teste }\end{array}$ & 8,36 & 1 & 1,15 & 8,36 & 9,61 & \multirow{3}{*}{1} & \multirow{3}{*}{39,24} \\
\hline & Tempo de Teste & 25,26 & 1 & 1,15 & 25,26 & 25,26 & & \\
\hline & Desconectar Fiação & 3,8 & 1 & 1,15 & 3,8 & 4,37 & & \\
\hline \multirow{2}{*}{5} & $\begin{array}{l}\text { Conectar Fiação na } \\
\text { Bateria }\end{array}$ & 20,13 & 1 & 1,15 & 20,13 & 23,14 & \multirow{2}{*}{1} & \multirow{2}{*}{33,69} \\
\hline & $\begin{array}{l}\text { Encaixar Tampa no } \\
\text { Equipamento }\end{array}$ & 9,17 & 1 & 1,15 & 9,17 & 10,54 & & \\
\hline
\end{tabular}


Tabela 7 - Descrição do processo anterior ao balanceamento (continuação)

\begin{tabular}{|c|c|c|c|c|c|c|c|c|}
\hline Posto & Descrição operação & $\operatorname{Tr}$ & $\begin{array}{c}E-90 \% a \\
110 \%\end{array}$ & $\mathrm{Ft}$ & Tn & $\mathrm{Tp}$ & $\begin{array}{l}\text { Mod por } \\
\text { posto }\end{array}$ & $\begin{array}{l}\text { Tempo de } \\
\text { operação }\end{array}$ \\
\hline \multirow[t]{2}{*}{6} & $\begin{array}{l}\text { Parafusar Tampa (5 } \\
\text { Parafusos) }\end{array}$ & 22,24 & 1 & 1,15 & 22,24 & 25,58 & \multirow[t]{2}{*}{1} & \multirow[t]{2}{*}{32,4} \\
\hline & Encaixar Aplique & 5,94 & 1 & 1,15 & 5,94 & 6,83 & & \\
\hline \multirow{7}{*}{7} & $\begin{array}{l}\text { Colocar Peças no } \\
\text { Burn-in }\end{array}$ & 6,2 & 1 & 1,15 & 6,2 & 7,13 & \multirow{7}{*}{1} & \multirow{7}{*}{31,86} \\
\hline & Acionar Burn-in & 1,55 & 1 & 1,15 & 1,55 & 1,79 & & \\
\hline & Ligar Peças & 1,3 & 1 & 1,15 & 1,3 & 1,5 & & \\
\hline & Tempo de Teste & 361,68 & 1 & 1,15 & 361,68 & 415,93 & & \\
\hline & $\begin{array}{l}\text { Retirar Peças do Burn- } \\
\text { in }\end{array}$ & 4,07 & 1 & 1,15 & 4,07 & 4,07 & & \\
\hline & $\begin{array}{l}\text { Colar Etiqueta de № de } \\
\text { Série no Aparelho }\end{array}$ & 3,53 & 1 & 1 & 3,53 & 3,53 & & \\
\hline & $\begin{array}{l}\text { Colocar Aparelho no } \\
\text { Saco Plástico }\end{array}$ & 12,05 & 1 & 1,15 & 12,05 & 13,86 & & \\
\hline \multirow{4}{*}{8} & $\begin{array}{l}\text { Colar Etiqueta de № de } \\
\text { Série na Caixa } \\
\text { Individual }\end{array}$ & 4,01 & 1 & 1,15 & 4,01 & 4,61 & \multirow{4}{*}{1} & \multirow{4}{*}{32,55} \\
\hline & Montar Caixa Individual & 9,39 & 1 & 1,15 & 9,39 & 10,79 & & \\
\hline & $\begin{array}{l}\text { Colocar Manual e } \\
\text { Aparelho na Caixa }\end{array}$ & 5,43 & 1 & 1,15 & 5,43 & 6,24 & & \\
\hline & Fechar Caixa Individual & 9,48 & 1 & 1,15 & 9,48 & 10,9 & & \\
\hline \multirow{5}{*}{9} & $\begin{array}{l}\text { Colocar } 2 \text { Aparelhos na } \\
\text { Caixa de Transporte }\end{array}$ & 15,32 & 1 & 1,15 & 15,32 & 17,62 & \multirow{5}{*}{1} & \multirow{4}{*}{33,14} \\
\hline & $\begin{array}{l}\text { Colar etiqueta de } n^{\circ} \text { de } \\
\text { série na caixa de } \\
\text { transporte }\end{array}$ & 4,93 & 1 & 1,15 & 4,93 & 5,67 & & \\
\hline & $\begin{array}{l}\text { Passa a Caixa de } \\
\text { Transporte pela } \\
\text { Embaladora }\end{array}$ & 3,64 & 1 & 1,15 & 3,64 & 4,19 & & \\
\hline & $\begin{array}{l}\text { Paletizar Caixa de } \\
\text { Transporte }\end{array}$ & 4,92 & 1 & 1,15 & 4,92 & 5,66 & & \\
\hline & & & & & & & & \\
\hline
\end{tabular}

Tabela 8 - Eficiência do processo anterior

\begin{tabular}{|c|c|c|c|}
\hline \multicolumn{1}{|c}{ Posto } & $\begin{array}{c}\text { Tempo de } \\
\text { Operação }\end{array}$ & Eficiência (E) \\
\hline Posto 01 A & 30,56 & 40,00 & $76 \%$ \\
\hline Posto 01 B & 30,56 & 40,00 & $76 \%$ \\
\hline Posto 02 & 31,57 & 40,00 & $79 \%$ \\
\hline Posto 03 & 27,80 & 40,00 & $69 \%$ \\
\hline Posto 04 & 39,24 & 40,00 & $88 \%$ \\
\hline Posto 05 & 33,69 & 40,00 & $81 \%$ \\
\hline Posto 06 & 32,40 & 40,00 & $80 \%$ \\
\hline Posto 07 & 31,86 & 40,00 & $81 \%$ \\
\hline Posto 08 & 32,55 & 40,00 & $83 \%$ \\
\hline Posto 09 & 33,14 & 40,00 & $81 \%$ \\
\hline TOTAL & 323,36 & 400,00 & P. \\
\hline
\end{tabular}

Com base na análise dos tempos apresentados no Gráfico 1e Tabela 3, foi possível constatar ociosidade na execução das operações do Posto $01 \mathrm{~A}$ ao Posto 03. Partindo dessa observação e objetivando equilibrar essas atividades foram realizadas as seguintes modificações: a) Operações do Posto 01 transferidas para o Posto 02:

- Encaixar Fiação Verde na Placa (GND)

- Encaixar Conector de 2 Vias do PortaFusível na Placa (CN4)

- Colocar Kit Placa/ Painel na Esteira 
b) Operação do Posto 01 transferida para o Posto 03:

- Encaixar 1 Fiação PR/BAT na Placa

c) Operação do Posto 02 transferida para o Posto 03:

- Encaixar Fiação BR/TR na Placa
Assim o tempo das operações ficou mais balanceado, possibilitando a redução de uma mão de obra. As demais tarefas continuaram a ser executadas nos mesmos postos. A operação 'Pegar Placa e Quebrar a Borda' do Posto 01 foi transferida para o fornecedor, logo o tempo respectivo a este posto diminuiu significativamente, pois a atividade incluía um tempo real de 8,49 s e tempo padrão de 9,76s

Gráfico 1- Balanceamento do processo anterior

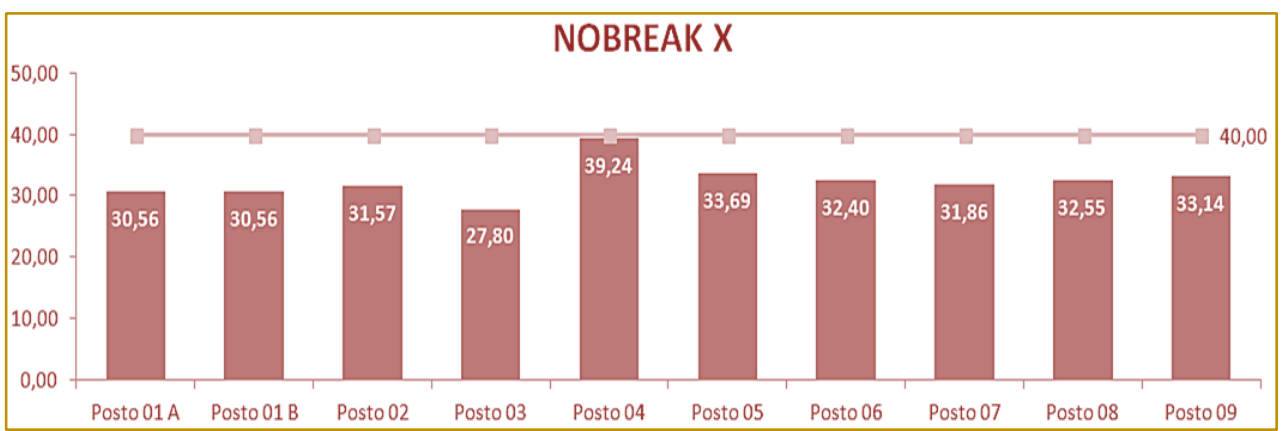

Tabela 3 - Capacidade produtiva

\begin{tabular}{|l|c|}
\hline Capacidade produtiva por hora & 83 \\
\hline Capacidade produtiva por dia & 673 \\
\hline Mão de obra necessária (MOD) & 10 \\
\hline Quantidade de postos & 09 \\
\hline Tempo de ciclo & 40 s \\
\hline
\end{tabular}

\subsection{BALANCEAMENTO ATUAL}

Após a redistribuição das operações ociosas, a nova formação consiste no seguinte modelo, conforme Tabela 4.

Tabela 4 - Descrição do processo posterior ao balanceamento

\begin{tabular}{|c|c|c|c|c|c|c|c|c|}
\hline Posto & Descrição operação & $\operatorname{Tr}$ & $\begin{array}{c}E- \\
90 \% a \\
110 \%\end{array}$ & $\mathrm{Ft}$ & Tn & $\mathrm{Tp}$ & $\begin{array}{c}\text { Mod } \\
\text { por } \\
\text { posto }\end{array}$ & $\begin{array}{l}\text { Tempo de } \\
\text { operação }\end{array}$ \\
\hline \multirow{6}{*}{1} & $\begin{array}{l}\text { Pegar Painel Traseiro e Encaixar no } \\
\text { Mocaf }\end{array}$ & 5,74 & 1,00 & 1,15 & 5,74 & 6,60 & \multirow{6}{*}{1} & \multirow{6}{*}{34,81} \\
\hline & Pegar Placa e Quebrar a Borda & & & & & & & \\
\hline & Encaixar Placa no Mocaf & 3,43 & 1,00 & 1,15 & 3,43 & 3,95 & & \\
\hline & Parafusar Placa no Painel & 5,24 & 1,00 & 1,15 & 5,24 & 6,03 & & \\
\hline & $\begin{array}{l}\text { Soldar } 3 \text { Barras de Saída do Painel } \\
\text { na Placa }\end{array}$ & 12,57 & 1,00 & 1,15 & 12,57 & 14,45 & & \\
\hline & $\begin{array}{l}\text { Encaixar Conector do Cooler na } \\
\text { Placa (CN2) }\end{array}$ & 3,29 & 1,00 & 1,15 & 3,29 & 3,79 & & \\
\hline \multirow{6}{*}{2} & $\begin{array}{l}\text { Encaixar Fiação Verde na Placa } \\
\text { (GND) }\end{array}$ & 3,53 & 1,00 & 1,15 & 3,53 & 4,06 & \multirow{6}{*}{1} & \multirow{6}{*}{37,55} \\
\hline & $\begin{array}{l}\text { Encaixar Conector de } 2 \text { Vias do } \\
\text { Porta-Fusível na Placa (CN4) }\end{array}$ & 3,56 & 1,00 & 1,15 & 3,56 & 4,10 & & \\
\hline & Encaixar 1 Fiação VM/BAT na Placa & 4,75 & 1,00 & 1,15 & 4,75 & 5,47 & & \\
\hline & Colocar Kit Placa/ Painel na Esteira & 2,54 & 1,00 & 1,15 & 2,54 & 2,92 & & \\
\hline & $\begin{array}{l}\text { Pegar Gabinete na Caixa, } \\
\text { Posicionar Gabinete LD na Esteira }\end{array}$ & 5,82 & 1,00 & 1,15 & 5,82 & 6,69 & & \\
\hline & $\begin{array}{l}\text { Pegar Trafo, Desenrolar Fiação, } \\
\text { Colocar no Gabinete }\end{array}$ & 12,45 & 1,00 & 1,15 & 12,45 & 14,32 & & \\
\hline
\end{tabular}


Tabela 4 - Descrição do processo posterior ao balanceamento (continuação...)

\begin{tabular}{|c|c|c|c|c|c|c|c|c|}
\hline Posto & Descrição operação & $\operatorname{Tr}$ & $\begin{array}{c}E- \\
90 \% \text { a } \\
110 \%\end{array}$ & $\mathrm{Ft}$ & Tn & $T p$ & $\begin{array}{l}\text { Mod } \\
\text { por } \\
\text { posto }\end{array}$ & $\begin{array}{l}\text { Tempo de } \\
\text { operação }\end{array}$ \\
\hline \multirow{7}{*}{3} & Encaixar 1 Fiação PR/BAT na Placa & 4,94 & 1,00 & 1,15 & 4,94 & 5,68 & \multirow{7}{*}{1} & \multirow{7}{*}{38,35} \\
\hline & Encaixar Fiação BR/TR na Placa & 4,24 & 1,00 & 1,15 & 4,24 & 4,88 & & \\
\hline & Encaixar Fiação AZ/TR na Placa & 3,44 & 1,00 & 1,15 & 3,44 & 3,95 & & \\
\hline & Pegar Bateria e Colocar na Esteira & 3,64 & 1,00 & 1,15 & 3,64 & 4,19 & & \\
\hline & $\begin{array}{l}\text { Encaixar Conector de } 6 \text { vias na } \\
\text { Placa (CN1) }\end{array}$ & 3,57 & 1,00 & 1,15 & 3,57 & 4,10 & & \\
\hline & $\begin{array}{l}\text { Encaixar Conector de } 2 \text { vias na } \\
\text { Placa (CN3) }\end{array}$ & 3,30 & 1,00 & 1,15 & 3,30 & 3,80 & & \\
\hline & $\begin{array}{l}\text { Encaixar Kit Placa/ Painel no } \\
\text { Gabinete LD }\end{array}$ & 10,22 & 1,00 & 1,15 & 10,22 & 11,75 & & \\
\hline \multirow{3}{*}{4} & Conectar Fiação para Teste & 8,36 & 1,00 & 1,15 & 8,36 & 9,61 & \multirow{3}{*}{1} & \multirow{3}{*}{39,24} \\
\hline & Tempo de Teste & 25,26 & 1,00 & & 25,26 & 25,26 & & \\
\hline & Desconectar Fiação & 3,80 & 1,00 & 1,15 & 3,80 & 4,37 & & \\
\hline \multirow{2}{*}{5} & Conectar Fiação na Bateria & 20,13 & 1,00 & 1,15 & 20,13 & 23,14 & \multirow{2}{*}{1} & \multirow{2}{*}{33,69} \\
\hline & Encaixar Tampa no Equipamento & 9,17 & 1,00 & 1,15 & 9,17 & 10,54 & & \\
\hline \multirow{2}{*}{6} & Parafusar Tampa (5 Parafusos) & 22,24 & 1,00 & 1,15 & 22,24 & 25,58 & \multirow[b]{2}{*}{1} & \multirow{2}{*}{32,40} \\
\hline & Encaixar Aplique & 5,94 & 1,00 & 1,15 & 5,94 & 6,83 & & \\
\hline \multirow{7}{*}{7} & Colocar Peças no Burn-in & 6,20 & 1,00 & 1,15 & 6,20 & 7,13 & \multirow{7}{*}{1} & \multirow{7}{*}{32,39} \\
\hline & Acionar Burn-in & 1,55 & 1,00 & 1,15 & 1,55 & 1,79 & & \\
\hline & Ligar Peças & 1,30 & 1,00 & 1,15 & 1,30 & 1,50 & & \\
\hline & Tempo de Teste & 361,68 & 1,00 & & 361,68 & $\begin{array}{c}361,6 \\
8\end{array}$ & & \\
\hline & Retirar Peças do Burn-in & 4,07 & 1,00 & 1,00 & 4,07 & 4,07 & & \\
\hline & $\begin{array}{l}\text { Colar Etiqueta de № de Série no } \\
\text { Aparelho }\end{array}$ & 3,53 & 1,00 & 1,15 & 3,53 & 4,06 & & \\
\hline & Colocar Aparelho no Saco Plástico & 12,05 & 1,00 & 1,15 & 12,05 & 13,86 & & \\
\hline \multirow{4}{*}{8} & $\begin{array}{l}\text { Colar Etiqueta de № de Série na } \\
\text { Caixa Individual }\end{array}$ & 4,01 & 1,00 & 1,15 & 4,01 & 4,61 & \multirow{4}{*}{1} & \multirow{4}{*}{32,55} \\
\hline & Montar Caixa Individual & 9,39 & 1,00 & 1,15 & 9,39 & 10,79 & & \\
\hline & $\begin{array}{l}\text { Colocar Manual e Aparelho na } \\
\text { Caixa }\end{array}$ & 5,43 & 1,00 & 1,15 & 5,43 & 6,24 & & \\
\hline & Fechar Caixa Individual & 9,48 & 1,00 & 1,15 & 9,48 & 10,90 & & \\
\hline \multirow{4}{*}{9} & $\begin{array}{l}\text { Colocar } 2 \text { Aparelhos na Caixa de } \\
\text { Transporte }\end{array}$ & 15,32 & 1,00 & 1,15 & 15,32 & 17,62 & \multirow{4}{*}{1} & \multirow{4}{*}{33,14} \\
\hline & $\begin{array}{l}\text { Colar etiqueta de } n^{\circ} \text { de série na } \\
\text { caixa de transporte }\end{array}$ & 4,93 & 1,00 & 1,15 & 4,93 & 5,67 & & \\
\hline & $\begin{array}{l}\text { Passa a Caixa de Transporte pela } \\
\text { Embaladora }\end{array}$ & 3,64 & 1,00 & 1,15 & 3,64 & 4,19 & & \\
\hline & Paletizar Caixa de Transporte & 4,92 & 1,00 & 1,15 & 4,92 & 5,66 & & \\
\hline
\end{tabular}

A formação atual teve eficiência de utilização de mão de obra melhorada de $81 \%$ para $87 \%$, como mostra a Tabelas 5, por causa do balanceamento das operações do processo, visualizado no Gráfico 2. 
Tabela 5 - Eficiência do processo atual

\begin{tabular}{|c|c|c|c|}
\hline \multicolumn{1}{|c|}{ Posto } & $\begin{array}{c}\text { Tempo de } \\
\text { Operação }\end{array}$ & $\begin{array}{c}\text { Tempo de } \\
\text { Ciclo }\end{array}$ & Eficiência (E) \\
\hline Posto 01 & 34,81 & 40,00 & $87 \%$ \\
\hline Posto 02 & 37,55 & 40,00 & $94 \%$ \\
\hline Posto 03 & 38,35 & 40,00 & $96 \%$ \\
\hline Posto 04 & 39,24 & 40,00 & $98 \%$ \\
\hline Posto 05 & 33,69 & 40,00 & $84 \%$ \\
\hline Posto 06 & 32,40 & 40,00 & $81 \%$ \\
\hline Posto 07 & 32,39 & 40,00 & $81 \%$ \\
\hline Posto 08 & 32,55 & 40,00 & $83 \%$ \\
\hline Posto 09 & 33,14 & 40,00 & $87 \%$ \\
\hline TOTAL & 314,13 & 360,00 & \\
\hline
\end{tabular}

Gráfico 2 - Balanceamento do processo atual

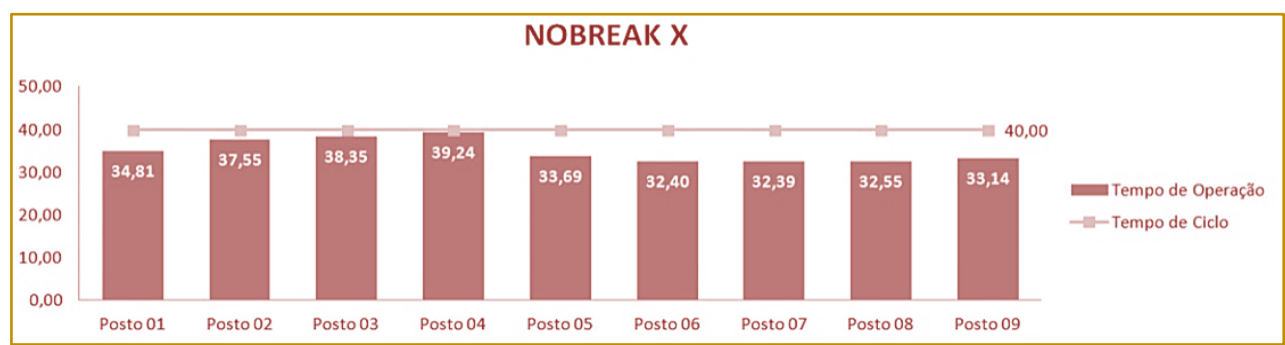

Tabela 6 - Capacidade produtiva

\begin{tabular}{|l|l|}
\hline Capacidade produtiva por hora & 83 \\
\hline Capacidade produtiva por dia & 673 \\
\hline Mão de obra necessária (MOD) & 09 \\
\hline Quantidade de postos & 09 \\
\hline Tempo de ciclo & 40 s \\
\hline
\end{tabular}

A Tabela 6 mostra a capacidade produtiva atual com a mão de obra necessária (MOD) reduzida em 1, mas aumentando a sua eficiência no processo.

\section{CONCLUSÃO}

Com base no estudo de tempos e métodos, e da ferramenta cronoanálise, o artigo objetiva verificar o tempo de realização de tarefas e a partir da análise desse dado, realizar um balanceamento de linha para redistribuir as atividades de modo a ficarem equilibradas,

\section{REFERÊNCIAS}

[1] Dembogurski, Renan Augusto.; Oliveira, Márcio.; Neumann, Clóvis. Balanceamento de Linha de Produção. XXVIII Encontro Nacional de Engenharia de Produção: A integração de cadeias produtivas com a abordagem da manufatura sustentável. Rio de Janeiro, 2008. Disponível em: < http://www.abepro.org.br/biblioteca/enegep2008_tn visando aumentar a produtividade e eficiência por meio da diminuição de movimentos desnecessários, otimização de materiais e esforços.

Após analisar os dados obtidos no estudo, concluiu-se que as atividades dos postos $01 \mathrm{a}$ 03 apresentavam ociosidade, o que diminuía a eficiência da mão de obra. Com o balanceamento de linha foi possível deixar as operações desses postos balanceadas, reduzir uma mão de obra, e aumentar a eficiência de $81 \%$ para $87 \%$.

_sto_069_490_11644.pdf>. Último acesso em: 24 de abril de 2016 .

[2] Diniz, Nayara Oliveira Sudario; Calife, Naiara FaiadSebba. Cronoanálise e Balanceamento de Linha de Montagem: Estudo de Caso em uma Montadora de Veículos. XXXV Encontro Nacional de Engenharia de Produção: 
Perspectivas Globais para a Engenharia de Produção. Fortaleza, p.3, 2015.

[3] Gaither, Norman; Frazier, Greg. Administração da Produção e Operações. Tradução de José Carlos

[4] Barbosa dos Santos. 8. ed. São Paulo: Pioneira Thomson Learning, 2001.

[5] Martins, Petrônio G.; Laugeni, Fernando Piero. Administração da Produção. 2. ed. rev., aum. e atual. São Paulo: Saraiva, p. 83-134, 2005.

[6] Mayer, Raymond R. Administração da produção. 1. ed. São Paulo: Atlas, 1984.

[7] Maynard, H. B. Manual de Engenharia de Produção: Técnicas de Medida do Trabalho. 1. ed. São Paulo:Edgard Blücher, 1970.

[8] Moreira, Daniel Augusto. Administração da produção e operação. 2. ed. ver. e ampl. São Paulo: Cengage Learning, 2013.
[9] Oliveira, Fabiola Negreiros de; Queiroz, Valeria Thalita de Medeiros.; Teixeira, Carla Simone de Lima., Ramos, Debora Saraiva., Gama, Ana Beatriz Camara Silva. Balanceamento de linha de produção: um estudo de caso em uma indústria naval; XXXII Encontro Nacional de Engenharia de Produção: Desenvolvimento Sustentável e Responsabilidade Social: As Contribuições da Engenharia de Produção. Bento Gonçalves, 2012. Disponível em: <http://www.abepro.org.br/biblioteca/enegep2012_ TN_STO_157_914_20754.pdf>. Último acesso em: 24 de abril de 2016.

[10] Slack, N.; Chambers, S. \& Johnston, R. Administração da produção. São Paulo: Atlas, 2009 


\section{GAPÍTULO 7}

\section{LOGISTICA REVERSA DE CANETA PILOTO: DIAGNÓSTICO EM UMA INSTITUIÇÃO DE ENSINO SUPERIOR NO SUL DA BAHIA.}

\section{Jacqueline Silva de Jesus}

\section{Aline Santana dos Santos}

\section{Celso Carlino Maria Fornari Junior}

Resumo: $O$ presente artigo apresenta o diagnóstico preliminar quantitativo de canetas pilotos, também conhecidas como marcadores para quadro branco, utilizadas por professores em uma instituição pública de ensino superior no Sul da Bahia. Com vista à implantação de um sistema de logística reversa. O produto em questão é de difícil decomposição por apresentar em sua composição resina termoplástica e, relevante grau de inflamabilidade, caracterizando-se como um resíduo inadequado para a disposição em aterro sanitário. Como resultado obtevese um total de 64.465 pilotos utilizados por professores entre 2012 e 2016, pode-se notar uma média de 12.893 pilotos por ano. A observância do volume de resíduo gerado em cinco anos, algo em torno de 1,29 toneladas, destinados ao aterro sanitário da região, ou seja, sem a observância das ações pós-consumo do material, aponta para a necessidade de destinação adequada dos resíduos, tais como: reciclagem e/ou reutilização de parte do material.

Palavras-chave: Logística Reversa, Resíduo Sólido, Caneta Piloto 


\section{INTRODUÇÃO}

Algumas características atuais de gestão dos resíduos sólidos no Brasil são similares às utilizadas na sociedade medieval, e continua descartando resíduos em aterros, ao invés de solucionar o problema do uso irracional de recursos. Ao longo do tempo a questão se agravou com a diversidade de resíduos produzidos nas atividades humanas, a exemplo dos resíduos passíveis de logística reversa, como pneus, pilhas e baterias, eletrônicos e outros.

As políticas de resíduos sólidos nacional em sua maioria, baseiam-se no paradigma da valorização dos resíduos como fonte de renda, de energia e de matéria prima. Tal paradigma parte da premissa que a promoção da sustentabilidade se dará pela maximização da retenção dos recursos naturais em uso na economia humana, e pelo adequado tratamento e valorização dos resíduos antes de serem devolvidos ao ambiente (ROSA, 2009).

Assim, concentrar esforços somente na disposição final dos resíduos e negligenciar atenção à geração do mesmo, é analisar apenas uma parte do sistema. As etapas do gerenciamento, por exemplo, são comumente consideradas de formas independentes, embora todas estejam interligadas e influenciadas pelas outras (SEADON, 2010).

Uma novidade apresentada pela Lei $n^{\circ}$ 12.305/2010 no âmbito legislativo de Gestão Integrada de Resíduos Sólidos é a introdução da logística reversa como ferramenta de desenvolvimento econômico e social, e a responsabilidade compartilhada, o que possibilita convocar a sociedade para participação no processo, bem como delegar competências individuais de interesse coletivo.

O paradigma atual na Gestão de Resíduos Solidos é a gestão integrada, que substitui as intervenções técnicas de engenharia que visavam à implantação de aterros sanitários como principal solução, por um conceito que se esforça para encontrar um equilíbrio na gestão, que seja ambientalmente eficaz, socialmente aceitável e economicamente viável (MARSHALL, FARAHBAKHSH, 2013).

O presente estudo tem por objetivo apresenta o diagnóstico preliminar quantitativo de canetas pilotos de canetas do tipo piloto para quadro branco utilizada por professores em uma instituição pública de ensino superior. Este estudo envolve o comportamento dos profissionais na área, as condições políticas da instituição de ensino e a situação física e material para a implantação futura de um projeto piloto de logistica reversa desse material. Estes itens são relevantes e impactantes na organização do processo logístico dassas canetas.

\section{REFERENCIAL TEÓRICO}

\subsection{RESÍDUO SÓLIDO}

A Política Nacional de Resíduos Sólidos (PNRS) conhecida como Lei № 12.305/2010 define Resíduo Sólido assim:

Resíduos sólidos: material, substância, objeto ou bem descartado resultante de atividades humanas em sociedade, a cuja destinação final se procede, se propõe proceder ou se está obrigado a proceder, nos estados sólido ou semissólido, bem como gases contidos em recipientes e líquidos cujas particularidades tornem inviável o seu lançamento na rede pública de esgotos ou em corpos d'água, ou exijam para isso soluções técnica ou economicamente inviáveis em face da melhor tecnologia disponível;

Segundo MONTEIRO (2013) a PNRS foi essencial no contexto histórico da gestão ambiental no Brasil, pois aproximou vários conceitos do cotidiano, tais como: geração de resíduo, destinação final e tratamento adequados dos resíduos sólidos em relação ao meio ambiente, redução de insumos no processo produtivo, ações que aumentem a educação ambiental e a reciclagem no país, não-geração, reutilização e reciclagem, entre outros. A figura 1 apresenta ordem de prioridades que deve ser observada na gestão de rejeitos sólidos. 
Figura 1 - Paradigma atual da gestão de resíduos sólidos urbanos.

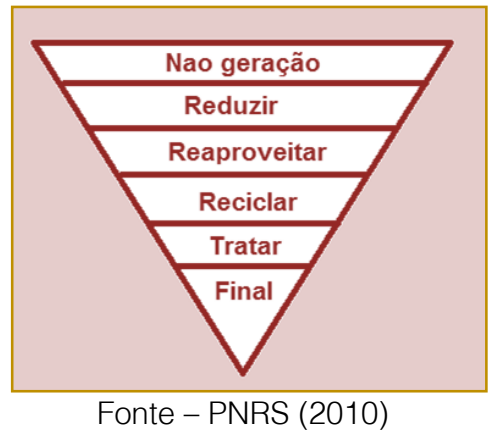

Para MAZETO e ABREU (2014) a Lei № $12.305 / 2010$ possui três aspectos importantes, que são: a delegação da responsabilidade dos rejeitos gerados, sendo esta considerado compartilhada na logística reversa de resíduos, proporcionar a inclusão dos catadores de produtos recicláveis no sistema de coleta seletiva e logística reversa, além de viabilizar a confecção do plano de gestão de resíduo, a partir de materiais dentro do ambiente municipal, estadual, regional e nacional.

\subsection{LOGISTICA REVERSA}

A logística reversa é definida por LEITE (2009) como sendo um ramo da logística empresarial capaz de assegurar o retorno de produtos e materiais ao ciclo produtivo através do planejamento, operações e controle do fluxo e informações. Engloba todas as atividades logísticas que vão desde a coleta, passando pelo desmanche e processamento de produtos utilizados com o interesse em uma restauração sustentável. Assim agregando valor ecológico, econômico, logístico, dentre outros e melhoria na imagem corporativa da empresa. Em suma, a logística reversa busca viabilizar o retorno dos materiais integrantes ou bens de consumo ao ciclo produtivo ou de negócios.

Em contrapartida, Larcerda (2002) define a logística reversa não como um campo da logística empresarial e sim um processo que integra à logística tradicional. Pois a ultima preocupa-se apenas em assegurar que 0 produto chegue aos clientes intermediários ou finais, já a logística reversa abrange todo o ciclo, preocupando-se também com o retorno dos produtos já usados ao ciclo produtivo.

Ao relacionar a logística reversa com a tradicional, Fernandes (2012), define a primeira como sendo uma recente esfera da logística empresarial que possui como principal função operacionalizar e administrar o retorno dos bens de pós-consumo e pósvenda ao ponto inicial do processo produtivo através de diferentes fluxos reversos, consequentemente agregando valor ecológico, econômico e legal. Em resumo, se a logística é uma ferramenta que se preocupa com a chegada do produto ao cliente, a logística reversa se apresenta como uma ferramenta para gerenciar fluxos reversos, como pode-se perceber na figura 2 abaixo.

Figura 2: Processo Logístico Reverso

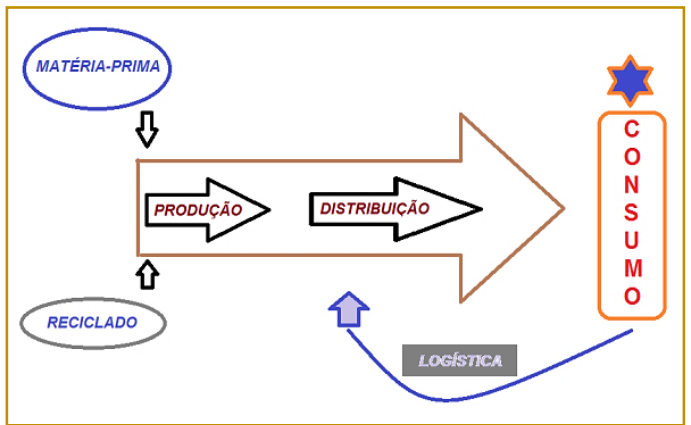

Fonte: Adaptado pelos autores de LACERDA (2002) 
Segundo Gonçalves \& Marins (2006) primeiramente é importante resaltar três aspectos relacionados a produtos e materiais e suas respectivas embalagens, para só depois definir logística reversa. São esses:

Do ponto de vista logístico, o ciclo de vida se prolonga ao recebimento do produto pelo cliente. Os produtos devem voltar ao seu ponto de origem quando se tornam deteriorados, obsoletos ou não funcionam para receberem o tratamento correto, podendo ser destinado ao descarte adequado ou a reutilização voltar ao ciclo após serem reparados;

Do ponto de vista financeiro, o fluxo reverso possui um custo adicional é incluso aos custos de transporte, aquisição de matéria prima, armazenamento e de produção, sendo levando em consideração na logística; e

Do ponto de vista ambiental, em um processo produtivo é necessário considerar e mensurar os impactos ao meio ambiente. Assim, é possível o planejamento da rede logística contempla todas as fases do ciclo do produto.

Assim, após as análises anteriores Gonçalves \& Marins (2006) definem a logística reversa como um processo que vai desde o planejamento do produto, passando pela realização e controle do fluxo de matéria prima até o produto acabado, do cliente até o ponto de origem, agregando valor ou dando um destino adequado ecologicamente.

Atualmente existe um decreto que apresenta o conceito recente de logística reversa. Este define logística reversa como sendo um "instrumento de desenvolvimento econômico e social caracterizado pelo conjunto de ações, procedimentos e meios destinados a viabilizar a coleta e a restituição dos resíduos sólidos ao setor empresarial, para reaproveitamento, em seu ciclo ou em outros ciclos produtivos." (Decreto № 7.404 de 23 de dezembro de 2010).

Portanto, a Logística Reversa é um processo que busca ampliar a responsabilidade empresarial com o meio ambiente, fazendo com que este se atenha não somente a produção do produto (Logística Tradicional), mas levando em conta todo o processo, desde a criação até o descarte final (Logística Reversa).

\subsubsection{TIPOS DE FLUXOS}

Para uma melhor compreensão da logistica reversa é importante entender como funciona o fluxo nas operações, pois este representa a facilidade com que uma informação, produto e material desenvolvem-se. Assim FERNANDES (2012) apresenta os dois tipos de fluxos o Direto e o Reverso:

Fluxo direto: o fluxo direto é realizado através do gerenciamento logístico, estes fluxos são caracterizados como percurso contínuo, onde um produto chega a alguém ou local, ou seja, é o movimento do produtor para o consumidor.

Fluxo reverso: já o fluxo reverso é o que se caracteriza pela direção oposta ao direto, ou seja é movimento contínuo de um determinado produto da parte do consumidor final para a origem (produtor) ou qualquer componente da cadeia, ou por algum problema e especificidades do desenvolvimento do produto.

\subsubsection{PRODUTOS DE PÓS-VENDA E PÓS- CONSUMO}

Segundo LEITE (2009, p. 18-19) a logística reversa possui duas grandes áreas de atuação a logística de pós-venda e de pósconsumo, é válido resaltar que embora estas sejam tratadas interdependentemente pelas demais literaturas, apontam diferenças em relação ao estágio e em qual fase o produto retornado se encontra com relação a vida útil. O esquema abaixo (Figura 3) apresenta resumidamente "o campo de atuação da logística reversa por meio das principais etapas dos fluxos reversos, nas duas áreas de atuação citadas, observando-se sua interdependência." 
Figura 3: Principais etapas dos fluxos reversos.

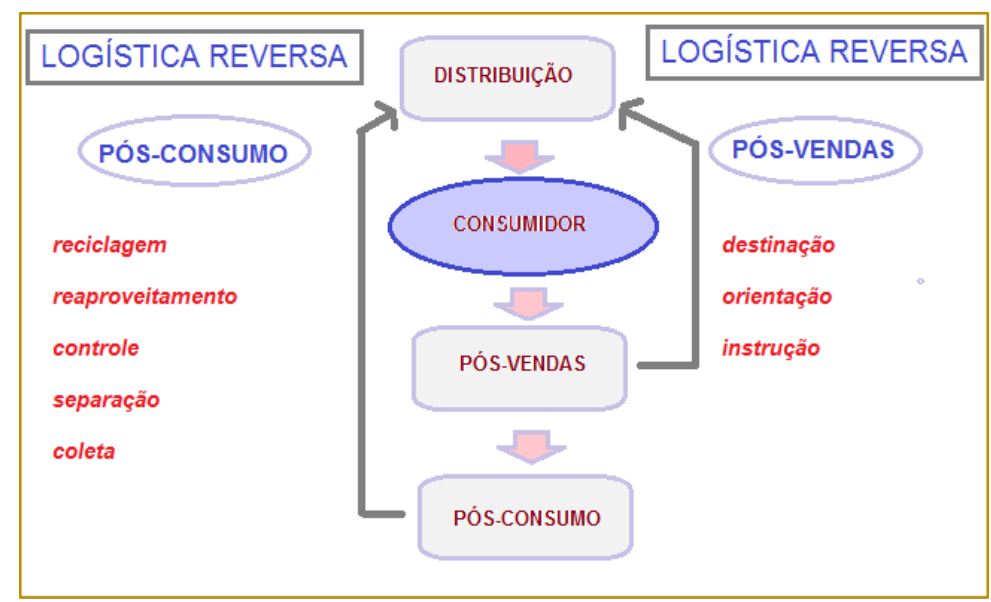

Fonte: Adaptado pelos autores de Leite (2009)

\subsection{INFORMAÇÕES TÉCNICAS - CANETAS PILOTO}

Muitas instituições de ensino têm feito uso de quadros branco, sendo assim, faz-se necessário o uso de canetas adequadas. Estas são rapidamente descartados devido ao uso intenso, ao pequeno volume de tinta que possuem e por não possuírem tinta refil, gerando gastos desnecessários, transtornos aos professores e não menos importante produzindo um resíduo pouco reciclável (SANTOS et al 2013).

Tais produtos são compostos por resinas termoplásticas, tinta à base de álcool, pigmentos, resinas, solventes e ponta de acrílico. Fabricados e comercializados em quatro cores: preto, azul, vermelho e verde (PILOT, 2016). Assim, são dois tipos de insumos (plástico e tinta) que descartados de forma inadequada podem trazer prejuízos sociais e ambientais.

A resina termoplástica são materiais fabricados a partir de insumos de origem natural não renovável, como o petróleo, por exemplo. Isso faz com que os impactos causados por esse produto estejam instalados nas extremidades de sua cadeia produtiva, pois provoca a exaustão da matéria-prima e grande aglomeração de resíduos de difícil decomposição (ZANIN e MANCINI, 2004). O tempo de decomposição desse tipo de material na natureza pode durar mais de 100 anos, podendo variar conforme as condições ambientais (COELHO, 2008).

Além dos danos causados pelo plástico, as canetas piloto contêm líquidos inflamáveis na composição de suas tintas. Logo, no seu estado sólido os pincéis não provocam detrimento à saúde do consumidor, todavia em sua deterioração a partir de queimadas descontroladas pode ser extremamente perigoso, pois libera o gás monóxido de carbono, o dióxido de carbono e outros hidrocarbonetos considerados tóxicos (PILOT, 2016).

Portanto, a reciclagem tem uma função ainda mais relevante, tendo em vista, que está busca reduzir os impactos ambientais causados por produtos de pós-consumo fabricados a partir destes materiais termoplásticos (ZANIN e MANCINI, 2004).

\section{METODOLOGIA}

Este estudo tem um caráter quantitativo e dividi-se em três etapas: (1) fase exploratória; (2) fase observacional e (3) análise e tratamento dos dados.

A fase exploratória envolveu a revisão bibliográfica em bases institucionais da unidade de ensino superior, principalmente na documentação acadêmica disponível no site da instituição sobre os aspectos referentes a instituição pública de ensino superior no sul da Bahia, como aspectos financeiro, social, cultural e ambiental e setores de almoxarifado e departamentos.

A instituição oferece 33 cursos de graduação presencial e conta com um quadro de 783 professores e um número de 12543 alunos matriculados (Relatório Anual, 2015). Com isso, a escolha do campo de estudo levou em 
consideração a quantidade de caneta do tipo piloto utilizada na atividade de docente e, consequentemente os resíduos gerados por tal atividade.

$\mathrm{Na}$ fase observacional, foram feitas investigações de campo nos setores responsáveis pela compra e distribuição das canetas piloto para os docentes, bem como nos locais de acondicionamento temporário pós-consumo.

Para tratamento dos dados quantitativo utilizou-se o programa Excel com os dados de 2012 a 2016, a fim de diagnosticar aspectos do consumo de caneta piloto por parte do corpo docente da instituição.

\section{RESULTADOS E DISCUSSÃO}

Com o intuito de investigar a existência na instituição de um sistema de logística reversa e, conhecer o fluxo logístico das canetas, foi realizado uma visita ao departamento de ciências exatas. Foi identificado que os professores precisam se dirigir ao seu departamento específico para adquirir a quantidade desejada de canetas. Após a utilização, os professores descartam os resíduos em lixeiras e papeleiras juntamente com outros resíduos sólidos da instituição, conforme mostra figura 4, e estes são encaminhados por meio da coleta pública para o aterro sanitário As canetas são distribuídas por departamentos, que solicitam através de pedido formal via sistema eletrônico ao almoxarifado, setor responsável por fazer o controle e compra da quantidade necessária de canetas pilotos que será utilizados por ano.

Figura 4: Descarte dos marcadores para quadro branco

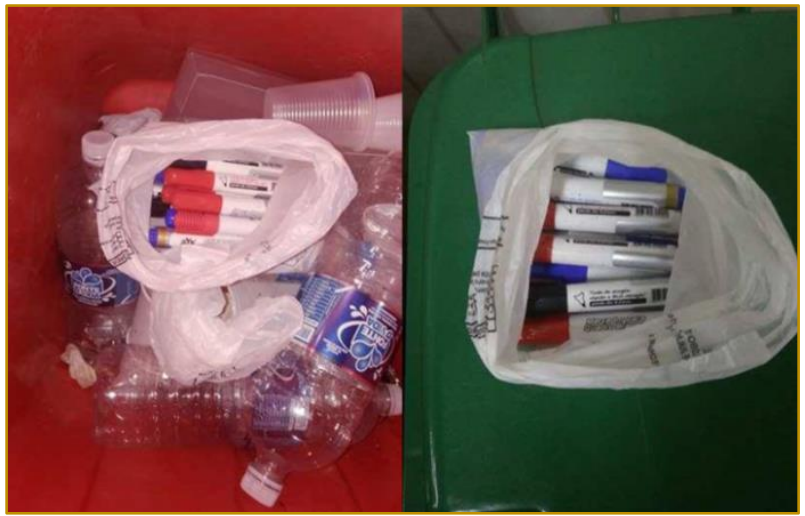

Fonte: Produzido pelos autores.

A figura 5 apresenta o fluxo logístico dos instrumentos de escrita estudado, desde a fabricação até o descarte final, ou seja, após o consumo os resíduos são encaminhados para a disposição final no aterro sanitário. Assim, a Logística Reversa não acontece, apenas a tradicional.

Figura 5: Fluxo logístico das canetas piloto.

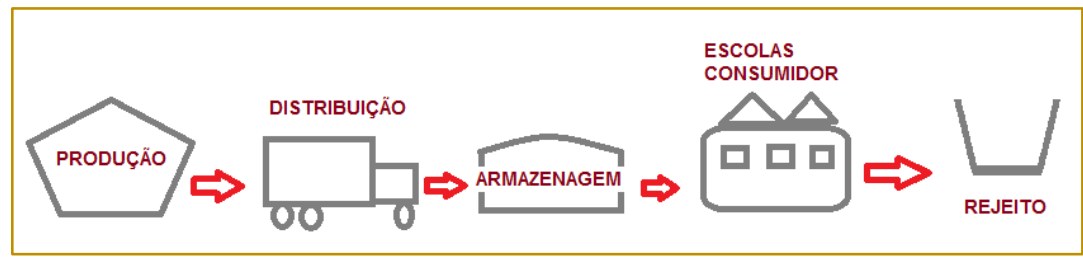

Fonte: Produzido pelos autores.

A figura 6 apontando a quantidade de caneta piloto consumida por ano. Em cada ano tem- se a quantidade por cor utilizada, sendo estas, azul, preto, verde e vermelho. 
Figura 6: Consumo de marcadores por ano e cor (unidade).

\begin{tabular}{|c|c|c|c|c|c|}
\hline Ano/Cor & Azul & Preto & Verde & Vermelho & Total \\
\hline 2012 & 10.325 & 13.644 & 1.971 & 4.401 & 30.341 \\
\hline 2013 & 4.139 & - & 1.049 & - & 5.188 \\
\hline 2014 & 8.311 & 2.730 & 1.057 & 2.730 & 14.828 \\
\hline 2015 & 3.254 & 369 & 1.224 & 175 & 5.022 \\
\hline 2016 & 3.130 & 3.893 & 170 & 1.893 & 9.086 \\
\hline Total & & & & & 64.465 \\
\hline
\end{tabular}

Fonte: Almoxarifado da instituição

Assim, considerando o total de 64.465 pilotos utilizados, em cinco anos, pode-se notar uma média de 12.893 pilotos por ano. Vale ressaltar, que em 2013 não houve pedidos de pilotos nas cores preto e vermelho. Entretanto, não quer dizer que não houve consumo, pois os pedidos são realizados conforme a necessidade, dessa forma é possível que os pilotos nas referidas cores mantiveram-se armazenados no estoque do departamento.
Com o auxílio da figura 7 que mostra a demanda total de cada cor de piloto ao longo de cinco anos, mostrando que o piloto na cor azul e o preto são os mais utilizados pelos professores, das quatro cores disponíveis, tendo um consumo de $45,23 \%$ e $32.27 \%$ respectivamente.

Figura 7: Consumo total de marcadores por cor e porcentagem (2012-2016).

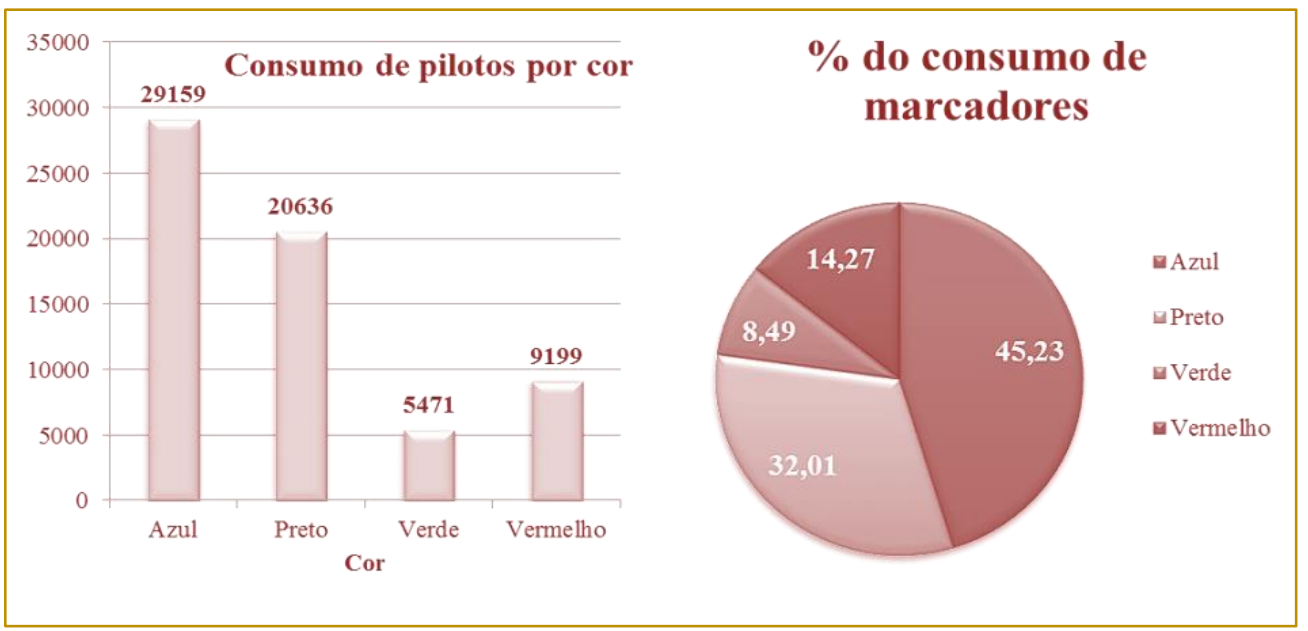

Fonte: Almoxarifado da instituição

Sabe-se que um piloto simples pesa em torno de 20 gramas (PILOT, 2016), ou seja, em cinco anos, tal instituição gerou um volume de aproximadamente 1290 quilogramas de resíduos,o equivalente a 1,29 tonelada.
Considerando as informações obtidas nos relatórios anuais, foi possível identificar o números de professores vinculados à instituição por ano (Figura 8), com a finalidade de mensurar a quantidade média das canetas utilizadas por professor no período de um ano 
Figura 8: Quantidade de professores (2012 à 2015)

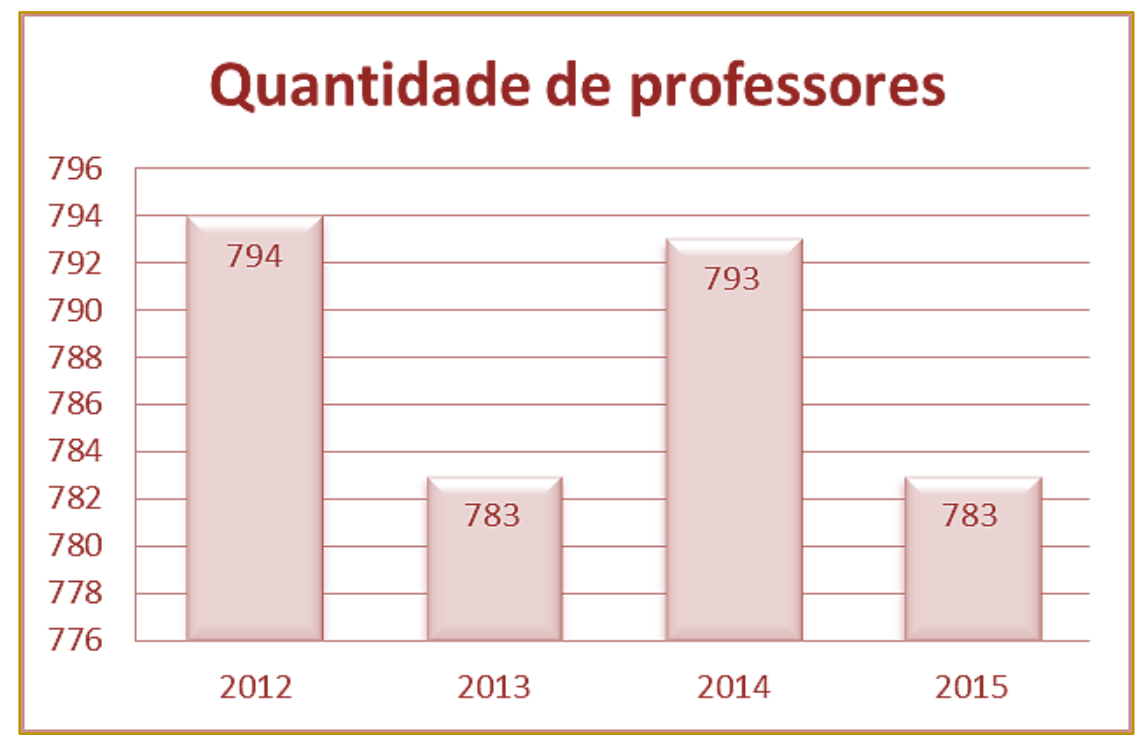

Fonte: Relatório Anual (2012-2015)

Dessa forma com o auxílio da tabela 1, na qual encontra-se o quantitativo de pilotos utilizado por anos, foi possível calcular o número de canetas consumidas por professor em cada ano. Assim, um professor nesta instituição usa em média 18 pilotos por ano.
Além de quantificar a geração de resíduos, foi realizado o levantamento dos custos equivalentes a aquisição desse material, a figura 9 apresenta os valores de compra por ano e por cor. A instituição obteve uma despesa de 65.255,36 reais ao longo de cinco anos, o que equivale a 13.051,07 reais em média, por ano.

Figura 9: Custo de aquisição dos marcadores $(R \$)$.

\begin{tabular}{|c|c|c|c|c|c|}
\hline Ano/Cor & Azul & Preto & \multicolumn{1}{c|}{ Verde } & Vermelho & Total \\
\hline 2012 & $\mathrm{R} \$ 12.340,45$ & $\mathrm{R} \$ 15.434,59$ & $\mathrm{R} \$ 1.778,51$ & $\mathrm{R} \$ 3.985,07$ & $\mathrm{R} \$ 33.538,62$ \\
\hline 2013 & $\mathrm{R} \$ 3.602,41$ & - & $\mathrm{R} \$ 815,49$ & - & $\mathrm{R} \$ 4.417,90$ \\
\hline 2014 & $\mathrm{R} \$ 7.370,22$ & $\mathrm{R} \$ 2.486,30$ & $\mathrm{R} \$ 894,64$ & $\mathrm{R} \$ 2.490,90$ & $\mathrm{R} \$ 13.242,06$ \\
\hline 2015 & $\mathrm{R} \$ 3.005,15$ & $\mathrm{R} \$ 387,45$ & $\mathrm{R} \$ 1.036,01$ & $\mathrm{R} \$ 183,75$ & $\mathrm{R} \$ 4.612,36$ \\
\hline 2016 & $\mathrm{R} \$ 3.225,26$ & $\mathrm{R} \$ 4.087,65$ & $\mathrm{R} \$ 143,86$ & $\mathrm{R} \$ 1.987,65$ & $\mathrm{R} \$ 9.444,42$ \\
\hline Total & & & & & $\mathrm{R} \$ 65.255,36$ \\
\hline
\end{tabular}

Fonte: Almoxarifado da instituição

\section{CONSIDERAÇÕES FINAIS}

No desenvolvimento do diagnóstico preliminar para identificação das caraterísticas relevantes do processo logístico da caneta piloto para quadro branco utilizado por professores em uma instituição de ensino superior, foi necessário cruzamento das informações obtidas nas fases documental e observacional para legitimar os resultados.

No processo de tratamento e análise dos dados pode-se concluir que o fluxo logístico existente na instituição de ensino é tradicional, sem a devida observância das ações pósconsumo do material. Como sugerido pela Lei no 12.305/2010 da Política Nacional dos Resíduos Sólidos que apresenta a logística reversa como ferramenta de desenvolvimento econômico e social, e responsabilidade compartilhada.

De acordo com os resultados obtidos quanto à quantidade de caneta piloto utilizada na instituição, verificou-se um consumo de 64.465 unidade entre 2012 e 2016, quantidade expressiva se levarmos em consideração que a análise se limitou a um único instrumento de escrita dos diversos utilizados em uma instituição de ensino, a 
exemplo de caneta esferográfica, marcadores de texto, lapiseiras, entre outros.

A observância do volume de resíduo gerado em cinco anos, algo em torno de 1,29 toneladas, destinados ao aterro sanitário da região, do ponto de vista ambiental, econômico e social, ou seja, com vista à sustentabilidade, aponta para a necessidade de destinação adequada dos resíduos, tais como: reciclagem ou reutilização de parte do material.

Outro ponto relevante é o custo de aquisição das canetas, que em cincos totalizou $65.255,07$ reais. Entretanto, na analise por ano foi observado diferenças significativas dos custos, o que permite inferir a utilização das canetas em estoque não necessitando da aquisição de novas ou redução do quadro de professores ao longo dos anos. Faz-se necessário aprofundar o diagnóstico nesse sentido.

A metodologia quantitativa utilizada possibilitou uma avaliação do fluxo logístico,

\section{REFERENCIAS}

[1] Coelho, Maria do Rosário Fonseca. Coleta Seletiva. 2008.2 Disponível em <http://www.lixo.com.br/documentos/coleta\%20sel etiva\%20como\%20fazer.pdf>. Acesso em 05/04/2017

[2] Decreto $n^{-} 7.404$, de 23 de dezembro de 2010. Regulamenta a Lei no 12.305, de 2 de agosto de 2010, que institui a Política Nacional de Resíduos Sólidos, cria o Comitê Interministerial da Política Nacional de Resíduos Sólidos e o Comitê Orientador para a Implantação dos Sistemas de Logística Reversa, e dá outras providências, 2010a.

[3] Fernandes, Kleber dos Santos. Logistica: Fundamentos e Processos. 1ํed. rev. Curitiba - PR : IESDE Brasil, 2012.

[4] Gonçalves, Marcus Eduardo. MARINS, Fernando Augusto Silva. Logística Reversa numa Empresa de Laminação de Vidros: um estudo de caso, Gestão \& Produção, v.13, n.3, p.397410,2006.

[5] Lacerda, Leandro. Logística Reversa Uma Visão sobre os Conceitos Básicos e as Práticas Operacionais. Rio de Janeiro: CEL Centro de Estudos em Logística. COPPEAD, UFRJ, 2002.

[6] Leite, Paulo Roberto. Logística Reversa meio ambiente e competitividade. São Paulo: Pearson Prentice Hall, 2009

[7] Mazeto, Carlo Cassiano; Abreu, Estela Pinheiro de. Implantação de Coleta Seletiva em um pois as etapas documental e observacional contribuíram para identificação das características preliminares do sistema. Porém, um elemento qualitativo é fundamental para melhor entendimento. Dito isto, para ampliação do diagnóstico preliminar se faz necessário uma etapa para aplicação de questionários aos professores, e demais profissionais envolvidos diretamente com o sistema de logística, como funcionários do almoxarifado e do gerenciamento dos resíduos sólidos da instituição de ensino.

Assim, com vista à implantação de um sistema de logística reversa para caneta piloto utilizada em quadro branco por professores em instituições de ensino, recomenda-se a complementação dos dados do diagnóstico preliminar bem como investigação de potenciais destinações corretas para os resíduos gerados, a fim de evitar a manutenção da logística tradicional atualmente praticada na instituição.

Condomínio Residencial em Curitiba. Trabalho de Conclusão de Curso de Tecnologia em Processos Ambientais do Campus Curitiba da Universidade Tecnológica Federal do Paraná. 2014.

[8] Marshall, Rachael.E., Farahbakhsh, Khosrow., Systems approaches to integrated solid waste management indeveloping countries, Waste Management, v. 33, p. 988-1003, 2013

[9] Monteiro, Milton Jonas; Paixao, Elane dos Santos da; Monteiro, Emmanuel Aldano de Franca; Almeida, Marcelo; Silva, Tharcia Suelen Vasconcelos. Logística Reversa: Análise diagnóstica da gestão dos resíduos sólidos rrbanos em áreas comerciais. XXXIII Encontro Nacional De Engenharia de Producao, Salvador, BA, Brasil, 08 a 11 de outubro de 2013.

[10] Pilot Pen do Brasil S.A. Indústria E Comércio. Ficha de informações de segurança de produto químico. 2016. Disponivel em: <http://www.pilotpen.com.br/wpcontent/uploads/2016/02/10-WBM-7-1.pdf> Acesso: 26 abril 2017.

[11] Prodnov, Cleber Cristiano; Freitas, Ernani Cesar de. Metodologia do trabalho científico [recurso eletrônico] : métodos e técnicas da pesquisa e do trabalho. $2^{\circ}$. ed. - Novo Hamburgo: Feevale, 2013.

[12] Rosa, Humberto D. O resíduo como um valor: Novo paradigma de gestão de resíduos. Guia para uma gestão sustentável dos resíduos. Edição para autarcas. Lipor, 2009 p. 10-11 Disponível: 
<http://www.rcc.gov.pt/SiteCollectionDocuments/M anualAutarca_LIPOR.pdf> Acesso: 17 mar 2014.

[13] Santos, M. Bulhões dos.; Colpani, D.; Dorilêo, I. Corrêa; Boneti, J. dos Santos; Produção de Tintas para Marcadores de Quadro Branco a partir do Pigmento do Urucum (Bixa Orellana L.). 53ํㅡㄹ Congresso Brasileiro de Quimica, Rio de Janeiro,RJ, Brasil, 14 a 18 de Outubro de 2013.
[14] Seadon, Jeffrey K. Sustainable waste management systems. Journal of Cleaner Production, 2010. Disponível em: www.elsevier.com/ locate/jclepro. Acesso em: 12 out 2013.

[15] Zanin, Maria. Mancini, Sandro Donnini. Resíduos Plásticos e Reciclagem - aspectos gerais e tecnologia, 1aㅡ Ed., EdUFSCar, São Carlos, 2004. 


\section{CAPÍTULO 8}

\section{IMPLANTAÇÃO DE UMA FERRAMENTA PARA DETERMINAR EFICIENNCIA GLOBAL DOS EQUIPAMENTOS (OEE) EM UMA USINA DE BIODIESEL.}

\section{Thiago Roncada Guedes}

\section{Mabio Teodoro Borges}

Resumo: Trata-se de um estudo de caso, exploratório, no qual foi embasado em depoimento e pesquisa de campo para levantamento dos dados. O objetivo foi demonstrar a aplicação da ferramenta OEE (Overall Equipment Effectiveness) em uma usina de produção de biodiesel, visando à eficiência da produtividade com eliminação dos gargalos do processo. Com esta ferramenta de controle, buscou-se envolver todo o processo de fabricação de biodiesel, principalmente os desvios que ocorrem na produção que afetam a eficiência da planta fabril. Os dados foram coletados diariamente com ajuda dos colaboradores, gestores da empresa e da ferramenta de controle da eficiência OEE desenvolvida especificamente para empresa. Verificou-se mediante análise dos dados, que bons resultados foram alcançados com a ferramenta, das quais elenca-se: altos índices de produtividade, qualidade e menores índices de erros. Tendo em vista que a ferramenta possibilita a aplicação de medidas corretivas no momento certo, o que reduz perda e desperdícios de insumos e matéria-prima. Diante do exposto, constatou-se que um sistema piloto de controle da eficiência é capaz de gerir o funcionamento ideal na produção em uma empresa com sistema de produção de biocombustíveis.

Palavras-chave: Overall Equipment Effectiveness. Qualidade. Disponibilidade. Performance. 


\section{INTRODUÇÃO}

No cenário atual devido à elevação dos preços dos combustíveis derivados do petróleo, algumas alternativas devem ser buscadas para suprir a necessidade do mercado atual através de bio-combustível, mais específico o biodiesel (PACHECO, 2006).

Hoje o Brasil é líder do mercado em produção de biodiesel, e dentre os fatores que corroboram para esse desempenho elenca-se o clima favorável, e milhões de hectares de terras para a produção de grãos como a soja, que é a principal matéria prima utilizada para a produção do biodiesel (PACHECO, 2006).

Com o aumento dos preços dos combustíveis derivados do petróleo, a projeção para o ano de 2020 é que esses combustíveis sofram uma crescente substituição para os combustíveis de biomassa que são derivados da cana-de-açúcar, óleo de soja, mamona, milho, etc (CHING, 2004).

Devido a está projeção, as indústrias do setor de biodiesel terão um aumento significativo da sua capacidade produtiva para atender toda a demanda do seu mercado. Com isso abre a busca por processos mais eficientes, tecnológicos e livre de falhas para um aumento da produtividade e lucratividade.

Shingo (1996), explica que os processos podem ser melhorados de duas maneiras. Inicialmente deve-se melhorar o produto a partir da engenharia de valor, posteriormente aperfeiçoar os métodos de fabricação por meio da tecnologia de fabricação ou do ponto de vista da engenharia de produção.

De acordo com Andrade (2009), os avanços tecnológicos e a modernização das indústrias têm tornado a manufatura mais complexa, assim exigindo maiores esforços do setor de manutenção.

Kardec e Nascif (2013), apontam a manutenção eficiente como importante estratégica para melhoria dos resultados, visto que a mesma contribui para o aumento da competitividade entre as organizações.

Slack, Chambers e Johnston, (2009), justificam que os objetivos estratégicos de uma organização só poderão ser cumpridos se o processo produtivo for enxuto, com isso é necessário que a empresas busquem melhorar a eficiência de seus equipamentos a fim de identificar e eliminar as ocorrências de perdas de produtividade.
Por isso um dos grandes desafios da TPM (Total Productive Maintenance) é eliminar as perdas de produtividade ou reduzir essas perdas. Segundo Kardec e Nascif (2013), a TPM tem por objetivo a melhor eficácia da empresa por meio da qualificação das pessoas e o melhoramento dos equipamentos.

Segundo Santos e Santos (2010), o indicador OEE (Overral Equipment Effectivenses) é utilizado na metodologia TPM. Define também que o OEE é uma ferramenta utilizada para mensurar as melhorias que foram implantadas na TPM.

Com a implantação da ferramenta as empresas conseguem analisar as reais condições de seus ativos, as perdas existentes no processo produtivo, acompanhar índice de disponibilidade e confiabilidade de equipamentos, desempenho e qualidade.

Com base nas definições abordadas sobre a implantação da ferramenta $O E E$, o presente trabalho tende a analisar a utilização da ferramenta para a real eficiência de uma usina de biodiesel no norte do Brasil.

\section{OBJETIVOS}

\subsection{OBJETIVO GERAL}

Elaborar uma ferramenta de apoio à tomada de decisão, com indicadores de desempenho para monitoramento e controle da eficiência da produtividade de biodiesel.

\subsection{OBJETIVOS ESPECÍFICOS}

- Elaborar uma ferramenta de apoio a tomada de decisão gerencial, utilizando o software EXCEL, baseado na metodologia OEE (Overral Equipment Effectivenses);

- Identificar os pontos críticos do processo de produção de biodiesel, que afetam direta e indiretamente o índice de eficiência global;

- Promover melhorias no acompanhamento, controle e monitoramento do processo de produção e minimizar os gargalos do processo. 


\section{REFERENCIAL BIBLIOGRÁFICO}

\subsection{MANUTENÇÃO}

Pode-se definir manutenção como a combinação de ações técnicas e administrativas, destinadas a manter ou recolocar o equipamento a desempenhar sua função requerida (KARDEC e NASCIF, 2013).

É importante ressaltar que Kardec e Nascif (2013), afirmam para que o equipamento ter a sua função requerida desejada, o mesmo necessita de um acompanhamento constante e efetivo da sua manutenção, por isso define os 3 tipos de manutenção mais utilizados, como as manutenções corretivas, preventivas e preditivas.

Kardec e Nascif (2013), apontam para essa nova visão de mercado onde a manutenção ocorre preventivamente, gerando para a empresa confiabilidade, disponibilidade e produtividade.

Martins e Laugeni (2005), fazem uma análise bem cuidadosa sobre produtividade, podendo ser ela definida da seguinte forma.

a) Produtividade parcial: é a relação do que foi produzido com o que foi utilizado de insumo para a produção, sendo assim a produtividade de mão-de-obra acaba sendo uma produtividade parcial.

b) Produtividade total: é a soma de todos os fatores de entrada os (inputs), avaliando o impacto que os fatores de inputs tiveram sobre a saída os (outputs).

c) Kardec e Nascif (2013), definem confiabilidade como a probabilidade de um item ou equipamento desempenhar a sua função requerida pelo maior intervalo de tempo.

Segundo Kardec e Nascif (2013), a definição de disponibilidade é a capacidade de um item ou equipamento estar em condições de executar determinada função em um dado instante de tempo.

Para Kardec e Nascif (2013), a ferramenta mais importante para alcançarmos os requisitos de confiabilidade, disponibilidade e produtividade é a TPM.

\subsection{TPM (TOTAL PRODUCTIVE MAINTENANCE)}

Arno Koch (2007), define TPM como uma ferramenta como foco de melhorar a eficiência e o tempo de vida útil dos equipamentos, afim de eliminar as perdas do processo produtivo. Nakajima (1988), reafirma que a TPM representa uma forma de revolução, pois integra o homem, a máquina e a empresa, onde o trabalho de manutenção possa constituir o trabalho, a preocupação e a ação de todos.

\subsubsection{OBJETIVOS DA TPM}

Para Kardec e Nascif (2013), a TPM tem por objetivo a eficácia da empresa através de maior qualificação de seus colaboradores e melhoramentos introduzidos nos equipamentos. Kardec e

Nascif (2013), ressaltam que é neste momento que os operadores passam a executar as tarefas mais simples que antes eram feitas pela manutenção, como: lubrificação, ajustes da máquina, limpeza, troca de filtros, medição de vibração, troca de óleo, etc.

\subsubsection{OS OITO PILARES DA TPM}

Tem-se abaixo a Figura 3 demonstrando de forma didática, o retrato dos oito pilares que norteiam e sustentam a TPM.

Figura 3. Os Oito Pilares da TPM

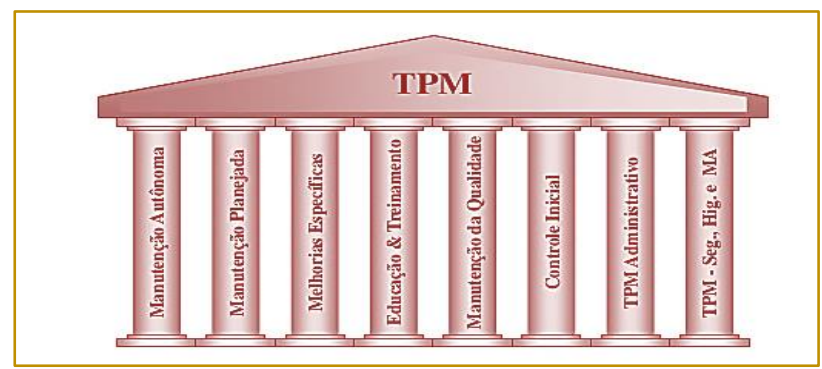

Fonte: KARDEC E NASCIF (2013) 
Segundo Kardec e Nascif (2013), para obter um melhor resultado da TPM dentro de uma organização, a mesma deve ser acompanhada pela ferramenta OEE (Overral Equipment Effectivenses), que visa mensurar a real eficiência de um processo.

\subsection{OEE (OVERRAL EQUIPMENT EFFECTIVENSES)}

Segundo Hansen (2006), o OEE é uma ferramenta utilizada apenas na TPM (Total Productive Maintenance), já nos anos 90 a ferramenta passou a ser vista como uma ferramenta autônoma, utilizada para medir o desempenho real de um equipamento por meio de alguns indicadores de desempenho.

Chiaradia (2004), ressalta que a perdas de um processo produtivo é a principal característica do OEE. Proença e Tubino (2010), afirmam que o OEE consiste em monitorar e melhorar a eficácia nos processos industriais.

Para Oliveira e Sangineto (2010), o cálculo do OEE é realizado a partir de três parâmetros que são eles: disponibilidade, performance e qualidade.

Abaixo a Figura 4 representa os fatores que formam o OEE e a seguir os cálculos dos indicadores.

Figura 4. Fatores que formam o OEE

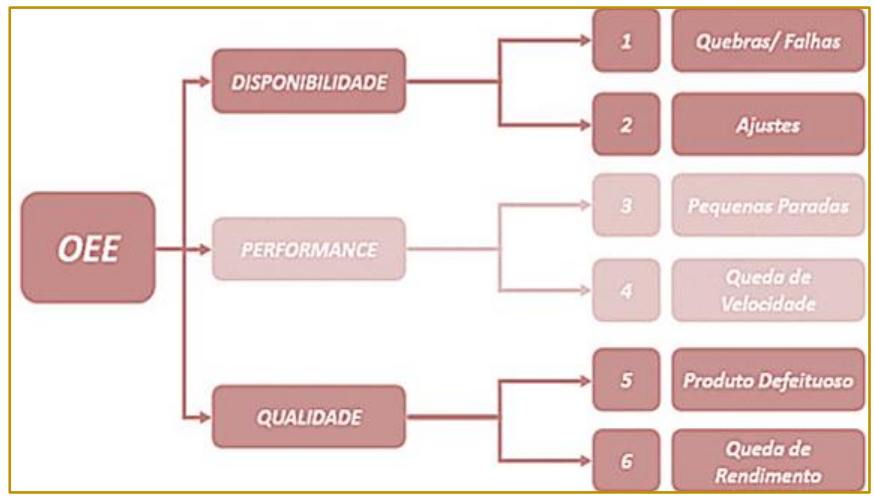

Disponível em: www.oee.com.br/formula-oee

\subsubsection{CÁLCULO DO OEE}

Para Nakajima (1989) a meta do índice de OEE a se atingir é de $85 \%$ para os equipamentos, para alcançar este percentual a empresa tem que atingir 90\% de disponibilidade, $95 \%$ desempenho e $99 \%$ qualidade.

Para Branco Filho (2002) disponibilidade é, a probabilidade de uma máquina estar produzindo ou disponível para produzir.

Disponibilidade $\%=$ (tempo produzindo $/$ tempo programado) * 100

Segundo Tavares (1996) a performance representa a razão entre o tempo total de operação de cada item controlado e a soma desse tempo com o tempo de manutenção para um determinado o período.

Performance\% = (Quantidade Produção Real $)$ Quantidade Produção Teórica) * 100\%".
Qualidade é quantidade de itens bons que foram produzidos, em relação ao total de itens produzidos.

Qualidade\% = (Quantidade de Produtos Bons / Quantidade Total Produzida) * 100\%.

Branco Filho (2002) define que OEE indica o quanto o equipamento produziu, comparado com 0 que ele poderia produzir se funcionasse sempre sem parar, com matéria prima sempre disponível, sem falhar e sem produzir peças com defeitos.

OEE $\%=$ Disponibilidade $\%$ * Performance $\%$ * Qualidade\%".

Muitos métodos podem ser utilizados para a implementação de um trabalho nesse formato, mas todos dependem de muito empenho, foco e dedicação para encontrar os adequados e se obter os resultados esperados. 


\section{METODOLOGIA}

Trata-se de um estudo de natureza aplicada e exploratória com abordagem qualiquantitativa e um estudo de caso.

Segundo Gil (2007), a pesquisa exploratória tem como objetivo proporcionar maior familiaridade com os problemas e torná-los mais explícitos ou a construir hipóteses.

Segundo Minayo (2008), a pesquisa qualitativa trabalha com o universo de significados, motivos, aspirações, crenças, valores e atitudes, o que corresponde a um espaço mais profundo das relações, dos processos e dos fenômenos que não podem ser reduzidos à operacionalização de variáveis.

Para Fonseca (2002), pesquisa quantitativa se centra na objetividade, recorre à linguagem matemática para descrever as causas de um fenômeno, as relações entre variáveis.

O estudo de caso deve ser bem planejado. Segundo Martins (2006), deve ser baseado em ensinos advindos do referencial teórico e das características próprias do caso. O estudo de caso também deve fornecer informações suficientes para se replicar o estudo, ou aplicá-lo em outro caso de características semelhantes.

a) Visitas frequentes à empresa estudada para obter todas as informações e dados pertinentes à execução do estudo;

b) Coleta de dados do processo;

c) Tabulação dos dados através do software de planilha eletrônica EXCEL, para alcançar o índice OEE.

\subsection{IMPLANTAÇÃO DA FERRAMENTA}

Para implantação e desenvolvimento da ferramenta foi utilizada o modelo A-F, que para De Bes e Kotler (2011) o método é utilizado para que a empresa possa definir as funções e os objetivos de cada individuo especifico, então estabelecendo objetivos, recursos e prazos para determinado processo.

Para De Bes e Kotler (2011) para alcançar os objetivos que foram estabelecidos cada atividade tem que ter o seu processo de implantação traçados da seguinte forma:

Objetivos $\rightarrow$ Pesquisa $\rightarrow$ Ideias $\rightarrow$ Avaliação $\rightarrow$ Desenvolvimento $\rightarrow$ Execução

Ainda segundo os autores, para se obter êxito na implantação de algo inovador é necessário estabelecer algumas funções como:

a) Ativadores: colaboradores que iniciarão o processo de implantação da ferramenta;

b) Buscadores: pessoas que buscarão informações sobre a determinada ferramenta para facilitar o andamento das atividades;

c) Criadores: responsáveis por criar a ferramenta que será utilizada para coletar os dados;

d) Desenvolvedores: serão os responsáveis de agrupar todas as informações e ideias de melhorias, e coloca-las em prática;

e) Executores: grupo que terá como responsabilidade aplicar 0 que foi desenvolvido;

f) Facilitadores: serão os gestores da área que darão todo o suporte técnico para a equipe caso haja algum imprevisto, facilitadores esses que serão responsáveis por não deixar o processo parar.

Posteriormente com o embasamento teórico foi desenvolvida uma planilha com o software Excel, contendo os preceitos da metodologia OEE para quantificar a eficiência de produtividade de uma usina de produção de biodiesel.

\subsection{DADOS DA PRODUÇÃO}

A Figura 6 apresenta alguns dados da produção que compõe a ferramenta e será analisado detalhadamente, cada um deles. 
Figura 5: Dados de Produção

\begin{tabular}{|l|r|r|l|}
\hline \multicolumn{2}{|c|}{ DADOS DE PRODUÇÃO } & \multicolumn{1}{c|}{ META } & \multicolumn{1}{c|}{ UNID } \\
\hline PRODUÇÃO MENSAL & & $16.500,0$ & {$[\mathrm{t}]$} \\
\hline PRODUÇÃO NÃO-CONFORME & & 165 & {$[\mathrm{t}]$} \\
\hline TEMPO PROGRAMADO & 36.120 & 31.551 & \\
\hline TEMPO OPERACIONAL & 31.551 & & $\begin{array}{l}\mathrm{min}] \\
{[\mathrm{min}]}\end{array}$ \\
\hline TEMPO OPERACIONAL LÍQUIDO & {$[\mathrm{min}]$} \\
\hline
\end{tabular}

Fonte: Autor (2016)

a) Produção mensal: é o quanto foi produzido em 24 horas de operação, tal informação é retira pelo relatório de troca de turno onde cada turno informa a sua produção. A meta é baseada pela produção que está aprovada pela ANP (Agência Nacional do Petróleo), que hoje é de 550 toneladas a cada 24 horas;

b) Produção não-conforme: é o produto que está fora do padrão de qualidade exigido pela ANP, a meta é $10 \%$ da produção diária;

c) Tempo programado: é o tempo total disponível que é o tempo disponível em 30 dias menos o tempo de parada programada que é definido pela empresa; d) Tempo operacional: é a subtração do tempo total programado pelo tempo das perdas por parada;

e) Tempo operacional líquido: é o tempo operacional menos as perdas por performance.

\subsection{TEMPO DE PARADA}

A Figura 7 expõe dados de perdas por paradas

Figura 6: Tempo de Paradas

\begin{tabular}{|l|r|r|l|}
\hline \multicolumn{1}{|c|}{ TEMPO PARADAS } & META & \multicolumn{1}{c|}{ UNID } \\
\hline PARADAS PROGRAMADAS & 7.080 & & [min] \\
\hline PERDAS POR PARADAS & 4.569 & [min] \\
PERDAS POR PERFORMANCE & 0 & \\
\hline PERDAS POR QUALIDADE & 0 & [min] \\
\hline PARADAS TOTAL & 11.649 & [min] \\
\hline
\end{tabular}

Fonte: Autor (2016)

a) Paradas programadas: são as paradas que são programadas pela empresa;

b) Perdas por paradas: são perdas que são creditas as falhas de manutenção, podendo ser elas elétrica, mecânica ou de instrumentação;

c) Perdas por performance: são perdas que por algum motivo foi obrigado a redução da vazão de produção, podendo ser essa redução causada por vários fatores exemplo uma baixa pressão de vapor ou até mesmo a quebra de uma centrífuga de separação;

d) Perdas por qualidade: é todo aquele tempo para reprocessar algum produto fora do padrão de especificação.

\section{4 ÍNDICES DE PERFORMANCE}

A Figura 8 apresenta os índices de performance OEE. 
Figura 7: Índices de performance

\begin{tabular}{|c|c|c|c|}
\hline CICLOTEÓRICO & 2,62 & & [] \\
\hline CICLO EFETIVO & 3,16 & & [] \\
\hline \multicolumn{2}{|c|}{ ÍNDICES DE PERFORMANCE } & META & UNID \\
\hline UTILIZAÇÃO & $83,6 \%$ & $85,0 \%$ & [\%] \\
\hline DISPONIBILIDADE & $87,4 \%$ & $90,0 \%$ & [\%] \\
\hline PERFORMANCE & $0,0 \%$ & $95,0 \%$ & [\%] \\
\hline QUALIDADE & $0,0 \%$ & $99,0 \%$ & [\%] \\
\hline OEE & $0,00 \%$ & $84,6 \%$ & [\%] \\
\hline
\end{tabular}

Fonte: Autor (2016)

a) Utilização: é a divisão do tempo total disponível pelo tempo total programado;

b) Disponibilidade: é a divisão do tempo operacional pelo tempo programado;

c) Performance: é feita pela divisão do ciclo teórico pelo ciclo efetivo.

- Ciclo teórico: é o quanto a linha de produção deve produzir em 24 horas. Exemplo: a cada 24 horas temos 1440 minutos e uma produção de 550 toneladas dias, portanto a divisão 1440 minutos por 550 toneladas resulta em 2,62 min/ton, significa que a cada 2,62 min será produzido uma tonelada de biodiesel;
- Ciclo efetivo: é a divisão o tempo operacional líquido pela quantidade que foi produzida no mês.

Qualidade: é a divisão da produção total no mês pela soma da produção total mais a produção não-conforme.

\subsection{PERDAS POR PARADA PROGRAMADA}

A Figura 9 apresenta alguns itens que são considerados como paradas programadas.

Figura 8: Perdas por parada programada

\begin{tabular}{|c|c|c|c|c|}
\hline \multicolumn{5}{|c|}{ TEMPO PARADAS PROGRAMADAS } \\
\hline & TURNO & A & B & C \\
\hline 1.1 & Estoque baixo de Matéria-prima & & & \\
\hline 1.2 & Estoque alto de Biodiesel & & & \\
\hline 1.3 & Estoque alto de Glicerina & & & \\
\hline 1.4 & Manutenção Planejada & 7.080 & & \\
\hline 1.5 & Solicitação do Comercial & & & \\
\hline 1.6 & Teste Planejado & & & \\
\hline
\end{tabular}

Fonte: Autor (201

A figura acima retrata alguns exemplos de paradas programadas que foram definidas junto a diretoria da empresa, e a quantidade de minutos de parada em cada turno.

\subsection{PERDAS POR PARADA DE MANUTENÇÃO}

A Figura 10 apresenta alguns itens que são considerados como perdas por paradas, podendo classificar essas paradas como paradas de manutenção. 
Figura 9: Perdas por paradas manutenção

\begin{tabular}{|c|l|c|c|c|}
\hline \multicolumn{5}{|c|}{ TEMPO PERDAS POR PARADAS } \\
\hline $\mathbf{2 . 1}$ & Quebra de sensor de movimento & A & B & C \\
\hline $\mathbf{2 . 2}$ & Queima de transmissor de pressão/pressostato & & & \\
\hline $\mathbf{2 . 3}$ & Queima de trasmissor de nível/chave de nível & & 4.569 & \\
\hline $\mathbf{2 . 4}$ & Queima de trasmissor de temperatura/termostato & & & \\
\hline $\mathbf{2 . 5}$ & Queima de Soft Start & & & \\
\hline $\mathbf{2 . 6}$ & Queima de inversor de frequência & & & \\
\hline
\end{tabular}

Fonte: Autor (2016)

A Figura 10 está representando algumas paradas de manutenção. Paradas essas que impactam diretamente na disponibilidade da usina, causando perda de eficiência produtiva.

\subsection{PERDAS POR PERFORMANCE}

A Figura 11 elenca alguns itens que são considerados como perdas por performance.

Figura 10: Perdas por performance

\begin{tabular}{|c|l|c|c|c|}
\hline \multicolumn{5}{|c|}{ TEMPO PERDAS POR PERFORMANCE } \\
\hline $\mathbf{6 . 1}$ & Falha em sensor de movimento & A & B & C \\
\hline $\mathbf{6 . 2}$ & Falha em transmissor de pressão/pressostato & & & \\
\hline $\mathbf{6 . 3}$ & Falha em trasmissor de nível/chave de nível & & & \\
\hline $\mathbf{6 . 4}$ & Falha em trasmissor de temperatura/termostato & & & \\
\hline $\mathbf{6 . 5}$ & Falha em Soft Start & & & \\
\hline $\mathbf{6 . 6}$ & Falha de inversor de frequência & & & \\
\hline
\end{tabular}

A figura acima elenca algumas falhas que podem ocorrer no processo ocasionando uma perda de performance. A perda de performance ficou definida pela empresa com: qualquer perda que possa ocasionar a redução de vazão do processo produtivo.

\section{PERDAS POR QUALIDADE}

A Figura 12 identifica alguns itens que são considerados como perdas por qualidade. 
Figura 11: Perdas por qualidade

\begin{tabular}{|c|l|l|l|l|}
\hline \multicolumn{5}{|c|}{ TEMPO PERDAS POR QUALIDADE } \\
\hline $\mathbf{9 . 1}$ & Produção não-conforme & & & \\
\hline $\mathbf{9 . 2}$ & Partida/Ajustes (depois de paradas programadas) & & & \\
\hline $\mathbf{9 . 3}$ & Paradas/esvasiar equipamentos (parada programad & & & \\
\hline
\end{tabular}

Fonte: Autor (2016)

Uma vez desenvolvida a ferramenta, deu-se início aos treinamentos dos colaboradores responsáveis pelo processo produtivo, afim de mostrar qual o real objetivo da ferramenta e a importância de registrar qualquer desvio que possa ocorrer dentre os três requisitos básicos do OEE que são:

- Disponibilidade

- Performance;

- Qualidade.

\section{COLETA DE DADOS}

Os dados para elaboração deste projeto foram coletados no processo de fabricação de biodiesel que é composto pelas etapas de transesterificação, lavagem e secagem do biodiesel.

Para obter um melhor resultado, os dados foram coletados de maio de 2015 a maio de 2016, no ano 2015 as informações foram solicitadas ao setor de planejamento da empresa e em 2016 houve o acompanhamento diário do processo, utilizouse também depoimentos de operadores do processo para entender alguns desvios que são observados no processo de fabricação.

Analisando mais a fundo a ferramenta é definida como tempo de parada de qualidade os desvios que possam ter relação com a qualidade do produto, desvios esses que podem ser, star up da planta que possa ter ocorrido depois de uma parada programada, sendo assim levando um tempo para que produto possa estar dentro dos padrões de qualidade estabelecidos.

Já as paradas por disponibilidade são consideradas alguns desvios que impactam diretamente ao processo, com por exemplo a quebra de uma bomba, sendo preciso parar a produção para que o equipamento possa ser recolocado em operação, ocasionando a perda de disponibilidade.

Perdas por performance foi definida como qualquer interferência que ocorra no processo ocasionando a queda de rendimento, como por exemplo baixa pressão de vapor no processo, dentre outros fatores que exigem trabalhar com o processo em baixa vazão.

E por fim as paradas programadas, que são determinadas pela empresa, podendo ser elas por falta de matéria-prima, parada programada para manutenção, limpeza do processo produtivo, etc.

Após o levantamento dos dados, foram feitas as tabulações dos mesmos para uma melhor análise da eficiência do processo e identificar possíveis desvios que possa ter afetado a disponibilidade, performance e qualidade da produção.

a) Performance: é a divisão do que se esperava a ser produzido pela produção real.

b) Disponibilidade: é o tempo total de minutos disponíveis no mês menos os minutos de hora programada que foram informados pela empresa resultando nos minutos totais disponíveis, posteriormente caso haja alguma parada não programada, é descontado desses minutos disponíveis, resultando no tempo operacional, por fim o cálculo de disponibilidade é feito pela divisão do tempo operacional pelos minutos totais operacionais.

c) Qualidade: o indicador qualidade será considerado nos meses operacionais como $100 \%$ devido alguns controles laboratoriais, onde um produto fora do especificado será acrescentado a outro produto com os padrões de qualidade acima do especificado chamando-o assim blend. 
Gráfico 3. Indicadores OEE

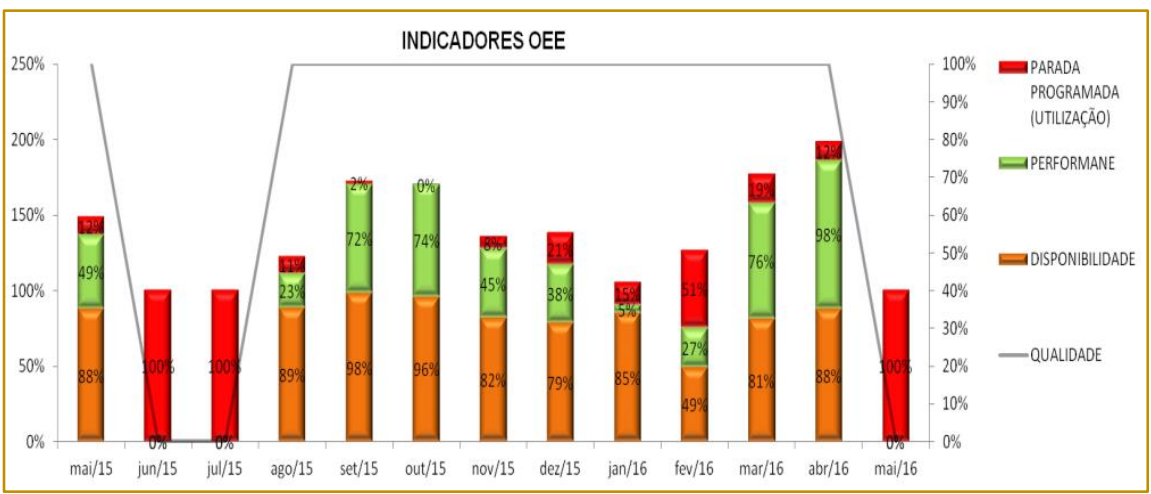

Fonte: O autor 2016

Analisando o gráfico 2, nota-se que no mês de agosto, o indicador de disponibilidade foi de $89 \%$, mas com performance de apenas $23 \%$, dado este fato é atribuído as perdas por parada de manutenção e parada programada da planta de biodiesel que afetam diretamente no indicador performance. Já nos meses de setembro e outubro o indicador performance foi de $72 \%$ e $74 \%$ respectivamente, observe no gráfico 2 que as perdas por manutenção e parada programada foram irrisórias em relação ao mês de agosto, consequentemente aumentando a disponibilidade e a performance.

O Gráfico 3 representa o índice real do OEE de cada mês a partir de maio de 2015 a maio de 2016.

Gráfico 4. Índice OEE

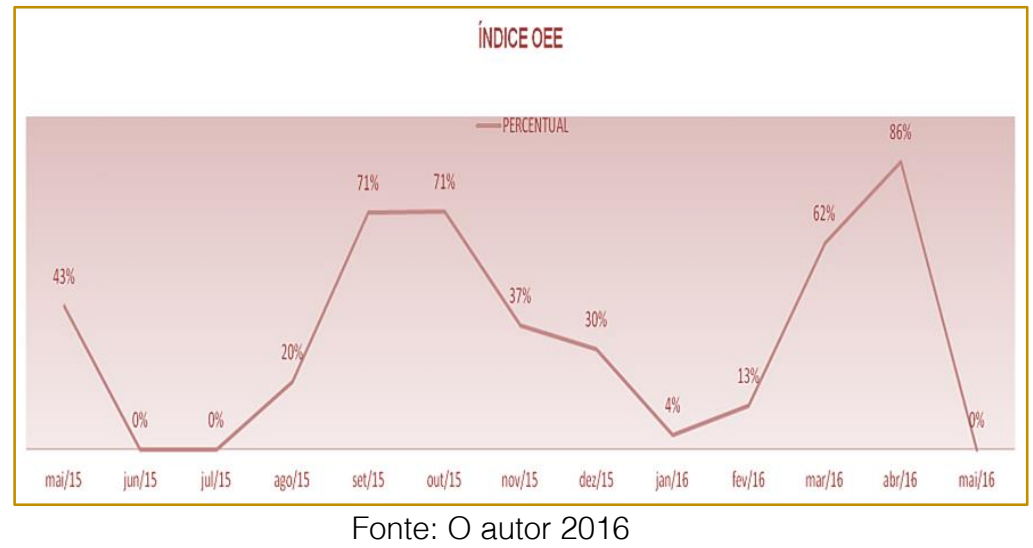

O gráfico 3 justifica o que foi representado no gráfico 2, onde no mês de agosto o indicador performance foi de apenas 23\% levando o índice OEE para 11\%, já nos meses setembro e outubro os índices OEE foi de $70 \%$ e $71 \%$ respectivamente.

Nos meses de janeiro e fevereiro a queda do índice se deu pelo fato de que no mês de janeiro a parada programada foi de $66 \%$ e em fevereiro a para por manutenção foi de $51 \%$, com isso reduzindo a eficiência para $1 \%$ e $11 \%$ concomitantemente.

O Gráfico 4 nós traz os percentuais de desvios que foram observados no processo que impactaram no índice OEE. 
Gráfico 5. Percentual de Falhas

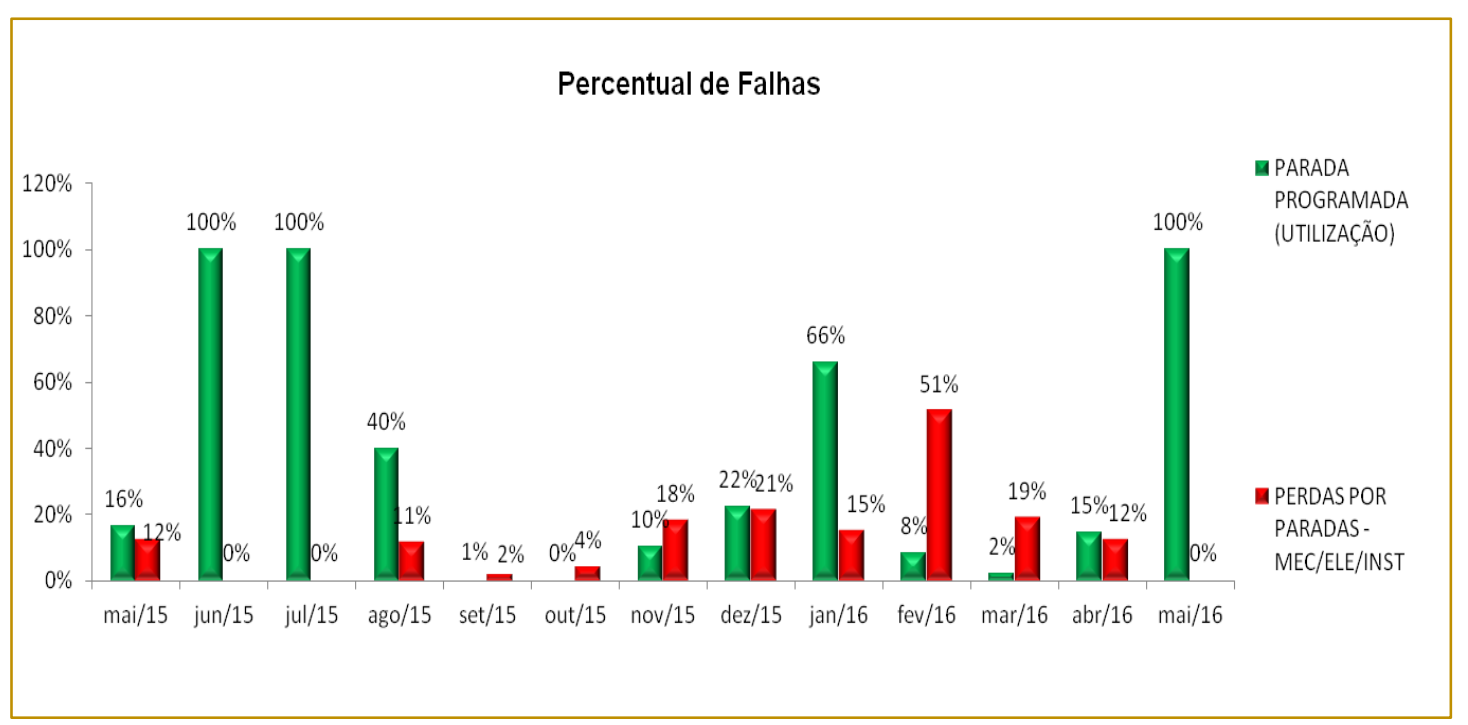

Fonte: O autor 2016

O Gráfico 4 traz uma análise de indicadores que influenciam na eficiência do processo, onde as paradas programadas e as perdas por paradas de manutenção diminuem a disponibilidade da linha de produção levando o índice OEE a percentuais baixíssimos.

Tal fato pode ser observado que nos meses de janeiro e fevereiro as paradas programadas e paradas de manutenção foram altíssimas levando o índice OEE a patamares abaixo do esperado como mostra o Gráfico 3.

\subsection{PONTOS CRÍTICOS DO PROCESSO}

Um dos objetivos proposto por esse trabalho é identificar alguns pontos críticos do processo, afim de elimina-lós e/ou minimizalos.

Sendo assim, analisando o Gráfico 4, mais precisamente nos meses de fevereiro, março e abril de 2016 tivemos em média 27,3\% de perdas por paradas sejam elas mecânicas, elétricas ou de instrumentação, tais perdas que impactaram diretamente no processo produtivo, onde em fevereiro obteve-se uma produção de 3990 toneladas de biodiesel onde o esperado para o mês era de 15000 toneladas.

\subsection{SUGESTÕES DE MELHORIAS}

Com base em identificar os pontos críticos, a empresa constatou que nos meses de fevereiro, março e abril de 2016, teve em média $27,3 \%$ do seu tempo de produção reduzido devido as falhas de manutenção, com isso a empresa proporcionou aos seus colaboradores do setor de manutenção alguns treinamentos para obter uma manutenção de qualidade e de confiabilidade.

Para os colaboradores da mecânica foram ofertados treinamentos de manutenção em bombas utilizadas no processo, o treinamento foi ministrado pelos próprios fabricantes podendo citar a KSB e a Netzsch,

Os colaboradores da área elétrica, sendo eles eletricistas e instrumentistas tiveram treinamentos de motores elétricos e instrumentos de medição, a capacitação foi feita pelos fabricantes da BAM que são fornecedores dos motores elétricos e pela Endress Hauser que fornecem os instrumentos de medição.

\section{CONCLUSÃO}

Através deste trabalho foi possível demonstrar a importância da aplicação de alguns dos fundamentos da engenharia de produção, para a melhoria na eficiência de uma usina de biodiesel. 
O foco do projeto foi desenvolver um modelo para implantação de um sistema piloto específico de controle da eficiência produtiva e torná-la uma ferramenta de acompanhamento e tomada de decisões gerenciais.

Com o modelo proposto obteve-se êxito, onde, com os preceitos da metodologia OEE conseguiu-se identificar a eficiência da produtividade e gerenciar as perdas que ocorrem no processo, pois estas corroboram

\section{REFERÊNCIAS}

[1] Andrade, L.; Scherer, C. Estudo de caso da aplicação do indicador de eficiência global de equipamentos (oee) para diagnóstico e melhoria de produtividade em uma linha de produção automotiva. In: ENEGEP , 29, 2009, Salvador, BA, Brasil, Anais ..., Salvador: ABEPRO, 2009.

[2] Branco Filho G., Indicadores e índices de manutenção, in VII Congresso de Manutenção SEMAPI, Campinas, São Paulo, Outubro, 2002. Biodiesel no Brasil. 2010. Disponível em:<http://www.biodieselbr.com/biodiesel/brasil/bi odiesel-brasil.htm>. Acesso em: 05 abr.2016.

[3] Ching. W. H. Cartilha biodiesel sebrae, Brasília, 2004.

[4] Chiaradia, A. Utilização do indicador de eficiência global de equipamentos na gestão e melhoria contínua dos equipamentos: um estudo de caso na indústria automobilística. Dissertação de Mestrado em Engenharia: PPGEP-UFRGS, Porto Alegre, 2004.

[5] DE BES, F. T.; Kotler, P. A bíblia da inovação: princípios fundamentais para levar a cultura da inovação contínua ás organizações. São Paulo: Lua de Papel, 2011

[6] Fonseca, J. J. S. Metodologia da pesquisa científica. Fortaleza: UEC, 2002. Apostila.

[7] Gil, A. C. Como elaborar projetos de pesquisa. 4. ed. São Paulo: Atlas, 2007.

[8] Hansen, R. C. Eficiência global dos equipamentos: uma poderosa ferramenta de manutenção/produção para aumento dos lucros. Porto Alegre: Bookman, 2006. diretamente com o percentual de produtividade.

Conclui-se que a metodologia adotada foi eficaz e que os objetivos foram atingidos. Considerando que para um período de tempo de um ano, foi perceptível a melhoria do acompanhamento da eficiência do processo e seus desvios, obtendo assim a afirmação de que a longo prazo os resultados poderão ser mais alvissareiros.

[9] Kardec, Alan; Nascif, Júlio. Manutenção: Função estratégica. 4.ed. Rio de Janeiro: Qualitymark, 2013

[10] Koch, A. Discover the hidden machine. OEE for production team. Metamorfose Vertalingen (Trad). The Netherlands: FullFact BV, 2007.172p.

[11] Martins, P.G.; Laugeni, F.P. Administração da produção. 2 ed. São Paulo: Saraiva, 2005.

[12] Minayo, M. C. S. O desafio do conhecimento: pesquisa qualitativa em saúde. 8. ed. São Paulo: Hucitec, p. 316, 2008.

[13] Nakajima, S. Introdução ao TPM. São Paulo: IMC Internacional Sistemas Educativos, 1989

[14] Oliveira, D.; Sangineto, M. Otimização do processo de envase de lubrificantes por meio da aplicação do indicador de eficácia global de equipamentos e da teoria das restrições. In: ENEGEP, 30, 2010, São Carlos, SP, Brasil, São Carlos: Abepro, 2010

[15] Pacheco, E. M. Cartilha do Biodiesel. Brasília, 2006.

[16] Slack, N.; Chambers, S.; Johnston, R. Administração da produção. 3. ed. São Paulo: Atlas, 2009.

[17] Santos, A.; Santos, M. Utilização do indicador de eficácia global de equipamentos (OEE) na gestão de melhoria contínua do sistema de manufatura - Um Estudo de Caso. In: ENEGEP, 30, 2010, São Carlos, SP, Brasil, Anais..., São Carlos: Abepro, 2010

[18] Tavares L., Excelência na manutenção: estratégias para otimização e gerenciamento, ed. Casa da Qualidade, Salvador, Bahia, 1996. 


\section{GAPÍTULO 9}

\section{APLICAÇÃO DOS CONCEITOS DE TAKT TIME E TEMPO DE CICLO PARA O CÁLCULO DA EFICIÊNCIA NOS PROCESSOS DE UM PRONTO ATENDIMENTO HOSPITALAR}

\section{Maria Suzanna Maia Costa}

\section{Carlos Henrique de Oliveira}

Emerson Jose de Paiva

Sandra Miranda Neves

Marcio Dimas Ramos

Resumo: A implementação do Lean Healthcare vem acontecendo de forma gradativa nos hospitais, sendo possível garantir resultados significativos. O presente artigo tem como propósito aplicar a filosofia Lean Healthcare por meio do uso dos conceitos de takt time e tempo de ciclo a fim de determinar a eficiência do pronto atendimento de um Hospital, localizado na cidade de Itabira, interior de Minas Gerais. O foco deste estudo de caso, com caráter exploratório e quantitativo é a análise do tempo de espera do paciente desde a chegada até o primeiro contato com o médico. Por meio da relação entre o takt time e tempo de ciclo determinou-se a eficiência do pronto atendimento para assim propor melhorias baseadas na filosofia Lean. O presente estudo analisou os dados de tempo de espera de quatro meses e constatou-se que o pronto atendimento apresenta eficiência média de 49\%, considerada baixa.

Palavras-chave: Pronto atendimento. Lean healthcare. Takt time. Tempo de ciclo. Eficiência 


\section{INTRODUÇÃO}

O alto índice de espera nos atendimentos de urgência em hospitais faz com que essas organizações busquem por ferramentas da engenharia de produção para ajustar a sua capacidade de atendimento e melhorar a adequação dos processos, com a intenção de satisfazer seus clientes. Uma área de conhecimento que vem se destacando nesses tipos de organizações é o Lean Healthcare, que é baseada na filosofia Lean Thinking, filosofia essa que surgiu a partir dos princípios do Sistema Toyota de Produção. A partir de adaptações para a área do gerenciamento de recursos voltados à saúde, prevê o mínimo de desperdício no fluxo de atendimento para melhorar os serviços prestados a seus usuários.

O Lean Healthcare tem sido adotado em grande número de hospitais apresentando resultados consideráveis. Em um case apresentado por Womack (2005), os resultados vieram após dois anos de implementação: em 2004 obtiveram efeitos surpreendentes, com ganho de mais de um milhão de dólares devido à redução de estoque, aumento da produtividade em $46 \%$, redução do espaço utilizado em 41\%, redução da distância entre produtos de $72 \%$, redução do tempo de setup em $82 \%$, redução com custo de pessoal de $44 \%$ e redução do lead time em $65 \%$.

No entanto, o uso da filosofia Lean Healthcare no pronto atendimentos, não se limita somente à eficiência do processo. Além disso, muitas outras ferramentas podem ser utilizadas com objetivo de aprimorar o gerenciamento de recursos e assim, melhorar o processo de atendimento aos pacientes que utilizam este tipo de serviço.

O uso do takt time pode ser considerado o primeiro passo na verificação da eficiência de atendimento em um hospital. E, a partir daí, podem-se implantar melhorias para o nivelamento dos atendimentos, a fim de eliminar atividades que não agregam valor aos pacientes, garantindo maior eficiência nos serviços prestados.

Neste trabalho, utilizaram-se os conceitos de takt time e tempo de ciclo para determinar a eficiência do pronto atendimento para a "primeira assistência ao paciente".

O objetivo desta pesquisa é estabelecer uma classificação no pronto atendimento do hospital, quanto à eficiência, utilizando os conceitos de takt time e tempo de ciclo. Os objetivos específicos foram: classificar as atividades dos processos existentes no pronto atendimento; identificar fontes de desperdícios utilizando os conceitos do Lean Healthcare e, por fim, apresentar sugestões de melhorias.

O objeto de estudo foi o pronto atendimento para os planos de saúde, recém implantado em um hospital, na cidade de Itabira-MG, considerada atividade gargalo desta instituição.

Para a realização deste estudo de caso, de caráter exploratório e quantitativo, realizaramse os seguintes passos: identificação e mapeamento dos processos de atendimento; cálculo do tempo de ciclo; cálculo do takt time; cálculo e a classificação da eficiência e, por fim, definição das sugestões de melhorias.

\section{REFERENCIAL TEÓRICO}

\subsection{LEANTHINKING}

O Lean Thinking ou pensamento enxuto, foi desenvolvido por Taiichi Ohno na Toyota Motors Company, com início em 1945 e teve alterações ao longo dos anos seguintes. "(...) Ohno sabia que o trabalhador era seu recurso mais valioso. (...) Nos anos seguintes, Ohno desenvolveu atividades para envolver os membros da equipe em melhorias de forma total - o que era absolutamente inovador" (DENNIS, 2008).

O Lean Thinking é fundamentado no pensamento do zero desperdício, baseado em sete fontes, que são descritos por Ohno (1997) como: superprodução, espera, transporte desnecessário, processamento dispensável, estoque, movimentação e produtos defeituosos. "A eliminação desses desperdícios pode aumentar a eficiência de operação por uma ampla margem. Para fazêlo, deve-se produzir apenas a quantidade necessária, liberando, assim, a força de trabalho extra" (OHNO, 1997).

Esta filosofia foi trazida para o ocidente em 1991, adotando a nomenclatura de Lean Manufacturing no livro "A máquina que mudou o mundo" de Daniel Jones e James Womack. Atualmente, já existem outras aplicações, de acordo com a área de atuação, decorrentes do Lean Thinking, como exemplos o Lean Office, Lean Startup e o Lean Healthcare. 


\subsection{LEAN HEALTHCARE}

O Lean Healthcare, se destaca pelas suas aplicações voltadas às melhorias no ambiente hospitalar. Os principais aspectos chaves que indicam que o Lean Thinking é adaptável em setores da saúde são: "o estímulo ao encorajamento e participação da equipe de funcionários e os conceitos utilizados, como as melhorias contínuas e incrementais" (SOUZA, 2009).

A aplicação da metodologia Lean para os sistemas de saúde, de acordo com Buzzi (2011), deve-se a diversos fatores, tais como:

- Alto grau de descontentamento por parte de quem utiliza o sistema;

- Processos com longas esperas e/ou atividades duplicadas;

- Sistema carente de qualidade no atendimento e com limitação de recursos;

- Colaboradores passam, também, por alto nível de estresse devido a longas jornadas de trabalho e pressão para atingir o nível de qualidade desejado;

- Desperdício de recursos financeiros que são alocados, em subutilização, mau uso de equipamentos, fluxo de informação defectível.

- $\quad$ Ainda de acordo com Buzzi (2011), com o uso dessa metodologia, o sistema de saúde pode prover:

- Segurança, para funcionários e pacientes;

- Eficácia na prestação de serviços que agregam valor do ponto de vista do paciente, assim como àquelas que atendem a necessidade do mesmo;

- Diminuição do tempo de espera e atrasos, de ambas as partes;

- $\quad$ Eficiência para evitar perdas;

- Atendimento igualitário para todos os pacientes.

Holland (2013), ressalta que os hospitais podem ser comparados à indústria, quando se considera que os pacientes são como o produto final de um processo produtivo. Em um atendimento hospitalar, o produto final paciente - deve passar por diversas atividades que devem agregar valor ao produto - processo. O processo de atendimento, requer que os colaboradores ministrem diversos medicamentos, equipamentos hospitalares e itens de auxílio ao atendimento, 0 que indicaria 0 uso eficiente de técnicas de gestão de estoque. Em termos de recursos humanos, tanto as indústrias, quanto os hospitais, devem geri-los de maneira eficaz para que não haja subutilização de recursos ou carga de trabalho excessiva, fazendo com que todas as atividades exercidas agreguem valor ao produto final do ponto de vista do cliente, sejam eles paciente ou acompanhantes.

Ainda, mesmo que existem semelhanças entre a manufatura e o sistema de saúde, devem-se realizar adequações às pequenas diferenças presentes entre os mesmos. Assim, as modificações e melhorias propostas devem provir, também, do estudo aprofundado da presença dos sete desperdícios. 
Quadro 1 - Sete desperdícios e respectivas ocorrências baseadas no Lean Healthcare

\begin{tabular}{|c|c|}
\hline Excesso de produção & $\begin{array}{l}\text { Esse erro ocorre quando há produção excessiva de algum item. Em } \\
\text { hospitais, é comum acontecer em testes ou documentação. }\end{array}$ \\
\hline Estoque & $\begin{array}{l}\text { O armazenamento de medicamentos pode custar muito para um hospital, e } \\
\text { ainda se tornar obsoleto ou de uso inviável depois de um tempo parado, } \\
\text { alocando recursos financeiros em estoque não utilizado. Deve-se manter o } \\
\text { menor estoque possível. }\end{array}$ \\
\hline Movimentação & $\begin{array}{l}\text { A má distribuição logística projetada para os hospitais, tem como } \\
\text { consequência uma movimentação desnecessária, fazendo com que o } \\
\text { colaborador em questão perca tempo e disposição para trabalhar. }\end{array}$ \\
\hline Transporte & $\begin{array}{l}\text { Para a saúde, o transporte desnecessário acontece transportando exames, } \\
\text { pacientes, suprimentos ou informações. Também ocorre devido ao layout } \\
\text { de hospitais mal projetados. }\end{array}$ \\
\hline $\begin{array}{l}\text { Excesso de } \\
\text { processamento/ } \\
\text { processamento inútil }\end{array}$ & $\begin{array}{l}\text { Ocorre quando é realizado mais do que o pedido, ou seja, etapas } \\
\text { redundantes ou desnecessárias do ponto de vista do paciente, isso se } \\
\text { deve ao fato da comunicação deficiente ou um sistema burocrático, que } \\
\text { são ações não amigáveis para o usuário. Como por exemplo, múltiplos } \\
\text { formulários preenchidos pelos pacientes. }\end{array}$ \\
\hline $\begin{array}{l}\text { Defeitos ou } \\
\text { desconexão }\end{array}$ & $\begin{array}{l}\text { Tratando de saúde, defeitos, correções, ajustes ou informações } \\
\text { incompletas são ações que podem causar uma interrupção indesejada no } \\
\text { processo. Essa atitude, acarreta à criação de uma "má impressão" do } \\
\text { sistema para o paciente, exemplos desse desperdício são excesso/falta de } \\
\text { leitos ou medicamentos, tratamento inadequado, ociosidade, etapas mal } \\
\text { conectadas repercutindo em áreas adjacentes. }\end{array}$ \\
\hline Espera & $\begin{array}{l}\text { De alguma maneira, espera é um desperdício. Por exemplo, um paciente } \\
\text { esperando na sala de emergência por um atendimento, é um desperdício } \\
\text { para ele; um colaborador esperando por um instrumento, outro } \\
\text { colaborador, ou informação necessária pode ser considerado um } \\
\text { desperdício de tempo também. }\end{array}$ \\
\hline
\end{tabular}

Fonte: Adaptado de Manos et al (2006)

Muitos hospitais que já aplicaram o Lean Healthcare em diversos países. Como exemplo de aplicação, Womack (2005) apresenta o caso no Virginia Mason Medical Center (EUA), hospital que passava por uma fase crítica financeira e o uso adaptado do
Lean Manufacturing foi a saída para que o hospital se reerguesse e revertesse a situação negativa na qual se encontrava. A Tabela 1 mostra os resultados alcançados pelo hospital ao aplicar os conceitos do Lean Healthcare.

Tabela 1 - Resultados do uso de LeanHealthcare no Virginia Mason Medical Center

\begin{tabular}{|c|c|}
\hline \multicolumn{1}{|c|}{ Indicador } & Resultados Alcançados \\
\hline Produtividade & $45-75 \%$ \\
\hline Redução de custos & $25-55 \%$ \\
\hline Aumento do fluxo & $60-90 \%$ \\
\hline Qualidade & $50-90 \%$ \\
\hline Estoque reduzido & $60-90 \%$ \\
\hline Espaço reduzido & $35-50 \%$ \\
\hline Redução do Lead Time & $50-90 \%$ \\
\hline
\end{tabular}

Fonte: Adaptado de Womack (2005)

Outro caso, apresentado por Morilhas (2013), é o hospital ThedaCare, também nos EUA, que apresentou, entre outras melhorias, a diminuição do número de mortalidade dos pacientes. Os gestores comentaram que os resultados foram provenientes de um conjunto de atitudes dos médicos que foram examinados e melhorados, a partir da identificação de valor sob a ótica do usuário. Neste hospital, os ganhos foram: a queda do número de dias em que um paciente permanecia no hospital, de 6,3 para 4,9 dias; queda do custo de cirurgia coronária em $22 \%$; redução do tempo de espera para cirurgias ortopédicas de 14 semanas para 31 horas; e economia de cerca de US\$27 milhões. 
De acordo com Costa (2013), o hospital exemplo para Lean Healthcare no Brasil é o hospital São Camilo - Pompeia, em São Paulo. O projeto teve início a partir de uma parceria com a empresa Johnson \& Johnson, em 2007, e o início das atividades em fevereiro de 2008. Em 2010, a gestão já havia implantado a metodologia Lean em 6 processos com 63 projetos no total. O critério de escolha dos processos foi baseado no tempo takt e nível de ociosidade, com o projeto piloto aplicado em uma sala de cirurgia com uso dos kaizens de processos, a implementação takt time, a redução tempo de setup e o kanban para diferentes tipos de suprimentos. Os resultados para o projeto piloto foram: redução do tempo de setup de 1,5 hora para 0,5 hora, aumento de $33 \%$ da produtividade, e economia de, aproximadamente, $\mathrm{R} \$ 8$ milhões. Resultados como esses, fizeram com que o hospital adotasse o sistema de melhoria constante, disseminando a cultura Lean em todos os setores do hospital.

\subsection{TAKT TIME E TEMPO DE CICLO}

O takt time é uma métrica que estabelece o ritmo em que um produto deve ser realizado. Dennis (2008), define o tempo takt de um período conforme a Equação 1

$$
\text { TaktTime }=\frac{\text { Tempooperacional no período }}{\text { Volume de produção necessário no período }}
$$

Onde:

Tempo Operacional por período $=$ Tempo de produção - paradas

Baseado em Abdelhad (2015), o tempo de operação e o volume de produção necessário no período pode ser substituído por tempo disponível para atendimento e quantidade de pacientes atendidos nesse mesmo período de tempo, respectivamente. Portanto, o tempo takt, em se tratando de hospitais, pode ser calculado conforme a Equação 3.

Takt Time $=\frac{\text { Tempo disponível para atendimento }}{\text { Quantidade de pacientes atendidos }}$

O tempo de ciclo é o tempo que passa do início de um processo ou atividade individual até o seu término. Diversos tempos de ciclo podem estar incluídos em um processo ou função individual " (TAPPING e SHUKER, 2010). O tempo de ciclo inclui o tempo gasto fazendo atividades que agregam e aquelas que não agregam valor ao produto final.

Segundo Abdelhadi (2015), o cálculo para determinar a eficiência de um processo hospitalar pode ser realizado pela razão do takt time e o tempo de ciclo, podendo avaliar o quão longe do ideal o processo está. Assim, quanto mais próximo de 1, melhor é a eficiência. Logo, as atividades que tiverem baixa eficiência, serão as classificadas como atividade gargalo no processo de pronto atendimento. A razão entre os tempos é dada pela Equação 4.

$$
\varepsilon=\frac{\text { Takt Time }}{\text { Tempo de ciclo }}
$$

Ainda de acordo com Abdelhadi (2015), a comparação dos tempos também pode sugerir se a atividade realizada está acontecendo da maneira adequada; se a linha de produção está sendo subutilizada; e, por último, se é uma linha de produção incapaz de atender a demanda, tendo, como resultado, a saída de produtos de baixa qualidade. A comparação citada acima é resumida pela Figura 1: 
Figura 1 - Comparação entre tempo de ciclo e takt time relacionando-os à situação do processo

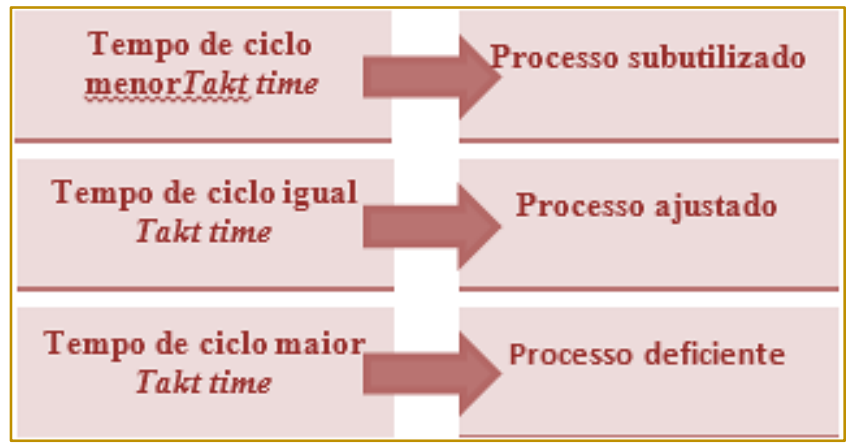

Fonte: Autoria própria

Para a atual pesquisa, entende-se que a demanda de pacientes no pronto atendimento não é atendida quando o tempo de ciclo for maior que o takt time.

\section{METODOLOGIA}

Os dados coletados correspondem aos meses de maio, junho, julho e agosto de 2016. A fim de determinar a existência de processos gargalos no pronto atendimento do hospital, determinou-se a eficiência do atendimento, com base na razão dos tempos. Para isso, realizaram-se as seguintes etapas:

a) Identificação e mapeamento dos processos no atendimento:

b) Cálculo do tempo de ciclo; c) Cálculo do takt time;

d) Cálculo da eficiência do atendimento e identificação da situação do pronto atendimento;

e) Sugestões de melhorias para os processos deficientes.

Os softwares utilizados nesta pesquisa foram disponibilizados pela Universidade Federal de Itajubá no Campus de Itabira, no LOSI Laboratório de Otimização e Simulação.

\section{RESULTADOS E DISCUSSÕES}

A primeira etapa deste estudo de caso, foi o conhecimento do processo do pronto atendimento do hospital. O mapeamento do processo foi realizado, conforme Figura 2:

Figura 2 - Mapeamento do processo de atendimento ao paciente, discriminado de acordo com a classificação de risco utilizada.

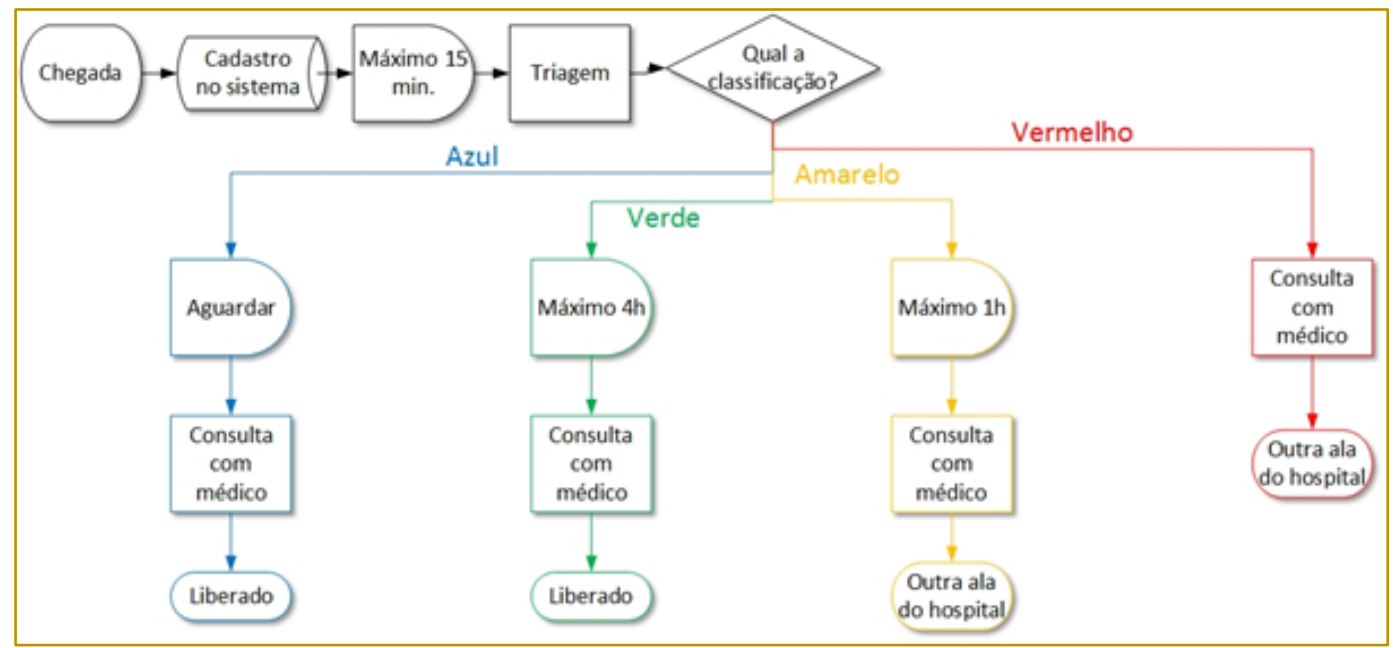

Fonte: Autoria própria 
No momento em que o paciente chega ao pronto atendimento, é realizado o cadastro no sistema, nas mesas de recepção. Em seguida, se aguarda, no máximo, 15 minutos para seguir para a triagem com um enfermeiro, onde o mesmo o classifica de acordo com a regra utilizada. A partir desse momento, o paciente volta à sala de recepção onde aguarda pelo atendimento, de acordo com a sua classe determinada e com a demanda de pacientes a serem atendidos.

Na Tabela 2 encontram-se os dados obtidos e os resultados encontrados para a eficiência do pronto atendimento referente aos meses de maio, junho, julho e agosto.

Tabela 2 - Dados obtidos e resultados encontrados para os meses analisados

\begin{tabular}{|c|c|c|c|c|c|c|}
\multicolumn{2}{c}{$\begin{array}{c}\text { Mês de } \\
\text { análise }\end{array}$} & $\begin{array}{c}\text { Número total de } \\
\text { pacientes }\end{array}$ & $\begin{array}{c}\text { Tempo } \\
\text { total } \\
\text { (horas) }\end{array}$ & $\begin{array}{c}\text { Tempo de ciclo } \\
\text { (horas/paciente }\end{array}$ & $\begin{array}{c}\text { Tempo takt } \\
\text { (horas/paciente }\end{array}$ & \multicolumn{2}{c|}{$\begin{array}{c}\text { Eficiência } \\
\text { Classificaçã } \\
0\end{array}$} \\
\hline Maio & 1587 & 1960 & 1,24 & 0,47 & $264 \%$ & $\begin{array}{c}\text { Processo } \\
\text { deficiente }\end{array}$ \\
\hline Junho & 1200 & 1140 & 0,95 & 0,60 & $158 \%$ & $\begin{array}{c}\text { Processo } \\
\text { deficiente }\end{array}$ \\
\hline Julho & 1890 & 1485 & 0,79 & 0,39 & $203 \%$ & $\begin{array}{c}\text { Processo } \\
\text { deficiente }\end{array}$ \\
\hline Agosto & 1982 & 1634 & 0,82 & 0,38 & $216 \%$ & $\begin{array}{c}\text { Processo } \\
\text { deficiente }\end{array}$ \\
\hline
\end{tabular}

Fonte: Autoria própria

Os cálculos realizados para obter os valores do mês de maio da Tabela 2, estão discriminados a seguir.

$$
\begin{gathered}
\text { Tempo de ciclo }=\frac{1960 \text { horas }}{1587 \text { pacientes }}=1,24 \text { horas } / \text { paciente } \\
\text { Takt Time }=\frac{\text { Tempo Disponível para atendimento }}{\text { Quantidade de pacientes }}=\frac{744}{1587}=0,47 \text { horas } / \text { paciente }
\end{gathered}
$$

$$
\varepsilon=\frac{\text { Takt Time }}{\text { Tempo de ciclo }}=\frac{0,47}{1,24}=38 \%
$$

Uma outra maneira de interpretar os resultados é fazendo um cálculo inverso, de

$$
\% \text { de utilização relativa }=\frac{\text { Tempo de ciclo }}{\text { Takt Time }}=\frac{1,24}{0,47}=2,64
$$

O resultado mostra que tempo de ciclo é 2,64 vezes maior do que o takt time. Em outras palavras, no mês de maio o cliente teve que esperar 0,77 horas a mais para ser atendido no pronto atendimento, e que, portanto, ressalta a deficiência do processo.
A Figura 3 apresenta a comparação entre os tempos de ciclo e o takt time para cada mês de análise, além disso, é perceptível a diferença entre esses tempos, o que confirma a ineficiência do pronto atendimento do hospital em análise. 


\section{0}

Figura 3 - Comparação entre o tempo de ciclo e o takt time do pronto atendimento dos meses analisados

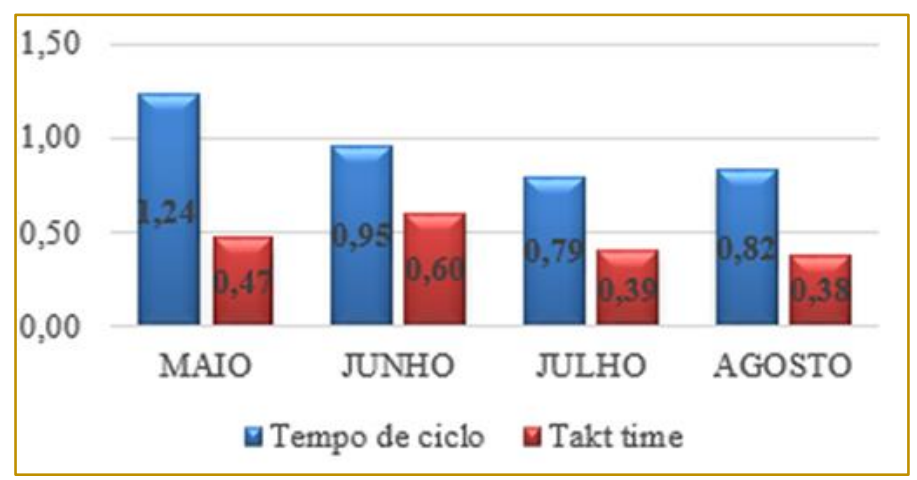

Fonte: Autoria própria

A Tabela 3 contém as médias das quantidades de pacientes, do tempo total de atendimento, do tempo de ciclo, do takt time e a eficiência para o pronto atendimento do hospital observado durante o período de levantamento de dados.

Tabela 3 - Média dos dados obtidos e resultados encontrados para os quatro meses de análise

\begin{tabular}{|c|c|c|c|c|}
\hline Número total de pacientes & Tempo total & $\begin{array}{l}\text { Tempo } \\
\text { de ciclo }\end{array}$ & $\begin{array}{c}\text { Tempo } \\
\text { takt }\end{array}$ & Eficiência \\
\hline 1665 & 1555 & 0,95 & 0,46 & $208,7 \%$ \\
\hline
\end{tabular}

Após os cálculos realizados, a última etapa desta pesquisa foi identificar as fontes de desperdícios dos processos do pronto atendimento. Para isso, formou-se uma equipe de trabalho com o objetivo de identificar essas perdas e, a partir da experiência e conhecimento do processo, levantar as atividades de não agregação de valor. A equipe era formada por 3 médicos clínicos gerais, 3 enfermeiras, 3 técnicas de enfermagem e 2 atendentes administrativas (recepcionistas), além dos pesquisadores. Assim foi possível identificar as fontes de desperdícios e, consequentemente, as sugestões de melhorias, feitas pela equipe de trabalho, de acordo com o Quadro 2. 
Quadro 2 - Desperdícios encontrados com suas respectivas fontes e alterações de melhorias sugeridas

\begin{tabular}{|c|c|c|}
\hline Desperdício & Fonte & Propostas de melhorias \\
\hline $\begin{array}{l}\text { Falta de dados na } \\
\text { ficha de informação } \\
\text { do paciente }\end{array}$ & \multirow{2}{*}{$\begin{array}{l}\text { Falha do programa } \\
\text { computacional utilizado, } \\
\text { visto que os dados são } \\
\text { gerados automaticamente } \\
\text { e não está programado } \\
\text { para evitar erros nos } \\
\text { documentos gerados. }\end{array}$} & \multirow{2}{*}{$\begin{array}{l}\text { Orientar a equipe de TI a ocorrência dessas } \\
\text { falhas para que seja feito uma revisão no } \\
\text { programa computacional, afim de prever falhas } \\
\text { (criar poka-yoke para o software). }\end{array}$} \\
\hline $\begin{array}{l}\text { Documentação } \\
\text { duplicada }\end{array}$ & & \\
\hline $\begin{array}{l}\text { Burocracia para } \\
\text { pedido de exames }\end{array}$ & $\begin{array}{l}\text { Falhas no sistema de } \\
\text { informática. Paciente tem } \\
\text { que voltar na recepção } \\
\text { para fazer pedido ao } \\
\text { plano de saúde. }\end{array}$ & $\begin{array}{l}\text { Implementar conceitos de prova de erros no } \\
\text { programa para minimizar os erros de informática. } \\
\text { Fazer o mapeamento de processos SIPOC } \\
\text { (Supplier_Input_Process_Output_Costumer) do } \\
\text { fluxo de pedidos de exames, identificando as } \\
\text { atividades que não agregam valor e } \\
\text { posteriormente eliminando-as do fluxo. }\end{array}$ \\
\hline $\begin{array}{l}\text { Falta de comunicação } \\
\text { entre os setores }\end{array}$ & $\begin{array}{l}\text { Comunicação entre os } \\
\text { médicos, enfermeiros e } \\
\text { recepcionistas é falho } \\
\text { principalmente no } \\
\text { momento de alta } \\
\text { demandas. }\end{array}$ & $\begin{array}{l}\text { Desenvolver um estudo de mapeamento de } \\
\text { processos SIPOC, para melhor entender como } \\
\text { funciona o processo de comunicação e realizar } \\
\text { melhorias no fluxo das informações. }\end{array}$ \\
\hline $\begin{array}{l}\text { Insumos de consulta } \\
\text { desorganizados }\end{array}$ & $\begin{array}{l}\text { Devido à alta demanda, } \\
\text { falta tempo para } \\
\text { organização de } \\
\text { documentos e } \\
\text { prontuários. }\end{array}$ & $\begin{array}{l}\text { Utilizar o } 5 \text { S para a organização de documentes. } \\
\text { Estabelecer rotina de trabalho para a } \\
\text { organização de documentos. }\end{array}$ \\
\hline $\begin{array}{l}\text { Longas } \\
\text { movimentações } \\
\text { movimentações } \\
\text { desnecessárias } \\
\text { (colaboradores) }\end{array}$ & $\begin{array}{l}\text { Deslocamento até o } \\
\text { laboratório para pedir } \\
\text { agilidade nos exames; } \\
\text { Buscar por medicamentos } \\
\text { na farmácia do hospital, } \\
\text { localizado no } 2^{\circ} \text { andar do } \\
\text { hospital. }\end{array}$ & $\begin{array}{l}\text { Estabelecer padronização de trabalho para o } \\
\text { laboratório (requer estudo aprofundado), para } \\
\text { que seja realizado os exames de emergência do } \\
\text { pronto atendimento de maneira mais ágil. } \\
\text { Aumentar a capacidade do mesmo; Segunda } \\
\text { unidade de farmácia (em menor escala e com o } \\
\text { mesmo sistema de gestão de estoque) dentro do } \\
\text { pronto atendimento. }\end{array}$ \\
\hline $\begin{array}{l}\text { Transporte de } \\
\text { suprimentos em } \\
\text { excesso }\end{array}$ & $\begin{array}{l}\text { Em função da farmácia } \\
\text { estar distante do local de } \\
\text { atendimento, as técnicas } \\
\text { de enfermagem levam } \\
\text { medicações em excesso } \\
\text { para o local de trabalho. }\end{array}$ & $\begin{array}{l}\text { Segunda unidade de farmácia (em menor escala } \\
\text { e com o mesmo sistema de gestão de estoque) } \\
\text { dentro do pronto atendimento. }\end{array}$ \\
\hline $\begin{array}{l}\text { Interrupções no } \\
\text { processo de } \\
\text { atendimento }\end{array}$ & $\begin{array}{l}\text { Interrupções para sanar } \\
\text { dúvidas de equipe } \\
\text { médica via telefone ou } \\
\text { pessoalmente e de } \\
\text { pacientes. }\end{array}$ & $\begin{array}{l}\text { Novas regras quanto à comunicação entre } \\
\text { equipe médica: não interromper consultas, } \\
\text { somente em urgência. Para dúvidas via telefone, } \\
\text { aderir sistema de caixa de mensagens na rede } \\
\text { interna do pronto atendimento. }\end{array}$ \\
\hline
\end{tabular}

Fonte: Autoria própria

Percebe-se que os gargalos do pronto atendimento são dos setores em que os resultados influenciam diretamente em seu desempenho. O erro humano: erros frequentes ao realizar o cadastro dos pacientes; O laboratório de exame: distante e que necessita de melhorias em seu sistema de priorização de exames; A farmácia: por ser a única unidade para todo hospital e estar distante do pronto atendimento, gera uma perda com deslocamentos frequentes dos funcionários que vão até lá a procura de medicamentos e suprimentos.

O Quadro 2 evidencia claramente que o pronto atendimento necessita de melhorias e as sugestões apresentadas nessa pesquisa foi o primeiro passo para que o hospital iniciasse o processo de mudança em seu pronto atendimento e o dar início a jornada do Lean Healthcare. 


\section{CONSIDERAÇÕES FINAIS}

O resultado dessa pesquisa permitiu identificar o tempo de permanência do paciente no pronto atendimento do hospital estudado, desde o primeiro contato com o serviço até a sua saída. A percentagem de utilização relativa mostra que o tempo de permanência do paciente é, aproximadamente, 2,1 vezes maior do que o takt time estabelecido, ou seja, o paciente fica em média 1,07 horas a mais no pronto atendimento, o que acarreta uma enorme insatisfação por parte do usuário do hospital.

Com a análise entre os tempos de ciclo e o takt time, foi possível identificar o tamanho da ineficiência do processo, permitindo identificar as atividades gargalos e assim, propor sugestões de melhorias para os

\section{REFERÊNCIAS}

[1] Abdelhadi, Abdelhakim. Investigating emergency room service quality using leanManufacturing. International Journal of Health Care Quality Assurance, v.28, n. 5, p. 510 $519,2015$.

[2] Buzzi, Deize.; Plytiuk, Crislayne. F. Pensamento enxuto e sistemas de saúde: um estudo da aplicabilidade de conceitos e ferramentas lean em contexto hospitalar. Revista Qualidade Emergente, Curitiba, v. 2, n. 2, p. 18-38, 2011.

[3] Costa, Daniele A. Lean Healthcare Unicamp: Relato de Experiência Hospital São Camilo. In: Fórum Permanente de Empreendedorismo e Inovação, Campinas, 2013. Disponível em: <http://www.foruns.unicamp.br/foruns/projetocotuc a/biblioteca_virtual/arquivos/Daniela\%20Akemi.pdf > Acesso em: 12 set. 2016.

[4] Dennis, Pascal. Produção Lean Simplificada. $2^{\underline{a}}$ ed. Porto Alegre, Bookman. 2008.

[5] Fonseca, João J. Metodologia da pesquisa científica. Fortaleza: UCE. Universidade Estadual do Ceará. 2002.

[6] Gil, Antônio C. Como elaborar projetos de pesquisa. 4. ed., São Paulo, Atlas, 2002.

[7] Holland, Dutch; ROHE, Duke. Implementing Lean Healthcare projects: On target on time on budget. 1aㅡ ed. Canada, Xlibris, 2013. problemas apresentados.

Como proposta de trabalhos futuros, tem-se a implementação e acompanhamento das sugestões apresentadas nesta pesquisa, a fim de trazer melhorias para o pronto atendimento. Realizar um estudo de cronoanálise para estabelecer padrões de tempos para as atividades do pronto atendimento, facilitando o dimensionamento da mão-de-obra necessária para atender as flutuações de demanda. Implementar o sistema de gestão da qualidade que avalie a classificação de risco utilizada pelo hospital quanto à sua aplicabilidade de acordo com a demanda e capacidade do pronto atendimento em estudo.

[8] Manos, A; Sattler, M.; Alukal, G. Make Healthcare Lean. Quality Progress, p. 24 - 30, jul, 2006

[9] Morilhas, Leandro. J.; Nascimento, Paulo Tramboni. S.; Fedichina, Marcio Antônio. H. Análise para a melhoria da gestão de operações na área hospitalar: um estudo a partir da utilização da filosofia lean healthcare. In: Simpósio de Administração de Produção, Logística e Operações Internacionais, v.16, Anais, 2013

[10] Ohno, Taichi. O sistema Toyota de Produção: além da produção em larga escala. s/n. Porto Alegre, Bookman. 1997

[11] Souza, Luciano. B. Trends and approaches in lean healthcare. Leadership in Health Services, v. 22, n. 2, p. 121 - 139, 2009.

[12] Tapping, Don; Shuker, Tom. Lean Office: Gerenciamento do fluxo de valor para áreas administrativas. $1^{\underline{a}}$ ed. São Paulo, Leopardo Editora. 2010.

[13] Turrioni, João B.; Mello, Carlos Henrique P. Metodologia de Pesquisa em Engenharia de Produção. Itajubá: Unifei. Universidade Federal de Itajubá ,2012.

[14] WOMACK, Jones P et al. Going Lean in Health Care. Innovation Series, Institute for Healthcare Improvement. 2005 


\section{CAPÍTULO 10}

\section{VIRTUALIZACÃO DE DOCUMENTOS E MÉTODO ELETRÔNICO DE ARQUIVAMENTO: AVALIACÃO DOS RESULTADOS DA GESTÃO DA TECNOLOGIA EM MPES}

\section{Roberto Carlos Santos Pedroga}

\section{Cristopher Santos Pedroga}

Resumo: Este estudo de avaliação de intervenção objetivou identificar e solucionar deficiências relacionadas à realização de atividades de gestão da tecnologia, de documentos e de informação dentro das áreas de interesse nas MPEs da região norte de Minas Gerais, mostrando a realidade das organizações de menor porte da região. De entendimento qualitativo, o estudo fundamentou-se basicamente da observação e coleta de informações verbalmente através de entrevistas individuais com os colaboradores envolvidos no processo de gestão documental, comumente nas áreas de administração, finanças e contabilidade dentro das empresas estudadas. Como toda empresa busca diferenciar-se de outras na busca de maiores parcelas do mercado em que se está inserida, as MPEs possuem a característica de favorecer-se de metodologias e ferramentas que simplificam e agilizam processos, quando utilizadas corretamente. Pensando nisso, o foco principal deste estudo está na melhoria e implantação de processos, ferramentas e metodologias simples e de baixo custo para a troca de informações dentro das MPEs.

Palavras-chave: Virtualização, tecnologia, gestão, documentos. 


\section{INTRODUÇÃO}

Diante das constantes mudanças que há em todo o mundo quando se trata de tecnologia e informação, uma organização que se mantém constantemente atualizada e integrada dos novos conceitos e tendências é aquela que se mantém por mais tempo no mercado ou que adquire a habilidade de conquistar ainda mais parcelas do mercado no qual está inserida.

Este estudo de avaliação de intervenção visa apresentar os resultados obtidos com a gestão tecnológica dentro de um grupo de micro e pequenas empresas, no que tange a gestão de documentos, de diversos assuntos, visto que as mesmas possuíam entre si deficiências semelhantes para manipular esses documentos e informações dentro de suas unidades administrativas.

O perfil dos micro e pequenos empresários brasileiros é, em sua maioria, homens (61\%), com idade entre 35 e 54 anos (54\%), com ensino médio completo $(39,7 \%)$, possuindo entre 1 e 4 funcionários (66\%), sendo cerca de $89 \%$ dos empregados são registrados. Presentes no mercado há mais de 9 anos (87\%), a dificuldade de conquistar e manter clientes é presente em 15\% dos casos. (CDL; SPC Brasil, 2015).

Para o estudo aqui realizado, levaram-se em consideração as informações presentes em três micro e pequenas empresas da região norte de Minas Gerais. Atuantes em diferentes setores, porém com um fator em comum: a deficiência na gestão documental e precariedade da gestão de tecnologia e comunicação.

Apesar das empresas serem de diferentes ramos de atuação dentre outras características incomuns, possuíam um fator dificultador em comum quando se tratava da administração de seus documentos e manipulação das informações dentro da instituição, por não possuírem ou possuírem de forma deficiente uma metodologia para a gestão desses documentos, que por sua vez causava transtornos e atrasos em tramitações com clientes, fornecedores e com os próprios colaboradores das instituições.

Portanto este trabalho descreve a busca pela melhoria das metodologias de gestão de documentos e informações dentro das MPEs, aplicando ferramentas simples, intuitivas e de baixo custo de implantação e manutenção.

\section{METODOLOGIA}

Para a produção deste estudo, a metodologia de pesquisa base é a qualitativa, onde buscou-se analisar a aplicação de ferramentas eletrônicas e digitais, objetivando a realização das tarefas envolvidas ao processo de gestão de documentos no âmbito administrativo das micro e pequenas empresas. Sendo assim, determinado para a percepção das informações, foi realizada uma entrevista com cada equipe e colaborados envolvidos na atividade de gestão documental, além da observação participante de todo o processo e subprocessos envolvidos no setor administrativo de três micro e pequenas empresas de ramos distintos, localizadas no norte de Minas Gerais.

A escolha da entrevista como método de coleta de informações do meio estudado, deve-se ao fato de muitas vezes os dados relevantes para a pesquisa não estarem registrados em documentos físicos ou digitais, obtendo-os somente verbalmente a partir dos colaboradores envolvidos no processo que obtiveram o conhecimento dessas informações através do contato direto com o processo ou atividade. Além de ser "muitas vezes superior a outros sistemas de obtenção de dados", conforme afirma Best (1972 apud LAKATOS e MARCONI, 2010).

De acordo com Sampieri et al (2003 apud LAKATOS e MARCONI, 2011), a entrevista qualitativa pode ser traduzida como um diálogo entre duas ou mais pessoas, sendo um o entrevistador e os demais, entrevistados.

Com o objetivo de obter respostas para as questões levantadas para a realização do estudo, segundo Lakatos e Marconi (2011), durante o diálogo entre o entrevistador e o entrevistado, pode-se utilizar de diversos meios para a obtenção de informações, como por exemplo, anotações, computadores, celulares e fotografias, porém as informações sempre são fornecidas verbalmente pelo entrevistado ao entrevistador. Ainda que o entrevistado não tenha fornecido a informação que o entrevistador necessita, não deve haver tensão, tendenciosidades e perturbações na conversa, buscando sempre o entrevistador manter a calma, espontaneidade e aprofundamento do diálogo.

Para Lakatos e Marconi (2011), a observação qualitativa, também conhecida como observação de campo, objetiva a exploração de um ambiente e suas diferentes atividades 
empregadas pelos agentes presentes, descrevendo o meio $e$ interpretando $o$ significado das atividades individualmente e como parte de um todo. Abrangendo também a compreensão de processos, culturas, contextos e eventos periódicos ou esporádicos, tornando facilitado o processo de identificação de problemas e fundamentação para formular hipóteses que poderão ser utilizadas para a criação de novos estudos. Há na observação qualitativa a importância do pesquisador imergir progressivamente no ambiente que estuda para que não seja relacionado como um agente estranho.

Segundo Grinnell (1997 apud LAKATOS e MARCONI, 2011), as informações coletadas pelo pesquisador podem ser de natureza da observação direta ou interpretativa, sendo esta relacionada a forma como o observador entende e relata aspectos subjetivos (emoções, relacionamentos e fatores culturais, dentre outros), além daquela, que é a forma como são descritas as interpretações dos sentidos do observador (visão, audição, olfato, paladar e tato) e do entendimento do contexto e do ambiente, examinando os fatos e organizando as informações na sequência que surgem, ou seja, cronologicamente.

Pode-se entender também, como as observações feitas no contexto real, relatando os eventos quando e onde são ocorridos, sem possibilidade de planejamento, de forma espontânea, o que estreita a propensão de preferências e manipulação de informações. Contando com a participação direta e verdadeira do pesquisador no ambiente, se confundindo com os membros do ambiente, fazendo com que ele se misture ao grupo e esteja colaborando com as atividades do meio estudado (LAKATOS e MARCONI, 2010).

Com base nos perfis das empresas e dados coletados durante as entrevistas e observações in company, posteriormente, foram selecionadas as propostas de melhoria que englobassem as ferramentas e técnicas que deveriam ser utilizadas no combate as deficiências que as três instituições possuíam em comum.

\section{DESENVOLVIMENTO}

Serão apresentados aqui as rotinas e aplicações realizadas durante todo o estudo, buscando relatar os estágios desenvolvidos, além de evidenciar a grande importância das características observadas em cada situação.

\subsection{INFORMAÇÕES DO PROJETO}

Algumas características e dados das instituições que serviram de base para este estudo foram tratadas aqui como incógnitas, devido ao fato dessas organizações optarem por sigilo na publicação de determinados dados.

A instituições onde foram realizadas as intervenções foram identificadas e possuem as características conforme discriminado abaixo:

Empresa A possui um faturamento anual de $\mathrm{R} \$$ 381.479,32 para o exercício de 2016, pertencente ao ramo da indústria de construção e atua há 5 anos no mercado, contando com 19 funcionários, todos registrados, além do próprio sócioadministrador, sendo seu perfil enquadrado como homem de 42 anos, possuindo ensino médio completo e renda mensal entre 5 e 10 salários mínimos vigentes;

Empresa B possui um faturamento anual de $\mathrm{R} \$ 247.951,49$ para o exercício de 2016, pertencente ao ramo da indústria de transformação e atua há 7 anos no mercado, contando com 5 funcionários, nenhum deles é registrado, além do próprio sócioadministrador, sendo seu perfil enquadrado como homem de 47 anos, possuindo ensino fundamental completo e renda mensal entre 1 e 5 salários mínimos vigentes;

Empresa $\mathrm{C}$ possui um faturamento anual de $\mathrm{R} \$$ 335.219,68 para o exercício de 2016, pertencente ao ramo de serviços e atua há 4 anos no mercado, contando com 8 funcionários, todos registrados, além do próprio sócio-administrador, sendo seu perfil enquadrado como homem de 39 anos, possuindo ensino médio completo e renda mensal entre 1 e 5 salários mínimos vigentes.

Todas as empresas utilizam serviços de assessoria contábil por meio de terceirizado, desde o registro no Cadastro Nacional de Pessoas Jurídicas, até a elaboração do balanço patrimonial realizado anualmente para cada período de exercício. Algo muito comum entre micro e pequenas empresas, que corriqueiramente, não dispõe de departamento contábil ou conhecimento sólido para a realização de atividades relacionadas. Com o envolvimento desses 
agentes externos, aumenta-se o risco de extravio, perda e ausência de controle de documentos e informações das instituições.

No decorrer do estudo, identificou-se os problemas mais recorrentes, nos setores com grande fluxo de documentos, nas três empresas. Sendo eles os seguintes:

- Ausência de controle financeiro, administrativo e documental;

- Ausência de pessoal qualificado para gestão documental;

- Ausência de um plano de gestão documental;

- Assessoria contábil precária;

- Dificuldade de afirmar a identidade visual da instituição;

- Dificuldade de alocar documentos físicos;

- Dificuldade em localizar documentos para comprovação fiscal;
- Dificuldade em traçar a história da instituição;

- Documentos em condições precárias (armazenados de forma errada);

- Equipamentos e móveis precários ou em péssimo estado de conservação, dificultando o desenvolvimento das atividades:

\section{- Extravio de documentos.}

Observando uma tendência à categorização das deficiências, foram identificadas três palavras-chaves para diferenciá-las entre si. Com base nessas informações, cada situação foi classificada conforme três categorias denominadas como Ferramentas, Processos e Pessoas.

Cada problema identificado foi categorizado conforme a Tabela 1 abaixo:

Tabela 9 - Categorização das deficiências observadas

$$
\text { Ferramentas }
$$
Processos Pessoas

\begin{tabular}{|c|c|c|}
\hline $\begin{array}{l}\text { Ausência de controle financeiro, } \\
\text { administrativo e documental; }\end{array}$ & $\begin{array}{l}\text { Ausência de um plano de gestão } \\
\text { documental; }\end{array}$ & $\begin{array}{c}\text { Ausência de pessoal qualificado } \\
\text { para gestão documental; }\end{array}$ \\
\hline $\begin{array}{l}\text { Dificuldade de alocar documentos } \\
\text { físicos; }\end{array}$ & $\begin{array}{c}\text { Dificuldade de afirmar a } \\
\text { identidade visual da instituição; }\end{array}$ & Extravio de documentos; \\
\hline $\begin{array}{l}\text { Equipamentos e móveis precários } \\
\text { ou em péssimo estado de } \\
\text { conservação, dificultando o } \\
\text { desenvolvimento das atividades; }\end{array}$ & $\begin{array}{l}\text { Dificuldade em traçar a história da } \\
\text { instituição; }\end{array}$ & \\
\hline $\begin{array}{l}\text { Documentos em condições } \\
\text { precárias (armazenados de forma } \\
\text { errada); }\end{array}$ & $\begin{array}{c}\text { Dificuldade em localizar } \\
\text { documentos para comprovação } \\
\text { fiscal; }\end{array}$ & \\
\hline
\end{tabular}

Fonte: PEDROGA (2017)

Levando-se em consideração o procedimento de classificação dos problemas existentes, ao definir as três grandes áreas para intervenção, pode-se identificar a distribuição comum dessas necessidades, observando que é mais intensa quando estão relacionadas a utilização de ferramentas, posteriormente com a deficiência dos processos e menos intensa quando diz respeito as pessoas envolvidas, conforme pode-se observar na Figura 1. 
Figura 12 - Gráfico da proporção de problemas por categoria

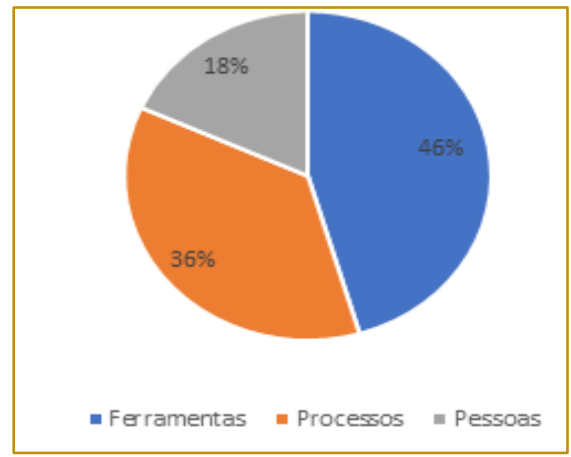

Fonte: PEDROGA (2017)

Os desperdícios gerados pelo sistema atual de gerenciamento de informações dentro das MPEs, torna possível visualizar com clareza a necessidade de melhorias das atividades existente, eliminação das atividades que não agregam valor e são dispendiosas, além da remodelagem ou implantação de novas ferramentas e metodologias de gerenciamento de arquivos.

\subsection{PROPOSTAS DE MELHORIA}

Conforme Lerner (1982), objetivou-se alcançar resultados satisfatórios propondo-se a implantação de metodologias que se adequavam a realidade das instituições. Para tal levou-se em consideração a aplicação das seguintes características:

- Controle simplificado e facilitado para os usuários;

- Facilidade de acesso, mesmo com níveis de restrição;

- Facilidade de ordenar documentos e informações;

- Manter a integridade da informação;

- Portabilidade para diversas plataformas de análise;

- Tamanho de alocação físico reduzido.
Em consonância com as restrições propostas pelos responsáveis de nível estratégico dentro de cada organização, sugeriu-se a implantação de infraestrutura informática (redes, móveis, cabeamento, impressoras), aquisição de terminais (computadores), organização do arquivo físico (metodologia de arquivamento), orientação e treinamento dos envolvidos no processo de gestão documental, aumento de frequência no uso de serviço de e-mail, implantação da metodologia de arquivamento de computação em nuvem, utilização de sistemas digitais para controle (de contas, vencimento de boletos, controle de notas e data de registros diversos).

\subsection{RESULTADOS OBTIDOS}

Algumas propostas foram consideradas pelas organizações, outras não tiveram êxito em serem aceitas pelas três MPEs paralelamente. Com base na observação do ambiente no qual houve o estudo, ficou clara a transformação positiva que as melhorias provocaram.

Após a análise das novas observações em campo e entrevistas com os participantes dos processos de gestão documental dentro das organizações, pôde-se constatar a redução significativa dos itens relacionados na Tabela 2 que se segue. 
Tabela 10 - Resultados qualitativos obtidos com a implantação das melhorias

\begin{tabular}{|c|c|c|}
\hline Ferramentas & Processos & Pessoas \\
\hline $\begin{array}{l}\text { Redução de rasuras e } \\
\text { desperdício de papel }\end{array}$ & $\begin{array}{l}\text { Redução com movimentação para } \\
\text { a busca de informações em } \\
\text { arquivos }\end{array}$ & $\begin{array}{l}\text { Redução de estresse } \\
\text { (complicações com o } \\
\text { desempenho das atividades) }\end{array}$ \\
\hline $\begin{array}{l}\text { Aumento da capacidade de } \\
\text { análise dos dados }\end{array}$ & $\begin{array}{l}\text { Agilidade na realização de } \\
\text { pesquisas por documentos ou } \\
\text { dados pertinentes }\end{array}$ & $\begin{array}{l}\text { Ambiente de trabalho mais } \\
\text { agradável }\end{array}$ \\
\hline \multirow[t]{2}{*}{$\begin{array}{l}\text { Melhoria do aspecto físico do } \\
\text { ambiente }\end{array}$} & $\begin{array}{l}\text { Redução do tempo de resposta } \\
\text { para clientes, fornecedores e } \\
\text { colaboradores }\end{array}$ & $\begin{array}{l}\text { Aumento da motivação no } \\
\text { empenho das atividades dos } \\
\text { colaboradores }\end{array}$ \\
\hline & $\begin{array}{l}\text { Elevação do nível de segurança } \\
\text { dos dados das instituições }\end{array}$ & \\
\hline
\end{tabular}
Fonte: PEDROGA (2017)

\section{CONSIDERAÇÕES FINAIS}

Este trabalho científico contribui para a demonstração de um caso de intervenções simples, de baixo custo para as empresas e grande influência tanto no interior como no exterior das organizações. Estabelecendo também uma linha de conscientização para as micro e pequenas empresas no âmbito do aprimoramento organizacional e melhorias no registro e controle da informação nas instituições. Servindo ainda de princípio para a realização de futuros outros estudos, objetivando a melhoria contínua da gestão de tecnologia de informação e comunicação em organizações, principalmente no que tange a gestão documental.

Segundo Oliveira (2007), é "importante dizer que cada vez mais os livros vão sendo

\section{REFERÊNCIAS}

[1] Cdl; Brasil, SPC. Perfil Das Micro E Pequenas Empresas Brasileiras. 2015. Disponível em:

https://www.spcbrasil.org.br/uploads/st_imprensa/r elatorio_perfil_mpe1.pdf>. Acesso em: 01 de maio de 2017

[2] Freiberger, Zélia. Gestão de Documentos e Arquivística. Curitiba: IFAP, 2012. Disponível em: <http://ead.ifap.edu.br/netsys/public/livros/Livros\% 20Curso\%20Servi\%C3\%A7os\%20P\%C3\%BAblicos /M\%C3\%B3dulo\%20I/Livro\%20Gestao\%20de\%20D ocumentos\%20e\%20Arquivistica/Livro\%20Gestao \%20de\%20Documentos\%20e\%20Arquivistica.pdf> Acesso em: 01 de maio de 2017.

[3] Lakatos, Eva Maria; Marconi, Marina de substituídos por métodos eletrônicos de arquivamento. O importante é que se garanta a publicidade, a eficácia, a segurança e a autenticidade dos registros".

Por fim, é possível concluir que a utilização da virtualização documental e metodologia eletrônica de arquivamento é, de fato, muito importante tanto para a descentralização da informação como para a redução de desperdícios de movimento e tempo relacionados a busca constante de informações nos arquivos físicos, além do incremento na agilidade de obtenção de informações, análises e o processo de tomada de decisões estratégicas baseadas nessas informações.

Andrade. Fundamentos de Metodologia Científica. Atlas. 7ed. 177-205p.

[4] Lakatos, Eva Maria; Marconi, Marina de Andrade. Metodologia Científica. Atlas. 6ed. 273$274 p$.

[5] Lerner, Walter. Organização, sistemas e métodos. ATLAS. 4ed. 101p.

[6] Oliveira, Ronaldo Santos de. Métodos de arquivamento. Revista Jus Navigandi, ISSN 15184862, Teresina, ano 12, n. 1366, 29 mar. 2007. Disponível em: <https://jus.com.br/artigos/9664>. Acesso em: 01 de maio de 2017. 


\section{GAPÍTULO 11}

\section{O PROCESSO DE IMPLANTAÇÃO DO TERMINAL PORTUÁRIO DE NOVO REMANSO E AS PERSPECTIVAS DE TRANSFORMAÇOEES ECONOMICAS LOCAIS}

\section{Marcos Antônio de Souza Queiroz}

\section{Rute Holanda Lopes}

\section{Renata de Oliveira Teixeira}

Pollyanna Menezes de Sousa

Yara Almeida da Rocha

\section{Alessandra Ferreira Reis}

Resumo: O município de Itacoatiara localiza-se as margens do Rio Amazonas que devido a seu calado permite a navegabilidade durante todo o ano. Estas características geográficas permitem receber embarcações de grande porte, o que Ihe confere atratividade para empresas portuárias e de navegações. O presente estudo vem acompanhar o impacto que a construção de um Terminal Portuário no Novo Remanso na economia de Itacoatiara-AM, mapeando os empreendimentos já existentes e os que serão abertos e desenvolvidos com o início da obra. A metodologia buscou foco em estudo bibliográfico, embasamento teórico buscando artigos, dissertações e teses relacionadas à pesquisa, estudo de campo por meio de entrevistas locais e observação, buscando identificar as mudanças ocorridas durante o tempo estabelecido pela pesquisa, com análise qualitativa dos dados.

Palavras-chave: Desenvolvimento Regional, Terminal Portuário do Novo Remanso, Itacoatiara. 


\section{INTRODUÇÃO}

O município de Itacoatiara localiza-se as margens do Rio Amazonas que devido a seu calado permite a navegabilidade durante todo o ano. Devido a características geográficas permite receber embarcações de grande porte, o que the confere atratividade para empresas portuárias e de navegações. Neste sentido, Silva (1997) afirma que, Itacoatiara tornou-se destaque em sua localização por conta do seu calado fluvial ser navegável o ano inteiro devido a profundidade do rio Amazonas na região portuária. Conforme Alfredini e Arasaki (2009) o panorama do mercado hidroviário está intimamente associado a competitividade internacional. De um ponto de vista logístico a perspectiva da instalação de um terminal Portuário em Novo Remanso, que dista aproximadamente 140 quilômetros da sede municipal, colocou a vila em evidência quanto ao seu desenvolvimento.

Para o desenvolvimento econômico e sua inserção no mercado mundial, há a necessidade do distrito potencializar seus diferenciais competitivos, gerar empregos e criar fontes de renda tornando sua capacidade regional em distribuição e logística ativamente concorrente, com isso o desenvolvimento da economia com características locais, dentre as quais podemos citar o potencial hidroviário característico fortemente evidente na região, por ser um modal onde o transporte da produção mantém a qualidade com custo baixo, tendo em vista esses aspectos a construção de um terminal portuário no distrito, acarretará várias mudanças locais trazendo o desenvolvimento econômico desta região. Moura e Botter (2011) cita que a cabotagem aliada aos demais modais de transportes, ferroviário, rodoviário e hidroviário, pode contribuir muito para redução dos custos logísticos nacionais, além de reduzir avarias de transporte, acarretando diferentes benefícios. Em virtude de as principais vias de transporte no estado do Amazonas ser por hidrovias, empresas acabam tendo enfoque na localidade do Distrito do Novo Remanso.

Os objetivos do presente estudo situou-se em acompanhar o processo de transformação econômica na Vila de Novo Remanso em Itacoatiara-AM a partir do início das obras de implantação do Terminal Portuário Novo Remanso (TPNR); especificamente: mapear os empreendimentos existentes no período inicial das obras de implantação do TPNR; acompanhar o crescimento dos existente e o surgimento de novos empreendimentos na estrada de acesso e no núcleo urbano de Novo Remanso durante a execução da obras de implantação do TPNR; avaliar os impactos na economia de Novo Remanso a partir do início das obras de implantação do TPNR.

Portanto, a perspectiva de desenvolvimento econômico nesta região a partir do início da construção do TPNR e com o desenvolvimento de suas atividades em uma área onde não existem outros empreendimentos de grande porte é uma oportunidade ímpar de e tornou-se imprescindível o acompanhamento deste processo para se medir e analisar os impactos sobre o desenvolvimento econômico regional do Distrito de Novo Remanso.

Nesta primeira fase, dado o caráter embrionário na implantação do TPNR, o trabalho limitou-se a caracterizar o estado de desenvolvimento atual do Distrito de Novo Remanso, mapeando seus atuais empreendimentos.

\section{REVISÃO DA LITERATURA}

\subsection{DESENVOLVIMENTO REGIONAL}

O desenvolvimento econômico condiz com a qualidade de vida local, quando há a presença de uma economia crescente, os padrões de vida do entorno onde a dinamização do desenvolvimento econômico está ocorrendo traz inúmeros benefícios a região local. Para Rodrigues e Simões (2004) ressaltam que acerca das discussões do desenvolvimento regional e fatores aglomerativos como empresas e industrias são pontos determinantes para a geração de renda e emprego, e incentivos que propõem as desigualdades econômicas, sociais e regionais. Tendo em base esse pensamento, as expectativas positivas tidas pela população do Distrito do Novo Remanso com o início das obras do TPNR, vem não somente atender a uma melhora na qualidade de vida local, mas também o avanço no principal fator econômico local que é a plantações de abacaxi.

De acordo com Monteiro et al (2017) ressalta que os índices de Desenvolvimento Humano Municipal (IDHMs) de todos os estados amazônicos são inferiores comparados aos valores restante do Brasil, reforçando a necessidade de uma convergência inter e interregional. Focando na problemática do 
Distrito do Novo Remanso a viabilidade do desenvolvimento econômico local está na inserção do TPNR, que em consequência de sua estratégia empresarial a melhora na qualidade de vida local utilizando a característica predominante da região amazônica: grandes rios navegáveis e priorizando o recrutamento de mão de obra local. Em contrapartida a construção de vias rodoviárias é uma aspecto negativo da região norte do Brasil que ainda de acordo com Monteiro et al (2017) afirma que conexões por estradas entre as cidades no interior da Amazônia legal são custosas e o clima úmido não ajuda em sua manutenção.

A análise do potencial hidroviário do Distrito do Novo Remanso, além do interesse comercial, mostra também o aspecto positivo do desenvolvimento regional. Por se tratar de um distrito onde um de seus focos econômicos é a produção do abacaxi, a construção da obra do TPNR possibilita a viabilização da produção local por um custo baixo. Araújo (1999) frisa que há a necessidade de tratar a questão do desenvolvimento regional brasileiro de modo geral e especifico analisando seus potenciais econômicos de forma a inserir a economia brasileira na economia mundial extremamente competitiva.

Quanto ao desenvolvimento regional Barquero (2001) coloca que os empreendimentos não competem isoladamente, mas junto com seu entorno institucional, estimulando uma nova organização das cidade e regiões onde está inserido. Conforme Amaral Filho (2009) afirma as mudanças radicais nas formas e nos modos de produção e de organização industriais é consequência de flexibilização e descentralização, dentro e fora das organizações ocasionando reestruturação funcional do espaço. De acordo com esse pensamento pode-se propor que a escolha do Distrito do Novo Remanso como ponto estratégico para a construção do TPNR tem em vista interesses próprios da empresa responsável pelo terminal em reconhecimento do panorama atual mundial e do potencial de Novo Remanso quando se trata do escoamento de produção, tendo em vista a escolha do Rio Amazonas nesta região pelo seu potencial hidroviário.

Por ter como atrativo uma característica regional, que atua como diferencial competitivo, no caso a localização estratégica para transbordo de cargas de grandes embarcações para outras de médio e pequeno porte considerando-se os demais investimentos logísticos existentes na região, espera-se que este processo gere um desenvolvimento endogenizado. Fatores endógenos para Becker (2002) o objetivo do crescimento endógeno é o desenvolvimento regional tendo como principal foco as características locais como o estudo da potencialização incluindo o povo, a cultura, sociedade, meio-ambiente e de sua infraestrutura, transformando-as em algo que possa ser usado em sua competitividade.

\subsection{ECONOMIA LOCAL}

Economicamente, podemos observar que o mercado de trabalho de Itacoatiara é composto principalmente pelo setor público e tem como empregadores privados empresas de grande porte que se instalaram no município. Dentre estes empreendimentos instalados na localidade, destacam-se empresas com o foco logístico como a Hermasa Navegação e a Terminais Fluviais do Brasil S/A, e devido a abundância de recursos naturais e tradição de exploração tem-se ainda a Mil Madeireira, empresa que extrai e exporta madeira certificada. Estes movimentam o comércio local e pequenas indústrias produtoras de cerâmica vermelha, móveis e o setor terciário com bancos, hotéis, restaurantes, entre outros.

Além da sede municipal, destacam-se como núcleos urbanos, em Itacoatiara, as vilas de Lindóia, Engenho e Novo Remanso pela concentração urbana da população. Estes distritos distam da sede municipal mais de 100 quilômetros e mantém suas economias com forte concentração no setor primário, nos pequenos comércios e emprego público.

Observa-se que a mesma possui comércio em desenvolvimento, sendo responsável pelo abastecimento da vila e de comunidades vizinhas, que caracteriza-se como diversificado e de pequeno porte, sendo composto por: supermercados, drogarias material de construção, pequenas lojas, postos de combustíveis em terra e fluvial (Pontão).

$\mathrm{Na}$ área rural, seus principais produtos agrícolas são: abacaxi, cupuaçu, carne e leite bovinos e o pescado, esta produção é, majoritariamente, escoada para Manaus. Para suporte a esta produção, possui uma agroindústria, uma pequena fábrica de 
lacticínios e outra de gelo para abastecimento local.

O Terminal Portuário Novo Remanso (TPNR) é um empreendimento que se situará na margem esquerda do rio Amazonas, na região da localidade de Novo Remanso, no município de Itacoatiara, no estado do Amazonas (Figura1).

Figura 01 - Localização do Empreendimento

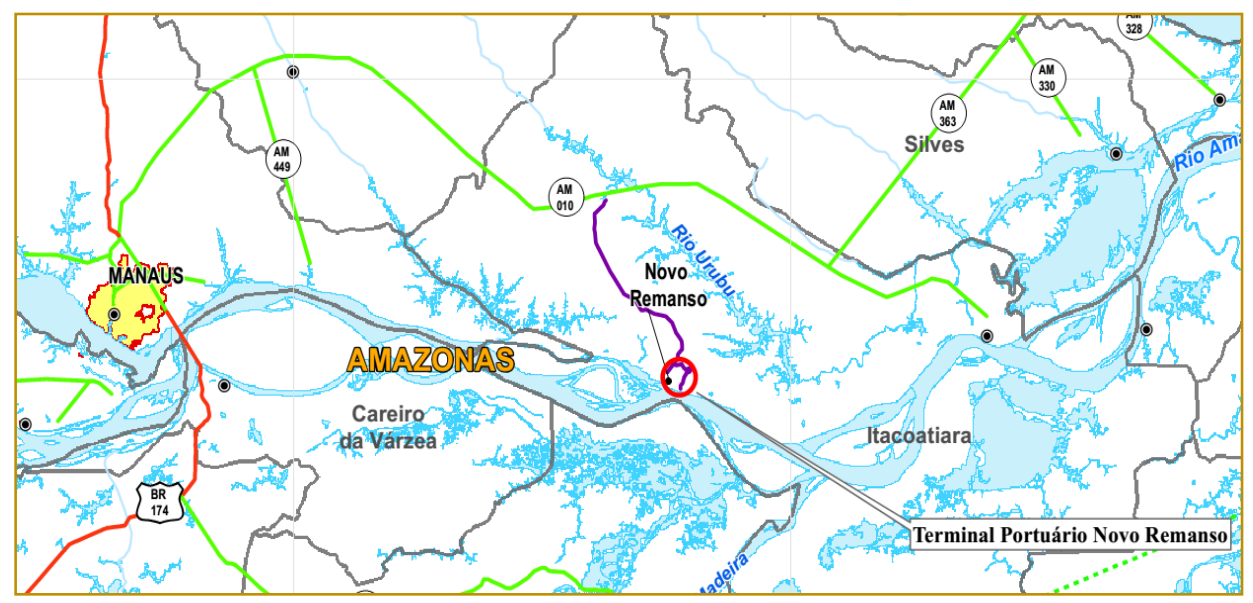

Fonte: Adaptado de RIMA-TPNR (2015)

O acesso se dá a partir da área urbana de Novo Remanso por mais aproximadamente 10 quilômetros por vias rurais não pavimentadas, no pelo Ramal do Macaco Cego, dos quais 6,6 quilômetros em estradas rurais e outros 3,1 quilômetros dentro da propriedade da Terminal Portuário Novo Remanso S/A. (EIA TPRN, 2015). específicos em três píeres, dedicados à movimentação de, Graneis Líquidos: Terminal de Graneis Líquidos (TGL); de Minérios: Terminal de Granéis Sólidos Minerais (TGSM); de Granéis Sólidos Agrícolas: Terminal de Granéis Sólidos Agrícolas (TGSA); e de Carga Geral: Terminal de Carga Geral (TCG), (Figura 02).

\subsection{TERMINAL PORTUÁRIO DE NOVO REMANSO}

O empreendimento, quando concluído, englobará um conjunto de quatro terminais

Figura 02 - Representação da posição geral das estruturas principais (terminais) do TPNR

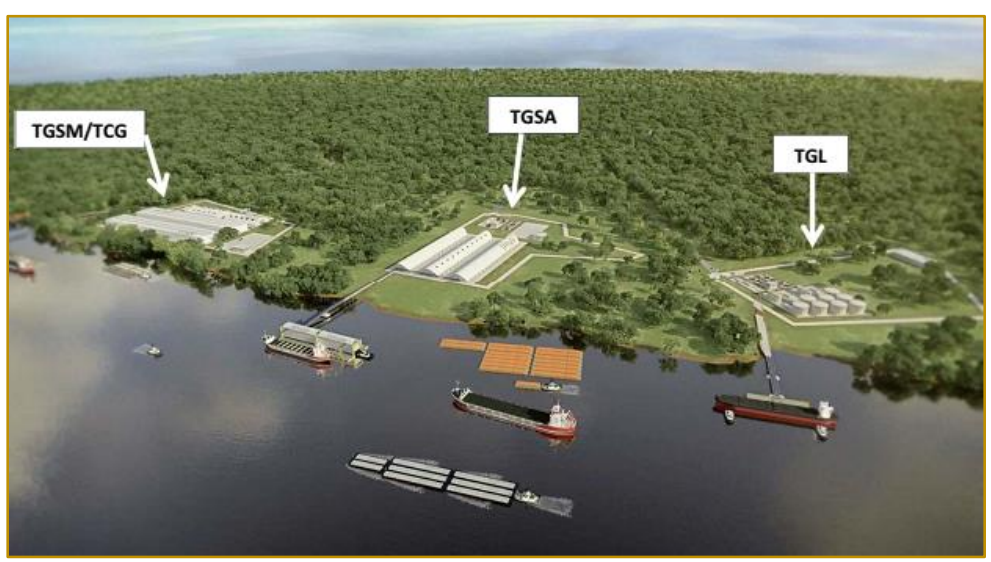

Fonte: EIA TPNR (2015) 
O período de implantação previsto é de 27 meses, empregando até 426 trabalhadores durante sua construção. Após sua conclusão, quando todos os terminais estiverem funcionando, o mesmo deverá empregar mais de 800 funcionários (EIA TPNR, 2015). Por seu grande porte, e pela quantidade de empregos gerados, esta obra deverá desencadear um processo de mudança na estrutura econômica da região do distrito de Novo Remanso. Podendo iniciar ondas de desenvolvimento inicialmente no comércio e que poderão se expandir para outras áreas da economia local. Pensar em desenvolvimento regional é, antes de qualquer coisa, pensar na participação da sociedade local no planejamento contínuo da ocupação do espaço e na distribuição dos frutos do processo de crescimento (OLIVEIRA, 2017).

O processo de acompanhamento da transformação de uma região a partir da implantação de uma empresa de grande porte torna-se essencial para análise da dinâmica econômica e para ser utilizada como parâmetros para estudos futuros. A chegada de novos empreendimentos traz inicialmente investimentos financeiros e geração de empregos para a região de forma direta e indireta que se tornam os responsáveis pelo impulso econômico na região.

Segundo o EIA TPNR (2015) na fase de implantação do empreendimento está prevista a utilização de aproximadamente 426 trabalhadores durante o período de pico, considerando a implantação simultânea de três terminais: TGL, do TGSA e do TGSM/TCG. Esse contingente de trabalhadores inclui profissionais como engenheiros, topógrafos, encarregados, motoristas, operadores de equipamentos, pedreiros, ajudantes, armadores, técnicos de escritório, administradores e serventes. Esse conjunto de profissionais será recrutado preferencialmente na região do distrito Novo Remanso, Itacoatiara e em Manaus, mas podendo utilizar os profissionais que integram os seus quadros técnicos, residentes em outras localidades.

Assim sendo, espera-se que já a partir de sua implantação haja um processo de mudança econômica no distrito, a partir do efeito multiplicador proposto por Keynes. Neste sentido, Keynes (1983) acreditava na atuação do efeito multiplicador na economia, que consiste na ação da demanda dos trabalhadores gerando novos empregos que aumentam, ainda mais, a renda e o consumo, criando um círculo virtuoso de crescimento econômico.

\section{METODOLOGIA}

A pesquisa inicialmente foi exploratória por meio de um estudo bibliográfico buscando-se em artigo, dissertações e teses outros casos já estudados e disponíveis na literatura além do embasamento teórico. Esta etapa atende a Boaventura (2011), que pede que o aluno busque monografias, dissertações e tese sobre o tema apresentado em comunidades cientificas mais próximas, ou em outras que possa ter acesso. Para Flick (2009) a o entrevistado pode ser auxiliado a uma situação especifica por meio por meio de uso de materiais e de questões correspondentes. Mediante essa ferramenta houve a necessidade de visitas in loco com entrevistas não estruturadas tendo o objetivo de conhecer melhor o objeto de estudo, com base a percepção dos moradores e comerciantes sobre o inicio da construção e dos impactos que a obra poderá trazer para a Vila de Novo Remanso. Outra ferramenta utilizada nesta fase foi a observação das estruturas existentes e identificação das mesmas.

Nesta primeira fase da pesquisa, o estudo foi qualitativo, pois ateve-se ao dados coletados com as entrevistas e a observação, tratandoos e analisando-os na busca por se atender aos primeiros objetivos estabelecidos. Flick (2009) afirma, que as práticas e as interações dos sujeitos na vida cotidiana não são situações artificiais criadas em laboratórios. Tomando-se por base esse pensamento a observação da população local é imprescindível para o presente estudo, analisando de forma a compreender o cotidiano do Distrito do Novo Remanso.

Para Bervian, P. A., Cervo. AL., Silva, R. da (2007) abordam que a pesquisa descritiva com as seguintes características de observar, registrar, analisar e correlacionar fatos ou fenômenos, ou seja as variáveis, sem manipulá-los procurando descobrir de forma precisa a frequência com que o fenômeno ocorre. $\mathrm{Na}$ segunda fase, a pesquisa descritiva teve como ferramenta a pesquisa de campo que se se iniciou com as visitas a Vila, quando se mapeou desde o início da estrada de acesso a partir da AM 010, incluindo o centro urbano deste distrito os 
empreendimentos encontrados principalmente comércios, restaurantes, hotéis, prestação de serviços, entre outros. Os pontos foram registrados por meio de fotografias para um melhor acompanhamento durante as demais fases da pesquisa. Este procedimento foi repetido trimestralmente.

Durante a fase principal, a ferramenta utilizada foi a de observação dos empreendimentos existentes que permitiu acompanhar quais os processos de mudança ocorridos e quais as dinâmicas observadas.

$\mathrm{Na}$ terceira parte do trabalho foi realizadas análises dos dados coletados, onde se observou como e quais mudanças ocorreram a partir do surgimento ou encerramento das atividades dos empreendimentos, e em que tipos de negócios foram mais expressivos. Fachin (2006) ressalta que no método de estudo de caso dá-se com a obtenção de uma descrição e compreensão completa das relações dos fatores em cada caso, contudo os dados foram coletados com visitas regulares sendo analisados de forma intensiva e organizados para a melhor compreensão, como um todo, do assunto investigado.

\section{RESULTADOS E DISCUSSÃO}

Incialmente, durante as primeiras visitas em outubro de 2016, observou-se que os impactos na estrutura comercial e de serviços ainda eram imperceptíveis. Desta forma, optou-se por fazer um levantamento e catalogação dos empreendimentos existentes, onde se identificou incialmente 20 empreendimentos (Tabela 01), registrando-se por meio de imagens suas características físicas. Paralelamente, realizou-se também um processo e coleta de informações por meio de entrevistas não estruturadas para um melhor entendimento deste processo.

Tabela 01 - Levantamento dos Empreendimentos existentes

\begin{tabular}{|c|c|}
\hline Empreendimento & Quantidade \\
\hline Mercadinhos, mercearias. & 10 \\
\hline Panificadora & 01 \\
\hline Lanchonete & 01 \\
\hline Hotéis & 02 \\
\hline Postos de Gasolina & 04 \\
\hline Loja de Roupas & 02 \\
\hline Total & 20 \\
\hline
\end{tabular}

Fonte: Autor (2016)

Por meio das entrevistas constatou-se que a empresa durante o processo de EIA-RIMA havia divulgado para a população todas as etapas e que as mesmas estavam cientes do que seria desenvolvido pela empresa, da estrutura a ser instalada e das futuras oportunidades que poderiam surgir. No entanto, ainda não haviam surgido novos postos de trabalho ou empreendimentos identificados pelos mesmos. Como benefício gerado pelo empreendimento, alguns citaram o consumo em supermercados do distrito de Novo Remanso para produzir refeições para os operários e engenheiros.

De um modo geral todos relataram que já sabiam sobre a futura construção do porto, e que os representantes da empresa responsável pela construção fez divulgação no distrito esclarecendo informações sobre como a implantação desse terminal portuário iria atingir o distrito, por meio de oficinas e audiências públicas.

Nas visitas de Janeiro, observou-se que novas estruturas haviam surgido, tais como uma um mercantil (Figura 03) e drogaria (Figura 04), estas estruturas geraram além dos empregos familiares aproximadamente 04 novos postos de trabalho. Inicialmente, os empreendedores afirmaram que o TPNR não foi diretamente responsável pela abertura do negócio, mas que tem a expectativa de que os novos postos de trabalho possam trazer procura por seus produtos. 
Figura 03 - Mercearia Brasil

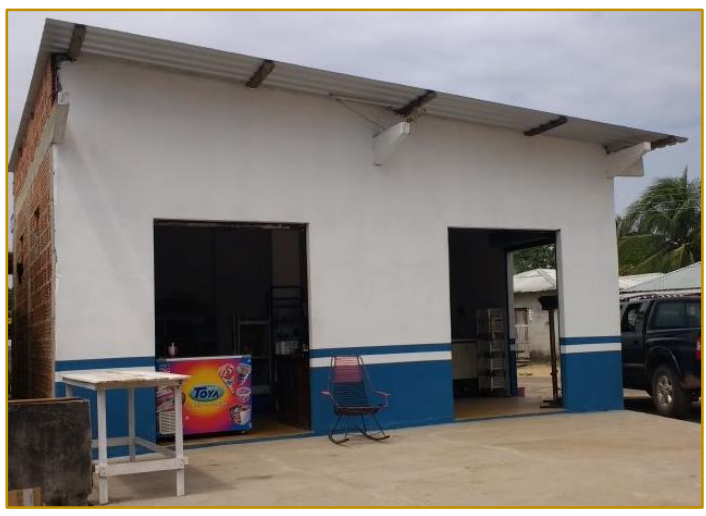

Fonte: Autor (2017)
Figura 04 - Drogaria Pague Menos

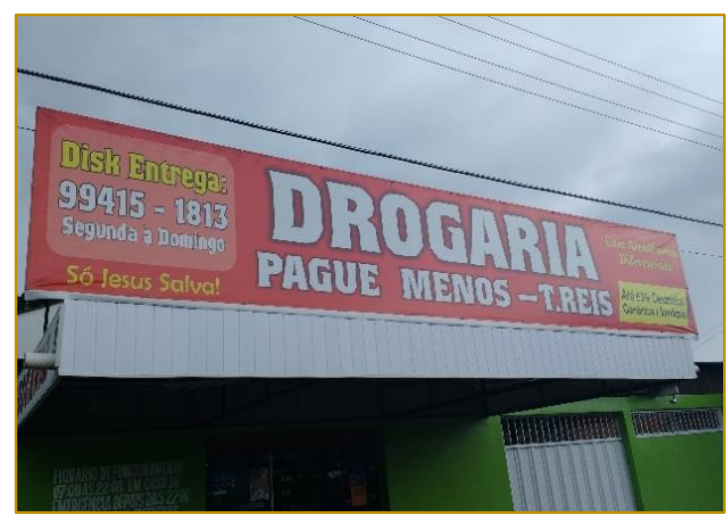

Fonte: Autor (2017)
Nas visitas de Abril, identificou-se a abertura do primeiro restaurante da cidade (Figura 05), atendendo diariamente para almoço e janta. As proprietárias ao serem questionadas sobre a influência do porto na decisão de iniciar o empreendimento, as mesmas falaram que não havia sido um fator decisivo, pois o TPNR localiza-se fora da área urbana e possuem uma cantina interna 0 que traz mais movimento para os supermercados. No

Figura 05 - Restaurante Irmãs Cunhas

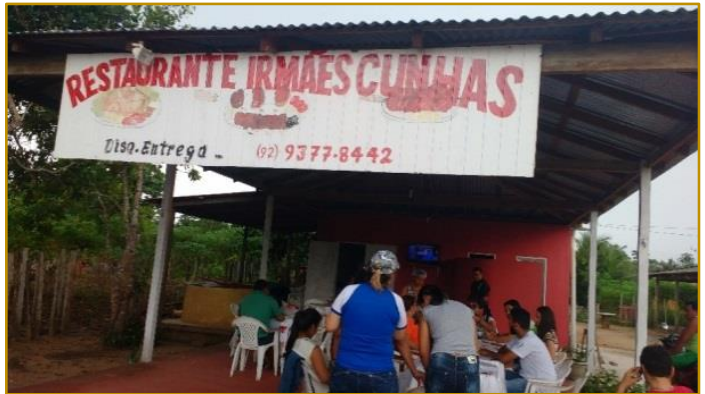

Fonte: Autor (2017)

De um modo geral, abordando-se sobre o assunto da construção do Terminal Portuário, as mudanças ainda não são perceptíveis na região, mas gera grande expectativa para melhoria na economia do distrito quando se observa o discurso dos entrevistados.

Nesta fase, pode-se compreender pelos dados obtidos com o questionário, que 0 desenvolvimento ainda é muito superficial e pouco perceptível e não mostram resultados quantitativos relativos ao desenvolvimento pelo prisma dos empreendedores. Quanto a divulgação proposta no EIA-RIMA esta foi entanto, afirmou que alguns funcionários do terminal portuário frequentam seu estabelecimento quando em visita a sede do município, registrando a presença de um engenheiro durante a entrevista. Outro empreendimento que já se encontra em andamento é a construção de um posto de combustíveis (Figura 06) e que deverá gerar em torno de 10 postos de trabalho para a Vila de Novo Remanso.

Figura 06 - Posto de gasolina em construção

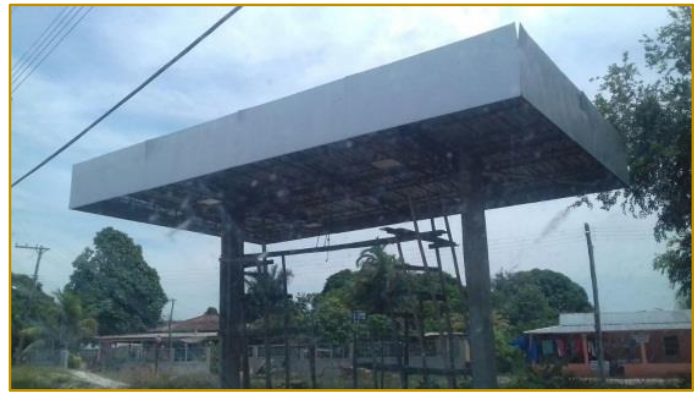

Fonte: Autor (2017)

citada por todos os empreendedores que relataram que as reuniões ocorreram em diferentes momentos e que todos foram convidados. A maioria dos empreendedores participaram destes eventos e tem consciência das diversas etapas de implantação, mas mesmo aqueles que não puderam participar, sabem da construção do TPNR e mantem expectativas quanto a sua execução e os reflexos que poderão trazer. No Distrito de Novo Remanso, devido a divulgação realizada durante o processo de EIA-RIMA todos os moradores, até mesmo da área rural, demonstram ter conhecimento do 
projeto, o que gera expectativas quanto ao acesso a estes benefícios.

Segundo a EIA TPNR (2015) dentre os impactos positivos gerados pela construção do TPNR estão:

- Aumento da massa salarial;

- Geração de empregos diretos e indiretos durante a construção;

- Geração de empregos diretos e indiretos durante a operação;

- Aumento do nível de arrecadação fiscal;

- Dinamização da economia local.

Esta expectativa é apontada pela maioria dos entrevistados, as perspectivas quanto aos benefícios como geração de emprego e renda, qualificação de mão de obra no Distrito e migração de trabalhadores, são esperadas por todos e apontadas como possíveis alavancas do crescimento econômico do município.

Constata-se que eles esperam da construção desse Terminal Portuário uma oportunidade de melhoria de vida. Nas visitas de Abril de 2017, os entrevistados colocaram que esta expectativa já estava se concretizando uma vez que por meio deste empreendimento o Serviço Nacional de Aprendizagem Industrial (SENAI), já disponibilizou um caminhão para qualificação dos moradores em associação com a empresa e o mesmo já se encontrava presente no distrito para iniciar o processo de qualificação dos moradores da região com o objetivo formar mão de obra local para futura contratação (Figura 07). Outro fato citado pelos moradores foi a contratação de alguns moradores para a função de porteiro, mesmo incipiente este dado foi registrado para compor futuras análises do processo.

Figura 07 - Posto de treinamento do SENAI

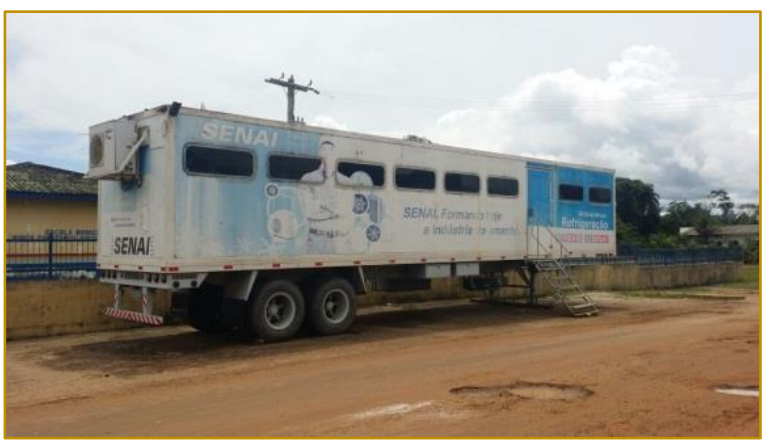

Fonte: Autor (2017)

Durante a pesquisa observou-se que estes impactos significativos ainda não estão ocorrendo, devido à distância do local onde será construído o TPNR em relação ao centro urbano do Distrito de Novo Remanso e a fase embrionária do processo, todos relataram que ainda não tiveram nenhum tipo de retorno. No entanto, observa-se que aos poucos alguns processos começam a ocorrer, como o consumo em supermercados, novos clientes para os empreendimentos existentes e o inicio do processo de qualificação dos moradores.

Nas visitas de realizadas no primeiro semestre de 2018, foi possível notar que as obras do Terminal Portuário do Novo Remanso - TPNR já iniciaram. Segundo os moradores locais o serviço no período estava limitado ao desmatamento da área em que será construída a estrutura da obra. A informação obtida com pessoas contratadas foi de que as obras iniciaram em dezembro de 2017 , limitando-se a contratação de aproximadamente 25 pessoas, dentre elas 8 são moradores locais da região. Nesta fase primaria da obra, durante a realização do desmatamento do local onde a TPNR será implantada, pode-se citar dentre esses profissionais, as seguintes funções: operadores de motosserras, assistentes de construtores (pedreiro) e operadores de roçadeiras.

Foi possível que verificar que a via "Vicinal do Macaco Cego", estrada que liga o distrito ao local onde será construída a TPNR, está, em parte, asfaltada e possui uma sinalização improvisada, como mostrado na (Figura 08). 
Figura 08- Estrada que dá acesso ao local de construção da TPNR

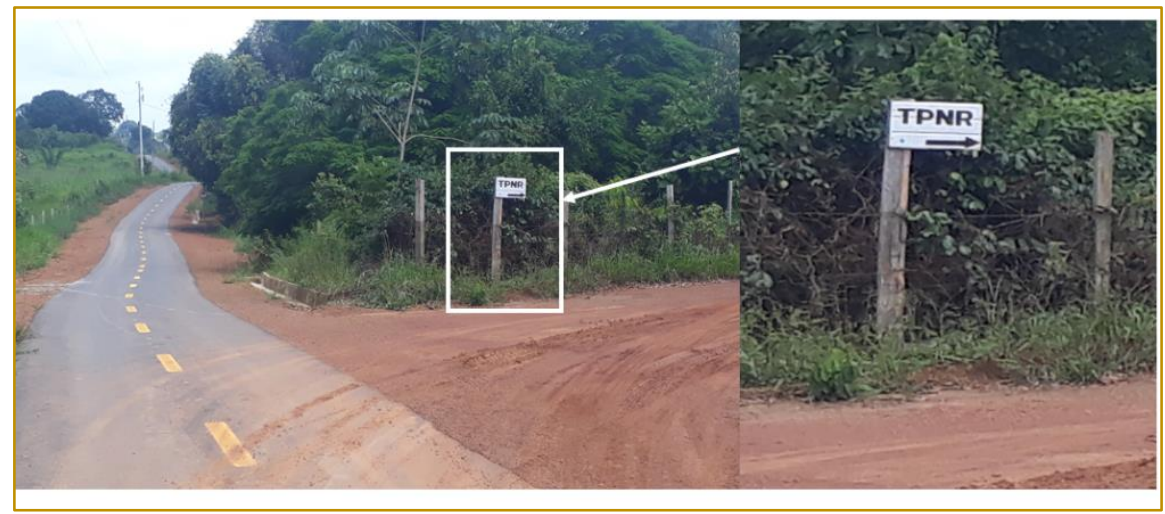

Fonte: Autor (2018).

Segundo os moradores do Distrito do Novo Remanso as obras iniciaram a cerca de dois meses, no entanto os impactos econômicos ainda não foram perceptíveis em torno da região local. Mas, já há a geração de empregos diretos e indiretos, pois há o fornecimento de alimentação para os trabalhadores da obra por microempreendedores locais, com o fornecimento diário de marmitas e sucos para os trabalhadores da obra.

Esta atividade também gera movimento na economia local, pois segundo o fornecedor de alimentos, toda a matéria-prima é comprada em supermercados e açougues no próprio distrito de Novo Remanso. Ainda segundo ele, o fornecimento diário varia entre 22 e 25 marmitas, o que comprova as informações quanto ao número de trabalhadores atuais. Logo há a relação entre a geração de emprego direto e indireto, pois com essa linha de consumo haverá uma dinamização da economia local. Alguns proprietários de supermercados e lojas de variedades já perceberam um aumento nas vendas e o consumo dos próprios trabalhadores.

Foram registrados o desenvolvimento de novos empreendimentos, conforme Figura 09, porém obteve-se a informação de que essas microempresas não estão ligadas diretamente aos benefícios do desenvolvimento econômico que serão trazidas com a implantação do TPNR, no entanto há um trabalho do SEBRAE para dinamizar e preparar a economia local pela expectativa de melhorias para a região.

Figura 09 - Novos empreendimentos abertos.

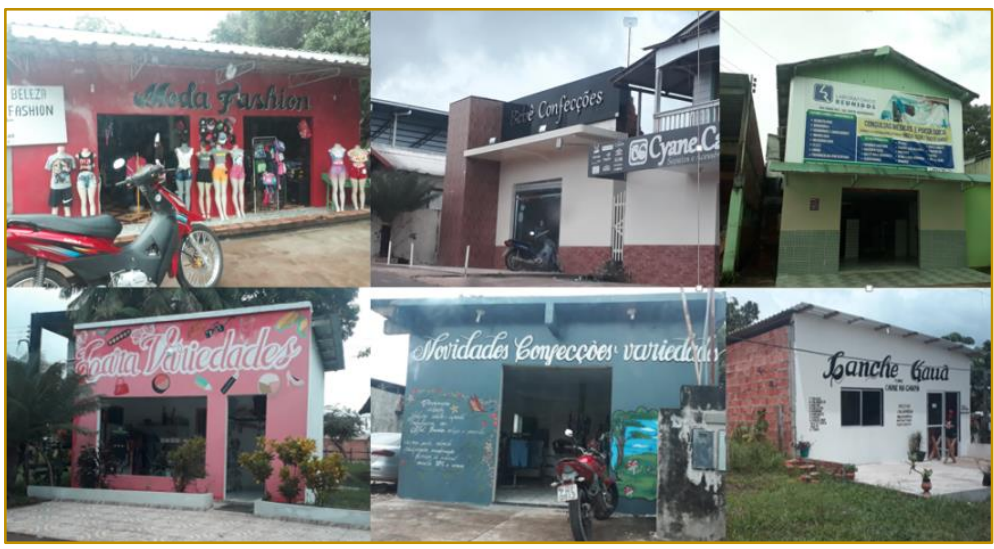

Fonte: Autor (2018)

Observou-se que houve uma tendência na região em negócios específicos em confecções e variedades, logo é notável que os negócios estão melhorando em sua estrutura física visando a diferenciação na concorrência. Foi possível constatar uma microempresa local específica, que é uma policlínica que varia em atendimentos com 
médicos especializados, e junto a esse mesmo negócio um laboratório de análises clínicas. Segundo os moradores, esta empresa se instaurou no Distrito do Novo Remanso visando atender as empresas responsáveis pela construção da TPNR, no que se trata de análises clinicas para a contratação dos trabalhadores locais, evitando que os colaboradores tenham de se deslocar até ao município de Itacoatiara.
A Tabela 02 representa os empreendimentos que surgiram comparando o ano de 2016 ao ano de 2018. Comparando-se a Tabela 01, houve a alteração de "Lanchonetes" para "Restaurantes e Lanchonetes", e a Criação de três novas categorias que são: Confecções e Variedades; Policlínicas e Laboratórios; e por último Moto peças. Essas categorias estão destacadas na tabela abaixo.

Tabela 02 - Levantamento dos Empreendimentos existentes.

\begin{tabular}{|l|c|c|}
\multicolumn{1}{|c|}{ Empreendimento } & $\begin{array}{c}\text { Quantidade } \\
(2016)\end{array}$ & $\begin{array}{c}\text { Quantidade } \\
\text { (Novos) } \\
(2018)\end{array}$ \\
\hline Mercadinhos, mercearias. & 10 & 01 \\
\hline Panificadora & 01 & 04 \\
\hline Restaurantes e Lanchonetes* & 01 & \\
\hline Hotéis & 02 & 01 \\
\hline Postos de Gasolina & 04 & 05 \\
\hline Loja de Roupas $^{*}$ & 02 & 01 \\
\hline Confecções e Variedades* $^{*}$ & & 01 \\
\hline Policlínicas e Laboratórios $^{*}$ & & 13 \\
\hline Moto peças & & \\
\hline & 20 & 33 \\
\hline TOTAL & \multicolumn{2}{|c|}{} \\
\hline
\end{tabular}

Fonte: Autor (2018), atualizada.

Logo é possível verificar que houve uma alteração significativa relacionada a variedades de pequenos empreendimentos existentes no local, é possível deduzir que pela abertura de novos negócios tendem a suprir a demanda requerida pela população, porem vale ressaltar que, segundo os proprietários dos negócios, essas microempresas não estão diretamente ligadas a implantação da TPNR, logo que a dinamização da economia local por ora, não é evidente, pois o terminal portuário ainda está em fase embrionária de construção, embora todos tenham expectativas quanto ao crescimento a partir da intensificação das contratações locais.

$\mathrm{Na}$ fase seguinte, será iniciado o processo de terraplanagem e os currículos já começaram a ser recolhidos, a expectativa é que nesta fase sejam contratados até 300 trabalhadores e haverá futuramente o emprego de mais trabalhadores para a construção, logo a geração de renda será mais evidente na região de forma a dinamizar a economia local.

\section{CONCLUSÃO}

Quanto à implantação de grandes empreendimentos, observa-se que o planejamento inicial gera expectativas na população quanto a melhorias e/ou riscos que as mudanças geradas a partir de sua chegada possam trazer. Em regiões com população pequena e pouco desenvolvimento econômico, espera-se que o impacto seja sentido de uma maneira mais efetiva, trazendo alterações em setores como economia e a educação, bem como processos migratórios que possam ser desencadeados a partir do início das obras.

Com os resultados obtidos é possível notar que, nesta fase as mudanças no âmbito econômico na Vila do Novo Remanso não são significativas/perceptíveis, a geração de empregos diretos ainda não ocorreu e os indiretos ainda não são facilmente identificados. A qualificação profissional que começa a ser ofertada ainda é muito restrita e deverá ser aplicada ao longo de 2017, sem perspectivas para contratação imediata como esperado pela população local.

Tendo em vista esse cenário sem alterações significativas, considerando-se que a mão de obra ainda se restringe a engenheiros e 
técnicos que estão planejando o início da construção, e a capacitação da população local com associação do SENAI, constata-se que há um movimento muito pequeno que não gera impacto significativo na economia local. As primeiras contratações e prestação de serviços já podem ser identificadas e esperase que

Desta forma, podemos concluir que este processo ocorrerá de maneira lenta e em fluxos, de acordo com a demanda da empresa. A população poderá beneficiar-se, mas no curto prazo estes reflexos ainda não são suficientes para impulsionar o desenvolvimento econômico da Vila de Novo

\section{REFERÊNCIAS}

[1] Alfredini, Paolo; Arasaki, Emilia. Obras e gestão de portos e costas: a técnica aliada ao enfoque logístico e ambiental. Edgard Blücher, 2009.

[2] AMARAL FILHO, Jair do. A endogeneização no desenvolvimento econômico regional e local. Planejamento e políticas públicas, n. 23, 2009.

[3] Barquero, Antonio Vásquez. Desenvolvimento endógeno em tempos de globalização. Porto Alegre: Fundação de Economia e Estatística, 2002. 278 p.

[4] Becker, Dinizar F.(org). Desenvolvimento sustentável: necessidade e/ou possibilidade?. 4 ed. Santa Cruz do Sul: EDUNISC, 2002.

[5] Bervian, P. A. Cervo. AL. Silva, R. da. Metodologia Científica. 6a ed. São Paulo: Pearson Prentice Hall, 2007.

[6] Boaventura, Edivaldo M. Metodologia da pesquisa: monografia, dissertação e tese. 1 ed. São Paulo: Editora Atlas S. A., 2011.

[7] DE Oliveira, Gilson Batista; DE Souza Lima, José Edmilson. Elementos endógenos do desenvolvimento regional: considerações sobre o papel da sociedade local no processo de desenvolvimento sustentável. Revista da FAE, v. 6 , n. 2, 2017.

[8] DE Araujo, Tânia Bacelar. Por Uma Política Nacional De Desenvolvimento Regional. Revista Econômica Do Nordeste, Banco do Nordeste, Vol.30 n.2 abr -jun de 1999.

[9] EIA - Tpnr. Estudo de Impacto Ambiental do Terminal Portuário Novo Remanso. Volume III,
Remanso. Espera-se que até a conclusão da obra estas mudanças tornem-se perceptíveis a população, gerando o efeito esperado no comércio e na geração de empregos.

\section{AGRADECIMENTOS}

Agradecendo pelo apoio financeiro da Fundação de Amparo à Pesquisa do Estado do Amazonas (FAPEAM), pela realização desse projeto junto ao Programa Institucional de Bolsas de Iniciação Científica e Tecnológicas (PIBIC - PAIC).

Dezembro de 2015. JGP Consultoria e Participações.

[10] EIA - Tpnr. Matriz 12.0 a Cruzamento de Impactos por Programas. Volume I, Dezembro de 2015. JGP Consultoria e Participações.

[11] Fachin, Odília. Fundamentos de Metodologia. 5 ed. [rev.]. São Paulo: Saraiva, 2006.

[12] Flick, Uwe. Introdução à Pesquisa Qualitativa-3. Artmed Editora, 2009.

[13] Keynes, J. M. A Teoria Geral do Emprego, dos Juros e da Moeda. São Paulo, Abril Cultural, 1983.

[14] Monteiro Neto, Aristides Organizador; Castro, César Nunes de Organizador; Brandão, Carlos Antonio Organizador. Desenvolvimento regional no Brasil: políticas, estratégias e perspectivas. Rio de Janeiro: Ipea, 2017.

[15] Moura, Delmo Alves; Botter, Rui Carlos. O transporte por cabotagem no Brasil-potencialidade para a intermodalidade visando a melhoria do fluxo logístico. Revista Produção Online, v. 11, n. 2, p. 595-617, 2011.

[16] RIMA- TPNR. Relatório de Impacto Ambiental: Terminal Portuário do Novo Remanso. Dezembro de 2015. JGP Consultoria e Participações.

[17] Rodrigues, Clarissa Guimarães; SIMÕES, Rodrigo Ferreira. Aglomerados industriais e desenvolvimento socioeconômico: uma análise multivariada para Minas Gerais. Ensaios FEE, v. 25, n. 1, 2004.

[18] Silva, Francisco Gomes da. Cronografia de Itacoatiara. Manaus, Papyros Ind. Gráf, 1997 


\section{GAPÍTULO 12}

\section{ANÁLISE DO NÍVEL DE PRESSÃO SONORA EM UMA BIBLIOTECA DE UMA INSTITUIÇÃO DE ENSINO SUPERIOR}

\section{Rodrigo Costa Silva}

Matheus das Neves Almeida

Aianna Rios Magalhães Véras e Silva

Bárbara Cristina Costa Bacelar de Carvalho

Hélio Cavalcanti Albuquerque Neto

Resumo: $O$ conforto acústico em ambientes de ensino é de fundamental importância para o melhor desenvolvimento de tarefas e atividades daqueles os usufruem. Quando se trata de uma biblioteca, o bom desempenho acústico tornase imprescindível, uma vez que os usuários têm este espaço como um ambiente calmo e tranquilo para leitura e realização de outras atividades educativas. Diante disso, o objetivo do estudo está em verificar se há ou não a existência do conforto acústico nos espaços de leitura da biblioteca estudada. Para isso, a pesquisa contemplou medições dos níveis de pressão sonora na área interna da biblioteca com o uso de decibelímetro e dosímetro digital, a organização e comparação desses dados com os valores estabelecidos pelas NBR 10152 (1987) e NR-15 e análise estatística para possíveis correlações entre esses dados. A partir da análise, pode-se constatar que os níveis de ruído encontrados não estão dentro do limite aceitável, configurando assim o ambiente dessa biblioteca como ruidoso e barulhento. Percebeu-se que os elevados níveis de pressão sonora são ocasionados por fontes internas, como sistema de ventilação interno e os próprios usuários. Ademais, também se identificou que há diferenças estatisticamente significativas entre os locais de coleta e os diferentes pisos, contudo não há diferenças entre os turnos. Por fim, traçou-se sugestões que visam garantir o conforto acústico para o ambiente estudado.

Palavras-chave: Acústica, biblioteca, ruído. 


\section{INTRODUÇÃO}

A saúde e a qualidade de vida do indivíduo em seu espaço de trabalho podem estar relacionadas a aspectos econômicos, sociais e tecnológicos, bem como em certos casos, onde os problemas são causados pelos riscos de natureza físico-química, mecânica ou ergonômica, contribuindo para um agravo na condição e saúde do sujeito ao longo da vida (SERVILHA; LEAL; HIDAKA, 2010).

Considerando que o ambiente de trabalho das bibliotecas é mais do que uma fonte de livros e periódicos acadêmicos, pois desempenham um papel importante nas escolas, faculdades e universidades. Elas funcionam como espaço de trabalho, estudo, reuniões e difusão de acessibilidade ao conhecimento, cumprindo dessa forma, uma função social.

Assim, a preocupação em estudar os níveis de ruído neste ambiente torna-se necessária quando níveis de pressão sonora inadequados podem interferir no desenvolvimento e execução das atividades de seus usufruístes (LEVANDOSKI, 2013). Diante disso, o presente trabalho tem por objeto analisar os níveis de pressão sonora em que usuários de uma biblioteca de uma Instituição de Ensino Superior estão submetidos durante sua permanência neste tipo de recinto.

\section{FUNDAMENTAÇÃO TEÓRICA}

\subsection{ERGONOMIA}

O termo ergonomia significa, etimologicamente, o estudo das leis do trabalho; da relação entre o homem e seus meios, os métodos e o ambiente de trabalho; tendo como objetivo central uma melhor adaptação dos meios tecnológicos de produção e dos ambientes de trabalho e de vida do homem. Logo, essa ciência consiste numa importante ferramenta para o bom desempenho do trabalhador em seu cotidiano, tendo em vista todas as normas e leis que visam garantir a segurança do trabalho nas mais diversas funções a serem executadas no meio laboral (FIDELIS; FERNANDES, 2015; SILVA; LUCAS, 2009; FALZON, 2009).

Portanto, a ergonomia pode ser vista como uma ciência capaz de prover resoluções para os problemas entre o homem, os componentes do sistema e o meio ambiente de trabalho, adaptando-os para a melhora da qualidade de vida, bem-estar e satisfação do trabalhador e sua produtividade, e consequentemente, para uma melhor eficiência do desenvolvimento de suas tarefas e de um ambiente de trabalho favorável. Para tanto, é necessário que seja feita uma análise ergonômica, cabendo ao empregador realizar esta análise, e esta deve abordar, no mínimo, as condições de trabalho conforme estabelecido pela Norma Regulamentadora 17 (PAULA; HEIDUKE; MARQUE, 2016).

\subsection{ANÁLISE ERGONÔMICA}

A análise ergonômica apoia-se no conjunto de coletas de dados e informações que possibilitam ao ergonomista realizar as modelagens necessárias para prover mudanças no ambiente laboral (AGAHNEJAD, 2011).

As cinco principais áreas mais abordadas pela análise ergonômica são: "métodos e técnicas", "características humanas", "projeto de trabalho e de organização", "saúde e segurança" e "design do local de trabalho e equipamento". O estudo das tarefas, dos postos de trabalho, dos produtos, dos ambientes e dos sistemas é imprescindível, de modo a torná-los mais compatíveis e coerentes às necessidades, habilidades e limitações dos seres humanos, podendo receber, dessa forma, contribuições significativas dos profissionais da área de ergonomia (RADJIYEV et al, 2015; ABERGO, 2016).

Moreira Neto, Tavares e Almeida (2009) relatam que a partir da análise ergonômica também é possível identificar situações problemáticas sobre as condições ambientais, que podem representar focos de risco, causando danos ao desempenho e à saúde do trabalhador. Dentre estas variáveis, os autores destacam as condições de temperatura, iluminação e ruído. O conjunto dessas variáveis ajudam a compor o conforto ambiental identificado por um indivíduo.

\subsection{CONFORTO AMBIENTAL}

O conforto ambiental pode ser definido como o equilíbrio harmônico do sujeito no ambiente em que ele está inserido, ou seja, a situação de conforto ambiental proporciona ao homem sensação de bem-estar, em seu espaço de atividade. Essa condição pode ser alcançada 
a partir do equilíbrio de três parâmetros: conforto térmico, conforto lumínico e conforto acústico (COUTINHO FILHO et al, 2007; OCHOA, 2010).

A sensação de conforto ambiental é relativa, visto que varia da percepção de cada pessoa, de acordo com o seu tipo de vida, sua atividade, sua idade, e pode ser extremamente trabalhosa e complexa a sua quantificação, quando se consideram todos os parâmetros envolvidos nessa questão (RITTER, 2014).

No Brasil, o Ministério do Trabalho e Emprego estabelece condições mínimas de ergonomia e conforto ambiental segundo a Norma Regulamentadora NR-17 - Ergonomia, fixando parâmetros para as condições ambientais de trabalho, levando em conta as características psicofisiológicas dos trabalhadores e à natureza do trabalho a ser executado (BRASIL, 2007).

\subsection{CONFORTO ACÚSTICO}

O conforto acústico, para Ochoa (2010), está relacionado ao processo de se ouvir o necessário, sem interferências que acarretem o estresse ou distorções sobre o foco de atenção da atividade desenvolvida. Para o autor, o som tem características subjetivas, visto que o ruído de um inseto, durante a noite, pode representar tanto incômodo quanto o ruído da turbina de um avião, apesar de apresentarem grande diferença de pressão sonora entre si.
O ruído é considerado um dos aspectos do conforto acústico mais importante da saúde ocupacional, quando inadequado, pode provocar às lesões do aparelho auditivo, à fadiga auditiva, e, provavelmente, aos efeitos psicofisiológicos negativos, relacionados ao estresse psíquico - perturbação da atenção e do sono, sintomas neurovegetativos tais como taquicardia e aumento da tensão muscular (WACHOWICZ, 2013).

Os estudos de Teles e Medeiros (2007) afirmam que a exposição ao ruído pode causar trauma acústico agudo ou crônico, e de ordem extra-auditiva, como distúrbios cerebrais, distúrbios nos sistemas nervoso, circulatório, digestivo, endócrino, imunológico, vestibular, muscular, nas funções sexuais e reprodutivas, e ainda, distúrbios psíquicos, no sono, na comunicação e no desempenho de tarefas físicas e mentais.

\section{MATERIAIS E MÉTODOS}

\subsection{DESCRIÇÃO DO AMBIENTE ESTUDADO}

A Biblioteca escolhida faz parte de uma Instituição de Ensino Superior, localizada na cidade de Teresina-PI. Mais especificadamente, as áreas analisadas foram: os espaços reservados para leitura individual e em grupo, localizados respectivamente no piso inferior e piso superior da biblioteca, como delimitados e apresentados pelas Figuras 1 e 2. Ademais, as figuras apresentam os pontos definidos para coleta de dados. 
Figura 1 - Pontos definidos na planta baixa do piso inferior

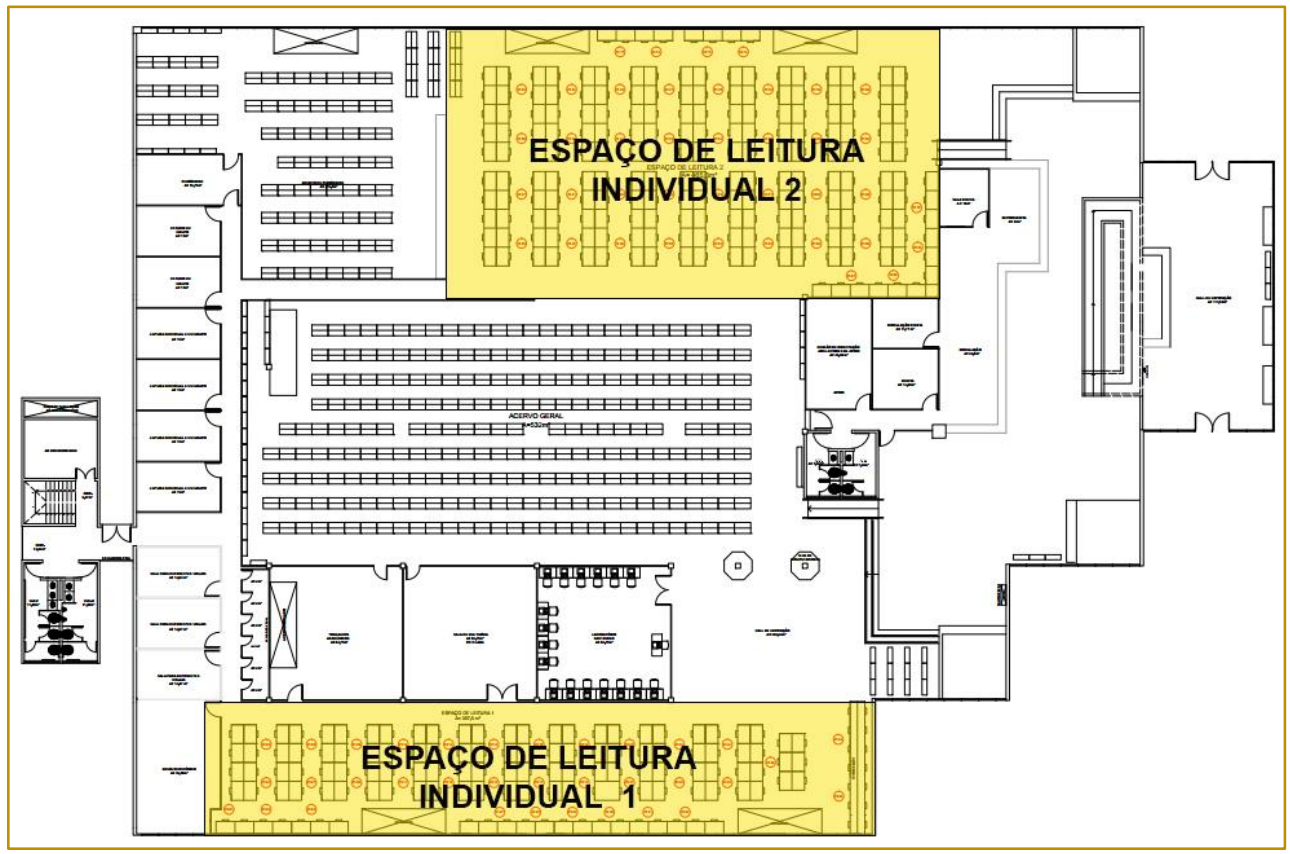

Figura 2 - Pontos definidos na planta baixa do piso superior

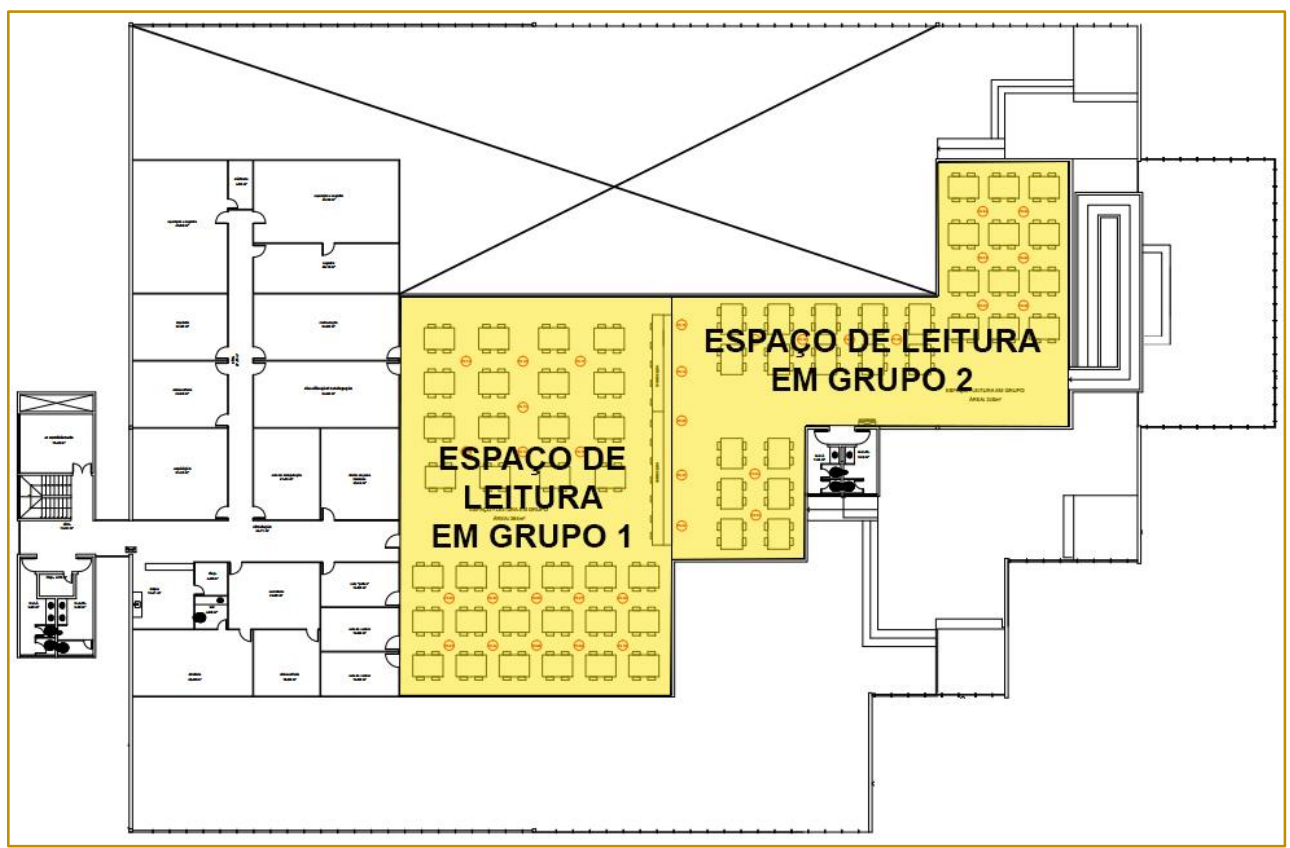




\subsection{FERRAMENTAS E PROCEDIMENTOS DE COLETA DE DADOS}

Inicialmente, a coleta de dados referente ao processo de avaliação dos níveis de ruído na biblioteca, foi dividida em duas etapas: medições pontuais em pontos específicos da área interna da biblioteca (Figura 1 e 2) e realização de dosimetria em usuários em pontos específicos dentro da Biblioteca (Anexo 5 e 6).

Para as medições pontuais, utilizou-se 0 decibelímetro da marca Vectus, modelo SL824, seguindo os procedimentos definidos de acordo com a NBR-10151 (ABNT, 2000), além das instruções no manual do aparelho, que especifica alguns ajustes, como: ponderação de frequência "A", que simula a forma que 0 ouvido humano captura as frequências e o tempo de resposta Slow (lento), que faz as medições em intervalos de 1 segundo. Dentre as faixas para medição pelo aparelho - 30 a 80,50 a 100 ou 60 a 120 - a faixa escolhida foi a de 50 a $100 \mathrm{~dB}$, que apresentou melhor compatibilidade com os níveis sonoros presentes nos ambientes de leitura da biblioteca.

Os pontos definidos e a delimitação dos espaços de leitura na planta baixa da biblioteca podem ser visualizados com melhor resolução nos Anexos 1, 2, 3, 4. Os pontos na planta baixa do piso inferior da biblioteca foram nomeados com a sigla "PI", juntamente com a numeração do ponto. Para os pontos definidos no Piso Superior, seguiu-se o mesmo protocolo, só que sendo enumerados com a sigla "PS".

O processo de medição se realizou durante os turnos de funcionamento da biblioteca, que no período de medição funcionou apenas nos turnos manhã e tarde, devido à greve dos técnicos administrativos da Instituição de Ensino Superior. Esse processo aconteceu entre os dias 07/11/2016 à 11/11/2016, nos horários e 09:00h às 12:00h (manhã) e 13:30h às 17:00h (tarde), de acordo com a disponibilidade do pesquisador. Esta etapa consistiu na mensuração dos níveis de pressão sonora, onde as medições foram feitas nos pontos especificados na planta baixa, com intervalos de 1 minuto, tendo duração de 5 minutos cada, para se estabelecer o máximo de nível de pressão sonora captado em cada ponto.

Para a fase de dosimetria utilizou-se o dosímetro da marca Instrutherm, Modelo DOS-600, devidamente calibrado, que segundo seu fabricante, está de acordo com as normas IEC 61672-1 tipo 2, IEC 61252, IEC 60651 tipo 2, IEC 60804 tipo 2, e ANSI S1.25 tipo 2, além de atender a todas as especificações da norma NR-15. O equipamento opera em faixas de medição de 60 a $130 \mathrm{~dB}$ e de 70 a $140 \mathrm{~dB}$, e realiza medições em escalas de compensação "A" e "C", e de resposta fast (rápida) e slow (lenta).

A função do aparelho é fornecer e armazenar as medidas do nível de pressão sonora equivalente, ao mesmo tempo em que faz a dosimetria. No caso deste estudo, o processo de dosimetria seguiu os parâmetros específicos de medição conforme a recomendação da NR-15, como tempo de resposta slow e a escala de compensação "A", que indica que os níveis medidos estão sendo ponderados pelas frequências de acordo com a subjetividade.

Foram realizadas 6 dosimetrias em usuários distintos da biblioteca. Realizaram-se as medições entre os dias 30/01/2017 e 11/02/2017. Cada dosimetria contemplou 6 horas diárias em dias distintos e pontos específicos da deste ambiente. O Anexo 5 e 6 apresentam a localização dos usuários nas áreas da biblioteca durante esse processo. Cada usuário foi nomeado com numeração de 1 a 6 para facilitar na análise estatística.

\subsection{FERRAMENTAS E PROCEDIMENTOS DE ANÁLISE DOS DADOS}

Todos os dados referentes aos valores do nível de pressão sonora levantados nos processos de medição pontual e dosimetria foram reunidos em planilhas eletrônicas do software Microsoft Excel (versão estudanti), de forma que cada aspecto levantado pôde ser tabulado distintamente em esta planilha. Posteriormente, utilizou-se o software $R$ project x64 2.15.0 @ para efetuar os cálculos estatísticos e gerar tabelas e gráficos dos resultados resumido de forma sistêmica os dados levantados.

Após a tabulação, os dados coletados passarão por uma análise que comtempla: 1) comparação dos dados com a norma e; 2) análise estatística inferencial sobre os dados.

1) Comparação dos dados com as normas:

Os dados levantados quanto ao nível de pressão sonora foram confrontados com os valores estabelecidos pela NBR-10.152 (1987), para verificação da aceitabilidade dos 
níveis de ruído presentes na biblioteca, além do cumprimento aos valores estabelecidos pela NR-15 para o turno de 8 horas.

2) Análise estatística inferencial sobre os dados:

Os dados mensurados quanto a nível de pressão sonora foram confrontados, buscando verificar se há diferenças estatisticamente significativa entre as

Quadro 1 - Questionamentos, eixos comparativos e tipo de teste estatístico utilizado

\begin{tabular}{|l|c|c|c|}
\hline \multicolumn{2}{|c|}{ Perguntas a nível geral } & $\begin{array}{c}\text { Eixo de comparação } \\
\text { Há diferenças entre os turnos? }\end{array}$ & $\begin{array}{c}\text { Tipo(s) de teste } \\
\text { grupos }\end{array}$ \\
\hline Há diferenças entre os locais de coleta? & $\begin{array}{c}\text { Comparação de quatro } \\
\text { grupos }\end{array}$ & \multicolumn{2}{|c|}{ Kruskal-Wallis } \\
\hline $\begin{array}{l}\text { Há diferença entre o piso superior e } \\
\text { inferior? }\end{array}$ & $\begin{array}{c}\text { Comparação de dois } \\
\text { grupos }\end{array}$ & Mann-Whitney & Mediana \\
\hline
\end{tabular}

\subsection{RESULTADOS E DISCUSSÕES}

Os dados levantados foram organizados de forma sistêmica para uma análise detalhada. O processo de tratamento dos dados constou de tabulação e organização das medições medições feitas nos turnos de manhã e da tarde, além dos pisos superior e inferior. No mais, também buscou-se verificar se há diferenças estatisticamente significativa entre os diferentes locais de coleta. Para a realização dessas análises, adotaram-se testes não paramétricos de acordo com eixo de comparação dos dados, conforme pode ser observado no Quadro 1.

Tabela 1 - Níveis de Pressão Sonora (em dB) coletados no Espaço de Leitura Individual 1 (Piso Inferior)

\begin{tabular}{|c|c|c|c|c|c|c|c|c|c|c|c|c|c|c|c|c|c|}
\hline Turno & 101 & $\mathrm{PIO2}$ & 103 & $\mathrm{PIO4}$ & $\mathrm{PI05}$ & PI06 & $\mathrm{Pl07}$ & PI08 & PI09 & 110 & Pl11 & Pl12 & & & Pl15 & Pl16 & $\mathrm{Pl} 17$ \\
\hline Manh & 6,1 & 77,7 & 31 & 713 & 74,8 & & 726 & 69,7 & & & & & & & & & \\
\hline & & 7 & & & & & & & & & & & & & & & \\
\hline & P & 19 & & & & & 124 & & & & & & & & & & \\
\hline & & & & & & & & & & & & & & & & & \\
\hline Tarde & 4,2 & 70,3 & 6,0 & 0,3 & 73,4 & 79,1 & 5,0 & 3,3 & 71,0 & 73,5 & 73,5 & 71,2 & 3,3 & 5,1 & 2,4 & 1,3 & \\
\hline
\end{tabular}

Tabela 2 - Níveis de Pressão Sonora (em dB) coletados no Espaço de Leitura Individual 2 (Piso Inferior)

\begin{tabular}{|c|c|c|c|c|c|c|c|c|c|c|c|c|c|c|c|c|c|}
\hline Turno & PI35 & PI36 & PI37 & PI38 & PI39 & $\mathrm{Pl} 40$ & $\mathrm{Pl} 41$ & $\mathrm{PI} 42$ & $\mathrm{Pl} 43$ & $\mathrm{PI} 44$ & $\mathrm{Pl} 45$ & $\mathrm{PI} 46$ & $\mathrm{Pl} 47$ & $\mathrm{PI} 48$ & $\mathrm{Pl} 49$ & PI50 & PI51 \\
\hline Manhã & 70,9 & 73,1 & 79,1 & 70,4 & 74,2 & 70,8 & 71,6 & 72,6 & 69,2 & 71,3 & 75,1 & 76,3 & 73,7 & 72,6 & 72,9 & 69,1 & 71,9 \\
\hline Tarde & 69,2 & 70,3 & 72,6 & 76,0 & 75,2 & 76,1 & 72,9 & 71,6 & 73,3 & 69,1 & 73,3 & 74,4 & 75,3 & 76,1 & 70,8 & 70,7 & 70,1 \\
\hline & PI52 & PI53 & Pl54 & PI55 & PI56 & PI57 & PI58 & PI59 & PI60 & PI61 & PI62 & Pl63 & Pl64 & PI65 & PI66 & PI67 & PI68 \\
\hline Manhã & 67,7 & 73,0 & 70,1 & 73,0 & 74,6 & 69,1 & 70,7 & 70,3 & 69,3 & 70,3 & 69,7 & 79,5 & 74,4 & 77,7 & 70,7 & 67,8 & 67,3 \\
\hline Tarde & 73,8 & 71,8 & 72,0 & 69,1 & 71,9 & 72,6 & 71,3 & 73,2 & 79,1 & 73,3 & 74,8 & 69,7 & 79,5 & 73,2 & 71,3 & 72,6 & 76,0 \\
\hline & PI69 & $\mathrm{Pl} 170$ & $\mathrm{Pl} 171$ & $\mathrm{Pl} 72$ & $\mathrm{Pl} 73$ & $\mathrm{Pl} 74$ & & & & & & & & & & & \\
\hline Manhã & 74,4 & 79,1 & 71,3 & 75,5 & 73,3 & 72,3 & & & & & & & & & & & \\
\hline Tarde & 72,3 & 72,0 & 71,3 & 72,6 & 73,6 & 70,8 & & & & & & & & & & & \\
\hline
\end{tabular}

A média dos níveis de pressão sonora correspondentes aos pontos de medição no Espaço de Leitura Individual 1 apresentados na Tabela 1, foi igual a $72,3 \mathrm{~dB}(\mathrm{~A})$ no período da manhã, e $72,8 \mathrm{~dB}(\mathrm{~A})$ no período da tarde. De acordo com NBR-10.152 (1987), os valores aceitáveis de níveis de pressão sonora para este tipo de ambiente devem com o auxílio de planilha eletrônica do software Microsoft Excel. Os níveis de pressão sonora coletados nos pontos definidos do piso inferior estão dispostos de acordo com o tipo do espaço, respectivamente, na Tabela 1 e 2. 
presentes no recinto não estão dentro do limite tolerável estabelecido pela norma.

Para os Espaços de Leitura em Grupo do Piso Superior da BCCB, os níveis de pressão sonora coletados estão dispostos nas Tabelas 3 e 4.

Tabela 3 - Níveis de Pressão Sonora (em dB) coletados no Espaço de Leitura em Grupo 1 (Piso Superior)

\begin{tabular}{|c|c|c|c|c|c|c|c|c|c|c|c|c|c|c|c|}
\hline Turno & PS01 & PS02 & PS03 & PS04 & PS05 & PS06 & PS07 & PS08 & PS09 & PS10 & PS11 & PS12 \\
\hline Manhã & 73,0 & 77,6 & 76,3 & 75,4 & 76,3 & 79,5 & 76,8 & 72,6 & 77,1 & 77,0 & 77,0 & 72,6 \\
\hline Tarde & 76,3 & 76,7 & 75,1 & 78,3 & 73,9 & 76,8 & 77,1 & 77,5 & 73,9 & 77,8 & 76,0 & 75,5 \\
\hline & & & & & & & & & & & & \\
\hline & PS13 & PS14 & PS15 & PS16 & PS17 & PS18 & PS19 & PS20 & PS21 & PS23 & PS23 & \\
\hline Manhã & 78,1 & 79,9 & 74,5 & 75,5 & 76,0 & 76,4 & 72,1 & 83,2 & 77,3 & 90,1 & 77,0 & \\
\hline Tarde & 75,2 & 77,0 & 79,2 & 74,9 & 73,8 & 72,4 & 76,2 & 79,4 & 74,1 & 75,5 & 73,2 & \\
\hline
\end{tabular}

Tabela 4 - Níveis de Pressão Sonora (em dB) coletados no Espaço de Leitura em Grupo 2 (Piso Superior)

\begin{tabular}{|c|c|c|c|c|c|c|c|c|c|c|c|c|c|}
\hline Turno & PS23 & PS24 & PS25 & PS26 & PS27 & PS28 & PS29 & PS30 & PS31 & PS32 & PS33 & PS34 \\
\hline Manhã & 79,5 & 74,9 & 78,5 & 75,5 & 73,8 & 76,3 & 75,4 & 74,6 & 76,0 & 77,1 & 76,4 & 73,9 \\
\hline Tarde & 78,1 & 77,3 & 74,9 & 75,3 & 73,9 & 74,5 & 76,3 & 76,4 & 76,0 & 74,8 & 72,3 & 75,5 \\
\hline
\end{tabular}

Os valores encontrados a partir das medições no Piso Superior apresentaram médias superiores às médias calculadas das medições do Piso Inferior. No Espaço de Leitura em Grupo 1, a média dos valores coletados da Tabela 3, foi de $75,7 \mathrm{~dB}(\mathrm{~A})$ no período da manhã, e 76,8dB(A) no período da tarde. O Espaço de Leitura em Grupo 2 registrou médias de $75,4 \mathrm{~dB}(\mathrm{~A})$ e $76,0 \mathrm{~dB}(\mathrm{~A})$ nos respectivos períodos. Esse aumento na média dos níveis de pressão sonora nestes espaços justifica-se pela grande movimentação e conversação de pessoas no ambiente. O resultado da dosimetria em cada usuário está disposto no Quadro 12

Quadro 2 - Resultados da dosimetria realizada nos usuários

\begin{tabular}{cc|c|c|c|c|}
$\begin{array}{c}\text { Localização } \\
\text { (Piso) }\end{array}$ & \multicolumn{2}{c}{$\begin{array}{c}\text { Usuário } \\
\text { exposição }\end{array}$} & $\begin{array}{c}\text { Tempo de } \\
\text { exojetada } \\
(8 h)\end{array}$ & $\begin{array}{c}\text { Nível médio } \\
\text { de exposição }\end{array}$ & $\begin{array}{c}\text { Nível de } \\
\text { exposição } \\
\text { normalizado (8h) }\end{array}$ \\
\cline { 2 - 6 } Inferior & 1 & $366 \mathrm{~min}$ & 0,9 & $51,8 \mathrm{~dB}(\mathrm{~A})$ & $49,9 \mathrm{~dB}(\mathrm{~A})$ \\
\cline { 2 - 6 } & 2 & $364 \mathrm{~min}$ & 0,9 & $51,8 \mathrm{~dB}(\mathrm{~A})$ & $49,7 \mathrm{~dB}(\mathrm{~A})$ \\
\hline \multirow{3}{*}{ Superior } & 3 & $386 \mathrm{~min}$ & 1,2 & $53,7 \mathrm{~dB}(\mathrm{~A})$ & $52 \mathrm{~dB}(\mathrm{~A})$ \\
\hline & 4 & $388 \mathrm{~min}$ & 1,7 & $56,0 \mathrm{~dB}(\mathrm{~A})$ & $54,3 \mathrm{~dB}(\mathrm{~A})$ \\
\hline & 6 & $392 \mathrm{~min}$ & 7,9 & $67,6 \mathrm{~dB}(\mathrm{~A})$ & $66 \mathrm{~dB}(\mathrm{~A})$ \\
\hline
\end{tabular}

A partir do Quadro 2, pode-se constatar o nível de exposição em que os usuários dos distintos pontos da planta baixa da biblioteca, estão em conformidade com a Norma Regulamentadora 15, a qual estabelece o nível máximo de exposição de $85 \mathrm{~dB}(\mathrm{~A})$ para o turno de 8 horas diárias. Os usuários localizados no piso inferior da Biblioteca registraram menores níveis de exposição se comparado aos usuários localizados no piso superior. Como citado anteriormente, na análise dos dados coletados nas medições pontuais, essa diferença justifica-se pela grande movimentação e conversação de pessoas no pavimento superior da biblioteca.

Percebeu-se que os elevados níveis de ruído encontrados sofrem influência direta de fatores, como: ruído de fundo constante ocasionado pelo sistema de ventilação da biblioteca, arrasto de cadeiras para 
acomodação dos usuários nas cabines e grande circulação e conversas entre os usuários no piso superior. Vale ressaltar, que esses níveis foram medidos nas condições de funcionamento pleno da biblioteca, onde haviam grande circulação de usuários no edifício.

A análise dos resultados dados do nível de pressão sonora nesta etapa indicou que, em geral, os ambientes investigados, nos turnos matutino e vespertino, embora estejam em conformidade com a NR-15, ainda não estão adequados aos valores estabelecidos pela Norma NBR-10.152, caracterizando esse ambiente acusticamente como desconfortável e barulhento.

Posteriormente, com o intuito de analisar os dados de forma mais minuciosa deu-se início a análise inferencial, conforme evidenciado na subseção 3.3 intitulada Ferramentas e procedimentos de análise dos dados. Os resultados estão em sintonia com os testes estatísticos evidenciados no Quadro 2, nos quais verificavam-se os valores de $\mathrm{p}$-value $(p)$ calculados. Se o valor fosse menor que 0,05 $(p<0,05)$ rejeitava-se a hipótese nula, caso o contrário reteve-se a hipótese nula $(p>0,05)$. Os resultados obtidos são exibidos sucintamente no Quadro 3.

Quadro 3 - Questionamentos, resultados do testes estatísticos e conclusões holísticas

\begin{tabular}{|c|c|c|c|c|}
\hline Perguntas a nível geral & \multicolumn{2}{|c|}{ Resultados do teste } & \multicolumn{2}{|c|}{ Conclusão(ões) } \\
\hline $\begin{array}{l}\text { Há diferença entre os } \\
\text { turnos? }\end{array}$ & $p=0,602$ & $p=0,684$ & $\begin{array}{c}\text { As distribuições dos dados é a } \\
\text { mesma entre as categorias de } \\
\text { turno }\end{array}$ & $\begin{array}{c}\text { As medianas dos dados } \\
\text { é a mesma entre as } \\
\text { categorias de turno }\end{array}$ \\
\hline $\begin{array}{l}\text { Há diferença entre os } \\
\text { locais de coleta? }\end{array}$ & \multicolumn{2}{|c|}{$p=0,0$} & \multicolumn{2}{|c|}{$\begin{array}{c}\text { As distribuições dos dados são diferentes entre as } \\
\text { categorias de local de coleta de dados }\end{array}$} \\
\hline $\begin{array}{l}\text { Há diferença entre o } \\
\text { piso superior e inferior? }\end{array}$ & $p=0,0$ & $p=0,0$ & $\begin{array}{c}\text { As distribuições dos dados são } \\
\text { diferentes entre as categorias } \\
\text { de piso }\end{array}$ & $\begin{array}{l}\text { As medianas dos dados } \\
\text { são diferentes entre as } \\
\text { categorias de piso }\end{array}$ \\
\hline
\end{tabular}

Diante dos resultados do Quadro 3, constatase que conforme se modifica os locais de coleta de dados e o piso, há diferença nos níveis de ruído. Sendo assim, o ruído no piso superior é diferente do ruído no piso inferior, tal como, o ruído no espaço de leitura individual é diferente do ruído no espaço de leitura em grupo, por exemplo. Por outro lado, não se verificou uma diferença estatisticamente significativa entre os turnos, ou seja, o nível de ruído pela manhã é semelhante ao nível de ruído encontrado a tarde.

\section{CONSIDERAÇÕES FINAIS}

Este artigo teve como objetivo central, a verificação dos Níveis de Pressão Sonora (NPS) existentes na biblioteca de uma Instituição de Ensino Superior. Inicialmente, constatou-se, a partir de comparação dos valores de NPS encontrados com os estipulados pela Norma NBR-10152, que estes dados estão acima dos valores aceitáveis, configurando assim o ambiente deste recinto como barulhento e ruidoso. Posteriormente, a partir de dosimetria realizada nos usuários, verificou-se que os valores encontrados estão de acordo com os valores estabelecidos pela NR-15 para o turno de 8 horas, porém ainda não satisfazem aos valores elencados pela NBR-10152.

Por conseguinte, fez-se a análise inferencial na qual constatou-se que há diferenças estatisticamente significativas entre os diferentes locais de coleta e os diferentes pisos o que revela que conforme altera-se o ambiente de estudo, os níveis de ruído sofrem modificações. Não obstante, revelou-se que não há diferenças estatísticas entre os turnos estudados, acarretando a conclusão que não importa o período temporal que o indivíduo está na biblioteca, pois os níveis de ruído tendem a se manter semelhante.

A partir das observações in loco durante a coleta de dados, percebeu-se que as fontes de ruído que provocaram o desconforto acústico não são oriundas de uma fonte exterior a biblioteca, corredores e repartições próximas, mas sim originada no interior deste recinto, provocadas por aqueles que estão inseridos neste ambiente de trabalho, além do ruído de fundo constante ocasionado pelo sistema de ventilação.

Logo, o tratamento acústico deve, então, ser priorizado, visto que as atividades desenvolvidas neste tipo de ambiente 
requerem alto grau de concentração, ficando evidente que nesta Biblioteca isso não acontece de forma facilitada.

A partir dos resultados obtidos e com base nas leituras em artigos, periódicos e teses, faz-se necessário sugerir alterações no ambiente da Biblioteca Central da UFPI, a fim de torná-lo mais confortável acusticamente aos seus usuários. Para isso, são sugeridas as alternativas a seguir:

Manutenção ou troca do sistema de ventilação atual da biblioteca;

Campanhas que visem conscientizar os usuários sobre a necessidade de silêncio neste recinto;

\section{REFERÊNCIAS}

[1] Abergo. Associação Brasileira de Ergonomia. O que é ergonomia. Disponível em: <http://www.abergo.org.br/internas.php?pg=o_que _e_ergonomia> Acesso em: 9 de nov. de 2016

[2] Agahnejad, Payman. Análise Ergonômica no Posto de Trabalho numa Linha de Produção Utilizando Método Niosh - Um Estudo de Caso no Pólo Industrial de Manaus. 2011. 92 f. Dissertação (Mestrado em Engenharia Elétrica) - Universidade Federal do Pará, Belém, 2011.

[3] Associação Brasileira de Normas Técnicas (ABNT). NBR 10151: acústica - avaliação do ruído em áreas habitadas, visando o conforto da comunidade - Procedimento. Rio de Janeiro, 2000.

[4] Associação Brasileira de Normas Técnicas (ABNT). NBR 10152: níveis de ruído para conforto acústico. Rio de Janeiro, 1987.

[5] Brasil. Normas Regulamentadoras de Segurança e Medicina do Trabalho. NR 15 Atividades e Operações Insalubres. Brasília, Ministério do Trabalho e Emprego, 1978.

[6] Coutinho Filho, E. F.; et al. Avaliação do conforto ambiental em uma escola municipal em João Pessoa. In: Encontro de Extensão, 9, 2007, João Pessoa. Anais... João Pessoa: Editora Universitária, 2007, p.1-6.

[7] Falzon, Pierre. Manual de Ergonomia. Madrid: Modus Laborandi, 2009. 712p.

[8] Fidelis, N.V.W; Fernandes, C. A. F. Análise Ergonômica do Trabalho de um Operador de Torno Mecânico em uma Universidade do Paraná. In: Encontro Nacional de Engenharia de Produção, 25., 2015, Fortaleza. Anais... Fortaleza, 2015.

[9] Moreira Neto, L.Z; Tavares, D.M.L.; Almeida, A.V.C. Análise Ergonômica do Trabalho:
Mudança das acomodações dos usuários, bem como cadeiras, pois estas são fontes consideráveis de ruído quando deslocadas pelos usuários;

Aplicar as determinações da NBR 10152: Níveis de ruído para o Conforto Acústico, que recomenda que os níveis máximos de ruído, especificamente em bibliotecas, devem estar situados entre 35 a $45 \mathrm{~dB}$;

Por fim, tendo em vista que a biblioteca da Instituição de Ensino Superior é extremamente importante no contexto da universidade, fazse a utilização de meios para garantir melhores condições de conforto acústico para a comunidade acadêmica e seus usuários.

O Caso de uma Empresa de Perfumaria e Cosméticos na Região Metropolitana de Belém. In: Simpósio de Engenharia de Produção, 12., 2015. Bauru. Anais... Bauru, 2015.

[10] Ochoa, J. H. Análise do Conforto Ambiental em Salas de Aula da Universidade Federal de Goiás. 2010. 149 f. Dissertação (Mestrado em Geotecnia, Construção Civil e Mecânica das Estruturas) - Universidade Federal de Goiás, Goiania, 2010.

[11] Paula, A.; Haiduke, I.; Marques, I.A. Ergonomia e Gestão: complementaridade para a redução dos afastamentos e do stress, visando melhoria da qualidade de vida do trabalhador. Revista Conbrad, Maringá, v.1, n.1, p.121-136, 2016.

[12] Radjiyev, A; et al. Ergonomics and sustainable development in the past two decades (1992-2011): Research trends and how ergonomics can contribute to sustainable development. Applied Ergonomics, Coreia do Sul, v. 46, part-A, p.67-75, jan. 2015

[13] Silva, A. A.; Lucas, E. R. O. Abordagem Ergonômica do Ambiente de Trabalho na Percepção dos Trabalhadores: Estudo de Caso em Biblioteca Universitária (2009). Revista ACB: Biblioteconomia em Santa Catarina, Florianópolis, v.14, n.2, 382-406, jul./dez., 2009.

[14] Teles, R. M.; Medeiros, M. P. H. Perfil audiométrico de trabalhadores do distrito industrial de Maracanaú - CE. Revista da Sociedade Brasileira de Fonoaudiologia, Fortaleza, vol.12, n.3, p.233-239, 2007.

[15] Wachowicz, M. C. Ergonomia. Curitiba: Rede e-Tec Brasil, 2013. 176p. 
ANEXO 1

Delimitação e pontos definidos para medição pontual no Espaço de Leitura Individual 1

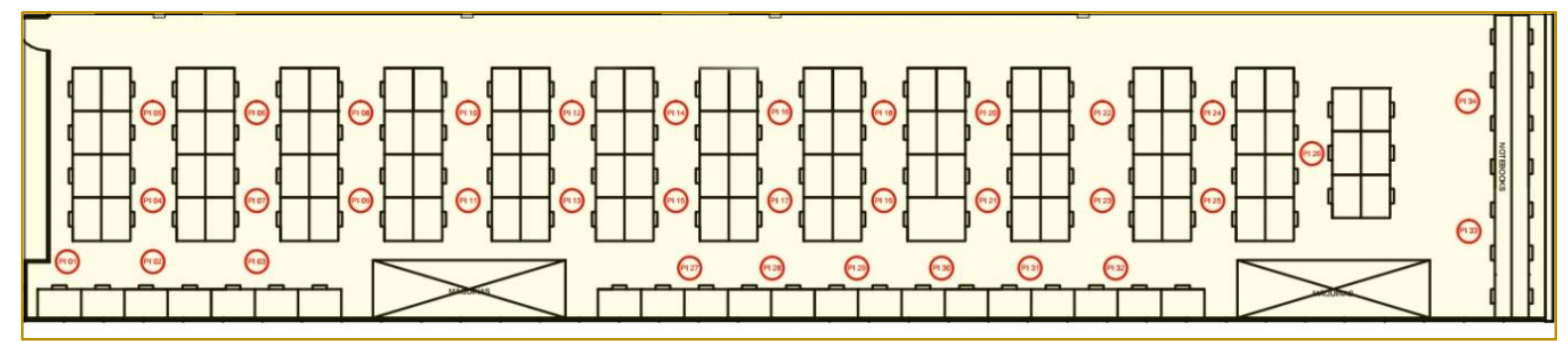

ANEXO 2

Delimitação e pontos definidos para medição pontual no Espaço de Leitura Individual 2

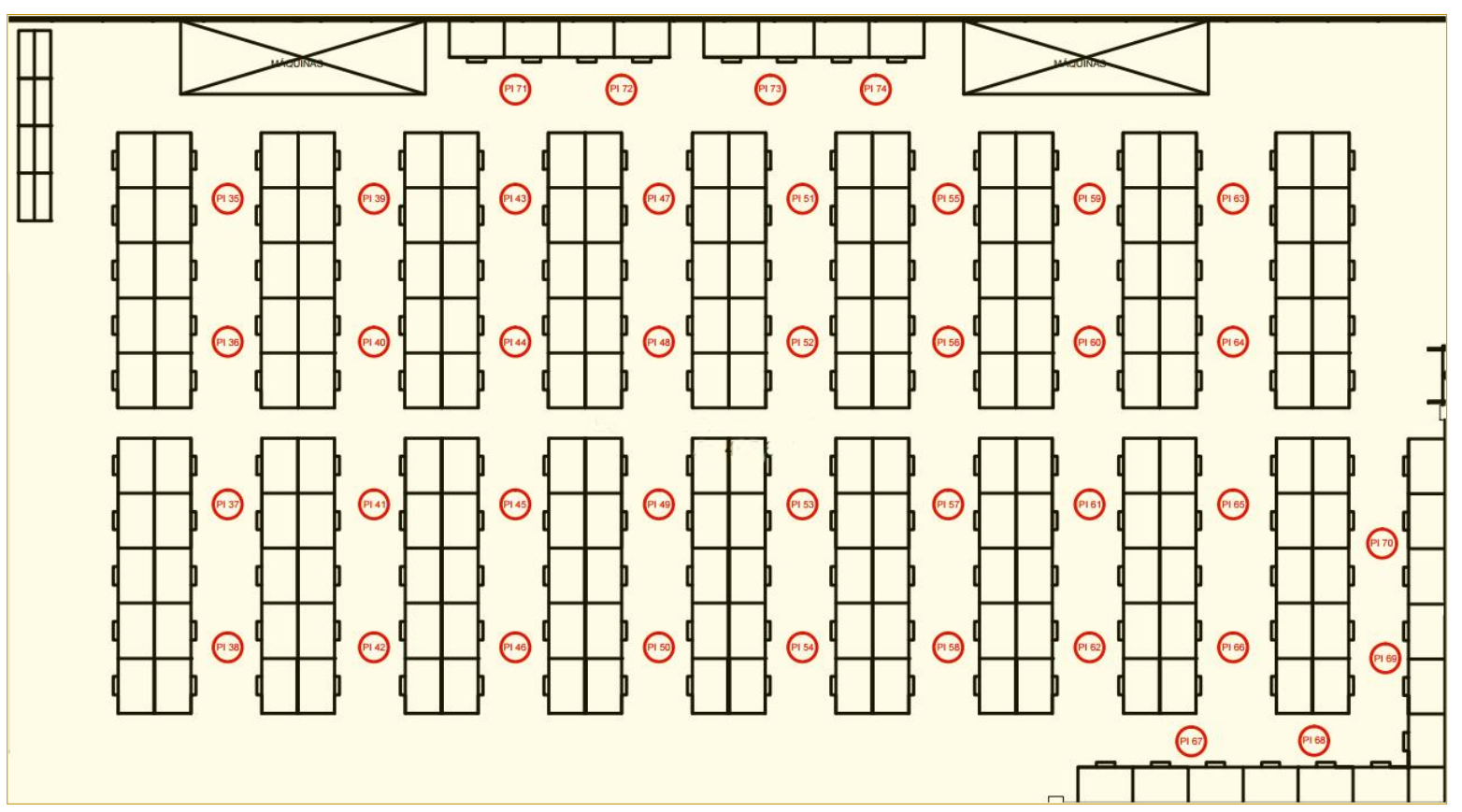


ANEXO 3

Delimitação e pontos definidos para medição pontual no Espaço de Leitura em Grupo 1

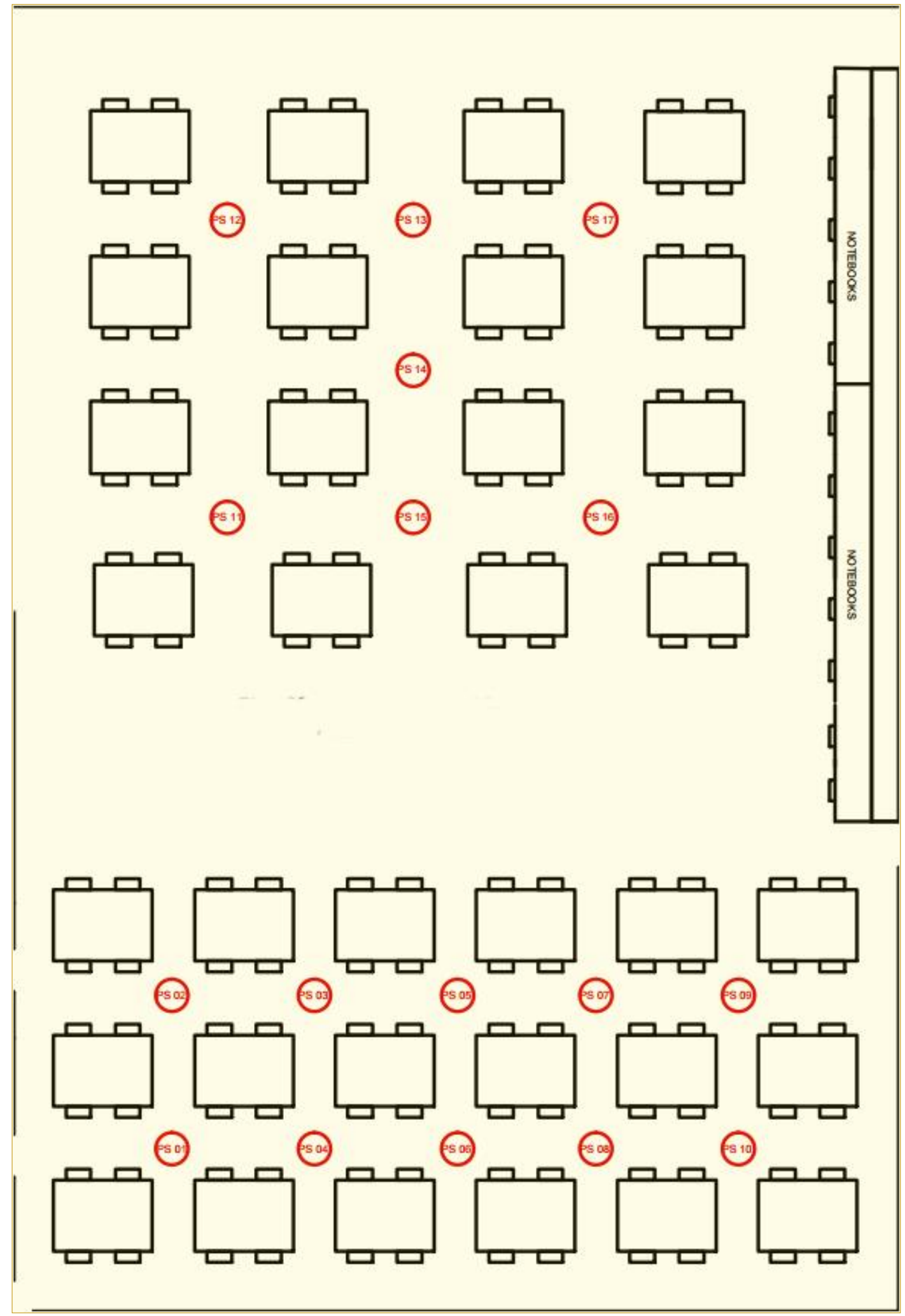


ANEXO 4

Delimitação e pontos definidos para medição pontual no Espaço de Leitura em Grupo 2

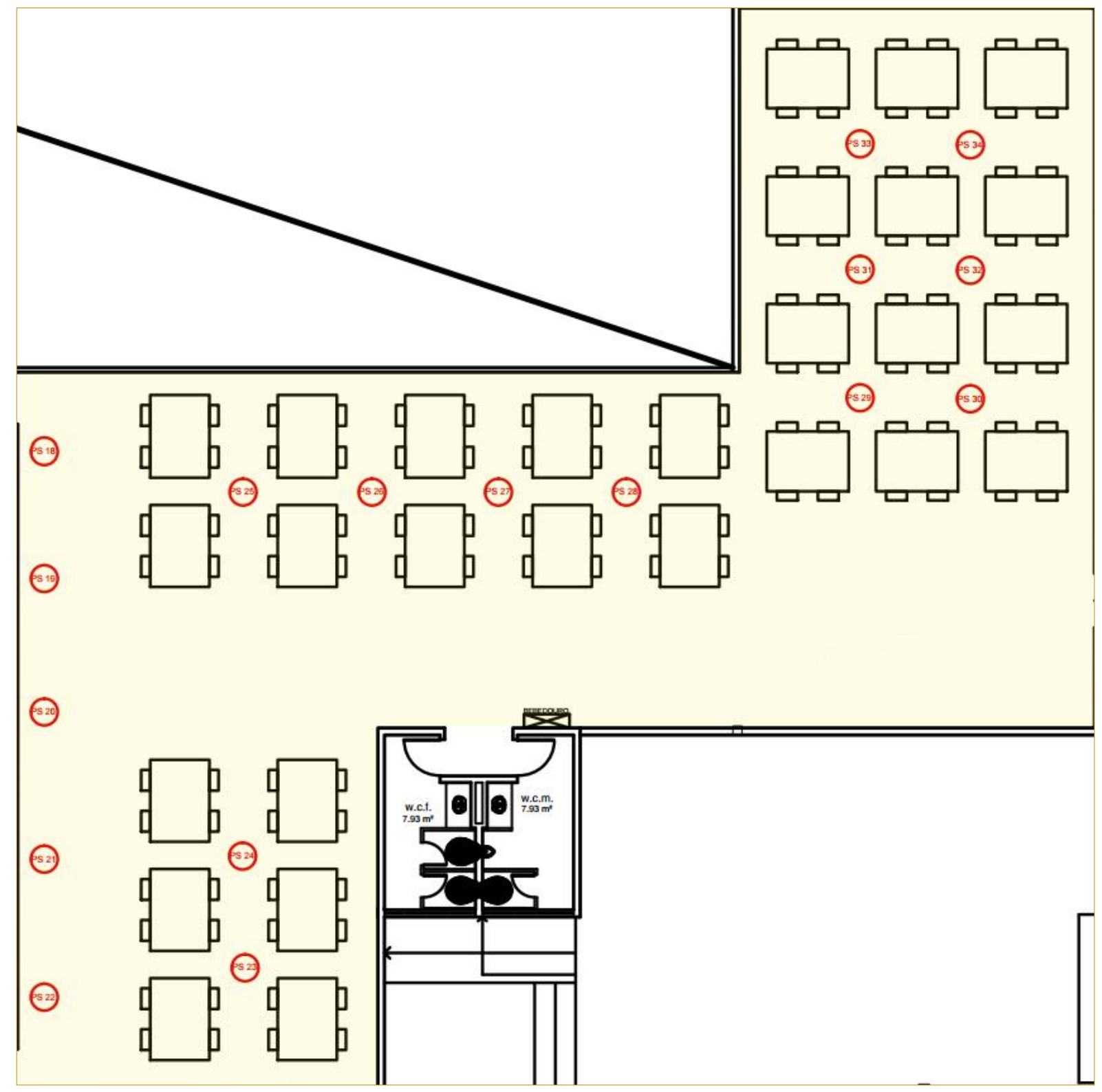


ANEXO 5

Pontos de localização dos usuários na planta baixa do piso inferior no fase de dosimetria

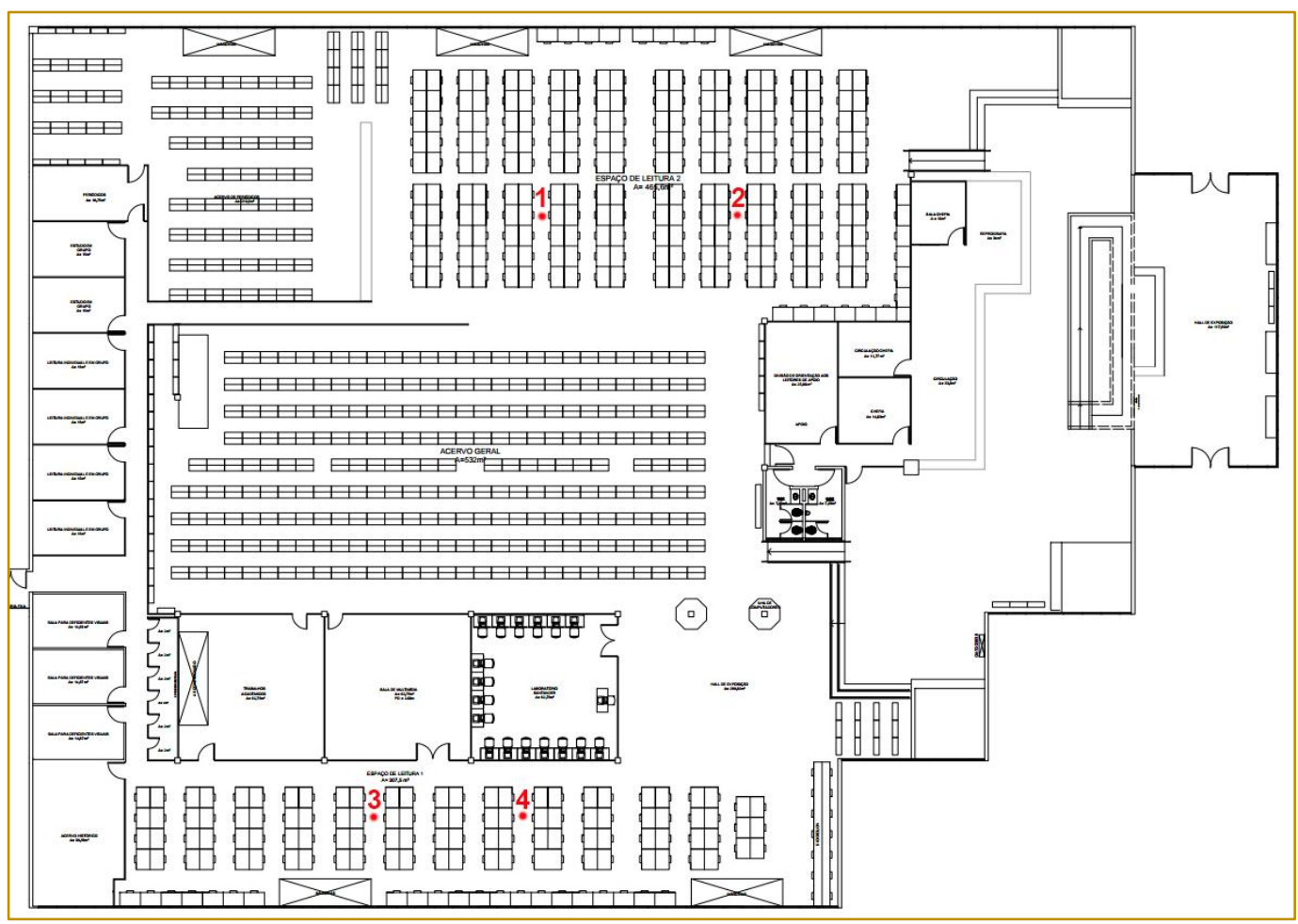

ANEXO 6

Pontos de localização dos usuários na planta baixa do piso superior na fase de dosimetria

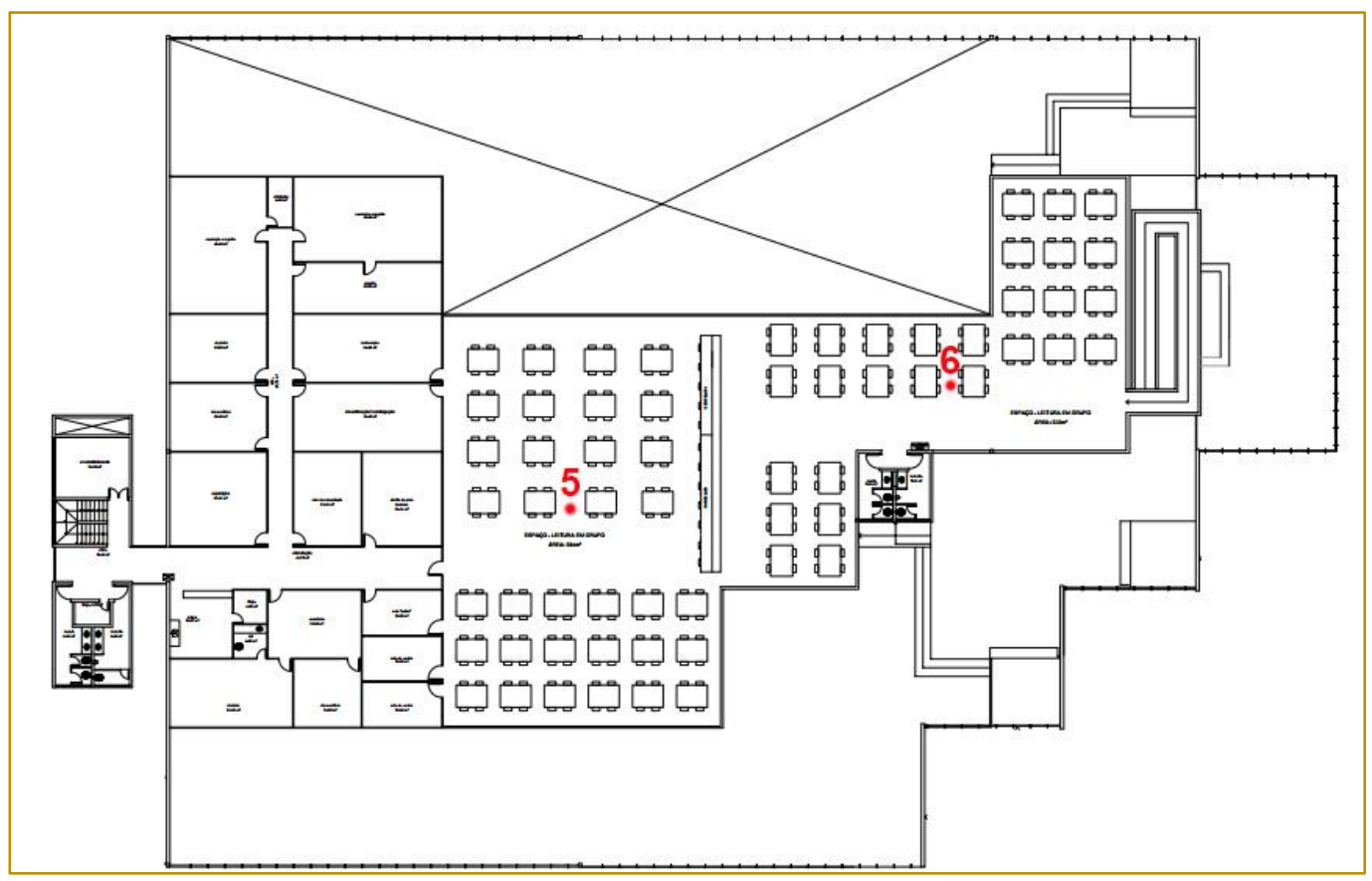




\section{CAPÍTULO 13}

\section{ANÁLISE ERGONÔMICA DO TRABALHO: UTILIZACÃO DOS METTODOS OWAS E RULA EM UMA EMPRESA DE CONFECCÓES NA CIDADE DE MOSSORÓ-RN}

\section{Paulo Ricardo Fernandes de Lima}

Cryslaine Cinthia Carvalho Nascimento

Sonagno de Paiva Oliveira

Manoel Isac Maia Junior

Thuana Maria de Melo Gonzaga

João Victor Nunes Lopes

Resumo: Atualmente várias empresas já entendem que seus recursos humanos são tão importantes quanto os materiais e financeiros. A negligência com a saúde de funcionários pode pôr em risco os objetivos organizacionais. Desta forma, ela deve ter especial atenção. Este estudo tem como objetivo realizar uma avaliação ergonômica em postos de trabalhos de uma indústria de confecções localizada na cidade de Mossoró-RN utilizando os métodos OWAS e RULA. Para tanto, realizouse levantamento bibliográfico sobre o tema, agendou-se visitas técnicas à empresa e reunião com representante da mesma, além de coletarem-se informações para análises. Optou-se por trabalhar com dois postos de trabalho: I - Produção e costuraria; II - Corte de tecidos. Por suas características, o trabalho classifica-se como qualitativo, exploratório, aplicado com estudo de caso. Utilizou-se o software Ergolândia, versão 5.0, para a tabulação dos dados. Os resultados apontaram que o posto de trabalho I apresentou grau 2 de criticidade, ou seja, recomendam-se ações de correção das condições atuais de trabalho a médio prazo. Já o posto de trabalho II apresentou grau 3, indicando condições laborais mais severas. Isto implica em ações corretivas mais urgentes. Por fim, elaborou-se um plano de ações como forma de minimizar a realidade encontrada.

Palavras-Chave: Ergonomia; Análise ergonômica do trabalho; OWAS; RULA. 


\section{INTRODUÇÃO}

A relação do homem com seu ambiente de trabalho, apesar de ser essencial, sempre foi marcada por problemas que iam desde lutas salariais até o requerimento de condições dignas para exercer sua atividade. Castanho (2009) relata que desde a Revolução Industrial houve um grande desrespeito aos direitos humanos, pois as condições de trabalho e de vida, nos primeiros anos da revolução, eram demasiadamente sofridas.

Séculos depois, apesar dos direitos e vantagens adquiridos, o trabalhador ainda se encontra em meio a dilemas laborais. A Organização Internacional do Trabalho (OIT, 2013) aponta que, anualmente, morrem em média mais de 2 milhões de pessoas vítimas de doenças associadas ao trabalho. Os números também são expressivos em relação às doenças não letais decorrentes do trabalho: 160 milhões de pessoas. Os dados são alarmantes e comprovam a necessidade de medidas de proteção ao trabalhador e promoção de saúde laboral.

Patriota e Santos (2015) alertam que não é raro encontrar trabalhadores em exercício sem equipamentos de proteção adequados e, portanto, expostos a riscos. Isto explica os dados supracitados e a constatação de uma realidade que, apesar de apresentar melhorias quando comparada a outrora, ainda reflete um alto índice de complicações e doenças do trabalho.

A indústria costuma ser um setor que apresenta altos índices de "doenças do trabalho". As produtoras de bens e prestadoras de serviços costumam enfrentar problemas deste gênero por conterem, dentro da sua linha de processo, atividades operacionais repetitivas e exaustivas. Esses problemas apresentam-se em ambientes diversos, independentemente do ramo ou do porte empresarial e podem acometer de forma séria a saúde do trabalhador.

Neste contexto, este trabalho tem como objetivo principal realizar uma avaliação ergonômica em postos de trabalhos de uma indústria de confecções localizada na cidade de Mossoró-RN utilizando os métodos OWAS e RULA.
2 REFERENCIAL TEÓRICO

\subsection{ERGONOMIA E ANÁLISE ERGONÔMICA DO TRABALHO}

Segundo a Associação Internacional de Ergonomia (IEA, 2000), ergonomia é a parte da ciência que cuida da relação dos colaboradores com seus ambientes de trabalho de forma a propiciar saúde e bemestar aos funcionários, bem como equilibrar sua importância no sistema em que estão inseridos, sem comprometer seu desempenho laboral. Os estudos ergonômicos direcionamse no sentido de analisar e propor melhorias em produtos, métodos, tarefas e postos de trabalhos afim de moldá-los a conceitos que visem as reais necessidades e que prezem pela capacidade e limitação humana.

Uma das principais atuações dos profissionais de ergonomia trata-se da realização da Análise Ergonômica do Trabalho (AET). Segundo a Norma Regulamentadora NR 17, a AET atua na observação das relações do trabalhador com o sistema laboral, propondo intervenções quando as atividades desenvolvidas acarretem risco à saúde do profissional ou interfira negativamente em sua produtividade (BRASIL, ABNT, 1990). Entre outros aspectos analisados na AET destacam-se: conforto posicional, climático, visual, auditivo, conforto motor-operacional e psico-organizacional.

Entretanto, para que a análise faça sentido deve-se favorecer o surgimento de boas práticas que configurem-se em mudanças positivas à organização. Burke (1998) enfatiza a praticidade desta análise, já que, se bem realizada, produz efeitos concretos a todos os envolvidos no processo, trazendo ganhos reais ao ambiente de trabalho.

\subsection{MÉTODOS DE AVALIAÇÃO POSTURAL}

Existem diversos métodos ergonômicos de análise postural utilizados atualmente. Cada um busca direcionar seus conhecimentos para determinada problemática existente. Alguns conseguem mesclar informações de tal forma que têm capacidade de extrair resultados mais amplos e completos. Entre eles destacam-se os métodos OWAS e o RULA. 


\subsubsection{MÉTODO OWAS}

Cardoso Júnior (2006) explica que o método OWAS (Ovako Working Posture Analysing System) surgiu na Finlândia, por parte de um instituto de promoção à saúde, cuja finalidade era a identificação, avaliação e resolução de posturas inadequadas. $O$ fator estimulante para o desenvolvimento desta ferramenta foi a diminuição de absenteísmo, incapacidades e custos extras ocasionados por fatores de trabalho.

Másculo e Vidal (2011, p. 375) colocam que:

A ferramenta OWAS oferece um método simples para análise das posturas de trabalho. Os resultados gerados são baseados no posicionamento da coluna, braços e pernas, além disso, o OWAS considera as cargas e forças utilizadas. A pontuação atribuída à postura avaliada que indica a urgência na tomada de medidas corretivas para reduzir a exposição dos trabalhadores a riscos.

A Figura 1 mostra as principais áreas analisadas por este método e as posições de trabalho que podem estimular doenças ocupacionais em funcionários e colaboradores.

Figura 13 - Posturas analisadas no método OWAS

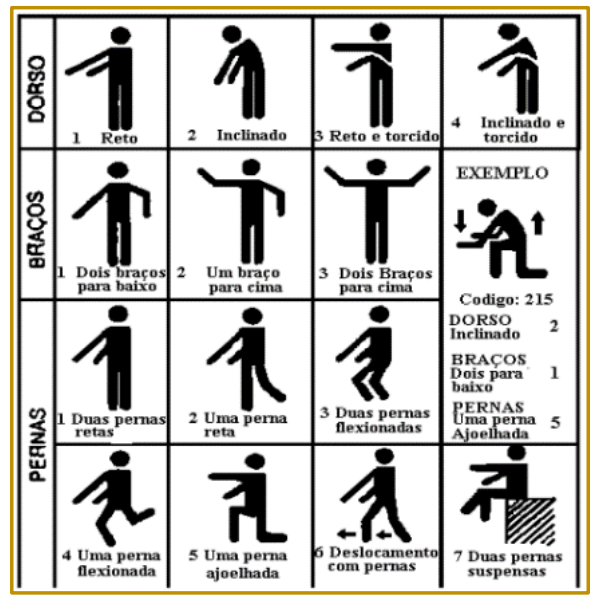

Fonte: lida (1990)

Para que a análise fosse mensurada precisouse estabelecer critérios e limites para sua quantificação. lida (1990) explica que foi desenvolvida uma escala, contendo quatro prontos, em que os valores finais de cada estudo deveriam ser alocados. A escala possuía, em uma das extremidades, resultados que apontavam "postura normal, sem desconforto e sem efeito à saúde" e na outra "postura ruim, desconforto com risco de danos à saúde". A Tabela 1 mostra os valores correspondes aos intervalos de análise do método OWAS.

Tabela 11 - Intervalos de análise do Método OWAS

\begin{tabular}{c|l|l|}
$\begin{array}{c}\text { Categoria } \\
\text { de ação }\end{array}$ & \multicolumn{2}{c|}{ Definição } \\
\hline 1 & $\begin{array}{l}\text { Postura normal e natural sem efeitos danosos para o } \\
\text { sistema músculo-esquelético }\end{array}$ & Não requer ação de intervenção \\
\hline 2 & $\begin{array}{l}\text { Postura com possibilidade de causar dano } \\
\text { Ações corretivas são requeridas num } \\
\text { futuro próximo }\end{array}$ \\
\hline 3 & $\begin{array}{l}\text { Postura com efeitos danosos sobre o sistema } \\
\text { músculo-esquelético }\end{array}$ & $\begin{array}{l}\text { Ações corretivas são necessárias, o } \\
\text { quanto antes. }\end{array}$ \\
\hline 4 & $\begin{array}{l}\text { A carga causada por esta postura tem efeitos } \\
\text { danosos } \\
\text { imediatos sobre o sistema músculo-esquelético }\end{array}$ & Ações corretivas imediatas. \\
\hline
\end{tabular}

Fonte: Martinez (2005) 
Percebe-se que nesta classificação há indicações quanto à urgência de intervenções. Dependendo do grau de criticidade deve-se tomar medidas imediatamente, a médio ou longo prazo ou, ou ainda, se for o caso, não necessitar de ações corretoras. A escala não especifica o tempo exato de intervenção, apenas indica seu horizonte em longo, médio ou curto prazo.

\subsubsection{MÉTODO RULA}

De acordo com Stand (2004), o RULA (Rapid Upper Limber Assessment) foi desenvolvido em 1993 pelos pesquisadores McAtammey e Corlett e sua utilização é recomendada em situações onde haja uma sobrecarga ou esforço repetitivo nos membros superiores. A avaliação direciona-se para as posturas e movimentos das seguintes partes do corpo: braço, antebraço, punho, rotação do punho, pescoço, tronco, pernas e carga levantada. A Figura 2 mostra algumas das posturas analisadas pelo método.

Figura 14 - Algumas posturas analisadas no Método RULA

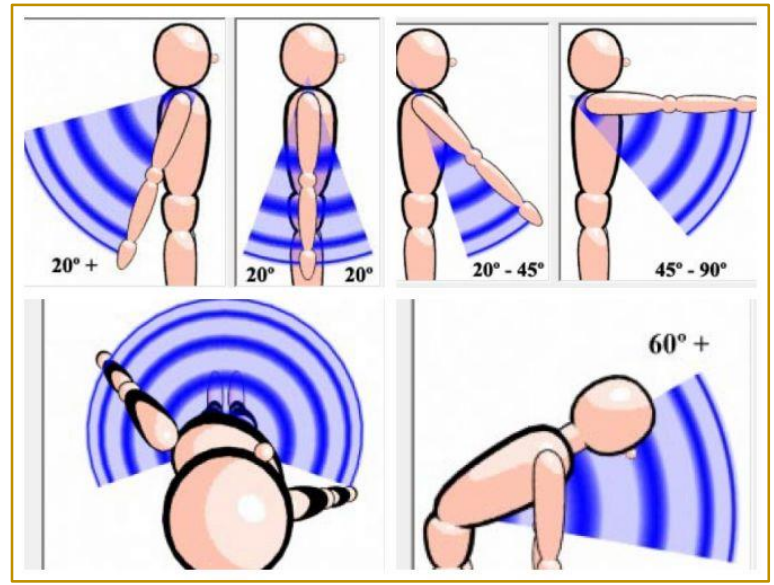

Fonte: Ergolândia (2016)

\section{METODOLOGIA}

O estudo metodológico seguiu algumas etapas que contemplaram desde 0 planejamento inicial até as fases de coleta de dados e aplicação de conhecimentos ergonômicos. A Figura 3 mostra de forma sucinta os passos percorridos neste estudo.

Figura 15 - Etapas da metodologia

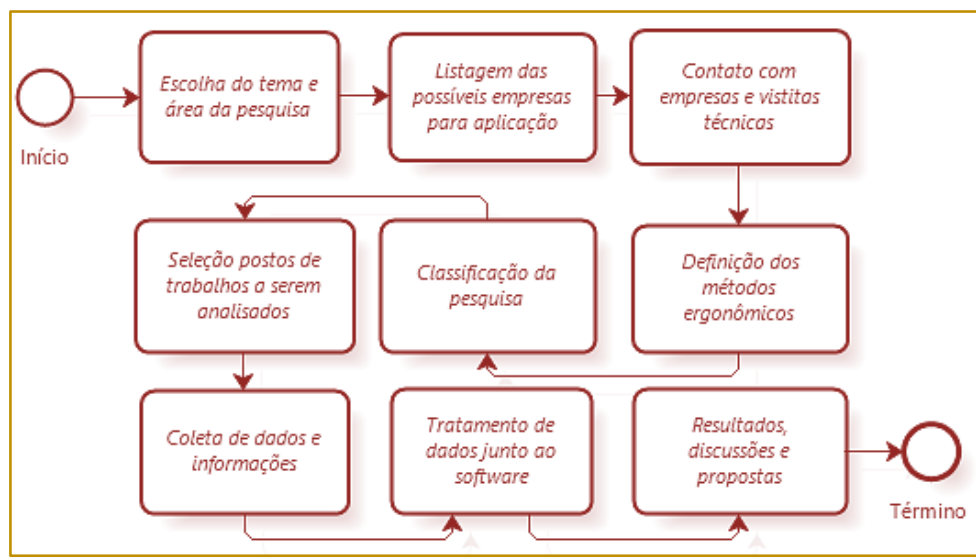

Fonte: Os autores (2016) 
A seguir encontram-se discriminadas as etapas presentes na metodologia, bem como os detalhes inerentes a cada uma, seus componentes e informações necessárias para que o objetivo central do trabalho fosse alcançado.

\subsection{O LOCAL}

Trata-se de uma empresa de pequeno porte situada na cidade de Mossoró, interior do Rio Grande Norte. Atuante há mais de uma década na manufatura de vestimentas, caracteriza-se como uma empresa produtora de bens, já que trabalha majoritariamente com a confecção de vestuários.

A empresa conta com 30 funcionários e uma jornada de oito horas diárias de trabalho, atuando durante cinco dias por semana. Divide-se basicamente em nove departamentos, responsáveis por todo fluxo produtivo, desde o input até o output. Seus principais setores são: presidência, gerência de produção, recebimentos de pedidos, design gráfico, corte de matéria prima, produção e manufatura, bordagem, inspeção de qualidade e embalagem.

\subsection{CLASSIFICAÇÃO E ETAPAS DO ESTUDO}

Quanto à abordagem empregada, o estudo classifica-se com qualitativo. Silvia e Menezes (2005) colocam que este tipo de intervenção tem como principal característica a compreensão de acontecimentos específicos e sua posterior tradução como forma de induzir o fenômeno. Já em relação aos objetivos, enquadra-se na categoria de pesquisa exploratória, que, segundo Gil (2007), são aquelas aplicações onde há uma aproximação do pesquisador com o objeto cuja finalidade é explicá-lo ou, em alguns casos, o fomento de questões hipotéticas.

Em relação à natureza científica o estudo é aplicado. Silvia e Menezes (2005) entendem que este tipo de pesquisa visa a formulação de conhecimentos aplicáveis que sirvam de base para a resolução de problemas e conflitos. Por fim, este trabalho configura-se como um estudo de caso, pois procura investigar com afinco uma situação real, possuindo condições de entender suas particularidades, como sugere Gil (2007).

\subsection{SELEÇÃO DOS POSTOS DE TRABALHO}

Para a realização deste estudo escolheu-se, dentre as atividades e funções existentes na empresa de confecções, dois postos de trabalhos específicos, são eles: produção/manufatura, corte de matéria prima. Estes cargos foram selecionados devido às suas características de atuação e estão apresentados na Tabela 2. O primeiro apresenta movimentos padronizados e extremamente repetitivos. O segundo é desempenhado com forte inclinação da coluna vertebral e da cervical, além de levantamento leve de peso, decorrente do instrumento de trabalho.

Tabela 12 - Postos de trabalho analisados

\begin{tabular}{|c|c|c|c|}
\hline Funcionário & Posto de trabalho & Atividade & $\begin{array}{l}\text { Carga } \\
\text { horária }\end{array}$ \\
\hline Funcionário 1 & I - Produção / Manufatura & Costura de peças de tecido & 8h/dia \\
\hline Funcionário 2 & II - Corte de Matéria Prima & $\begin{array}{l}\text { Modelar e seccionar o tecido deixando-o } \\
\text { no formato pronto para a costura }\end{array}$ & 8h/dia \\
\hline
\end{tabular}

Fonte: Dados da empresa (2016)

Dentre os vários métodos de investigação ergonômica existentes, optou-se por aplicar os métodos OWAS (Ovaco Working Posture Analysing System) e o RULA (Rapid Upper Limb Assessment). Entendeu-se que estes métodos se adequariam à realidade observada e dariam um retorno satisfatório à problemática encontrada na empresa.

\subsection{ANÁLISES DAS ATIVIDADES}

\subsubsection{LEVANTAMENTO DE DADOS E INFORMAÇÕES}

Ocorreram três visitas à empresa, nos dias 8, 9 e 12 de agosto de 2016. No primeiro momento houve um contato com o representante da mesma onde foi explicado o sentido da abordagem e de que forma aquele estudo poderia contribuir para os objetivos 
empresariais. Logo após, teve-se acesso aos departamentos contidos na organização, bem como o número e funcionários atuante em cada setor. A partir de então, escolheu-se os dois postos de trabalho, já mencionados neste documento, como alvos do estudo.

Os últimos momentos foram de conversas informais com os funcionários, com perguntas breves e abertas e levantamento de informações. A coleta de dados foi realizada através de observações, anotações e registros fotográficos de dentro das instalações da empresa. O resultado e aplicação destes registros podem ser conferidos na Seção 4 deste trabalho.

\subsubsection{TABULAÇÃO DOS DADOS}

Parte das informações consideradas foi repassada pela própria gerência da empresa e anotadas pelos pesquisadores, como por exemplo, o nome de cada setor, a quantidade de funcionários e carga horária diária. O registro fotográfico foi feito por câmera semiprofissional onde escolheu-se um ângulo que retratasse com fidelidade a atividade desempenhada por cada colaborador. Como não fazia parte do intuito central, a identidade dos personagens foi resguardada.

Os valores de angulação de membros e coluna foram atribuídos seguindo-se a uma lógica visual proposta pelo software Ergolândia (ver Figuras 1 e 2). Juntando-se as posições pré-definidas pelo programa com as observações feitas in loco, chegou-se aos valores considerados neste estudo. Já para a aferição de pesos utilizou-se uma balança simples, sem tara, pra o cálculo de peso transportado em cada exercício.

Os dados foram tabelados no software Excel, versão 2013, e posteriormente inseridos no software Ergolândia 5.0, que realiza os cálculo necessários e oferece resultados em uma escala de criticidade que varia de acordo com o método ergonômico selecionado.

\section{APLICAÇÃO, RESULTADOS E DISCUSSÕES}

A seguir encontram-se expostas as aplicações e análises em cada posto de trabalho analisado segundo os métodos OWAS E RULA.

\subsection{POSTO DE TRABALHO I}

O primeiro posto de trabalho analisado foi o de produção e manufatura. Nesta função as colaboradoras exercem basicamente a atividade de costura de peças de roupas e tecidos de forma que cada uma é responsável por uma parte isolada da peça e, no fim, há uma junção dos componentes cujo resultado (output) é o produto requerido. A Figura 5 mostra algumas funcionárias em exercício em seus postos de trabalho.

Figura 16 - Posto de trabalho I: produção/manufatura

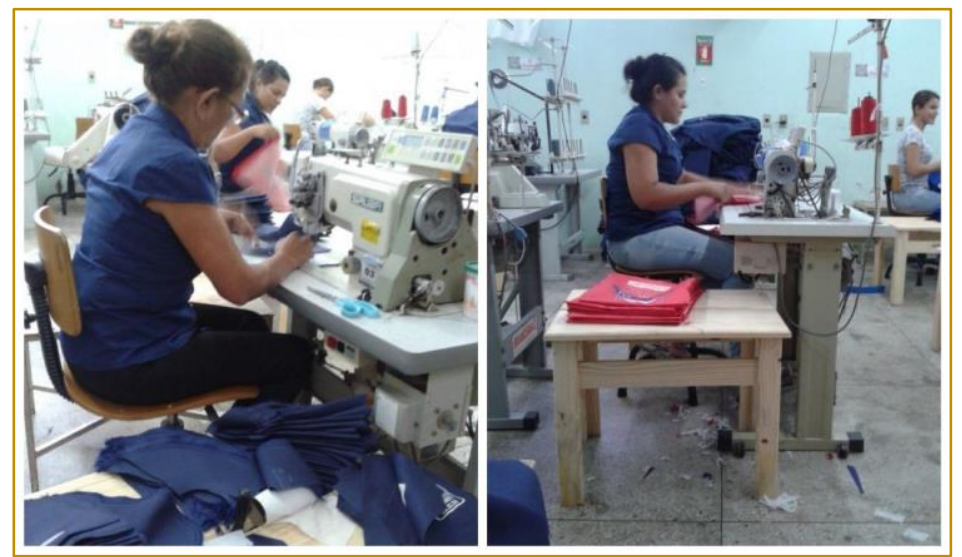

Fonte: Os autores (2016)

De acordo com a dinâmica de trabalho constatou-se que este posto apresenta as seguintes particularidades apresentadas na
Tabela 3. Ela mostra de forma sucinta todas as informações relevantes e necessárias para a alimentação do software Ergolândia. 
Tabela 13 - Dados ergonômicos do posto de trabalho I

\begin{tabular}{|c|c|c|c|}
\hline \multicolumn{3}{|c|}{ Departamento } & Produção e manufatura \\
\hline & \multirow{2}{*}{ Posição da coluna } & Tronco & Tronco levemente inclinado $\left(10^{\circ}\right.$ a $\left.20^{\circ}\right)$ \\
\hline- & & Pescoço & Pescoço levemente inclinado $\left(10^{\circ}\right.$ a $\left.20^{\circ}\right)$ \\
\hline 읃 & \multirow{3}{*}{$\begin{array}{l}\text { Posição dos membros } \\
\text { superiores }\end{array}$} & Braços & Os dois braços abaixo do ombro \\
\hline$\overline{\bar{\sigma}}$ & & Antebraços & Rotação de 0 a $60^{\circ}$ \\
\hline$\frac{\sqrt{0}}{\sqrt{0}}$ & & Punhos & Rotação inferior a $15^{\circ}$ \\
\hline \multirow{3}{*}{$\begin{array}{l}\vdash \\
0 \\
0 \\
0 \\
\frac{0}{00} \\
0 \\
0\end{array}$} & $\begin{array}{l}\text { Posição dos membros } \\
\text { inferiores }\end{array}$ & Pernas & $\begin{array}{l}\text { A maior parte do tempo sentada; } \\
\text { Postura estática mantida por mais de um minuto ou } \\
\text { repetitiva }\end{array}$ \\
\hline & $\begin{array}{l}\text { Jornada de trabalho } \\
\text { nesta postura }\end{array}$ & 8h/dia & 100\% do tempo nesta posição \\
\hline & $\begin{array}{l}\text { Levantamento de } \\
\text { cargas }\end{array}$ & & Transporta cargas inferiores a $10 \mathrm{Kg}$ \\
\hline
\end{tabular}

Fonte: Dados da pesquisa (2016)

Estas informações foram inseridas na seção OWAS do software Ergolândia que considerou a situação apresentada como sendo de Grau 2. Isto quer dizer que serão necessárias ações de promoção à saúde laboral em um futuro próximo para que não comprometa a vida e o desempenho da colaboradora. A Figura 5 mostra a aplicação dos dados no software.

Como o caso analisado apresentou grau 2, entende-se que a postura adotada na atividade apresenta certo risco à saúde da colaboradora. Nestas situações, os preceitos ergonômicos apresentados pelo software indicam mudanças a médio prazo (futuro próximo). Porém, como neste setor específico a maioria das funcionárias possuem idade entre 35 e 50 anos de idade, e atuam nesta função há alguns anos, entende-se que estas intervenções devam ocorrer de forma mais breve.

Figura 17 - Posto de trabalho I: a) Método OWAS; b) Método RULA

(a)

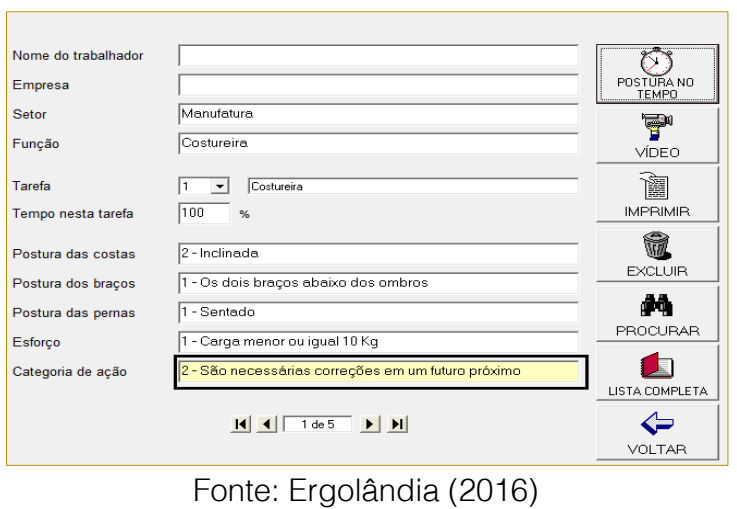

Em relação ao método RULA foram inseridos valores referentes à rotação de braços, antebraços, punhos, pescoço e tronco. Este método também leva em consideração a posição das pernas e de grupos de musculaturas pré-definidos, além da carga exercida pelo trabalhador. O programa indicou uma pontuação igual a 4, encaixandose no nível de ação 2. Situações que obtenham entre 3 e 4 pontos apontam (b)

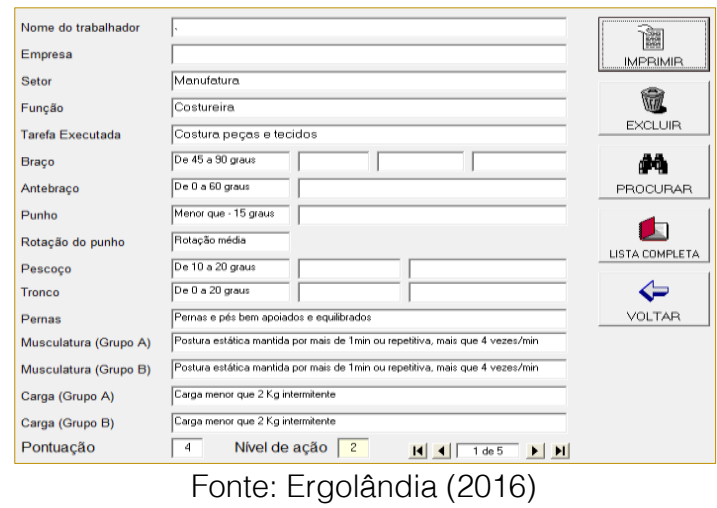

necessidades de investigações mais detalhadas.

\subsubsection{POSTO DE TRABALHO ॥}

O segundo posto analisado foi o de corte de matéria prima. O colaborador é responsável por modelar os tecidos (inputs) com uma ferramenta de corte e depois enviar os modelos para o departamento de produção (Posto I) para prosseguimento da cadeia 
produtiva. A Figura 6 mostra um dos função diária. funcionários deste setor exercendo sua

Figura 18 - Posto de trabalho II: Corte de matéria prima

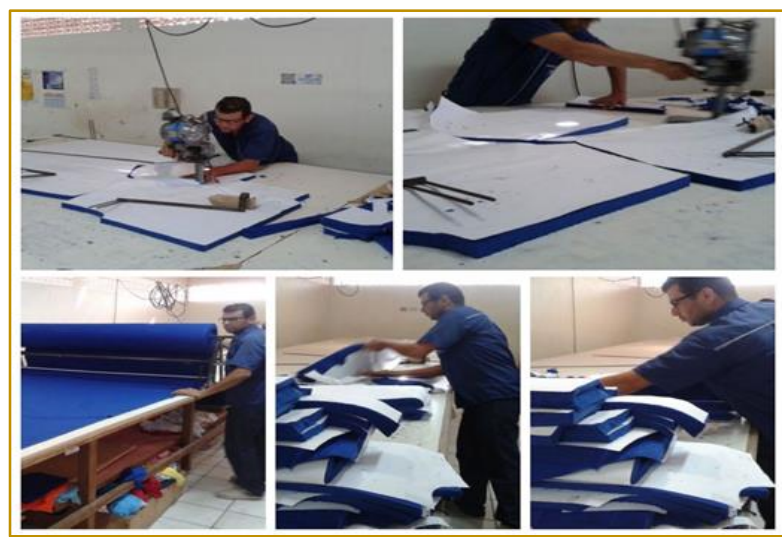

Fonte: Os autores (2016)

Para esta situação foram extraídas as informações contidas na Tabela 4. Pernebe-se que representa uma situação mais severa que o posto de trabalho analisado anteriormente.
Ainda que não esteja exposto todo o tempo a essas condições, o trabalhador analisado tende a sofrer maiores danos.

Tabela 14 - Dados ergonômicos do posto de trabalho II

\begin{tabular}{|c|c|c|c|}
\hline \multicolumn{3}{|c|}{ Departamento } & Corte de matéria prima \\
\hline & & Tronco & Tronco inclinado $\left(20^{\circ}\right.$ a $\left.60^{\circ}\right)$ \\
\hline & 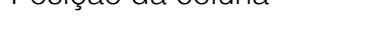 & Pescoço & Pescoço levemente inclinado (menor que $20^{\circ}$ ) \\
\hline$\overline{\bar{o}}$ & \multirow{3}{*}{$\begin{array}{l}\text { Posição dos membros } \\
\text { superiores }\end{array}$} & Braços & Os dois braços abaixo do ombro (de 20 a $45^{\circ}$ ) \\
\hline $\begin{array}{l}\overline{\bar{\sigma}} \\
\text { อ }\end{array}$ & & Antebraços & Rotação de 0 a $60^{\circ}$ \\
\hline$\stackrel{\text { బ }}{\models}$ & & Punhos & Rotação inferior a $15^{\circ}$ \\
\hline $\begin{array}{l}\frac{0}{0} \\
\frac{0}{00}\end{array}$ & $\begin{array}{l}\text { Posição dos membros } \\
\text { inferiores }\end{array}$ & Pernas & $\begin{array}{l}\text { A maior parte do tempo em pé. Sem apoio para } \\
\text { equilíbrio }\end{array}$ \\
\hline 口 & $\begin{array}{l}\text { Jornada de trabalho nesta } \\
\text { postura }\end{array}$ & 8h/dia & $50 \%$ do tempo nesta posição \\
\hline & Levantamento de cargas & & $\begin{array}{l}\text { Transporta cargas superiores a } 10 \mathrm{Kg} \text { e inferiores a } \\
20 \mathrm{Kg}\end{array}$ \\
\hline
\end{tabular}

Fonte: Dados da pesquisa (2016)

A Figura 7 mostra a interface dos dados inseridos no programa para este posto de trabalho. Verifica-se uma categoria de ação nível 2, ou seja, deve haver mudanças nas atuais condições de trabalho a médio prazo sob pena de prejudicar a saúde do trabalhador e comprometer seu rendimento funcional.
Apesar de não desempenhar esta função em toda jornada diária de trabalho, o funcionário apresentou nível 2 de criticidade. Entre outros fatores que contribuíram para este resultado, destaca-se o fato de o mesmo trabalhar em pé, com ambas as pernas esticadas, e, sobretudo, manusear durante muito tempo um objeto pesado (a máquina de corte tem peso superior a $10 \mathrm{Kg}$ ). 
Figura 19 - Posto de trabalho II: a) Método OWAS; b) Método RULA

(a)

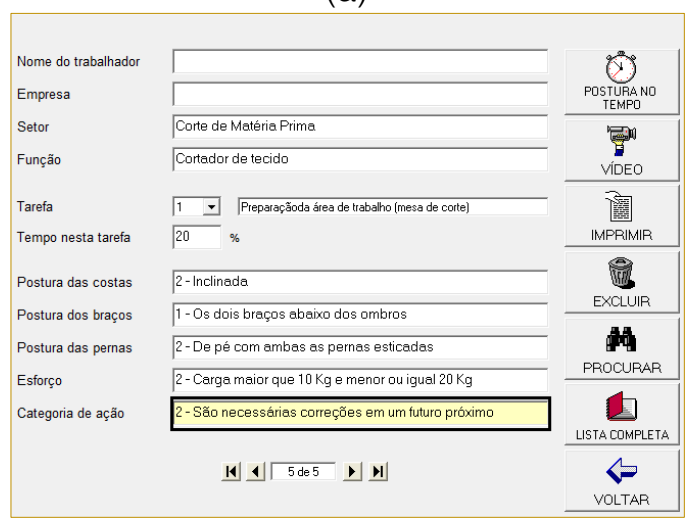

Fonte: Ergolândia (2016)

O tempo dispendido para esta atividade, nas condições apontadas, não é fixo. A porcentagem usada nesta análise foi calculada a partir de uma média de valores das amostras coletadas nos dias observados. Entretanto, o próprio funcionário alertou que esse percentual varia de acordo com a demanda existente, chegando a duplicar o percentual observado em épocas de maiores fluxos de trabalho, como também pode ser menor que o registrado neste estudo.

Apesar disto, entende-se que o resultado proposto pelo programa é aceitável, uma vez que não apontou medidas extremistas: nem nível 1 (postura de trabalho ideal), nem nível 4 (necessidade urgente de mudanças). Como as informações representaram um comportamento médio, esperava-se como resposta a solicitação de acompanhamento e a realização paliativa de medidas a médio prazo, afim de sanar ou minimizar as preocupações posturais existentes. (b)

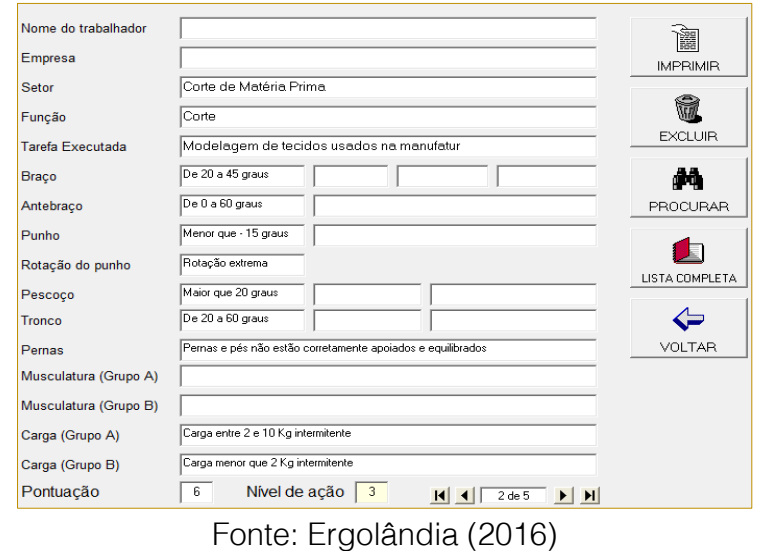

Quando analisado segundo os preceitos do RULA, o trabalho de corte de matéria prima recebeu os seguintes dados expressos na Figura 7 (b). A situação analisada apresentou uma pontuação igual a 6 e um nível de ação Grau 3. Segundo McAtamney e Corlett (1993), valores entre 5 e 6 , indicam que investigações e mudanças devem ocorrer brevemente. Ou seja, as condições de trabalho a que o funcionário está exposto coloca-o em risco laboral, sendo, portanto, necessárias medidas corretivas o quanto antes.

\subsection{PLANO DE AÇÕES}

Construiu-se um plano de ações, apresentado na Tabela 5, com medidas mitigadoras em relação à realidade encontrada. As indicações visam amenizar as maiores problemáticas ergonômicas aferidas pelo software Ergolândia como longos tempos em uma mesma posição, desconforto de mobília e atividades em pé. 
Tabela 15 - Plano de ações

\begin{tabular}{|c|c|c|c|c|}
\hline $\begin{array}{l}\text { Posto de } \\
\text { Trabalho }\end{array}$ & $\begin{array}{l}\text { Método } \\
\text { OWAS }\end{array}$ & $\begin{array}{l}\text { Método } \\
\text { RULA }\end{array}$ & $\begin{array}{l}\text { Horizonte } \\
\text { de ações }\end{array}$ & Indicação de melhorias \\
\hline I & Nível 2 & Nível 2 & $\begin{array}{l}\text { Médio } \\
\text { prazo }\end{array}$ & $\begin{array}{l}\text { Introdução de exercícios laborais de pausas intermediárias de } \\
\text { trabalho; } \\
\text { Alternância de atividades e máquinas entre as funcionárias para } \\
\text { que permaneçam em uma mesma postura por muito tempo; } \\
\text { Aquisição de uma cadeira de trabalho ergonomicamente projetada } \\
\text { para que a acomodação seja confortável e os movimentos de } \\
\text { rotação sejam facilitados. }\end{array}$ \\
\hline II & Nível 2 & Nível 3 & $\begin{array}{l}\text { Curto } \\
\text { prazo }\end{array}$ & $\begin{array}{l}\text { Estudo de métodos e processos para que o funcionários não adote } \\
\text { uma postura desgastante sem prejudicar a atividade empresarial; } \\
\text { Elaborar um cronograma de atividades para que haja um } \\
\text { revezamento entre colaboradores; } \\
\text { Construir um assento, com altura calculada em relação à bancada } \\
\text { de trabalho, para que o funcionário não trabalhe majoritariamente } \\
\text { em pé. }\end{array}$ \\
\hline
\end{tabular}

Fonte: Os autores (2016)

\section{CONCLUSÕES}

A ergonomia é uma área de importância estratégica, uma vez que prima pelas boas condições de trabalhado dos recursos humanos de uma organização. Com a análise ergonômica de trabalho utilizando-se dois métodos (OWAS e RULA) em dois postos de trabalho em uma empresa de confecções entende-se que o objetivo central traçado no início do projeto foi alcançado.

Os resultados principais apontaram que posto de trabalho I (costureira / produção e manufatura) apresenta certo nível de criticidade (Grau 2). Isto significa que, a médio prazo, serão necessárias medidas corretivas ergonômicas para que os funcionários continuem exercendo suas atribuições sem pôr em risco a saúde.

\section{REFERÊNCIAS}

[1] Abnt - Associação Brasileira de Normas Técnicas NBR 17: Segurança e medicina do trabalho. São Paulo: Abnt, 1990.

[2] Burke, M. Ergonomics Tool Kit, Aspen Publication. Maryland, USA, 1998.

[3] Cardoso Júnior, M. M. Avaliação Ergonômica: Revisão dos Métodos para Avaliação Postura. Revista Produção Online - Florianópolis, SC, ed. 36, fev. 2006.

[4] Castanho, A. M. Direitos Humanos na primeira Revolução Industrial. 2009. Disponível em $<$

http://intertemas.unitoledo.br/revista/index.php/ETI
O posto de trabalho II (Corte de matéria prima) apresentou resultados que implicam cuidados maiores. Como indicou grau 3 recomenda-se uma intervenção mais rápida, a curto prazo, nas condições de trabalho do colaborador. Devido ao cenário apresentado, entende-se que mudanças devem ocorrer de forma mais breve sob pena de acometer doenças sérias ao funcionário.

Por fim, após o diagnósticos dos locais de trabalho, sugeriu-se à empresa a adoção de medidas intervencionistas como forma de minimizar os impactos das condições atuais na medição dos métodos usados. Como sugestão para expansão da pesquisa, pretende-se acompanhar o processo e mudança e verificar, após a readaptação, se os indicadores refletirão as melhorias imaginadas.

C/article/viewFile/1602/1516> Acesso em: 3 set. 2016.

[5] Gil, A. C. Como elaborar projetos de pesquisa. 4. ed. São Paulo: Atlas, 2007.

[6] IEA (Organização Internacional de Ergonomia) Definition and Domains of Ergonomics. 2000. Disponível em < http://www.iea.cc/whats/index.html> Acesso em 3 set. 2016.

[7] lida, I. Ergonomia - Projeto e produção. São Paulo: Edgard Blücher Ltda, 1990.

[8] Martinez, G. M. Una guía de introducción al método OVAKO working posture 
[9] Másculo, F. S.; VIDAL, M. C. Ergonomia: Trabalho adequado e eficiente. Rio de Janeiro: Elsevier Ltda, 2011.

[10] Mcatamney, L.; Corlett, E. N. Rula: survey method for the investigation of work-related upper limb disorders. Applied Ergonomics, v. 24, n.2 p. 91-99, 1993.

[11] OIT (Organização Internacional do Trabalho). Doenças profissionais são principais causas de mortes no trabalho. 2013. Disponível em< http://www.oitbrasil.org.br/content/doencas- profissionais-sao-principais-causas-de-mortes-notrabalho> Acesso em: 1 set. 2016.

[12] Patriota, L. F. Santos, H. H. Análise Ergonômica do Trabalho dos Borracheiros de João Pessoa: Relação entre o estresse postural e a exigência muscular na região lombar. Dissertação de Mestrado em Engenharia de Produção. CT/UFP. 2015.

[13] Silva, E. L, Menezes, E. M. (Dr.), Metodologia da Pesquisa e Elaboração de Dissertação. 4a ed. revisada e atualizada. 2005. 


\section{CAPÍTULO 14}

\section{O TRABALHO EM UM CENTRO DE EQUOTERAPIA SOB A COMPREENSÃO DA ERGONOMIA DA ATIVIDADE.}

\section{Maria de Lourdes Santiago Luz}

Marcelo Dondelli Boaretto

\section{Jullia Maria Zullim Rodrigues}

Resumo: Esse artigo descreve e discute o trabalho em um Centro de Equoterapia. Para a compreensão do trabalho, o estudo é conduzido por meio da ergonomia da atividade ancorada pela metodologia da Análise Ergonômica do Trabalho (AET) que permite evidenciar as múltiplas lógicas existentes nas atividades laborais. A equoterapia, está restrita ao método terapêutico que estabelece todas as práticas que utilizem o cavalo com técnicas de equitação, com o objetivo de educar, além de reabilitar as pessoas portadoras de deficiência. É necessário um acompanhamento multidisciplinar de profissionais da saúde, os quais estão expostos a desgastes físicos e dores constantes, objetos da demanda estudada pelo projeto de extensão vinculado a universidade. Os levantamentos preliminares e alguns resultados constatados pelo projeto possibilitou conhecer a organização do trabalho, os determinantes entre tarefa e atividade e ações de melhorias na qualidade de vida laboral. 


\section{INTRODUÇÃO}

A Ergonomia é uma disciplina científica relacionada ao entendimento das interações entre os seres humanos e outros elementos ou sistemas, e à aplicação de teorias, princípios e métodos a projetos a fim de otimizar o bemestar humano e o desempenho do sistema. As intervenções contribuem para o planejamento, projeto e a avaliação de tarefas, postos de trabalho, produtos, ambientes e sistemas de modo a torná-los compatíveis com as necessidades, habilidades e limitações das pessoas (ABERGO, 2016).

A ergonomia da atividade ancorada pela metodologia da Análise Ergonômica do Trabalho (AET) permite evidenciar as múltiplas lógicas existentes nas atividades laborais. Possibilita uma visão do trabalho, útil para elucidação dos elementos de complexidade, variabilidades presentes nas atividades exercidas nas organizações.

No contexto desse artigo tem-se como foco principal apresentar as observações e análises ancoradas sob o olhar da atividade, discussões e ações que contribuem em propostas de melhorias nas condições de trabalho em um Centro de Equoterapia. A demanda surgiu a partir dos profissionais da equoterapia, nominados equoterapeutas, com a manifestação de dores músculoesqueléticas que podem vir a comprometer os atendimentos terapêuticos. Os estudos e a aplicação da análise ergonômica são conduzidos por meio de um projeto de extensão em andamento, vinculado à universidade.

A equoterapia é a aplicação de método terapêutico com práticas que utiliza o cavalo e técnicas de equitação, com o objetivo de educar, além de reabilitar as pessoas portadoras de deficiência. Constatou-se por meio de revisão bibliográfica, a discussão e divulgação de diversos estudos e artigos científicos direcionados às especificidades de reabilitação ou tratamento aos pacientes, porém, com foco nas condições de trabalho e das tarefas de um profissional que atua na reabilitação dos pacientes com equoterapia, há uma carência relevante. Em uma única publicação disponibilizada via meios eletrônicos a respeito, o autor sugere pesquisas que relacionem as principais demandas ergonômicas levantadas pelos trabalhadores de equoterapia em relação aos diversos Centros de Equoterapia espalhados pelo país e os problemas de saúde que podem ocorrer como consequência dos constrangimentos provocados por essas demandas (CHIARAMONTE, 2004).

\section{FUNDAMENTAÇÃO TEÓRICA}

A ergonomia tem por objeto o trabalho, mas segundo Guérin et al. (2008) a palavra trabalho é utilizada conforme o caso, para designar as condições de trabalho (trabalho penoso, trabalho pesado...), o resultado do trabalho ou a própria atividade de trabalho. Para os mesmos autores, a palavra trabalho compreende a unidade destas três realidades, isto é, não existem independentemente uma das outras. É O resultado de uma dialética entre a ação efetiva dos diversos atores e o conjunto de prescrições, que de acordo com Abrahão et al. (2009), pressupõe um investimento individual e/ou coletivo nessa gestão.

Terssac e Maggi (2004) citam que a ergonomia ao buscar compreender o trabalho, se constrói em torno de três proposições fundamentais, que constituem diversas reviravoltas de perspectiva: a noção de variabilidade, a distinção entre tarefa e atividade, e a noção de regulação. Para Garrigou et al. (2007) as variabilidades contextuais podem estar relacionadas a variações de matérias-primas, produtos, procedimentos, variações ambientais, etc. Quanto às variabilidades organizacionais temse: faltas ou variações dos funcionários, horários diferentes, sazonalidades, etc.. As situações de trabalho não se mantém uniforme no decorrer do tempo, desde uma variabilidade prevista como os efeitos sazonais às variabilidades imprevisíveis decorrentes de eventos inesperados, flutuações nas demandas, entre outras, exigindo do trabalhador a elaboração de estratégias operatórias que possibilitem a resoluções de problemas. Quanto à variabilidade dos indivíduos, a ergonomia as classificam em variabilidade intra-individual (considera alterações psicofisiológicas que o indivíduo sofre com o envelhecimento, a fadiga, os ritmos, etc.) e a inter-individual (considera a diversidade de características de uma população de trabalhadores, as diferentes estratégias operatórias, experiências, etc.) (ABRAHÃO et al., 2009; GARRIGOU et al., 2007; GUÉRIN et al., 2008). Os indivíduos em situação de trabalho modificam as estratégias operatórias e as 
ações futuras decorrentes de sua experiência dentro e fora do trabalho, das alterações fisiológicas como envelhecimento e adoecimento, devido ao ambiente compartilhado com outros indivíduos, etc. Nessas condições, a organização real necessita constantemente se recompor, se reconstruir, apoiando-se em competências profissionais, tanto individuais quanto coletivas, que podem flutuar enormemente (GARRIGOU et.al, 2007).

A tarefa segundo Guérin et al. (2008) mantém uma estreita relação com o trabalho por meio de suas condições e resultados. Mas essa relação é a do objetivo à realidade, cujas condições determinadas não são as condições reais e o resultado antecipado não configura o resultado efetivo, logo a tarefa não pode ser confundida com o trabalho. Quanto a atividade de trabalho, Guérin et al. (2008) a posicionam como o elemento central que organiza e estrutura os componentes da situação de trabalho, é o modo de como os resultados são obtidos e os meios utilizados. A compreensão dos determinantes estabelecidos entre tarefa e atividade são propostos, pelos autores supracitados, com um modelo integrador da atividade de trabalho, sintetizado pelos elementos determinantes da atividade de trabalho: o trabalhador, a empresa e os fatores que contribuem para a organização desses dois conjuntos (Figura 1).

Figura 1 - Determinantes da atividade de trabalho

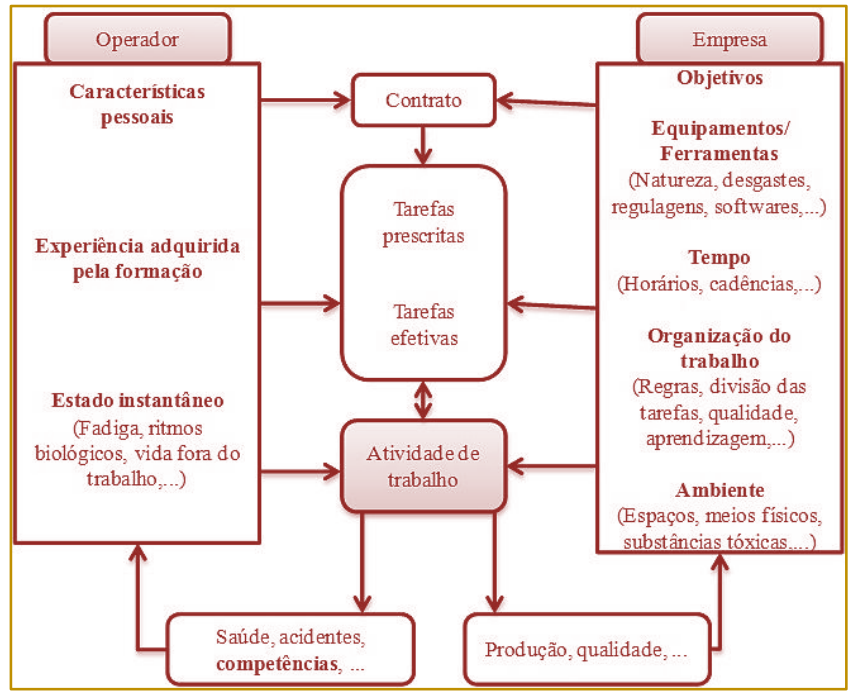

Fonte: Adaptado de Guérin et al. (2008)

Falzon (2007) define a regulação como um mecanismo de controle que confronta a produção desejada com os resultados de um processo e os ajusta em relação à diferença constatada. O mesmo autor situa que 0 conceito de regulação é utilizado em ergonomia de acordo com o objeto em que a regulação incide, ou seja, sobre o sistema (trabalhador como supervisor, comparador e regulador de um processo) ou da própria atividade humana (trabalhador regula sua atividade a fim de evitar repercussões negativas em si mesmo, atingir os objetivos da tarefa, ou aprender). De acordo com Terssac e Maggi (2004), os resultados ou a eficiência do sistema só são obtidos devido à capacidade de regulação da atividade desenvolvida pelos indivíduos, para gerenciar as variações das condições externas e internas da atividade e para levar em conta os efeitos da atividade. Assim sendo, a atividade produz efeitos relativos à tarefa (incidem sobre o desempenho em quantidade, qualidade, estabilidade, etc.) e relativos ao trabalhador que repercutem na saúde, acidentes de trabalho e nas suas competências (FALZON, 2007).

\section{METODOLOGIA}

A AET procura captar o fazer do trabalhador nas circunstâncias e condições em uma situação real no trabalho. A metodologia faz com que a pesquisa seja flexível, 
dependendo do dia a dia nos postos de trabalho e fazendo com que as hipóteses iniciais sejam quebradas ao longo do processo investigativo.
Neste contexto, uma ação ergonômica abrange desde a análise da demanda até o diagnóstico e recomendações, conforme ilustrado na Figura 2 (GUÉRIN et al., 2008).

Figura 2 - Etapas da análise ergonômica do trabalho.

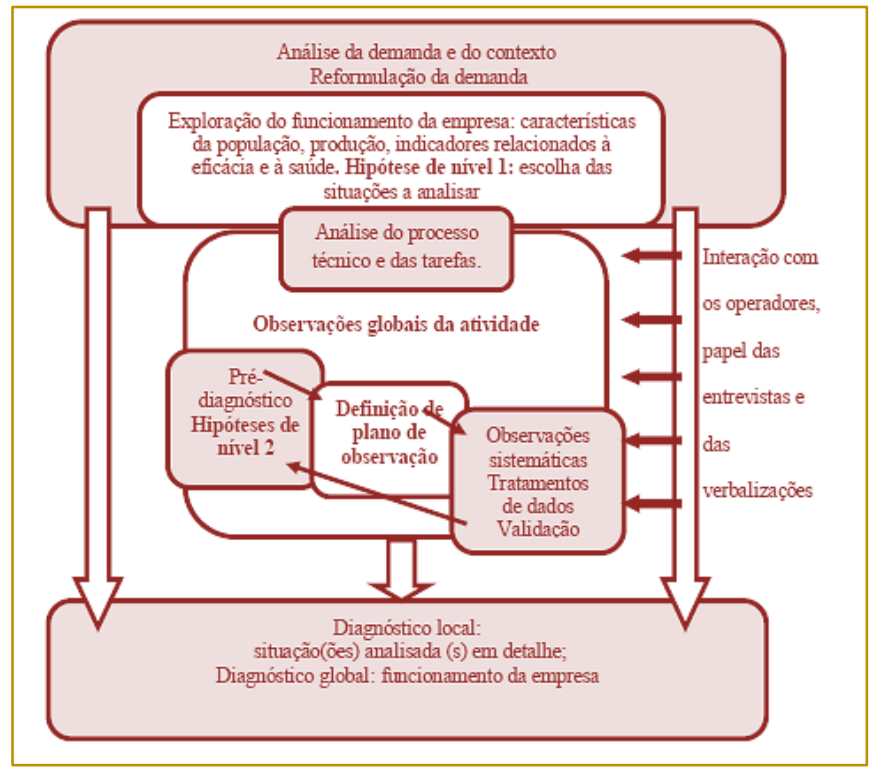

Fonte: Adaptado de Guérin et al. (2008)

\subsection{DESCRIÇÃO E DESENVOLVIMENTO DAS ETAPAS \\ O projeto e as etapas encontram-se em processo de desenvolvimento, resumidamente descritos.}

- Análise da demanda: por meio do acadêmico de engenharia de produção que atuava como voluntário nas atividades de apoio ao Centro de Equoterapia, constatou-se com a observação das tarefas e as conversas com os profissionais equoterapeutas, a manifestação de dores localizadas e esforços biomecânicos exigidos nas atividades. A partir dessa demanda, implementou-se um projeto de extensão coordenado pelo docente do curso de Engenharia de Produção.

- Coleta de informações sobre a empresa e organização: período de conhecimento do ambiente organizacional. A partir das primeiras visitas e por meio de entrevistas obteve-se o histórico do estabelecimento do Centro de Equoterapia, a estrutura organizacional e o perfil profissiográfico dos funcionários;

- Análise do processo técnico e das tarefas: etapa ainda em fase de conhecimento, porém, com coletas de informações por meio de observações globais e sistemáticas das atividades dos profissionais, entrevistas individuais, aplicação de questionário de percepção e técnicas de análise aos esforços biomecânicos e fatores organizacionais;

- Pré-diagnóstico/ Diagnóstico: etapa que serão analisados os dados coletados. Para essa etapa são usadas ferramentas de apoio e principalmente discussões com os profissionais por meio da confrontação dos dados com todos os atores envolvidos e com a coordenadora do projeto para identificar possíveis ações de melhorias ou revisão e adequação do pré-diagnóstico/diagnóstico estabelecido;

- Finalização: período em que serão apresentados e identificados os parâmetros, as distorções, recomendações de mudanças, confrontação com os atores se os aspectos ou ações de melhorias atenderam a demanda dos profissionais envolvidos no Centro de Equoterapia e quais as melhorias identificadas de modo geral. 


\section{RESULTADOS E DISCUSSÃO}

O Centro de Equoterapia está instalado em um espaço cedido pela Sociedade Rural (uma associação civil, sem fim lucrativos, formada por pessoas ou entidades diretamente relacionadas às atividades agrícolas, pecuárias e agroindustriais). Existe um contrato de parceria entre a Sociedade Rural e a Coordenadora Geral do Centro de Equoterapia. Nesse contrato a Sociedade Rural tem a responsabilidade da manutenção das baias onde os cavalos ficam no período da noite; manutenção do local de acordo com a vigilância sanitária. Por parte do Centro de
Equoterapia a manutenção do espaço cedido é de sua responsabilidade, é necessário apresentar os projetos e as alterações físicas devem ser aprovadas. O Centro de Equoterapia possui um escritório utilizado para $\mathrm{O}$ atendimento e agendamento das consultas, estrutura de apoio com cozinha e banheiro, os espaços de atendimentos e as baias para os cavalos. Os espaços de atendimento são compostos por uma pista coberta com piso de areia, duas pistas ao ar livre, sendo uma com piso de areia fina e outra de cepilho, além do espaço no parque de eventos que tem o piso de asfalto (Figura 3).

Figura 3 - Espaços de atendimento

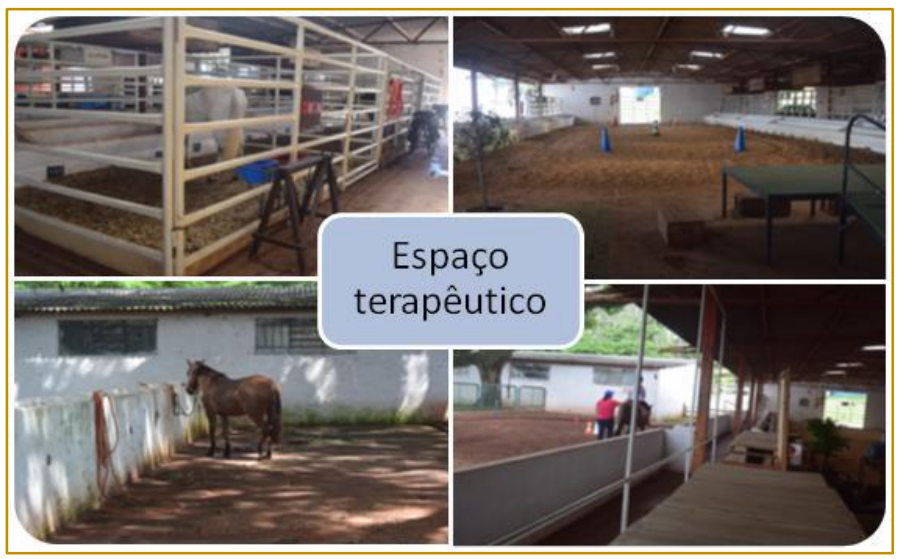

Fonte: Autores

No quesito terapêutico, a andadura do cavalo em cada tipo de solo influencia no tratamento, pois o comportamento muscular se diferencia nesses diversos tipos de solo e o piso é selecionado de acordo com a necessidade do trabalho muscular no paciente.

\subsection{ESTRUTURA ORGANIZACIONAL}

O centro de equoterapia é composto por uma equipe multidisciplinar de equoterapeutas na área da saúde e educação. Dentre essas, há uma fisioterapeuta, uma fonoaudióloga, uma psicóloga e uma educadora especial. A organização apresenta um organograma hierárquico, conforme esquematizado na Figura 4. Destaca-se a fisioterapeuta como a líder do local, responsável pelo projeto de equoterapia e da sua estruturação estabelecida pelos equipamentos, materiais de encilhamento, materiais para higiene dos cavalos, rampas adaptadas, cavalos e o contrato de parceria com a Sociedade Rural. Coordena, também, as demais profissionais da área da saúde e educação, dividindo a responsabilidade com as equoterapias. As profissionais são autônomas em relação aos atendimentos dos pacientes e parceiras nas despesas e manutenção para usufruto da estrutura oferecida. Complementado o quadro organizacional há os auxiliares operacionais que são responsáveis pela higienização, encilhamento e condução dos cavalos no período de atendimento. 
Figura 4- Estrutura hierárquica

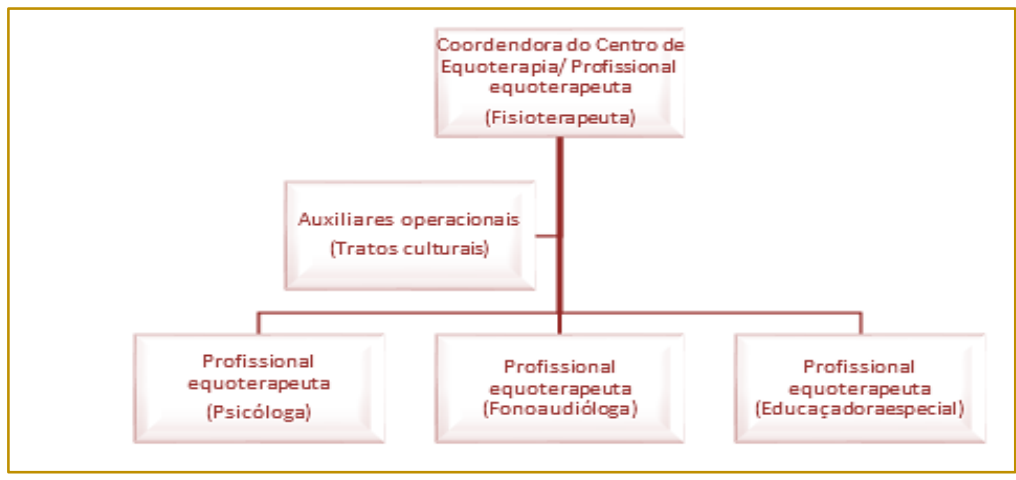

Fonte: Autores

\subsection{DESCRIÇÃO DAS TAREFAS}

\subsubsection{O ATENDIMENTO}

O centro por ter uma equipe multidisciplinar atende pessoas com diversas patologias, entre as quais destacam-se: deficiências motoras, linguísticas, comportamental e social. Para o tratamento com equoterapia é preciso de uma indicação médica e encaminhamento do paciente ao Centro. Posteriormente, a fisioterapeuta realiza uma anamnese em uma primeira conversa com os pais e analisa qual profissional dentro da sua equipe que mais se adequaria à criança. $A$ equipe mínima para realizar um trabalho de equoterapia é composta por um profissional que conduzirá o cavalo e uma equoterapeuta.

O tempo de atendimento com finalidade terapêutica é de 30 minutos por paciente, pois acima desse período causa desgastes desnecessários e aquém não alcança os objetivos terapêuticos. Sendo assim, os atendimentos ocorrem durante 30 minutos, estando presentes duas equoterapeutas, por período matutino e vespertino, cada uma com o seus pacientes. A organização dos cavalos a serem utilizados se dá conforme a terapia e o controle e programação (equoterapia e cavalo) é informado e visualizado por todos pelo quadro ilustrado na Figura 5.

Figura 5 - Quadro de Controle e Programação Semanal de Atendimento

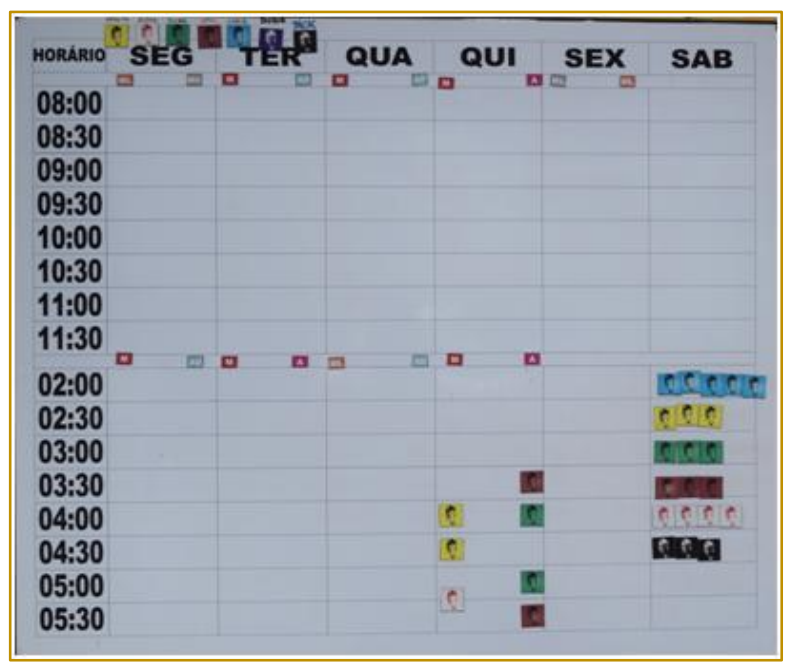

Fonte: Autores

A utilização do cavalo com finalidade terapêutica torna-se muito abrangente, varia com o tipo de caminhar do cavalo, com diferenças como o andar mais solto (cavalo que transpista), mais recomendado para pacientes com dificuldades motoras mais leves, beneficiando movimento pélvico e de cintura. Adultos com AVC escolhe-se o cavalo 
que antepista. Para crianças pequenas recomenda-se um cavalo petisco, porque cria uma identidade psicológica com a criança. Além disso, a escolha dos cavalos vai muito da estratégia adotada pelo profissional. Os equipamentos utilizados também influenciam: a sela favorece o movimento pélvico anti posterior, que ajuda a criança a começar a caminhar, a manta trás mais liberdade para a profissional que permite a integração sensorial, pelo tato no cavalo, calor e tremores.

\subsubsection{ROTEIRO DIÁRIO}

As tarefas principais são subdivididas entre os condutores de cavalo e as equoterapeutas. Inicia-se com os auxiliares (condutores), responsáveis por pegar os setes cavalos nas baias e levar até o local estabelecido para a equoterapia. Por meio do quadro de controle, seleciona-se os cavalos que serão utilizados. $\mathrm{Na}$ sequência começam a fazer a higienização dos animais que serão utilizados. Com a higienização feita um dos auxiliares busca os materiais equestres necessários para os respectivos dos atendimentos enquanto outro fica responsável por soltar os cavalos que não serão utilizados. Caso haja algum tempo disponível o auxiliar deve treinar os cavalos conforme a necessidade e no final do dia recolhe-los às baias. Em paralelo a tarefa citada, as equoterapeutas preparam o ambiente de trabalho: colocam os brinquedos, que auxiliam na terapia e nas pistas escolhidas. Nesse meio tempo, o paciente chega ao centro de equoterapia dando início a atividade principal que é o atendimento. Cada uma das profissionais da saúde recepciona o paciente, enquanto isso, os auxiliares que também são os condutores do cavalo, colocam os cavalos nas rampas adaptadas. Após a recepção a próxima tarefa das equoterapeutas é colocar o praticante sobre o cavalo - atividade que gera um grande esforço biomecânico. Posteriormente, coloca-se o cinto de segurança e inicia-se o atendimento. Nessa etapa, o condutor fica responsável por conduzir o cavalo enquanto a equoterapeuta faz o atendimento de 30 minutos. No final do atendimento o cavalo é conduzido até a rampa adaptada. A equoterapeuta retira o cinto de segurança e logo em seguida retira o paciente do cavalo. Por fim, caso o cavalo seja utilizado novamente no próximo atendimento, ele volta ao início, sendo posicionado próximo a rampa adaptada. Caso não seja utilizado ele retorna à baia, finalizando o processo de atendimento.

$\mathrm{Na}$ Figura 6, apresenta-se de modo esquemático a descrição das tarefas.

Figura 6 - Representação esquemática do roteiro diário das tarefas

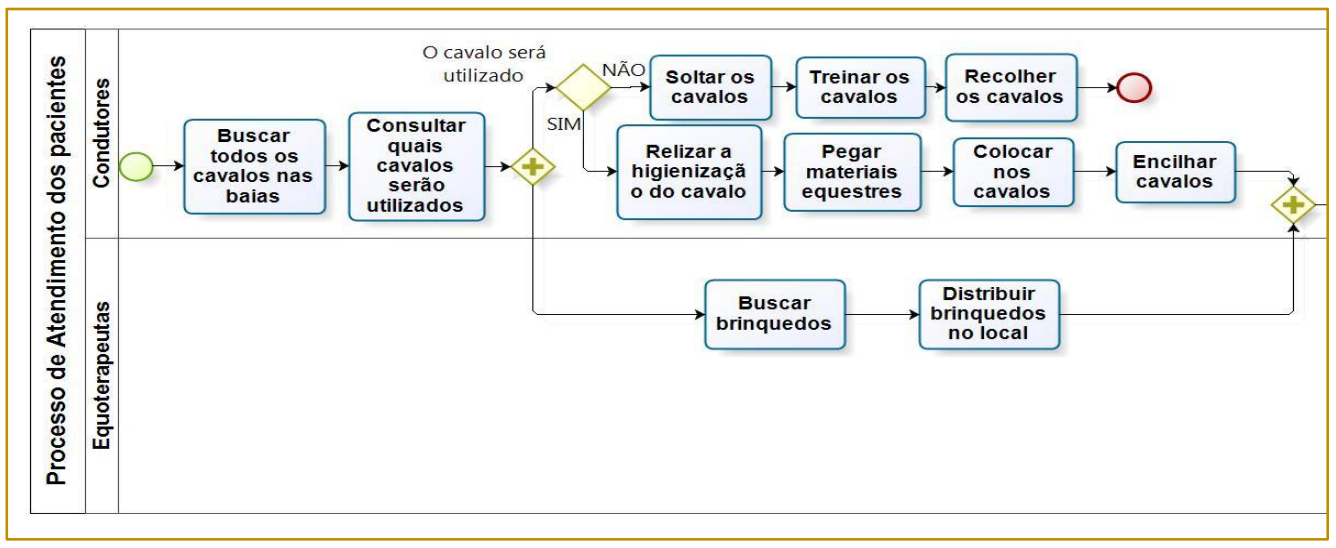

(continuação...) 


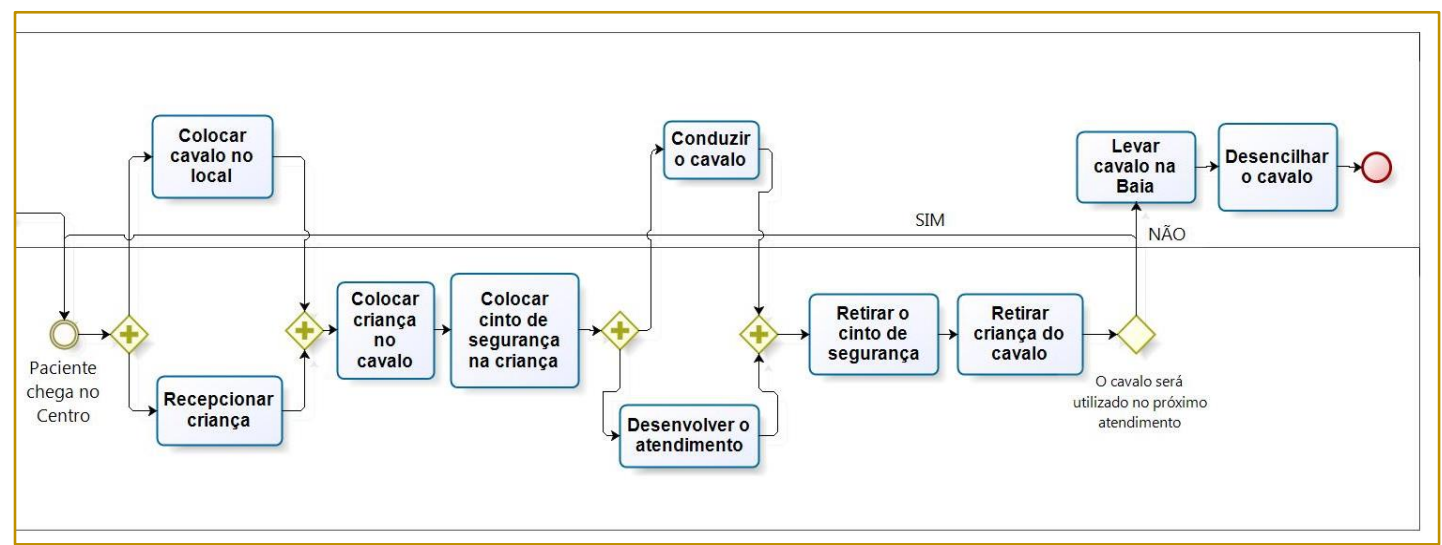

Fonte: Autores

\subsubsection{VARIABILIDADE DE EQUIPAMENTOS}

Destaca-se como a variabilidade dos equipamentos e material de apoio influencia no tratamento e também no nível do esforço físico impactante ao equoterapeuta. A escolha do material se dá conforme a necessidade do paciente e o objetivo terapêutico determinado.
No Centro há diferentes tipos de materiais adaptados à equoterapia sendo eles: manta com alça, manta com selote, manta sem alça, sela clássica rural, sela clássica de hipismo (Figura 7).

Figura 7 - Equipamentos equestres

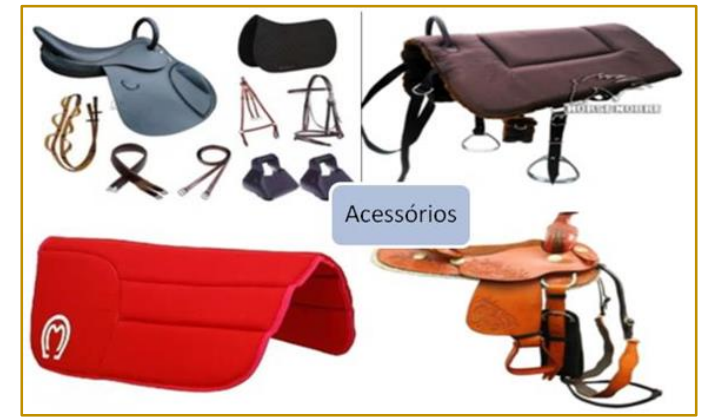

Fonte: Figuras Ilustrativas de Horse Nobre (2017); Kelpam Couros (2017)

Entre os materiais citados o que mais gera estabilidade ao paciente é a sela clássica rural pelo maior tamanho do colo e por apresentar estribos que dão sustentação, depois a sela clássica de hipismo que também apresenta estribos, porém, com um colo menor e por fim as mantas com alça e com selote que apresentam funções similares, enquanto a manta sem alça gera uma maior instabilidade, pois o paciente não tem onde se segurar.

\subsection{TRATAMENTOS TERAPÊUTICOS VERSUS CONSTRANGIMENTOS BIOMECÂNICOS}

Dentro do tratamento da equoterapia existem diferentes formas de terapia por meio da utilização do cavalo.
Trabalho de solo - o paciente não fica montado no cavalo. Esse método em relação aos esforços biomecânicos exigidos ao equoterapeuta é um dos que menos exigem, pelo fato da interação terapeuta com o paciente não necessitar de contato de apoio e o paciente é estimulado a interagir com o cavalo, o conduzindo e sendo guia, além de outras dinâmicas de estímulo. O equoterapeuta e paciente com um cabresto longo ficam localizados no centro de um círculo e o cavalo fica circulando por ambos através de estímulos. Isso é possível com pacientes que apresentam uma autonomia e a finalidade é aumentar as percepções e coordenação motora do paciente (Figura 8). 
Figura 8 - Trabalho de solo

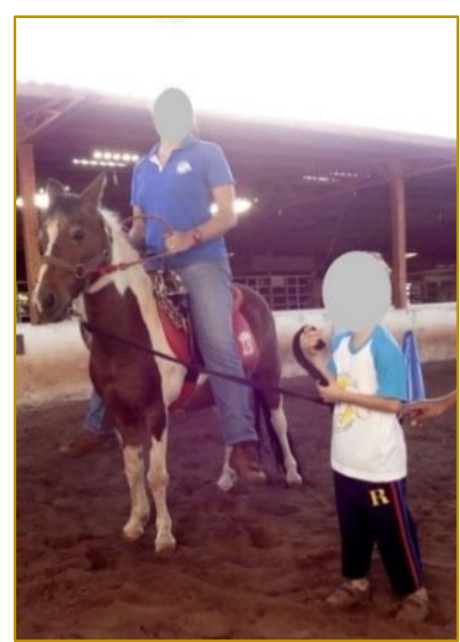

Fonte: Autores

Montaria - pode ser subdividida em montaria dupla e montaria individual. A montaria dupla implica que $\mathrm{o}$ paciente $\mathrm{e} O$ condutor permaneçam juntos montados no cavalo sendo o paciente à frente do condutor, principalmente com crianças com dificuldade de estabilidade do dorso. Nesse caso, assim como o trabalho de solo há pouco exigência dos equoterapeutas no quesito esforço físico, uma vez que eles caminham ao lado do cavalo sem que haja a necessidade de segurar o paciente.

$\mathrm{Na}$ montaria individual, o paciente está sozinho sobre o cavalo, podendo ser estratificada em em 3 tipos: quando o paciente é autônomo e fica sozinho no cavalo, com finalidade de aumentar a independência, além dos trabalhos de fortalecimentos musculares e terapêuticos, ocasionando desconfortos mínimos nas equoterapeutas; quando o paciente necessita da equoterapeuta ao lado, com um cinto de segurança apropriado à equoterapia ou com a mesa almofadada de sustentação para auxiliar na sustentação do corpo do paciente e prevenir acidentes. Essa prática é a que mais exige esforços biomecânicos das equoterapeutas, pois implica em braços esticados acima do ombro, rotação do tronco e pescoço, com uma força contrária ao movimento do cavalo (Figura 9).

Figura 9 - Registro postural da equoterapeuta

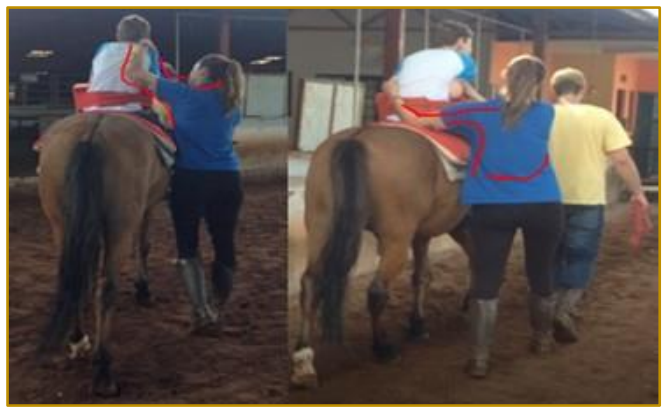

Fonte: Autores

Por fim, o atendimento duplo, na qual o paciente necessita de duas pessoas, uma em cada lado do cavalo, o que geram desconfortos parecidos ao anterior, porém a carga da força para contenção do paciente é dividida entre ambos. A Figura 10 ilustra as técnicas supramencionadas. 
Figura 10 - Atividades terapêuticas por Montaria

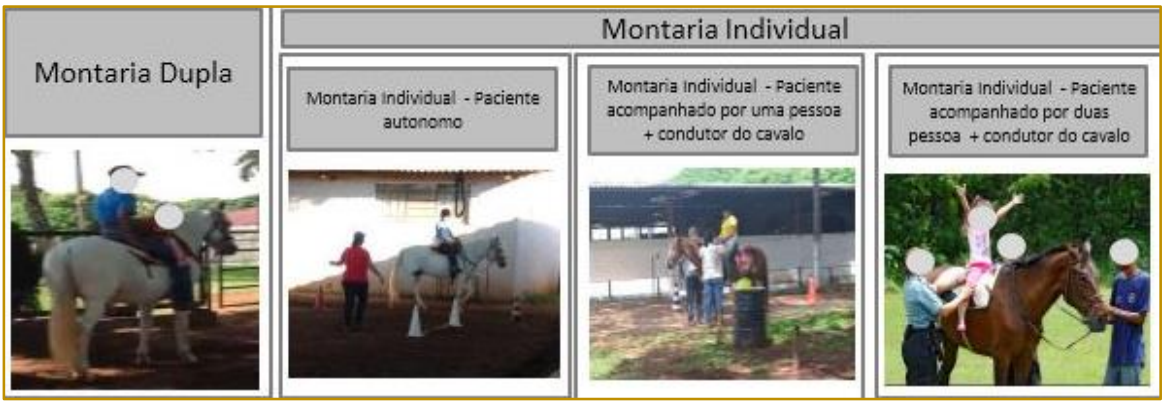

Fonte: Autores

Entre as técnicas de atendimentos, o mais usual é com o paciente que faz montaria individual, cerca de 90\%. O grau de constrangimentos físicos é relativo ao biotipo (altura e peso) de cada paciente, material escolhido, o cavalo (estatura diferentes), estabilidade do paciente e local de atendimento (areia, solo batido, asfalto). Os outros $10 \%$ são montarias duplas e pacientes autônomos, além dos que ocorrem raramente com atividades extras e perceptivas.

\subsection{O CASO DA ALTERNÂNCIA DE MONTARIA}

No decorrer do projeto, ocorreu um caso com um dos pacientes que apresenta um quadro diagnóstico de síndrome de Down e alguns sinais do TEA (Transtornos do Espectro Autista). O paciente é um adolescente com 15 anos de idade e apresenta dificuldades motoras e linguísticas. Pratica a equoterapia há cerca de 3 anos. $O$ atendimento é realizado uma vez por semana. O tratamento era conduzido por meio de montarias duplas. Porém, com o intuito de estimular o paciente com novos desafios terapêuticos, a equoterapeuta decidiu alternar da montaria dupla para individual. O paciente, por sua vez, com seu biotipo (altura e peso elevados) dificultava, também, sua condução por meio da montaria dupla.

$\mathrm{Na}$ primeira tentativa de adaptação, a equoterapeuta colocou o paciente sobre a manta em conjunto com uma mesa (estrutura almofadada e firme) à sua frente para servir de apoio e auxiliar no equilíbrio do paciente. Por não apresentar equilíbrio do dorso, o paciente acabava caindo para parte posterior do cavalo, e apesar da mesa, não era possível manter a postura dele de forma estável e ereta, sobrecarregando ombros, costas e quadril da equoterapeuta, com os braços na posição diagonal acima da cabeça para segurar o paciente, tronco rotacionado e uma força contrária ao movimento do cavalo. O resultado não surtiu o efeito esperado, pois na maioria das vezes o cavalo ficava parado, o que se configura como trabalho estático e ocasionava um desconforto muscular na equoterapeuta com dores e fadiga muscular. Essa tentativa se repetiu por duas semanas e o cavalo utilizado era de estatura média. Devido as dificuldades que se apresentavam na condução da terapia, a equoterapeuta aventou com uma quase desistência à continuidade ao tratamento do paciente devido aos esforços biomecânicos insuportáveis, gerando desgaste físico e dores, além da não evolução nos objetivos terapêuticos.

A segunda tentativa foi trocar o equipamento para a sela de porte pequeno, pois ela oferece maior firmeza ao paciente e possibilitaria um maior equilíbrio, ajudando a equoterapeuta a segurá-lo. Além disso trocouse o cavalo para uma estatura menor a fim de minimizar os efeitos das dores devido ao posicionamento da altura dos braços da equoterapeuta. Os problemas e os resultados continuavam os mesmos, havia o desequilíbrio para frente, a mesa não dava a sustentação necessária e novamente a maior parte do trabalho foi estática. Além disso, a sela escolhida não proporcionou o encaixe correto do quadril do paciente.

$\mathrm{Na}$ terceira tentativa optou-se pela troca da sela pequena por uma maior, porém os estribos, outro equipamento pertencente a sela, que auxiliam na sustentação do corpo não alcançava a altura dos pés do paciente, o qual exigiu uma condução com atendimento duplo (duas pessoas segurando o paciente e uma terceira conduzindo o cavalo). A dificuldade dessa alternativa é que o cavalo caminha em círculo no espaço terapêutico e a 
pessoa que vai do lado externo da curva acaba sendo afastada do corpo do cavalo pelo próprio animal. Observou-se com o novo equipamento a evolução do paciente em relação a postura, conseguindo atingir por algum tempo a postura ereta.

$\mathrm{Na}$ quarta tentativa, a sela foi adaptada, fazendo com que o estribo alcançasse o pé do paciente, com o cavalo de estatura menor. Com a sela maior que se mostrou mais apropriada para o quadril do paciente, com o estribo da sela na altura do pé, conseguiu-se atingir os objetivos que a equoterapeuta buscava que era a resposta aos estímulos terapêuticos e minimização dos constrangimentos musculares.

\section{CONSIDERAÇÕES FINAIS}

O trabalho em um Centro de Equoterapia apresenta uma demanda elevada de desconfortos e constrangimentos físicos aos equoterapeutas. Por meio da AET, ainda em condução, conforme salientado nesse artigo, discutiu-se aspectos determinantes

\section{REFERÊNCIAS}

[1] Abergo - Associação Brasileira de Ergonomia. O que é Ergonomia. Rio de Janeiro, Disponível em:

http://www.abergo.org.br/internas.php?pg= o_que_e_ergonomia. Acesso em: mai. 2016.

[2] Abrahão, J et al..Introdução à ergonomia: da prática à teoria. São Paulo: Edgard Blucher, 2009.

[3] Chiaramonte, L. C. M. "Levantamento das condições de trabalho em um serviço de equoterapia® segundo a visão macroergonômica". Porto Alegre: UFRGS, 2004. Dissertação (Mestrado Profissionalizante em Engenharia) - Escola de Engenharia, Universidade Federal do Rio Grande do Sul, Porto Alegre, 2004. Disponível em: <http://www.lume.ufrgs.br/handle/10183/2/browse? value $=$ Chiaramonte $\% 2 \mathrm{C}+\mathrm{Lu} \% \mathrm{C} 3 \% \mathrm{ADs}+\mathrm{Cl} \% \mathrm{C} 3 \%$ A1udio+Martins\&type=author $>$ Acesso em: 13 mar. 2016

[4] Falzon, P. Natureza, objetivos e conhecimentos da ergonomia - Elementos de uma análise cognitiva da prática. In: Falzon, Pierre (Editor). Ergonomia. São Paulo: Edgard Blucher, 2007, p. 3-19. estabelecidos entre tarefa e atividade e os fatores que contribuem para a organização do trabalho. Constatou-se constrangimentos físicos dos equoteapeutas no decorrer das observações sistemáticas e as ações de regulação para o cumprimento dos objetivos. Observou-se, por meio da análise da atividade, como o mecanismo de regulação foi utilizado pela equoterapeuta no caso da alternância da Montaria em que buscou-se alternativas para a mudança do modo operatório, procurando a compreensão de quais fatores geravam desconforto e quais ações de melhorias e adaptações nos recursos, tanto de equipamentos quanto terapêuticos, poderiam contribuir na melhoria da atividade e na sua continuidade. Mecanismos que Terssac e Maggi (2004) citam que só são obtidos devido à capacidade de regulação da atividade desenvolvida pelos indivíduos, para gerenciar as variabilidades da atividade e para levar em conta os efeitos da atividade. O olhar sob a atividade propicia o conhecimento sobre o trabalho e viabiliza soluções na obtenção de uma melhor qualidade de vida laboral.

[5] Garrigou, A. et al. Contribuição da ergonomia à prevenção dos riscos profissionais. In: Falzon, Pierre (Editor). Ergonomia. São Paulo: Edgard Blucher, 2007, p. 423-439.

[6] Guérin, F. et al. Compreender o trabalho para transformá-lo. 4aㅡ reimpressão. São Paulo: Ed. Edgar Blücher, 2008.

[7] Horse Nobre. Equoterapia. Disponível em <http://www.horsenobre.com/equoterapia/mantasela-equoterapia-simples-completa-com-alca-decouro> Acesso em: 08 abr. 2017.

[8] Kelpam Couros. Selas. Disponível em:<http://www.kelpamcouros.com.br/produto/420/ Sela-Tambor-e-Baliza-Especial >Acesso em: 08 abr. 2017

[9] Terssac, G. e Maggi, B. O trabalho e a abordagem ergonômica. In: Daniellou, F. (Coord.). Ergonomia em busca de seus princípios: debates epistemológicos. São Paulo: Edgard Blücher, p. 79 - 104, 2004. 


\section{CAPÍTULO 15}

\section{ANÁLISE ERGONÔMICA DO TRABALHO: UM ESTUDO DE CASO EM UM SETOR DE PRODUÇÃO DE UM FRIGORIFICO}

\section{Thiago Dan Said}

Cristiano Manhães de Oliveira

Tiago Andrade Muniz Terra

Ailton Silva Ferreira

Resumo: Atualmente algumas indústrias vêm implantando o trabalho ergonômico, visando uma melhor qualidade de vida de seus funcionários e tentando se adequar a legislação vigente, visto que essas técnicas são consideradas como uma das principais armas de estratégia para que as empresas se mantenham e se tornem cada vez mais competitivas no mercado. O presente trabalho apresenta um estudo de caso realizado em um frigorifico no interior do estado do Rio de Janeiro, com o objetivo de analisar as posturas de cada funcionário no setor de desembarque. Esse estudo teve por base uma análise ergonômica neste setor, com o auxílio de fotos e análise descritiva, além do método OWAS e do aplicativo WinOWAS. O foco deste estudo é demonstrar as melhores formas de trabalho ergonômico a fim de reduzir ou eliminar os riscos de acidente de trabalho e reduzir os índices de afastamento dos seus funcionários decorrentes as doenças do trabalho. Acreditase que o objetivo proposto possa ser atingido através das recomendações feitas no decorrer deste trabalho, fazendo com que ele se torne cada vez mais eficaz e eficiente.

Palavras-Chave: Ergonomia, Análise Postural do Trabalho, Condições Ambientais 


\section{INTRODUÇÃO}

O mercado encontra-se cada vez mais competitivo, portanto as organizações tendem a adotar diferentes estratégias (EVANGELISTA, 2011). Diante desse mercado tão competitivo as empresas estão tomando cuidados, principalmente com a saúde dos trabalhadores, e estão buscando melhorias, para assim tentar diminuir as doenças que acabam ocasionando o afastamento do trabalhador por alguma conduta mal realizada dentro da própria empresa.

Devido a grande carga de trabalho e de movimentos repetitivos constantemente, vários trabalhadores adquirem doenças músculo esqueléticas nos membros superiores e inferiores (DELWING, 2007).

Muitos trabalhadores de empresas como frigoríficos relatam sentir dores nas mãos, nas articulações, tendões, queimação, fraqueza muscular e até mesmo afetando o lado psicológico, com esses relatos iniciam-se doenças conhecidas como LER (Lesões por esforços repetitivos) e a DORT (Distúrbios Osteomusculares Relacionados aos Trabalhos), com isso as empresas estão se preocupando mais com a qualidade de vida dos seus funcionários, proporcionando-lhes melhores condições de trabalho e um melhor bem estar com a implantação de ações ergonômicas dentro da empresa, com trabalhos de ginástica laboral, com uma equipe multidisciplinar trabalhando juntos possibilitando de mais segurança e qualidade, conseguindo melhorar mais a postura proporcionando mais flexibilidade, gerando menos riscos de doenças desenvolvidas para os trabalhadores.

As empresas devem estar sempre orientando os seus funcionários sobre suas posturas, para que eles busquem um melhor controle postural. A conscientização estabelece uma boa relação entre as articulações corporais e o ambiente que está sendo realizado o trabalho buscando uma melhor estabilização corporal (FREITAS, 2003).

Portanto, o objetivo deste artigo é investigar as posturas de acordo com os cargos ocupados nos setores de desembarque em um frigorifico. Atualmente, a implantação do trabalho ergonômico tem sido prioridade para algumas empresas brasileiras, que buscam atender a legislação e proporcionar uma melhor qualidade de vida para os seus colaboradores. Diante deste cenário, surge o seguinte questionamento: As posturas dos trabalhadores que ocupam cargos nos setores de desembarque de um frigorífico, durante a realização do trabalho, estão adequadas com a legislação vigente.

O artigo está organizado da seguinte forma: a sessão 2 apresentará uma revisão da literatura, a sessão 3 a metodologia utilizada, a sessão 4 Análise de um setor da empresa, a sessão 5 Conclusão e, por último, na sessão 6 as Considerações Finais.

\section{REVISÃO BIBLIOGRÁFICA}

Para esse estudo foi desenvolvido, uma breve revisão bibliográfica, o local de trabalho de uma empresa tem menos importância quando se fala de unidade produtiva, quando se fala no homem e o seu local de trabalho, a ergonomia se destaca como um dos maiores enfoques de analise de trabalho (IIDA, 2005).

De acordo com Deliberato (2002), o termo Ergonomia se da pela formação de leis que regem o trabalho, já que essa palavra é de origem grega e é formada por ergo, que significa trabalho e nomos, que significa leis ou regras. Já Oliveira et al. (1998), apresentando uma visão específica, conclui que as leis e normas que vem a definir o trabalho e que representam a palavra ergonomia é o estudo das normas e regras do trabalho, visando sempre a humanização.

A ergonomia bem aplicada gera resultados muito importantes que elevam as condições de trabalho, diminuindo as exigências biomecânicas. As análises ergonômicas desempenham um trabalho muito participativo e construtivo para o reconhecimento de problemas complexos dentro da empresa que poderiam atingir $\mathrm{O}$ desempenho e a produtividade (SLACK et al., 2002). Para que uma empresa possa colocar em prática a ergonomia dentro da empresa deve estar de acordo com as legislações, para que não sofra nenhum tipo de penalização, as principais normas regulamentadoras são NR 17 que fala sobre a ergonomia, são usadas também a NR 15 atividades insalubres.

Dentro do campo do conhecimento da ergonomia, um dos principais objetivos é analisar a área de trabalho podendo com isso transformar ou contribuir para a concepção de algumas situações que pode vim a acontecer no local. Através de uma análise real do trabalho, a ergonomia determina algumas informações que podem ser favoráveis para um operador realizar as suas 
funções, proporcionando uma nova situação de trabalho: o ambiente e a sua organização do trabalho, os meios de trabalho e os dispositivos técnicos, além das representações e das competências de um operador (MATOS e PROENÇA, 2003; SOUSA e PROENÇA, 2004; BRASIL, 2003).

Com as evoluções no conhecimento mais recente na área da psicologia cognitiva, sendo aplicadas em vários projetos, o estudo da ergonomia vem ganhando um amplo significado. Buscando um entendimento melhor entre o trabalho e os aspectos humanos, a ergonomia tem tentado implantar soluções melhores para o ser humano em relação ao trabalho, usando as metodologias e as teorias para uma melhor compreensão da ação, do fazer (SZELWAR et al., 2004).

Segundo Couto (1995:11) a ergonomia é uma relação entre ciência e a tecnologia que sempre procura se adaptar de forma confortável e produtiva entre o empregado e o seu posto de trabalho, procurando sempre adaptar o posto de trabalho as características do empregado. O objeto principal de estudo é o trabalho e o homem, tendo como objetivo a qualidade de vida na jornada de trabalho e na produtividade.

Para concluir os seus objetivos a ergonomia analisa o estudo do homem de acordo com as suas características sendo elas físicas, fisiológicas e sociais dos trabalhadores, a máquina a ser operada como os equipamentos, ferramentas, mobiliário e instalações, o seu ambiente de trabalho temperatura, ruídos, vibrações, luz, cores, gases e outros, as informações como as comunicações entre os elementos de um sistema, e as organizações sendo elas os horários, turnos de trabalho, formação de equipes, políticas de recursos humanos, etc. e por fim as consequências ocorridas do trabalho tarefas de inspeção, estudo de erros e acidentes, estudos sobre gastos energéticos, saúde, fadiga e estresse, sempre a partir de uma visão antropocêntrica (XAVIER, 2013).

Dependendo do ambiente de trabalho no qual é exposto o trabalhador, sua qualidade poderá está comprometida de uma maneira expressiva (ALVAREZ, 1996). Um ambiente de trabalho deve proporcionar ao trabalhador condições sadias e agradáveis para desenvolver sua função, agregando o máximo de proteção, prevenindo de acidentes, doenças ocupacionais, ocasionando uma melhor interação entre a empresa e o empregado (FIELDER; VENTUROLI; MINETTI, 2006). Deve-se destacar alguns fatores relacionados ao ambiente do trabalho, como temperatura, ventilação, umidade, cor, iluminação, sonorização, movimento e a postura (SILVA, 1995).

Segundo Abergo (2000) a ergonomia uma disciplina científica que procura alterar o ambiente de trabalho, em que a principal preocupação é ajustar as atividades desenvolvidas com as limitações e habilidades por cada profissional que trabalha no setor, com o objetivo de desenvolver com mais eficiência o seu processo de produção. Diante de deste contexto, a Análise Ergonômica do Trabalho pode ser aplicada através de conceitos ergonômicos.

De acordo com Oliveira (1998), a Norma Regulamentadora 17 (NR 17) que foi responsável pela criação da análise ergonômica do trabalho, que no início teve o seu desenvolvimento voltado para a área de informática, contudo seus parâmetros podem ser usados de uma forma diferente em várias áreas e formas de trabalho.

Numa empresa a realização da Analise Ergonômica do Trabalho (AET) é uma das principais etapas para o diagnóstico das condições laborais. De acordo com DEFANI (2007) a norma regulamentadora 17 que é responsável pela aplicação e elaboração da $\mathrm{AET}$, mesmo que ela não apresenta de uma maneira clara um roteiro a ser seguido, apresentando assim somente alguns tópicos que devem ser seguidas e consideradas pela AET. DEFANI (2007) propõe ainda que algumas ocupações como transporte, descarga individual de materiais, levantamento, mobiliários e equipamentos dos postos de trabalho e as condições que alguns ambientes de trabalho são considerado básico e de grande importância de um estudo no desenvolvimento e na formulação de uma AET.

Segundo IIDA (2005), a Análise Ergonômica do Trabalho (AET) é um método de ergonomia que busca a correção de uma forma geral no ambiente de trabalho, analisa, diagnostica e corrigir todos os errados apresentados. Sendo constituída de 5 etapas: análise da tarefa, análise da demanda, análise da atividade, diagnóstico e as recomendações (GUÉRIN et al., 2001, citados por IIDA, 2005).

A ergonomia é aplicada sistematicamente identificando as maiores ocorrências dos 
problemas ergonômicos, que são identificados facilmente através dos altos índices de erros, absenteísmo, doenças ocupacionais, acidentes e alta rotatividade de funcionários. Segundo lida (1997), esses erros podem está ocorrendo devido a falta de treinamento e adaptação aos equipamentos, máquinas e por outros fatores como deficiências ambientais podendo provocar tensões musculares, problemas psíquicos nos próprios funcionários e por problemas ocasionados por falhas na organização do trabalho.

\subsection{SISTEMA OWAS}

Segundo Karhu et al., (1977) O sistema OWAS (Ovako Working Posture Analysing System) foi criado na Finlândia com o função de analisar as posturas de trabalho na indústria de aço, sendo implementado por pesquisadores finlandeses com o auxílio do Instituto Finlandês de Saúde Ocupacional.

OWAS é um método que visa principalmente analisar as posturas de trabalho que se apresentam inadequadas de acordo com cada função desenvolvida, podendo assim identificar as posturas que são mais prejudiciais e ainda analisando as principais regiões que são atingidas (RIBEIRO et al., 2004).

Para que possamos obter registro dos dados, podemos utilizar a observação indireta através de registros por vídeo ou fotográfico, e também direta ou observação indireta, facilitando assim a análise através da aplicação deste método pelo pesquisador ou usando softwares específicos, como o programa WinOWAS (MANUAL WINOWAS, 2009).
Segundo Kivi e Matilla (1991) as avaliações posturais assumidas durante o trabalho, são realizadas com a ferramenta computacional WinOWAS. Essa ferramenta é baseada no método OWAS (KARHU et al., 1977) que, de acordo com as posturas de trabalho e nas forças que são exigidas durante uma ação específica, classificam-se o grau de risco em quatro categorias:

- Categoria 1: postura normal, não se exige nenhuma medida corretiva;

- Categoria 2: deve ser verificada a postura durante a próxima avaliação de rotina dos métodos de trabalho. Sendo assim a carga física que a postura sofre é levemente prejudicial, sendo necessário uma adotar medidas corretivas da postura em um futuro mais próximo;

- Categoria 3: a carga física que a postura sofre é prejudicial, necessitando mudanças da postura o mais rápido possível;

- Categoria 4: a carga física que a postura é exigida acaba sendo extremamente prejudicial, necessitando de ações corretivas imediatamente, para que se melhore a postura.

O método OWAS funciona como uma ferramenta de amostra que proporciona catalogar algumas posturas combinadas entre costas, pernas, braços, podendo assim considerar ainda as forças exercidas, que podem determinar o resultado sobre 0 sistema musculoesquelético, facilitando o exame do tempo relativo gasto em uma determinada postura específica para cada região corporal (GUIMARÃES e PORTICH, 2002). A classificação das posturas pelo sistema OAWS é mostrada na Fig. 1 : 
Figura 20- Classificação das posturas pelo sistema OWAS

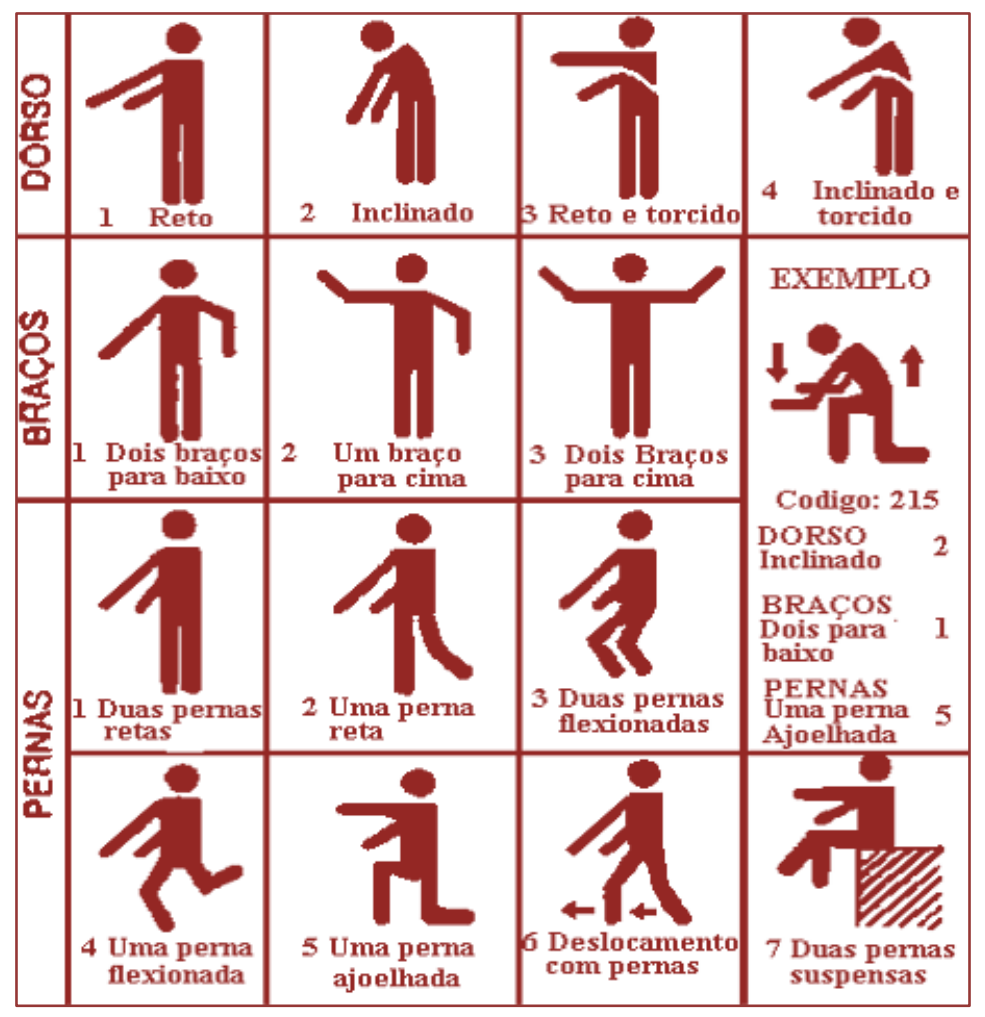

Fonte: lida (2005)

\section{METODOLOGIA}

Neste trabalho busca-se apresentar um estudo de caso, no qual foi realizado uma análise ergonômica das atividades desenvolvida em um frigorífico de carne seca.

Segundo Yin (1989) pode-se definir um estudo de caso como sendo uma pesquisa empírica que tem como função a investigação de um acontecimento real ou recente, na qual se identifica a relação que existe entre o contexto de sua realidade e aquele acontecimento.

Esta pesquisa foi desenvolvida através de uma Análise Ergonômica do Trabalho (AET), cuja sua etapa inicial, de acordo com IIDA (2005) relacionando a definição do problema ou a situação problemática, justificando assim a necessidade de uma ação ergonômica, levando-se em consideração as noticias dadas pela nota técnica do ministério do trabalho e emprego (2004) fazendo com que este setor seja um dos mais problemáticos no que se fala de segurança e saúde dos trabalhadores.

Os erros na busca e tentativas de um processo de inovação são considerados normais, tendo em vista que é de fundamental importância compartilhar o conhecimento que foi adquirido durante a realização da pesquisa.

Duas ferramentas para o desenvolvimento deste trabalho foram utilizadas: registros fotográficos e a observação direta. Os registros fotográficos foram feitos para verificar as posturas inadequadas assumidas pelos trabalhadores com uma câmera digital, diante disso utilizou-se da observação direta considerada mais clínica.

O presente trabalho foi realizado em meados de 2015, em uma empresa do ramo alimentício de carne seca. A empresa esta localizada no interior do Rio de Janeiro. O setor em que foi realizado o estudo conta com uma área construída de aproximadamente $13,50 \mathrm{~m}^{2}$, contendo no seu quadro de funcionários um total de 200 trabalhadores.

Diante de vários setores de produção do frigorífico, buscou-se dar uma maior ênfase aqueles que ergonomicamente possuíam uma maior necessidade, em que nesse caso apresentado foi o setor de desembarque. As atividades avaliadas foram as seguintes:

- Descarregar peças de carne, de 15 a 45 $\mathrm{kg}$, da carreta para os ganchos; 
- Empurrar o gancho para desossa (sistema de dois trabalhadores um empurra e o outro puxa).

\section{SETOR DE DESEMBARQUE EM ANÁLISE}

A Indústria Frigorífica apresenta frequentemente ocorrências de acidentes de trabalho e doenças ocupacionais. É um setor da indústria que gera bastante preocupação quando o assunto é Segurança do Trabalho. Um dos riscos associados à ergonomia que são enfoque deste trabalho é: a posição de trabalho realizada na maioria das vezes em pé, a repetitividade (questão da LER/DORT), o transporte manual de cargas e o frio. Neste setor os trabalhadores permanecem muito tempo em pé, ou seja, durante toda a jornada se movimentando bastante pelos demais setores.

Iniciamos o nosso trabalho analisando, a estrutura do local que desempenha a função de desembarque. A tabela 1 apresenta as características gerais do ambiente.

Tabela 1 - Características gerais do ambiente

\begin{tabular}{|c|c|}
\hline \multicolumn{2}{|c|}{ Características Gerais Do Ambiente } \\
\hline Área aproximada & $13,50 \mathrm{~m}$ \\
\hline Construção & Em alvenaria. Revestido com cerâmica ate o teto \\
\hline Piso & Cerâmico. \\
\hline Pé direito & $3,5 \mathrm{~m}$ \\
\hline Cobertura/telhado & Estrutura metálica com telhas metálicas. \\
\hline Ventilação & Natural e artificial. \\
\hline Iluminação & Artificial. \\
\hline
\end{tabular}

Figura 2 - Setor de desembarque

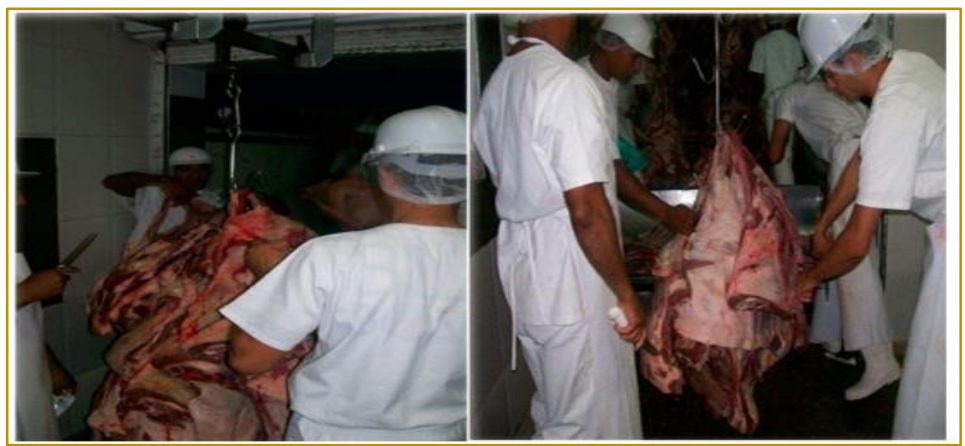

Fonte: Própria

$\mathrm{Na}$ Tabela 2 apresenta-se a análise da função de cada trabalhador desde o controle da quantidade de carne que chega no local para o desembarque, passando pela sua carga de trabalho no desempenho daquela função, chegando na remuneração.

Tabela 2 - Análise da função

\begin{tabular}{|c|c|}
\hline & Análise Da Função \\
\hline Posto de trabalho & Setor Desembarque \\
\hline Localização & Produção \\
\hline Total de Funcionários & 10 \\
\hline Horários de trabalho & $8: 00$ h às 17:00h de Segunda à Sexta \\
\hline Controle de produção & Quantidade da carga descarregada \\
\hline Tipo de remuneração & Mensal fixa \\
\hline
\end{tabular}

Fonte: Própria

No Quadro 1 apresenta-se como que é feito o trabalho de descarga desde o início até o final, sendo feito um levantamento de quanto que pesa cada peça transportada e como que isso é feito, analisando o mobiliário existente no local, e como que os funcionários mantenham a sua postura no decorrer de sua funções que lhe são atribuídas. 
Quadro 1 - Levantamento e transporte manual de materiais, mobiliário existente, equipamentos, descrição das tarefas e postura de trabalho.

\begin{tabular}{|c|}
\hline $\begin{array}{l}\text { Descarregar peças de carne da carreta para os ganchos, peças que variam de } \\
15 \text { a } 45 \mathrm{~kg} \text { Empurrar } 0 \text { gancho para a desossa (sistema de dois trabalhadores } \\
\text { um empurra e outro puxa). }\end{array}$ \\
\hline MOBILIARIO EXISTENTE NO POSTO DE TRABALHO \\
\hline $\begin{array}{l}\text { Banqueta para o trabalhador que este parado analisando } 0 \text { valor do peso na } \\
\text { balança. }\end{array}$ \\
\hline EQUIPAMENTOS NO POSTO DE TRABALHO \\
\hline $\begin{array}{l}\text { Trilhos para carretilhas; } \\
\text { Espetos para carne. }\end{array}$ \\
\hline DESCRIÇĀO DAS TAREFAS \\
\hline $\begin{array}{l}\text { Fazer o descarregamento das carnes: Colocar as peças nos ganchos e levar o } \\
\text { ganche ate a área da desossa. }\end{array}$ \\
\hline POSTURA DE TRABALHO \\
\hline $\begin{array}{l}\text { Em pé para descarregar as peças do caminhão. } \\
\text { Sistema de revezamento e intervalos de } 10 \mathrm{~min} \text {. }\end{array}$ \\
\hline
\end{tabular}

Fonte: Própria

$\mathrm{Na}$ quadro 2 apresentam-se as normas de produção e sistema de qualidade, como que são feitas as exigências e a descrição do tempo do trabalhador no desempenho de sua função tempo esse entre uma descarga de uma peça e outra e o tempo de seu descanso, tendo em vista que as peças são pesadas e requer agilidade.

Quadro 2- Normas de produção e sistema de qualidade..

\begin{tabular}{|l|l|}
\hline Normas de produção & Sistema de qualidade \\
\hline Exigências de tempo & Tempo de acordo com a carga para a descarga \\
\hline Ritmo de trabalho & Tempo de ir e vir do trabalhador na descarga \\
\hline Outros & 1 hora para refeição e descanso \\
\hline
\end{tabular}

Fonte: Própria

A quadro 3 mostra as condições ambientais apresentadas no posto de trabalho, visando uma melhor condição de trabalho para seus funcionários, consequentemente proporcionando-Ihes um maior conforto e melhor desempenho de suas funções.

Quadro 3 - Condições ambientais no posto de trabalho

\begin{tabular}{|l|l|}
\hline Normas de produção & Sistema de qualidade \\
\hline Exigências de tempo & Tempo de acordo com a carga para a descarga \\
\hline Ritmo de trabalho & Tempo de ir e vir do trabalhador na descarga \\
\hline Outros & 1 hora para refeição e descanso \\
\hline
\end{tabular}

Fonte: Própria

\subsection{RECOMENDAÇÕES AMBIENTAIS NO POSTO DE TRABALHO}

Diante das posturas que o corpo assume durante uma determinada atividade, sempre acaba existindo algum tipo de problema para a saúde. (COUTO, 2012).

Segundo Couto (2012) a alternância de postura é considerado uma boa condição ergonômica tendo em vista sempre evitar a sobrecarga. É sempre importante observar que o mobiliário não é o único fator que compromete a postura, e sim a conjugação entre a área de manipulação de objetos, ferramentas e a área de visão.

A movimentação manual de cargas é perigos, fazendo com que aumente o fator de risco para o aparecimento de uma lesão. Umas das lesões mais comum para este tipo de atividade são as dores lombares, podendo também está relacionado ao ambiente de trabalho e ao próprio individuo. 
Durante o levantamento devemos escolher a melhor postura. Mantenha a coluna reta e use a musculatura das pernas durante o levantamento; A frequência dos levantamentos não deve ser de muita intensidade.

A duração do levantamento não deve ser maior que uma hora, e deve ser seguida de um período de descanso (ou tarefas mais leves) de 120 \% da duração da tarefa do levantamento, cargas grandes, compridas ou desajeitadas devem ser carregadas por duas ou mais pessoas, colocadas bem próximas do corpo com os braços esticados ou com o braço e o antebraço formando ângulo reto, com o corpo ligeiramente inclinado para traz, de modo que o centro de gravidade da carga se aproxime da vertical do corpo. Em seguida foi realizada a analise pelo software winowas, remetendo a uma analise pelo método Owas, que avalia a tensão à partir da postura, peso e repetição do método dentro da analise da figura 2 , onde foram realizadas filmagem, com o intuito de registrar a analise postuaral, sendo assim a figura 3 traz as analises preliminares.

Figura 3: Análise Winwovas
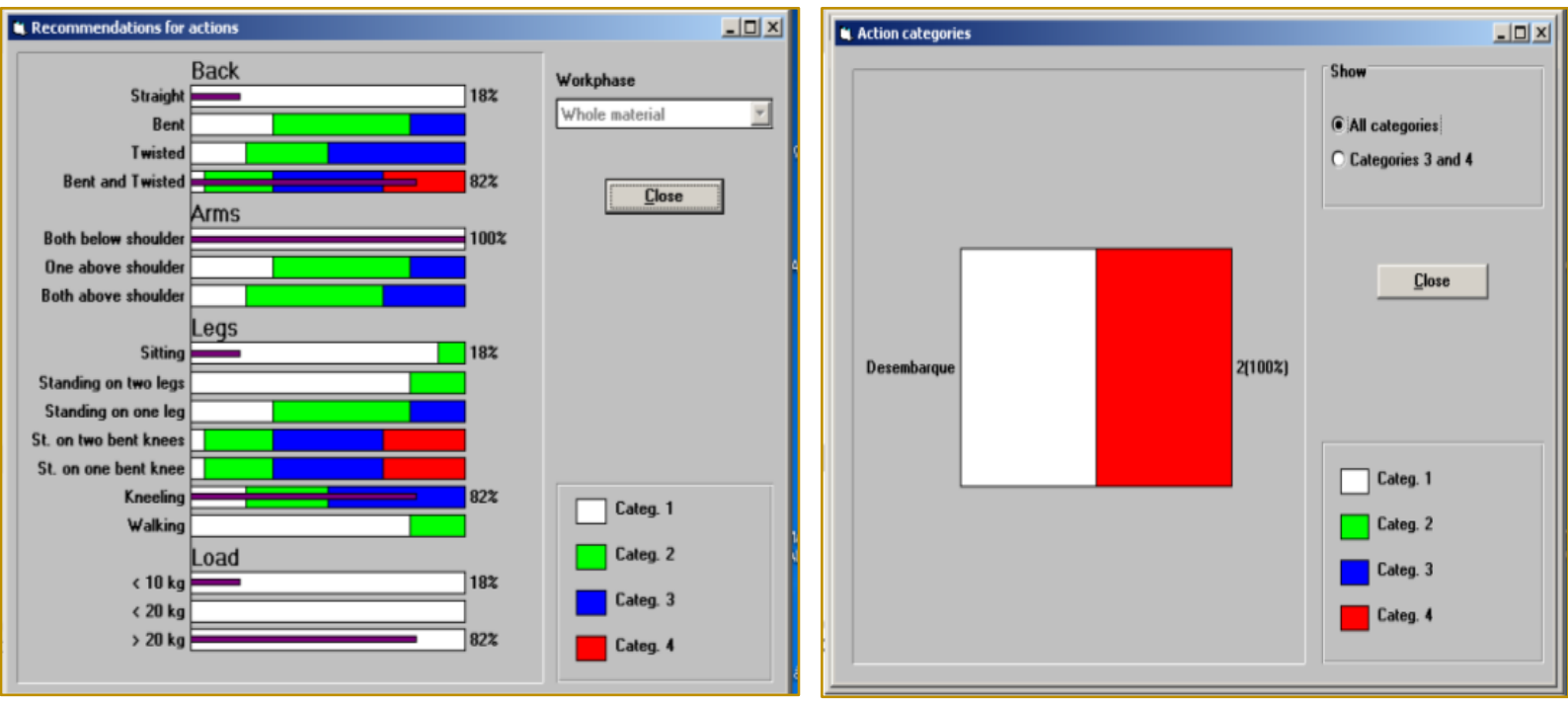

Fonte: Própria

A figura 06 pode-se constatar que a categoria 2 e 3 se prevalecem sendo a força e tensão segundo analise da metodologia Winwovas uma categoria que merece atenção e vislumbra a aplicação de metodologias como ginástica laboral.

O empregado continua com movimentos, também se enquadra na categoria 3 e pode exigem a visão de precauções do trabalho conforme na figura. Corroborando ainda estudos realizados no Brasil e mundo, e com a relevância do trabalho Análise ergonômica do trabalho,em conjunto com a metodologia OWAS, que determina a ginástica laboral e outras avaliações técnicas como variações no trabalho.

A relevância do estudo, então não fica somente na analise, mas também nas proposições de melhorias, onde o ambiente e o labor do trabalho em frigoríficos, serve de arcabouço para a analise de vários autores no mundo, sendo importante, mais um estudo em âmbito nacional e internacional, neste quesito.

\section{CONCLUSÃO}

Durante a jornada de trabalho no setor de desembarque, o trabalhador é orientado quanto à sua educação postural como forma de prevenção a futuras lesões, evitando assim fadigas musculares e, consequentemente, desempenhando melhor suas funções dentro da empresa.

Como forma de solucionar alguns problemas nesse setor foram recomendados algumas soluções: o levantamento deve possibilitar a escolha da postura; deve-se manter a coluna reta e usar a musculatura das pernas durante o levantamento; a frequência dos levantamentos não deve ser muito intenso; a duração do levantamento deve ser no máximo uma hora, e deve ter períodos de pausas. 
Cargas grandes, compridas ou desajeitadas devem ser carregadas por duas ou mais pessoas, colocadas bem próximas do corpo com os braços esticados ou com o braço e o antebraço formando ângulo reto, com o corpo ligeiramente inclinado para trás, de modo que o centro de gravidade da carga aproxime-se da vertical do corpo.

Com este estudo, o objetivo proposto que foi investigar as posturas de acordo com os cargos ocupados nos setores de desembarque em um frigorifico foi atendido ao utilizar a NR 17 e sugerir mudanças no setor de trabalho, proporcionando assim um maior conforto no desenvolvimento de suas

\section{REFERÊNCIAS}

[1] Abergo (2000). Sistema Brasileiro de Certificação em Ergonomia. Disponível em $<w w w$.abergo.org.br>.Acesso em 18 de setembro de 2013.

[2] Alvarez, B.R. Qualidade de vida relacionada à saúde de trabalhadores. Dissertação. Florianópolis: Universidade Federal de Santa Catarina; 1996.

[3] Couto, H.A. Ergonomia aplicada ao trabalho: manual técnico da máquina humana. Belo Horizonte: ERGO. 1995. Vol 1. 353p

[4] Couto, H. A. Índice TOR-TOM: 25 Aplicações práticas na análise ergonômica, na avaliação do risco ergonômico, na prescrição de ações corretivas e no gerenciamento da produtividade segura. 2. ed. Belo Horizonte: Ergo, 2012

[5] Brasil. Ministério do Trabalho e Emprego. Nota técnica - medidas para controle de riscos ocupacionais na indústria de abate e processamento de carnes. Brasília, 2004.

[6] Defani, J.C. Avaliação do perfil antropométrico e análise dinanométrica dos trabalhadores da agroindústria do setor de frigoríficos e abatedouros: o caso da Perdigão Carambel.. Dissertação (Mestrado em Engenharia de Produção) - Universidade Técnica Federal do Paraná, Ponta Grossa, PR, 2007.

[7] Deliberato P. C. P. Fisioterapia Preventiva: Fundamentos e Aplicações. Editora: Manole, edição 1ํ ano 2002.

[8] Delwing. E.B. Análise das condições de trabalho em uma empresa do setor frigorífico a partir de um enfoque macroergonômico.. 132 f. Dissertação (Mestrado em Engenharia de Produção) - Universidade Federal do Rio Grande do Sul, Porto Alegre, RS, 2007.

[9] Evangelista, Wemerton Luís, D.Sc., Universidade Federal de Viçosa, agosto de 2011. tarefas.

Os carrinhos de transporte têm uma forte importância dentro de um serviço, tanto na área de recepção e inspeção de materiais como para transporte dos mesmos para os pontos de estocagem ou uso, bem como para transporte das mantas prontas para o setor de empacotamento economizando vários deslocamentos e evitando a fadiga.

Espera-se que este estudo possa contribuir para outras organizações, procurando sempre manter a segurança e a saúde dos seus empregados, melhorando a autoestima dos funcionários e o seu rendimento.

Análise ergonômica do trabalho em um frigorífico típico da indústria suinícola do Brasil.

[10] Fielder, N.C.; Venturoli, F.; Minetti, L.J. Análise de fatores ambientais em mercenarias no Distrito Federal. Revista Brasileira de Engenharia Agrícola e Ambiental, v. 10, p. 679-85, 2006.

[11] Freitas, P. Acoplamento sensório motor no controle postural de idosos: efeitos da atividade física. Dissertação (Mestrado em Ciências da Motricidade) - Instituto de Biociências, Universidade Estadual Paulista, 2003.

[12] Guimarães L. B. de M.; Portich P. Análise postural da carga de trabalho nas centrais de armação e carpintaria de um canteiro de obras. In: Abergo - Congresso latino-Americano de Ergonomia, VII., 2002. Recife. Anais... Recife, 2002.

[13] lida, Itiro. Ergonomia: Projeto e Produção. 4. ed. São Paulo: Edgard Blucher Ltda, 1997.

[14] lida, I. Ergonomia: projeto e produção. 2.ed. São Paulo: Edgard Blucher, 2005.

[15] Karhu, O.; Kansi, P.; Kuorinka,I. Correcting working postures in industry: a practical method for analysis. Applied Ergonomics, V.8, n.4, p. 199-201, 1977.

[16] Kivi, P.; Matilla, M. - Analysis and improvement of work postures in the building industry: application on the computerized OWAS method. Applied Ergonomics, 22 (1), p. 43 -48, 1991.

[17] Manual WinOWAS. A computerized system for the analysis of work postures. Disponivel em: http://turva1.me.tut.fi/owas . Acesso em: 02 mar. 2009.

[18] Matos, C.H.; Proença, R.P.C. Condições de trabalho e estado nutricional de operadores do setor de alimentação coletiva: um estudo de caso. Revista Nutrição, v. 16, p. 493-502, 2003. 
[19] Oliveira, C. R. de e col. Manual Prático da LER. Belo Horizonte: Livraria e Editora Health, 1998.

[20] Ribeiro, S. B., Souto, M. do S. M. L.; Araujo Junior, I. C. Análise dos riscos ergonômicos da atividade do gesseiro em um canteiro de obras através do software Winowas. In: Enegep, 24, 2004, Florianópolis. CD ROM. Florianópolis: UFSC, 2004.

[21] Silva, M.C. Meio ambiente como fator limitante no desempenho do trabalho e segurança do trabalhador. R. Cad Inf Prev Acid, 183, p. 32-40, 1995.

[22] Slack, Nigel; chambers, Stuart; Johnston, Robert. Administração da Produção. Tradução de
Maria Teresa Corrêa de Oliveira, Fábio Alher. 2. ed. São Paulo: Atlas, 2002.

[23] Szelwar, L.I.; Lancman,S.; Johlben, W.M.; Alvarinho, E.; Santos, M. Análise do trabalho e serviço de limpeza hospitalar: contribuições da ergonomia e da psicodinâmica do trabalho. Revista Produção.; 14:45-57, 2004.

[24] Xavier, Dr. Antonio Augusto de Paula. Apostila: Ergonomia. Curso de Especialização em

[25] Engenharia de Segurança do Trabalho, 2013

[26] YIN, Robert K. .Case study research.Design and methods. London: Sage Publications, 1989 


\section{CAPÍTULO 16}

\section{ANÁLISE DOS FATORES DE RISCO DE ACIDENTE NO TRABALHO: UM ESTUDO DE CASO EM UMA MOVELARIA DO MUNICÍPIO DE ITACOATIARA-AMAZONAS}

\section{Adriano da Mata Gama;}

\section{Ariane Batista Maquine;}

\section{Camila Martins de Oliveira;}

João Marcos de Oliveira

RESUMO: O sucesso empresarial dependente da capacidade da organização em manter seus colaboradores, pois são eles que dão vida aos projetos e planos traçados. Contudo, na indústria moveleira é dado pouca ou nenhuma atenção aos seus trabalhadores, em relação ao bem estar, saúde e segurança. Neste sentido, o presente trabalho objetivou analisar os fatores de risco, responsáveis pelos acidentes de trabalho no setor moveleiro, visto que há uma incidência frequente nesta área de atuação, deixando os colaboradores na maioria das vezes com lesões permanentes. Para investigar o problema, adotou-se um enfoque qualitativo de natureza descritiva, empregando como procedimento técnico o estudo de caso. A partir das observações feitas no local de trabalho, verificaram-se alguns problemas como: a falta de equipamentos de proteção individual e coletivo, desorganização, falta de limpeza, máquinas sem a proteção, prática de atividades ergonomicamente inadequadas e risco químico e biológico. Com isso, foi proposto à implementação do programa 5S para melhorar a organização da movelaria, também foi sugerido melhorias para os problemas internos apresentados indicando possíveis soluções para sanar os riscos químicos, físicos, biológicos e ergonômicos, presentes no ambiente de trabalho, para então, criar um espaço organizado e com mais segurança.

Palavras-chave: Setor Moveleiro; Qualidade; Programa 5S. 


\section{INTRODUÇÃO}

O êxito de qualquer atividade empresarial é diretamente proporcional ao fato de se manter a sua peça fundamental - o trabalhador onde se deve criar um ambiente de integração entre as partes, alinhado às ótimas condições de saúde (GIMENEZ, 2010), pois os trabalhadores que dão existência aos projetos e planos traçados pelas organizações.

A indústria moveleira do Brasil teve início com os imigrantes que nos colonizaram após o século XVI, tendo origem da cultura familiar com um desenvolvimento disperso pelo país (NUNES; FRAZONE, 2004). Nessa indústria, utiliza-se um grande volume de matéria-prima florestal, além de revelar pouca preocupação com a saúde do trabalhador e destinação de resíduos (PRADO; LORENZO, 2011).

Este trabalho teve como objetivo analisar os fatores de riscos, responsáveis por acidentes do trabalho no setor moveleiro, tendo como objeto de estudo uma movelaria de pequeno porte, situada no município de Itacoatiara Amazonas. Com isso, buscou-se avaliar a situação dos trabalhadores em relação a segurança e riscos do trabalho e orientar os administradores a respeito da importância da utilização dos equipamentos de proteção.

De acordo com uma pesquisa realizada pelo Serviço Social da Indústria (2004), a Região Norte é classificada com os maiores índices de acidentes de trabalho, típicos no setor moveleiro. Assim, justifica-se a formação deste projeto na empresa estudada para analisar e propor melhorias levando em consideração os problemas encontrados durante o estudo.

\section{REFERENCIAL TEÓRICO}

Nesta seção são abordados os conceitos necessários para o embasamento teórico da pesquisa, tais como: setor moveleiro na região e fatores de risco e acidentes de trabalho.

\subsection{SETOR MOVELEIRO NA REGIÃO}

Uma pesquisa publicada no Portal da Indústria em 2014 no setor moveleiro do Brasil estimava-se um crescimento de 3 a $5 \%$ para 2015, conduzido principalmente pelas regiões Nordeste e Norte.

Contudo, o setor moveleiro no Amazonas é formado por empresas de micro porte, nas quais apresentam dificuldades de equipamentos, infraestrutura, logística e carência de mão-de-obra especializada (SILVA et al., 2002 apud LUCA FILHO; PIO; FERREIRA, 2010), fatores que poderiam gerar dificuldade para aproveitar o crescimento no segmento. E Gaspar (2004) relata que cerca de $60 \%$ dos proprietários dizem que um dos maiores problemas de mão-de-obra é a alta rotatividade dos funcionários e 14\% destacam a carência de pessoal qualificado.

Não diferindo do cenário regional, o setor moveleiro de Itacoatiara é composto de pequenas e microempresas com maioria em atividade a mais de dez anos. O maquinário usado na produção de móveis é quase sempre artesanal, o marceneiro usa de sua criatividade para a produção dos mesmos (SOUZA, 2008). Os insumos utilizados na produção de móveis como vernizes, thinner, selador, lixas e outros, não possuem um local apropriado para seu armazenamento e isso é um dos fatores atuantes na organização das movelarias. Santos (2008) alega que alguns desses insumos são produtos químicos e tóxicos que podem causar males a saúde do trabalhador, principalmente quando do manuseio destes no setor de acabamento e pinturas.

\subsection{FATORES DE RISCO E ACIDENTES DE TRABALHO}

Os riscos profissionais se subdividem em riscos de operação, como a perda de membros por causa das máquinas de corte, retrocesso das ferramentas, entre outros, e os riscos causados pelo ambiente de trabalho, como riscos químicos, físicos, biológicos e ergonômicos (GIMENEZ, 2010).

Consideram-se agentes físicos o clima, a iluminação, a vibração e o ruído (GIMENEZ, 2010). Sendo assim, os ambientes devem ser analisados quanto à: temperatura do ar; excesso e/ou a falta de iluminação, que poderão provocar cansaço visual e deficiência permanente da visão (GIMENEZ, 2010, p.21); ruídos, pois nas movelarias as máquinas como serra circular, serra de fita, seccionadora automática, furadeira, lixadeira, grampeador e tupia são fontes de intenso barulho; e vibrações, porque elas podem causar fadiga, irritação, danos ao sistema nervoso e por vezes, danos físicos permanentes (Serviço Nacional de Aprendizagem Industrial - SENAI, 2008).

Os agentes químicos considerados no local de trabalho são a poeira, o fumo, a névoa, a 
neblina, os gases, os vapores, ou seja, substâncias em geral que possam penetrar no organismo pela via respiratória, por meio de alguma operação de trabalho realizada (GIMENEZ, 2010).

Os agentes biológicos podem ser: vírus, bactérias, protozoários, fungos, parasitas e bacilos. Já os ergonômicos podem ser causados por esforço físico intenso, levantamento e transporte manual de peso, exigência de postura inadequada, jornada de trabalho prolongada, monotonia entre outros fatores (GIMENEZ, 2010).

\section{METODOLOGIA}

Este projeto constitui-se de um enfoque qualitativo de natureza descritiva, pois os dados foram colhidos nas condições normais de trabalho sem intervenção do pesquisador nas atividades laborais. Para identificar os riscos, inerentes à atividade moveleira, foram realizadas visitas in loco descrevendo os fatos observados e registro das observações por meio de fotografias para ressaltar o relatório final. Os riscos considerados foram decorrentes da ausência de proteção de uso individual, coletivo e proteção das máquinas. Também foi sugerido implementar o programa 5S na movelaria para melhorar a organização do ambiente de trabalho, pois o programa dos 5S trata da organização, limpeza, asseio e autodisciplina no ambientes de trabalho com propósito de melhorar as condições e produtividade na empresa (FRANCO, 2008; MENDONÇA et al., 2011).

\section{RESULTADOS E DISCUSSÕES}

\subsection{CONDIÇÕES GERAIS DO AMBIENTE DE TRABALHO NA EMPRESA ESTUDADA}

Durante as visitas realizadas na movelaria, pôde-se observar o ambiente de trabalho como um todo. Isso permitiu verificar a falta de organização, higiene e limpeza, ausência no uso de uniformes e equipamentos de proteção individual ou coletivo, além da dificuldade de locomoção dos funcionários, acarretado por sobras de madeira deixadas no chão.

Além da falta de organização, higiene e limpeza do ambiente de trabalho, as máquinas não oferecem qualquer segurança aos funcionários, ficando com suas partes móveis expostas, o que aumenta o risco de ocorrer graves acidentes.
No processo de fabricação dos móveis é preciso secar a madeira, para isso utiliza-se estufa, a mesma é feita de maneira improvisada, não possuindo qualquer sistema de captação da fumaça gerada, permitindo sua inalação pelos funcionários.

Observou-se também que as instalações elétricas são bastante deficientes, porque apresentam fios desencapados pelo chão, interruptores das máquinas inadequados e amarrados com fios soltos no chão, o painel elétrico é feito de madeira e foi encontrado aberto. Essas condições podem causar incêndios e pôr a vida dos funcionários em risco, pois não foi encontrada nenhuma prevenção contra incêndios como extintores e caixas d'água com torneiras de fácil acesso. Também foram identificados riscos químicos, físicos, biológicos e ergonômicos como: colas, vernizes, seladores, ruídos e poeiras gerados pelas máquinas entre outros.

Considerando as condições expostas, sugere-se, inicialmente, implementar o programa dos $5 S$ e na sequência algumas propostas para os problemas descritos, o que pode melhorar o ambiente de trabalho, aumentar o rendimento dos funcionários e oferecer segurança.

\subsection{IMPLEMENTAÇÃO DOS 5S NA MOVELARIA}

Para melhorar a organização do ambiente de trabalho foi proposto o programa dos 5 s que trata da organização e limpeza em ambientes de trabalho.

Segundo Franco (2008) este termo é derivado de cinco palavras em japonês, todas iniciadas com a letra $S$, que em sua tradução em português não se encontrou palavras que iniciem com tais letras, então se utiliza "senso de" antes de cada uma delas. Para melhor compreensão está descrito abaixo cada um dos sensos mencionados e seus objetivos sugeridos, para assim, melhorar as condições de trabalho na movelaria foco do nosso estudo.

\subsubsection{SENSO DE SELEÇÃO (SEIRI)}

Como pode-se observar na Figura 01, na movelaria há muitos entulhos, pedaços de madeira, garrafas, copos descartáveis, latas jogadas no chão, pó de serragem em baixo das máquinas, móveis em processo de acabamento espalhados por todo o lugar, e 
alguns materiais como lixas e serras, deixadas por cima das máquinas e até mesmo pelo chão. Com isso, confirma-se a necessidade de propor a implementação do primeiro senso na empresa, pois o mesmo trará benefícios como o melhor aproveitamento do espaço físico, maior controle do estoque e maior comodidade para os funcionários devido ao espaço mais limpo e organizado.

Figura 01 - Movelaria

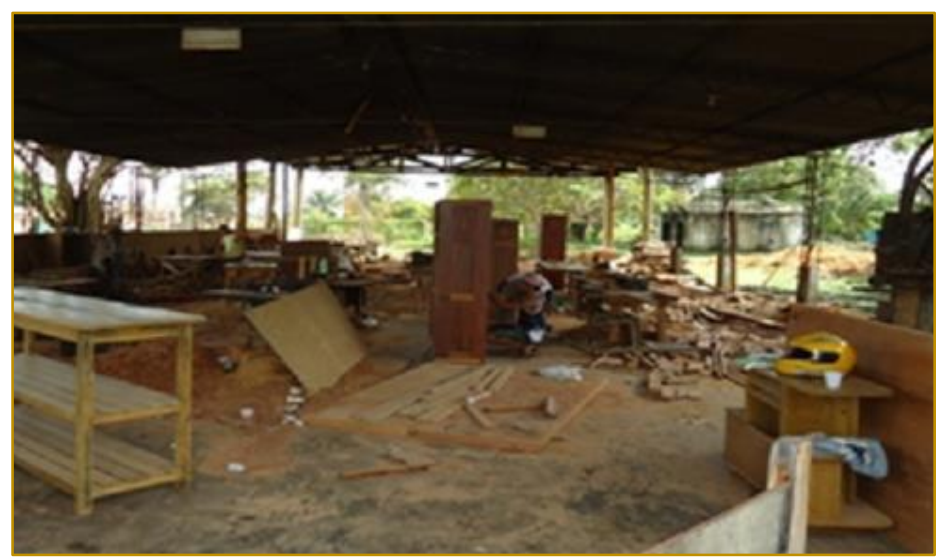

Fonte: Autores (2017)

Este senso é caracterizado pela capacidade de definir e distinguir o que é necessário. Assim devem ser selecionados:

a) Materiais de uso frequente: que ficarão no local de trabalho;

b) Materiais de uso eventual: que ficarão em um depósito;

c) Materiais desnecessários: que devem ser "descartados".

\subsubsection{SENSO DE ORDENAÇÃO (SEITON)}

A movelaria conta com um depósito sem um padrão ou identificação para armazenamento dos materiais, partes de móveis são encontrados no meio do depósito e na área de produção gerando dificuldade de locomoção dos funcionários. Também foi identificado armários em péssimas condições de uso e sem organização, além disso, ferramentas estavam no chão, sem uso no momento, podendo assim ser danificadas e causar acidentes, gerando prejuízos para o proprietário.

Após uma seleção correta, descartando o que for desnecessário, é preciso guardar e acomodar cada coisa em seu lugar.

\subsubsection{SENSO DE LIMPEZA (SEISOH)}

As serragens (resíduo da madeira) ficam espalhadas por toda parte, e são de difícil eliminação, as mais finas ficam pairando no ar, as mais grossas como as de plainagem e desengrosso ficam por cima e por baixo das máquinas e essas serragens não são retiradas das bancadas após a realização das atividades, o ambiente é limpo apenas uma vez por semana.

Faz-se necessário manter as máquinas, as ferramentas e o ambiente limpo. Essa tarefa é dever de todos os colaboradores na empresa, os quais podem utilizar a audição, o olfato, o paladar e a visão como inspetores das tarefas, assim é mais fácil manter o local limpo.

\subsubsection{SENSO DE HIGIENE (SEIKETSU)}

Os trabalhadores fazem uso de vestimentas impróprias, porque em sua maioria usam sandálias, bermudas, bonés e camisetas. Não usam nenhum tipo de uniforme (botas, calças, jalecos) o que pode ser visto na Figura 02. Para mudar esse quadro, o quarto senso é primordial. 
Figura 02 - Trabalhadores sem uniforme

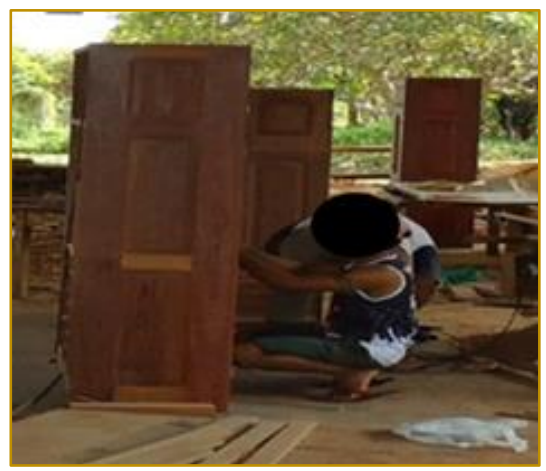

Fonte: Autores (2017)

Os funcionários devem trabalhar com vestimentas adequadas e limpas, contribuindo com a limpeza do ambiente e proporcionando condições saudáveis a si e aos colegas. Os benefícios desta atitude são tornar o ambiente de trabalho mais agradável e padronizado, o que poderá reduzir acidentes de trabalho.

\subsubsection{SENSO DE DISCIPLINA (SHITSUKI)}

Segundo Franco (2008, p.59) o desenvolvimento do Senso de Autodisciplina significa estimular as pessoas a realizarem o seu trabalho corretamente:

- Compartilhar a missão, visão e os princípios da empresa;

- Educar para a criatividade;

- Melhorar as comunicações em geral;

- Atribuir responsabilidades e delegar autoridade;

- Criar um clima de confiança e solidariedade.

\subsection{EQUIPAMENTOS DE PROTEÇÃO INDIVIDUAL (EPIS)}

Não foi observado o uso de EPIs, e de acordo com relato do dono da empresa e dos trabalhadores até então nunca houve nenhum tipo de acidente grave, apenas um trabalhador sofreu um pequeno corte nas mãos, mas que não deixou sequelas.

Para a segurança na realização das tarefas pelos trabalhadores, os EPIs recomendados são: uniformes para padronizar os funcionários e para sua proteção, isso poderia evitar respingos de produtos químicos direto no corpo; botas para proteção contra impactos de quedas de objetos sobre os dedos dos pés, contra agentes cortantes e perfurantes; óculos para proteger os olhos; máscara para proteger as vias respiratórias contra poeiras e névoas; e protetor auricular contra níveis de pressão sonora.

\subsubsection{EQUIPAMENTOS DE PROTEÇÃO COLETIVA (EPCS)}

As máquinas utilizadas na movelaria são de cortes, lixas, furos e outros, e as atividades desempenhadas por elas são grandes geradoras de pó, e não tem nenhum equipamento para coletar este resíduo. Neste caso é proposto o uso de coletor de pó para intensificar a proteção contra esses agentes.

Os funcionários também fazem uso de esmeril, sem nenhuma proteção nas mãos, rosto e pescoço ficando assim expostos aos respingos $e$ as radiações luminosas resultantes desta atividade. Por mais que essa atividade possa não prejudicar o funcionário, recomenda-se o uso de protetor facial para proteção do rosto e pescoço.

\subsection{MÁQUINAS DA EMPRESA}

As marcenarias expõem os trabalhadores aos mesmos riscos da indústria em geral, porém pode vir a acontecer casos mais sérios, devido aos riscos elevados de acidentes, incluindo perda dos membros (SOUZA, 2004).

Souza (2004) explica que, para garantir o trabalho em condições seguras, há necessidade de proteções diversificadas e adequadas a cada máquina utilizada no processo produtivo, e de trabalhadores orientados para utilizá-las corretamente a cada operação a ser executada. Na Tabela 1 são expostos alguns riscos e sugestões para as máquinas. 
Tabela 01 - Problemas e sugestões para as máquinas

\begin{tabular}{|c|c|c|}
\hline Máquina & Riscos & Sugestão \\
\hline $\begin{array}{l}\text { Serra circular de } \\
\text { bancada }\end{array}$ & $\begin{array}{l}\text { Contato direto com os dentes do disco, retrocesso } \\
\text { da peça de madeira a ser cortada e projeção do } \\
\text { disco ou parte dele, onde na maioria desses casos } \\
\text { atinge o operador pondo sua vida em risco. }\end{array}$ & $\begin{array}{l}\text { Capas de proteção do disco e } \\
\text { cutelo divisor, que podem ser } \\
\text { utilizados em todas as máquinas } \\
\text { que possuem a mesma } \\
\text { característica. }\end{array}$ \\
\hline Serra de fita & $\begin{array}{l}\text { Serra exposta e seu rompimento podem ocasionar } \\
\text { lesões graves ao operador, podendo até mesmo } \\
\text { levar a morte, nela está adaptado um tipo de } \\
\text { "proteção" feito de madeira, seu funcionamento é } \\
\text { igual ao de uma porta, mas este não presta } \\
\text { segurança, pois pode abrir com facilidade. }\end{array}$ & $\begin{array}{l}\text { Souza (2004) a proteção à ser } \\
\text { usada para aumentar a segurança } \\
\text { do operador neste tipo de máquina } \\
\text { é o protetor de regulagem manual. }\end{array}$ \\
\hline Tupia & $\begin{array}{l}\text { Ruptura ou projeção da ferramenta de corte; } \\
\text { contato com a ferramenta; retrocesso imprevisto } \\
\text { da peça. }\end{array}$ & $\begin{array}{l}\text { Para a proteção dos operadores } \\
\text { nesta máquina é sugerido o } \\
\text { protetor do tipo túnel. }\end{array}$ \\
\hline Desempenadeira & $\begin{array}{l}\text { As lâminas não têm nenhuma proteção o que pode } \\
\text { ocasionar acidentes graves, como perda de } \\
\text { membros, ruptura ou projeção das lâminas afiadas } \\
\text { da ferramenta de corte. }\end{array}$ & $\begin{array}{l}\text { Recomendam-se protetores de } \\
\text { regulagem manual, que permite a } \\
\text { regulagem lateral e altura. Este } \\
\text { deve ser ajustado pelo operador a } \\
\text { cada peça diferente a ser } \\
\text { trabalhada }\end{array}$ \\
\hline
\end{tabular}

Fonte: Autores (2017)

\subsection{INSTALAÇÕES ELÉTRICAS}

As instalações elétricas observadas no local são bastante precárias, nas quais foram encontradas várias situações de risco, como: fios pelo chão, desencapados e sem proteção; os painéis elétricos são feitos de madeira e, na maioria, abertos; alimentação de equipamentos com seus disjuntores presos com fita isolante (Figura 3). Tais problemas podem ocasionar choque elétrico ou incêndios, pondo em risco a segurança dos funcionários.

Figura 03 - Instalações elétricas na movelaria

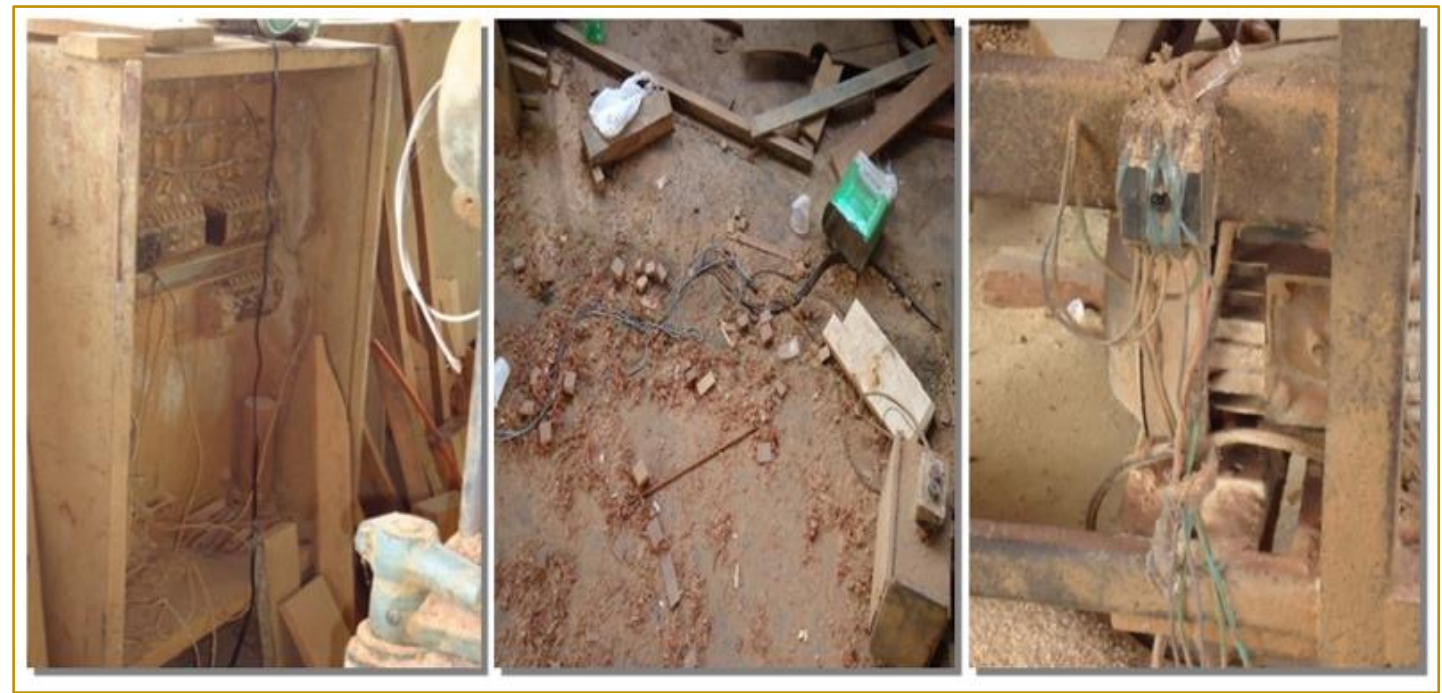

Fonte: Autores (2017) 
Algumas sugestões de melhorias na instalação elétrica são:

1 Substituição dos painéis de madeira por painéis de metal, possuindo advertência na tampa;

2 Arrumar os fios que ficam jogados pelo chão, adotando instalação fixa utilizando elétrodutos;

3 Substituir as instalações dos interruptores das máquinas por instalações fixas, com indicação da posição dos dispositivos de manobra dos circuitos elétricos: (Verde - "D", desligado e Vermelho - "L", ligado).

\subsection{RISCOS BIOLÓGICOS E ERGONÔMICOS}

Na Tabela 2 sugerem-se algumas sugestões para

solucionar os problemas identificados.

Tabela 02 - Problemas e sugestões para os riscos biológicos e ergonômicos

\begin{tabular}{|c|c|c|}
\hline Risco & Problema & Sugestão \\
\hline Biológicos & $\begin{array}{l}\text { Fungos: encontrados na madeira devido } \\
\text { ao armazenamento ao ar livre, na qual elas } \\
\text { ficam constantemente expostas a chuvas; } \\
\text { Bactérias: a evidência desses } \\
\text { microrganismos são os buracos formados } \\
\text { na madeira, que são causados pelas } \\
\text { bactérias formadoras de Túneis ("tunneling } \\
\text { bacteria"), bactérias escavadoras } \\
\text { ("cavitation bacteria") e bactérias erosivas } \\
\text { ("erosion bacteria"), também devido à } \\
\text { umidade e podem ocasionar problemas de } \\
\text { saúde. }\end{array}$ & $\begin{array}{l}\text { Com o proposito de minimizar este problema, } \\
\text { sugere-se definir uma área coberta adotando o } \\
\text { FIFO (first-in, first-out) na utilização desta } \\
\text { matéria-prima. } \\
\text { Também se sugere adoção de alguns EPIs } \\
\text { como: óculos, calçados, uso de roupas } \\
\text { adequada como camisa manga longa, } \\
\text { máscara de pó e luvas para o manuseio da } \\
\text { madeira. }\end{array}$ \\
\hline Ergonômicos & $\begin{array}{l}\text { Os trabalhadores exercem suas atividades } \\
\text { adotando posturas incorretas; ritmo } \\
\text { excessivo; trabalho físico pesado. E } \\
\text { apresentam sintomas como; dores na } \\
\text { coluna, causadas por esforços musculares } \\
\text { contínuos; e essa atividade exige que os } \\
\text { trabalhadores passem a maior parte do } \\
\text { tempo em pé, e as tarefas são bastante } \\
\text { repetitivas. }\end{array}$ & $\begin{array}{l}\text { Evitar curvar-se para frente, pois quando o } \\
\text { tronco inclina-se para frente, há contração dos } \\
\text { músculos e das costas para manter essa } \\
\text { posição; } \\
\text { Evitar movimentos bruscos que produzem } \\
\text { tensões musculares, pois se sabe que } \\
\text { levantamentos rápidos de carga podem } \\
\text { produzir fortes dores nas costas; } \\
\text { Alternar posturas e movimentos, fazendo } \\
\text { rodízios nas atividades e em postos de } \\
\text { trabalho, alternado tarefas em pé ou andando } \\
\text { por aquelas sentadas; } \\
\text { Dar pausas curtas e frequentes distribuídas ao } \\
\text { longo da jornada de trabalho. }\end{array}$ \\
\hline
\end{tabular}

Fonte: Autores (2017)

\section{CONSIDERAÇÕES FINAIS}

O presente artigo buscou observar e propor soluções para uma movelaria, citando os riscos recorrentes aos trabalhadores, sendo os mesmos, ergonômicos, biológicos e físicos, além de mais proteção nas máquinas usadas pela empresa. Também foi proposto à implementação do 5S.

De maneira geral, as indústrias desse ramo apresentam condições de trabalho que podem ser aprimoradas a partir do reconhecimento de suas inadequações e da implantação de medidas de controle necessárias, além da utilização de técnicas mais modernas de gestão, incluindo às de segurança no trabalho, visto que uma organização é constituída desde a alta gerência até os operários que executam as tarefas.

Assim, a segurança do trabalho no setor moveleiro deve ser melhorada, visto que, a qualidade de vida dos seres humanos está diretamente relacionada a melhores condições de trabalho. 


\section{REFERÊNCIAS}

[1] Franco, M. R. Padrões de qualidade de produtos moveleiros: um estudo de casos no pólo de Arapongas, Paraná. 2008. Tese (Doutorado em Engenharia Florestal) - Universidade Federal do Paraná, Curitiba, 2008. Disponível em: $<$ http://www.floresta.ufpr.br/pos-

graduacao/defesas/pdf_dr/2008/t244_0286-

D.pdf. >. Acesso em: 28 abr. 2012.

[2] Gaspar, L. S. dos S. Aspectos do Setor Madeireiro do Município de Borba /AM. 2004. Monografia (Tecnólogo em Indústria da Madeira) Instituto de Tecnologia da Amazônia, Manaus, 2004

[3] Gimenez, J. R. Higiene e Segurança no Trabalho. Itacoatiara, 2010. Material didático do CETAM.

[4] Mendonça, M. S. et al. Análise da eficácia da implantação do programa 5S: um estudo de caso em uma indústria moveleira. Perspectivas Online. Rio de Janeiro, v. 4, n. 13, p. 20-35, 2010. Disponível em: <http://seer. perspectivasonline.com.br/index.php/r evista_antiga/article/view/408/318>. Acesso em: 11 abr. 2017.

[5] Luca Filho, F. C.; PIO, N.da S.; Ferreira, D. R. Método QFD como Ferramenta para Desenvolvimento Conceitual de Produtos de Madeiras da Amazônia. Acta Amazônica. Manaus, v. 40, n. 4, p. 675-686, 2010. Disponível em: $<$ http://acta.inpa.gov.br/fasciculos/40-

4/BODY/v40n4a06.html>. Acesso em: 06 de abril 2012.

[6] Nunes, E. L. S.; Franzoni, A. M. B. Gestão do processo aliada a ergonomia para microempresas. In: Encontro Nacional de Engenharia de Produção, 24., 2004, Florianópolis. Anais... Florianópolis, 2004. Disponível em:
<www.abepro.org.br/biblioteca/ENEGEP2004_Ene gep04030767.pdf>. Acesso em: 15 mar. 2012.

[7] Portal da Indústria. Indústria Moveleira. Disponível em: www.portaldaindustria.com.br/agenciacni/noticias/ 2014/09/industria-moveleira-1/. Acesso em: 16 abril de 2017.

[8] Prado, L. L.; Lorenzo, H. C. A questão socioambiental nas empresas moveleiras do Pólo de Votuporanga - SP. Revista Brasileira de Gestão e Desenvolvimento Regional, São Paulo, v.7, n.3, p. 28-51, 2011. Disponível em: < http://www.rbgdr.net/revista/index.php/rbgdr/article /view/509 >. Acesso em: 13 de Abril 2017.

[9] Santos, G. da C. Avaliação do Perfil de trabalhadores e das condições de trabalho no Setor Moveleiro de Itacoatiara-AM. 2008. Monografia (Engenharia Florestal) Universidade Estadual do Amazonas, Itacoatiara, 2008.

[10] Serviço Nacional de Aprendizagem Industrial - Senai. Departamento nacional. Segurança do Trabalho: a conexão. Porto Alegre, 2008.

[11] Serviço Social da Indústria. Panorama em Segurança e Saúde no Trabalho (SST) na indústria: Brasil e Unidades da Federação 2004: setor moveleiro e indústrias diversas. Brasília, 2004.

[12] Souza, T. C. de. Prevenção dos Riscos Laborais nas Marcenarias e carpintarias. [S.L.], 2004. Material didático. Disponível em: <http://www.segurancaetrabalho.com.br/download/ marcenarias-telmo.pdf>. Acesso em: 13 de Abril 2017.

[13] Souza. E. B. de. Diagnóstico Moveleiro da sede do Município de Itacoatiara-AM. 2008. Monografia (Engenharia Florestal) Universidade Estadual do Amazo 


\section{GAPÍTULO 17}

\section{GESTÃO DA RADIOPROTEÇÃO HOSPITALAR: UM ESTUDO SOBRE A PROTEÇÃO RADIOLÓGICA EM RADIODIAGNÓSTICOS MÉDICOS}

\section{Claudio Covas Fernandes}

Resumo: Instituições de atenção à saúde estão utilizando, em seus ambientes, instalações radiativas para realização de diagnósticos médicos. Devido os danos que esta atividade pode causar a saúde dos trabalhadores, acompanhantes e pacientes, podemos considerar este tipo de atividade como sendo um procedimento de alto risco. Neste estudo descrevemos sobre os tipos de radiações ionizantes, as características do raio $\mathrm{X}$, os dosímetros e os equipamentos de proteção. Argumentamos que, a partir da discussão sobre os princípios da proteção radiológica, as execuções dos radiodiagnósticos podem ocorrer de forma a produzir o menor risco possível. Abordamos também a interação da radiação ionizante com a matéria, seus efeitos biológicos e a prevenção de efeitos adversos da exposição à radiação para radiodiagnóstico médico. Identificamos e levantamos as referências bibliográficas e os requisitos legais de proteção radiológica aplicável ao radiodiagnóstico médico. Posteriormente, através de um estudo de caso no setor de radiologia em uma instituição médica, realizamos observações não participativas analisando, comparativamente, os procedimentos adotados pelo setor de radiologia da instituição envolvida e os requisitos legais aplicáveis. Logo, concluímos apresentando sugestões de melhorias para conscientização dos trabalhadores envolvidos e para a adequação aos requisitos legais com otimização da proteção radiológica.

Palavras-chave: Proteção Radiológica, Radiodiagnóstico Médico, Raios X 


\section{INTRODUÇÃO}

Verificamos que, atualmente, cada vez mais médicos apoiam suas avaliações com base nos radiodiagnósticos tornando o "serviço de diagnóstico por imagem, um dos mais importantes instrumentos de apoio a inúmeras áreas da medicina" (FERNANDES et. al, 2005).

A radiação pode ser dividida em: radiação ionizante e radiação não-ionizante. Como o foco do estudo são os diagnósticos médicos, que utilizam fontes de raios $X$, vamos apenas nos deter na radiação ionizante. Conforme define CNEN (2006), a radiação ionizante é qualquer partícula ou radiação eletromagnética que ao interagir com a matéria, ioniza seus átomos ou moléculas.

Considerando a exposição à radiação ionizante, que são submetidos os trabalhadores do setor radiológico, faz-se necessário implementar um conjunto de medidas que busquem protegê-los. Além disso, tais medidas devem também garantir a proteção aos pacientes e seus acompanhantes evitando os efeitos probabilísticos da radiação. Esse conjunto de medidas é denominado Proteção Radiológica ou Radioproteção.

Segundo Pereira (2004), o objetivo primário da proteção radiológica é proporcionar um padrão de proteção para o homem, sem limitar as práticas benéficas que envolvem exposição à radiação. A Comissão Internacional de Proteção Radiológica (ICRP, 1990) recomenda que providências devam ser tomadas para reduzir exposições desnecessárias.

Neste artigo apresentamos resultados parciais de uma pesquisa realizada no ano de 2007 , para obtenção do título de especialista em Engenharia de Segurança do Trabalho, na Escola de Engenharia da Universidade
Federal Fluminense. Propomos observar e analisar os conjuntos de medidas de Proteção Radiológica realizados na instituição estudada, tendo como foco a utilização de fontes de raios $X$ para os radiodiagnósticos na área médica.

Além das atividades com radiação ionizante, ocorrem outras atividades dentro do ambiente hospitalar. Porém, este artigo limitar-se-á aos serviços de radiodiagnósticos médicos realizados no setor de radiologia da instituição hospitalar estudada. Apresentamos uma análise conceitual da bibliografia e da legislação brasileira sobre a proteção radiológica, não se propondo a discutir os aspectos referentes ao projeto, construção e cálculos de blindagem.

\section{RADIOPROTEÇÃO EM RADIODIAGNÓSTICOS MÉDICOS}

\subsection{RADIAÇÕES IONIZANTES}

Conforme definição da CNEN (2006), a radiação ionizante se apresenta em duas formas físicas, por meio de partículas nucleares (prótons e/ou nêutrons) ou radiação eletromagnética. A emissão da radiação ionizante ocorre quando um átomo está muito energético, ou seja, com excesso de partículas ou cargas, assim tentando estabilizar-se emite algumas partículas nucleares (prótons e/ou nêutrons) podendo emitir também, em alguns casos, a radiação eletromagnética. Segundo Jabarra (2006), a exceção deste seria na emissão do Raio $X$ de freamento, que ocorre através do freamento de partículas carregadas.

Conforme descreve Azevedo (2005), a radiação ionizante de origem artificial encontra seu maior emprego no setor da saúde, mais especificamente na área dos radiodiagnósticos. 
Figura 1 - Fração da dose na população para fontes artificiais

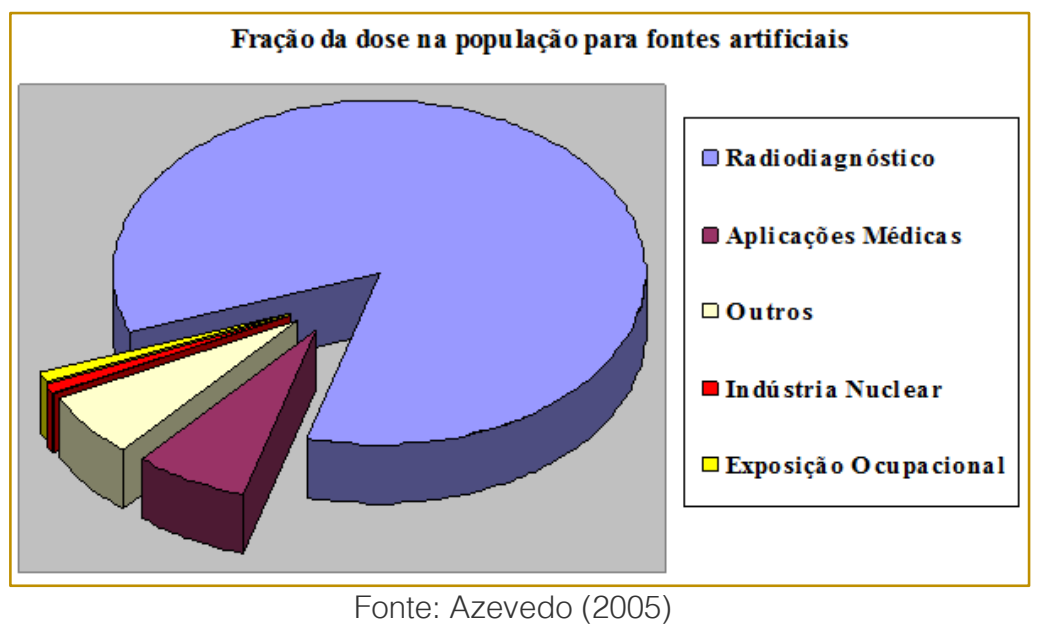

Deste modo, atendendo a necessidade de estabelecer condições e procedimentos técnicos seguros, as autoridades públicas reconhecem que "o uso das radiações ionizantes representa um grande avanço na medicina, requerendo, entretanto, que as práticas que dão origem a exposições radiológicas na saúde sejam efetuadas em condições otimizadas de proteção" (ANVISA, 1998). Logo, diversos autores defendem que "com o crescimento da utilização da radiação ionizante em diagnóstico médico" (AZEVEDO, 2005) muitas instituições de atenção à saúde podem, paradoxalmente, ter sua imagem associada a danos à saúde, visto que "qualquer exposição de um tecido envolve um risco carcinogênico" (TAUHATA et al., 2003), bem como "qualquer exposição das gônadas pode levar a um detrimento genético nos descendentes do indivíduo exposto" (TAUHATA et al., 2003).

Figura 2 - Distribuição das Instalações Radiativas no Brasil

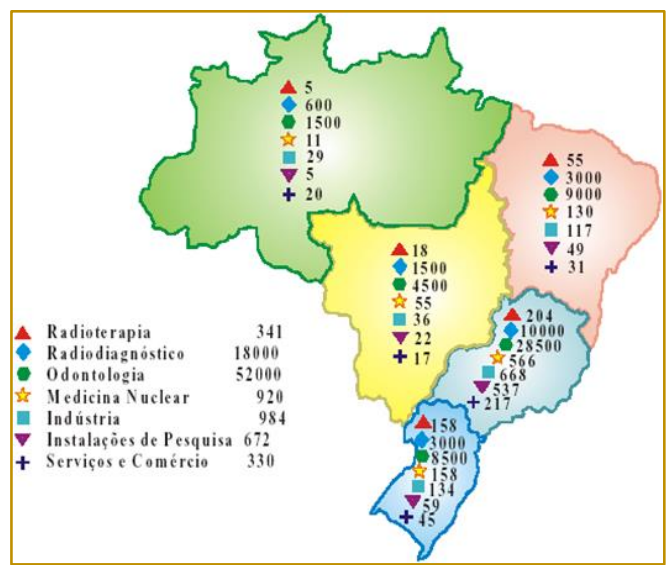

Fonte: Tauhata [et al.] (2003)

\subsection{CARACTERÍSTICAS DO RAIO X}

Segundo Tauhata [et al.] (2003), o feixe de elétrons do raio $X$ é gerado por emissão termiônica em um filamento aquecido. O campo elétrico é obtido aplicando-se uma alta voltagem entre os terminais do tubo de raios $\mathrm{X}$, onde o alvo metálico, anodo, é polarizado positivamente e o filamento, catodo, negativamente. A emissão de raios $X$ só ocorre, obviamente, quando estiver ligada a alta tensão. Quando maior a tensão aplicada ao tubo, maior será a energia dos raios $X$ gerados e maior será também o seu poder de penetração. Assim, aumentando-se a corrente, aumenta-se a intensidade do feixe.

As máquinas geradoras de radiação $X$ artificial são equipamentos elétricos de alta tensão, que podem ser desligadas deixando de produzir os raios X. Esta característica distingue os raios $X$ das fontes radioativas. 
Figura 3 - Equipamento de Raio X

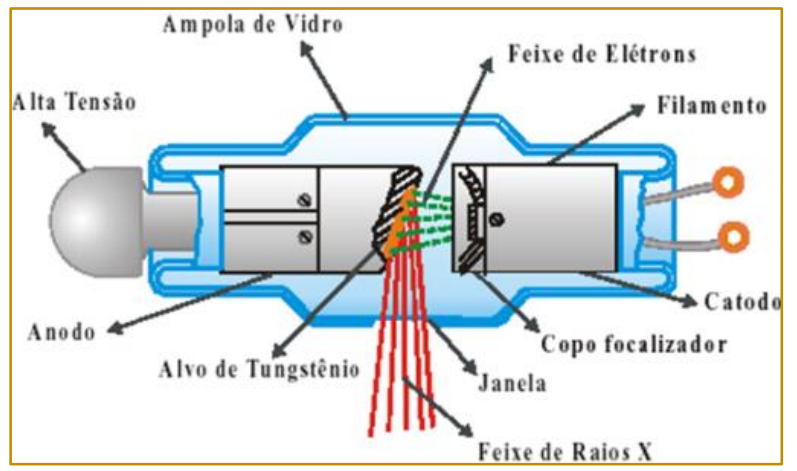

Fonte: TAUHATA, 2003

Segundo Gomes (2002), as características de um feixe de raios $X$ estão relacionadas com a intensidade da radiação, que é o número de fótons emitidos, dependendo da intensidade da corrente do tubo e do tempo de duração da exposição. Primeiro tais condições fornece-nos uma referência da taxa de dose absorvida. Uma segunda característica trata quantidade da radiação, que depende da tensão do tubo e do filtro que se introduz no feixe. O sistema de filtração retira fótons de baixa energia que são produzidos e evita a interferência na formação da imagem radiológica atenuando a dose na pele dos pacientes.

\subsection{PRINCÍPIOS DE PROTEÇÃO RADIOLÓGICA}

\subsubsection{JUSTIFICAÇÃO}

Segundo CNEN (2006), um dos objetivos da proteção radiológica é a diminuição a níveis aceitáveis ou a eliminação das exposições à radiação para prevenir seus efeitos biológicos. Deste modo, deve-se avaliar toda a atividade que utilize radiações ionizantes, garantindo que o uso deste procedimento seja totalmente justificável. Neste caso, existindo outro método que o substitua, com o mesmo benefício, este deverá ser preferido à radiação ionizante, independentemente do seu custo financeiro.

Conforme determina a ANVISA (1998), o princípio da justificação na medicina deve ser aplicado considerando:

a) Que a exposição médica deve resultar em um benefício real para a saúde do indivíduo e/ou para sociedade, tendo em conta a totalidade dos benefícios potenciais em matéria de diagnóstico ou terapêutica que dela decorram, em comparação com o detrimento que possa ser causado pela radiação do individuo;

b) A eficácia, os benefícios e riscos de técnicas alternativas disponíveis com o mesmo objetivo, mas que envolvam menos ou nenhuma exposição a radiações ionizantes.

\subsubsection{OTIMIZAÇÃO}

Conforme descreve Jabarra (2006), o principio básico da proteção radiológica ocupacional estabelece que todas as exposições devem ser mantidas tão baixo quanto razoavelmente exequíveis. Tal princípio é conhecido como ALARA (As Low As Reasonably Achievable). O princípio ALARA estabelece, portanto, a necessidade do aumento do nível de proteção a um ponto tal que aperfeiçoamentos posteriores produziriam reduções menos significantes do que os esforços necessários.

A ANVISA (1998) determina que a otimização da proteção deve ser aplicada em dois níveis. $\mathrm{O}$ primeiro refere-se aos projetos e construções de equipamentos e instalações. Segundo, nos procedimentos de trabalho. As exposições médicas de pacientes devem ser otimizadas ao valor mínimo necessário para obtenção do objetivo radiológico, compatível com os padrões aceitáveis de qualidade de imagem. Logo, a ANVISA (1998) determina que no processo de otimização de exposições médicas deve-se considerar:

a) A seleção adequada do equipamento e acessórios;

b) Os procedimentos de trabalho;

c) O programa de garantia da qualidade;

d) Os níveis de referência de radiodiagnósticos para pacientes; 
e) As restrições de dose para indivíduo que colabore, conscientemente e de livre vontade, fora do contexto de sua atividade profissional, no apoio e conforto de um paciente, durante a realização do procedimento radiológico.

Conforme afirma Da Silva [et al.] (1993), nas práticas com exposições médicas, pouca atenção tem sido dada à otimização, já que os procedimentos são claramente justificáveis e relacionam-se diretamente ao benefício do indivíduo. Entretanto, existem vários procedimentos de redução das doses em radiologia diagnóstica que podem ser aplicáveis sem provocar perda de informações.

\subsubsection{LIMITE DE DOSE}

Conforme explica Jabarra (2006), o princípio do limite da dose são valores estabelecidos para limitar a dose efetiva ou equivalente em exposições normais de indivíduos ocupacionalmente expostos e indivíduos do público. A limitação da dose "não deve ser considerada como uma fronteira entre o seguro e perigoso" (ANVISA, 1998).

Segundo Da Silva [et al.] (1993), limites de doses são necessários como parte do controle da exposição ocupacional, impondo um limite na escolha da restringências de dose e proporcionando uma proteção contra a ocorrência de erros de julgamento na aplicação da otimização. A dose limitante pode ser expressa como a dose recebida uniformemente no tempo de vida (durante toda a vida de trabalho) ou como a dose anual recebida em todo um ano de trabalho.

Aplicando este princípio do limite de dose, a ANVISA (1998) determina níveis de referência para as atividades com radiodiagnósticos, conforme descritos nos quadros abaixo:

Quadro 1 - Níveis de referência de radiodiagnóstico por radiografia para paciente adulto típico

\begin{tabular}{|l|c|c|}
\hline \multicolumn{2}{|c|}{ EXAME } & $\begin{array}{c}\text { DEP } \\
(\mathbf{m G y})^{*}\end{array}$ \\
\hline \multirow{2}{*}{ Coluna lombar } & AP & 10 \\
& LAT & 30 \\
Abdômen, urografia e & JLS & 40 \\
\hline colecistografia & AP & 10 \\
\hline Pelve & & \\
\hline Bacia & AP & 10 \\
\hline \multirow{2}{*}{ Tórax } & AP & 10 \\
\hline \multirow{2}{*}{ Coluna Torácica } & PA & 0,4 \\
& LAT & 1,5 \\
\hline \multirow{2}{*}{ Odontológico } & AP & 7 \\
& LAT & 20 \\
\hline \multirow{2}{*}{ Crânio } & Periapical & $3,5^{* *}$ \\
& AP & 5 \\
\hline \multirow{2}{*}{ Mama*** } & AP & 5 \\
& LAT & 3 \\
\hline & CC com grade & 10 \\
& CC sem grade & 4 \\
\hline
\end{tabular}

Notas: PA: projeção póstero-anterior; AP: projeção antero-posterior; LAT: projeção lateral; CC: projeção crânio-caudal; JLS: junção lombo-sacro.

$\left({ }^{*}\right)$ DEP, dose de entrada da pele. Estes valores são para receptor de imagem de sensibilidade média, velocidade relativa de
200. Para combinações filme-tela mais rápidas (400-600) estes valores devem ser reduzidos por um fator de 2 a 3 .

$\left.{ }^{(* *}\right)$ para filme do grupo $\mathrm{E}$.

$\left({ }^{\star \star \star}\right)$ determinada em uma mama comprimida de $4,5 \mathrm{~cm}$ para sistema tela-filme e uma unidade com anodo e filtração de molibdênio. 
Quadro 2 - Níveis de referência de radiodiagnóstico em Tomografia para paciente adulto típico

\begin{tabular}{|l|c|}
\hline \multicolumn{1}{|c|}{ Exame } & $\begin{array}{c}\text { Dose média em cortes múltiplos } \\
\text { (mGy)* }\end{array}$ \\
\hline Cabeça & 50 \\
\hline Coluna lombar & 35 \\
\hline Abdômen & 25 \\
\hline
\end{tabular}

${ }^{*}$ ) determinada no eixo de rotação em fantoma de água, comprimento de $15 \mathrm{~cm}$ e diâmetro de $16 \mathrm{~cm}$ para cabeça e $30 \mathrm{~cm}$ para coluna e abdômen.

\subsection{FATORES DE PROTEÇÃO RADIOLÓGICA}

As radiações ionizantes externas podem ser controladas considerando três fatores: tempo, distância e blindagem.

\subsubsection{TEMPO}

A CNEN (2006) afirma que quanto menor o tempo de exposição à radiação ionizante menor será a dose absorvida, considerando que a dose absorvida de uma pessoa é diretamente proporcional ao tempo em que ficou exposta a uma determinada taxa de dose de radiação ionizante.

Segundo descreve Tauhata [et al.] (2003), qualquer atividade que utilize a radiação ionizante deve ser cuidadosamente programada para que esta seja realizada no menor tempo possível. Porém, o recurso mais eficaz de redução do tempo de execução de uma tarefa é o treinamento do operador, ou seja, a otimização de sua habilidade.

\subsubsection{DISTÂNCIA}

Conforme apresenta Tauhata [et al.] (2003), dobrando-se a distância entre a fonte geradora e o detector reduz-se a taxa de dose a $1 / 4$ de seu valor inicial. Dessa forma, o modo mais fácil de se defender contra as radiações ionizantes é distanciando-se da fonte geradora.

Figura 4 - Fator de redução de dose pela distância

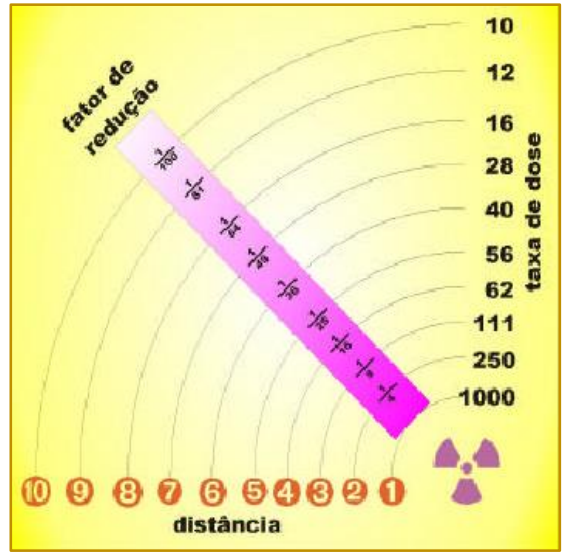

Fonte: IPEN (2002)

\subsubsection{BLINDAGEM}

CNEN (2006) define blindagem como todo sistema destinado a atenuar um campo de radiação por interposição de um meio material entre a fonte de radiação e as pessoas ou objetos a proteger. Logo, a blindagem é considerada o método mais importante de proteção contra a radiação ionizante.
Conforme afirma Elbern (2002) o método mais prático para a estimativa da espessura de blindagem para a radiação $X$ é a utilização do conceito da camada semi-redutora (CSR). A camada semi-redutora de um material utilizado para blindagem é a espessura necessária para reduzir a intensidade de radiação à metade. Elbern (2002) descreve 
ainda que é possível determinar a espessura de um material, que irá compor a blindagem, através da lei de atenuação exponencial expressa por:

$$
I=I_{0} \cdot e^{\mu \cdot x} \text { ou } I=I_{0} \cdot e^{\frac{0,693}{C S R} \cdot x}
$$

Onde,

I0 é a Intensidade inicial da radiação;

I é a intensidade atenuada da radiação;

$\mu$ é o coeficiente de atenuação total do material para energia de radiação;

x é a espessura da blindagem;

CSR é a camada semi-redutora do material.

Figura 5 - Curva de Atenuação

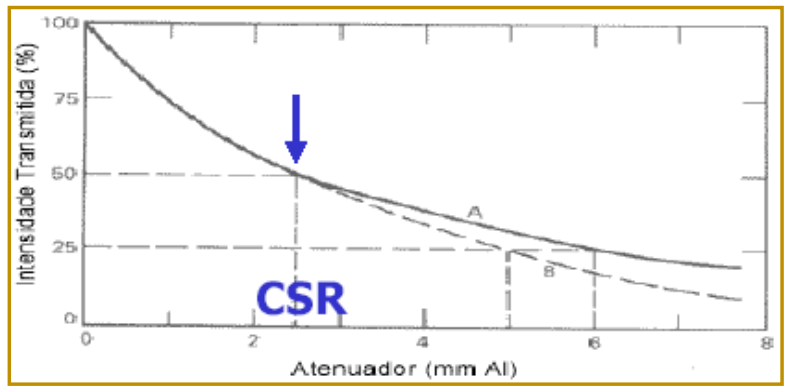

Fonte: Elbern (2002)

No quadro abaixo, Tauhata [et al.] (2003) apresenta os valores da camada semiredutora (CSR) para o chumbo, o concreto e o ferro em função da quilovoltagem pico do tubo de raios $X$.

Quadro 3 - Valores da camada semi-redutora (CSR) para o chumbo, o concreto e o ferro

\begin{tabular}{|l|l|l|l|}
\hline \multirow{2}{*}{$\begin{array}{c}\text { Quilovoltagem } \\
\text { Pico }\end{array}$} & \multicolumn{3}{|c|}{ CSR do Material Atenuador } \\
\cline { 2 - 4 } & Chumbo (cm) & Concreto (cm) & Ferro (cm) \\
\hline 50 & 0,006 & 0,43 & - \\
\hline 70 & 0,017 & 0,84 & - \\
\hline 100 & 0,027 & 1,6 & - \\
\hline 125 & 0,028 & 2 & - \\
\hline 150 & 0,03 & 2,24 & - \\
\hline 200 & 0,052 & 2,5 & - \\
\hline 250 & 0,088 & 2,8 & - \\
\hline 300 & 0,147 & 3,1 & - \\
\hline 400 & 0,25 & 3,3 & - \\
\hline 500 & 0,36 & 3,6 & - \\
\hline 1.000 & 0,79 & 4,4 & - \\
\hline 2.000 & 1,25 & 6,4 & - \\
\hline 3.000 & 1,45 & 7,4 & - \\
\hline 4.000 & 1,6 & 8,8 & 2,7 \\
\hline 6.000 & 1,69 & 10,4 & 3 \\
\hline 8.000 & 1,69 & 11,4 & 3,1 \\
\hline 10.000 & 1.66 & 11.9 & 3.2 \\
\hline & Fonte: Tauhata [et al.] (2003) & \\
\hline
\end{tabular}




\subsection{DOSIMETRIA}

Para prevenir os efeitos biológicos da radiação, seguindo os princípios do limite de dose, é necessário monitorar a dose equivalente que os trabalhadores são expostos durante suas atividades com radiação ionizante.

Segundo IPEN (2002), a dosimetria é a avaliação de dose de radiação recebida pelo corpo humano e os dosímetros são instrumentos utilizados para medir a dose equivalente de uma exposição do corpo inteiro, órgãos ou tecido humano à radiação ionizante.
Jabarra (2006) afirma que atualmente os dosímetros utilizam o princípio da excitação. Os materiais utilizados nos dosímetros são selecionados de forma que os elétrons excitados, devido a exposição à radiação ionizante, fiquem estáveis a temperatura normal. Jabarra (2006) descreve que para medir a dose recebida o material do dosímetro é aquecido à uma temperatura conveniente, usualmente $200{ }^{\circ} \mathrm{C}$, e os elétrons capturados são liberados e retornam a banda de valência com a emissão de um fóton de luz. Portanto, quando o material do dosímetro é aquecido no escuro, a luz por ele emitida pode ser medida e esta será proporcional a dose recebida.

Figura 6 - Dosímetro

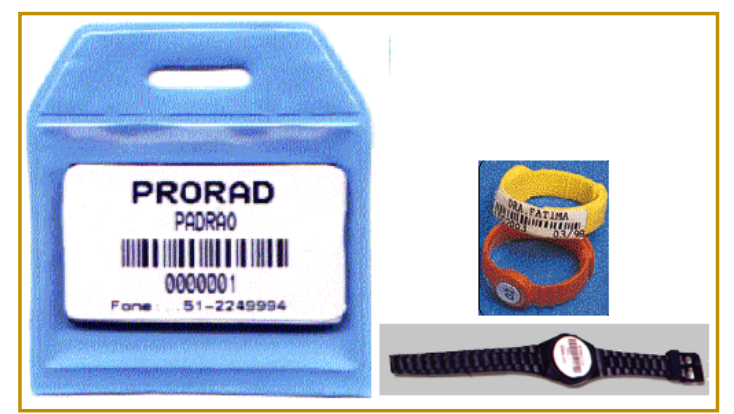

Fonte: <www.prorad.com.br>, acesso em 16/12/2007

\subsection{EQUIPAMENTOS DE PROTEÇÃO INDIVIDUAL}

Segundo Gomes (2002), os serviços de radiodiagnósticos médicos devem possuir equipamentos de proteção individual (EPIs) de acordo com o tipo de exame a ser realizado para equipe técnica, pacientes e acompanhantes. Os equipamentos de proteção individual devem ser disponibilizados em quantidade suficiente para a realização de exames simultâneos, em todas as salas de radiodiagnóstico do serviço de radiologia.

Abaixo estão relacionados os principais equipamentos de proteção individual, que devem estar presentes nos locais serviços de radiodiagnósticos médicos, indicados por Gomes (2002): Avental plumbífero, Protetor de tireóide, Protetor de gônadas, Óculos plumbíferos e Luvas plumbíferas

\section{ESTUDO DA RADIOPROTEÇÃO EM AMBIENTE HOSPITALAR}

\subsection{A INSTITUIÇÃO}

A unidade hospitalar em estudo foi inaugurada em março de 2005, construída com o compromisso de prestação de serviços à população oferece atendimentos de assistência médica emergencial e radiodiagnósticos. A instituição é definida como uma unidade hospitalar privada de grande porte, com capacidade para atendimento de 6.000 pacientes/mês, encontra-se funcionando atualmente com 149 leitos do total de 152. Além disso, oferece serviços para todo o município do Rio de Janeiro, atendendo a clientes particulares e conveniados. Com o total de 496 funcionários, sendo que 30 funcionários estão envolvidos com o setor de radiologia.

\subsection{O SETOR DE RADIOLOGIA}

O setor de radiologia da unidade hospitalar em estudo fica localizado no térreo de um prédio de 11 andares e tem uma área 
aproximada de $335 \mathrm{~m}^{2}$.

O principal objetivo do radiodiagnóstico é a obtenção de ótima qualidade radiográfica com a menor exposição do paciente. Logo, para alcançar tal objetivo, deve-se ajustar alguns parâmetros, entre os quais a quilovoltagem, a miliamperagem, o tempo de exposição, filtração total, distância foco-filme, colimação, grades, combinação filme-ecran e os parâmetros de processamento do filme. Como os mesmos contribuem essencialmente para a qualidade da imagem, a alteração de um deles levará consequentemente a alteração da imagem. Na prática, para a manutenção de um padrão radiográfico, a modificação de um parâmetro implicará em novo ajuste de outros. Entretanto, o uso dessas radiações deve ser controlado devido à possibilidade de ocorrer efeitos biológicos ao interagir com as células humanas.

O setor de radiologia da unidade hospitalar estudada atende a pacientes do setor de emergência, do centro cirúrgico e da enfermaria. São realizados exames de raios $X$ e tomografia computadorizada para diagnóstico de doenças com tumores benignos ou malignos, distúrbios de funções e disfunções orgânicas, displasias ósseas, doenças metabólicas e endócrinas dos ossos, afecções diversas - osso e articulação, estômago, intestino delgado, cólon, vias urinárias, afecções pulmonares diversas.

O setor de radiologia está diretamente ligado ao Diretor Médico, como mostra o organograma abaixo:

Figura 7 - Organograma adaptado

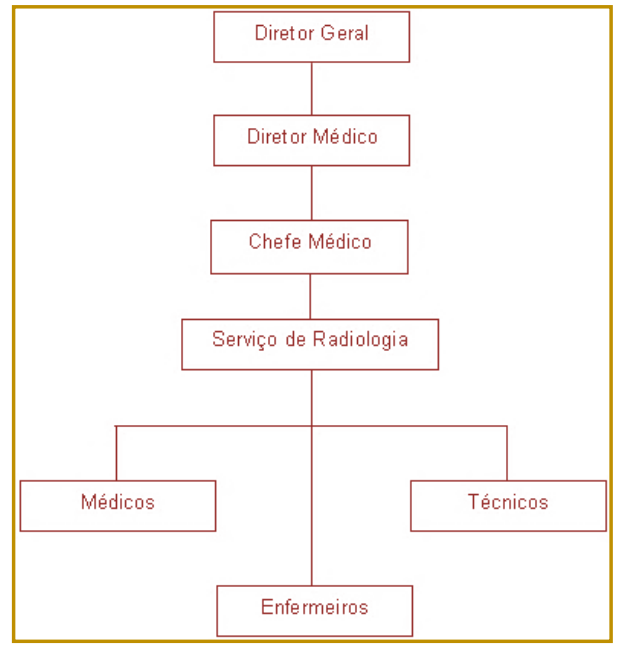

O funcionamento do setor de Radiologia conta com equipe de profissionais que trabalham no sistema de escala, ou seja, plantão de 24 horas de trabalho por 72 horas de descanso, para atendimento aos pacientes. A equipe do setor de radiologia é formada por:

Quadro 4 - Profissionais do Setor de Radiologia

\begin{tabular}{|c|c|}
\hline Profissionais & Quantidade \\
\hline Médicos & 10 \\
\hline Técnicos em Radiologia & 24 \\
\hline Enfermeiros & 2 \\
\hline Técnico em Enfermagem & 4 \\
\hline
\end{tabular}

\subsection{RESULTADOS DAS OBSERVAÇÕES}

Foi realizada, no período de julho a agosto de 2007, no setor de radiologia da unidade hospitalar estudada, "observações não participativas" (RICHARDSON, 1999) seguindo roteiros previamente elaborados com o objetivo de avaliar o cumprimento das legislações e das recomendações existentes sobre proteção radiológica. 


\subsubsection{ANÁLISE DAS SALAS}

Com base nos relatórios emitidos pelo Laboratório de Ciências Radiológicas da Universidade Estadual do Rio de Janeiro, foi desenvolvida uma lista de verificação (check list) para a observação de não conformidades quanto à estrutura física das salas de raios $\mathrm{X}$, tomografia, câmara escura e sala de laudos. Como resultado, não foram identificadas não conformidades nestes locais, no período observado, de acordo com a lista de verificação (check list) aplicada.

\subsubsection{DOSIMETRIA}

O dosímetro de controle fica em um quadro localizado na sala de laudos, onde não há radiação. Quando os funcionários da radiologia terminam os seus trabalhos, guardam os respectivos dosímetros junto ao dosímetro de controle. O dosímetro de controle é a referência de leitura mensal da exposição em cada dosímetro.

A maioria dos funcionários apresentava o uso correto do dosímetro, que é preso no bolso do jaleco. Observou-se que alguns funcionários não estavam utilizando $\mathrm{o}$ dosímetro ou estavam utilizando incorretamente, fixando-o atrás do crachá de identificação. Para os funcionários que não utilizaram o dosímetro corretamente, provavelmente, a dose medida ao final de cada mês não representava fielmente a dose recebida.

A partir deste estudo, sugeriríamos que os funcionários recebam um novo treinamento, com o objetivo de conscientizar o uso do dosímetro e posicioná-lo corretamente.

\subsubsection{EQUIPAMENTO DE PROTEÇÃO INDIVIDUAL}

Observa-se a adequada utilização dos equipamentos de proteção individual para funcionários, pacientes e acompanhantes durante as visitas realizadas no setor em estudo.

\subsubsection{PROTEÇÃO COLETIVA}

No setor de radiologia, observa-se a preocupação com a proteção coletiva dos técnicos em radiologia durante a execução dos radiodiagnósticos.

\subsubsection{PROTOCOLO DE TÉCNICAS RADIOGRÁFICAS}

Conforme exige ANVISA (1998) junto ao painel de cada equipamento deve existir um protocolo de técnicas radiográficas (tabela de exposição), especificando para cada exame realizado as seguintes informações: tipo de exame, tamanho e tipo da combinação telafilme a serem utilizados, distancia foco-filme a serem utilizados. Constatou-se que apenas alguns equipamentos possuíam a tabela com valores médios, contendo os valores de $\mathrm{kV}$ e mA para aplicação em um determinado exame.

\subsubsection{PROCEDIMENTOS OPERACIONAIS}

Embora tenham sido observadas algumas anotações isoladas, verificou-se que estas não constituem um procedimento estruturado. Neste sentido, o setor de radiologia deve transcrever estas anotações para que sejam feitos os procedimentos padrões e que os mesmos estejam disponíveis para a consulta.

No que diz respeito sobre posicionamento do feixe de raios $X$ no paciente, os funcionários informaram ter conhecimento do procedimento, porém, não existe um documento escrito e aprovado na unidade hospitalar estudada.

\subsubsection{TREINAMENTOS}

Observou-se que a unidade hospitalar analisada não cumpre integralmente 0 item 3.38 da Portaria ANVISA $n^{\circ}$ 453/98, que determina que os titulares (Diretores) devem implementar um programa de treinamento anual, integrante do programa de proteção radiológica.

\section{CONSIDERAÇÕES FINAIS}

Em uma instituição hospitalar podemos encontrar diferentes tipos de riscos. Porém, no setor de radiologia, o mais preocupante é o risco das radiações ionizantes. Como salientamos ao longo deste artigo, por serem de difícil mensuração e avaliação, as radiações ionizantes podem afetar 0 trabalhador após vários anos da exposição, acarretando danos genéticos e hereditários. Nesse sentido, este estudo levantou e analisou as referências bibliográficas e os requisitos legais de proteção radiológica em radiodiagnóstico médico. Buscando contribuir 
com dados e análises sobre medidas preventivas e protetivas nos trabalhos com radiação ionizante, visando minimizar suas exposições e consequentemente seus efeitos biológicos.

Tal preocupação se estende também aos acompanhantes e pacientes, que normalmente são expostos a radiação ionizante por um tempo muito curto, comparado aos trabalhadores do setor de radiologia. Nesse caso, não é possível medir ou conhecer a taxa de dose equivalente que são submetidos, estando estes indivíduos amparados pelo princípio da justificação (ver item 2.3.1)

A Norma Regulamentadora ํㅡㄴ 15, classifica as radiações ionizantes como um risco físico. Porém, afirma Tauhata [et al.] (2003) que os efeitos da radiação ionizante possuem características físicas, químicas e/ou biológicas para todos os indivíduos expostos. Logo, ao pesquisarmos os requisitos legais e normas aplicáveis ao segmento de radiodiagnóstico médico, verificamos que a preocupação com a sua utilização no Brasil teve início na Comissão de Energia Nuclear (CNEN) através de suas normas sobre proteção radiológica. Porém, a proteção radiológica adquiriu maior aderência na área hospitalar a partir da Portaria Federal no 453,

\section{REFERÊNCIAS}

[1] Anvisa - Agência Nacional de Vigilância Sanitária, Portaria do ㄲo 453, Diretrizes de proteção radiológica em radiodiagnóstico médico e odontológico, de 1 de junho de 1998. Publicada em Diário Oficial da União em 02/06/1998.

[2] Azevedo, A. Radioproteção em serviços de saúde. FIOCRUZ - Rio de Janeiro, 2005. Disponível em: http://www.fiocruz.br/biossegurancahospitalar/dado s/material10.pdf Acesso em: 26/05/2006

[3] Cnen - Comissão Nacional de Energia Nuclear, CNEN-NN-3.01, Diretrizes básicas de proteção radiológica. Portaria CNEN/PR 007 de 17/01/2006 (Alterações). Publicada em Diário Oficial da União em 18/01/2006.

[4] Da Silva, Teógenes et. al. Sinopse das recomendações de 1990 da "International Commission on Radiological Protection" (publicação ICRP 60). COPPE, UFRJ, Rio de Janeiro, 1993

[5] Elbern, Alwin. Formação da imagem radiográfica, Colégio Brasileiro de Radiologia, 2002.

Disponível de 1o junho de 1998, da ANVISA, que regula sobre as diretrizes de proteção radiológica em radiodiagnóstico médico e odontológico. O Ministério do Trabalho e Emprego aprovou, no ano de 2005, a Norma Regulamentadora no 32 que estabelece as diretrizes básicas para a segurança e saúde no trabalho em serviços de saúde, que no item 32.4 estabelece também algumas exigências com relação às radiações ionizantes na área da saúde.

Todas as observações e análises deste estudo foram entregues a unidade hospitalar, com a sugestão de que implementem as ações necessárias para as correções das não conformidades.

Assim, concluímos que é necessária uma total participação dos funcionários e diretores das unidades hospitalares onde são realizados os radiodiagnósticos médicos. Defendemos a importância da implantação de uma política de segurança dos funcionários ocupacionalmente expostos às radiações ionizantes. Deste modo, a preocupação com a segurança e a saúde dos trabalhadores devem fazer parte da cultura das unidades hospitalares com o objetivo de que todas as atividades com radiações ionizantes sejam planejadas e executadas de forma eficaz baseadas nos princípios e nos fatores de proteção radiológica.

$<$ http://www.cefetsc.edu.br/ radiologia/downloads. html> Acesso em: 19 de Julho de 2007.

[6] Ferreira, Aurélio. Novo dicionário eletrônico Aurélio versão 5.0. Positivo Informática, 2004.

[7] Fernandes, Geraldo Sérgio et. al. Avaliação dos riscos ocupacionais de trabalhadores de serviço de radiologia, São Paulo, v. 38, n. 4, 2005. Disponível em: $<$ http://www.scielo.br

/scielo. .php?script=sci_arttext\&pid=S010039842005000400009\&lng=en\&nrm=iso $>$. Acesso em: 19 de Julho de 2007.

[8] Gomes, Robson Spinelli. Condições do meio ambiente de trabalho e riscos da exposição aos raios $x$ no serviço de radiodiagnóstico de um hospital público. Fundacentro, 2002.

[9] Icrp - International Commission on Radiological Protection. Recommendations of the International Commission on Radiological Protection, ICRP Publication 60, Pergamon Press, New York, 2002.

[10] IPEN - Instituto de Pesquisas Energéticas e Nucleares. Noções básicas de proteção radiológica. Coord. Sandra A. Bellintani e Fátima das Neves Gili. IPEN, São Paulo, 2002. 
[11] Jabarra, Cleber. Apostila do Curso de Supervisor de Radioproteção, Jabarra Radioproteção - Rio de Janeiro, 2006.

[12] Mte - Ministério do Trabalho e Emprego. Norma Regulamentadora no 32, Segurança e saúde em estabelecimento de saúde. Aprovada pela Portaria 483/2005 de 11 de novembro e publicada em 16/11/2005 seção 1 páginas 80-94. Diário Oficial da União, Brasília, 2005.

[13] Pereira, Leslie. Caracterização e implantação de feixes de radiação para estudo de dispositivos de proteção individual com equivalência em chumbo utilizados em práticas de radiodiagnóstico. Dissertação (Mestrado) - Instituto de Radioproteção e Dosimetria - Rio de Janeiro, 2004.

[14] Richardson, Roberto Jarry. Pesquisa Social: métodos e técnicas. 3a edição. Editora Atlas. São Paulo, 1999

[15] Tauhata, L. et. al. Radioproteção e dosimetria: fundamentos. IRD/CNEN, 5a revisão, Rio de Janeiro, 2003. 


\section{CAPÍTULO 18}

\section{ESTUDO DE CASO: IDENTIFICACÃO E AVALIACÃO DOS RISCOS OCUPACIONAIS EM UMA MARMORARIA NA CIDADE DE MARABÁ - PA}

\section{Andressa dos Santos Araújo}

\section{Eduardo Zimmer Zen}

\section{Giovanna Brito de Araújo}

\section{Maria Luiza Oliveira Ferreira}

Resumo: O presente estudo tem como objetivo identificar, e em seguida avaliar os possíveis riscos ocupacionais existentes em uma marmoraria na cidade de Marabá/PA, nas quais os trabalhadores que atuam nesse ramo são diariamente expostos a inúmeros riscos à saúde durante a jornada de trabalho, tais como a elevada exposição à poeira que contém a sílica, umidade elevada e manuseio inapropriado dos equipamentos utilizados no processo produtivo. Nesse sentido, desenvolveu-se um estudo de caso através de uma visita in loco e entrevista com o gestor e colaboradores da empresa, no intuito de favorecer a identificação dos agentes causadores dos riscos presentes no local. Após a identificação, são expostas as respectivas causas e efeitos, estes são agrupados de acordo com a classificação dos riscos ambientais observada na revisão bibliográfica. Em seguida são apresentadas as medidas preventivas concernentes a cada tipo de agente causador de forma individual e detalhada. O estudo torna evidente o fato de que a segurança e bem estar do trabalhador influenciam diretamente na produtividade da empresa, e daí surge a importância de seguir as recomendações apresentadas neste artigo.

Palavras-chave: Marmoraria; Riscos ocupacionais; Doenças ocupacionais, Medidas preventivas. 


\section{INTRODUÇÃO}

Para obter-se o êxito empresarial, as organizações dos diversos ramos dedicamse, e almejam o maior padrão de qualidade possível que sua produção possa ter. Nesse contexto, o ramo marmoreiro possui uma larga área de atuação; sendo o Brasil um grande exportador de mármore, com várias jazidas sendo exploradas em todo o território nacional, as empresas que trabalham nesse setor podem atender as demandas de clientes, nos mercados interno e externo, que buscam acrescentar um toque de refinamento em suas obras (SILVA \& ANDRADE, 2014).

Entretanto, essa concorrência, proposta pelo capitalismo e fortemente apoiada pela Revolução Industrial, não apresenta preocupações de cunho humano - social fator que na maioria das vezes proporciona ao funcionário, condições precárias de trabalho.

Neste intuito, o ramo marmoreiro, devido a sua cadeia de produção composta pela mineração ou lavra de pedras ornamentais, pelo processamento e pela distribuição dessas pedras, favorece a existência de vários riscos para a saúde dos trabalhadores desse ramo. A elevada exposição à poeiras está entre os principais e mais perigosos riscos do trabalho em marmorarias, provocando e favorecendo o aparecimento de doenças do sistema respiratório, principalmente a silicose (SANTOS, et al., 2007)

Apesar de a silicose ter papel de destaque como um grave problema nesse setor e este ser amplamente estudado, sabe-se que o ramo marmoreiro é um setor que apresenta grande precariedade de instalações, além de sobrecarga de trabalho, por se tratarem de tarefas extremamente manuais e artesanais, que exigem grande habilidade, destreza e elevado esforço físico por parte dos funcionários para a fabricação dos produtos (SILVA, 2011).

Em vista dos riscos apresentados, entende-se por riscos ambientais os elementos ou substâncias presentes em diversos ambientes, que acima dos limites de tolerância podem ocasionar danos à saúde das pessoas (BRESSI, 2016).

Tais riscos podem ser classificados conforme sua natureza e a forma com que atuam no organismo humano. A partir da compreensão dos riscos ambientais, nas quais os trabalhadores estão expostos, o presente trabalho por meio de um estudo de caso, com observação in loco, vem analisar o processo produtivo e identificar os riscos presentes. Assim como, avaliar a necessidade de medidas de proteção, por uso de Equipamentos de Proteção Individual (EPI's) e Equipamentos de Proteção Coletiva (EPC's).

Em vista disso, o artigo tem por objetivo apresentar recomendações técnicas, visando a prevenção e o controle dos principais riscos à saúde dos trabalhadores de marmoraria. A estrutura do trabalho é composta por uma prévia introdução sobre o assunto, referencial teórico, metodologia, estudo de caso, sendo este dividido em duas partes: caracterização da empresa, e identificação e avaliação de riscos, na sequência são apresentadas as medidas preventivas para os riscos identificados, seguido por conclusão e referências.

\section{REFERENCIAL TEÓRICO \\ 2.1 MARMORARIA}

A marmoraria produz peças de várias formas, de rara beleza e de grande importância econômica que são aplicáveis na construção civil. São utilizadas na produção rochas como granitos, ardósias, mármores e também produtos fabricados como o Silestone e o Limestone. Os processos e procedimentos utilizados em marmorarias envolvem transporte de chapas, polimento, corte e acabamento. Para o desenvolvimento destas atividades existem riscos para os trabalhadores devidos à geração de poeira, ruído, vibração, além de riscos de acidentes e problemas ergonômicos (SILVA et al., 2007).

\subsection{RISCOS OCUPACIONAIS E GRAU DE RISCO}

Os riscos ocupacionais são os perigos que incidem sobre a saúde humana e o bem-estar dos trabalhadores associados a determinadas profissões. Embora sejam feitos esforços para reduzir os riscos de acidentes no trabalho, esses riscos continuam presentes em indústrias, empresas em geral, estabelecimentos comerciais e demais ambientes profissionais. Reconhecer os riscos ocupacionais é o primeiro passo para elaborar e implementar em programas de segurança do trabalho e redução de riscos com o intuito de manter a qualidade de vida dos trabalhadores, especialmente os que 
atuam em locais insalubres, como na indústria de mineração ou no setor elétrico (BRANCO, 2011). De acordo com a Redação Tuiuti (2016), "a possibilidade da saúde ou integridade física de um funcionário sofrer algum prejuízo durante a execução de suas atividades profissionais é chamada de risco ocupacional. A maioria desses riscos está associada a ambientes em que o trabalhador fica exposto a ruídos, vibrações, gases, iluminação inadequada ou outras situações que podem colocar a saúde em risco".

Para avaliar se determinado ambiente de trabalhado oferece riscos, a Classificação Nacional de Atividades Econômicas (CNAE) descreve a classificação de grau de risco de um local. Esta pode variar entre 1 e 4 , de acordo com a intensidade do risco. O grau de risco de acidente de trabalho é atestado também pela NR-4, sendo que toda empresa que trabalha em atividades perigosas deve apresentar a NR-4 em sua CNAE (REDAÇÃO TUIUTI, 2016).

\subsection{CLASSIFICAÇÃO DOS OCUPACIONAIS E SEUS AGENTES}

RISCOS

Os riscos no ambiente laboral podem ser classificados em cinco tipos, de acordo com a Portaria ํㅡ 3.214, do Ministério do Trabalho do Brasil, de 1978. Esta Portaria contém uma série de normas regulamentadoras que consolidam a legislação trabalhista, relativas à segurança e medicina do trabalho. Encontramos a classificação dos riscos na sua Norma Regulamentadora ํㅡ 5 (NR-5):

- Riscos físicos: consideram-se agentes de risco físico as diversas formas de energia a que possam estar expostos os trabalhadores, tais como: ruído, calor, frio, pressão, umidade, radiações ionizantes e não ionizantes, vibração, etc.;

- Riscos ergonômicos: qualquer fator que possa interferir nas características psicofisiológicas do trabalhador, causando desconforto ou afetando sua saúde. São exemplos de risco ergonômico: o levantamento de peso, ritmo excessivo de trabalho, monotonia, repetitividade, postura inadequada de trabalho, etc.;

Riscos químicos: consideram-se agentes de risco químico as substâncias, compostos ou produtos que possam penetrar no organismo do trabalhador pela via respiratória, nas formas de poeiras, fumos gases, neblinas, névoas ou vapores, ou que seja, pela natureza da atividade, de exposição, possam ter contato ou ser absorvido pelo organismo através da pele ou por ingestão;

Riscos de acidentes: qualquer fator que coloque o trabalhador em situação vulnerável e possa afetar sua integridade, e seu bem estar físico e psíquico. São exemplos de risco de acidente: as máquinas e equipamentos sem proteção, probabilidade de incêndio e explosão, arranjo físico inadequado, armazenamento inadequado, etc.;

Riscos biológicos: consideram-se como agentes de risco biológico as bactérias, vírus, fungos, parasitos, entre outros.

\subsection{DOENÇAS OCUPACIONAIS}

Doenças ocupacionais são aquelas produzidas pelo exercício do trabalho, pela contaminação acidental e/ou pela exposição ou contato direto provenientes do trabalho. Estas doenças são desenvolvidas lentamente e em muitos casos quando aparecem já estão em um estágio evoluído. Por esta demora dos sintomas, torna-se mais difícil relacionar a doença aos riscos do ambiente do trabalho e em alguns casos pode levar mais de 15 anos (GONÇALVES FILHO, 2012).

Para Silva et al. (2007) nas atividades operacionais realizadas em marmorarias, os trabalhadores estão expostos a agentes ambientais como poeira contendo sílica, que podem causar doenças como silicose e câncer; e ruído, que pode ocasionar a perda auditiva induzida pelo ruído (PAIR), além de riscos de acidentes e ergonômicos.

\subsection{MEDIDAS PREVENTIVAS}

Coltre (2011) diz que "a Segurança no Trabalho é uma ferramenta indispensável para o desenvolvimento das atividades na construção civil de forma a obter eficiência e eficácia no processo de trabalho e para a qualidade de vida do trabalhador". A responsabilidade pela vida e saúde do trabalhador e da população recai sobre o Estado e as organizações, cabendo aos trabalhadores colaborar para o sucesso da implementação das ações estabelecidas (ARAUJO, 2004, p.20).

De acordo com Neto (2013), evitar acidentes de trabalho requer disciplina de 
administradores e funcionários. Grosso modo, temos como sugestão algumas medidas simples que poderão ser eficiente no combate ao acidente. São diversas as formas de medidas de prevenção, dentre elas:

- Conscientização: a segurança do trabalho só flui na empresa através de conscientização. É necessário que a empresa adote uma linguagem clara no tocante a aos riscos e as medidas que deverão ser adotadas;

- Divulgação dos riscos: a empresa precisa divulgar de forma clara os riscos a que estão expostos os funcionários da empresa;

- Divulgação das medidas preventivas: antes de fornecer o EPI o funcionário deve ser orientado. Muitas empresas entregam o EPI e obrigam o uso sem nem ao menos se dar ao trabalho de mostrar para que serve, e como usar;

- Fornecimento de EPC's (Equipamentos de Proteção Coletiva): deve ser a primeira opção a ser analisada para atenuação ou eliminação dos riscos no ambiente de trabalho;

- Fornecimento de EPl's (Equipamentos de Proteção Individual): são muito usados e conhecidos na maioria das empresas. São uma medida fornece proteção por um preço bem em conta. Diálogos individuais e palestras podem ajudar muito na conscientização dos funcionários mais resistentes ao uso.

Neto (2013) também apresenta algumas ferramentas de prevenção, como:

- DDS (Diálogo Diário de Segurança): é uma ótima ferramenta de conscientização dos funcionários. São palestras curtas, que normalmente não chegam a 15 minutos. Habitualmente ministradas no próprio ambiente de trabalho. Com temas focados nos riscos presentes no ambiente, e nas medidas preventivas adotadas pela empresa;

- Organização do ambiente: sabemos que um ambiente desorganizado é um convite ao acidente. Então, devemos também estar de olho na organização e até na limpeza do ambiente.

\section{METODOLOGIA}

Segundo Strauss \& Corbin (1998), o método de pesquisa é um conjunto de procedimentos e técnicas utilizados para se coletar e analisar os dados. A partir deste conceito, e para atender os objetivos propostos no trabalho, realizou-se a pesquisa em uma marmoraria situada na cidade de Marabá, no estado do Pará. A fim de coletar dados para o estudo, realizou-se uma visita in loco, na qual iniciouse com uma entrevista com o gestor da empresa, e posteriormente, fez-se uma observação sistemática para identificação e avaliação dos riscos existentes no local.

A pesquisa caracteriza-se como qualitativa, que segundo Silva \& Menezes (2001, p. 20), "a interpretação dos fenômenos e a atribuição de significados são básicas no processo de pesquisa qualitativa. Não requer o uso de métodos e técnicas estatísticas. O ambiente natural é a fonte direta para coleta de dados e o pesquisador é o instrumento-chave"; e o estudo configura-se como exploratório/descritivo.

Diante das informações obtidas na pesquisa de campo, realizou-se a identificação dos riscos, e em seguida, os mesmos passaram por avaliação. Posteriormente, apresentou-se estes riscos de forma classificatória no arranjo físico da empresa, e por fim, propôs-se as medidas preventivas para cada risco.

\section{ESTUDO DE CASO}

\subsection{ATIVIDADE DESENVOLVIDA PELA EMPRESA}

A marmoraria pesquisada atua no município de Marabá, no Estado do Pará, desde 2011. Caracteriza-se como sendo um estabelecimento de pequeno porte, contendo apenas 5 funcionários e os mesmos trabalham 48 horas semanais. Trata-se de um estabelecimento onde se prepara e vende peças extraídas da natureza, como mármore e granitos, além de peças utilizando materiais sintéticos. Sua produção abrange a confecção de soleiras, bancadas para banheiro e cozinha, peitoril e tampos de mesas. 
Figura 01: Tipos de mármore e granitos

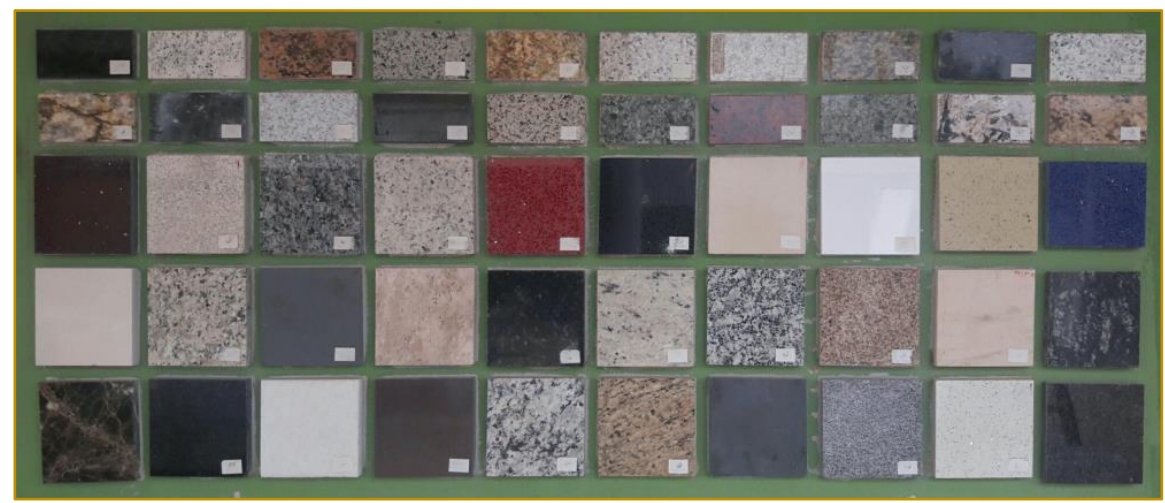

Fonte: Pesquisa de campo (2016). Organização: Os autores

Devido à pequena quantidade de funcionários a empresa não é obrigada a constituir SESMTServiços Especializados em Engenharia de Segurança e em Medicina do Trabalho e a CIPA - Comissão Interna de Perversão de Acidentes. De acordo com a NR-4 - Serviço Especializado em Segurança e Medicina do Trabalho, sua atividade se enquadra no Código 23.91-5 - Aparelhamento e outros trabalhos em pedras, e apresenta nível 3 de grau de risco.

\subsection{PROCESSO PRODUTIVO DA EMPRESA}

O processo de produção da marmoraria é a combinação de recursos naturais (matériaprima) com mão-de-obra, tecnologia, equipamentos e insumos utilizados com métodos eficazes de trabalho, resultando em produtos com alto valor agregado. A empresa se caracteriza por ter uma produção do tipo puxada (o processo produtivo inicia-se somente após o pedido do consumidor). A marmoraria tem como objetivo o tratamento final da rocha, adequando as placas às especificações de dimensões e acabamento superficial que o produto final deve possuir, de acordo com o pedido do cliente.

Os processos utilizados pela marmoraria iniciam-se no recebimento das chapas de mármore e granito. Em seguida, de acordo com as especificações solicitadas pelos clientes, são feitos os cortes das peças. Posteriormente, ocorre o acabamento, que envolve os subprocessos de lixamento, polimento e lustração de bordas e superfícies, e por fim, a montagem e acabamento final da peça. A dinâmica do processo da produção encontra-se representado no Fluxograma 01.

Fluxograma 01: Processo de produção da marmoraria

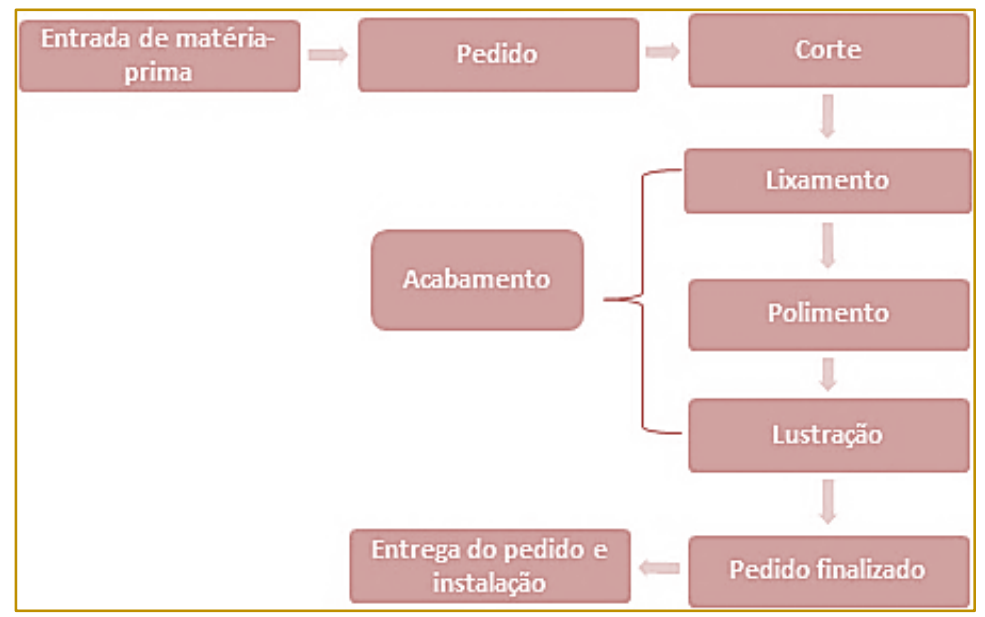

Fonte: Pesquisa de campo (2016). Organização: Os autores 
5. IDENTIFICAÇÃO E AVALIAÇÃO DE RISCOS

\subsection{APRESENTAÇÃO DOS RISCOS EXISTENTES E SUAS FONTES GERADORAS}

Segundo Batalha (2012), "a identificação de perigos e avaliação de riscos é essencial para garantir a segurança das empresas e de todos os seus colaboradores". Partindo deste conceito, e através da visita in loco, foi possível identificar os riscos, os agentes causadores e seus respectivos efeitos:

\subsubsection{RISCOS FísICOS}

a) Agente: Vibrações na serra-mármore;

Efeitos: Pode ocasionar problemas de ordem vascular, neurológica, ósteoarticular, muscular, entre outros.

Figura 02: Colaborador manuseando a serra-mármore

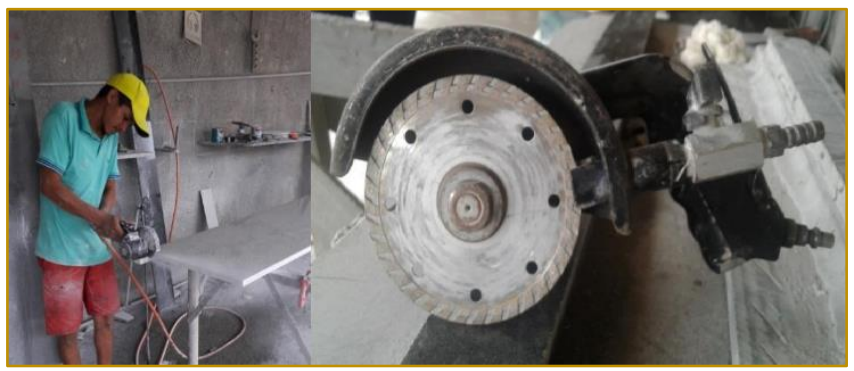

Fonte: Pesquisa de campo (2016). Organização: Os autores

b) Agente: Exposição ao ruído;

Efeitos: Zumbido no ouvido, alterações digestivas e cardíacas, úlcera estomacal, distúrbio do sono, fadiga, dor de cabeça, redução na concentração, e Perda Auditiva Induzida pelo Ruído (PAIR), que é de caráter irreversível. c) Agente: Exposição à umidade.

Efeitos: Doenças respiratórias, como pneumonia e resfriados, doenças circulatórias, reumáticas, quedas e doenças de pele.

Figura 03: Umidade excessiva no ambiente de trabalho

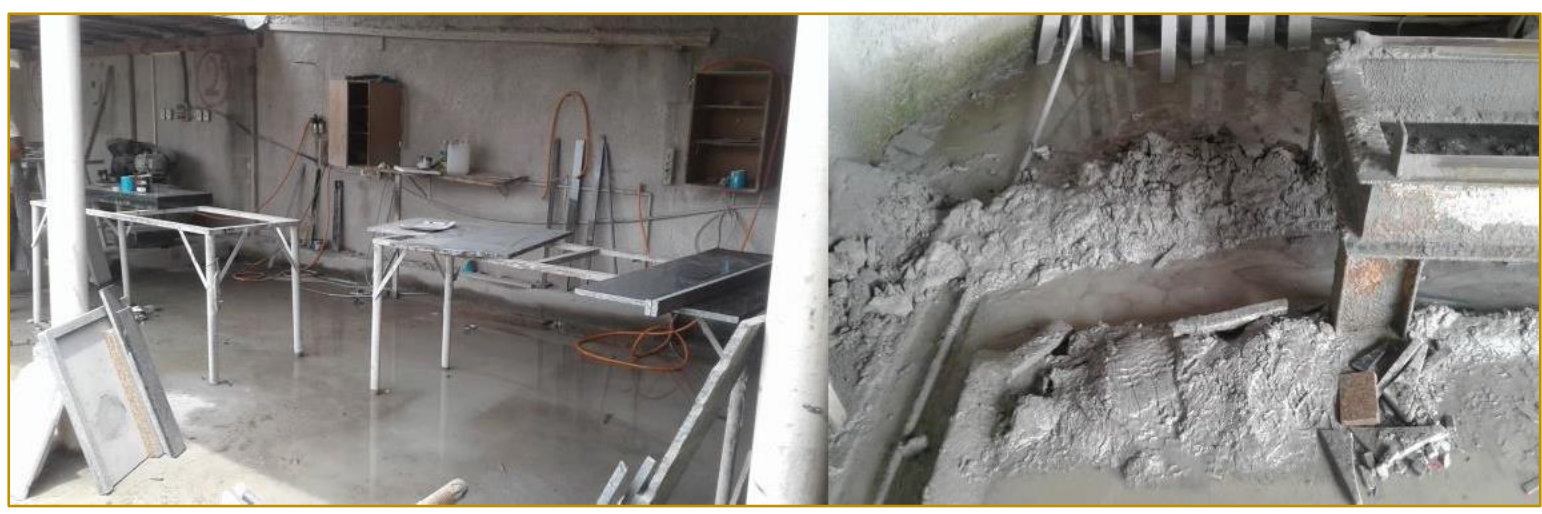

Fonte: Pesquisa de campo (2016). Organização: Os autores 


\subsubsection{RISCOS ERGONÔMICOS}

a) Agente: Levantamento, transporte e movimentação das pedras de forma inadequada.
Efeitos: Desgaste da coluna, quebra de vértebras, escoliose (desvio para o lado) ou cifose (desvio para frente).

Figura 04: Carrinho de transporte das pedras

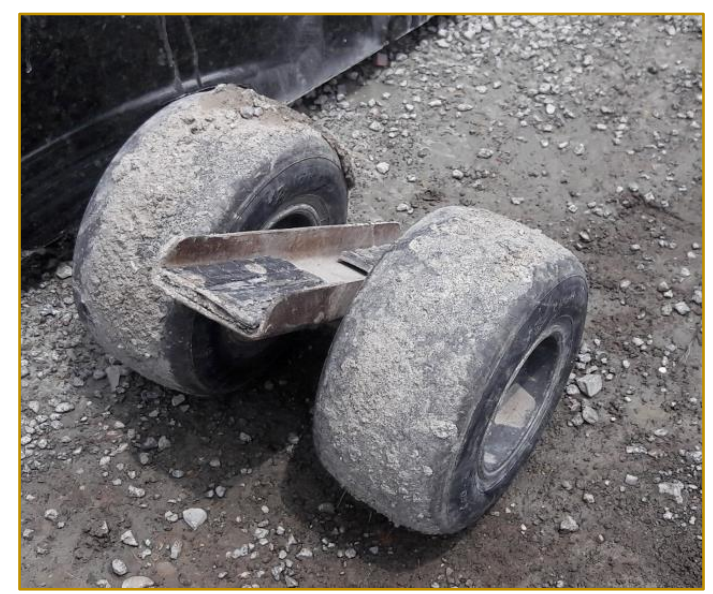

Fonte: Pesquisa de campo (2016). Organização: Os autores

\subsubsection{RISCOS QUÍMICOS}

a) Agente: Manuseio inadequado da massa plástica;

Efeitos: Irritação e queimadura nos olhos, dor de cabeça, vertigens e náuseas.

b) Agente: Inalação da poeira de sílica durante o acabamento a seco.

Efeitos: Agressão aos tecidos pulmonares, dificuldades respiratórias, tosse, emagrecimento e falta de ar, que são os sintomas da silicose, que consiste numa doença incurável.

Figura 05: Massa plástica utilizada na colagem das peças

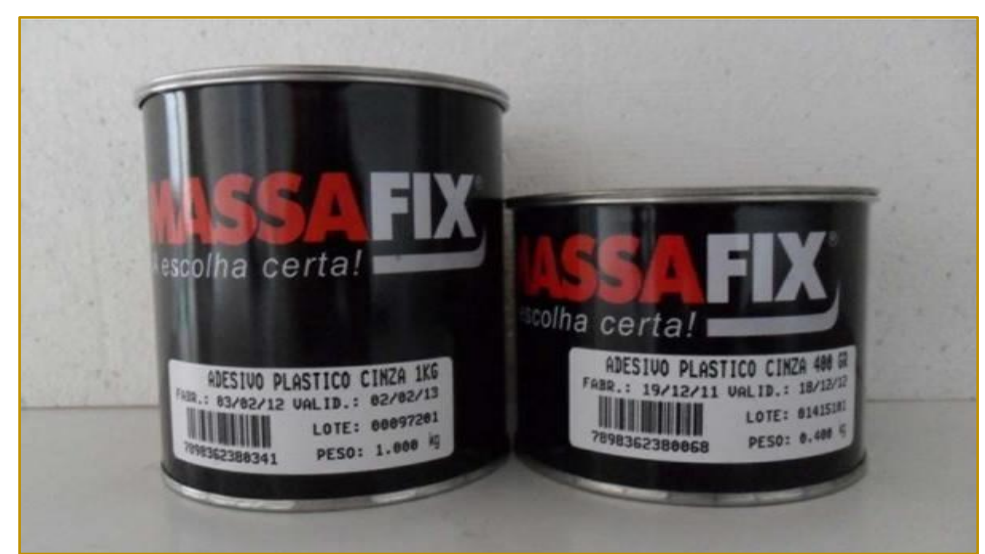

Fonte: Pesquisa de campo (2016). Organização: Os autores 
Figura 06: Poeira de sílica gerada durante o corte

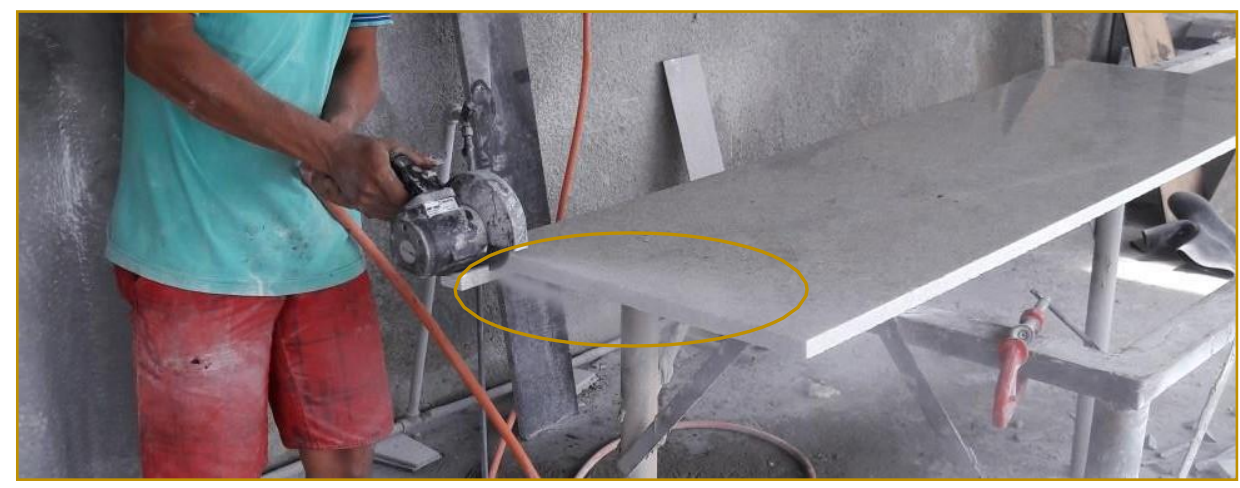

Fonte: Pesquisa de campo (2016). Organização: Os autores

\subsubsection{RISCOS DE ACIDENTES}

a) Agente: Projeção de partículas;

Efeitos: Ferimentos graves e irreversíveis nos olhos. b) Agente: Arranjo físico inadequado;

Efeitos: Escorregões, tropeços, colisões e outras situações de lesão física.

Figura 07: Ambiente de trabalho desorganizado

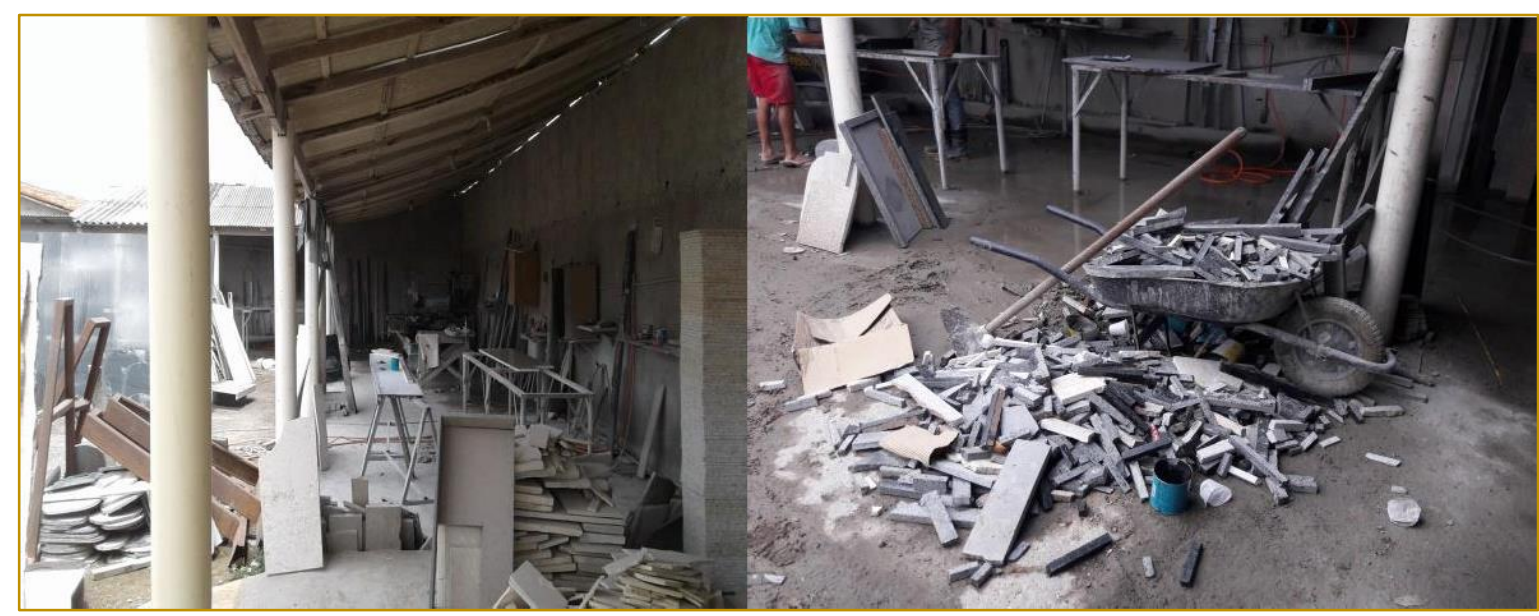

Fonte: Pesquisa de campo (2016). Organização: Os autores

a) Agente: Utilização da serra grande de maneira inadequada.

Efeitos: Cortes nas mãos ou perda do membro. 
Figura 08: Colaborador utilizando a serra grande de maneira incorreta

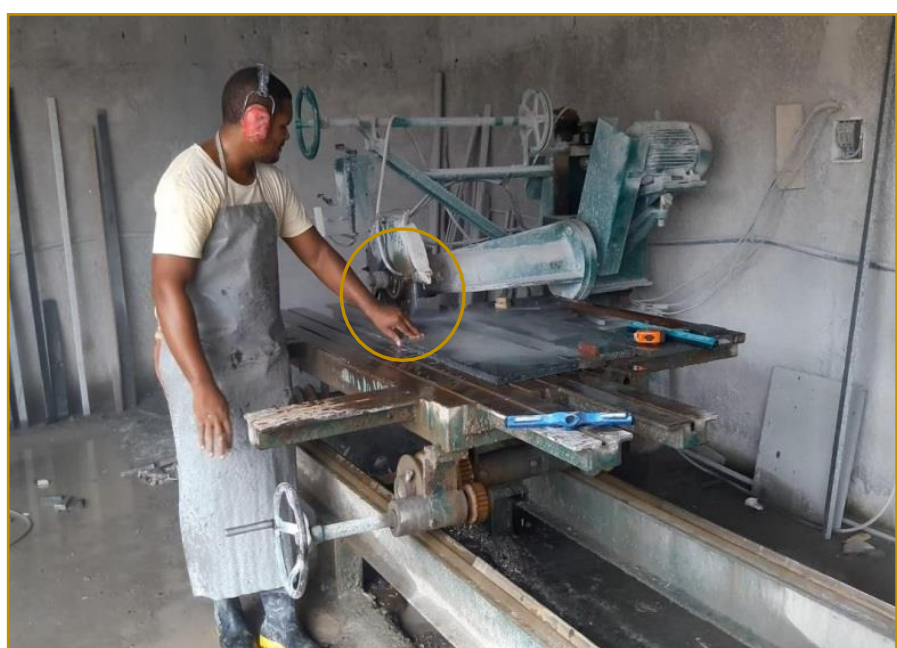

Fonte: Pesquisa de campo (2016). Organização: Os autores

\subsection{APRESENTACÃO DOS RISCOS forma qualitativa. Os riscos identificados são EXISTENTES EM LAYOUT representados pelas cores assinaladas na \\ A Figura 9 expõe de forma demonstrativa, o legenda, de acordo com a figura acima.} layout da empresa estudada, de modo a apontar onde ocorre cada risco dentro do estabelecimento, sendo estes indicados de

Figura 09: Layout do estabelecimento e os riscos identificados

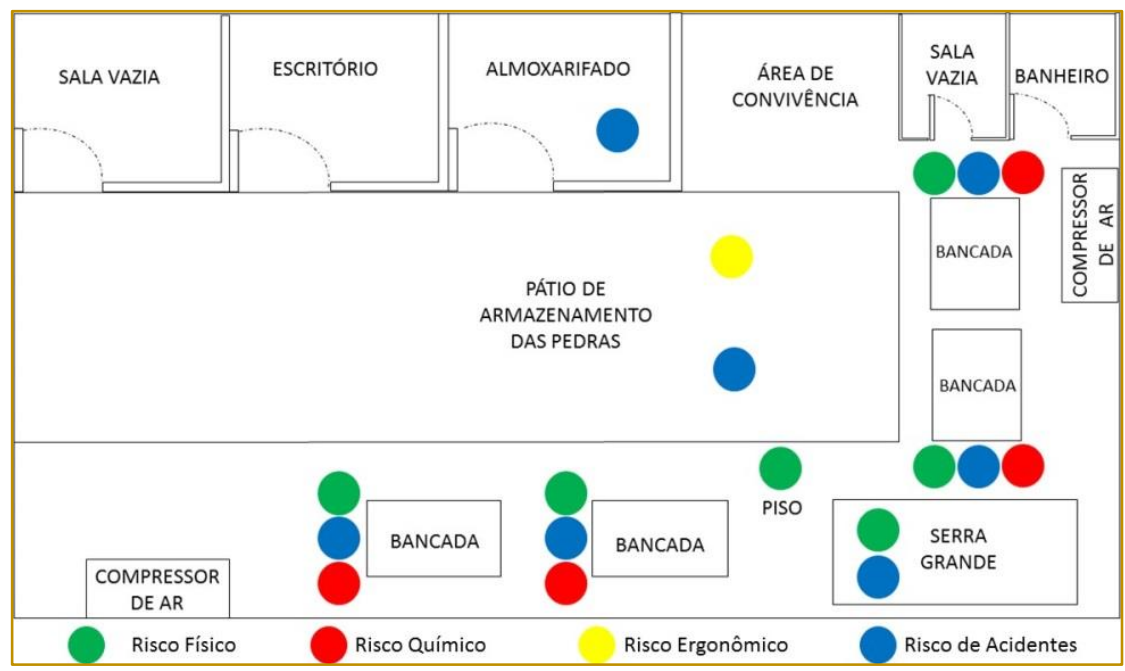

Fonte: Pesquisa de campo (2016). Organização: Os autores 


\section{MEDIDAS PREVENTIVAS PARA OS medidas de prevenção respectivas à cada RISCOS IDENTIFICADOS risco identificado.}

\section{A Tabela 01 demonstra as propostas de}

Tabela 01: Riscos e suas respectivas recomendações e medidas de prevenção

\begin{tabular}{|c|c|}
\hline \multicolumn{2}{|r|}{ Medidas prever } \\
\hline Vibrações & $\begin{array}{l}\text { Adquirir máquinas e ferramentas de trabalho pneumáticas com sistema } \\
\text { antivibração; } \\
\text { Estabelecer uma manutenção adequada dos equipamentos de } \\
\text { trabalho (substituir peças gastas, fazer apertos, etc.). }\end{array}$ \\
\hline Exposição ao ruído & Uso de protetor auditivo circum-auricular. \\
\hline Exposição à umidade & $\begin{array}{l}\text { Construção de canaletas com grades de proteção para permitir o } \\
\text { escoamento da água utilizada nas tarefas de polimento, corte, } \\
\text { acabamento e limpeza; } \\
\text { Utilizar calçado de proteção tipo bota de borracha (cano longo). }\end{array}$ \\
\hline \multicolumn{2}{|r|}{ Ergonômico } \\
\hline $\begin{array}{l}\text { Levantamento, transporte e } \\
\text { movimentação das pedras de } \\
\text { forma inadequada. }\end{array}$ & $\begin{array}{l}\text { Adoção do carrinho transportador de chapas de mármore, com quatro } \\
\text { rodas de náilon para facilitar o deslizamento da chapa e outras quatro } \\
\text { rodas para evitar o tombamento da chapa em terreno irregular. }\end{array}$ \\
\hline \multicolumn{2}{|r|}{ Químico } \\
\hline $\begin{array}{l}\text { Manuseio inadequado da massa } \\
\text { plástica }\end{array}$ & $\begin{array}{l}\text { Máscara de proteção respiratória PFF1 com Válvula } 8013 \text { - 3M; } \\
\text { Luvas de proteção em borracha nitrílica. }\end{array}$ \\
\hline $\begin{array}{l}\text { Inalação da poeira de sílica } \\
\text { durante o acabamento a seco }\end{array}$ & $\begin{array}{l}\text { Uso de respirador do tipo peça semifacial com filtro P3; } \\
\text { Utilização de coletor de pó, ideal para coletar pó leve de máquinas de } \\
\text { pequeno porte, tais como lixadeiras e serras. }\end{array}$ \\
\hline \multicolumn{2}{|r|}{ Acidentes } \\
\hline Projeção de partículas & Uso de óculos de ampla visão e anti-embaçante. \\
\hline Arranjo físico inadequado & $\begin{array}{l}\text { Usar containers para o descarte das pedras que não serão } \\
\text { reaproveitadas; } \\
\text { Instalar prateleiras no almoxarifado. }\end{array}$ \\
\hline $\begin{array}{l}\text { Utilização da serra grande de } \\
\text { maneira inadequada }\end{array}$ & $\begin{array}{l}\text { Utilizar a peça apropriada já existente na máquina, para a movimentação } \\
\text { da pedra durante o corte. } \\
\text { Usar camisas de segurança com punhos elásticos. }\end{array}$ \\
\hline
\end{tabular}

Fonte: Pesquisa de campo (2016). Organização: Os autores

\section{CONCLUSÃO}

Após a obtenção dos resultados da análise dos riscos, foi possível identificar quais os riscos que os trabalhadores da marmoraria em estudo estavam expostos. Além disso, detectaram-se também os possíveis agentes (causas) e efeitos para cada risco, e em seguida, propuseram-se as medidas preventivas correspondentes a cada agente causador.

Diante do que foi observado, podem ser feitas algumas sugestões. Com relação ao piso e cobertura, uma manutenção corretiva nos aspectos construtivos da instalação resolveria o problema de irregularidade do piso e as falhas na cobertura da fábrica.

A empresa deve promover treinamentos para orientar os trabalhadores sobre a importância do uso do EPI's, além de realizar a fiscalização quanto à segurança e saúde dos funcionários, visto que, a mesma poderia ter sua capacidade produtiva comprometida por um acidente de trabalho; e a prática do DDS (Diálogo Diário de Segurança) para a conscientização dos empregados sobre a importância do uso dos EPI's para a sua segurança e preservação da saúde no ambiente de trabalho, pois, apesar de existirem alguns EPI's no estabelecimento os funcionários muitas vezes não fazem uso dos mesmos.

A saúde do trabalhador que se expõe à poeira contendo sílica e outros agentes em uma marmoraria deve ser acompanhada por meio de exames médicos e a empresa deve garantir que os trabalhadores realizem esses exames conforme a NR-7 - Programa de Controle Médico de Saúde Ocupacional (PCMSO).

Além de todas essas medidas protetivas, o trabalhador deve manter bons hábitos em relação à higiene pessoal, como: não sacudir, 
escovar ou soprar a poeira da roupa de trabalho; antes de deixar o loca de trabalho, tomar banho e trocar de roupa; guardar as roupas de trabalhado em local separado das roupas comuns; lavar as mãos e o rosto antes de se alimentar; não realizar refeições no local de trabalho. Seguindo essas orientações, os trabalhadores conseguirão obter um melhor nível de segurança em relação às atividades realizadas, prevenindo que danos, muitas

\section{REFERÊNCIAS}

[1]. Araújo F. I; Macedo, P. P.; Soares F. A. M. Avaliação de Riscos no Ambiente de Trabalho de uma Empresa do Setorial de Mármores e Granito. In: Encontro Nacional de Engenharia de Produção, XXXVIII, 2008, Fortaleza, CE: ENEGEP, 2008.

[2]. Araújo, Giovanni Moraes de. Elementos do Sistema de Gestão de Segurança, Meio Ambiente e Saúde Ocupacional - SMS. 1 ed. V. 1. Rio de Janeiro: Gerenciamento Verde Editora, 2004.

[3]. Avelino, Thiago. Vestimenta Tipo Blusa. Consulta CA, 2016. Disponível em: $<$ https://consultaca.com/28887>. Acesso em 09 dez. 2016.

[4]. Batalha, Ana. Identificação de Perigos e Avaliação de Riscos. In: Instituto Politécnico de Setúbal (IPS). Recife, 2012. Disponível em: <https://comum.rcaap.pt/bitstream/10400.26/3882/ 1/Ana\%20Batalha\%20\%20Trabalho\%20Final\%20S HT.pdf>. Acesso em: 08 dez. 2016.

[5]. Bento, Herbert. Marmorarias: Beleza ou Preocupação. DDS Online, 2015. Disponível em: <http://ddsonline.com.br/dds-temas/39seguranca/459-marmorarias-beleza-oupreocupacao.html>. Acesso em 09 dez. 2016.

[6]. Brasil. NR-4 - Serviços Especializados em Engenharia de Segurança e em Medicina do Trabalho. Ministério do Trabalho e Emprego. Brasília, 2008. Disponível em: <http://trabalho.gov.br/images/Documentos/SST/N R/NR4.pdf>. Acesso em: 09 dez. 2016.

[7]. Brasil. NR-5 - Comissão Interna de Prevenção de Acidentes. Ministério do Trabalho e Emprego. Brasília, 2011. Disponível em: <http://trabalho.gov.br/images/Documentos/SST/N R/NR6.pdf>. Acesso em: 09 dez. 2016.

[8]. Brasil. NR-6 - Equipamento de Proteção Individual. Ministério do Trabalho e Emprego. Brasília, 2015. Disponível em: <http://trabalho.gov.br/images/Documentos/SST/N R/NR6.pdf>. Acesso em: 09 dez. 2016.

[9]. Brasil. NR-7 - Programa De Controle Médico De Saúde Ocupacional. Ministério do Trabalho e Emprego. Brasília, 2013. Disponível em: $<$

http://trabalho.gov.br/images/Documentos/SST/NR/ NR7.pdf>. Acesso em: 09 dez. 2016. vezes irreversível, Ihes acometam.

De fato, a segurança tem influência direta sobre a produtividade. Para que os funcionários produzam bem é preciso que trabalhem de maneira confortável e se sintam bem naquele ambiente, e cabe à empresa fornecer tais condições, porque somente assim os riscos poderão ser reduzidos ou até mesmo eliminados.

[10]. Brasil. NR-12 - Segurança no Trabalho em Máquinas e Equipamentos. Ministério do Trabalho e Emprego. Brasília, 2016. Disponível em: <http://trabalho.gov.br/images/Documentos/SST/N R/NR12/NR-12-atualizada- 2016-lb.pdf.> Acesso em: 09 dez. 2016.

[11]. Brasil. NR-15 - Atividades e Operações Insalubres. Ministério do Trabalho e Emprego. Brasília, $2015 . \quad$ Disponível em: <http://trabalho.gov.br/images/Documentos/SST/N R/NR15/NR15-ANEXO15.pdf.> Acesso em: 09 dez. 2016.

[12]. Bressi, Raffaella. O que são riscos ambientais e como prevenir. INBEP, 2016. Disponível em: <http://blog.inbep.com.br/o-quesao-riscos-ambientais/>. Acesso em: 09 dez. 2016.

[13]. Coltre, Juliane Cristina. Safety and health: the prevention of accidents in construction. 2011. (65 páginas). Trabalho de Conclusão Curso, do curso de Tecnologia em Materiais de Construção. Universidade Tecnológica Federal do Paraná, Campo Mourão, 2011.

[14]. Costa E. D. T; Pinto, A. R. L. S; Matos H. H. Análise da Postura Exigida no Trabalho em Marmorarias: Utilização do Método OWAS. In: Encontro Nacional de Engenharia de Produção, XXXV, 2015, Fortaleza, CE: ENEGEP, 2015

[15]. Costa E. D. T; Pinto, A. R. L. S; Matos H. H. Análise Preliminar de Riscos de Acidentes em Marmorarias do Município de Betim. In: Encontro Nacional de Engenharia de Produção, XXXV, 2015, Fortaleza, CE: ENEGEP, 2015

[16]. Gonçalves Filho, Anastácio Pinto. Saúde e segurança do trabalho em serviços de saneamento - 2012. Secretaria Nacional de Saneamento Ambiental. Salvador. 34p. Disponível em: <http://www.unipacvaledoaco.com.br/ArquivosDive rsos/Saude_e_seguranca_no_trabalho_em_servico s_de_sane amento_RECESA.pdf $>$. Acesso em 30 abr. 2017.

[17]. NETO, Nestor Waldhelm. Como evitar acidentes de trabalho. Blog Segurança do Trabalho NWM. Goiânia, 2013.

[18]. Redação Tuiuti. O que é grau de risco de acidente de trabalho. Tuiuti Equipamentos de Segurança. Disponível em: < http://www.epituiuti.com.br/blog/o-que-e-grau-de-risco-deacidente-de-trabalho/>. Acesso em: 30 abr. 2017. 
[19]. Santos, Alcinéa Meigikos dos Anjos; Cançado, Raul Zanoni Lopes; Anjos, Roberto Meigikos dos; Amaral, Norma Conceição do; Lima, Leila Cristina Alves. Características da exposição ocupacional a poeiras em marmorarias da cidade de São Paulo. Revista Brasileira Saúde Ocupacional. São Paulo, 2007.

[20]. Silva, E. L. da; Menezes, E;M. Metodologia da Pesquisa e Elaboração de Dissertação. Florianópolis: Laboratório de Ensino à Distância da UFSC, 2001.
[21]. SILVA, Maria Cristina A da; ANDRADE, Leandro. Boletins SEBRAE: Marmorarias. SEBRAE, $2014 . \quad$ Disponível em: <http://www.sebraemercados.com.br/wpcontent/up loads/2015/10/2014_08_06_BO_Agosto_Construca oCivil_m armores_pdf.pdf>. Acesso em 09 dez. 2016.

[22]. Strauss, Anselm; Corbin, Juliet. Basics of Qualitative Research-Techniques and Procedures for Developing Grounded Theory. United States: Sage Publications, 1998. 


\section{CAPÍTULO 19}

\section{ANÁLISE DE DISTÚRBIOS MUSCULARES: UM ESTUDO DE CASO NA ÁREA DE ESTÉTICA}

\section{Gabriela de Souza Raymundo}

\section{Ivana Salvagni Rotta}

Resumo: O número de profissionais na área de estética e a procura por tratamentos estéticos vem aumentando significativamente. Durante um tratamento ou sessão estética o profissional fica propenso a posições não ergonômicas e a prática de movimentos repetitivos podendo causar distúrbios musculares. Esses distúrbios podem ser prevenidos se identificados antecipadamente através de estudos de ergonomia. Esse trabalho visa estudar os distúrbios ocasionados pelas atividades desenvolvidas em clínica, durante os procedimentos estéticos executados pelas alunas do curso de Estética de um Centro Universitário. Aplicando os questionários de avaliação ergonômicas REBA e Nórdico que avaliam os movimentos, posições de trabalho e identificam dores/desconfortos no corpo durante a performance do profissional. Além da análise dos distúrbios musculares, a pesquisa também visará mostrar a importância dos estudos de ergonomia para melhorar a qualidade de vida do profissional de estética.

Palavras chave: Distúrbios musculares, Ergonomia, Estética. 


\section{INTRODUÇÃO}

O setor de estética, no Brasil, vem crescendo a cada ano. O número de profissionais na área de estética e a procura por esse serviço também vem aumentando. De acordo com a Associação Brasileira da Indústria de Higiene Pessoal, Perfumaria e Cosméticos (ABIHPEC), o ramo de Estética cresce, em média 10\% ao ano. Independente de período de crise econômica, continua apresentando altos lucros, em 2013, houve o crescimento de 32\% (ABIHPEC, 2017). Durante um tratamento ou sessão estética o profissional fica propenso a posições não ergonômicas e pratica movimentos repetitivos, dos quais podem gerar distúrbios musculares. Esses distúrbios podem ser prevenidos se identificados antecipadamente através de estudos de ergonomia.

As análises dos possíveis distúrbios musculares são identificadas com a aplicação de questionários de avaliação ergonômicas que avaliam os movimentos do corpo durante a performance do profissional. Estudos realizados por Devitt (2010) e Surdival (2010) em Podólogos demonstraram que durante as práticas, existem riscos de desenvolver distúrbios musculares no punho. A análise realizada com $\mathrm{O}$ eletrogoniômetro e $\mathrm{O}$ questionário de ergonomia evidenciaram posições não ergonômicas para mãos e punhos além de ações repetitivas com o punho, desconforto musculares em outras partes do corpo e movimentos repetitivos. O questionário Rapid Entire Body Assessement (REBA) propôs mudanças imediatas para algumas atividades desenvolvidas por esses profissionais, devido ao risco de desenvolver tais distúrbios.

$\mathrm{Na}$ área de odontologia, estudo brasileiro constatou que cerca de $95 \%$ dos profissionais apresentam um risco alto de desenvolver distúrbios musculares, mais especificamente dores nas costas, artrites e tendinites se comparados com outros profissionais (ALEXANDRE et al., 2011). As análises de distúrbios musculares feitas usando REBA, aplicado no processo de salga de carne em uma fábrica de charque observou-se que este questionário é muito eficiente e de fácil aplicação na área da saúde, apresenta resultados confiáveis e determina possíveis riscos que o trabalhador está sujeito no ambiente de trabalho (PALUDO, PALUDO, 2015; PINTO, 2009).
Diante desse contexto, esse projeto visa analisar as atividades executadas pelos alunos do curso de Estética e Cosmetologia do Centro Universitário durante os atendimentos dos pacientes na clínica, verificando as posições não ergonômicas e a prática de movimentos repetitivo. A associação destes podem causar distúrbios musculares, os quais ainda são descritos em esteticistas, visto ser uma profissão nova no mercado. Para prevenir possíveis problemas, propõe-se a análise ergonômica, com a aplicação de questionários visando verificar e prevenir tais distúrbios desta forma garantindo a qualidade de vida aos futuros profissionais.

\section{REFERENCIAL TEÓRICO}

\subsection{ERGONOMIA}

O surgimento da Ergonomia se deu após a Segunda Guerra Mundial quando começou a notar trabalho interdisciplinares executados por diversos profissionais (IIDA, GUIMARÃES, 2016).

Ergonomia é o conhecimento do trabalho, que considera as pessoas que executam-no, a maneira como ele é elaborado, ferramentas e equipamentos usados, tudo isso inseridos em um ambiente onde aspectos da situação de trabalho são levados em consideração psicossocial (PHEASANT, 1998).

lida (2016) afirma que a ergonomia é considerada um estudo de visão ampla. É estudado além das condições prévias, as consequências do trabalho. Afinal, a Ergonomia visa a adaptação do trabalho ao homem.

De acordo com Bridger (2009) a ergonomia estuda a relação das pessoas com o seu trabalho, e os fatos associados a essa relação. A finalidade de estudar ergonomia é melhorar a performance desse colaborador e a interação dele com o meio em que está desenvolvendo suas funções. A ergonomia prioriza proporcionar efetividade e eficiência, isso vinculado ao bem-estar e saúde adaptando o trabalho ao homem (CYBIS et al., 2007).

O estudo da ergonomia tem como objetivo aumentar o conforto do trabalhador, para isso é necessário muitas vezes reduzir o cansaço, os acidentes de trabalho e os erros cometidos pelos trabalhadores. A ergonomia vai além do ambiente físico, é uma ciência que abrange atividades de planejamento e projeto. Todo 
esse estudo feito através dela é importante para que o trabalho seja executado de forma correta, assim atingindo os resultados desejados (IIDA, GUIMARÃES, 2016). A melhora do posto de trabalho é uma das primeiras medidas tomadas na visão da ergonomia (GUÉRIN et al., 1997).

Ainda há uma ausência de estudos na Ergonomia de profissionais na área de estética, o que pode aumentar a incidência de problemas como LER/DORT entre outros distúrbios.

\subsection{TRABALHO REPETITIVO E LER/DORT}

O trabalho repetitivo leva às Lesões por Esforço Repetitivo ou Distúrbios Osteomusculares Relacionados ao Trabalho mais conhecidos pela sigla LER/DORT vários sintomas são diagnosticados, como dor, sensação de peso, fadiga geralmente de pescoço e membros superiores mas que podem acometer membros inferiores também (BRASIL, 2003). De acordo com Oliveira et al. (1998) LER é um conjunto de distúrbios que aparecem durante a vida profissional de acordo com as condições de trabalho, isso pode variar dependendo da época, relações sociais e econômicas, o que determinam a forma de trabalho dentro das organizações.

A preocupação com doenças osteomusculares se deu após a Revolução Industrial, que foi intensificada a partir da mecanização e $O$ aparecimento dos computadores (OLIVEIRA, 2007). LER é considerada quando manifestadas em membros superiores e pescoço associados ao trabalho. Existe uma diferença entre LER e DORT, o primeiro conceito aplica-se a pessoa que já apresenta alguma lesão ou trauma, já o termo DORT verifica-se o aparecimento de sintomas como dor e formigamento nos membros, sem ocorrer nenhuma lesão prévia (BOSCOLO, 2002). De acordo com Gonçalves e Camarotto (2015), o trabalho é considerado repetitivo, com análises da atividade no momento em que ela é executada e sabe-se que esses movimentos repetitivos podem estar diretamente ligados a causa de dores e lesões levando a ocasionar esses distúrbios (BRIDGER, 2009).

A Pesquisa Nacional de Saúde (PNS) realizada pelo IBGE em 2013, apontou que cerca de 3.568.095 trabalhadores apresentaram diagnóstico para ter LER/DORT, no mesmo ano, os dados da Previdência
Social registraram 101.814 afecções musculoesqueléticas ocupacionais. Nota-se que dentre as doenças ocupacionais existentes, LER/DORT é a que possui maior número de diagnósticos médicos dentre os trabalhadores (MAENO; TAVARES; LIMA, 2016). A relevância de estudos ergonômicos associados a redução de incidência desses distúrbios, visto que o ambiente de trabalho leva em consideração vários aspectos desde o meio em que a ação ocorre, a criação de equipamentos mais ergonômicos para a execução dessas tarefas e a organização dos postos de trabalho.

\subsection{MASSOTERAPIA}

A massagem surgiu em tempos pré-históricos. A combinação de exercícios e massagem sempre foi um cuidado com a saúde. Esse procedimento desde então foi aplicado em várias situações até os dias de hoje que é usado de forma estética para melhorar a circulação, reduzir a retenção de líquidos e até mesmo para o relaxamento do corpo. É de extrema importância que o profissional conheça a técnica para uma passagem eficaz, não é necessário golpes fortes ou pesados, também se atentar a posição em relação a maca para que o tratamento seja feito da forma correta, sem lesionar o paciente e o profissional atuante. A preocupação com o conforto do paciente muitas vezes é maior que a posição de trabalho do massagista e isso pode ocasionar em problemas a longo prazo para o profissional (CASSAR, 2001). De acordo com Fritz (2002) uma boa postura ao se desenvolver a massagem é importante, afinal, a distensão muscular, fadiga e uso excessivo dos membros pode comprometer a saúde do profissional reduzindo assim seu tempo de atuação na área.

A postura mais adequada é aquela que o profissional se sinta confortável e que consiga manter os pés no chão, e ao mesmo tempo tendo liberdade para executar os seus movimentos durante a sessão.

O domínio das diversas técnicas de massagem além das diversas posições para executa-las devem ser levadas em consideração e feitas de maneira correta pelo massagista (CASSAR, 2001).

A massoterapia pode ser feita em três lugares como a maca, cadeira ou colchonete. O paciente pode determinar se tiver alguma 
preferência e de acordo com o tratamento a ser feito (CIAPPINA; PUERARI, 2011).

No caso da massoterapia no qual é desenvolvida pelos esteticistas, o trabalho muitas vezes estático e em pé, juntamente com movimentos repetitivos pode induzir a fadiga neuromuscular isso a longo prazo levando ao aparecimento da LER/DORT (FRITZ, 2002).

\subsection{MÉTODOS DE AVALIAÇÃO ERGONÔMICA}

De acordo com lida e Guimãraes 2016 a análise e avalições das tarefas, faz com que o comportamento do profissional seja estudado, levando a atuação do pesquisador, resolvendo e/ou propondo soluções para os problemas observados durante a performance, além de muitas vezes podendo melhoras os equipamentos usados.

Existem diversos métodos para a avaliar a ergonomia de um posto de trabalho e a partir das avalições riscos são levantados e melhoras podem ser sugeridas ao trabalhador. Esse estudo observacional vai contar com dois desses métodos os Questionário Nórdico e o REBA.

O questionário Nórdico foi desenvolvido para o auto-preenchimento, os profissionais avaliados serão guiados com uma figura dividindo o corpo em 9 partes e terão que responder dizendo sim ou não para as partes que sentem algum desconforto, o objetivo é descobrir a ocorrência de LER/DORT (IIDA, GUIMARÃES, 2016). Esse método visa facilitar e padronizar os relatos dos sintomas osteomusculares (KUORINKA,1987).

O método REBA foi desenvolvido por Sue Hignett e Lynn McAtmney (1995) é uma ferramenta desenvolvida para investigar atividades aonde apresentam riscos de LER/DORT. O REBA usa a pontuação da postura que vem do Rapid Upper Limb Assessment (RULA) outro método de avaliação ergonômica.

O REBA dividi o corpo em dois grupos, $\mathrm{A}$ e $\mathrm{B}$. No grupo A serão avaliados o tronco, pescoço e pernas, no grupo B braços, antebraços e pulso. Cada um desse membros possuem ângulos pré-definidos que vem representados nas tabelas A e B. Ao final das marcações observadas terá um valor final que será o Score REBA, a avalição desse valor será feito com a tabelas de níveis que apresenta os riscos para cada valor (HIGNETT; MCATAMNEY,2000). Este método avalia instantaneamente a postura do profissional durante o trabalho executado, o avaliador tem a oportunidade durante a avaliação de determinar o momento mais crítico. O REBA permite uma coleta de dados mais padronizada e que leva em conta fatores de risco que estão diretamente ligados aos distúrbios musculares (JUNIOR, 2006).

\section{METODOLOGIA}

A adesão para a participação do estudo foi de 24 alunos, que estagiaram na clínica, durante o primeiro semestre de 2017, fazendo tratamentos faciais como limpeza de pele, peeling, estimulador facial, LED/LASER, micro correntes entre outros possíveis tratamentos. Um questionário sobre informações gerais sobre os participantes, também foi aplicado, seguido dos métodos de avaliação ergonômicos, Nórdico e REBA conduzido pelo observador, também foram realizadas observações, e anotadas as queixas entre as estagiárias durante os tratamentos, com vista a comparar os procedimentos ergonômicos usados. Todas as alunas participantes da pesquisa assinaram e preencheram o termo de consentimento livre e esclarecido (TCLE).

\section{ESTUDO DE CASO}

\subsection{CLÍNICA DE ESTÉTICA}

O estudo foi desenvolvido na clínica de Estética, aonde as alunas do curso exercem as atividades de estágio. O atendimento é aberto a comunidade, as pessoas tem a oportunidade de marcarem os tratamentos desejados por um preço mais acessível. Esse projeto de extensão traz benefícios tanto aos pacientes quanto as alunas que podem fazer o estágio, que é obrigatório para a sua formação, dentro da universidade. As estagiárias atendem dois pacientes por dia com um intervalo de 30 minutos entre os atendimentos. Este é um meio das estudantes aperfeiçoarem e aprenderem mais com as práticas de estética.

Visto que os tratamentos executados por elas requer muitos movimentos repetitivos e posições não ergonômicas esse estudo análise os possíveis distúrbios musculares que podem vir acometer essas profissionais. 


\subsection{ANÁLISE DE DADOS}

As figuras, quadros e gráficos apresentam os resultados obtidos nesse estudo. A idade média das 44 participantes da pesquisa foi de $22 \pm 3,27$. O questionário verificou que $45 \%$ das alunas já trabalham na área, o que deve ser levado em consideração, pois as possíveis dores podem estar aparecendo devido ao trabalho exercido fora do estágio. Durante a aplicação do questionário de informações gerais verificou-se a porcentagem de alunas que conhecem o termo ergonomia que está representada na figura 1.

Figura 1 - Alunas que conhecem o termo Ergonomia

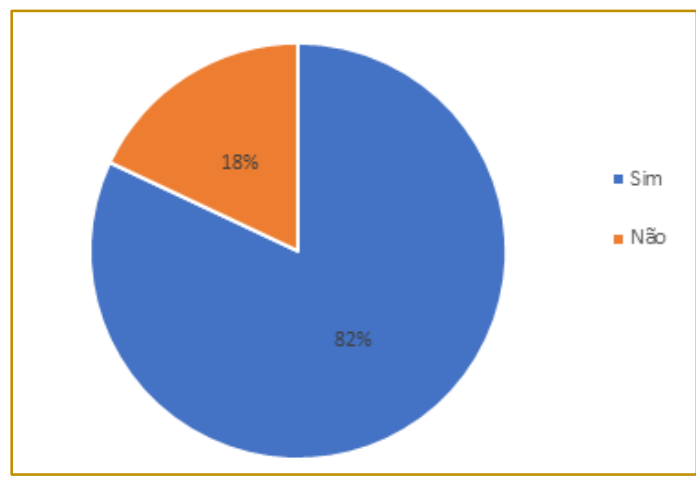

Fonte: Elaborado pelo autor

Quando se questiona sobre dores e ou desconfortos no corpo devido ao trabalho exercido cerca de $82 \%$ das estudantes sentem dores ou desconfortos no corpo, quando estão exercendo suas atividades (Figura 2).

Figura 2 - Porcentagem de alunas que sentem ou não dores/desconfortos musculares

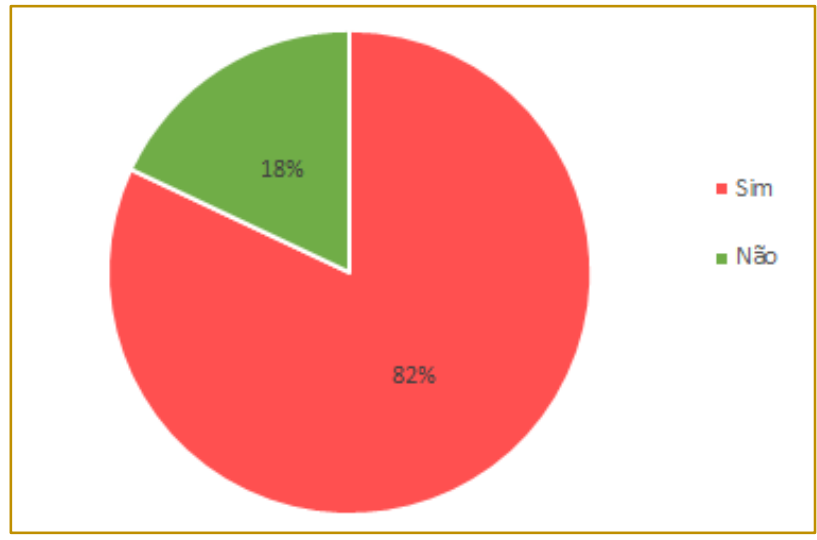

Fonte: Elaborado pelo autor

O Questionário Nórdico foi utilizado para se verificar os possíveis problemas com dores e desconfortos das participantes nos últimos 7 dias e nos últimos 12 meses (Figura 3).
Através do questionário foram sinalizadas 9 membros do corpo aonde pode ocorrer dores e desconfortos. 
Figura 3 -Partes dos corpos que apresentaram dores/desconfortos no período dos últimos 7 dias e 12 meses

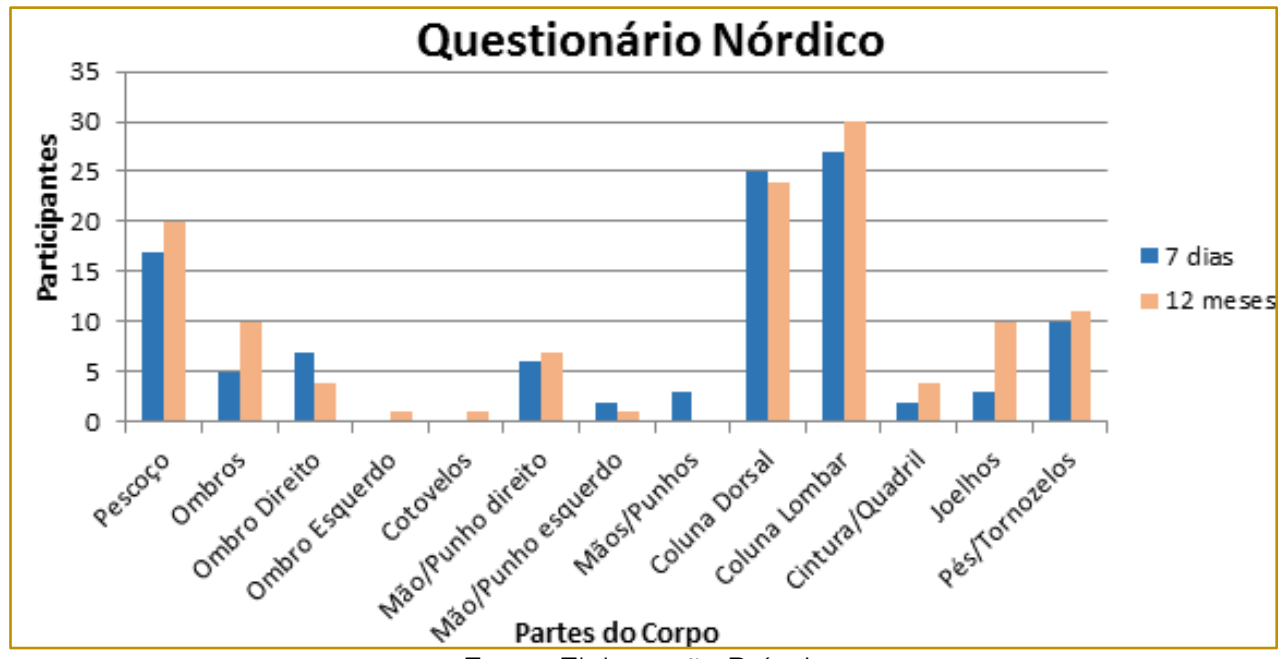

Fonte: Elaboração Própria

Comparando os resultados teve um aumento de dor e/ou desconforto no pescoço, ombros, mãos, punhos, coluna lombar, joelhos, tornozelos e pés. A coluna lombar, dorsal e o pescoço foram as partes do corpo com maior número de queixas entre as alunas. A dor e/ou desconforto no ombro esquerdo e cotovelos só foi reportado nas queixas entre os últimos 12 meses. Devido a movimentos repetitivos adotados durante a execução dos tratamentos nas pacientes, dores e desconfortos musculares nas mãos e punhos foram reportado pelas alunas. As queixas de desconfortos musculares nos pés e tornozelos foram relates, pois em alguns procedimentos as profissionais ficam em pé. A coluna lombar e dorsal são as partes do corpo que mais trazem dores e ou desconfortos as estudantes. Isso ocorre devido a posição em que os tratamentos são realizados, pois elas permanecem sentadas no mocho durante todo o tempo.

Em um estudo também feito com profissionais da estética MASSAMBANI (2011) aponta que durante os tratamentos faciais os esteticistas permanecem em uma posição que com frequência pode trazer desconfortos e ou dores ao pescoço, punhos, coluna, ombros, braços também podendo ocorrer em pernas e pés, a autora compara os esteticistas com profissionais que trabalham com microscópios. No estudo, as estagiárias analisadas apresentaram dores e ou desconfortos nas mesmas partes do corpo e ainda na coluna dorsal acometendo a maioria delas.

As participantes se queixam do desconforto gerado pelo mocho, devido as regulagens quebradas o que resulta em posições não ergonômicas, durante as sessões, para se ajustar à altura da maca que é fixa e ao paciente deitado na mesma.

O terceiro questionário, REBA, apresenta os riscos de distúrbios musculares entres as alunas participantes, o que também confirma as queixas de dores/desconforto entre elas. Os resultados desse questionário estão apresentados na figura 4 e o grau de risco foi verificado utilizando a escala representada na figura 5, contatou-se que a maior parte das alunas avaliadas apresentam riscos de nível médio e nível alto, podendo desenvolver distúrbios musculares devido as atividades executadas nas observações. 
Figura 4 - Resultados obtidos com a aplicação do questionário REBA

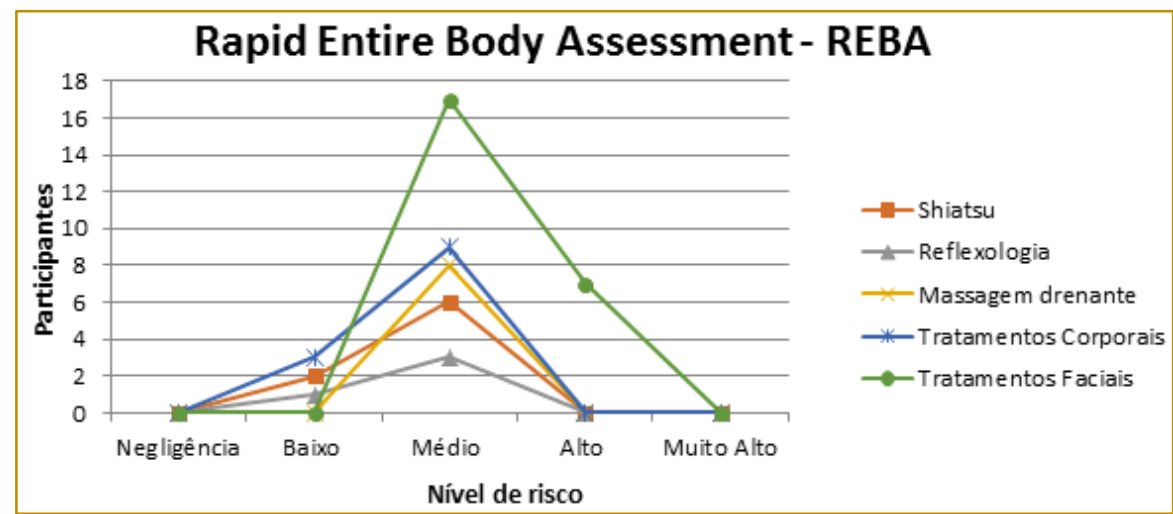

Fonte: Elaborado pelo autor

De acordo com a figura 5 usada para avaliar os níveis de riscos apresentados pela figura 4, investigações e mudanças devem ser implementadas, como se pode ver no grau de riscos obtidos com essa pesquisa que em sua maioria ficou entre 4-7 e 8-10.

Figura 5 - Nível de riscos de distúrbios musculares REBA

\begin{tabular}{|c|c|}
\hline Resultado & Nível de risco de Distúrbios Musculares \\
\hline 1 & Negligencia, mudança desnecessária \\
\hline $2-3$ & Baixo, pode ser necessária mudança \\
\hline $4-7$ & Médio, investigação para possível mudança \\
\hline $8-10$ & Alto, investigação e implementação de mudança \\
\hline $11+$ & Muito alto, implementar mudança \\
\hline
\end{tabular}

Fonte: Adaptado REBA's level of Musculoskeletal Disorders

Durante as observações as participantes se queixam do desconforto gerado pelo mocho, devido a algumas regulagens quebradas 0 que resulta em posições não ergonômicas, e também uma dificuldade para se ajustar à altura da maca que é fixa, levando a não adequação dos equipamentos para todos os indivíduos estudados, gerando desconfortos nos momentos da atividade profissional. A altura das alunas foi considerada devido a esses fatores, tem-se uma média 162 $\pm 6,26$ $\mathrm{cm}$.
A figura 6 mostra uma tabela elaborada para avaliar a posições das alunas que permanecem sentadas durante os procedimentos de tratamentos faciais. Verificou-se que as alunas de baixa estatura não conseguem apoiar os dois pés no chão, o que fazem adotarem a segunda ou terceira posição representadas na Figura 6, já as estagiárias mais altas adotam a primeira posição, que seria a mais indicada, para a execução das sessões. 
Figura 6 - Posições sentadas utilizadas na avaliação REBA

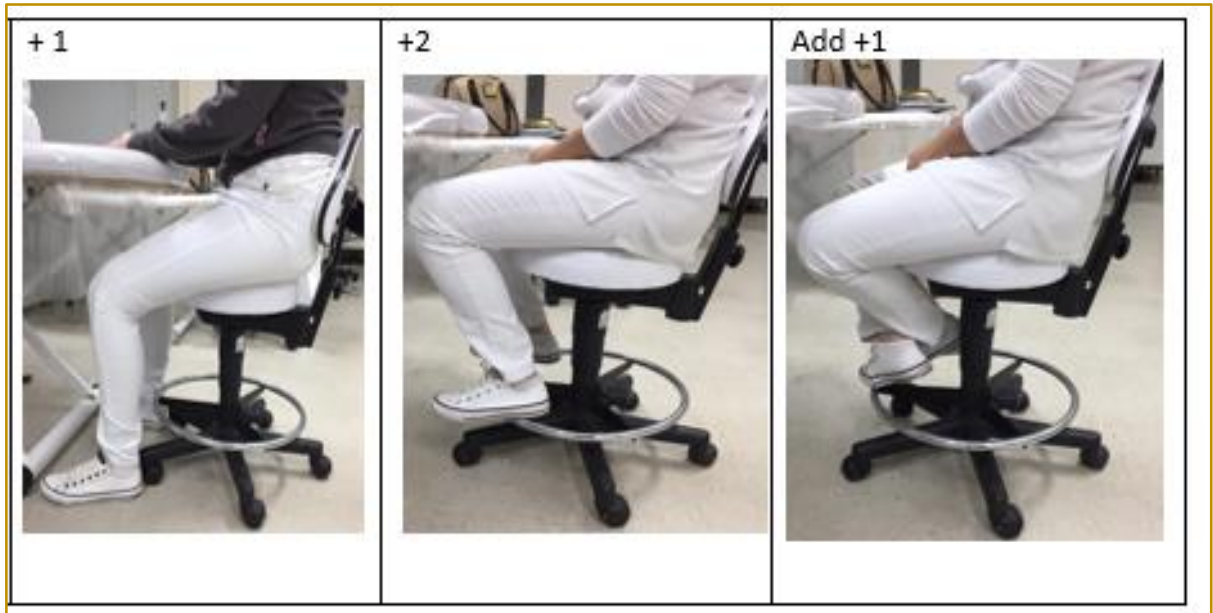

Fonte: Elaborado pelo autor

$\mathrm{Na}$ figura 7 estão representados alguns procedimentos faciais feitos durante 0 atendimento, na primeira e na segunda figura o profissional está executando a limpeza de pele na paciente, esse procedimento necessita de uma maior força e precisão dos punhos e das mãos, já na terceira e na quarta figura é feita a higienização e hidratação da pele da paciente nota-se alguns movimentos repetitivos com as mãos durante essa etapa.

Figura 7- Procedimentos de estética facial

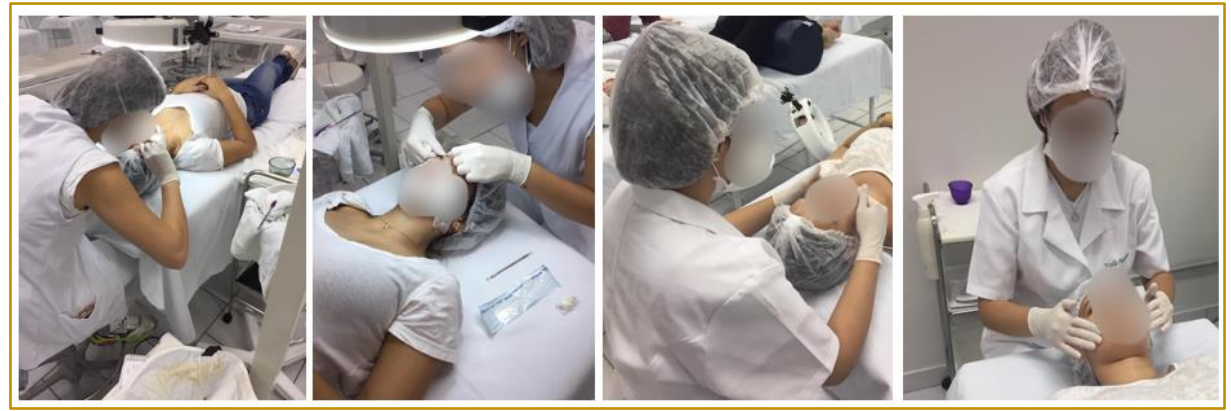

Fonte: Elaboração Própria

\section{CONSIDERAÇÕES FINAIS}

Com os dados obtidos através do questionário Nórdico e REBA verificou-se que a maioria das alunas estagiárias podem desenvolver distúrbios musculares no decorrer da execução de suas atividades.
Observou-se também que os riscos encontrados estavam entre o nível médio e alto. Sendo assim, nota-se a importância da proposta de alternativas para a execução do trabalho e treinamentos, além de novos equipamentos para reduzir os riscos de distúrbios musculares como LER/DORT. 


\section{REFERÊNCIA}

[1] Abihpec Institucional. Anuário Disponível em < https://abihpec.org.br/publicacao/panoramado-setor-2017/ > Acesso em 19 jan. 2018.

[2] Alexandre, P. Câmara, V. Meyer, A. Palácios M. Silva, I. Souza, L. "Musculoskeletal disorders among brazilian dentists." Archives of Environmental \& Occupational Health, v.66, n.4, 2011.

[3] Boscolo, E. F. P. LER/DORT e ações ergonômicas nas empresas: estudo de casos na indústria calçadista. 2002. 102 f. Dissertação (Mestrado) - Curso de Engenharia de Segurança e em Medicina do Trabalho, Universidade Federal de São Carlos, São Carlos, 2002. Cap. 6.

[4] Brasil, INSS. Norma Técnica sobre Lesões por Esforços Repetitivos-LER ou Distúrbios Osteomusculares Relacionados ao TrabalhoDORT, Brasília: Ministério da Saúde, 2003, 97p.

[5] Bridger, R.S.. Introduction to Ergonomics. 3. ed. FL: CRC Press, 2009.

[6] Cassar, M. P. Manual de Massagem Terapeutica. Barueri: Manole, 2001.

[7] Ciappina, F. S.; Puerari, A. C. Projeto Ergonômico de Maca Massoterápica. Trabalho de Conclusão de Curso. Curso de Tecnologia em Design de Móveis, Universidade Tecnológica Federal do Paraná, 94 f, 2011.

[8] Cybis, W.; Betiol, A. H.; Faust, R. Ergonomia e Usabilidade: Conhecimento Métodos e Aplicações. 2. ed. São Paulo: Novatec, 2007.

[9] Devitt, K. A comparative study of three observational techniques to establish if podiatrists are at risk of musculoskeletal ill-health. M.Sc. Occupational Health, Safety \& Ergonomics. National University of Ireland, Galway, 2010, (unpublished thesis).

[10] Fritz, S. Fundamentos da massagem terapêutica. 2ª Edição. São Paulo: Manole, 2002.

[11] Gonçalves, J. M.; Camarotto, J. A. Estratégias operatórias frente ao trabalho repetitivo. Production, v. 25, n. 1, p.190-200, mar. 2015

[12] GUÉRIN, F. et al. Compreender o trabalho para transformá-lo: A prática da Ergonomia. São Paulo: Edgard Blücher Ltda, 1997.

[13] Hignett, S.; Mcatamney, L. Rapid entire body assessment (REBA). Applied ergonomics, v. 31, n. 2, p. 201-205, 2000.

[14] lida, I., Guimarães, L. B. de M.: Ergonomia: projeto e produção. 3. ed. São Paulo: Blucher (2016).
[15] Junior, M. M. C. Avaliação ergonômica: Revisão dos métodos para avaliação postural. Revista produção online, v. 6, n. 3, 2006.

[16] Kuorinka, I. et al. Standardised Nordic Questionnaires for the Analysis of Musculoskeletal Symptoms. Applied Ergonomics, v. 18, n. 3, p. 23337, 1987.

[17] Maeno, M.; Tavares D. S.; Lima C. Q. B. 2016: a precarização do trabalho, a desconstrução dos direitos, a desigualdade social e as LER/DORT. Disponivel em <https://cut.org.br/system/uploads/ck/files/LERDORT-28-fev-2016-final-2.pdf> Acesso em 26 set. 2017.

[18] Massambani, E. M. Incidência de distúrbios músculo esqueléticos em profissionais de estética: suas repercussões sobre a qualidade de vida e de trabalho. Arq. Ciênc. Saúde UNIPAR, Umuarama, v. 15, n. 1, p. 51-62, jan./abr. 2011.

[19] Mcatamney, L.; Hignett, S. REBA: A rapid entire body assessment method for investigating work related musculoskeletal disorders. In: Proceedings of the 31st annual conference of the Ergonomics Society of Australia. Melbourne: The Society, 1995.

[20] Middlesworth, M. A Step-by-Step Guide to the REBA Assessment Tool. Ergonomics plus. Disponível em http://ergo-plus.com/rebaassessment-tool-guide/ Acesso em: mar, 2017.

[21] Oliveira, C. R. de et al. Manual Prático de LER. 2. ed. Belo Horizonte: Health, 1998.

[22] Oliveira E. R. Prevalência de doenças Osteomusculares em cirurgiões dentistas da rede pública e privada de Porto Velho - Rondônia. Dissertação de Mestrado UNB. Brasília, 2007.

[23] Paludo, H. C. M. Paludo V. Analise Ergonomica do Trabalho (AET) Aplicado no Processo de Salga da Carne de uma fábrica de Charque. In: ENEGEP 35. Anais, Fortaleza, 2015.

[24] Pheasant, S. Bodyspace: Anthropometry, Ergonomics and the Design of Work. 2. ed. Great Britain: Taylor \& Francis, 1998.

[25] PINTO, A. M. P. "Análise ergonômica dos postos de trabalho com equipamentos dotados de visor em centros de saúde da administração regional de saúde do centro." Dissertação de Mestrado da Faculdade de Medicina da Universidade de Coimbra, 2009.

[26] SURDIVAL, L. Wrist Posture and Wrist Repetition as Possible Risk Factors During Podiatry Work. M.Sc. Occupational Health \& Safety and Ergonomics National University of Ireland, Galway, 2010. (unpublished thesis) 


\title{
GAPÍTULO 20
}

\section{SEGURANÇA DO TRABALHO: PERFIL DAS EMPRESAS DE PEQUENO PORTE DA CONSTRUÇÃO CIVIL EM ANGICOS/RN}

\author{
Thalis Paulino Ginani \\ Marcos Antonio Araujo da Costa \\ Adriana Georgia Borges Soares \\ Allan Araujo Veloso \\ Fabricia Nascimento de Oliveira
}

Resumo: Na atualidade, existe uma preocupação muito grande no que diz respeito à segurança do trabalho. Um dos setores que se destacam negativamente nesse assunto é o da indústria da construção civil. Este é reconhecido como um dos que mais geram acidentes. Dessa forma, o presente trabalho propõe-se em analisar a situação da segurança do trabalho em empresas da construção civil na cidade de Angicos/RN. O estudo foi desenvolvido em três empresas de pequeno porte e para cada empresa, foi aplicado um checklist que englobava aspectos sobre as condições administrativas e relações trabalhistas, condições de engenharia e segurança no trabalho e as condições de saúde e higiene. A pontuação das empresas foi obtida pela razão entre número de SIMs encontrados pelo número de quesitos aplicáveis e, por conseguinte, multiplicado por 100. Logo em seguida, calculou-se o coeficiente de risco à saúde que foi obtido multiplicando a quantidade de situações perigosas por cinco por cento (5\%). Encontrou-se o resultado final com a subtração da pontuação pelo coeficiente de risco à saúde. Dessa forma, a empresa A obteve 60,6\%, recebendo classificação "bom", a empresa B obteve $38,8 \%$, classificação "ruim" e, por fim, a empresa C que obteve $15,87 \%$, recebendo a atribuição "péssimo". Percebe-se que apenas a empresa $A$ apresenta resultado satisfatório. Já as empresas $B$ e C, tem muito que melhorar no que tange a segurança no trabalho para reduzir os riscos inerentes à atividade da construção civil.

Palavras-chave: Canteiro de obra, prevenção do trabalhador, NR 18. 


\section{INTRODUÇÃO}

O crescimento das cidades normalmente está atrelado às atividades econômicas que ali são desenvolvidas. Todavia, há casos em que atividades desenvolvidas no âmbito nacional, como por exemplo, o programa de aceleração do crescimento, intervém nas economias locais, promovendo assim um crescimento mais significativo. Dentre as mais diversas atividades econômicas que tem proporcionado crescimento, não só para pequenas cidades, mas também para as grandes cidades, tem-se a indústria da construção civil, que é uma das que mais se destaca (PINTO, 2012).

Atualmente, a construção civil é um dos segmentos mais importante para economia brasileira e tem contribuído significativamente para o crescimento do País, impulsionada pela disponibilidade de crédito, recuperação de investimento e dentre outros fatores (LOBO $J R, 2008)$.

Nesse sentido, uma das áreas que merecem destaque neste segmento é o de segurança do trabalho que tem por finalidade a redução do número de acidentes de trabalho, proteção do trabalhador e implantação de medidas de prevenção.

A implantação da segurança e medicina do trabalho se dá através de normas regulamentadoras que fornecem orientações sobre os procedimentos obrigatórios que prezam pela saúde e segurança do trabalhador. Todavia, na indústria da construção tais procedimentos não são seguidos na maioria das vezes, culminando assim no maior quantitativo de acidentes (LOBO JR, 2008).

Em meio a essa situação da construção civil no que tange a segurança do trabalho, surge o interesse de analisar a situação da segurança do trabalho em empresas de pequeno porte da construção civil que atuam no município de Angicos/RN, no sentido de averiguar se estas estão de acordo com as principais normas regulamentadoras voltadas para a indústria da construção civil: NR 5, NR 6, NR 18, NR 24 e NR 35.

\section{SEGURANÇA DO TRABALHO}

As ações de segurança no ambiente de trabalho consistem em evitar perdas, sejam elas do tipo humana ou de ação técnica, que culminam na redução das funções laborais (produtivas, humanas, dentre outras). Além disso, é por meio da segurança que se alcança a redução dos acidentes (VIEIRA, 2000).

Sendo assim, infere-se que a segurança do trabalho é de suma importância para os trabalhadores e também para as empresas. A aplicação ineficiente ou sua ausência acarreta em vários prejuízos para os trabalhadores, como lesões corporais e, também, para a empresa, como por exemplo, o comprometimento de sua produção. Portanto, é imprescindível aplicação de uma política de segurança eficiente de modo que evite esses prejuízos e preserve a integridade física dos seus trabalhadores.

\subsection{SEGURANÇA DO TRABALHO NA CONSTRUÇÃO CIVIL}

A construção civil difere dos outros ramos de indústria por possuir peculiaridades, de modo que, uma dessas é a pouca importância de máquinas e tecnologias para obtenção do produto. E também, a maior dependência está quase que exclusivamente, na mão de obra. (GROHMANN, 1997)

Para Lobo Jr (2008) outro fator que afeta a segurança do trabalho na construção civil é o baixo grau de instrução de seus colaboradores, o que implica no maior quantitativo de acidentes de trabalho. Além desse, tem-se a dificuldade de informar e treinar para o uso correto dos Equipamentos de Proteção Individual (EPIs).

Segundo Grohmann (1997) os EPIs são equipamentos que tem por finalidade proteger os trabalhadores durante a realização das suas tarefas e muitas empresas não tem conhecimento dos EPIs básicos para a construção civil e, algumas desconhecem que os mesmos são obrigatórios. No quadro 1 se tem uma relação dos equipamentos de proteção individuais mais usados no âmbito da construção civil. 
Figura 1 - EPIs mais usados na construção civil

\begin{tabular}{|c|c|c|}
\hline Capacete & Proteção Respiratória \\
\hline Protetor Auricular & Fonte: Cosme (2013). \\
\hline Capa de Chuva & Avental \\
\hline
\end{tabular}

Estes equipamentos têm uma importância significativa no tocante à saúde e segurança do trabalhador. Eles não evitam os acidentes, mas dão uma amenizada nas consequências geradas por estes.

Cardoso (2010) relata que a alta quantidade de acidentes de trabalho na construção civil também está relacionada com a situação precária no que diz respeito à higiene, treinamento, segurança, meio ambiente e são descritos a uma série de peculiaridades que deixam as medidas preventivas muito complexas.

Uma forma de minimizar essa situação da segurança do trabalho na construção civil está no fato de promover treinamentos e incentivos à educação por parte das empresas, logo que a mão de obra da construção civil é muito carente no que diz respeito à escolaridade. Funcionários que passam por esse tipo de capacitação tendem a entender que suas obrigações têm como objetivo simplesmente manter sua integridade física. (SILVA; CARREIRO, 2014)

\subsubsection{SEGURANÇA DO TRABALHO EM EMPRESAS DE PEQUENO PORTE}

De acordo com SEBRAE (2014), é considerada empresa de pequeno porte aquela que contém entre 20 e 99 colaboradores. Partindo desse quantitativo, pode-se verificar a necessidade de profissionais da área de segurança do trabalho, tais como, técnicos de segurança, engenheiro de segurança do trabalho, dentre outras. Portanto, a quantidade de profissionais dessa área são determinados de acordo com a quantidade de trabalhadores e - grau de risco da atividade, tendo como base a tabela do SESMT (Serviço Especializado em Engenharia de Segurança e em Medicina do Trabalho).Como as empresas da construção civil apresentam grau de risco 3 ou 4, o SESMT poderá ser dimensionado da seguinte forma: para o primeiro, não há necessidade de profissionais da área de segurança, enquanto que o segundo haveria necessidade de um técnico de segurança para as empresas que possuíssem de 50 a 100 trabalhadores. 


\subsection{NORMAS REGULAMENTADORAS}

No âmbito da segurança e saúde do trabalhador na construção civil, são usadas algumas normas regulamentadoras que são descritas pela portaria 3.214, de 8 de junho de 1978, do Ministério do Trabalho e Emprego. Nesse contexto, destacam-se a NR 5 (comissão Interna de Prevenção de Acidentes - CIPA), NR 6 (Equipamento de Proteção Individual), a NR 18 (Condições e Meio Ambiente de Trabalho na Indústria da Construção), a NR 24 (Condições Sanitárias e de Conforto nos Locais de Trabalho) e a NR 35 ( Trabalhos em altura).

\section{METODOLOGIA}

O presente estudo foi desenvolvido em empresas de pequeno porte da construção civil na cidade de Angicos/RN. Com o intuito de atingir os objetivos efetuou-se uma revisão bibliográfica acerca do tema e selecionou-se três empresas de pequeno porte que atuam na cidade.

Utilizou-se o método de checklist proposto pela Comissão Interinstitucional de Prevenção de Acidentes de Trabalho e Doenças Ocupacionais no programa de avaliação das condições de trabalho nos canteiro de obra da construção civil, pelo fato de ter uma boa aceitação no segmento de segurança, e também, por ser uma ferramenta que apresenta uma facilidade na quantificação e qualificação do local e das condições de trabalho (BRASIL, 2003).

Logo em seguida, foram obtidos os resultados. Esses últimos foram divididos de modo que, no início, tem-se a descrição das empresas, por conseguinte, tem-se o resultado para as condições administrativas e relações trabalhistas, condições de engenharia e segurança no trabalho e, as condições de saúde e higiene. E ao término de cada condição tem-se uma pontuação que é obtida da seguinte forma:

\section{Pontuação $=\frac{\text { no de SIMs encontrado }}{n^{\circ} \text { de quesitos aplicados }} \times 100$}

Após essas etapas tem-se o resultado final de todos os quesitos aplicáveis que é obtido seguindo as seguintes etapas: (1) somatório de todos os quesitos (2) Risco à Saúde e com isso obteve-se (3) o resultado final, para caracterizar as empresas de pequeno porte de Angicos/RN (BRASIL, 2003).

\section{(1) Somatório de todos os quesitos $=\frac{n^{\circ} \text { de SIMs encontrados }}{n^{\circ} \text { de quesitos aplicáveis }} \times 100$}

(2) Coeficiente de Risco à Saúde = (№ de situações perigosas que configuram risco iminente à saúde) $\times 5 \%$

(3) Resultado Final=(somatório de todos os quesitos)-(Coeficiente de risco à saúde)

Obtido o resultado final, atribui-se a seguinte classificação:

- Péssimo - 0 a 20\%;

- Ruim-20,1 a 40\%;

- Regular-40,1 a 60\%;

- Bom-60,1 a 80\%;

- Ótimo - 80,1 a 100\%

Após a coleta de dados, elaboraram-se gráficos que possibilitam estabelecer parâmetros comparativos entre as empresas no município de Angicos/RN.

\section{RESULTADOS E DISCUSSÕES}

\subsection{DESCRIÇÃO DAS EMPRESAS}

As empresas que foram alvo da presente pesquisa apresentam o seguinte quantitativo de funcionários: Empresa $A, 19$ funcionários; Empresa B, 13 funcionários e a Empresa C, 7 funcionários. Os questionários aplicados nas empresas A e B foram respondidos por um Técnico de Segurança do Trabalho. Já a empresa C, foi respondido por um encarregado da obra, visto que a mesma não apresenta profissionais da área de segurança. 


\subsection{ANÁLISE DOS RESULTADOS DO} CHECKLIST

\subsubsection{AVALIAÇÃO DAS CONDIÇÕES ADMINISTRATIVAS E RELAÇÕES TRABALHISTAS}

A primeira etapa do questionário aplicado nas empresas analisa as condições administrativas das empresas e as relações trabalhistas. O Gráfico 1 apresenta os resultados inerentes sobre estas condições.

Através dos resultados do Gráfico 1, percebese que as empresas A e B apresentam resultados satisfatórios. Todavia, a empresa $\mathrm{C}$ apresenta um resultado insatisfatório. Essa última não estava de acordo com a maioria dos itens sobre as condições administrativas e relações trabalhistas, dentre os quais, citase os mais relevantes, como é o caso dos trabalhadores não apresentarem registros e, consequentemente, não há recolhimento de INSS e FGTS. Dessa forma, tal empresa fica a desejar no quesito relações trabalhistas e pode ter problemas futuros tais como causas judiciais. Todas as três empresas apresentaram em comum 0 fato de não disporem de vale alimentação e vale transporte.

\section{Gráfico 1 - Distribuição dos resultados inerentes as condições administrativas}

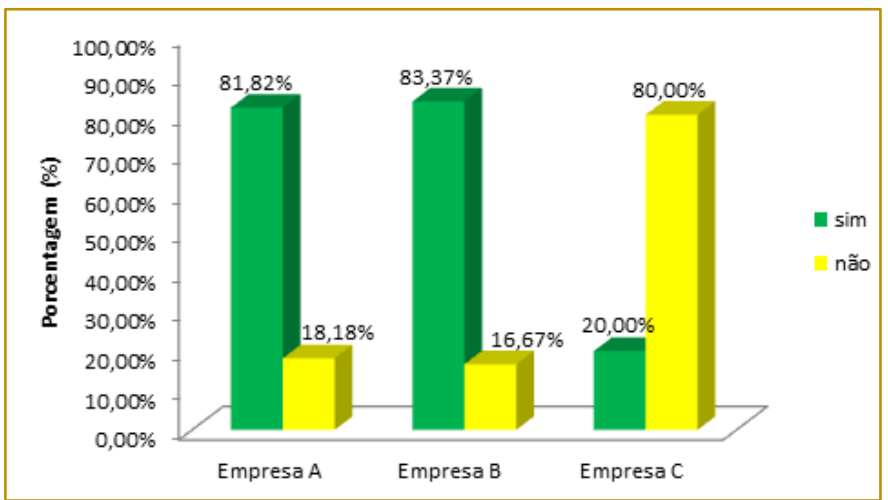

Fonte: Autoria Própria, 2014.

\subsubsection{AVALIAÇÃO DAS CONDIÇÕES DE ENGENHARIA E SEGURANÇA NO TRABALHO}

No presente item serão abordadas as condições de engenharia e segurança no trabalho nos diversos segmentos do canteiro: PCMAT, carpintaria, armações de aço, andaimes e proteção contra quedas em altura, instalações elétricas, operação de máquinas e equipamentos, EPIs, armazenamento de materiais, sinalização do canteiro e limpeza do canteiro.

\subsubsection{PCMAT E COMUNICAÇÃO PRÉVIA}

O Programa de Condições e meio Ambiente de Trabalho na Indústria de Construção mostrou-se presente em apenas uma das empresas, a empresa B. Na empresa C, o PCMAT não se aplica, pelo quantitativo de funcionários. E a empresa $A$ não apresenta o PCMAT. E a Comunicação Prévia junto à
Delegacia Regional do Trabalho foi realizada nas empresas $A$ e B. A empresa $C$ está em desacordo com a NR-2 que diz que é obrigatória a comunicação prévia antes do início das atividades.

\subsubsection{CARPINTARIA}

Abordam-se nesse item aspectos inerentes a carpintaria das empresas em estudo. As empresas A e C apresentaram boas condições no que tange as condições da carpintaria. Já a empresa B não apresentou resultados satisfatórios.

Dentre os itens que a empresa B não cumpriu, pode citar o fato da carpintaria não apresentar serra circular dotada de mesa estável, piso resistente, nivelado e antiderrapante e, também, o fato de ser expostas as intempéries, dessa forma, não protegendo os trabalhadores (Figura 2). 
Figura 2 - Carpintaria Empresa B, Angicos/RN, 2014.

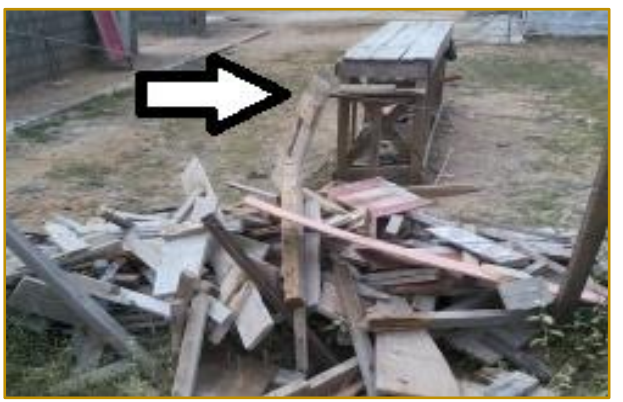

Fonte: Autoria Própria, 2014.

Já a empresa A, apenas não cumpriu um item no qual está relacionado com a proteção da iluminação da carpintaria. A empresa A apresenta uma preocupação com seus trabalhadores quando se usa proteção contra intempéries e, além disso, dispunha de extintor.

\subsubsection{ARMAÇÕES DE AÇO}

O presente quesito trata-se das armações de aço e o modo como elas são trabalhadas nas empresas. As empresas A e C apresentaram resultados relativamente bons. Já a empresa $B$ não apresentou um bom resultado. A empresa $A$ apenas não cumpriu o item em que a iluminação não estava protegida contra a projeção de partículas ou vergalhões. Já a empresa B apresentou o mesmo descumprimento, acrescido das pontas verticais de vergalhões de aço não estarem protegidas contra acidentes, tornado assim os colaboradores mais vulneráveis a acidentes. $\mathrm{E}$ a empresa $C$ apenas não cumpriu o fato de isolar a área para descarga de vergalhões de aço.

\subsubsection{PROTEÇÃO CONTRA QUEDAS EM ALTURAS/ANDAIMES}

Com relação aos andaimes e proteção contra quedas em altura, as empresas apresentaram resultados muito parecidos. Todas as três não cumpriram o fato de disporem de sistema guarda-corpo e rodapé e, também, o fato dos dimensionamentos dos andaimes serem executados por pessoas não habilitadas para tal fim. Dessa maneira, ficando comprometido, podendo ocasionar algum problema.

\subsubsection{INSTALAÇÕES ELÉTRICAS}

No que se refere as instalações elétricas, a empresa A se destaca em relação as demais.
As empresas B e C apresentam um percentual menor pelo fato das instalações elétricas não serem desenvolvidas por pessoas legalmente habilitadas, o que pode comprometer de alguma maneira as instalações das empresas. Outro fator relevante que foi diagnosticado também nessas duas empresas foi a falta de identificação dos circuitos que não são mantidos trancados, assim qualquer pessoa pode vir a manuseá-los.

\subsubsection{MÁQUINAS E EQUIPAMENTOS}

Com relação às máquinas e equipamentos usados, foi possível observar que a empresa A e C apresentam o mesmo desempenho e a $\mathrm{B}$ apresentou um melhor resultado. Nas três empresas foi constatada a ausência de trabalhadores capacitados para trabalharem com as máquinas. Nas empresas B e C, foi diagnosticado que os trabalhadores não são treinados e instruídos para a utilização segura das ferramentas, dessa forma, estando sujeitos a riscos. Um ponto positivo que as três empresas apresentaram foi o fato de submeterem as maquinas e equipamentos para manutenções preventivas e periódicas.

\subsubsection{EPIS E ARMAZENAMENTO DE MATERIAIS}

O assunto abordado no presente quesito está relacionado como as empresas armazenam e estocam materiais e, verificar a situação das mesmas quanto o fornecimento de Equipamentos de Proteção Individual. A empresa A estava de acordo com a grande maioria dos itens, como por exemplo, o fornecimento de EPIs e placas de sinalização. As outras duas apresentaram resultados não muito bons, mas semelhantes. Mas teve um quesito em que todas as três não cumpriram, que foi o fato do cinto de segurança não possuir dispositivo de trava-quedas e não 
estar ligado a cabo de segurança independente da estrutura do andaime.

\subsubsection{MEDIDAS DE SEGURANÇA E SINALIZAÇÃO DO CANTEIRO}

No que se refere as medidas de segurança e sinalização dos canteiros, a única empresa que apresentou aspectos positivos no que tange ao assunto em estudo foi a empresa A, cumpriu na sua grande maioria com os quesitos em análise, tais como, sinalização com objetivo de: alertar quanto à obrigatoriedade do uso de EPI, manter comunicação através de avisos e cartazes, indicar as saídas por meio de dizeres ou setas, dentre outras. Já as empresa B e C não apresentaram sinalizações em seus canteiros e muito menos medidas de prevenção, como por exemplo, equipamentos de combate ao fogo e sinalizações de advertência contra perigo de contato com partes móveis das máquinas e equipamentos, e dessa forma, tendo muito que melhorar.

\subsubsection{CANTEIRO DE OBRAS E TREINAMENTOS}

O presente tópico traz informações acerca dos treinamentos que os colaboradores recebem e, também, do modo como está organizado o canteiro. Os resultados estão sumarizados no Gráfico 2.

\section{Gráfico 2 - Resultados referentes à segurança nos canteiros das obras e treinamento realizado pelas empresas.}

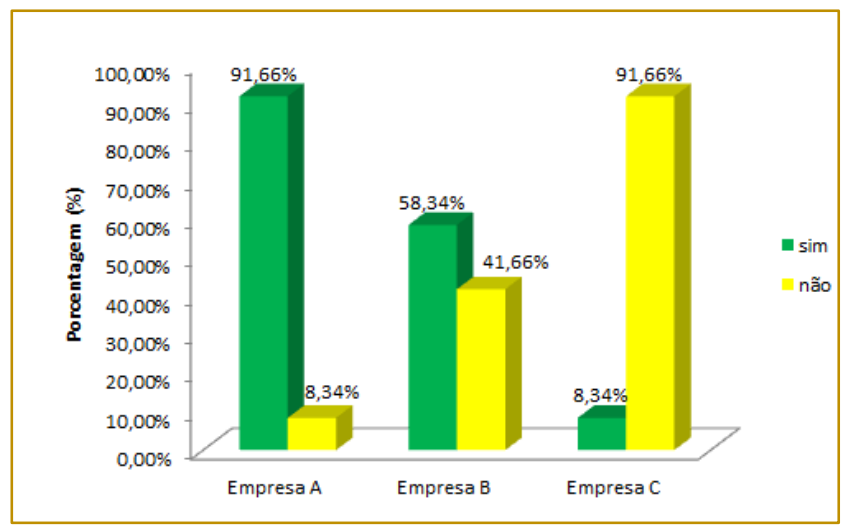

Fonte: Autoria Própria, 2014.

O Gráfico 2 aborda um contraste entre as empresas. A empresa A estava de acordo com os principais itens, exceto, a não entrega das cópias de procedimentos aos trabalhadores que estão envolvidos nas atividades. Já a empresa B, descumpre alguns itens, tais como, desorganização no canteiro, falta de limpeza, os trabalhadores não possuíam cópias de procedimentos e operações a serem realizadas com segurança, dentre outras. E por fim, a empresa C estava de acordo com apenas um item abordado neste quesito, que era a proibição da queima de lixo dentro do canteiro de obras, enquanto que os demais, a empresa não estava cumprindo, dessa forma, não demonstrando preocupação com seus colaboradores e também com a questão da produtividade.

\subsubsection{AVALIAÇÃO DAS CONDIÇÕES DE SAÚDE E HIGIENE}

O presente tópico aborda o perfil das atividades inerentes às condições de saúde e higiene na qual verifica-se aspectos relacionados ao Programa de Controle Médico de Saúde Ocupacional (PCMSO) e das condições das áreas de vivência.

No âmbito da saúde ocupacional, observa-se que as empresas $\mathrm{A}$ e $\mathrm{C}$ não estão de acordo com nenhum item relacionado ao PCMSO, dessa forma, não dando atenção devida à saúde dos trabalhadores, implicando em uma dificuldade maior em diagnosticar precocemente algum dano que possa vir a comprometer a saúde dos mesmos e, também, podem estar sujeitas a multas. Já a empresa B apresentou um resultado satisfatório no que tange ao PCMSO, apresentando todos itens previstos nessa 
análise. Dessa maneira, mostrando uma preocupação com a saúde dos seus colaboradores.

No que se refere às condições das áreas de vivência das empresas, o Gráfico 3 apresenta as condições e, logo abaixo, tem-se os itens baseados na Norma 18 (NR 18) que foram utilizados para efetuar a análise das empresas:

Gráfico 3 - Distribuição dos dados referentes às condições das áreas de vivência das empresas.

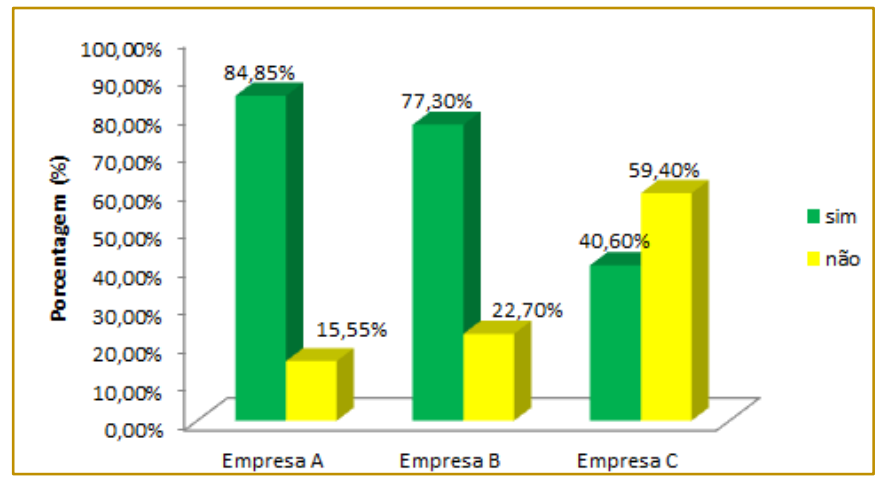

Fonte: Autoria Própria, 2014.

Com base no Gráfico 3 a empresa A apresentou resultados satisfatórios, como também a empresa B e a empresa C ficando a desejar.

A empresa A apresentou deficiências nos vestiários e nos alojamentos. Em ambos não tinha armários individuais com fechaduras, em números suficientes e higienizados. Já a empresa B foi a que apresentou o segundo melhor desempenho no quesito em estudo. Todavia, apresentou um número maior de não conformidades quando comparada com a empresa A. Dentre essas, destaca-se o fato de não ter iluminação e ventilação adequadas nas instalações sanitárias.

Como citado anteriormente, a empresa C foi a que apresentou os piores resultados quando se trata das áreas de vivência. Dentre os diversos itens que não estão de acordo com a norma pode citar a ausência de ventilação e iluminação adequada nas instalações sanitárias, nos alojamentos e nos vestiários. Outro fator importantíssimo em que a empresa não cumpre é a ausência de material para primeiros socorros.

\subsection{RESULTADO FINAL}

(1) Somatório de todos os quesitos $=\frac{n^{\circ} \text { de SIMs encontrados }}{n^{\circ} \text { de quesitos aplicáveis }} \times 100$

EMPRESA $A=(93 / 123) \times 100=75,60 \%$

EMPRESA B $=(65 / 108) \times 100=60,18 \%$

EMPRESA C $=(49 / 108) \times 100=45,37 \%$

(2) Coeficiente de Risco à Saúde = (№ de situações perigosas que configuram risco iminente à saúde) $\times 5 \%$

EMPRESA $A=30 \times 5 \%=15 \%$

EMPRESA B $=43 \times 5 \%=21,5 \%$

EMPRESA C $=59 \times 5 \%=29,5 \%$ 
(3) Resultado Final =(somatório de todos os quesitos)-(Coeficiente de risco à saúde)

EMPRESA A $=75,60 \%-15 \%=60,6 \%$

EMPRESA B $=60,18 \%-21,5 \%=38,68 \%$

EMPRESA C $=45,37 \%-29,5 \%=15,87 \%$

Com base no resultado final, classificou-se de acordo com a pontuação obtida no questionário. A empresa $A$ recebeu classificação "bom" pelo fato de estar compreendido no intervalo entre 60,1 a $80 \%$ da pontuação. Já a empresa $\mathrm{B}$ recebeu a denominação de "ruim" pelo fato de está com pontuação entre $20,1 \%$ a $40 \%$ e a empresa C recebeu a denominação de "péssimo" por está entre 0 a $20 \%$ da pontuação obtida. E as denominações que as empresas não foram enquadradas são a "regular", que está entre 40,1 a $60 \%$, e a "ótimo" que compreende o intervalo de 80,1 a 100\%. O Gráfico 4 apresenta o resultado final das empresas.

Gráfico 4 - Resultado final das empresas.

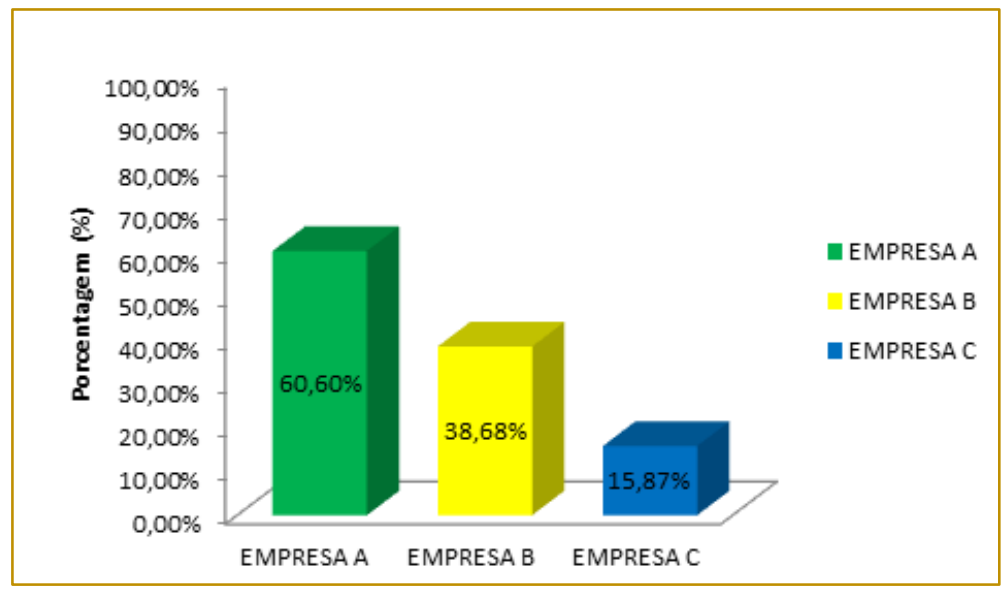

Fonte: Autoria Própria, 2014

De acordo com os dados apresentados, a empresa $A$ se destaca em relação às demais quando o assunto é segurança do trabalho e recebeu uma boa classificação quando comparada com as outras (60,60\%). E a empresa que apresentou pior situação no geral foi à empresa C com 15,87\% de pontuação.

\section{CONCLUSÃO}

A partir desta pesquisa foi possível constatar que quanto maior o número de trabalhadores nas empresas, maior a preocupação com segurança do trabalho. Um dos fatores que mostra tamanha preocupação com a segurança do trabalho, na empresa que apresenta o maior quantitativo de funcionários, é a prática da ginástica laboral, por exemplo. Outro fator que chama a atenção é a atuação dos técnicos de segurança do trabalho nas empresas, pois observa-se que na empresa que apresenta a maior quantidade de funcionários é maior a fiscalização por parte do técnico. Já na outra empresa que tem esse profissional, a fiscalização não era rigorosa quanto na primeira.

No que tange as condições de ambiente de trabalho, apenas a empresa A apresenta resultados adequados em relação aos itens presentes no check list. Já as empresas B e C apresentam resultados insatisfatórios. Dessa forma, nessas últimas, existe uma probabilidade maior de ocorrer acidentes pelo fato de não obedecer aos parâmetros relacionados à segurança do trabalho, como por exemplo, o canteiro está desorganizado, sujo, material impedindo a passagem dos trabalhadores, uso inadequado de EPIs, dentre outros. 
Percebe-se que em todas as empresas há o uso de EPIs. Todavia, nas empresas B e C apresenta ausência do uso de EPIs adequados para cada função. Dessa forma, expondo os colaboradores aos riscos, aumentando assim a chance de ocasionar acidentes. Outro fator relevante é a falta de treinamento dos colaboradores quanto ao uso dos EPIs.

A empresa $A$ se destaca no que se refere às medidas preventivas que as empresas utilizam, pelo fato de ter um canteiro sinalizado, apresenta extintores para combater pequenos focos de incêndio, possui coifa protetora na sua carpintaria, as pontas de vergalhões estão protegidas contra acidentes. Já as outras empresas não apresentam por completo essas medidas.

A empresa C apresenta o pior resultado, dentre as empresas entrevistadas. Talvez por esta não possuir nenhum profissional da área de segurança. Dessa forma, deixando seus

\section{REFERÊNCIAS}

[1] Brasil. Ministério do Trabalho e Emprego. Comissão Interinstitucional de Prevenção aos Acidentes de Trabalho e Doenças Ocupacionais. Programa de Avaliação das Condições de Trabalho da Indústria da Construção Civil. Jundiaí: CEREST, 2003. Disponível em: <http://www.fiocruz.br/biosseguranca/Bis/manuais/ construcao\%20civil/Programa\%20de\%20Avaliacao \%20das\%20Condicoes\%20de\%20Trabalho\%20da \%20Industria\%20da\%20Construcao\%20Civil.pdf>. Acesso em: 05 de abr. 2014.

[2] Cardoso, T. M. Análise de acidentes de trabalho na cidade de Araranguá no segundo semestre de 2009. 70 f. Trabalho de graduação (curso de Engenharia Civil) - Universidade do Extremo Sul Catarinense - UNESC, Criciúma, 2010.

[3] Cosme, Alice Kaliane da Silva. Acidentes do trabalho na perspectiva dos trabalhadores da construção civil na cidade de ASSU/RN. Angicos, 2013.

[4] Grohmann, M. Z. Segurança no trabalho através do uso de epi's: estudo de caso realizado na construção civil de Santa Maria. 7 f. 1997. Disponível

em:< http://www.segurancaetrabalho.com.br/download/e pis-construcao.pdf>. Acesso em: 29 de abr. 2014.

[5] Lobo JR, A. C. C. Segurança do trabalho: perfil das empresas de médio porte da construção colaboradores expostos aos riscos. Já as outras duas empresas apresentam um profissional da área de segurança, fator esse que contribui para uma classificação melhor que a empresa $\mathrm{C}$..

Durante o estudo percebe-se nas empresas, de modo geral, falta de investimento no setor de segurança do trabalho. Dessa forma, recomenda-se que realize cursos inerentes à segurança do trabalho na indústria da construção civil, emprego e uso de EPIs adequados para cada função, capacitação dos colaboradores quanto ao uso correto de EPIs, implantação de um técnico na empresa que não possui esse profissional, melhoria nas instalações sanitárias, o uso do cinto de segurança que possua dispositivo travaquedas e esteja ligado acabo de segurança independente da estrutura do andaime, sinalização dos canteiros, melhoria nas instalações elétricas e que estas sejam realizadas por profissional legalmente habilitado, dentre outras.

civil de feira de Santana, 2008. Monografia (graduação em Engenharia Civil) - Universidade Estadual de Feira de Santana. Feira de Santana, Bahia, 2008.

[6] Pinto, I. C. M. S. Utilização de equipamentos de proteção individual pelos trabalhadores da construção civil no município de Angicos-RN. 43 f. TCC (Graduação - Curso de Ciência e Tecnologia), Universidade Federal Rural do Semi-Árido, Angicos, 2012.

[7] Sebrae. Critérios de Classificação de empresas: El - ME - EPP. Santa Catarina, Disponível em: $<$ http://www.sebraesc.com.br/leis/default.asp?vcdt exto=4154 >. Acesso em: 07 de maio 2014 .

[8] Silva, T. M.; Carreiro, A. A Influência da mão de obra em acidentes na construção civil, $2014 . \quad$ Disponivel em: <http://http://info.ucsal.br/banmon/Arquivos/Art3_00 77. pdf >. Acesso em: 01 maio 2014.

[9] Vieira, S. I. Manual de saúde e segurança do trabalho. Florianópolis: Mestra, v. 2, 2000. Disponível em: <http://www.medicinaetrabalho.med.br/arquivos/Cu stos $\% 20$ e\%

20benef\%C3\%ADcios\%20da\%20seguran\%C3\%A7 a\%20do\%20trabalho.pdf>. Acesso em: 30 de abr. 2014. 


\section{CAPÍTULO 21}

\section{A PERCEPCÃO DOS AGENTES DE RISCO EM FRIGORIFICOS DO EXTREMO OESTE DO PARANÁ}

\section{Grasielly Bruna Vincenzi Rockenbach}

Evandro Andre Konopatzki

Resumo: Objetivando identificar a percepção dos empregados de frigoríficos instalados no Extremo Oeste do Paraná sobre os riscos a que estão expostos foi aplicado um questionário que caracterizou ocorrência de acidentes por setor, função, idade e turno. Os resultados mostraram que as funções com maior índice de acidentes foram as de auxiliar de refeitório, assistente operacional, pedreiro e pintor. Enquanto os agentes ruído, umidade e iluminação foram significativos para a maioria dos entrevistados sendo verificado que os empregados confundem conforto laboral com risco, dado que a maioria respondeu receber os EPI adequados para mitigação e que colocou o agente umidade no ambiente de trabalho. As conclusões enfatizam que as empresas deste setor devem concentrar seus esforços na avaliação dos agentes citados de forma a manter maior controle sobre os mesmos e conscientização dos empregados sobre a eficiência dos EPI fornecidos.

Palavras-chave: Acidente de trabalho, riscos físicos, segurança do trabalho 


\section{INTRODUÇÃO}

O setor de frigorífico impulsionou a economia brasileira nos últimos anos, o que acarretou o aumento do número de acidentes do trabalho e obrigou os órgãos legisladores a criarem uma legislação de segurança específica para este setor. Assim, novas regras surgiram para controlar fatores ambientais de risco, ergonomia, jornada de trabalho, pausas psicofisiológicas e treinamentos; todas com o objetivo de tornar mais seguro e saudável o labor.

Mas os empregados têm uma percepção, por vezes, diferente dos empregadores e, neste contexto, este estudo objetivou identificar se os empregados percebem corretamente os riscos e perigos que existem no seu ambiente de trabalho.

\section{O ACIDENTE DE TRABALHO E A LEGISLAÇÃO CORRELATA}

O acidente do trabalho abrange toda lesão corporal, perturbação funcional ou as doenças produzidas pelo exercício do trabalho ou geradas em consequência dele. (BRASIL, 1934).

Em 1978 foi promulgado o Decreto n. 03.214 pelo qual o Ministério do Trabalho e Previdência Social (MTPS) tornou públicas as Normas Regulamentadoras (NR) relativas à segurança e medicina do trabalho. BRASIL (1978). Atualmente são 36 normas, das quais algumas têm relação direta com as atividades de frigoríficos abatedouros. Sendo:

- NR-01 - Estabelece a obrigatoriedade do cumprimento das normas regulamentadoras por todas as empresas e órgãos que possuem empregados regidos pela Consolidação das Leis do Trabalho (CLT).

Esta NR rege a aplicação da Ordem de Serviço (OS) que traz ao funcionário informações como a seção, atividade e função a serem desempenhadas. Também apresenta os riscos com suas causas potenciais e efeitos sobre a saúde, comentando orientações de segurança, os Equipamentos de Proteção Individual (EPI) e Equipamentos de Proteção Coletiva (EPC) necessários para mitigação ou eliminação dos riscos.

A OS deve ser gerada e assinada em duas vias, uma para o empregador e outra para o empregado. (BRASIL, 2009)
- NR-02 - Institui a Inspeção Prévia relacionada a aprovação das instalações antes do início das atividades de qualquer estabelecimento ou na realização de alterações no ambiente de trabalho. (BRASIL, 1983)

- - NR-03 - Trata das condições de Embargo ou Interdição realizados nas situações de risco grave e iminente aos trabalhadores. (BRASIL, 2011a)

- - NR-04 - Estabelece a obrigatoriedade da implementação e manutenção dos Serviços Especializados em Engenharia de Segurança e em Medicina do Trabalho - SESMT. O quadro técnico de profissionais integrantes do SESMT é composto de Técnico de Segurança do Trabalho, Engenheiro de Segurança do Trabalho, Auxiliar de Enfermagem do Trabalho, Enfermeiro do Trabalho e Médico do Trabalho.

O dimensionamento do SESMT leva em consideração a gradação do risco da atividade principal e o número total de empregados. (BRASIL, 2016f)

Os frigoríficos estão incluídos na Classificação Nacional de Atividades Econômicas - CNAE com código 10.12-1, que denomina o abate de suínos, aves e outros pequenos animais, com grau de risco 3. (BRASIL, 2006)

- $\quad$ - NR-05 - Apresenta a criação de grupos de trabalhadores para discussão dos riscos percebidos na empresa, a Comissão Interna de Prevenção de Acidentes (CIPA).

O acompanhamento da CIPA nas atividades apropria-se dos conhecimentos dos empregados que executam as atividades e conseguem desenvolver planos de ações preventivas para cada risco identificado.

- NR-06 - Apresenta os EPI que devem ser fornecidos e controlados pelo empregador de acordo com o risco da atividade. (BRASIL, 2015b)

- NR-07 - Institui o Programa de Controle Médico de Saúde Ocupacional (PCMSO) para prevenir, rastrear e diagnosticar precocemente os agravos à saúde do trabalhador.

O PCMSO inclui a realização de exames admissionais, periódicos, de retorno ao trabalho, de mudança de função e demissionais. (BRASIL, 2013) 
- NR-09 - Apresenta o Programa de Prevenção de Riscos Ambientais (PPRA) como formalização de procedimentos para análise dos riscos existentes no ambiente laboral, riscos físicos, químicos, biológicos e mecânicos. (BRASIL, 2016a)

- NR-10 - Esta norma tem por objetivo a implementação de medidas de controle e prevenção para trabalhadores que atuam em serviços com eletricidade. As medidas de proteção coletiva compreendem prioritariamente a desenergização ou caso não possível, o emprego de tensão de segurança.

Como medidas de proteção individual estão o uso de vestimentas apropriadas à atividade, atentando-se à condutibilidade, inflamabilidade e influências eletromagnéticas, assim como a proibição do uso de adornos pessoais. (BRASIL, 2016e)

- NR-11 - Trata das regras para transporte, movimentação, armazenagem e manuseio de Materiais referenciando a operação de elevadores, guindastes, transportadores industriais e máquinas transportadoras, bastante comuns na indústria frigorífica, trazendo regras que garantam resistência, segurança e conservação de tais máquinas em perfeitas condições de trabalho. (BRASIL, 2016d)

- NR-12 - Estabelece requisitos mínimos para a prevenção de acidentes no transporte, montagem, instalação, ajuste, operação, limpeza, manutenção, inspeção, desativação e desmonte de máquinas ou equipamentos.

As medidas de proteção devem incluir primeiramente as medidas de proteção coletiva, posteriormente medidas administrativas ou de organização do trabalho, e por último, medidas de proteção individual. (BRASIL, 2016b)

- NR-13 - Aborda regras de segurança para construção e manutenção de caldeiras, vasos de pressão e tubulações, comuns nos frigoríficos. (BRASIL, 2014b)

- NR-15 - Estabelece os limites de tolerância para os agentes insalubres verificados no ambiente por meio do PPRA. (BRASIL, 2014a) Dentre os riscos constatados em frigoríficos abatedouros, os mais comuns são:

a) Ruído - abordado nos Anexos N. 01 e 02 da NR-15, é compreendido como som indesejável, perturbador e desagradável, produzido na indústria frigorífica por máquinas, equipamentos ou processos, e que possuem potencial para causar danos à saúde humana. (BRASIL, 2014a)

b) Umidade - descrita no Anexo N. 10 da NR15, descreve como insalubres as atividades e operações realizadas em locais com umidade em excesso, que causem dano à saúde do trabalhador. (BRASIL, 2014a)

c) Temperatura - Para o calor excessivo, o Anexo N. 3 da NR-15 regulamenta os limites de tolerância para exposição ao calor através do Índice de Bulbo Úmido Termômetro de Globo (IBUTG). (BRASIL, 2014a)

Já para o frio, o Anexo N. 09 vincula o limite de tolerância às regiões climáticas do Instituto Brasileiro de Geografia e Estatística (IBGE). Sendo considerado labor insalubre ambiente inferior a $10{ }^{\circ} \mathrm{C}$ na $5^{\underline{a}}$ região - local abrangido neste estudado - quando não forem entregues vestimentas adequadas. (BRASIL, 2014a e BRASIL, 2002)

A desossa de carcaças provenientes do resfriamento deve possuir ambiente de ar condicionado a uma temperatura que não exceda a $16^{\circ} \mathrm{C}$. Nas câmaras de estocagem de congelados a temperatura não deve ser superior a $-18^{\circ} \mathrm{C}$. Já nas câmaras de resfriamento de carcaças a temperatura deve atingir de $1^{\circ} \mathrm{C}$ a $-1^{\circ} \mathrm{C}$. $\mathrm{E}$ nas câmaras de carnes resfriadas deve ser de $0^{\circ} \mathrm{C}$. (BRASIL, 1995)

d) Vibração - Este risco físico é caracterizado insalubre desde que seja superado o limite diário de exposição de mãos e braços ou corpo inteiro. (BRASIL, 2014a)

- NR-16 - Determina as atividades e operações consideradas perigosas, como explosivos, inflamáveis, segurança pessoal e patrimonial, eletricidade, motociclismo, radiações ionizantes ou substâncias radioativas. (BRASIL, 2015a)

- NR-17 - Propõe adaptação do trabalho às condições psicofisiológicas do trabalhador, com objetivo de proporcionar conforto, segurança e eficiência durante a jornada por meio de Análise Ergonômica do Trabalho - AET. (BRASIL, 2007)

- NR-24 - Designa os requisitos mínimos para conforto nos locais de trabalho, no caso dos frigoríficos o isolamento das privadas deve ser feito da forma mais rigorosa possível, para evitar a poluição e 
contaminação dos locais de trabalho.

Esta norma prevê um consumo de 60 litros de água por empregado, vestiários separados por sexo, com armários individuais e refeitório. (BRASIL, 1993)

- NR-25 - Define a coleta, acondicionamento, armazenamento, transporte, tratamento e encaminhamento dos resíduos industriais e, principalmente, aborda a necessidade de construção de ações de proteção à segurança e saúde dos trabalhadores envolvidos neste processo. (BRASIL, 2011C)

- NR-26 - Delimita áreas, identifica de tubulações e equipamentos de segurança por cores, para facilitar o entendimento do trabalhador em interpretar a rotulagem e prevenção. Informando os perigos, os riscos, as medidas preventivas e $\mathrm{O}$ procedimento em caso de emergência. (BRASIL, 2015c)

- NR-33 - Define espaço confinado e apresenta as regras para trabalhos por meio de treinamentos e uso de Permissão de Entrada e Trabalho (PET). (BRASIL, 2012)

- NR-35 - Aborda o trabalho em altura a fim de garantir aos trabalhadores informações atualizadas sobre os riscos e as medidas de controle em altura. (BRASIL, 2016c)

- NR-36 - Especifica as particularidades das indústrias abatedouras e de processamento de carnes e seus derivados apresentando regras de adequação das rotinas às condições ambientais.

Esta norma busca orientar as empresas a organizar as atividades, gerenciar os riscos e disponibilizar as informações, causas, efeitos e medidas de prevenção através de treinamentos em segurança e saúde no trabalho.

Ela abrange todos os trabalhadores, desde a recepção até a expedição, prevê pausa de 10 a 20 minutos ao longo da jornada, totalizando 60 minutos a serem distribuídos de forma a não coincidir com a primeira hora de trabalho, próxima ao intervalo das refeições ou última hora de trabalho. (BRASIL, 2016g)

\section{METODOLOGIA}

O levantamento de dados consistiu na percepção dos agentes causadores de doenças ou de acidentes de trabalho pelos empregados dos frigoríficos e na quantificação dos acidentes ocorridos nas unidades abatedouros da microrregião de Medianeira - PR, isto por meio de um questionário aplicado juntamente com o Sindicato dos Trabalhadores em Cooperativas Agropecuárias, Agrícolas e Agroindustriais (SINTRASCOOM).

A motivação da pesquisa se deu pela estatística de que $10 \%$ da população do município trabalha nos abatedouros da região, onde localizam-se várias unidades de frigoríficas de suínos e de aves.

A pesquisa foi realizada por meio de um questionário, aplicado à 50 pessoas, 25 pessoas do gênero feminino e 25 do gênero masculino, em sua maioria na faixa etária de 19 à 29 anos, conforme gráfico a seguir. Todos os questionários foram aplicados com consentimento dos entrevistados, sendo avaliado e aprovado pelo conselho de ética da Universidade Tecnológica Federal do Paraná.

\subsection{QUESTIONÁRIO}

O questionário é constituído de perguntas gerais, apresentadas com o intuito de conhecer os trabalhadores de frigoríficos da região nos aspectos gênero, idade, profissão, horário de trabalho, boas condições de higiene e segurança, classificação do ambiente de trabalho relativamente aos fatores iluminação, ruído, vibrações, temperatura e umidade; ocorrência de acidente de trabalho; identificação pelo trabalhador do risco a que está exposto, qualidade, segurança e conforto dos equipamentos de proteção disponibilizados pela empresa e seu uso em toda a jornada de trabalho; e promoção de treinamento periódico na área de segurança.

Estas perguntas trazem informações sobre a ocorrência de acidentes do trabalho, como turnos e setores onde há maior número de acidentes, levantando prováveis razões para o acontecimento, como a natureza da atividade e riscos envolvidos no processo. Através destas, pretende-se constatar se há percepção por parte do trabalhador dos efeitos da repetitividade e ritmo intenso, bem como dos riscos a que estão expostos e do modo de organização produtiva dentre as causas de acidente do trabalho.

Os dados foram apresentados na forma 
gráfica e analisados estatisticamente de forma quantitativa e descritiva.

\section{RESULTADOS E DISCUSSÕES}

A faixa etária dos entrevistados mostra que os trabalhadores de frigoríficos apresentam uma

Gráfico 1 - Faixa etária dos entrevistados

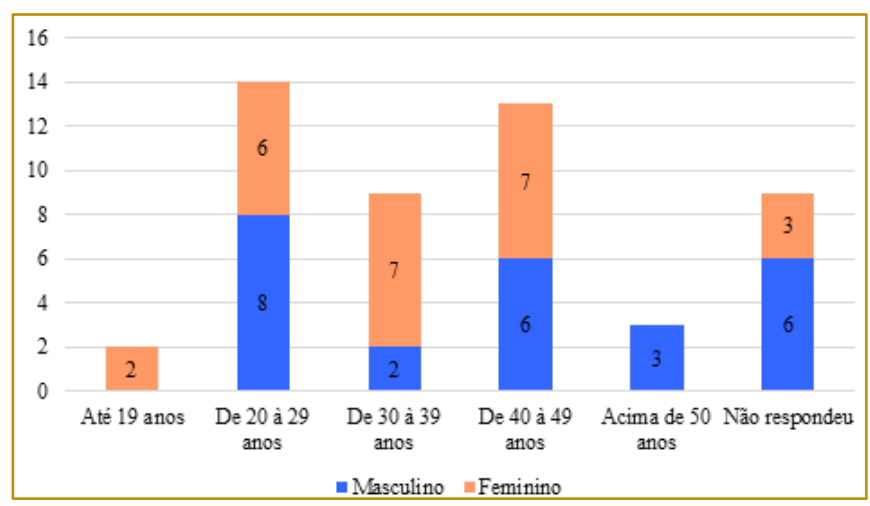

Fonte: Autor idade média de 30,7 anos, sendo que a moda se encontra na faixa de 20 a 29 anos implicando na afirmação de que a maioria dos empregados de frigoríficos possui menos de 30 anos de idade.
Do gráfico 1 se observa que o número de trabalhadores do gênero feminino é igual ao do gênero masculino, ambos correspondendo a $50 \%$ cada.

O número de entrevistados no $1^{\circ}$ turno, onde a jornada de trabalho é das 6:00 hs às 15:45 hs foi 29 trabalhadores, assim como 20 entrevistados no $2^{\mathrm{o}}$ turno com jornada iniciando às 16:00 hs até às 01:25 hs e 1 entrevistado com jornada de trabalho das 00:30 hs até às 06:00 hs, pertencendo ao $3^{\text {o }}$ turno. No $1^{\circ}$ turno $41,38 \%$ dos trabalhadores sofreram acidentes, enquanto que no $2^{\circ}$ turno o índice de acidentes é de $20 \%$ e no 3 o turno de $100 \%$.

É através do fator biológico que ocorre o controle das funções vitais no organismo do trabalhador, portanto com a mudança de rotina do dia para a noite há inversão no funcionamento do organismo. A produção de muitos hormônios fundamentais, o descanso de fato e a reposição de energia se dão somente à noite, na ausência de luz, com temperatura corporal mais baixa e presença de hormônios reguladores do sono.

Outro fator relacionado à diminuição da qualidade de vida e aumento de acidentes do trabalho é a alimentação, que quando disponível na empresa muitas vezes não é adaptada ao período noturno. A dificuldade em conciliar horários de lazer com a família e amigos promove o distanciamento social, que quando agregado a outros fatores promove a fadiga e o estresse do trabalhador, o que reflete no número de acidentes por tuno.

Dentre o número de acidentados a função mais significativa nos frigoríficos é de auxiliar de produção, correspondente a $62 \%$ dos entrevistados, seguido por operador de máquinas, $6 \%$, e posteriormente auxiliar de refeitório, assistente operacional, pedreiro e pintor, que representam individualmente $2 \%$ do total de trabalhadores entrevistados em cada função. No gráfico 2 são apresentados os acidentes por função. 
Gráfico 2 - Acidentes por função

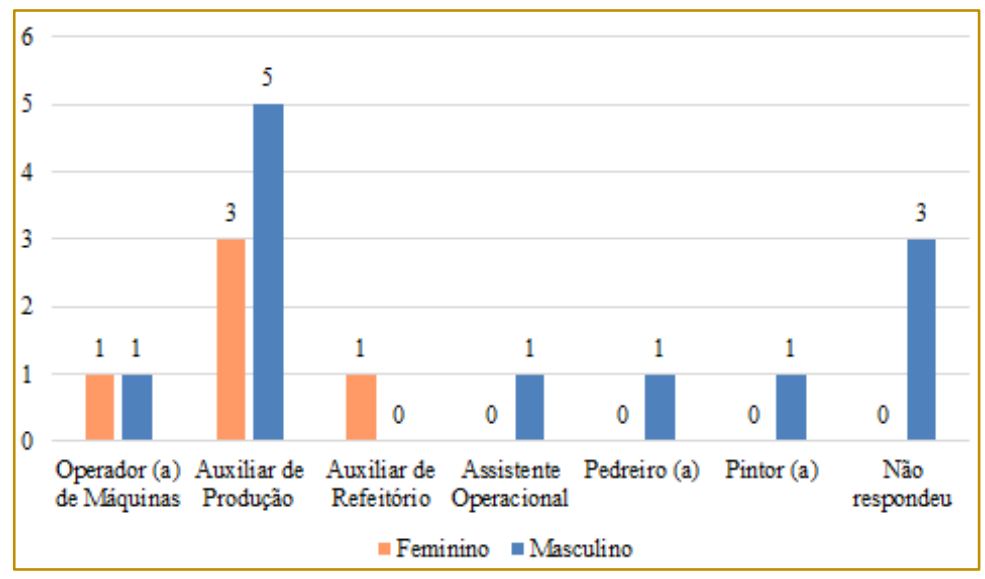

Fonte: Autor

Foi constatado que o número de acidentes foi maior entre os homens $(70,6 \%)$ do que com as mulheres $(29,4 \%)$, sem levar em consideração gravidade, agente causador, turno de trabalho, entre outros fatores.

Uma provável causa se dá pelas diferentes funções que ambos desempenham, em que o gênero masculino desempenha funções classificadas com maior risco - como pedreiro e pintor, por exemplo - e por ocupar postos de trabalho que envolvem maior atividade braçal.

A porcentagem de trabalhadores acidentados por função para auxiliar de produção é de $26 \%$, assim como de $66 \%$ para operador de máquinas e 100\% para auxiliar de refeitório, assistente operacional, pedreiro e pintor. Portanto, apesar da função auxiliar de produção ser mais representativa em número de acidentes, é também a função com maior número de trabalhadores. Assim sendo, proporcionalmente, as funções que mais geram acidentes são auxiliar de refeitório, assistente operacional, pedreiro e pintor, todas com um índice de 100\% dos trabalhadores acidentados.

\section{Gráfico 3 - Riscos físicos}

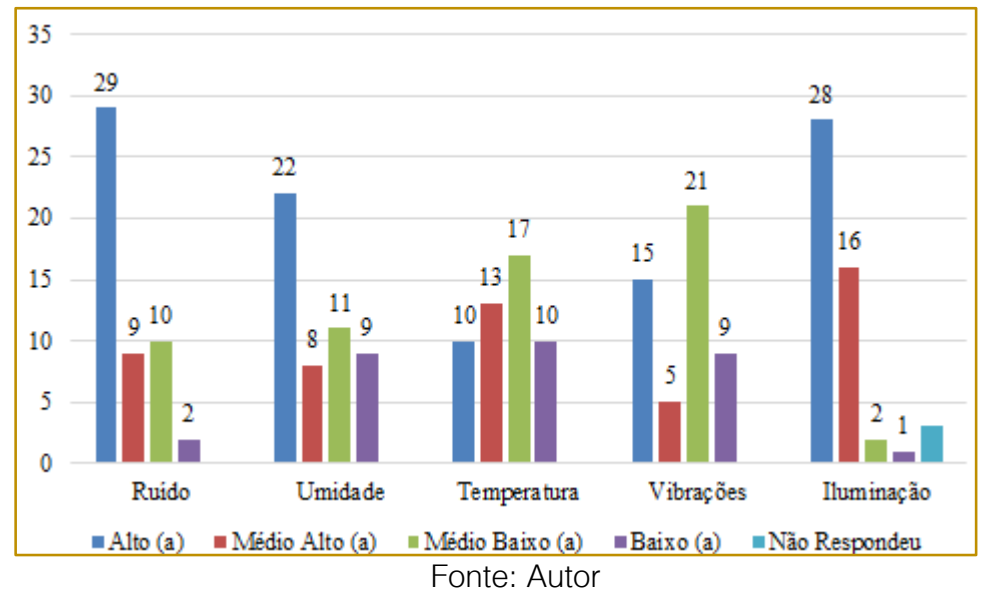

Apesar de $100 \%$ dos entrevistados terem respondido receber os EPI's adequados para o risco de sua função, observa-se, por meio do gráfico 3, que há uma percepção de que os riscos físicos ruído são altos (58 \%) e que a umidade apresenta alto risco para $44 \%$ dos entrevistados.

Já a iluminação representa alto risco para
56 \% dos entrevistados e não há EPI para este agente, logo as empresas frigoríficas devem gerar planos de ação para constatação dos níveis de iluminância nos diversos setores da empresa. 


\section{CONCLUSÕES E RECOMENDAÇÕES}

O levantamento da percepção dos acidentes e dos riscos a que os empregados dos abatedouros estão expostos mostrou que as empresas do setor devem direcionar esforços para as funções auxiliar de refeitório, assistente operacional, pedreiro e pintor, uma vez que estas mostraram maiores índices de acidente.

Ainda foi constatado que os agentes ruído, umidade e iluminação devem ser objeto de investigação do SESMT e da CIPA.

As empresas devem usar os treinamentos e

\section{REFERÊNCIAS}

[1] Brasil. CLT Decreto $n^{\circ} 24.637$, de 10 de Julho de 1934. Diário Oficial [da] União. República Federativa do Brasil, Rio de Janeiro, 10/07/1934. Dos Acidentes do Trabalho. Disponível em:<http://www2.camara.leg.br/legin/fed/decret/19 30-1939/decreto-24637-10-julho-1934-505781-

publicacaooriginal-1-pe.html> Acesso em 26 de Fevereiro de 2017.

[2] Brasil. Concla Resolução Concla $n^{\circ} 1$, de 04 de Setembro de 2006. Diário Oficial [da] União. República Federativa do Brasil, Brasília, 05/09/2006. Classificação Nacional de Atividades Econômicas 2.0. Disponível em: <http://concla.ibge.gov.br/images/concla/documen tacao/ResConcla1-2006.pdf> Acesso em 25 de Abril de 2017

[3] Brasil. Portaria MAPA no 711, de 01 de Novembro de 1995. Diário Oficial [da] União. Poder Executivo, Brasília, DF, 03/11/1995. 1995. Normas Técnicas de Instalações e Equipamentos para Abate e Industrialização de Suínos. Disponível em: $<$

http://www3.servicos.ms.gov.br/iagro_ged/pdf/714_ GED.pdf> Acesso em 26 de Abril de 2017.

[4] Brasil. Portaria MTb no 1.109, de 21 de Setembro de 2016. Diário Oficial [da] União. Poder Executivo, Brasília, DF, 21/09/2016. 2016a. NR 09 Programa de Prevenção de Riscos Ambientais. Disponível

em:<http://trabalho.gov.br/images/Documentos/SS T/NR/NR09/NR-09-2016.pdf> Acesso em 14 de Março de 2017

[5] Brasil. Portaria MTb no 1.111, de 21 de Setembro de 2016. Diário Oficial [da] União. Poder Executivo, Brasília, DF, 22/09/2016. 2016b. NR 12 Segurança no Trabalho em Máquinas e Equipamentos. Disponível em:<http://www.trabalho.gov.br/images//Document os/SST/NR/NR12/NR12.pdf> Acesso em 15 de Março de 2017. as semanas internas de prevenção para apresentar os riscos e perigos existentes e, conscientizar os empregados sobre tais condições, não deixando de ouvi-los por saber que são os conhecedores do ambiente que laboram e das suas deficiências.

\section{AGRADECIMENTOS}

À Universidade Tecnológica Federal do Paraná.

Ao Sindicato dos Trabalhadores em Cooperativas Agropecuárias, Agrícolas e Agroindustriais.

[6] Brasil. Portaria MTb no 1.113, de 21 de Setembro de 2016. Diário Oficial [da] União. Poder Executivo, Brasília, DF, 22/09/2016. 2016c. NR 35 Trabalho em Altura. Disponível em:<http://trabalho.gov.br/images/Documentos/SS T/NR/NR35/NR-35-2016.pdf> Acesso em 18 de Abril de 2017.

[7] Brasil. Portaria MTE n 05, de 07 de Janeiro de 2015. Diário Oficial [da] União. Poder Executivo, Brasília, DF, 08/01/2015. 2015a. NR 16 Atividades e Operações Perigosas. Disponível em:

[8] <http://trabalho.gov.br/images/Documento s/SST/NR/NR16.pdf> Acesso em 12 de Abril de 2017.

[9] Brasil. Portaria MTE no 1.297, de 13 de Agosto de 2014. Diário Oficial [da] União. Poder Executivo, Brasília, DF, 14/08/2014. 2014a. NR 15 Atividades e Operações Insalubres. Disponível em:<http://trabalho.gov.br/images/Documentos/SS T/NR/NR15/NR15-ANEXO15.pdf> Acesso em 06 de Fevereiro de 2017

[10] Brasil. Portaria MTE $n-1.409$, de 29 de Agosto de 2012. Diário Oficial [da] União. Poder Executivo, Brasília, DF, 31/08/2012. 2012. NR 33 Segurança e Saúde nos Trabalhos em Espaços Confinados. Disponível em: <http http://trabalho.gov.br/images/Documentos/SST/NR/ NR33.pdf> Acesso em 15 de Abril de 2017.

[11] [16] Brasil. Portaria MTE no 1.892, de 09 de Dezembro de 2013. Diário Oficial [da] União. Poder Executivo, Brasília, DF, 11/12/2013. 2013. NR 07 Programa de Controle Médico de Saúde Ocupacional. Disponível em:<http://trabalho.gov.br/images/Documentos/SS T/NR/NR7.pdf> Acesso em 10 de Abril de 2017.

[12] Brasil. Portaria MTE $n^{\circ} 3.214$, de 08 de Junho de 1978. Diário Oficial [da] União. Poder Executivo, Brasília, DF, 08/06/1978. 1978. Normas Regulamentadoras. Disponível em: <http://www.camara.gov.br/sileg/integras/839945.p df > Acesso em 01 de Março de 2017. 
[13] Brasil. Portaria MTE no 505, de 16 de Abril de 2015. Diário Oficial [da] União. Poder Executivo, Brasília, DF, 17/04/2015. 2015b. NR 06 Equipamento de Proteção Individual - EPI. Disponível

em:<http://trabalho.gov.br/images/Documentos/SS T/NR/NR6.pdf> Acesso em 17 de Março de 2017.

[14] Brasil. Portaria MTE no 594, de 28 de Abril de 2014. Diário Oficial [da] União. Poder Executivo, Brasília, DF, 02/05/2014. 2014b. NR 13 Caldeiras, Vasos de Pressão e Tubulações. Disponível em:<http://trabalho.gov.br/images/Documentos/SS T/NR/NR13.pdf> Acesso em 15 de Março de 2017.

[15] BRASIL. Portaria MTE n 704, de 28 de Maio de 2015. Diário Oficial [da] União. Poder Executivo, Brasília, DF, 29/05/2015. 2015c. NR 26 Sinalização de Segurança. Disponível em:<http://trabalho.gov.br/images/Documentos/SS T/NR/NR26.pdf> Acesso em 13 de Abril de 2017.

[16] Brasil. Portaria MTPS n505, de 29 de Abril de 2016. Diário Oficial [da] União. Poder Executivo, Brasília, DF, 02/05/2016. 2016d. NR 11 Transporte, Movimentação, Armazenagem e Manuseio de Materiais. Disponível em: <http http://trabalho.gov.br/images/Documentos/SST/NR/ NR11.pdf> Acesso em 10 de Abril de 2017.

[17] Brasil. Portaria MTPS no508, de 29 de Abril de 2016. Diário Oficial [da] União. Poder Executivo, Brasília, DF, 02/05/2016. 2016e. NR 10 Segurança em Instalações e Serviços em Eletricidade. Disponível

em:<http://trabalho.gov.br/images/Documentos/SS T/NR/NR-10-atualizada-2016.pdf> Acesso em 09 de Abril de 2017

[18] Brasil. Portaria MTPS no510, de 29 de Abril de 2016. Diário Oficial [da] União. Poder Executivo, Brasília, DF, 02/05/2016. 2016f. NR 04 Serviço Especializado em Engenharia de Segurança e em Medicina do Trabalho. Disponivel em: <http://trabalho.gov.br/images/Documentos/SST/N R/NR4.pdf> Acesso em 03 de Abril de 2017.

[19] Brasil. Portaria MTPS no 511, de 29 de Abril de 2016. Diário Oficial [da] União. Poder Executivo, Brasília, DF, 02/05/2016. 2016g. NR 36 Segurança e Saúde no Trabalho em Empresas de Abate e Processamento de Carnes e Derivados. [27]
Disponível em: <http://trabalho.gov.br/images/Documentos/SST/N R/NR36.pdf> Acesso em 15 de Março de 2017.

[20] Brasil. Portaria SIT nำ13, de 21 de Junho de 2007. Diário Oficial [da] União. Poder Executivo, Brasília, DF, 26/06/2007. 2007. NR 17 Ergonomia. Disponível

em:<http://trabalho.gov.br/images/Documentos/SS T/NR/NR17.pdf> Acesso em 10 de Abril de 2017.

[21] Brasil. Portaria SIT nำ199, de 17 de Janeiro de 2011. Diário Oficial [da] União. Poder Executivo, Brasília, DF, 19/01/2011. 2011a. NR 03 Embargo ou Interdição. Disponível em:<http://trabalho.gov.br/images/Documentos/SS T/NR/NR3.pdf> Acesso em 05 de Abril de 2017.

[22] Brasil. Portaria SIT n-253, de 04 de Agosto de 2011. Diário Oficial [da] União. Poder Executivo, Brasília, DF, 08/08/2011. 2011b. NR 25 Resíduos Industriais. Disponível em:<http://trabalho.gov.br/images/Documentos/SS T/NR/NR25.pdf> Acesso em 13 de Abril de 2017.

[23] Brasil. Portaria SIT no84, de 04 de Março de 2009. Diário Oficial [da] União. Poder Executivo, Brasília, DF, 12/03/2009. 2009. NR 01 Disposições Gerais. Disponível em: <http://trabalho.gov.br/images/Documentos/SST/N R/NR1.pdf> Acesso em 03 de Abril de 2017.

[24] Brasil. Portaria SSMT n35, de 28 de Dezembro de 1983. Diário Oficial [da] União. Poder Executivo, Brasília, DF, 29/12/1983. 1983. NR 02 Inspeção Prévia.Disponível em:<http://trabalho.gov.br/images/Documentos/SS T/NR/NR2.pdf> Acesso em 06 de Abril de 2017.

[25] Brasil. Portaria SSST $\mathrm{n}-13$, de 17 de Setembro de 1993. Diário Oficial [da] União. Poder Executivo, Brasília, DF, 21/09/1993. 1993. NR 24 Condições Sanitárias e de Conforto nos Locais de Trabalho. Disponível em:[42] <http://trabalho.gov.br/images/Documentos/SST/N R/NR24.pdf> Acesso em 15 de Abril de 2017.

[26] Brasil. Mapa de Clima do Brasil. Rio de Janeiro: IBGE, 2002. Escala 1: 5000000. Disponível em:<http://portaldemapas.ibge.gov.br/portal.php\# mapa852> Acesso em 25 de Abril de 2017 


\section{GAPÍTULO 22}

\section{LEVANTAMENTO DO RISCO FÍSICO RUİDO: UM ESTUDO DE CASO NUMA MARCENARIA NA CIDADE DE CAMPINA GRANDE}

\section{Luan Emerson Soares de Lima}

\section{Antonio Carlos de Queiroz Santos}

Suelyn Fabiana Aciole Morais de Queiroz

Vanessa Nobrega da Silva

Resumo: Este trabalho consiste em um estudo de caso fundamentado no objetivo central de levantar os riscos ambientais e ocupacionais presentes em uma empresa do ramo moveleiro localizada na cidade de Campina Grande. A organização possui duas unidades ou plantas produtivas que trabalham de forma independente e produzem artefatos de madeira sob encomenda, uma manufatura portas e esquadrias, e a outra produz móveis planejados. Quanto ao processo metodológico presente neste estudo de caso, inicialmente delimitaram-se os objetivos geral e específicos, então foi desenvolvido o levantamento bibliográfico dos assuntos ligados ao tema da pesquisa, posteriormente foram realizadas visitas a empresa para o reconhecimento das unidades produtivas e realizadas medições quantitativas no ambiente laboral, buscando mensurar os valores do ruído. O agente físico quantificado foi o ruído, no qual obteve valores médios emitido pelas máquinas da planta de portas e esquadrias através das máquinas em cada bancada durante as atividades de manufatura de uma porta, pode-se constatar que a máquina desengrossadeira apresentou o maior nível de pressão sonora. Já os valores médios do ruído emitido pelas máquinas da planta de móveis planejados emitidos pelas máquinas em cada bancada durante as atividades para produção de móveis planejados foi a serra circular.

Palavras-chave: Riscos, Ruído, Máquinas, Marcenaria. 


\section{INTRODUÇÃO}

Com a incorporação da energia a vapor aos processos produtivos na Europa no século XVIII, deu-se o princípio da industrialização do continente, a partir desse advento que recebeu o nome de Primeira Revolução Industrial, a atividade produtiva deixou de ser majoritariamente manual e artesanal e passou a ser em escala. Tal evento intensificou a exploração e o consumo da força de trabalho, submetida a condições laborais desumanas. Cresce então, o número de doentes, mutilados e mortos nos ambientes de trabalho (TEIXEIRA, 2012).

Durante a Segunda Guerra Mundial as condições de trabalho nas indústrias ainda eram excessivamente exaustivas e hostis. No entanto, o custo decorrente de mortes ligadas a acidentes de trabalho, ou mais frequentemente por doenças relacionadas a atividades laborais, começou a ser sentido por empregadores e companhias de seguro, que tinham de pagar pesadas somas de dinheiro em indenizações por incapacitações provocadas pelo trabalho (FUNDACENTRO, 2001).

No Brasil, a Saúde e Segurança do Trabalho e a Higiene Ocupacional são definidas por normas e leis, como a Consolidação das Leis do Trabalho (CLT) e as Normas Regulamentadoras, além de leis complementares como portarias, decretos e convenções internacionais da Organização Internacional do Trabalho (OIT) e Organização Mundial da Saúde (OMS) (MACHADO, 2016).

Atualmente no ambiente laboral, metas de produtividade abusivas são supervalorizadas. Trabalhadores então são expostos a condições laborais exaustivas, ultrapassando seus limites físicos e mentais para atender às exigências produtivas, potencializando assim a probabilidade de adoecerem devido às precárias condições de trabalho, comprometendo a saúde por medo do desemprego. A invisibilidade social dos agravos à saúde do trabalhador também representam conseqüências de um contexto social que banaliza as formas precárias de trabalho (BUTIERRES; MENDES, 2016).

Agravos que comprometem a saúde do trabalhador no Brasil apresentam grande relevância e desafiam as políticas públicas, a atuação do Estado e a gestão empresarial, requerendo assim, ações coordenadas e amplas que corroborem para reduzir os danos aos trabalhadores, ao orçamento da
Seguridade Social e à economia nacional (Ministério do Trabalho e Emprego, 2015).

Conforme Filipe (2010), o segmento de móveis sob encomenda é explorado majoritariamente por micro e pequenas empresas, em geral marcenarias, que atendem predominantemente ao mercado doméstico e utilizam como matéria-prima a madeira compensada conjugada em associação com madeiras nativas. Os equipamentos, bem como as instalações características desse tipo de empreendimento são quase sempre ultrapassados e deficientes. O Bureau Internacional do Trabalho (2009) reitera que qualquer condição de trabalho deficiente pode afetar a saúde e a segurança de um trabalhador.

Logo o presente trabalho baseia-se na necessidade de uma empresa de pequeno porte do ramo moveleiro da cidade Campina Grande em realizar o levantamento do risco físico ruído ao qual os trabalhadores estão expostos.

\section{REFERENCIAL TEÓRICO}

\subsection{BRASIL E SEGURANÇA DO TRABALHO}

Conforme Santos (2011), no Brasil, a adoção de normas e práticas de proteção à saúde dos trabalhadores ocorreu de forma tardia em relação aos países de economia central. Durante o período colonial e imperial (15001889), grande parte do trabalho braçal era realizada por escravos (índios e negros) e homens livres pobres. Logo, a preocupação com condições de segurança e saúde no trabalho era pequena e essencialmente privada. O desenvolvimento de uma legislação de proteção aos trabalhadores, então se deu durante a República Velha (1889- 1930) em virtude do processo de industrialização do País.

Inicialmente esparsa, a legislação trabalhista foi ampliada com a Consolidação das Leis do Trabalho, instituída pelo Decreto-Lei ${ }^{\circ} 5.452$, de 10 de maio de 1943, no governo do então Presidente da República Getúlio Vargas. A CLT buscou atender as demandas sociais e trabalhistas e as manteve sob o controle do Estado, nesse momento também foi criado o Ministério do Trabalho, Indústria e Comércio. Inúmeros conceitos originais dessa legislação ainda são utilizados até hoje, como o conceito de empregador e empregado, as características do vínculo empregatício e do contrato de trabalho, a Justiça do Trabalho e 
o Ministério Público do Trabalho, entre outros (MACHADO, 2016).

Pode-se afirmar que a concepção da saúde ocupacional no Brasil, do ponto de vista da regulamentação legal, deu-se em 22 de dezembro de 1977, com a entrada em vigor da Lei no 6.514, que determinou a nova redação ao Capítulo $V$ da Consolidação das Leis do Trabalho intitulada "Da Segurança e da Medicina do Trabalho". Neste capítulo, os serviços especializados em segurança e medicina do trabalho estão previstos no Art. 162, posteriormente foram disciplinados pela Norma Regulamentadora - NR-4 da Portaria $n^{\circ}$ 3.214, de 8 de junho de 1978 (TEIXEIRA, 2012).

A Constituição de 1988 ampliou no País as atribuições e responsabilidades dos estados e municípios na área de Saúde e Segurança do Trabalho. Foram revisadas algumas Normas Regulamentadoras e instaurados programas de prevenção, visando à preservação da saúde e a integridade física dos trabalhadores. Surgem, dessa forma, no âmbito do Ministério do Trabalho, o Programa de Prevenção de Riscos Ambientais (PPRA), o Programa de Controle Médico em Saúde Ocupacional (PCMSO), o Programa de Proteção Respiratória (PPR), o Programa de Conservação Auditiva (PCA), o Programa de Condições e Meio Ambiente de Trabalho na Indústria da Construção (PCMAT) e o Programa de Prevenção Ocupacional ao Benzeno (PPEOB) (FUNDACENTRO, 2001).

A abertura comercial brasileira a partir da década de 90 teve conseqüências sobre a saúde do trabalhador, decorrentes da adoção de novas tecnologias, de métodos gerenciais e da precarização das relações de trabalho (BRASIL, 2001).

A precarização do trabalho caracteriza-se pela desregulamentação da legislação trabalhista, com a legalização dos trabalhos temporários, a informalização do trabalho e a terceirização. Como consequências pode-se citar o aumento do número de trabalhadores autônomos, o aumento da jornada de trabalho, o acúmulo de funções, a maior exposição dos colaboradores a fatores de riscos que possam comprometer sua saúde, o descumprimento de regulamentos de proteção à saúde e segurança, o rebaixamento dos níveis salariais e o aumento da instabilidade no emprego. No que concerne a implantação de métodos gerenciais e novas tecnologias, intensificou-se a rotina de trabalho, assim como à instabilidade no emprego, modificando o perfil de adoecimento e sofrimento do trabalhador, possibilitando a prevalência de doenças relacionadas ao trabalho, como as Lesões por Esforços Repetitivos, os Distúrbios Osteomusculares Relacionados ao Trabalho, além do estresse e da fadiga física e mental (BRASIL, 2001).

O número de vínculos formais cujos trabalhadores sofreram afastamentos devido a acidentes de trabalho típico, acidentes de trajeto ou doença ocupacional chegaram a 557 mil em 2014 no Brasil. Quando comparado a 2004, esse número apresenta uma taxa de crescimento de crescimento de 23,7\% (DIEESE, 2016).

Ao redor do mundo calcula-se que cerca de 2,34 milhões de pessoas morrem anualmente em virtude de acidentes e doenças relacionados com o trabalho. Desse total, cerca de 2,02 milhões morrem de um vasto leque de doenças ligadas à atividade profissional (ORGANIZAÇÃO INTERNACIONAL DO TRABALHO, 2013).

As doenças ocupacionais promovem um extremo sofrimento e perdas de produtividade. Apesar de serem responsáveis anualmente pela morte de seis vezes mais pessoas do que os acidentes de trabalho no mundo permanecem em grande medida invisíveis. A natureza das doenças ocupacionais está mudando rapidamente, as mudanças tecnológicas e sociais, aliadas às condições da economia mundial, agravam os atuais perigos para a saúde e geram novos fatores de risco (ORGANIZAÇÃO INTERNACIONAL DO TRABALHO, 2013).

Salienta-se dessa forma a importância da evolução da legislação trabalhista para a preservação da saúde do trabalhador e os prejuízos que a exposição aos riscos ocupacionais e ambientais podem causar ao funcionário.

\subsection{RISCOS}

O risco pode ser definido como a combinação da probabilidade de um acontecimento e das suas consequências. $O$ simples fato de existir atividade, abre a possibilidade de ocorrência de eventos ou situações cujas consequências constituem oportunidades para obter vantagens (lado positivo) ou então ameaças ao sucesso (lado negativo) (FEDERAÇÃO 
DAS ASSOCIAÇÕES EUROPEIAS DE GESTÃO DE RISCOS, 2002).

Fundacentro (2001) define risco ocupacional como sendo a combinação entre o tempo de exposição aos fatores de risco e a gravidade dos efeitos da exposição ao agente para a saúde.

A exposição corresponde ao contato entre o agente e o receptor. Se não há esta interação, não existe a possibilidade de ocorrer o dano. A exposição leva em consideração a intensidade ou a concentração do agente no ambiente, a freqüência e tempo que o trabalhador está em contato com o agente (FUNDACENTRO, 2001).

Segundo Fundacentro (2001) os riscos podem ser divididos em duas categorias, de acordo com o Quadro 1, os riscos ambientais, que concerne na probabilidade de ocorrência de uma situação adversa ao ambiente ou seres que habitam nele e os riscos ocupacionais que provêm da possibilidade de uma pessoa sofrer determinado dano a sua saúde em virtude das condições de trabalho.

Quadro 1 - Categorias dos riscos laborais

\begin{tabular}{|l|c|}
\hline \multirow{2}{*}{ Classificação dos Riscos } \\
\cline { 2 - 2 } Riscos Ambientais & Físicos \\
\cline { 2 - 2 } & Químicos \\
\hline \multirow{2}{*}{ Riscos Ocupacion } \\
\cline { 2 - 2 }
\end{tabular}

Fonte: Fundacentro, 2001.

\subsection{RUÍDO}

Os valores de ruído aceitáveis no ambiente laboral são normalizados pela NR-15, que estabelece os limites de tolerância para atividades e operações insalubres, conforme Tabela 1 (BRASIL, 1978).

Tabela 1 - Limites de tolerância para ruído contínuo ou intermitente

\begin{tabular}{|c|c|}
\hline Nível de ruído dB (A) & $\begin{array}{c}\text { Máxima exposição diária } \\
\text { permissível }\end{array}$ \\
\hline 85 & 8 horas \\
\hline 86 & 7 horas \\
\hline 87 & 6 horas \\
\hline 88 & 5 horas \\
\hline 89 & 4 horas e 30 minutos \\
\hline 90 & 4 horas \\
\hline 91 & 3 horas e 30 minutos \\
\hline 92 & 3 horas \\
\hline 93 & 2 horas e 45 minutos \\
\hline 94 & 2 horas e 15 minutos \\
\hline 95 & 2 horas \\
\hline 96 & 1 hora e 45 minutos \\
\hline 98 & 1 hora e 15 minutos \\
\hline 100 & 1 horas \\
\hline 102 & 45 minutos \\
\hline 104 & 35 minutos \\
\hline 105 & 30 minutos \\
\hline 106 & 25 minutos \\
\hline 108 & 20 minutos \\
\hline 110 & 15 minutos \\
\hline 112 & 10 minutos \\
\hline 114 & 8 minutos \\
\hline 115 & 7 minutos \\
\hline
\end{tabular}

Fonte: Brasil, 1994. 
Entende-se por limite de tolerância, a concentração ou intensidade máxima ou mínima, relacionada com a natureza e o tempo de exposição ao agente, que não causará dano à saúde do trabalhador, durante a sua vida laboral. Em relação ao ruído ocupacional, os valores aos quais os trabalhadores estão expostos durante a jornada de trabalho influenciam diretamente na quantidade de horas recomendadas de labor. O termo "insalubre" deriva do latim e significa tudo aquilo que provoca doença, insalubridade por outro lado é a característica daquilo que é insalubre (FUNDACENTRO, 2001).

Os aparelhos usados para medir o nível de pressão sonora podem ser o decibelímetro ou dosímetro de ruído, isso para medição do ruído instantâneo ou da dose de ruído, respectivamente. Os níveis de ruído devem ser aferidos durante a jornada de trabalho do colaborador (FILIPE, 2010).

Não é permitida exposição a níveis de ruído acima de $115 \mathrm{~dB}(\mathrm{~A})$ para indivíduos que não estejam adequadamente protegidos. As atividades ou operações que exponham os trabalhadores a níveis de ruído, contínuo ou intermitente, superiores a 115 DB (A), sem proteção adequada, oferecerão risco grave e iminente (BRASIL, 1994).

\section{PROCEDIMENTOS METODOLÓGICOS \\ 3.1 CLASSIFICAÇÃO DA PESQUISA}

O presente trabalho pode ser classificado conforme a abordagem, objetivo, procedimento técnico e natureza da seguinte forma, ver Quadro 2:

Quadro 2 - Classificação da pesquisa

\begin{tabular}{|c|c|}
\hline \multicolumn{2}{|c|}{ Caracterização da Pesquisa } \\
\hline Abordagem & $\begin{array}{c}\text { Quantitativa } \\
\text { Qualitativa }\end{array}$ \\
\hline Objetivo & Exploratório \\
\hline Procedimento & Pesquisa Bibliográfica \\
Técnico & Estudo de Caso \\
Patureza & Pesquisa de Campo \\
\hline
\end{tabular}

Quanto à Abordagem a pesquisa pode ser descrita como:

Pesquisa Quantitativa por contemplar tudo que possa ser quantificável e utilizando de recursos e de técnicas estatísticas.

Pesquisa Qualitativa devido à consideração da relação dinâmica entre o mundo objetivo e a subjetividade do sujeito que não pode ser traduzido em números. A interpretação dos fenômenos e a pertinência de significados são básicas no processo de pesquisa qualitativa. Quanto ao Objetivo o trabalho pode ser discriminado como exploratório por proporcionar maior familiaridade com 0 problema, uma vez que busca torná-lo explícito, abrangendo para tanto: levantamento bibliográfico; entrevistas com pessoas que tiveram experiências práticas com o problema pesquisado e análise de exemplos que estimulem a compreensão. Assume, geralmente, a s formas de pesquisas bibliográficas e estudos de caso (SILVA; MENEZES, 2005).
Quanto ao Procedimento Técnico a pesquisa pode ser qualificada como:

Pesquisa Bibliográfica por fazer referência a fontes que abrangem a bibliografia já tornada pública em relação ao tema de estudo, desde publicações avulsas, boletins, jornais, revistas, livros, pesquisas, monografias, teses, material cartográfico etc., até meios de comunicação orais: rádio, gravações em fita magnética e audiovisuais: filmes e televisão (MARCONI; LAKATOS, 2008).

Estudo de Caso, pois envolve o estudo profundo e exaustivo de um ou poucos objetos de maneira que permita o seu amplo e detalhado conhecimento, tal conhecimento pode por sua vez, ser aplicado na solução de problemas (MARCONI; LAKATOS, 2008).

Pesquisa de Campo é aquela que tem por objetivo conseguir informações e/ou conhecimentos acerca de um problema, para o qual se procura uma resposta. Consiste na observação de fenômenos e fatos tal como ocorrem espontaneamente, na coleta de dados a eles referentes e no registro de 
variáveis que se presume relevantes, para analisá-Ios (MARCONI; LAKATOS, 2008).

Quanto à Natureza a pesquisa pode ser classificada como aplicada, pois objetiva gerar conhecimentos para aplicação prática e dirigidos à solução de problemas específicos, envolvendo verdades e interesses locais (SILVA; MENEZES, 2005).

\section{AMBIENTE DE PESQUISA - A EMPRESA OBJETO DE ESTUDO}

A empresa objeto de estudo é uma marcenaria localizada na cidade de Campina Grande, no Estado da Paraíba, e opera em duas plantas de produção independentes, sendo uma responsável pela manufatura de móveis projetados e a outra pela confecção de portas e esquadrias de madeira, todos os produtos são manufaturados mediante encomenda, ver Figura 1.

Figura 1 - Arranjo físico das plantas manufatureiras da empresa estudada

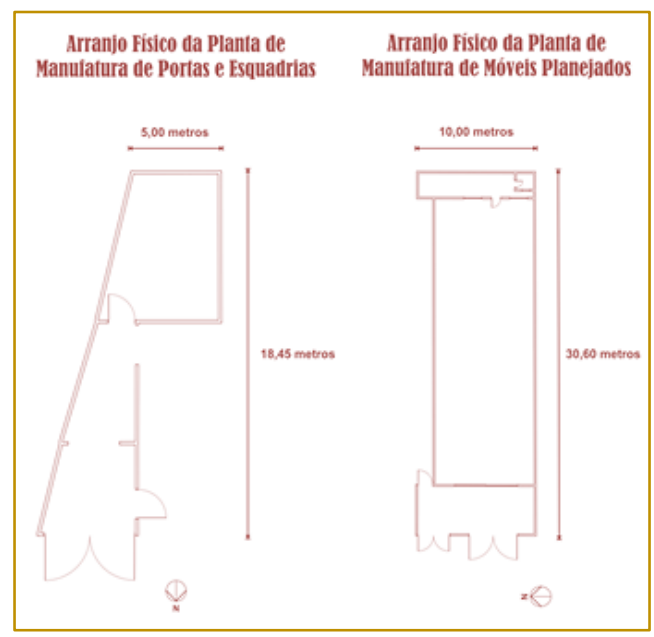

O empreendimento dispõe de 7 colaboradores que trabalham 40 horas semanais, executando as atividades de segunda a sexta-feira. As atividades laborais têm início às oito horas da manhã e encerramse ao meio dia, finalizando o primeiro turno de trabalho. Duas horas de descanso marcam o início do segundo turno de trabalho que se estende das duas às seis da tarde, completando o expediente.
Conforme a Figura 2 ilustra, a empresa possui 2 marceneiros no quadro de funcionários, os mesmos também são os proprietários da empresa. Cada marceneiro é responsável por uma das plantas de produção existe na empresa. Quando aos auxiliares, 3 colaboradores trabalham na planta que manufatura móveis planejados e 2 funcionários na linha de produção de portas e esquadrias. 
Figura 2 - Estrutura organizacional da empresa

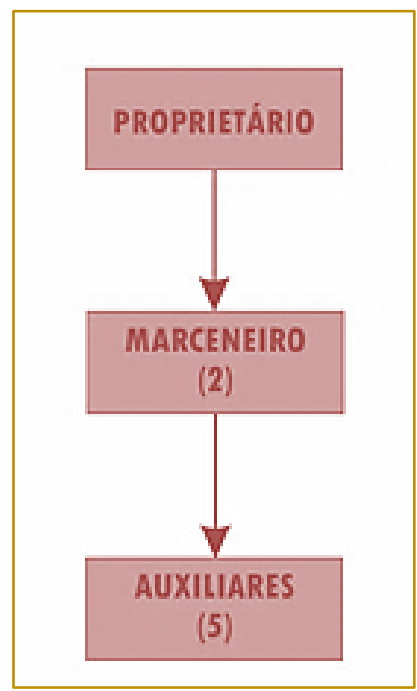

A produção em cada planta é liderada pelo marceneiro responsável por ela. O marceneiro dita o regime e o modo de produção e acerta os detalhes ligados a manufatura dos produtos. Os auxiliares ajudam o marceneiro nos processos de produção, realizando atividades que dão suporte ao trabalho dele. Logo os marceneiros são os indivíduos mais expostos aos riscos existentes na organização.

\subsection{ANÁLISE QUANTITATIVA DO RISCO FÍSICO RUÍDO}

Durante o reconhecimento das atividades desempenhadas nas plantas de manufatura, percebeu-se que os marceneiros são os únicos a operar as máquinas e equipamentos efetivamente, os auxiliares os apóiam com atividades secundárias. Os marceneiros por vezes também desempenham tais atividades. Logo, a análise quantitativa no presente trabalho teve como objeto de estudo os marceneiros e as atividades que eles desempenham nas bancadas, seja manuseando máquinas, equipamentos ou montando os produtos. Utilizou-se o decibelímetro para medir a pressão sonora a qual os marceneiros estavam expostos nas bancadas onde eles desempenham suas atividades.

\subsubsection{RUÍDO}

Enquanto os marceneiros desenvolviam as atividades nas máquinas e equipamentos do processo produtivo, ocorreram as medições do ruído emitido pelas máquinas ou equipamentos durante sua utilização. Dessa forma, obtiveram-se os seguintes valores médios de ruído emitido pelas máquinas e equipamentos durante a fabricação de cada produto, ver Tabelas 2 e 3.

Tabela 2 - Valores médios do ruído emitido pelas máquinas em cada bancada durante as atividades de manufatura de uma porta

\begin{tabular}{|c|c|}
\hline \multicolumn{1}{|c|}{ Máquina/Equipamento } & $\begin{array}{c}\text { Valor médio de ruído medido } \\
(\mathrm{dB} \mathrm{A})\end{array}$ \\
\hline Desengrossadeira & 144.4 \\
\hline Serra circular & 106.1 \\
\hline Tupia & 86.3 \\
\hline Desempenadeira & 99.4 \\
\hline Serra fita & 107.4 \\
\hline Lixadeira & 106.4 \\
\hline
\end{tabular}


Tabela 3 - Valores médios do ruído emitido pelas máquinas em cada bancada durante as atividades de manufatura de um metro de madeira linear

\begin{tabular}{|c|c|}
\hline Máquina/Equipamento/Processo & $\begin{array}{l}\text { Valor médio de ruído medido } \\
\qquad(\mathrm{dB} A)\end{array}$ \\
\hline Serra circular & 100.2 \\
\hline Serra circular manual & 98.5 \\
\hline Desempenadeira & 92.9 \\
\hline Furadeira & 87.1 \\
\hline Lixadeira & 95.4 \\
\hline
\end{tabular}

As Tabelas 4 e 5 mostram a relação entre o valor médio do ruído emitido pela máquina ou equipamento e o tempo máximo tolerável para que o operador esteja exposto a essa grandeza conforme a NR-15, em ambas as unidades fabris.

Tabela 4 - Valores médios do ruído emitido pelas máquinas da planta de portas e esquadrias e o tempo de exposição tolerável conforme a NR-15

\begin{tabular}{|c|c|c|}
\hline Máquina/Equipamento & $\begin{array}{l}\text { Valor médio ruído medido } \\
\qquad(\mathrm{dB} A)\end{array}$ & $\begin{array}{c}\text { Máxima exposição diária } \\
\text { permissível }\end{array}$ \\
\hline Desengrossadeira & 144.4 & ---------- \\
\hline Serra circular & 106.1 & 20 min. \\
\hline Tupia & 86.3 & 6 horas \\
\hline Desempenadeira & 99.4 & 1 hora \\
\hline Serra fita & 107.4 & 20 min. \\
\hline Lixadeira & 106.4 & 20 min. \\
\hline
\end{tabular}

A atividade desenvolvida na desengrossadeira pelo operador no setor de confecção de portas e esquadrias expõe o marceneiro a pressões sonoras que excedem o limite de 115 DB, valor máximo fixado pela
NR-15. Durante a atividade o operador não porta nenhum EPI para proteção. Portanto, não existe tempo tolerável para a exposição do trabalhador a valores de ruído acima de 115 DB, conforme pode ser visto na Tabela 5.

Tabela 5 - Valores médios do ruído emitido pelas máquinas da planta de móveis planejados e o tempo de exposição tolerável conforme a NR - 15

\begin{tabular}{|c|c|c|}
\hline Máquina/Equipamento & $\begin{array}{c}\text { Valor médio ruído medido } \\
(\mathrm{dB} \mathrm{A})\end{array}$ & $\begin{array}{c}\text { Máxima exposição diária } \\
\text { permissível }\end{array}$ \\
\hline Serra circular & 100.2 & 45 min. \\
\hline Serra circular manual & 98.5 & 1 hora \\
\hline Desempenadeira & 92.9 & 2 horas e 45 min. \\
\hline Furadeira & 87.1 & 5 horas \\
\hline Lixadeira & 95.4 & 1 hora e 45 min. \\
\hline
\end{tabular}

As Tabelas 6 e 7 ilustram a relação entre 0 tempo tolerável recomendado pela NR-15 para a exposição do trabalhador ao ruído nas bancadas de trabalho estudados, conforme dados extraídos das Tabelas 4 e 5, e o tempo médio em que os funcionários estão expostos efetivamente a cada máquina quando leva-se em conta uma jornada de trabalho de 8 horas e o número de produtos manufaturados em um dia de labor. Os valores mencionados nas tabelas em questão encontram-se em minutos. 
Tabela 6 - Relação entre o tempo em que o operador está exposto a pressão sonora na planta de portas e esquadrias e o tempo tolerável conforma a NR-15

\begin{tabular}{|c|c|c|}
\hline Máquina/Equipamento & $\begin{array}{c}\text { Máxima exposição diária } \\
\text { permissivel } \\
\text { (min.) }\end{array}$ & $\begin{array}{c}\text { Tempo de exposição diária } \\
\text { cronometrado } \\
\text { (min.) }\end{array}$ \\
\hline Desengrossadeira & 15 & 45 \\
\hline Serra circular & 20 & 45 \\
\hline Tupia & 360 & 45 \\
\hline Desempenadeira & 60 & 63 \\
\hline Serra fita & 20 & 14 \\
\hline Lixadeira & 20 & 35 \\
\hline
\end{tabular}

Tabela 7 - Relação entre o tempo em que o operador está exposto a pressão sonora na planta de móveis planejados e o tempo tolerável conforma a NR-15

\begin{tabular}{|c|c|c|}
\hline Máquina/Equipamento & $\begin{array}{c}\text { Máxima exposição diária } \\
\text { permissivel } \\
(\text { min.) }\end{array}$ & $\begin{array}{c}\text { Tempo de exposição diária } \\
\text { cronometrado } \\
\text { (min.) }\end{array}$ \\
\hline Serra circular & 45 & 90 \\
\hline Serra circular manual & 60 & 40 \\
\hline Desempenadeira & 165 & 60 \\
\hline Furadeira & 300 & 50 \\
\hline Lixadeira & 105 & 60 \\
\hline
\end{tabular}

\section{CONSIDERAÇÕES FINAIS}

Inicialmente utilizou-se a literatura presente para a delimitação do assunto a ser abordado, as fases de atuação propostas na metodologia do trabalho, portanto, foram cumpridas e consolidadas onde foram realizadas observações qualitativas e quantitativas na empresa. As observações quantitativas são referentes às medições dos valores de pressão sonora aos quais os trabalhadores estão expostos quando realizam suas atividades utilizando máquinas que emitem o risco físico ruído, tais atividades são realizadas nas bancadas de trabalho onde os trabalhadores desempenham atividades para fabricação de produtos na marcenaria como móveis e esquadrias.

Através dos valores médios do ruído emitido pelas máquinas da planta de portas e esquadrias emitidos pelas máquinas em cada bancada durante as atividades de manufatura de uma porta, pode-se constatar que a máquina desengrossadeira apresentou $\mathrm{O}$

\section{REFERÊNCIAS}

[1] Brasil. Casa Civil. Lei № 8.213, de 24 de julho de 1991. Dispõe sobre os Planos de Benefícios da Previdência Social e dá outras providências. Disponível em: . Acesso em: 12 de jan. de 2017. maior nível de pressão sonora equivalente a 144 DBA, vale ressaltar que durante esta atividade o colaborador que executava a ação não utilizava Equipamento de Proteção Individual, logo medidas mitigadoras devem ser aplicadas através de um plano de ação para minimizar este risco.

Já os valores médios do ruído emitido pelas máquinas da planta de móveis planejados emitidos pelas máquinas em cada bancada durante as atividades para produção de móveis planejados foi a serra circular, com valor médio de $100 \mathrm{dBA}$, vale ressaltar que para esta atividade também é necessário colocar medidas de ação em prática, como por exemplo ser desenvolvido pelo empregador em conjunto com um médico do trabalho o Programa de Controle Médico de Saúde Ocupacional (PCMSO) e também o Programa de Conservação Auditiva (PCA), para assim colocar em prática medidas eficazes para minimizar a exposição dos colaboradores ao agente físico ruído no ambiente laboral da marcenaria em estudo.

$[2]$ Ministério da Saúde do Brasil. Doenças relacionadas ao trabalho: manual de procedimentos para os serviços de saúde. Brasília, 2001. 
[3] Norma Regulamentadora 15. Portaria MTb N.ㅇ 3.214, de 08 de junho de 1978. Disponível em:

$<$ http://www.guiatrabalhista.com.br/legislacao/nr/nr1 5.htm>. Acesso em: 12 jan. 2017.

[4] Bureau Internacional do Trabalho. Introdução à saúde e segurança no trabalho. Genebra, 2009.

[5] Butierres, Maria Cecília; Mendes, Jussara Maria Rosa. A discriminação de vítimas de acidente do trabalho ou de doença ocupacional: uma situação de invisibilidade social potencializada. Sociedade em Debate, Pelotas, v. 22, n. 1, p. 237-260, 2016.

[6] Dieese - Departamento Intersindical de Estatística e Estudos Socioeconômicos. Anuário da saúde do trabalhador. São Paulo, 2016.

[7] Federação das Associações Europeias de Gestão de Riscos. Norma de gestão de riscos. Bruxelas, 2002

[8] Filipe, Alexandre Petusk. Segurança no trabalho para atividades de processamento mecânico da madeira. 2010. 57 f. Dissertação (Mestrado Ciência e Tecnologia da Madeira) Universidade Federal de Lavras, Lavras.

[9] Fundacentro. Introdução à Higiene Ocupacional. São Paulo, 2001.

[10] Norma de Higiene Ocupacional: procedimento técnico. São Paulo, 2001.

[11] Machado, Carolina Sampaio. Saúde e segurança no trabalho. 1. ed. Rio de Janeiro: SESES, 2016.
[12] Marconi, M. A.; Lakatos, E. M. Técnicas de Pesquisa: planejamento e execução de pesquisas, amostragem e técnicas de pesquisa, elaboração e interpretação de dados. 7. ed. São Paulo: Atlas, 2008.

[13] Morais, Suelyn Fabiana Aciole. Diagnóstico das normas regulamentadoras em uma marcenaria de pequeno porte de campina grande. 2015. 85 f. Monografia (Especialização em Engenharia de Segurança do Trabalho) Faculdade Anglo Americano, Campina Grande.

[14] Organização Internacional do Trabalho. A prevenção das doenças profissionais. Genebra: Bureau Internacional do Trabalho, 2013.

[15] Saliba, Tuffi Messias; Lanza, Maria Beatriz de Freitas. Manual prático de higiene ocupacional e PPRA: avaliação e controle dos riscos ambientais. 6. ed. São Paulo: LTr, 2014

[16] Santos, Antonio Carlos de Queiroz. Análise dos postos de trabalho e segurança de máquinas em uma marcenaria. 2015. 85 f. Monografia (Especialização em Engenharia de Segurança do Trabalho) - Faculdade Anglo Americano, Campina Grande.

[17] Silva, E. L. da; Menezes, E. M. Metodologia da pesquisa e elaboração de dissertação / Edna Lúcia da Silva, Estera Muszkat Menezes. - 4. ed. rev. atual. - Florianópolis: UFSC, 2005.

[18] Teixeira, Márcia Cunha. A invisibilidade das doenças e acidentes do trabalho na sociedade atual. Revista de Direito Sanitário, São Paulo, v. 13, p. 102-131, mar. /jun. 2012. 


$$
\text { Alutary }
$$




\section{ADRIANA GEORGIA BORGES SOARES}

Mestranda em Engenharia de Produção pela Universidade Federal do Rio Grande do Norte (UFRN) atuando na linha de pesquisa de Engenharia do Produto com ênfase em Energia Eólica. Possui Graduação em Engenharia de Produção pela Universidade Federal Rural do Semi-Árido (2017) e em Ciência e Tecnologia (2016) também pela mesma Universidade. Técnica em Agroecologia pelo Instituto Federal de Educação, Ciência e Tecnologia do Rio Grande do Norte - IFRN (2012). Membro do Grupo de Pesquisa - CNPq: Aplicativo GeoGebra no ensino das ciências exatas, tecnológicas e engenharias e do Grupo de Estudos e Pesquisas em Gestão e Melhoria de Redes de Valor - REVA, na linha de pesquisa de Produção Enxuta. Desempenhou a função de diretora da área Administrativa/Financeira da ProJr Consultoria- Empresa Júnior de Engenharia de Produção. Também foi monitora da Matriz Curricular Ciências da Natureza e Suas Tecnologias, no Projeto de extensão do Cursinho Pré-Universitário Popular da Ufersa-Angicos.

\section{ADRIANO DA MATA GAMA}

Graduando do Curso de Engenharia de Produção com ênfase em Mecânica pela Universidade Federal do Amazonas. Experiência em monitoria na disciplina de Cálculo 1 e foi participante no Programa Atividade Curricular de Extensão, onde foi realizado um projeto intitulado Feira "Qualimais" no município de Itacoatira-AM, na Feira do Agricultor, analisando aspectos sanitários, atendimento ao cliente e gestão de custos, para assim, contribuir no desenvolvimento dos empreendimentos dos feirantes. Atualmente participa em projeto de Iniciação Científica com estudo na aplicação de Controle Estatístico de Processos aplicado ao teste de qualidade de blocos cerâmicos.

\section{AIANNA RIOS MAGALHÃES VÉRAS E SILVA}

Possui graduação em Engenharia de Produção pela Universidade Federal do Piauí

\section{AILTON DA SILVA FERREIRA}

Fazendo Pós Doutoramento em Engenharia de Reservatórios pela Universidade Estadual do Norte Fluminense, Concluiu o Doutorado em Engenharia Metalúrgica e de Materiais pela Universidade Estadual do Norte Fluminense Darcy Ribeiro (2009),Mestrado em Engenharia de Produção pela Universidade Estadual do Norte Fluminense Darcy Ribeiro (2005), Pós Graduado em Tecnologia de Petróleo pela Universidade Salgado de Oliveira (2007), MBA em Docência Superior pela Faculdade de Filosofia de Itaperuna (2005), Graduação em Administração pela Universidade Federal Fluminense (2002) e Granduado em Engenharia de Produção pela Universidade Candido Mendes (2008). Atualmente é Coordenador do Curso de Administração da UFF/Macaé, Professor Adjunto IV da Universidade Federal Fluminense/Macaé e Professor Colaborador do Mestrado em Engenharia de Produção/UENF. Tem experiência na área de Engenharia de Produção, com ênfase em Engenharia de Petróleo, atuando principalmente nos seguintes temas:Administração da Produção, Modelagem, Planejamento e ERP, Qualidade, logística do petróleo, analise de viabilidade na cadeira petrolífiera, produção de petróleo e comercio internacional.

\section{ALESSANDRA FERREIRA REIS}

Bacharel em Engenheira de Produção pela Universidade Federal do Amazonas (2018). Atualmente atua como diretora do departamento de Fiscalização Ambiental pela Secretaria de Meio Ambiente - SEMA/Itacoatiara-AM. 


\section{ALEXANDRE DOS SANTOS SANTANA}

Graduando em Engenharia de Produção pela Universidade Tiradentes - Unit. Com formação técnica em logística - Senac. Atua a cinco anos no setor de logística, e responsável pelo setor de PCL - planejamento e controle logístico na empresa Fasouto distribuidor.

\section{ALINE SANTANA DOS SANTOS}

Mestrado em Engenharia Civil e Ambiental (UEFS), Especialização em Gestão Estratégica em Políticas Públicas (UNICAMP) e Bacharelado em Engenharia Ambiental (Faculdade de Ciência e Tecnologia/ Área 1 Devry Brasil). Atua como docente em instituições de ensino superior, bem como é assessora em Educação para Sustentabilidade (Sustentário) e na área de Engenharia Ambiental, com ênfase em Gestão de Resíduos Sólidos Urbanos.

\section{ALLAN ARAUJO VELOSO}

Técnico de Segurança do Trabalho pelo Instituto Federal de Educação, Ciência e Tecnologia do Rio Grande do Norte - IFRN (2017). Possui duas graduações a níveis de Bacharelado em Ciência e Tecnologia (2016) e Engenharia Civil (2017), ambas pela Universidade Federal Rural do Semi-árido - UFERSA, onde recebeu Menção Honrosa pelo excelente desempenho acadêmico no curso de Engenharia Civil. Atualmente, pós graduando em Engenharia de Segurança do Trabalho pela Estácio de Sá e Mestrando em Processos Construtivos e Estruturas pela Universidade Federal do Rio Grande do Norte - UFRN. Atua como professor extra-quadro no SENAI unidade São Gonçalo do Amarante/RN, ministrando as disciplinas de Princípios dos Solos e Fundações e Tecnologias dos Concretos e da Argamassa.

\section{ANDRESSA DE PAULA CRUZ}

Graduação em Engenharia de Produção pela Universidade Federal de Itajubá (UNIFEI campus Itabira). Participação em projetos de pesquisa do GEQProd (Grupo de Estudos em Qualidade e Produtividade). Possui experiência em mapeamento de processos, gerenciamento de projetos e melhoria contínua. Atualmente é analista de logística na John Deere LTDA.

\section{ANDRESSA DOS SANTOS ARAÚJO}

Graduanda do 10 período de Engenharia de Produção pela Universidade do Estado do Pará (UEPA). Entre seus artigos publicados, encontram-se os dispostos nos Anais Eletrônicos do EPAEP 2015, ENEGEP 2016, 2017 e 2018, SIMPROD 2017, dentre outros, e nas mais diversas áreas, tais como Estudo de Tempos e Movimentos, Metodologia PDCA, Teoria de Filas, Abordagem Seis Sigma, Sistema Toyota de Produção, Ergonomia e Segurança do Trabalho, entre outros. Por 2 anos, atuou como pesquisadora no Núcleo de Assuntos Estudantis (NAE) da UEPA, realizando projetos de pesquisa e extensão. Atualmente, atua como estagiária no Departamento de Projetos da Secretaria Municipal de Mineração, Indústria, Comércio, Ciência e Tecnologia (SICOM) em Marabá/PA.

\section{ANTONIO CARLOS DE QUEIROZ SANTOS}

Doutorando em Engenharia de Processos (UFCG), Coordenador dos cursos de Pós Graduação na Faculdade Integrada de Patos (Pós Graduação em Gestão da Manutenção e Produção e MBA em Gerenciamento de Obras).Foi professor da Universidade Federal de Campina Grande (UFCG), no curso de Engenharia de Produção (Campus Sumé). Atualmente é professor do Instituto Federal do rio Grande do Norte e Professor da Faculdade de Ciências Sociais Aplicadas (UNIFACISA) no curso de Administração. Mestre em Engenharia de Produção pela Universidade Federal de Pernambuco (UFPE) e Especialista em Engenharia de Segurança do Trabalho pela Faculdade Anglo Americano. Possui graduação em Engenharia de Produção pela Universidade Federal de Campina Grande (2012), possui curso 
na área de Higiene Ocupacional pela Treinare Engenharia. Participou de Projeto de Extensão, publicou artigos técnico-científicos, tem experiência como Gestor de Planejamento e Controle da Produção em empresas do estado da Paraíba e de Pernambuco.

\section{ARIANE BATISTA MAQUINE}

Possui graduação em Engenharia de Produção com ênfase em Mecânica pela Universidade Federal do Amazonas (2013). Mestranda em Engenharia Mecânica pela Universidade Federal de Santa Catarina (2018). Atualmente é Professora auxiliar da Universidade Federal do Amazonas (2017) ministrando disciplinas na graduação. Tem experiência na área de Engenharia de Produção, atuando principalmente nos seguintes temas: Ergonomia, Metrologia, Gestão de Projetos, Gestão de Resíduos e Avaliação e Apoio à Tomada de decisão.

\section{BÁRBARA CRISTINA COSTA BACELAR DE CARVALHO}

Graduanda em Engenharia de Produção pela Universidade Federal do Piauí (UFPI). Foi bolsista de graduação sanduíche CNPQ no programa Ciência sem Fronteiras, tendo cursado Production Engineering with Management pela University of Strathclyde, e realizou pesquisas no ramo de Séries Temporais pelo Programa Jovens Talentos pela Ciência. Atualmente é bolsista do Núcleo de Inovação e Transferência de Tecnologia da UFPI, onde executa o serviço de atualização e sistematização das informações do banco de dados, acompanha os pedidos de patentes e outras propriedades intelectuais junto ao INPI, e é responsável pela busca de anterioridade nos bancos de patentes tendo realizado a alimentação dos sistemas de informação. Também é estagiária no SEBRAE/PI, na área de Gestão de Projetos das soluções de educação empreendedora. Possui publicações de artigo em anais nacionais e dois capítulos num livro editado pela CRC Press (Taylor \& Francis), na área de Higiene e Segurança Ocupacional.

\section{BENEDITO MANOEL DE ALMEIDA}

Possui graduação em Engenharia Química pela Faculdade de Engenharia Química de Lorena (1989), graduação em Pedagogia - Licenciatura pela Faculdade de Educação de Guaratinguetá (2000), graduação em Prog Esp de Form Pedagógica Docente Licenciatura pela Faculdade de Filosofia, Ciências e Letras de Volta Redonda (2000) e mestrado em Educação pelo Centro Universitário Salesiano de São Paulo (1997). Doutorando em Engenharia Mecânica, Gestão e Otimização pela UNESP - Universidade Estadual Paulista Júlio de Mesquita Filho. Atualmente é professor do UNISAL - Centro Universitário Salesiano São Paulo.

\section{CAMILA MARTINS DE OLIVEIRA}

Possui doutorado em Química pelo Instituto de Química UNESP-Araraquara (2009) e pósdoutorado em Química pela USP-São Carlos (2010). Possui experiência em técnicas cromatográficas avançadas e na identificação e avaliação biológica de metabolitos secundários de origem vegetal e microbiana. Atua também no desenvolvimento de produtos economicamente viáveis a partir destes metabólitos. Atualmente é professora Adjunta IV da Universidade Federal do Amazonas e realiza pesquisas com produtos naturais de origem fúngica e de vegetais encontrados no Médio Amazonas.

\section{CARLA MONIQUE ROCHA DOS SANTOS}

Graduanda em Engenharia de Produção - FAINOR/BA. Integrante do grupo de pesquisa de Iniciação Científica: "Tecnologias Limpas na Produção do café na região do Planalto de Vitória da Conquista". Apresentação de mini-curso cujo tema foi: "A importância da Cronoanálise para Controle de Produção e Qualidade". Apresentado o resumo: "Aplicação do Lean Healthcare em uma Farmácia Hospitalar de Vitória da Conquista". Participação em 
Simpósios da Semana de Iniciação Científica com os temas: "Implantação de um sistema de automação comercial em uma farmácia hospitalar de Vitória da Conquista" (2016) e "Tecnologias Limpas no cultivo do café" (2017).

\section{CARLOS HENRIQUE DE OLIVEIRA}

Possui graduação em Engenharia Mecânica com ênfase em Produção, especialização em Qualidade e Produtividade e mestre em Engenharia de Produção pela Universidade Federal de Itajubá. Atualmente é professor assistente na Universidade Federal de Itajubá-campus avançado de Itabira e atua nas áreas de Estatística, Engenharia da Qualidade, Seis Sigma e Lean Manufacturing (Manufatura Enxuta).

\section{CELSO CARLINO MARIA FORNARI JUNIOR}

Graduado em Engenharia Química. Doutor pela Universidade Federal do Rio Grande do Sul e Université Paris VII. Pós-doutorado pela Curtin University, Austrália. Professor Pleno pela Universidade Estadual de Santa Cruz.Atua como docente pesquisador nos cursos de Engenharia de Produção e Química, na área de materiais poliméricos.Coordena o Laboratório de Polímeros e Sistemas - LAPOS

\section{CHARLES RECH}

Possui graduação em Engenharia Mecânica (1998/UFRGS). Mestrado em Energia (2001/UFRGS). Doutorado em Fenômenos de Transporte (2010/UFRGS), em análise numérica e experimental do escoamento em motores de combustão interna. Pós-doutorado em energia (UFRGS) atuando na pesquisa de sistemas de recuperação de energia, turbina Tesla. Atualmente é professor e coordenador do curso de Engenharia Mecânica e Engenharia de Produção na Universidade LaSalle Canoas.

\section{CLAUDIO COVAS FERNANDES}

Mestrando em Engenharia Industrial pela Universidade do Minho, MBA em Gestão de Negócios Sustentáveis, Especialização em Engenharia de Segurança do Trabalho e graduação em Engenharia de Produção. Ampla experiência profissional nas áreas da Segurança do Trabalho e da Gestão Ambiental, atuando principalmente em Industrias e empresas da Construção.

\section{CRISTIANO MANHAES DE OLIVEIRA}

Possui graduação em Ciência da Computação pela Universidade Candido Mendes (2005) e Engenharia de Produção pela UNILESTE-MG (2014). Mestrado em Engenharia de Produção (UENF), área de concentração: Pesquisa Operacional, situação em andamento Experiência na área de Ciência da Computação, com ênfase em Sistemas de Informação e na área de Engenharia de Produção na área de Gestão de Projetos

\section{CRISTOPHER SANTOS PEDROGA}

Tecnólogo em Gestão Pública pela Universidade Estadual de Montes Claros (UNIMONTES), tem experiência com cadeia de suprimentos, tributação e logística. Trabalhou como Analista de Suprimentos na Cia. Tecidos Santanense durante quase oito anos. Atualmente atua com o gerenciamento da cadeia de suprimentos na Adams\&Adams Iluminação atendendo todo o território nacional. 


\section{CRYSLAINE CINTHIA CARVALHO NASCIMENTO}

Bacharela em Ciência e Tecnologia (2014) e engenheira de Produção pela Universidade Federal Rural do Semiárido - UFERSA (2016). Mestranda em Engenharia de Produção pela Universidade Federal do Rio Grande do Norte - UFRN, atuando na linha de pesquisa de Ergonomia, saúde e segurança do trabalho atuando como bolsista CNPq. Integrante do Grupo de Extensão e Pesquisa em Ergonomia - GREPE. Possui experiência em gestão de projetos através da elaboração do plano habitacional da cidade de Caraúbas-RN pela empresa META assessoria (2014), atuação no setor de manutenção tendo elaborado o plano de manutenção da empresa Cristalina do Apodi (2016), experiência em Engenharia financeira no setor de compras da empresa Caicó Embalagens em Mossoró-RN (2018), Gerente de projetos no ano de 2016 na Project Jr na Universidade Federal Rural do Semiárido - UFERSA (2016) e atuação no setor de design da empresa BQMIL em Mossoró-RN (2018).

\section{EDUARDO ZIMIMER ZEN}

Graduando do $10^{\circ}$ período de Engenharia de Produção pela Universidade do Estado do Pará (UEPA). Consultor na Empresa FAPA Consultoria Júnior, onde ocupou o cargo de Trainee e atualmente de Diretor de Projetos, realizando atividades como: Gestão de Pessoas; Analise de Tempo e Movimento; Elaboração de Projetos etc. Possui artigos publicados nos Anais Eletrônicos do EPAEP 2015, ENEGEP 2017 e 2018, III Congresso Online de Engenharia de Produção (CONEP), dentre outros, e nas mais diversas áreas, tais como Estudo de Tempos e Movimentos, Metodologia PDCA, Teoria de Filas, Sistema Toyota de Produção, entre outros.

\section{EMERSON JOSE DE PAIVA}

Possui graduação em Matemática, mestrado em Engenharia de Produção, e doutorado em Engenharia Mecânica, na área de Projeto e Fabricação. Atualmente, é professor de Otimização e Simulação da Universidade Federal de Itajubá, Campus Itabira e é vice-líder do Grupo de Estudos em Qualidade e Produtividade - GEQProd, da Unifei, Campus de Itabira.

\section{EVANDRO ANDRE KONOPATZKI}

Engenheiro eletricista e de Segurança do Trabalho. Professor da Universidade Tecnológica Federal do Paraná - UTFPR.

\section{FABRICIA NASCIMENTO DE OLIVEIRA}

Possui graduação em Administração pela Universidade do Estado do Rio Grande do Norte (UERN). Especialização em Gestão Pública Municipal pela Universidade Federal do Rio Grande do Norte (UFRN). Engenheira Agrônoma, Mestre e Doutora em Fitotecnia/Agronomia pela Universidade Federal Rural do Semi-árido. Atualmente é professora Adjunto II da Universidade Federal Rural do Semi-árido, leciona a disciplina de Sistema de Gestão de Saúde e Segurança do Trabalho no curso de Ciência e Tecnologia da UFERSA. Desenvolve trabalhos de pesquisas, principalmente com os seguintes temas: segurança do trabalho, ergonomia e gestão de riscos.

\section{FERNANDA DE OLIVEIRA GALDIANO}

Possui graduação em Engenharia de Produção pela Universidade Federal de Itajubá (UNIFEI). Participação em projetos de pesquisa do GEQProd (Grupo de Estudos em Qualidade e Produtividade). Participação em projetos de melhoria contínua e análise de indicadores logísticos. Atualmente é Supervisora Logística focado no atendimento ao cliente na empresa Ambev. 


\section{GABRIELA DE SOUZA RAYMUNDO}

Cursando Engenharia de Produção no Centro Universitário Hermínio Ometto - FHOIUniararas Participou do Programa Ciências sem Fronteiras pela CAPES. Estudou na National University of Ireland, Galway (NUIG) (08/2015 a 07/ 2016). Discente do Grupo de Estudos em Organizações, e bolsista do Programa Institucional de Bolsas de Iniciação Científica e Apoio à Pesquisa (2016-2017- PIC), nas áreas: Qualidade de Vida no Trabalho e Ergonomia do Centro Universitário Hermínio Ometto - FHO (Uniararas).

\section{GIOVANNA BRITO DE ARAÚJO}

Graduanda do $10^{\circ}$ período de Engenharia de Produção pela Universidade Estadual do Pará (UEPA), Técnica em Saúde e Segurança do Trabalho pelo Centro Técnico Profissionalizante (CTP) e professora de inglês (nível básico) pela metodologia TPR e TPRS. Atualmente estagiária na empresa VALE na área da Oficina Eletromecânica, onde atua na gestão de rotina por meio do gerenciamento dos indicadores de Saúde, Segurança e Meio Ambiente, Qualidade e Produtividade, atuando por meio da utilização do sistema SAP.

\section{GLÁUCIA REGINA DE OLIVEIRA ALMEIDA}

Graduada em Engenharia de Produção pela Faculdade de Administração e Negócios de Sergipe - Fanese. Mestre em Engenharia de Processos pela Universidade Tiradentes. Doutorado em Engenharia de Processos. Consultora em Ergonomia. Possui experiência na área de química e engenharia com ênfase em eletroquímica e no desenvolvimento de novos materiais atuando principalmente nos seguintes temas: eletro-oxidação de metanol e etanol, desenvolvimento de nanomateriais, células a combustível. PRÊMIO PROFESSOR GIULIO MASSARANI como destaque de melhor trabalho na área de Engenharia de Materiais e Nanotecnologia no XX Congresso Brasileiro de Engenharia Química - COBEQ -2014, Associação Brasileira de Engenharia Química. Desenvolvimento de projetos integradores na área de Engenharia de Produção voltados para o desenvolvimento social. Membro de Colegiado do curso de Engenharia de Produção. Atualmente faz parte do Núcleo Docente Estruturante do curso de Engenharia de Produção da Universidade Tiradentes. Professora Adjunta dos cursos de Engenharia de Produção, Engenharia Civil, Engenharia Elétrica, Engenharia Mecatrônica e Engenharia de Petróleo. Possui certificação nível 1 nas ferramentas da G Suite for Education ( Google Certified Educator Level 1)

\section{GRASIELLY BRUNA VINCENZI ROCKENBACH}

Técnica em Segurança do Trabalho UTFPR. Graduanda de Engenharia de Produção UTFPR

\section{HELIO CAVALCANTI ALBUQUERQUE NETO}

Possui graduação em Engenharia de Produção pela Universidade Federal de Campina Grande (2010) e doutorado em Segurança e Saúde Ocupacionais da Universidade do Porto (2017), pesquisador do Grupo de Estudos em Produtos e Processos Agroindustriais do Cerrado e membro do Laboratório de Pesquisa em Economia Aplicada e Engenharia de Produção, atuando principalmente nos seguintes temas: ambiente térmico, segurança na construção civil e controle da qualidade.

\section{HICARO FERREIRA MATOS CARDIAL}

Engenheiro de Produção, Técnico em Mecânica, atualmente atuando na área de manutenção industrial na Europa. Experiência em Engenharia de Processos, Supervisão de Produção. Líder de Projetos de melhoria de Processos, Líder de eventos Kaizen, responsável pela implementação de Lean Manufacture em indústria de equipamentos eletrônicos. Auditor Interno das NBR ISO 9001:2015, ISO 14001:2015 e OHSAS 18001:2007 


\section{IVANA SALVAGNI ROTTA}

Engenheira de Produção Materiais (UFSCar). Mestre em Engenharia Mecânica (EESC-USP). Doutora em Engenharia de Produção (UFSCar). Atualmente docente do Núcleo de Engenharia. Integrante do Núcleo de Pesquisa em Engenharia (NUPENG), e Coordenadora do Grupo de Estudos em Organizações, com fomento do Programa Institucional de Bolsas de Iniciação Científica e Apoio à Pesquisa (2016-atual - PIC) do Centro Universitário Hermínio Ometto - FHO (Uniararas) .

\section{JACQUELINE SILVA DE JESUS}

Graduada em Engenharia de Produção pela Universidade Estadual de Santa Cruz (UESC). Atuou como consultora do Instituto de Assessoria para o Desenvolvimento Humano na implantação do projeto Escritórios Criativos, desenvolvido pela Secretaria de Educação do Estado da Bahia (SEC). Atua como bolsista na Diretoria de Empreendedorismo, Inovação e Institucionalização - SEC.

\section{JOÃO MARCOS DE OLIVEIRA}

Bacharel em Ciências da Computação pelo Centro Universitário Barão de Mauá (2004), MBA pela Fundação Getúlio Vargas - SP (2009) em Gestão Industrial e Mestrado em Ciência e Tecnologia pelo Instituto de Ciências Exatas e Tecnologia da Universidade Federal do Amazonas (2016). Tem experiência na área Industrial em automação, instrumentação, programação de CLP (Controlador Lógico Programável) e manutenção. Na área da educação, ministrou treinamentos e aulas em indústrias, no SENAI-SP e SENAI-AM. Atualmente é professor no curso de Engenharia de Produção na Universidade Federal do Amazonas, atuando nos seguintes temas: Gestão da qualidade, serviços e custos; Automação aplicada no ensino; Gestão da manutenção; Gerenciamento de projetos; Ensino de modelagem e simulação de processos.

\section{JOÃO THIIAGO DE GUIMARÃES ANCHIETA E ARAÚJO CAMPOS}

Professor assistente 20 horas do Departamento de Engenharia Mecânica (DEM) na Universidade Federal da Bahia - UFBA, Coordenador do curso de Engenharia de Produção da Universidade Federal da Bahia, coordenador Geral de Engenharia da Faculdade Delta UNIME. Engenheiro com habilitação em Produção e Sistemas pela Universidade Estadual de Santa Cruz em Ilhéus - BA. Mestre em Ciência, Inovação e Modelagem em Materiais (PROCIMM) pela Universidade Estadual de Santa Cruz em Ilhéus - BA, doutorando em Engenharia Industrial pela Universidade Federal da Bahia - UFBA. Atualmente é pesquisador na área de modelagem, simulação e otimização de sistemas produtivos com ênfase em teoria da decisão aplicada a análise de variabilidade.

\section{JONATHAS DO NASCIMENTO PEREIRA}

Engenheiro de Produção pela FAINOR. Atua na área de Planejamento, Programação e Controle de Manutenção em uma Indústria Multinacional utilizando a ferramenta de gestão de manutenção TPM. Tem Experiência na área de administração de materiais para MRO (manutenção, reparo e operações). Foi voluntário no projeto de iniciação científica: Collaborative indicator development as a competitive advantage in industry and services FAINOR, 2015/2017. Atuou, como estagiário, na área de Planejamento, Programação e Controle da Manutenção em uma Indústria Nacional do setor de Termoplásticos. Foi voluntário no projeto de iniciação científica: Logística Reversa de resíduos eletroeletrônicos FAINOR, 2014. Foi monitor de ensino em Cálculo Numérico e Automação Industrial. Tem formação complementar na área de Eficiência Energética e Sustentabilidade. Possui artigos científicos publicados no anais Abepro - Encontro Nacional de Engenharia de Produção. Tem formação de nível técnico em Eletromecânica - IFBA, onde atuou na área de retífica de motores à combustão. 


\section{JULLIA MARIA ZULLIM RODRIGUES}

Estudante do $5^{\circ}$ ano de Engenharia de Produção - Agroindustrial na Universidade Estadual de Maringá. No período da faculdade participou do Movimento Empresa Júnior durante três anos e após isso, se dedicou a pesquisa de extensão, sendo integrante do Grupo de Pesquisa em Ergonomia: Organização e Sociedade (GEOS). Participou de eventos em diversas áreas, como gestão empresarial, liderança e ferramentas de engenharia de produção e realizou cursos como: mapeamento de processos, previsão de demandas e logística humanitária. Atualmente, é estagiária em uma industria de alimentos na área de Gestão de Processos.

\section{KAMILA MATOS ANDRADE SILVA}

Engenheira de Produção pela FAINOR. Atua na área de administração de Empresas com experiência na gestão em Setores Alimentícios. Foi voluntária no projeto de iniciação científica: Collaborative indicator development as a competitive advantage in industry and services - FAINOR, 2016/2017. Atuou como estagiária em uma fábrica de Urnas Funerárias de Vitória da Conquista-BA, na área de Planejamento, Programação e Controle da Produção e Logística. Foi monitor da disciplina Planejamento, Programação e Controle da Produção (PPCP II). Possui publicações nos anais do Encontro Nacional de Engenharia da Produção (ENEGEP), atuando como pesquisadora na área de Simulação e Otimização de Processos Produtivos com ênfase na Teoria das Restrições (TOC) e Modelagem Computacional.

\section{LARISSA NAYARA OLIVEIRA DOS SANTOS}

Graduanda em Engenharia de Produção pela UNIT. Yellow Belt em Lean Six Sigma treinada pelo CEO Grupo . Já atuou como Jovem Aprendiz na empresa SERGIPEL auxiliando setor de Engenharia Industrial. Atualmente, atua como Auxiliar Financeiro na Pactual Digitações. Interessa-se por Planejamento e Controle da Produção, assim como Engenharia da Qualidade.

\section{LUAN EMERSON SOARES DE LIMA}

Graduado em Engenharia de Produção Plena pela Universidade Federal de Campina Grande, durante a formação atuou como monitor das disciplinas de Resistência dos Materiais, Equações Diferenciais Lineares e Fenômenos de Transporte; desenvolveu trabalho de pesquisa na área de Transformada de Wavelet Contínua com Banco de Dados Pluviométricos no Estado de Pernambuco, como extensionista vinculado ao Programa PROLCARIRI, ministrou aulas na disciplina de História, no Projeto do Pré-vestibular Solidário e no Projeto de Reforço Escolar, desempenhou a função de tutor da disciplina de Geografia para alunos do ensino infantil e fundamental.

\section{MABIO TEODORO BORGES}

Graduado em Engenharia de Produção pela Universidade do Estado do Pará- UEPA. Especialista em Engenharia de Segurança do Trabalho pela Faculdade de Tecnologia Machado de Assis - FAMA. Extensionista e Consultor Credenciado de Instituições como: SENAI-TO, IEL-TO e SEBRAE-TO. Docente do ensino superior nos cursos de Engenharia de Produção, Engenharia Ambiental, Engenharia Elétrica e Engenharia Civil na Faculdade Católica do Tocantins. Perito Judicial em Segurança do Trabalho para ao Tribunal de Justiça do Tocantins e perito cadastrado em todos os demais tribunais, principalmente o Federal e os do Trabalho. 


\section{MANOEL ISAC MAIA JUNIOR}

Possui graduação em Ciência e Tecnologia pela Universidade Federal Rural do Semi-Árido (2015), graduação em Engenharia de Produção pela Universidade Federal Rural do SemiÁrido (2017) e ensino-medio-segundo-graupelo Instituto Dantas Monteiro(2008). Tem experiência na área de Engenharia de Produção, com ênfase em Gerência de Produção.

\section{MARCEL HEIMAR RIBEIRO UTIYAMA}

Formação em Engenharia de Produção pela Universidade Federal de São Carlos (concluída em 2009). Em 2012 concluiu o mestrado em Engenharia de Produção pela Universidade Federal de São Carlos na área de Planejamento e Controle de Sistemas Produtivos. Em 2016 concluiu o doutorado em Engenharia de Produção pela Universidade Federal de São Carlos na área de Planejamento e Controle de Sistemas Produtivos. Fez estágio de férias na empresa Opto eletrônica no período de 07/01/08 a 31/07/2008 atuando na área de Planejamento e Controle da Produção. Foi estagiário na empresa ISS Servisystem do Brasil Ltda no período de 11/1108 a 10/11/09 atuando na área de melhoria de processos e projetos de postos de trabalho. Atuou como Engenheiro de Produção na empresa ISS Servisystem do Brasil Ltda no período de 11/01/10 a 20/08/10 exercendo atitividades na área de melhoria de sistemas produtivos e projetos de postos de trabalho. Sócio fundador da Associação dos Enxadristas de São Carlos, sendo Presidente da no período de 2007 a 2016. Iniciou sua atuação como docente de Engenharia de Produção em setembro de 2012. Desde março de 2014 é professor horista da Universidade de Franca (UNIFRAN) e desde fevereiro de 2016 professor horista no Centro Universitário FEl - Campus São Bernardo. Principais temas de interesse: Planejamento e Controle da Produção, Scheduling, redução do lead time, melhoria contínua, alocação de programas de melhoria, Teoria das Restrições, Lean Manufacturing, Factory Physics, System Dynamics, Sistemas de Coordenação de Ordens, Quick Response Manufacturing. Aprovado em segundo lugar no concurso para professor efetivo Edital № 054/16 da Ufscar Sorocaba.

\section{MARCELO DONDELLI BOARETTO}

Estudante do $5^{\circ}$ ano de Engenharia de Produção - Agroindustrial na Universidade Estadual de Maringá. Participou do Movimento Empresa Júnior durante dois anos e após isso se dedicou a área de pesquisa, sendo pesquisador e integrante do Grupo de Pesquisa em Ergonomia: Organização e Sociedade (GEOS). Participou de eventos da área de engenharia de produção. Foi voluntário no Centro de Equoterapia, e atualmente faz estágio na área de processos de uma industria de colchões.

\section{MARCIO DIMAS RAMOS}

Doutor em Engenharia Mecânica (UNIFEI/2015); Mestre em Engenharia Mecânica (UNIFEI/1997); Graduado em Engenharia Mecânica (UNIFEI/1994) e Bacharel em Matemática Aplicada à Informática (FEPI/1990). Atualmente, Professor Adjunto da Universidade Federal de Itajubá - Campus Itabira, área Metrologia. Atua em aproveitamento de Energia.

\section{MARCOS ANTONIO ARAUJO DA COSTA}

Possui graduação em Engenharia Civil pela Universidade Federal Rural do Semi-Árido (2015) e graduação em Ciência e Tecnologia pela Universidade Federal Rural do Semi-Árido (2012). Atualmente é pós-graduado em Engenharia de Segurança no Trabalho pela Universidade Potiguar e graduando em Engenharia de Produção na Universidade Federal Rural do SemiÁrido. 


\section{MARCOS ANTÔNIO DE SOUZA QUEIROZ}

Graduação em andamento em Engenheira de Produção na Universidade Federal do Amazonas - UFAM.

\section{MARIA DE LOURDES SANTIAGO LUZ}

Graduada como Engenheira Eletricista e Engenheira de Produção Eletricista pelo Centro Universitário da FEl. Possui pós-graduação em Especialização de Alimentos, Mestrado em Agronomia pela Universidade Estadual de Maringá e Doutorado em Engenharia de Produção pela Universidade Federal de São Carlos. Atualmente é Professora de Ensino Superior, na classe de Professor Adjunto do curso de Engenharia de Produção, da Universidade Estadual de Maringá. Desenvolve atividades de ensino e pesquisa nas áreas de conhecimento relacionadas à Gestão de Produção, Segurança do Trabalho e Ergonomia. Pesquisadora integrante do Grupo de Pesquisa em Ergonomia: Organização e Sociedade (GEOS).

\section{MARIA LUIZA OLIVEIRA FERREIRA}

Graduanda do 10 período de Engenharia de Produção pela Universidade do Estado do Pará (UEPA). Possui artigos publicados nos Anais Eletrônicos do EPAEP 2015, ENEGEP 2016, 2017 e 2018, SIMPROD 2017, dentre outros, e nas mais diversas áreas, tais como Metodologia PDCA, Sistema Toyota de Produção, Teoria de Filas, Estudo de Tempos e Movimentos, Abordagem Seis Sigma, Ergonomia e Segurança do Trabalho, entre outros.

\section{MARIA SUZANNA MAIA COSTA}

Graduada em 2017 em Engenharia de Produção pela Universidade Federal de Itajubá. Atua com Planejamento de Demanda no Grupo L'occitane.

\section{MATHEUS DAS NEVES ALMEIDA}

Atualmente professor titular da Universidade Federal do Piauí - UFPI do curso de Engenharia de Produção. Mestre em Engenharia de Produção pela Universidade Federal da Paraíba UFPB e graduação em Engenharia de Produção Mecânica pela Universidade Federal da Paraíba - UFPB. Participei de um intercambio acadêmico BRAFITEC pelo Institut National des Sciences Appliquées (INSA de Lyon - France). Engenheiro responsável de produção na empresa Construtora Norberto Odebrecht do Equador.

\section{MIGUEL BERGAMASSO MOURA}

Bacharel em Engenharia de Produção pela Universidade de Franca/SP (UNIFRAN); pósgraduando em Administração Pública Municipal pela Universidade Federal de Lavras/MG (UFLA). Atua há mais de cinco anos no serviço público municipal de São Sebastião do Paraíso/MG, como Fiscal de Urbanismo.

\section{NATHALIA STEPHANE SANTOS NASCIMENTO}

Graduanda em Engenharia de Produção pela Universidade Tiradentes - Unit. Excel avançado com ênfase em Engenharia. Interesse pelas áreas Gestão da Qualidade e Gestão da Produção.

\section{PAULO RICARDO FERNANDES DE LIMA}

Possui graduação em Ciência e Tecnologia pela Universidade Federal Rural do Semi-Árido (2014) e graduação em Engenharia de Produção pela Universidade Federal Rural do SemiÁrido (2016). Mestrando em Engenharia de Produção pela Universidade Federal do Rio Grande do Norte (UFRN). Atua como professor substituto na Universidade Federal Rural do Semi-Árido (UFERSA), campus Angicos-RN (2017), no curso de Engenharia de Produção lecionando as seguintes disciplinas: Engenharia de Métodos e Processos, Automação da 
Produção, Arranjos Produtivos, Gestão da Aprendizagem e Gestão da Inovação, Propriedade Intelectual e Transferência de Tecnologia.

\section{POLLYANNA MENEZES DE SOUSA}

Bacharel em Engenheira de Produção pela Universidade Federal do Amazonas - UFAM (2016). Já atou como supervisora de projetos, área de gestão de piscicultura, na Secretaria Executiva de Pesca e Aquicultura-SEPA. Atualmente, atua como Assessora no Gabinete da Superintendência do IBAMA - AM.

\section{RENATA DE OLIVEIRA TEIXEIRA}

Bacharel em Engenheira de Produção pela Universidade Federal do Amazonas - UFAM (2016), com especialização em andamento em Segurança do Trabalho e Gestão Ambiental pela Universidade Cândido Mendes - UCAM. Técnica em Mecânica pelo Instituto Federal de Educação, Ciência e Tecnologia do Amazonas - IFAM. Atualmente ocupa o cargo de Técnica dos Laboratórios de Engenharia do Instituto de Ciências Exatas e Tecnologia ICET - UFAM.

\section{ROBERTO CARLOS SANTOS PEDROGA}

Técnico de Edificações pelo Centro Profissional Luiz de Paula (SENAI-CFLP, 2011) e graduando em Engenharia de Produção na Faculdade de Ciência e Tecnologia de Montes Claros, tem experiência na área de custos para construção, planejamento de obras e gerenciamento de projetos. Trabalhou com fiscalização de obras públicas no âmbito da Universidade Federal dos Vales do Jequitinhonha e Mucuri e ainda com projetos e execução de obras no setor privado. Atualmente atua com investimentos em mercado de capitais, pesquisa acadêmica, assistência em projetos para construção e desenvolvimento de sistemas web e mobile, além de ser voluntário em entidades acadêmicas e sociais.

\section{RODRIGO COSTA SILVA}

Graduação em Engenharia de Produção pela Universidade Federal do Piauí (UFPI)

\section{RUTE HOLANDA LOPES}

Doutora em Ciências do Ambiente e Sustentabilidade da Amazônia pela Universidade Federal do Amazonas - UFAM (2015). Mestra em Desenvolvimento Regional pela Universidade Federal do Amazonas - UFAM (2008). MBA em Empresas e Negócios pelo Centro Integrado de Ensino Superior do Amazonas - CIESA (2003). Bacharel em Ciências Econômicas pelo Centro Integrado de Ensino Superior do Amazonas - CIESA (2001). Pesquisas na área de: Sustentabilidade, Economia Regional, Engenharia de Produção, Produção Agrícola, Cadeias Produtivas Locais e Agricultura Familiar. Atualmente é professora adjunto da Universidade Federal do Amazonas - UFAM/ ICET, coordenadora do Curso de Engenharia de Produção e Vice coordenadora do COMEXI - Comitê de Extensão do ICET e Tecnologia, Gestão e Inovação, além de Coordenadora Administrativa da Incubadora do ICET - ICETech.

\section{SANDRA MIRANDA NEVES}

Possui doutorado em Engenharia de Produção pela UNESP (FEG), mestrado em Engenharia de Produção pela Universidade Federal de Itajubá (UNIFEI) e graduação em Administração de Empresas pela Universidade Estadual de Montes Claros (UNIMONTES). Líder do Grupo de Estudos em Qualidade e Produtividade (GEQProd). Atualmente é Professora Adjunta na Universidade Federal de Itajubá (UNIFEI). Linhas de pesquisa e atuação: Gestão da Qualidade e Gestão de Projetos. 


\section{SIMONE FERIGOLO VENTURINI}

Graduanda em Engenharia de Produção pela Universidade LaSalle. Possui formação como Técnico Industrial de Nível Médio com Habilitação em Eletromecânica. Tem experiência na área de manutenção elétrica em redes de distribuição de baixa e média tensão e manutenção eletromecânica em usinas de geração de energia elétrica.

\section{SONAGNO DE PAIVA OLIVEIRA}

Possui graduação em Engenharia de Produção pela Universidade Federal Rural do SemiÁrido (2017) e graduação em Ciência e Tecnologia pela Universidade Federal Rural do SemiÁrido (2014).

\section{SUELEN CRISTIAN DE FREITAS MORAIS}

Possui graduação em Engenharia de Produção Mecânica pela UNITAU - Universidade de Taubaté. Atuação em pesquisa na área de Educação em Engenharia. Mestranda em Engenharia de Produção pela UNESP - Universidade Estadual Paulista Júlio de Mesquita Filho. Atua como professora de pós-graduação no UNISAL - Centro Universitário Salesiano São Paulo nas áreas Metodologia Científica e Qualidade. Tem experiência na área de Engenharia de Produção, com ênfase em Educação em Engenharia, atuando principalmente nos seguintes temas: educação em engenharia, survey, metodologia ativa, servqual e engenharia de qualidade.

\section{SUELYN FABIANA ACIOLE MORAIS DE QUEIROZ}

Doutoranda em Engenharia de Processos (UFCG), Mestre em Engenharia de Produção pela Universidade Federal de Pernambuco - UFPE (2014), Especialista em Engenharia de Segurança do Trabalho pela Faculdade Anglo Americano (2015), possui curso na área de Higiene Ocupacional pela Treinare Soluções Empresariais. Graduada em Engenharia de Produção pela Universidade Federal de Campina Grande (2011). Professora do Centro Universitário Maurício de Nassau. Foi professora Substituta da Universidade Federal de Campina Grande na Unidade Acadêmica de Engenharia de Produção. Membro do Núcleo Docente Estruturante do Curso de Tecnologia em Segurança do Trabalho (FMN) e Membro do Núcleo Docente Estruturante do Curso de Engenharia de Produção (UFCG). Coordenadora Adjunta do Núcleo de Pesquisa de Engenharias Gerais (NPEG), desde 2015, do Centro Universitário Maurício de Nassau - Campus de Campina Grande - PB, orientando e coordenando projetos na área de Segurança do Trabalho, Gestão Ambiental e Planejamento Urbano.

\section{TARCISIO GONCALVES DE BRITO}

Possui graduação em Engenharia Mecânica, especialização em Engenharia Ambiental, mestrado em Engenharia Mecânica e doutorado em Engenharia de Produção pela Universidade Federal de Itajubá (2015). Tem experiência nas áreas de Engenharia Mecânica e Produção, atuando nos seguintes temas: Processos de Manufatura, Desenho Técnico I e II, Elementos de Máquinas, Dinâmica de Máquinas, Controle de Qualidade. Atua na área de Projeto e Análise de Experimentos, Pesquisa Operacional. Atualmente professor adjunto A da Universidade Federal de Itajubá, Brasil. 


\section{THALIS PAULINO GINANI}

Possui curso Técnico em Geologia e Mineração pelo Instituto Federal de Educação, Ciência e Tecnologia do Rio Grande do Norte, IFRN (2009). Foi bolsista do CNPQ na modalidade ITI-A do Projeto Cajusol - Cadeias Produtivas do Caju e do Girassol: Tradição e Inovação na Perspectiva da Economia Solidária e Tecnologias Sociais (2010- 2012). Possui graduação em Ciência e Tecnologia na Universidade Federal Rural do Semi-Árido, UFERSA (2012) e Engenharia Civil (2014). Mestre em Engenharia Sanitária pela UFRN (2017).

\section{THIAGO DAN SAID}

Possui graduação em Fisioterapia pela Universidade Iguaçu (2004), graduado em Engenharia de Produção pela Universidade Iguaçu, Mestrando pela Universidade Estadual Norte Fluminense Darcy Ribeiro UENF. Tem experiência na área de Fisioterapia e Terapia Ocupacional, com ênfase em Fisioterapia e Terapia Ocupacional e Fisioterapia do Trabalho.

\section{THIAGO RONCADA GUEDES}

Graduado em Engenharia de Produção pela Faculdade Católica do Tocantins. Especialista em Engenharia de Qualidade pela Universidade Cândido Mendes. Possui experiência em processos produtivos.

\section{THUANA MARIA DE MELO GONZAGA}

Engenheira de Produção. Graduada pela UFERSA. Atuação na gestão de estoque de peças de reposição. Responsável pelo setor de compras, coordenando o fluxo contínuo de suprimentos e contribuindo para diminuição de gastos desnecessários. Realização do controle de estoque e controle de manutenção. Organizada, responsável, facilidade com trabalho em equipe. Em busca de crescimento profissional.

\section{TIAGO ANDRADE MUNIZ TERRA}

Mestrando em Engenharia de Produção na Universidade Estadual do Norte Fluminense Darcy Ribeiro. Possui graduação em Direito pela Universidade Iguaçu (2007) e graduação em Administração pela Universidade Iguaçu (2013). Tem experiência na área de Engenharia de Produção, com ênfase em Gerência de Produção

\section{VANESSA NOBREGA DA SILVA}

Graduada em Engenharia de Produção pela Universidade Federal de Campina Grande (2012). Mestre em Engenharia de Produção pela Universidade Federal de Pernambuco (UFPE). Lecionou na Faculdade Maurício da Nassau na unidade Campina Grande, no curso de Logística com a disciplina de Gestão de Produtos e Operação (GPO) e Tópicos Integradores, durante o ano de 2014. Atuou também no SENAI Campina Grande, como professora do curso de logística, na disciplina Gestão da Cadeia de Suprimentos. Lecionou ainda no Anglo Americano, no curso de Higiene e Segurança do Trabalho, ministrando a disciplina de Engenharia de Métodos. Participou de Projetos de Iniciação Científica (PIBIC) e do Programa de Bolsas de Iniciação Tecnológica (BITEC). Possui publicações de artigos nas diversas ênfases da Engenharia de Produção. Tem atuado principalmente nas seguintes áreas: Logística, Gestão da Produção e Operações, Arranjo Físico (layout). Atualmente é professora efetiva do Instituto Federal do Sertão Pernambucano-Campus de Serra Talhada e está como Chefe de Departamento de Ensino desde Maio de 2017.

\section{YARA ALMEIDA DA ROCHA}

Graduação em andamento em Engenheira de Produção na Universidade Federal do Amazonas - UFAM. 


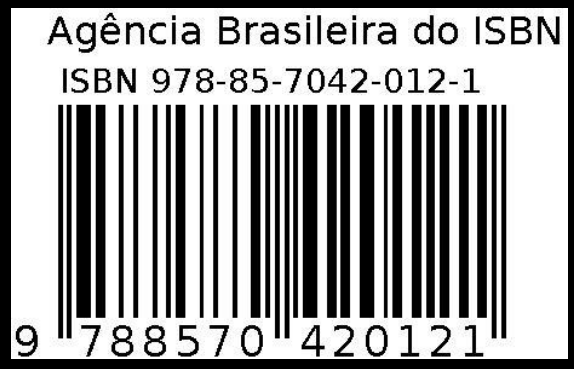

